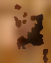

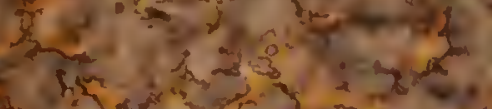

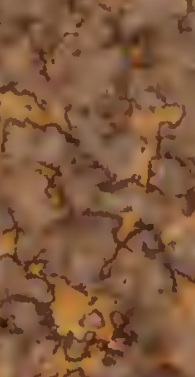

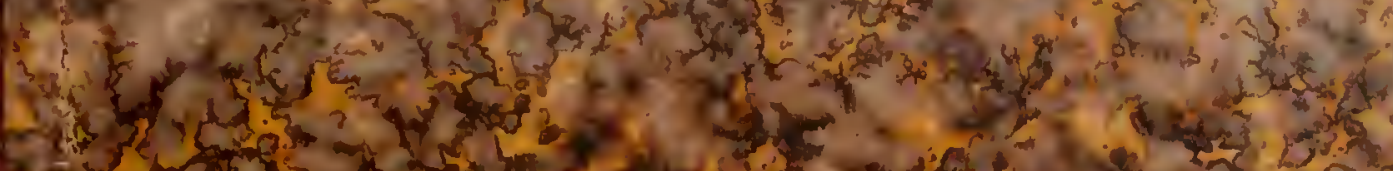
(5)

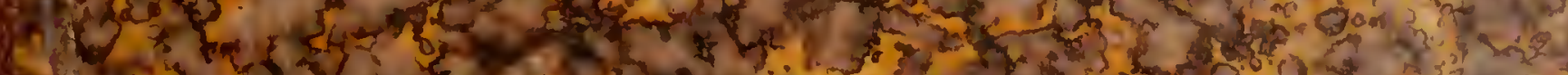

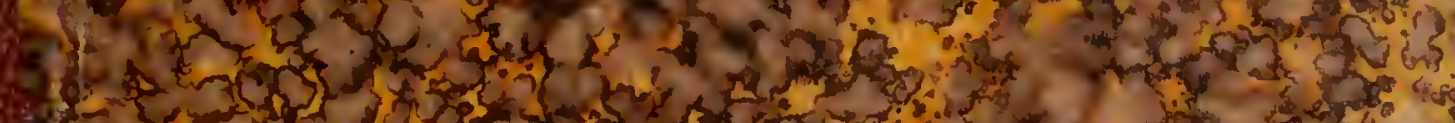

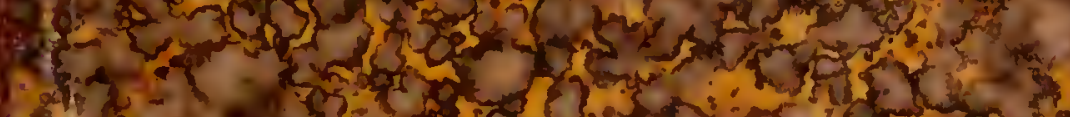

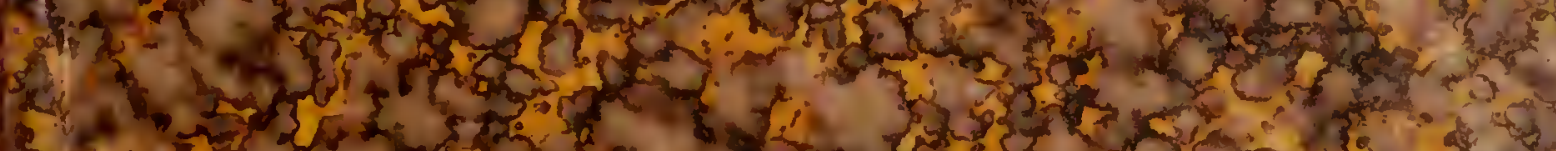

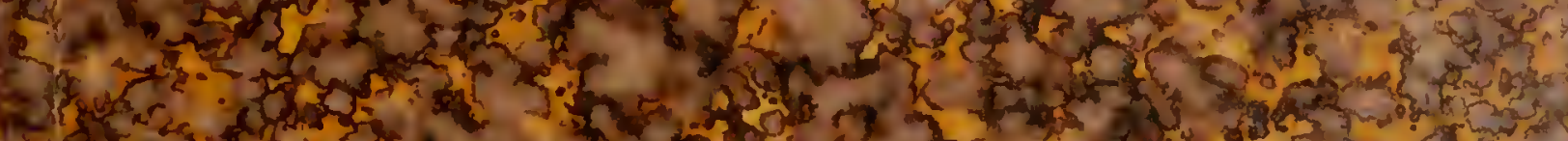

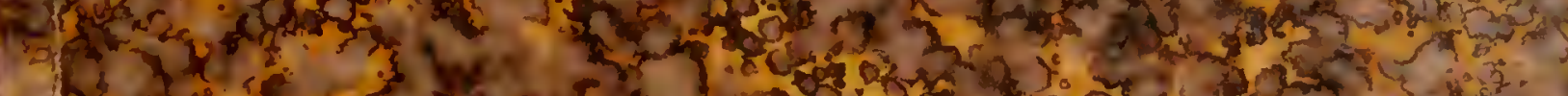

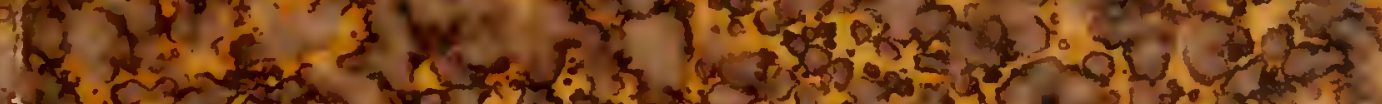

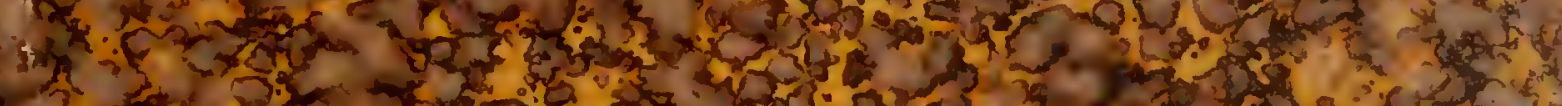

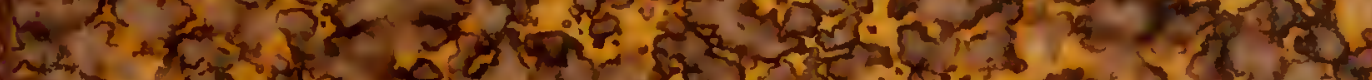

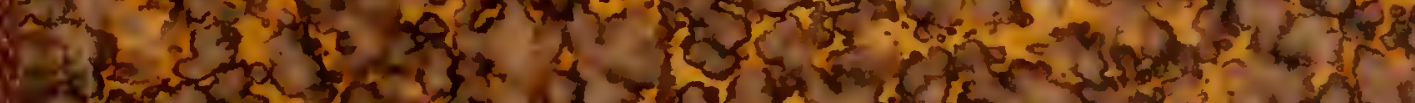

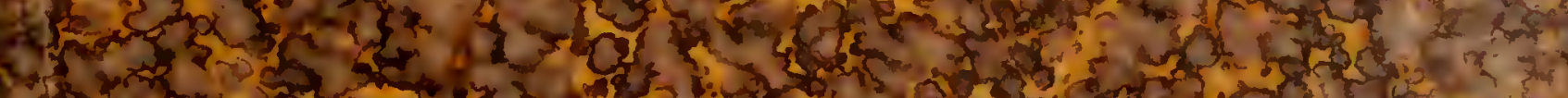

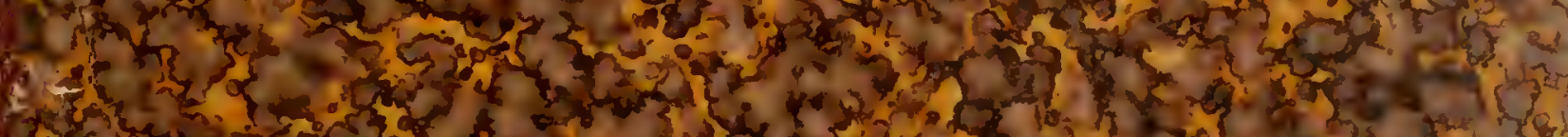

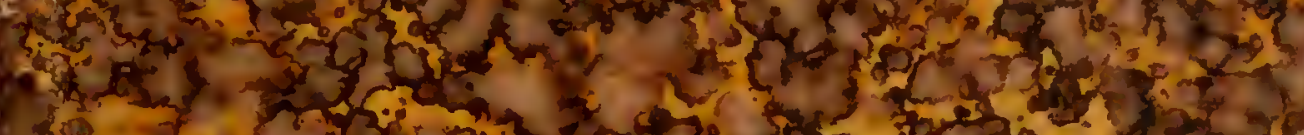

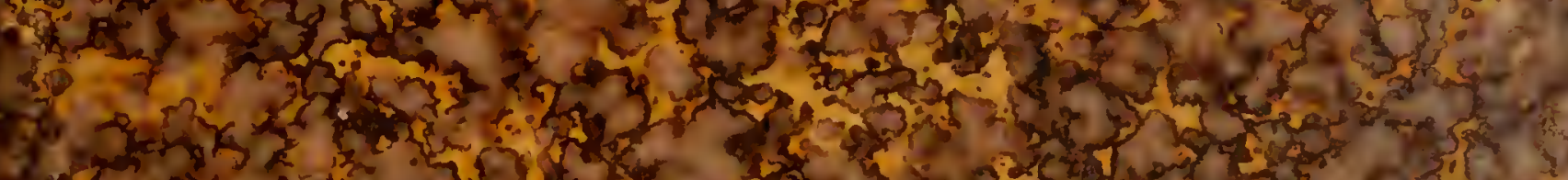

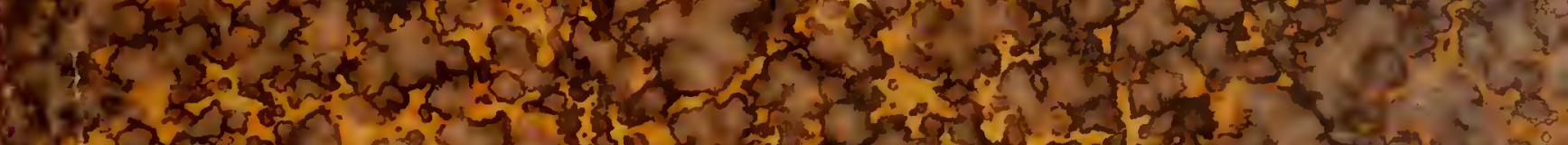

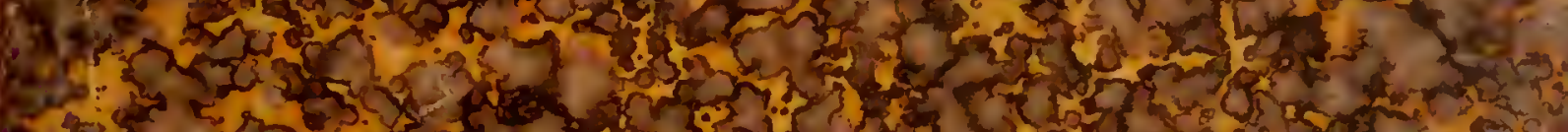

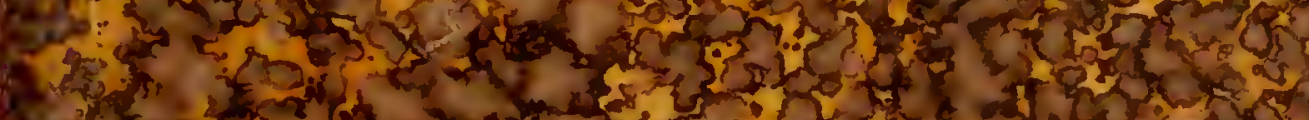

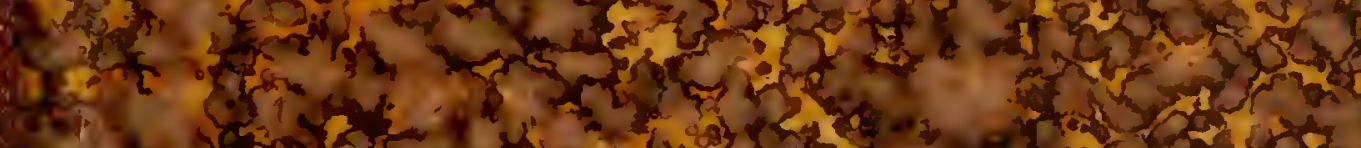

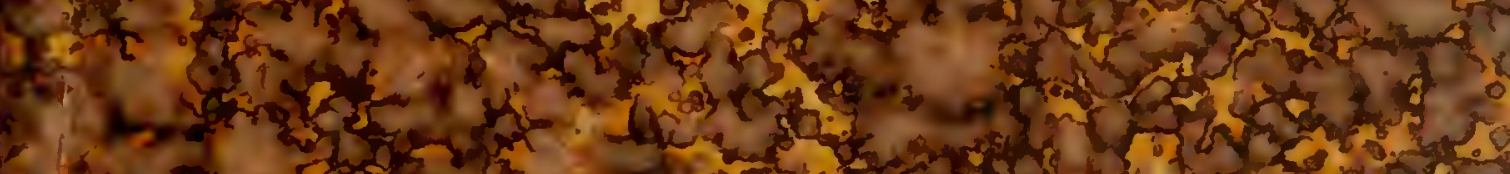

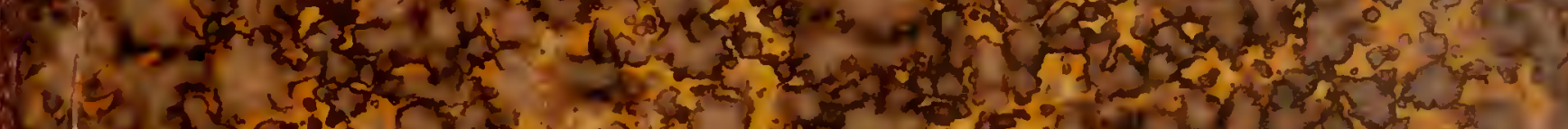

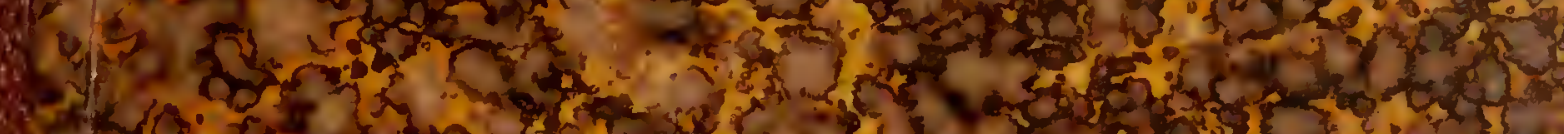

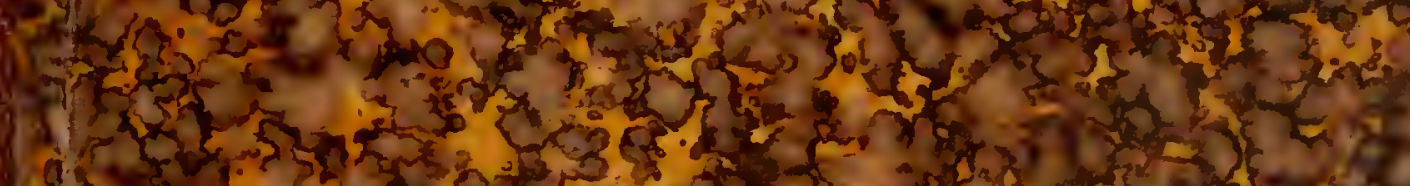

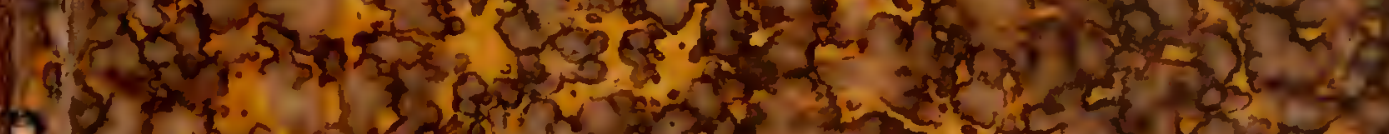


Marine Biological Laboratory WOODS HOLE, MASSACHUSETTS

IN MEMORY OF

Edward Gardiner Gardiner $1854-1907$ 
Hacekel, E.

Studien zur Gastraed -

Q1t $36 \% 5$ iheorie

Jena, 1877

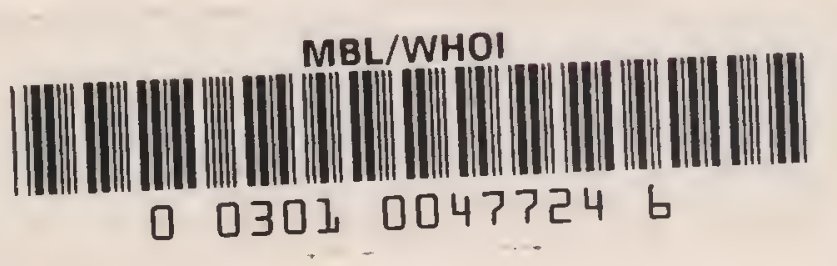






\section{BIOLOGISCHE STUDIEN.}

VoN

\section{$D^{R}$. ERNST HAECKEL, \\ Professor an der Universität Jena.}

ZWVITES HEFT:

STUDIEN ZUR GASTRAEA-THEORIE.

Mit 14 TAFELN.

\section{J E N A,}

VERLAG VON HERMANN DUFET. 


\title{
STUDIEN
}

\author{
ZUR \\ GASTRAEA-THEORIE. \\ VON
}

DR. ERNST HAECKEL,

Professor an der Universität Jena.

MIT 14 TAFELN.

I ENA,

VERLAG VON HERMANN DUFFT.

1877. 
3269 


\section{Inhalts -Verzeichniss.}

I. Die Gastraea-Theorie, die phylogenetische Classification des Thierreichs und die Homologie der Keimblätter.

Hierzu Taf. I.

(September 1873.)

1. Die causale Bedeutung der Pluylogenie für die Ontogenie. . . 3

2. Die cansale Bedeutung der Gastraer-Hheoric . . . . . . . . 10

3. Die phylogenctische Hêlentung der zwei primåren lieimblitter 17

4. Die phylogenctische kedentung der vier secundinen Kcimblitter 23

5. Die systematische Bedentung der Gastraea-Theorie . . . . . 29

6. Die Bedentung der Gustraea-Theorie fïr die Homologie der 'Typen 35

7. Hie phylogenetische Bedeutung der ontogenetischen Succession del Organ-Systeme . . . . . . . . . . . . . . . . . . 42

S. Inie Bcdentung der Gastraea-Theorie fiir die Typen-Theorie . . 46

I. Tabelle: Uebersicht über die phylogenetische Entwickelung der Organ-Systeme der Wirbelthiere, gegriindet auf die GastrucaTheorie und die ontogenetisehe Vergleiehung der Wirbelthiere und der. Wirbellosen . . . . . . . . . . . . .

II. Tabelle: Uebersilt über diejenigen Urorgane, welche mit Wahrsebeinlichkeit bei den Würmern, Gliederthieren, Weichthieren und Wirbelthieren als bomolog z $\mathrm{t}$ betrachten sind . . . . .

III. T a b e l 1 e: Tutwurf einer phylogenetisehen Classification des Thierreichs, gegriundet auf die Gastraea-Theorie und die Homologie der Keimbiätter, des Urdarms und des Coeloms

IV. 'T abelle: Monophyletisebcr. Stanmbatum des Thierreichs, gegründet auf die Gastraea-Theorie und die Homologie der lieinblätter .

Erklärung von Taf. I

II. Die Gastrula und die Eifurchung der Thiere.

Hierzu Taf. II-VIII.

(Oetober 1875.)

9. Die Berlentung der Palingenie und ảor Cenogenie.

V. T a belle: Uebersicht über die wiehtigsteu Versehiedenheiten in der Eifurchıng und Gastrulation der Thiere. . . . . . .

V1. Tabelle: Uebers̈icht über die fün ersten Keinnugsstufen rler Metazoen, verglichen mit ihren fünf ältesten Ahnenstufen. 
VII. Tabelle: Uebersicht über die fünf ersten Keimungsstufen der Metazoen, mit Rïcksicht auf die vier verschiedenen Hauptformen der Eifurchung . . . . . . . . . . . . . . 67

I. Das phylogenetische Verhältniss der Palingenie zur Cenogenic 68

II. Ontogenetische Heterochronien und Heterotopien . . . . . 71

III. Palingenetischer Bildungsdotter und cenogenetischer Nahrungsdotter . . . . . . . . . . . . . . . . . 75

10. Die vier Hauptformen der Eifurclung und Gastrulabildung • 78

I. Die primordiale Furchung und die Archigastrula (Taf. VIII.) 78

1I. Die inaequale Furchung und die Amphigastrula (Taf. VII.) • 83

III. Die discoidale Furchung und die Discogastrula (Taf. IV. V.) 91

IV. Die superficiale Furchung und die Perigastrula (Taf. VI.) . . 103

11. Die Eifurchung und Gastrulabildung in den Hauptgruppen des Thierreichs .

I. Gastrula und Eifurchung der Zoophyten . . . . . . . . 111

II. Gastrula und Eifurchung der Wiirmer . . . . . : . . . 116

III. Gastrula und Eifurchung der Mollusken . . . . . . . . 119

IV. Gastrula und Eifurchung der Echinodermen . . . . . . . I2I

V. Gastrula und Eifurchung der Arthropoden. . . . . . . . 123

VI. Gastrula und Eifurchung der Wirbelthiere . . . . . . . 127

12. Die plyylogenetische Bedentung der finf ersten ontogenetischen

Hotwickelungsstufen . . . . . . . . . . . . . . . 137

I. Das Moner und die Monerula . . . . . . . . . . . . 137

II. Die Amoebe und die Cytula . . . . . . . . . . . 112

III, Das Synamoebium und die Morula . . . . . . . . . . 146

IV. Die Planaea und die Blastula . . . . . . . . . . . . 148

V. Die Gastraea und die Gastrula . . . . . . . . . . 153

Nachschrift üher Gastrulation der Spongien . . . . . . 158

Erklärung der Tafeln II-VIII . . . . . . . . . 161

III. Die Physemarien (Haliphysema und Gastrophysema), Gastraeaden der Gegenwart.

Hierzu Taf. IX-XIV.

(August 18\%6.)

13. Bisherige Beobachtungen iber Physemarien . . . . . . . . I71

14. Das Genus Haliphysema . . . . . . . . . . . . . . . . I78

I. Haliphysema primordiale (Taf. IX) . . . . . . . . . 180

II. Haliphysema echinoides (Taf. X) . . . . . . . . . . . 186

III. Haliphysema globigerina (Taf, XI) . . . . . . . . . . 189

IV. Haliphysema Tumanowiczii . . . . . . . . . . . . 192

V. Haliphysema ramulosum . . . . . . . . . . . . . 193

15. Das Genus Gastropliysema . . . . . . . . . . . . . . 194

I. Gastrophysema dithalamium (Taf. XII-XIV) . . . . . . 196

II. Gastrophysema scopula . . . . . . . . . . . . . 206

16. Organisation und Lebenserscheinnngen der Physemarien . . 207

17. Phylogenetische Bedeutung der Plysemarien . . . . . . . 214.

Erklärung der Tafeln IX-XIV . . . . . . . . 222 
IV. Nachträge zur Gastraea-Theorie.

(November 18\%.)

1S. Histologische Bedentung Ier Gastruea-Theorie .

19. Primäe und secundhe Keimblitter. Exoderu, Mesolerm mud Entoderm . . . . . . . . . . . . . . . . . 233

0. Protozoen und Metazoen . . . . . . . . . . . . . . 240

21. Mesozoen. Gastraealen. Dicjemiden . . . . . . . . . . 245

2.2. Gastrulation der Singethiere . . . . . . . . . . . . . 250

29. Urdarm und Urmund. Primitiv-0rgane . . . . . . . . . 258

24. Heuristische Berlentung der Gastraen-Theorie . . . . . . 264 

I.

\title{
Die Gastraea-Theorie, die phylogenetische Classification des Thierreichs und die Homologie der Keimblätter.
}

\author{
Hierzu Tafel I.
}

Inlalt: 1. Die causale Bedeutung der Phylogenie für die Ontogenie. 2. Die causale Bedeutuug der Gasträa-Theorie. 3. Die phylogenetische Bedentung der zwei primären Keimblätter. 4. Die phylogenetische Bedeutung der vier secundären Keimblätter. 5. Die systematische Bedeutung der Gasträa'Theorie. 6. Die Bedeutung der Gasträa-Theorie für die Homologie der 'Typen. 7. Die phylogenetische Bedeutung der ontogenetischen Succession der Organ-Systeme. 8. Die Bedentung der Gasträa-Theorie für die Typen'Theorie. Anbang: Synoptische phylogenetische Tabellen. 
74.

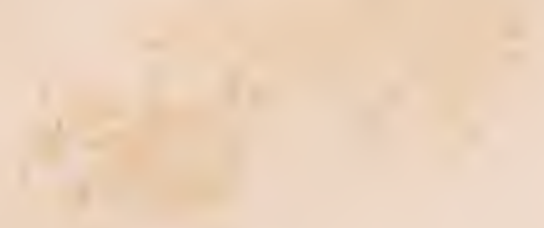

4

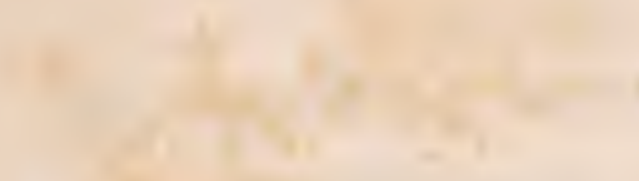

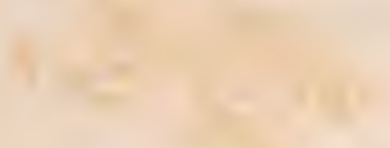

(n)

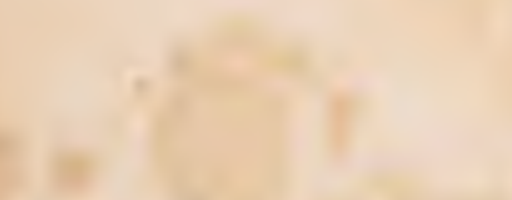

1
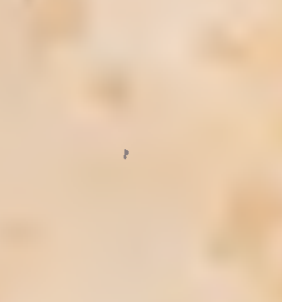

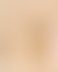
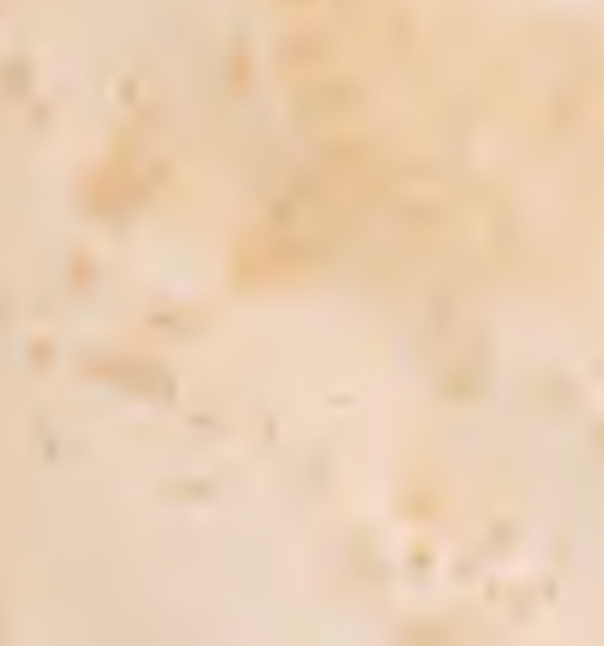


\section{Lie cansale Bedeutung der Plylogenie fïr die Ontogenie.}

Die Entwickelungsgeschichte der Organismen hat in jüngster Zeit eine neue Periode ihrer Entwickelung dadurch begonnen, dass sie sich von der empirischen Erforschung der von ilh verfolgten Thatsachen zu der philosoplischen Frage nach den natiurlichen Ursachen derselben erhoben hat. Allerdings waren die denkenden Forscher im Gebiete der Biogenie schon seit melır als einem halben Jahrhundert bemüht, durch die innige Verkniipfung von empirischer Beobachtung und philosophischer Reflexion sich über die blosse Kenntniss der biogenetischen ,Erscheinungeu zu einem tieferen Verständniss ilırer Bedeutung zu erheben, und nach "Gresetzen der organischen Entwickelung" zu suchen. Allein dieses verdienstvolle Streben konnte so lange keine causalen Erkenntnisse erzielen, so lange man ausschliesslich die Entwickelung des organischen Individuums an sich verfolgte. Vielmehr ist diese Befriedigung des wissenschaftlichen Causalitäts-Bedürfnisses erst möglich geworden, seitdem wir im letzten Decennium begonnen haben, die natürliche Entwickelung der organischen Species zu untersuchen, und durch diese Stammesgeschichte der organischen Arten die Keimesgeschichte der organischen Individuen zu erklären.

Nachdem Caspar Friedrich Wolff im Jahre 1759 durch seine "Theoria generationis" die Epigenesis zum unerschütterlichen Fundamente der gesammten Entwickelungsgeschichte erhoben und nachdem auf diesem festen, über ein halbes Jahrhundert hindurch unbekannt gebliebenen Grundsteine Christian Pander 1817 den ersten Entwurf der Keimblätter-The orie vorgezeiclmet hatte,

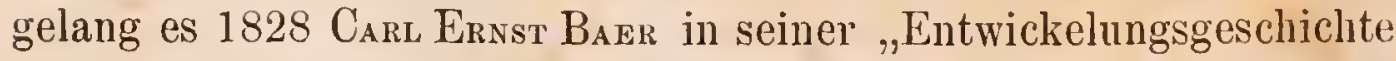
der Thiere", die Richtung zu bestimmen und die Bahn abzustecken, innerhalb deren die ganze folgende Embryologie sich bewegen musste. In diesem classischen Werke ist durch die glückliche Verbindung von sorgfältigster Beobachtung und philosophischer 
Reflexion, sowie durch die Verschmelzung der embryologischen mit der vergleichend-anatomischen und zoologisch-systematischen Forschung, die jngendliche Wissenschaft von der individuellen Entwickelung der Thiere zum Ausgangspunkte der gesammten wissenschaftlichen Zoologie erhoben, zu dem centralen Knotenpunkte geworden, in welchem alle verschiedenen Disciplinen der letzteren wieder zusammenlaufen müssen. Die glänzenden und fruchtreichen Arbeiten von Johannes Müluer und Heinrich Rathke, welche namentlich im Gebiete der niederen Thiere unsere Kenntnisse ausserordentlich erweiterten, haben sich ganz innerhalb jener Bahnen gehalten. Selbst die bedentendste Arbeit, welche die individuelle Entwickelungsgeschichte der Thiere nächst BaER's Fundamental-Werk aufzuweisen hat, die höchst werthvollen, ,Untersuchungen über die Entwickelung der Wirbelthiere" von Roветт Rемак (1851) müssen als unnittelbare Fortsetzung der BaEk'schen Forschungs-Richtung angesehen werden; iln originelles Hauptverdienst besteht darin, die empirisch-philosophische Untersuchung der embryologischen Processe von dem organologischen Gebiete auf das histologische hinübergeführt und die Richtigkeit der Grundsätze, welche BAER an den Individuen zweiter Ordnung, den Organen, aufgestellt hatte, auch an den Individuen erster Ordnung, den Zellen erprobt zu haben. Durch die weitere Ausbildung, die REMak der KeimblätterTheorie gab, wurde dieselbe zugleich zum Ausgangspunkte der Histogenie erhoben.

Wenn so einerseits die klare Berechtigung und volle Gültigkeit der yon WolfF und $B_{A E R}$ in die Entwickelungsgeschichte eingeführten Ideen, und vor allen der fundamentalen KeimblätterTheorie, sich positiv in dem massgebenden Einfluss zeigte, den sie auf die berleutendsten Untersuchumgen ihrer zahlreichen Nachfolger ausiibten, so wurde sie anderseits nicht minder negativ durch die Ohmmacht einzehner Gegner dargethan, welche die von jenen vorgezeichnete Bahn zu verlassen und eine neue, ganz abweichende Richtung einzuschlagen versuchten. Der prätensiöseste dieser Versuche ging yon Cart Boguslaus Reichert aus, der in zahlreichen einzelnen Schriften, besonders aber in seinem Aufsatze über ,das Entwickelungsleben im Wirbelthier-Reich" (1840) und in seinen „Beiträgen zur Kenntniss des Zustandes der heutigen Entwickelungsgeschichte" (1843) die Keimblätter-Theorie und die damit zusammenhängenden wesentlichsten Grundprincipien der Zoogenesis verwarf, und an ihre Stelle ein wüstes Conglomerat von phantastischen Einfüllen zu setzen suchte, das nicht einmal den Namen 
einer wissenschaftlichen Hypothese, geschweige denn einer Theorie verdient. Während die vorhergenannten Häupter der Fmbryologie durch klare leitende Gedanken und Aufstellung von EntwickelungiGesetzen Licht und Ordnung in die chatische Fülle der embryologischen Thatsachen zu bringen und die verwickelten Erscheinungen durch Zuriickfiuhrung anf einfache Principien zu erklären bemiiht waren, versuchte Reicherr ungekehrt, sich dadurch ein vor'übergehendes Ansehen zu erwerben, dass cr die einfachsten Thatsachen als höchst verwickelt, das Gleichartige als grundverschieden mol das Znsammengehörige als ganz getrennt darstellte. Seine höchst unklaren und verworrenen Gedanken-Knoten wïrden aber wohl ebenso in der Embryologie wie in der Histologie rasch wieder vergessen worden sein, wenn er es nicht verstunden hätte, ihnen durch eine schwïlstige und mit philosophischen Kunstimsdrücken verbrämte Phraseologie eine bunte Hülle überzuwerfen, und durch dieses äusserliche Blendwerk die Leere des Imnern zu verdecken. Obgleich num dadurch nicht Wenige sich wirklich blenden und zu einer bewundernden Anerkennung seiner confusen Behauptungen himreissen liessen, wurden dieselben doch bald durch BaEr, Rathke, Remak, Bischoff, Cari Vogr und Andere in ihrer wahren Nichtigkeit aufgedeckt, und dadurch nur mo so glänzender die fundamentale Sicherheit der Keimblätter-Theorie bewiesen, die Rencuert vergeblich zu zerstören versucht hatte ${ }^{1}$ ).

1) In historischen Betrachtungen über organische Lutwickelungsgeschichte wirl nicht selten neben und mit den Nimen von Wolff, Batr, Realak แ.. . anch derjenige ron PEIchert als eines verdienstrollen Fördres derselben genannt. Dies kamn nu so verstanden werden. dass Rexchert durch suine röllig verfehlten und ohne jedes tiefere Verständniss der Entwickrlungsgesclichto angestellten, ebenso eitlen wic anmassenten Versuehe eine lirätige Reaction hervorriet. Ebenso wie or in der Ilistologie durch seine abentenerlichen is. griffe auf die Protoplasma-Theorie nicht wenig beitrug, diescllo zn lirätigen, elienso hat er anch in dor Embryologie durch seine unrichtigr I,ehre von den "Lmhïllungshäuten": durch seinc falchen ..Bildungsgesetze" und durch seinse gänzlich verfehlten Anschaumgen ron der Fistogenese judiruct dis Wissenschaft mannichfach gefördert. Darini licgt aber doch kein Grunl, seine negatirun Verdieuste mit den positiven cines BAER, hitнkf, Revak u.s. W. zu vergleichen. die auch ilnerseits sich energisch dagegen relwahnt haben. Allerdings sind in REICHERT's ansgedehnten embryologischen Litersuchungen cinzeho hranchluare Brobachtungen rnthalten (bekantlich finder auch ein blindes Inun bisweilen ein Korn); allein im Grossen und Ganzen sind sie zn den Arbeiten nied(usten Ranges zu rechmen und mur mit denjenigen eines Dösitz, J)ursy, His 11 . w. zusammenzustellen. Einzelnc berleutende Jeen. die Renchert als sein Eigenthum ausgiebt, hat derselbe mur von RatHke und Auderen entlehnt. 
Den Anstoss zu einer bahnbrechenden neuen Richtung erhielt die Entwickelungsgeschichte erst hundert Jahre nach dem Erscheinen der Theoria generationis, als Charles Darwin 1859 sein epochemachendes Werk ïber die Entstehung der Arten veröffentlichte und durch die darin enthaltene Selections-Theorie eine höcht fruchtbare Reform der Descendenz-Theorie herbeiführte. Allerdings war diese letztere schon 1809 von JEAs LAMARCK in seiner tiefdurchdachten Philosoplie zoologiyue mit vollem Bewusstsein ihrer Bedentung als wahrer Grundgedanke der „biologischen Philosophie" hingestellt; sie wurde aber ebenso, wie WoufF's gleich bedentende Theoria generationis ein volles halbes Jahrhundert hindurch von der sogenannten „exacten" Naturwissenschaft todtgeschwiegen. Laмalick hatte bereits mit voller Bestimmtheit die gemeinsame Abstammung aller Organismen von einer einzigen oder einigen wenigen einfachsten Urformen behauptet. Indem $\mathrm{D}_{\mathrm{ARw}}$ as aber seine Theorie von der natürlichen Züchtung im Kampfe um's Dasein begründete, und nachwies, wie unter deren Einfluss die organischen formen einer beständigen langsimen Umbildung unterliegen, ging er weit über LaMaRck hinaus und lehrte uns für die von letzteren gelehrten Thatsachen die wahren bewirkenden Ursachen kennen: Die Wechselwirkung der Vererbung und Anpassung. Wenn nun auch zunächst dadurch nu der Ursprung der organischen Arten erklärt und eine „Entwickelungsgeschichte der Species" angebahnt werden sollte, so musste damit doch zugleich ein ganz neues Licht auch auf die Entwickelungsgeschichte der Individuen, anf die Embryologie fallen. Die innige Beziehung, in welcher diese beiden Zweige der organischen Entwickehungsgeschichte, diejenige der Arten und diejenige der Individuen, zu einander stehen, konnte $D_{\text {Arw in nicht }}$ entgehen. Doch hat er in seinem Hauptwerke, das vor Allem die Selections-Theorie zu begründen hatte, und ebenso in den übrigen darauf folgenden Schriften (namentlich in dem berühmten Werke über die Abstammung des Menschen) der Embryologie nur einen verhältnissmässig geringen Raum gewidmet und ihre hohe Bedeutung mehr gelegentlich gewürdigt

In meiner ,allgemeinen Entwickelungsgeschichte der Organismen" (inı zweiten Bande der generellen Morphologie, 1866) habe ich den Versuch unternommen, jenes imnige Verhältniss beider Zweige der Biogenie näher zu begriinden und seine eigentliche Bedeutung nachzuweisen. Ich habe daselbst die paläontologische Entwickelungsgeschichte der Arten, die Phylogenie oder Stam- 
mesgeschichte als die wahre Ursache dargestellt, auf deren mechanischer Wirksamkeit die gesammte Entwickelungsgeschichte der Individuen, die Ontogenic oder Keimesgeschichte überhaupt beruht. Olne die erstere wiirde die letztere überhaupt nicht existiren. Der Schwerpunkt dieses Verhältnisses liegt darin, dass der Zusammenhang zwischen beiden ein mechan isch-causaler ist. Die Ontogenie ist eine kurze Wiederholung der Phylogenie, mechanisch bedingt durch die Functionen der Vererbung und Anpassung '). Die Vererbung von gemeinsamen Vorfahren bewirkt die typische Uebereinstimmung in Form und Structur der Jugendzustände jeder Klasse. Die Anpassung an verschiedenartige Existenz-Bedingungen der Ungebung bewirkt die Unterschiede, welche die daraus entwickelten Formen in den verschicdenen Arten jeder Klasse bezüglich ihrer Form und Structur darbieten. Die Vererbung fällt als physiologische Function unter die Erscheiaungen der Fortpflanzung. Die Anpassung fällt ebenso als physiologische Function in das Gebiet der Ernährungs-Erscheinungen, wie im 19. Capitel der generellen Morphologie ausführlich nachgewiesen worden ist (S. 148-294).

Die Phylogenesis ist die mechanische Ursache der Ontogenesis. Mit diesem einen Satze ist unsere principielle monistische Auffassung der organischen Entwickelung klar bezeichnet, und von der Wahrheit dieses Grundsatzes hängt in erster

1) In meinen ,Ontogenetischen Thesen", im 20. Capitel der generellen Morphologie (Band II, S. 295-300) habe ich dieses , bi og en etisch e Grun u gesetz" mit folgenden Worten ansgedriickt: .Jic Ontogenesis oder die Entwickelung ler organischen Individuen, als die Reih" ron Form-Ýeränderungen, welche jeder individnelle Organismus während der gesammten Zeit seiner indivifluellen Existenz durchläuft, ist unmittelbar bedingt durch die Ply yogenesis oder die Entwickelung des organischen Stammes (Phylon), zu welchem derselbe gehört. Die Ontogenesis ist die kurze und sehuelle feecapitulation der Phylogenesis, bedingt durch die physiologischen Functionen der Vererbung (Fortpflanzug) und Anpassung (Eruährung). Das organische Individuum wiederholt während lles raschen ınd kurzen Laufes seiner individnellen Entwickelnug die wichtigsten von denjenigen Fornveränderungen, welche seine Voreltern wälırend des langsamen und langen Laufes ihrer paläontologisehen Entwickelung nach den Gesetzen der Vererbung und Anpassung durchlanfen haben." Dieses wahre „Grundgesetz der organischen Entwickelung: ist die unentbehrliche Grundlage, auf der das ganze innere Verständniss der Entwickelungsgeschichte heruht. Ich wiederhole dasselbe hier, weil einerseits suinu Anerkemung das Verständniss del nachfolgenden Erörterungen brdingt. und weil dasselbe anderseits noch jetzt von vielen angesehenen Naturfor'schern bekämpft wirl. 
Linie die Wahrheit der Gastraea-Theorie ab, deren Bedeutung nachstehend entwickelt werden soll. Für oder wider diesen Satz wird in Zukunft jeder Naturforscher sich entscheiden müssen, der in der Biogenie sich nicht mit der blossen Bewunderung merkwürdiger Erscheinungen begnügt, sondern darüber hinaus nach dem Verständniss ihrer Bedeutung strebt. Mit diesem Satze ist zugleich die unausfüllbare Kluft bezeichnet, welche die ältere, teleologische und dualistische Morphologie von den neueren, mechanischen und monistischen trennt. Wenn die physiologischen Functionen der Vererbung und Anpassung als die alleinigen Ursachen der organischen Formbildung nachgewiesen sind, so ist damit zugleich jede Art von Tele ologie, von dualistischer und metaphysischer Betrachtungsweise aus dem Gebiete der Biogenie entfernt; der scharfe Gegensatz zwischen den leitenden Principien ist damit klar bezeichnet. Entweder existirt ein directer und causaler Zusammenhang $z$ wischen Ontogenie und Phylogenie oder er existirt nicht. Entweder ist die Ontogenese ein gedrängter Anszug der Phylogenese oder sie ist dies nicht. Zwischen diesen beiden Annahmen giebt es keine dritte! Entweder Epigenesis und Descendenz - oder Präformation und Schöpfung!

In Beziehung auf diese entscheidende Alternative verdient Hrs besondere Anerkennung, weil er sich wiederholt und bestimmit gegen unser biogenetisches Grundgesetz und gegen jeden Zusammenhang von Ontogenie und Phylogenie ausgesprochen hat ${ }^{3}$ ). Er

1) His. Untersuchungen über die erste Anlage des Wirbelthierleibes. Leipzig 1868. \$. $211 \mathrm{ft}$., 223 u. s. w. Besonder's characteristisch sind für seine Anfiassung ler Biogenie die allgemeinen Betrachtungen in der Rede, uber die Bedentung der Entwickelungsgeschichte für die Auffassung der organischen Natmr" (Leiqzig, 1870, \$. 35). Hrs sieht sich hier ,genöthigt, die Ausprüche der inliviluellen Entwickelungsgeschichte gegeniiber der ïberwalloniten Hacht DARW'scher Anschanungen zu wahren" und meint, "lass die sämmtlichen, der Morphologie oder der Entwickelungsgeschichte entnommenen Argumente "fiu UARWix" desshalb nicht vou beweisender Kraft seien, weil sie als die unmittelbaren Folgen physiologischer Entwickelungsprincipien der Erklärung auf dem weiten Umwege genealogischer Verwandtsclatt gar nicht bediurfen. (!) Wenn die genealogische Vejwanltschatt der organischen Wesen wirklich in jener Alles mufassenden lusdehnung besteht, welche die Theorie zu statuiren pflegt, so erscheinen allerlings alle typischen und entwickelungsgeschichtlichen Vebereinstimmmgen als ganz selbstverständliche Consequenzen. (!:) Aus den typuschen und entwickelungsgeschichtlichen Uebereinstimmungen aut' die bluts verwanltschaft zurürkzuschliessen. möchte von dem Augenblick an nicht mehr gestattet sein, da sich Anssicht eröfliet, die verschiedenen Entwickelungsrichtungen ils erschopfende Verwirklichungen eines mathematisch bestimmten 
versucht statt dessen die ontogenetischen Erscheinungen in der oberflächlichsten Weise durch Krümmungen, Faltungen u. s. W. zu erklären, ohne dass er aber für diese ,mechanischen" Entrickelungs-Processe irgend cinen weiteren Grund, irgend eine bewirkende Ursache anzugeben weiss. Der unnütze Aufwand von mathematischen Berechmungen, den Hrs dabei entwickelt, vermag nicht den Mangel jedes wahren Causal-Princips zu verdecken, und seinen paradoxen Einfüllen irgend einen Werth zu verleihen. Wie ich schon in der Biologie der Kalkschwämne (S. 472) erklärt habe, erscheinen solche Einfälle „nur einer humoristischen Belenchtung, keiner ernstlichen Widerlegung fähig. Zugleich beweisen aber diese starken Missgriffe, wie nothwendig für Arbeiten auf dem schwierigen Felde der Ontogenie die Orientirung in den Gebiete der vergleichenden Anatomie und die Beziehmng der ontogenetischen Vorgänge auf ihre mechanischen phylogenetischen Ursachen, ilne wahren causae efficientes ist." Wenn His nur ein wenig mit den Thatsachen der vergleichenden Anatomie und mit der Ontogenie der wirbellosen Thiere bekannt gewesen wäre, würde er seine Versuche wohl schwerlich publicirt haben.

Um den vollen Gegensatz zwischen dieser angeblich exacten „physiologischen" Auffassung der Ontogenie und der von uns vertretenen Erklärung derselben durch die Phylogenie recht klar zu empfinden, braucht man mit jenen verunglückten Unter-

Kreises möglicher Wachsthumsweisen zu erkennen." Diese Erklärung von His widerlegt sich bei genauerer Prüfung von selbst. Um aber die völlige Haltlosigkeit seines Standpunktes einzuschen, braucht man nu näher aut' die .physiologischen Entwickelungsprincipien" einzugehen, durch welche His di: ontogenetischen Vorgänge ,mechanisch zu erklären", die Descendenz-Theoric zu eliminiren und dlen Zusammenhang zwischen Ontogenese und Phylogenese zu leugnen sucht. Hier dürfte zur Characteristik derselben die Anführungr eines einzigen Beispiels der Art und Weise genïgen, lurch welche His , Principien der Morphologie als nothwendige Folgen der mechanischen Entwickelungsgeschichte darzulegen" glaubt (a. a. O. S. 34). His sagt: „Wie eintach gestaltet sich die Homologie der vorderen und linteren Glierlmassen, wenn wir erkemen, dlass ihre Anlage, den vier Ecken eines Briefes ähnlich, bestimmt wird durch die Kreuzung ron vier den Körper umgrenzenden Falten(!). Wie klar wird anch der sonst so schwierige Vergleich des vorderen mit dem hinteren Körperende, wem wir anch hier anf das Grundrerhältniss zurückgehen, dass der Kopf sowohl, als das hintere Körperende mit einer sich umklappenden Falte ihren Abschluss finden, und dass alle mechanischen Verhältnisse, welche tine solche Faltenumklappung begleitev, vorn sowohl als hinten zum Vorschein kommen müssen." Es dürfte schwer sein, in der ganzen morphologischen Literatur ein Beispiel einer gluich rohen und oberflächlichen Auffassung morphologischer Verhältnisse zu finden. 
suchungen von His nur das mustergültige Bild der Entwickelungsgeschichte der Crustaceen zu vergleichen, welches Frivz Müller in seiner ideenreichen Schrift „Für Darwin" geliefert hat (Leipzig, 1864). Hier ist an dem vielgestaltigen Formenkreise einer ganzen Thierklasse der ummittelbare Zusammenhang der Ontogenese und Phylogenese nachgewiesen, und die erstere durch die letztere wirklich erlärt. Hier finden wir die beiden formbildenden Kräfte der Vererbung und Anpassung als die wahren ,physiologischen" U1sachen der Ontogenese dargelegt, und die Gesetze ihrer Wirksamkeit erkannt. Als zwei der wichtigsten Sätze, welche Frıтz Mülder hier ausspricht, und welche gerade für unser Thenta besondere Bedentung besitzen, sind namentlich folgende hervorzuheben: „Die in der Entwickelungsgeschichte (der Individuen) erhaltene geschichtliche Urkunde (von der Entwickelung der Vorfahren) wird allmählig verwischt, indem die Entwickelung einen immer geraderen Weg vom Ei zum fertigen Thiere einschlägt, und sie wird häufig gefälscht durch den Kampf um's Dasein, den die frei lebenden Larven zu bestehen haben. Die Urgeschichte der Art (Phylogenesis) wird in ihrer Entwickelungsgeschichte (Ontogenesis) un so vollständiger erhalten sein, je länger die Reihe der Jugendznstände ist, die sie gleichmässigen Schrittes durchläuft, und um so treuer, je weniger sich die Lebensweise der Jungen von der der Alten entfernt, und je weniger die Eigenthümlichkeiten der einzelnen Jugendzustände als aus späteren in frühere Lebensabschnitte zurückverlegt oder als selbstständig erworben sich auffassen lassen". (Für Darwin, S. 77, 81). Indem nun Fritz Müllek diese Gesetze durch die Ontogenese der verschiedenen Crustaceen begründet und aus der gemeinsamen Nauplius-Jugendform der verschiedensten Kruster auf eine gemeinsame, diesem Nauplius wesentlich gleiche Stammform der ganzen Kilasse zurückschliesst, erklärt er zugleich eine Fülle von merkwürdigen Frscheinungen, welche ohne diese Anwendung der Descendenz-Theorie völlig unerklärlich und unbegreiflich dastehen. Daraus ergiebt sich aber unmittelbar die causale Bedeutung der Phylogenie für die Ontogenie.

\section{Die causale bedentung der hastraea-Theorie.}

Die Anwendung des generellen biogenetischen Grundgesetzes auf die verschiedenen Theile der speciellen Biologie, vor allem auf das natürliche System der Organismen, ist eine wissenschaft- 
liche Anfgabe, welehe zwar von der ilenkenden Biologie selbstverständlich gefordert werden muss, welche aber bei jerlem Versuche ihrer durchgreifenden Ausfühnung auf die grössten Hindernisse stösst. Diese Hindernisse sind zunächst durch den niederen Entwickelungszustand unserer biologischen Kemtnisse in Allgemeinen bedingt, namentlich durch die geringe Thoilnahme. welche die Biologen bisher den beiden fundamentalen formbildenden bintwiekelungs- Functionen der Vererbung und Anpassung gewidmet haben, ganz besonders aber durch die grosse Lückenhaftigkeit und Unvolsständigkeit der mpirischen sogenannten „Schöpfungs-Urkunden," wetche uns die drei Disciplinen der Ontogenie, Paläontologie und vergleichenden Anatomie darbieten.

Trotz dieser grossen Hindermisse und Schwierigkeiten, deren Bedentung ich nicht unterschätzen konnte, habe ich 1866 in meiner generellen Morphologie den ersten Versuch gewagt, mit Hülfe des biogenetischen Grundgesetzes die Descendenz-Theorie auf das natiuliche System der Organismen anzuwenden, und in der ,Systematischen Einleitung in die allgemeine Entwicklungsgeschichte" (S. XVII-CLX des zweiten Bandes) die Phylogenie zur Basis des natürlichen Systems zu erheben. In mehr populärer Form habe ich diesen Versuch erneuert und verbessert in meiner "Natürlichen Schöpfungsgeschichte" (1868; vierte Aufiage 1873). Nun haben zwar diese ersten Versubhe (als welche ich sie von Anfang an ausdrücklich bezeichnet habe) mit wenigen Ausnahmen unter den zunächst betheiligten Fachgenossen nur lebhafte Missbilligung und entschiedenen Tadel gefunden; allein keiner derselben hat sich die Mühe gegeben, mein phylogenetisches System durch ein besseres zu ersetzen. Diese Aufgabe liegt aber für Jeden'vor, der ïberhaupt die Descendenz-Theorie anerkennt und nach einem causalen Verständniss der organischen Formen strebt ').

1) Die beste Vertheidigung gegen die vielfachen Angriffe, die mein phylogenetisches system der Urganismen erlitten Lat, scheint mir darin zu liegen, dass ich dasselbe beständig zu verbesseru und damit ein Verständniss von den c a us a len Z u s a m menhang derorganischen Formen zu gewimen suche, dlass anf anderem Hege überhaupt nicht gewonnen werden haun. Die Angrifte eines der heftigsten meiner Gegner, Rǘmmerer, nach dessen Ansicht tuberhaupt meine stammbäume nicht nit dem Darwinisnus und der DescendenzTheorie zusammenhängen, habe ich bereits in der Vorrede zur dritten Auflage der "Natürlichen sichöpfungsgeschichte" zurück gowieseu. Es genügt hier, deı naiven batz anzuführen. mit welchem fï̈rmerer selbst sein Verhältniss zur Descendenz- Theorie treffend characterisirt: „Mir erscheinen die Darwin'schen Lehren nur als eine Art Religion des Naturforschers, fül od or wider 
Auf den nachstehenden Seiten werde ich nun den Versuch machen, jenen ersten genealogischen Entwurf des natürlichen Systems wesentlich $\mathrm{zu}$ verbessern und mit Hülfe des biogenetischen Grundgesetzes einerseits, der fundamentalen Keimblätter-Theorie anderseits, eine Theorie zu begründen, welcher ich eine causale Bedeutung für das natürliche System des 'Thierreichs, fiur das Verständniss der Entwickelung seiner ,Typen" und der natiirlichen Verwandtschaft seiner Hauptgruppen beimesse, und welche ich kurz mit einem Worte die Gastraea-Theorie nemen will. Der wesentliche Inhalt dieser Gastraea-Theorie beruht anf der Annahme einer walren Homologie der primitiven Darmanlage und der beiden primären Keimblätter bei allen Thieren mit Ausnahme der Protozoen, und lässt sich kurz in folgenden Worten zusanmenfassen: „Das ganze Thierreich zeriällt in zwei Hauptabtheilungen: die ältere, niedere Gruppe der Protozoen (Urthiere) und die jüngere, höhere Gruppe der Metazoen (Darmthiere). Die Hauptabtheilung der Protozoen oder Urthiere (Animale Moneren und Amoeben, Gregarinen, Acineten, Infusorien) erhebt sich stets un zur Entwickelung der Thier-Individualitä erster oder zweiter Ordnung (Plastide oder Idorgan); die Protozoen bilden niemals Keimblätter, besitzen n i e mals ein en wah $r \in n D$ a $r m$ und entwickeln iberhaupt keine differenzirten Gewebe; sie sind wahrscheinlich polyphyletischen Ursprungs und stammen voll vielen verschiedenen, durch Urzeugung entstandenen Moneren ab. Die Hauptabtheilung der Metazoen oder Darmthiere (die sechs Thierstämme der Zoophyten, Würmer, Molnsken, Echinodermen, Arthropoden, Vertebraten) ist hingegen wahrscheinlich monophyletischen Uxsprungs und stanmt von einer einzigen gemeinsamen, aus einer Protozoen-Form hervorgegangenen Stammform, der G as trae a ab; sie erhebt sich stets zur Entwickelung der ThierIndividualität dritter oder vierter Ordnung (Person oder Cormus); die Metazoen bilden stets zwei primärc Keimblätter, besitzen stets einen wahren Darm (nur wenige $r$ iickgebildete Formen ausgenommen) und entwickeln stets differenzirte Gewebe; diese Gewebe stammen immer nur vo 1 den beiden primären Keimblättern ab, welchesich von

Welche man sejn kann: Allein ïber Glanhenssachen ist es bekanntich böse zu streiten und ich glanbe daher anch nicht, dass Viel dabei heraus. komm! !" 
der Gastraea auf sämmtliche Metazoen, vonder einfachsten Spongie bis zum Menschen hinauf vererbthaben. Die Metazoen-Gruppe spaltet sich zumächst wieder in zwei Abtheilungen, einerseits die Zoophyten (oder Coelenteraten), bei denen sich in Folge festsitzender Lebensweise der sogenaunte ,radiale Typus" ausbildet, anderseits die Bilaterien (oder Sphenoten), bei denen sich in Folge kriechender Lebensweise der sogenannte "bilaterale Typus" entwickelt. Unter den Bilaterien stimmen die niederen Würmer (Acoclomi) durch Mangel des Coelom (der "Leibeshöhle") und des Blutgefïsssystems mit den Zoophyten noch übcrein aus diesen primären älteren acoelomen Würmern haben sich erst secundär die höheren Würmer (Coelomati) durch Ausbildung eines Coelom und eines (damit zusammenhängenden) Blutgefäss-Systens entwickelt. Vier divergente Descendenten der coelomaten Würmer sind die vier typischen höchstentwickelten Thierstämme, die Thier-Typen oder Phylen der Mollusken, Echinodermen, Arthropoden und Vertebraten.

Die feste Grundlage für diese „Gastraea - Theorie" und für die weitreichenden Consequenzen, welche wir nachstehend daraus ableiten werden, liefert meine Monographie der Kalkschwämme (1872). Ich war bei der Ausarbeitung dieser Monographie allerdings zunächst nur bestrebt, einerseits eine möglichst gründliche und unfassende Darstellung sämmtlicher biologischer Verhältnisse dieser interessanten kleinen Thiergruppe zu liefern, anderseits auf Grund ihrer ausserordentlichen Formbieysamkeit eine , an a ly tische Lösung des Problems von der Entstehung der Arten"zu versuchen, einen analytischen Beweis für die Wahrheit der Descendenz-Theorie zu geben. Allein neben diesem besonderen Hauptzwecke führte mich die Entwickelungsgeschichte der Kalkschwämme, die Entdeckung ilner Gastrula-For'm, sowie die Frage nach ihrer natuirlichen Verwandtschaft und nach ihrer Stellung im Systeme des Thierreichs, von selbst und mit Nothwendigkeit zu der allgemeineren Frage nach der Homologie ihrer Keimblätter nit denjenigen der höheren Thiere, und somit weiterhin zu denjenigen Vorstellungs-Reihen, deren Kern mit einem Worte die Gastraea-Theorie bildet. Die Grundgedanken, welche nachstehend hier ausgefiihnt werden, sind alle bereits in der Monographie der Kalkschwämme enthalten; allein es fehlte dort an Raum und an passender Gelegenheit, sie weiter $\mathrm{zu}$ entwickeln. Indem ich diese Entwickelung der Gastraea-Theorie hier gebe, muss ich bezüglich der speciellen Beobachtungs-Reihen, 
welche mir dabei als sichere enpirische Basis dienen, durchgängig auf die Monographie der Kalkschwämme mich beziehen ').

Für die scharfe Trennung des Thierreichs in die beiden Hauptabtheilungen der Protozoen und Metazoen, zwischen denen als fester Grenzstein die Gastraea steht, wurde $\mathrm{nach}$ oben h in dadurch der sicherste positive Anbalt gewonnen, dass ich bei den Spongien die Existenz eines U r a rms und die Entwickelung aus denselben beiden primären Keimblättern nachwies, welche bei allen Metazoen bis zu den Wirbelthieren hinauf dieselbe gemeinsame Grundlage für die ursprüngliche Körperbildung abgeben. Auf der andern Seite erhob sich die Forderung, für jene feste Grenzbestimmung nach unten hin dadurch eine entsprechende negative Sicherheit zu gewinnen, dass für sämmtliche Protozoen der vollständige Mangel des Urdarms und der beiden primaeren Keimblätter nachgewiesen wurde. In dieser Beziehung boten eigentlich nur die Infusorien, insbesondere die Ciliaten, erhebliche Schwierigkeiten dar, da deren systematische Stellung bis in die neueste Zeit hinein zwischen den Urthieren, Pflanzenthieren und Würmern hin und her schwankte. Ich hoffe durch meine kürzlich veröffentlichten Untersuchungen „Zur Morphologie der Infusorien“2) diese schwierige Frage definitiv erledigt und auch den Angriffen der neuesten Zeit gegenüber die zuerst von SІЕвоLD (1845) aufgestellte Ansicht sicher begrïndet zu haben, dass die Infusorien einzellige Organismen, mithin echte Protozoen sind.

Für den Nachweis der wahren Homologie der beiden primären Keimblätter bei sämmtlichen Metazoen, ohne welchen die Gastraea-Theorie nicht haltbar ist, waren mir

1) Insbesondere sind folgende Abschnitte im ersten Bande der „Kalkschwämme" zu vergleichen: Individualitätslelıre (S. 89-124), Histologie (S. 130S. 180), Organologie des Canal-Systems (S. 210-292), Entwickelungsgeschichte (S. 328-360), Anpassung (S. 381-391), Vererbung (S. 399-402) und Philosophie rer Kalkschwämme (S. 453-484). Im letzteren 1 bschnitte sind namentlich die Reflexionen üher die Stammform der Spongien (D. 453), die Keimblätter-Theorie und den Stammbaum des Thierreichs (S. 464, 465), diss biogenetische Grundgesetz (\$. 471) and die Ursachen der Formbildnng (S. 4\$1) für die Gastraea-Theorie von Beleutung. Um unnütze Wiederholungen zu vermeiden muss ich auf diese Abschnitte aus dem ersten Bande (der Biologie der lialkschwämme) wiederbolt verweisen. Zilhlreiche bezügliche Beobachtungen sind im zweiten Bande (dem System der Kalkschwämme) speciell mitgetheilt. Die erlänternden Abbildungen dazu sind auf den 60 Tafeln zu finden, welche den dritten Band (den Atlas der Kalkschwämme) bilden.

2) Jenaische Zeitschrift, VII. Bd. 1873, S. 516, Taf. XXVII, XXVIII. 
von besonders hohem Werthe die ausgezeichneten Untersuchungen ïber die Ontogenie verschiedener niederer Thiere, welche A. Kowatevsky in den letaten sieben Jalnen (in den Memoiren der Petersburger Akademie) veröftentlicht hat, und welche ich unter allen neneren ontogenetischen Arbeiten für die wichtigsten und folgereichsten halten muss '). Allerdings giebt Kowalevsky die von uns behauptete complete Homologie der beiden primären Keimblätter bei den verschiedenen Thierstämmen nicht zu und hält \%. B. das Darmidrüsen - Blatt der Insecten, das Entoderm der Hydroiden u. s. w. für eigenthïmliche Bildungen. Auch in der Deutung der secundären Keimblätter weicht er sehr von der unsrigen ab. Allein im Grossen und Ganzen glaube ich bchaupten zu dürfen, dass die wichtigen, von ihm entdeckten Thatsachen lanter Beweise für die Wahrheit der Gastraea-Theorie sind. Dasselbe gilt von den ausgezeichneten und werthvollen Untersuchungen über die Ontogemie niederer Thiere, welche Edouard van Beneden jun. in verschiedenen Schriften, namentlich in seiner gekrönten Preisschrift über die Zusammensetzung und Bedeutung des Thier-Eies (1870) initgetheilt hat ${ }^{2}$ ).

In wesentlicher Uebereinstimmung mit den Vorstellungs-Reihen, welche mich zur Gastraea-Theorie geführt haben, hat kürzlich (im Mai 1873) E. Ray-Lankester einen sehr lesenswerthen Aufsatz iiber die primitiven Keimblätter und ihre Bedeutung für die Classification des Thierreichs veröffentlicht ${ }^{3}$ ). Zwar weichen im Einzelnen unsere Anschauungen melırfach ab und nannentlich ist unsere Auffassung der secundären Keimblätter, sowie des Coeloms und des Gefässsystems im Verhältniss zu den Urnieren u. s. w. grundverschieden. Jedoch in den meisten Beziehungen und beson-

1) Die ontogenetischen Arbeiten ron Kowalevskr, besonders diejenigen iiber Amphioxus, Ascidia, Enaxes, Holothuria u. s. w. haben bei Weitem noch nicht die Würdigung gefunden, welche sie wirklich rerdienen. Dieser Umstand erklärt sich zum grossen Theil wohl durch die ausseror'lentlich nachlässige und mordentliche Form seiner Darstellung. Nicht allein wird das Terständniss dadurch sehr erschwert, dass der springende Gedankengang der logischen Gliederung und folgerichtigen Anorduung sehr entbehrt, sondern auch dadurclı, dass die erlänternden Figuren zum Theil gar nicht erklärt, zum Theil falsch beziffert und ohne genügende Beziehung zum Texte gegeben sind.

2) Edodard van Bexeden, Recherches sur la composition et la signification de l'oeuf. Bruxelles, 1870.

3) E. Ray-Lankester, On the primitive cell-layers of the embryo as the basis of genealogical classification of animals, and on the origin of vascular and lymph systems. Annals and Mag. of nat. hist. 1873. Vol. XI. S. 321. 
ders in Rücksicht auf die Homologie der primären Keimblätter stimmt $R_{A Y}$-Lankester's Auffassung wesentlich mit der unsrigen überein. Diese Uebereinstimmung ist um so erfreulicher, als wir beide unabhängig von einander und auf verschiedenen Wegen zu denselben Resultaten gelangt sind.

In Betreff der Folgerungen, welche ich nachstehend aus der Gastraea-Theorie ableite, und welche einige der wichtigsten Grundfragen der vergleichenden Anatomie und Entwickelungsgeschichte. sowie der Systematik des Thierreichs betreffen, muss ich diejenige Berechtigung naturphilosophischer Speculation (oder mit anderen Worten: denkender Vergleichung empirischer Resultate) in Anspruch nehmen, ohne welche überhaupt nach meiner Ueberzeugung die allgemeine Biologie keinen Schritt vorwärts thun kann. Ich habe meine Auffassung dieser Berechtigung der nothwendigen Verschmelzung von empirischer und philosophischer Methode in meiner "kritischen und methodologischen Einleitung in die generelle Morphologie der Organismen" sowie in meiner "methodologischen Einleitung" zur Monographie der Kalkschwänme hinreichend erörtert und kann hier einfach auf jene ausführliche Rechtfertigung dieses Standpunktes verweisen.

Jedenfalls dürfte durch die nachstehenden Erörterungen schon jetzt der Nachweis geliefert sein, dass die Typen-Theorie von Cuvpler und Baer. welche über ein halbes Jahrhunderthindurch bis heute die Basis des zoologischen Systems bildete. durch die Fortschritte der Ontogenie unhaltbar geworden ist. An ihrer stelle errichtet die Gastraea-Theorie auf der Basis der Phylogenie ein neues System, dessen oberstes ClassificationsPrincip die Homologie der Keimblätter und des Urdarms, und demnächst die Differenzirung der Kreuzaxen und des Coeloms ist.

Grösserc Bedeutung aber, als durch diese fundamentale Umgestaltung des zoologischen Systems, dürfte die Gastraea-Theorie dadurch gewinnen, dass sie der erste Versuch ist, ein causales Verständniss der wichtigsten morphologischen Verhältnisse und der typischen Hauptunterschiede im Bau der Thiere herbeizuführen, sowie die historische Reihenfolge in der Entstehung der thierischen Organ-Systeme aufzuklären. Vererbung und Anpassung in ihrer. Wechselwirkung treten hier als die beiden einzigen formbildenden Factoren der organischen Form-Verhältnisse in ihr vollesLicht. Vererbung 
und Anpassung sind die beiden einzigen ,"mechanischen Ursacheu", mit deren Hülfe die Gastraea-Theorie die Entstehung der natiulichen Hauptgruppen des Thierreichs und ihrer characteristischen Organisations-Verhältnisse erklärt.

\section{3. i)ie phylogentelisclıe Bedentung der 2 wri primären Keimblälter.}

Diejenige individuelle Entwickelungs-Form des Thier'reichs, auf deren allgemeine Verbreitung sich die Gastraea-T'heorie zunächst stützt, ist die Gastrula (Taf. I, Fig. 1-8). Mit diesem Namen habe ich in der Biologie der Kalkschwämme denjenigen frühzeitigen Entwickelungszustand belegt, in welchem der embryonale Thierkörper die denkbar einfachste Form der Person darstellt: einen einaxigen ungegliederten hohlen Körper ohne Anhänge, dessen einfache Höhle (Urdarm) sich an einem Pole der Axe durch eine Mündung öffnet (Urmund), und dessen Körperwand aus zweiZellenschichten oder Blättern besteht: Entoderm oder GastralBlatt und Exoderm oder Dermal-Blatt ${ }^{1}$ ).

Die Gastrula ist die wichtigste und bedeutungsvollste Embryonal-Form des Thierreichs. Die ausserordentliche Bedeutung; welche ich derselben beimesse, stützt sich erstens darauf, dass dieselbe bei Thieren der verschiedensten Klassen, von den Spongien bis zu den Wirbelthieren in derselben characteristischen Form und Zusammensetzung wiederkehrt. und zweitens darauf. dass die morphologische und physiologische Beschaffenheit der Gastrula-Form an sich auf den monophyletischen Stammbaum des Thierreichs das hellste Licht wirft. Wollte man sich a priori eine möglichst einfache Thierform construiren, welche das wichtigste animale Primitiv-Organ, den Darın, und die beiden primären Keimblätter besitzt, so würde man zu derselben For'm kommen, welche die Gastrula in Wirklichkeit darstellt.

Die Zusammensetzung und Structur der Gastrula habe ich in der Ontogenie der Kalkschwämme genau beschrieben (a. a. 0 . S. 333-337). Sie kehrt bei allen drei Familien dieser Thiergruppe

1) Ueber den festen Individualitäts-Begriff der Person (als des Morphon oder des morphologischen Individuums dritter Ordnumg) vergl. meine Biologic der Kalksclıämme, S. 113. Ueber den festen Begriff der Gastrula rergl. ebendaselust S. 333. In vielen Fällen ist unsere Gastrula identisch mit der embryonalen Thierform, die man bisher Planula nannte; allein in vielen anderen Fällen ist die sogenannte .,Planula“" ein sehr verschieden zusammengesetzter Körper. 
stets in derselben Gestalt wieder, bei den Asconen (Asculmis armata, Taf. 13, Fig. 5, 6); bei den Leuconen (Leuculmis echinus, Taf. 30, Fig. 8, 9); bei den Syconen (Sycyssa Huxleyi, Taf. 44, Fig. 14, 15). Ueberall zeigt sie denselben wesentlichen Bau und unterscheidet sich nur in ganz unwesentlichen Verhältnissen. Der einaxige ungegliederte Körper ist bald kugelig, bald eiförmig oder länglich rund, seltener sphäroidal orler linsenförmig abgeplattet. Der Durchmesser beträgt meistens zwischen 0,1 und 0,2 Mm. Die primitive Magenhöhle oder der Urdarm (Progaster) ist von derselben Gestalt wie der Körper, und öffnet sich an einem Pole der Längsaxe durch eine einfache $M$ undöffnung (den Urmund, Prostoma). Die beiden Zellenschichten oder Blätter, welche die Magenwand zusammcnsetzen, unterscheiden sich in sehr characteristischer Weise. Die innere Zellenschicht, das Entoderm oder Gastralblatt, welches den inneren oder vegetativen Keimblatte der höheren Thiere entspricht, besteht aus grösseren, dunkleren, kugeligen oder subsphärisch-polyedrischen Zellen, welche wenig von den Furchungszellen der Morula verschieden sind und durchschnittlich 0,01 $\mathrm{Mm}$. Durchmesser haben. Die äussere Zellenschicht, das Exoderm oder Dermalblatt, welches dem äusseren oder animalen Keimblatte der höheren Thiere entspricht, besteht aus kleineren, helleren, cylindrischen oder prismatischen Zellen, von denen jede ein langes Flimmerhaar, eine schwingende Geissel trägt und bei $0,02 \mathrm{Mm}$. Länge nur 0,004 Mm. Dicke besitzt. (In den schematischen Darstellungen der Gastrula auf der zu diesem Aufsatze gehörigen Taf. I, Fig. 1-8, sind die Flimmerhaare des Exoderms absichtlich weggelassen.)

Im Stamme der Pflanzenthiere (Zoophyten oder Coelenteraten) kömmt dieselbe Gastrula-Form nicht allein bei den verschiedensten Schwämmen, sondern auch bei den Acalephen sehr verbreitet vor '), bei Hydroidpolypen und Medusen, bei Ctenophoren und Corallen (Taf. I, Fig. 2). Im Stamme der W ürmer findet sich dieselbe Gastrula (der sogenannte ,infusorien-artige Embryo") bald in ganz derselben, bald in mehr oder minder modificirter Form bei den Plattwürmern (Turbellarien, Taf. I, Fig. 3 und Trematoden), bei den Rundwïrmern (Nematoden, Sagitten), bei den Bryozoen

1) Die Gastrula der Pflanzenthiere ist schon in vielen älteren uud neueren Arbeiten über Spongien, Hydromedusen u. s. w. mehr oder weniger deutlich beschrieben und abgebildet worden. Vergl. die Mittheilungen von KoWALEvSKY , „ïber die Entwickelung der Coelenteraten" (Göttinger Nachrichten 1868, S. 154), ferner die Arbeiten von Agassiz, Aluxcan u. s. w. 
und Tunicaten (Ascidien, Taf. I, Fig. 4), bei den Gephyreen und Anneliden (Phoronis, Euaxes, Lumbricus, Chaetopoden)'). Im Stamme der Echinodermen scheint die Gastrula bei allen vier Klassen sehr verbreitet zu sein, namentlich bei den Asteriden und Holothurien $^{2}$ ) (Taf. I, Fig. 6). Im Stamme der A rthropoden ist die Gastrula zwar nirgends in der ursprünglichen reinen Form mehr vollständig conservirt; allein es ist sehr leicht, die frühesten Entwickelungsformen des Nauplius (als der gemeinsamen Crustaceen-Stammform) und vieler niederen Tracheaten auf die Gastrula zu reduciren ${ }^{3}$ ) (Taf. I, Fig. 7). Im Stamme der Mollusken scheint die Gastrula namentlich in den Classen der Muscheln und Schnecken sehr verbreitet $z u$ sein, wahrscheinlich auch bei den Spirobranchien ${ }^{4}$ ); unter den Schnecken ist sie zuerst bei Limnaeus beobachtet worden (Taf. I, Fig 5). Im Stamme der Vertebraten endlich ist die ursprüngliche Gastrula-Form nur noch bei den Acranien (Amphioxus) vollständig, conservirt (Taf. I, Fig. 8). Indessen lässt die Continuität. welche zwischen der Ontogenie des Amphioxus und der iibrigen Wirbelthiere existirt, keinen Zweifel darüber bestehen, dass auch die Vorfalıren der letzteren in früheren Zeiten der Erdgeschichte im Beginne ihrer Ontogenese die Gastrula-Form durchlaufen haben ${ }^{5}$ ).

Diese Erscheinung, dass die Gastrula als früher individueller Entwickelungszustand bei Repräsen-

1) Ueber die Gastrula der. Wülmer sind besonders die Arbeiten ron Kowalevsky zu rergleichen, Memoires de l'Acal. de St. Petersbourg, 'Tom. X. No. 15 (1867), 'Tom. XVI, No. 12 (18i1); seine Ontogenie der Plioronis, der Ascidien, und die embryologischen Studien an Würmern und Arthropoden.

2) Ueber die Gastrula der Echinodermen geben Aufschluss die Darstellungen von JoHannes MüLleR. vol Alexander AGassiz (Lmbryology of the Starfish. Taf. I, Fig. 25-28) und ron liowardevslix (Ontogenie der Holothurien).

3) Dass auch die Vorfahren der Arthropoden sich ans der Gastrula entwickelt haben müssen, ergiebt sich klar aus der Vergleichung ihrer einfachsten frühesten Jugendzustände mit der Gastrula der Würmer (Vergl. besonders die Arbeiten ron Edouard van Beneden und Bessels über die Ontogenip der Crustaceen, von Weismans über die Ontogenie der Insccten).

4) Die Gastrula der Mollusken hat in einer kürzlich erschieneneu Abhandlung E. Ray-Lankester beschrieben (Annals and. Mag. February 1873. S. 86, 87). Bei vielen Muscheln und Schnecken entwickelt sie sich genan in derselben Weise. wie bei den Zoophytes. Wümern, Echinodermen, Amphioxus u. S. W.

5) Die Gastrula der Wirbelthiere, welche jetzt mur noch Amphioxus besitzt, hat uns Kowalevsky in seiner Ontogenie dieses ältesteu Wirbelthieres kennen gelehrt (a. a. O. Taf. I. Fig. 16, 17). 
tanten aller Thierstämme (nur die Protozoen ausgenommen) in derselben wesentlichen Zusammensetzung und Form wiederkehrt, ist eine biogenetische Thatsache von der grössten Bedeutung, und gestattet nach dem biogenetischen Grundgesetze den sicheren Schluss, dass alle diese Phylen des Thierreichs (mit Ausschluss der Protozoen) von einer einzigen unbekannten Stammform gemeinsam abstammen, welche im Wesentlichen der Gastrula gleichgebildet war. Ich habe diese uralte, längst ausgestorbene Stammform, welche schon in früher Primordial-Zeit (während der laurentischen Periode) gelebt haben muss, in der Philosophie der Kalkschwämme Gastra e genannt (a. a. O. S. 345, 347, 467). Die Annahme dieser Stammform, deren nächste Nachkommen während jenes Zeitraums wahrscheinlich in vielen verschiedenen Gattungen und Arten von Gastraeaden aufraten, ist fest begrindet durch die Homologie oder die morphologische Identität der Gastrula bei del verschiedensten Thierstämmen. Ein Zeugniss von besonderer Bedeutung ist dafür der Umstand, dass die Zellen der beiden Keimblätter ihre unterscheidenden Charactere überall (durch Vererbung) bewahrt haben. Ueberall sind die Zellen des inneren Keimblattes oder Entod erms durch indifferentere Beschaffenheit ausgezeichnet; ihre Form ist kugelig oder irregulär-polyedrisch, ihr Protoplasma ist triibe, körnig, locker, fettreich und färbt sich durch Carmin rasch und intensiv; ihr Nucleus ist gewöhnlich kugelig; meistens flimmern sie nicht. Hingegen sind die Zellen des äusseren Keimblattes oder Exoderms weiter differenzirt; ihre Form ist meistens cylindrisch oder konisch; ihu Protoplasma ist hell, klar, dicht, fettarm und färbt sich durch Carmin langsamer und weniger intensiv; ihr Nucleus ist gewöhnlich länglich; meistens fimmern die ExodermZellen '). Offenbar sind dieselben durch Anpassung an die umgebende Aussenwelt stärker modificirt als die innen gelegenen Entoderm-Zellen, welche den ursprïnglichen Character der MorulaZellen getreuer bewahrt haben. Auch verläuft die ontogenetische Bildung und Vermehrung bei den Exoderm-Zellen rascher als bei den Entoderin-Zellen.

Aus der Homologie der Gastrula bei allen Thierstämmen (mit Ausschluss der I'rotozoen) folgt mit Nothwendig-

1) Die Unterschiede zwischen dem Protoplasma der Exoderm- und EntodermZellen sind ganz analog. wie dif Interschiede zwischen der byalinen Rindenschicht (Exoplasma) und rer körnigen II arkschicht (Endoplasma) in dem einzellige n 'Thierkörper' der Infusorieu, Amoeben u. s. w. 
keit die wahre Homologie der ursplünglichen Darmanlage bei allen Thieren, sowie die Homologie der beiden primären Keimblätter, auch bei allen jenen höheren Thieren, die nach dem Gesetze der abgekiirzten Vererbung den ursprïnglichen (iastrula-Zustand verloren haben. Diese Homologie halte ich für so ausserordentlich wichtig, dass ich darauf hin den monophyletischen Ursprung der sechs höheren Thierstämme von der gemeinsamen Stammform der Gastraea annehme und sie alle zusammen als fieimblatt-Thiere (Metuzoa oder Blastozoa) den noch nicht zur Keimblatt-Bildung gelangten Urthieren (Protozon) gegeniiber stelle. Diese Anmahme bildet den Kern der Gastraea-Theorie, deren wichtigste Consequenzen nachstehend entwickelt werden sollen.

Dass die beiden permanenten Bildungshäute der Acalephen, Entoderm und Exoderm, den beiden Keimblättern der höheren Thiere wirklich homolog sind, hatte schon 1849 Huxuey in seiner ausgezeichneten Abhandlung, ,On the anatomy and the affinities of the Medusae" behauptet"). Später ist dann vor Allen Kowalevsky in einer Reihe von berleutungsvollen ontogenetischen Arbeiten bemüht gewesen, diese Homologie über den grössten Theil des Thierreichs auszudehnen und zu zeigen, dass (mit wenigen Ausnahmen) die beiden wohlbekannten ursprïnglichen Keimblätter der Wirbelthiere auch bei den wirbellosen Thieren ter verschiedensten Stämme wiederkehren. Besonders wichtig wurde in dieser Beziehung seine glänzende Entdeckung von der identischen Ontogenese des Amphioxus nud der Ascidien (1867), eine der bedentendsten und folgenreichsten Entdeckungen der neueren Zoologie ${ }^{2}$. Am

1) Philosophical Transactions; $1849, \mathrm{~s} .425$. ...A complete identity of strucfure comects the foundation membranes of the Medusice with the curresponding membranes in the rest of the series; and it is curious to remark; that thronghout. the imner and outer membranes appear to bear the same physiologieal relation to one another as do the serous and mucous layers of the germ: the outer becoming developed into the muscular system and giving rise to the organs of offence and defence; the innes, on the other hand, appearing to be more closely subservient to the purposes of nutrition and generation."

2) Die bedeutende Tragweite, welche wir Kowalevsky's von Kupfrer liestatigter Entdeckung beimesseı, beruht nach unserer Aliffissung auf zwei Punkten. Erstens ist dadurch die tiefe Kluft zwischen den Wirbelthieren und den Wirbellosen ausgefüllt, welche bisher für mausfüllbar und für ein Haupthiuderniss der Descendenz-Theorie galt. Zweiteus ist dadurch auch für die Wirbelthiere, ebenso wie für die verschiedensten Wirbellosen, die ursprüngliehe ontogenetische Entwickelung aus der Gastrula, mithin die gemeinsame Descen- 
weitesten ausgeführt, zugleich aber doch theilweise beschränkt ist diese Homologie der beiden primordialen Keimblätter und der zunächst daraus entstehenden Organe in Kowalevsky's neuester Arbeit, den "embryologischen Studien an Würmern und Arthropoden" (1871). Die scharfsinnigste Beurtheilung und die entschiedenste Vertretung hat diese Theorie sodann durch Nirolaus Kueinenberg in seiner vortrefflichen Monographie der Hydra gefunden, einem Werke, welches durch die glückliche Verbindung von genauester objectiver Beobachtung und klarer philosophischer Reflexion eine hervorragende Stellung unter den neueren morphologischen Arbeiten einnimmt. Endlich habe ich selbst in der Biologie der Kalkschwämme (a. a. O. S. 464) nachgewiesen, dass bei den Spongien die beiden primären Kíeimblätter zeitlebens in ihrer einfachsten Form persistiren, dass das äussere animale Keimblatt hier gleichzeitig die animalen Functionen der Empfindung und Bewegung. Skeletbildung und Deckung versieht, während das innere vegetative Keimblatt lediglich die vegetativen Functionen der Ernährung und FortpHlanzung besorgt. Zugleich habe ich daselbst die Keimblätter-Theorie direct auf den monophyletischen Stammbaum des Thierreichs angewendet und dadurch dem natiurlichen System desselben die feste biogenetische Basis zu geben gesucht.

Als complet homolog im strengsten Sinne können durch die ganze Thierreihe hindurch (nach Ausschluss der Protozoen, also bei allen Metazoen, von den Spongien bis zu den Vertebraten hinauf) nur die beiden primären Keimblätter und die von ihnen umschlossene primitive Darmhöhle gelten. Die beiden Zellenschichten der Gastrula und der durch sie recapitulirten Gastraeaden, sowie das Exoderm und das Entoderm der Spongien sind in diesem strengsten Sinne unzweifelhaft complet homolog den beiden primären Keimblättern beim Embryo der Wirbelthiere, Gliederthiere, Weichthiere, Sternthiere und Wïrmer. Die scheinbaren Hindernisse, welche die Ausbildung eines Nahrungsdotters (und die damit zusammenhängende partielle Furchung) bei deu meisten höheren Thieren dieser completen Homologie bereitet. sind leicht zu beseitigen und durch secundäre Anpassung zu erklären. Hingegen wird diese Homologie incomplet. sobald sich die beiden primären Keim-

denz vou der Gastrad naehgewiesen. Alle Vursuche. welche in neuester Zeit von verschiedenen Antoren gemacht worden sind. die Thatsache dieser fumdamentalen Entrleckung zu hestruiten oder ihre Bedeutung zu entkräften. erscheinen so schwach, dass sie keiner Widerlegung bedürfen. 
blätter zu differenziren und zwischen ihnen cin mittleres Keimblatt (Mesoderm) zu entwickeln beginnt. Dic Ontogenese der Pflanzenthiere und Wümer lehrt dentlich, dass dieses mittlere Keimblatt stets als secundäres Product von einem der beiden primären Keimblätter oder von beiden zugleich abzuleiten ist. Eines oder beide primäre Keimblätter müssen daher nothwendig bei der Production des Mesoderms eine Differenzirung cingehen und können in Folge dessen jetzt nicht mehr mit den beiden unveränderten und permanenten Keimblättern der Gasträaden und Spongien (Exoderm und Entoderm) complet verglichen werden. Sie muissen jetzt vielmehr, gleich den Mesoderm-Schichten selbst, als secundäre $\mathrm{K}$ e imblätter unterschieden werden ${ }^{1}$ ).

\section{Die phylogentische Bedeutung der rier secmulären Keimblätler.}

Während sich dic Homologje der beiden primären Keimblätter mit dem Exoderm und Entoderm der Gastrula, und die phylogenetische Identität derselben in allen Thierstämmen (mit Ausnahme der Protozoen) schon jetzt ziemlich sicher annehmen lässt. so ist dagegen die Auffassung und Deutung des sogenannten Mesoderms oder des mittleren (dritten) Keimblattes, und aller der Theile, die sich aus diesem zwischen den beiden primären Keimblättern entwickeln, noch vielen Berlenken unterworfen. Die Widerspriiche,

1) Die urprüngliche llomologie der Gastrula in allen verschiedenen Thierstämmen, von den spongien lis zu den Vertebraten, ans der wir hier direct anf die wahre Homologie des Darmes bei allen diesen Thieren. und anf ihre gemeinsame Descendenz von der Gastraea schliessen. ist von solcher Berlentung, lass ich wenigstens den wichtigsten unter den. Einwirfen, die man dagegen erheben könnte. willerlegen will. Dieser Einwurf betrifft die scheinbar sehr verschiedene Entstehung der Gastrula aus der Morula. In den ineisten Fällen entstcht ans ler Morula zunächst eine kugelige Keimblase, deren Wand ans einer Zellenschicht zusammengesetzt ist. Indem sich diese Blase an eintr stelle selbst einstiilpt. entsteht ein zweihlitteriger Becher. Wenm diese Einstülpung vollendet ist, so rlass der eingestülpte Theil (Ento. derm oder (iastralblatt) sich innen an den änsseren, nicht eingestülpten Theil (Exoderm oder Dermalblatt) anlegt, ist die Gastrula! fertig. Dieser BildungsModus der Gastrula scheint der ursprüngliche zu sein. In anderen Fällen hingegen höhlt sich die Morula von innen her ans und die cẹntrale Höhlung (Nagenhöhle), deren Wand ans zwei Blättern besteht. bricht secundär nach aussen durch (Mundöffinnig). Dieser Bildungs-Modus der Gastrula scheint aus den ersteren llurch abgekürzte Vererbung zusammengezogen zo sein. Das Resultal ist in beiden Fällenganz dasselbe, und die scheinbar bedeutende Verschiedenheit der Genese ist secundär, als Anpassungs-Wirkung zu betrachten, wie $R_{A Y}$-LANEester $(0$. a. a. S. 330$)$ sehr gut gezeigt hat. 
welche in dieser Beziehung zwischen den verschiedenen Autoren existirel, sind so gross und so fundamental, dass es bei dem gegenwärtigen Zustande der ontogenetischen Literatur völlig unmöglich ist, dieselben in Uebereinstimmung zu bringen. Nicht allein wird der Ursprung und die weitere Entwiekelung des mittleren Keimblattes in den verschiedenen Thiergruppen ganz verschieden geschildert, sondern sogar bei ein em und demselben Thiere (wie z. B. beim Huhn. bei der Forelle) behaupten verschiedene Beohachter mit gleicher Sicherheit völlig entgegengesetzte Thatsachen. Der eine Autor lässt das Mesoderm eben su bestimmt aus dem unteren, wie der zweite Autor aus dem oberen Keimblatt hervorgehen; ein dritter Autor meint, dass ein Theil des Mesoderms aus dem unteren, ein anderer 'Theil aus dem oberen Keimblatt entstehe, und ein vierter Autor lässt gar einen Theil des mittleren Keimblatts oder auch wohl das Ganze aus dem nicht organisirten Nahrungsdotter "von aussen" hineinwandern! Will man nun auch einen grossen Theil dieser unvereinbaren Widersprüche durch die Schwierigkeit der Beobachtung entschuldigen. so ist doch sicher der grössere Theil nur durch das Hüchtige oder unmethodische Verfahren der Beobachter bedingt. Gerade in der Ontogenie des Mesorlerms zeigt sich schlagend, wie nothwendig für ontogenetische Cntersuchungen der beständige Hinblick auf die vergleichende Anatomie und die Phylogenie ist.

Um die Schwierigkeiten. welche die Entstehung des mittleren oder motorischen Keimblattes wirklich darbietet, zil bewältigen. dürfte es vor Allem gerathen sein. von vornherein die beiden wesentlich verschiedenen Bestandtheile zu sondern. aus denen dasselbe später zusammengesetzt erscheint, nämlich erstens die änssere Lamelle: Baer's Fle ischschicht, Remak's Hautplatte (besser: Hautfaserplatte) oder das Hautmuskelblatt (Parie(al-Blatt des Mesoderms); und zweitens die innere Lamelle: Barr's Gefässschicht, Renak's Darmfaserplatte oder das Darmmuskelblatt (Visceral-Blatt des Mesoderms). Es sprechen nänılich wichtige Gründe für die Amnahme. dass diese beiden Blätter phylogenetisch ursprünglich verschieden sind. obgleich sie on togen etisch bei vielen Thieren als secundäre Differenzirungen eines scheinhar einfachen mittleren Blattes auftreten. Diese Anschauung wurde bereits von $B_{A E R}$ vertreten, der jedes der beiden primären Keimblätter in zwei Lamellen zerfallen lässt. Aus der Spaltung des äusseren oder animalen Keimblattes entsteht die Hantschicht und die Fleischschicht: aus der Spaltung des inneren 
oder vegetativen Keimblattes entsteht die Gefässschicht und die Schleimschicht. Später wurde aber diese Anschaung fast allgemein verlassen und angenommen, dass zunächst nu aus cinem der beiden primären Keimblätter ein drittes, mittleres Blatt entsteht, und dass die "Fleischschicht" und „Gefüssschicht" Spaltungs-Producte dieses letzteren sind.

Allerdings scheint bei den Wirbelthieren schon die allererste Anlage des Mesoderms eine einheitliche zu sein, so dlass die ganze Zellenmasse desselbeı von einem der beiden primären Keimblätter abzuleiten wäre. Allein schon der Unstand, dass bei einem und demselben Wirbelthier cin 'Theil der zuverlässigeren Beobachter mit derselben Bestimmtheit das mittlere Blatt aus dem oberen (animalen), wie ein anderer Theil aus dem unteren (vegetativen) Keimblatte ableitet, lässt die Vermuthung aufkommen, dass beide primäre Keimblätter sich am Aufbau des mittlereu Keimblattes betheiligen. Diese Vermuthung wirl fast zur Gewissheit durch die Tergleichung der Mesorlerm-Entwickelung bei den verschiedenen Wirbellosen. wo in vielen Fällen nur das Hautmuskelblatt sich aus dem oberen Keimblatt, hingegen das Darmmuskelblatt aus dem unteren Keinblatt entwickelt. Unter vielen darauf bezïglichen Beobachtungen sind namentlich diejenigen von Kowalevsky über Eudxes bedentungsvoll (Petersb. Mem. 1871, T. XVI, Nr. 12. S. 16. Taf. III). Uebrigens liegen auch bei den Wirbelthieren aus nenester Zeit mehrfache Beobachtungen vor, aus denen zu folgen scheint, dass ursprünglich, primäl bei ihnen derselbe Entwickelungs-Modus stattfindet und dass die Vereinigung der beiden Muskelblätter in dem einfachen mittleren Keimblatt ein secundärer Vorgang; die darauf folgende Spaltung des letzteren in die beiden ersteren mithin ein tertiärer Process ist (Tergl. 'Taf. I, Fig. $11-16$ nebst Erklärung). Besonders wichtig erscheint hierfür die genaueste Untersuchung der Vorgänge in Axentheile der Vertebraten-Keimscheibe. Hier erscheinen schon sehr frühzeitig die sämmtlichen Keimblätter mehr oder minder innig zu der indifferenten Zellenmasse vereinigt. welche His mit dem Namen Axenstrang belegt und neben den Keimblättern zu den U ranlagen des Embryo rechnet. Diesc letztere Ansicht ist ganz gewiss falsch. Denn wie die Vergleichung der Gastrula bei den verschiedenen Thierstämmen lehrt, ist überall die Scheidung der beiden primären Keimblätter ursprünglich eine vollständige; ihre Verbindung im Axenstrange der Wirbelthiere ist als secundäre Concrescenz autzufassen. Sehr 
wichtig aber erscheint die Beobachtung, dass dieser Axenstrang aus Zellen des unteren und oberen Keimblattes zusammengesetzt ist, und Zellen sowohl für die untere wie für die obere Lamelle des Mesoderms liefert. Sehr bedeutungsvoll ist ferner der Umstand, dass anch bei vielen Wirbelthieren schon sehr frühzeitig. gleich nach der Sonderumg der Chorda von den Seitenplatten. und noch vor Differenzirung der Urwirbelplatten (!) eine horizontale Spaltung der Seitenplatten eintritt, die bis gegen die Axe hingeht. Allerdings verschwindet diese Sondermug des Mesoderms in zwei mittlere Blätter wieder während der Sonderung der Urwirbelplatten; sie ist aber doch wohl als Vorläufer der späteren bleibenden Spaltung der Seitenplatten aufzufassen. Eine entscheidende Bedeutung für diese wichtige Frage möchte ich der Beobachtung von Kowalevsky beilegen, wonach bei Amphioxus unzweifelhaft nur das Hautmuskelblatt vom äusseren, hingegen das Darmmuskelblatt vom immeren Keimblatt abstammt. Beide Muskelblätter sind hier ursprünglich völlig getrennt (a. a. O. S. 6: Taf. II, Fig. 20). Vergl. Taf. I, Fig. 13.

Betrachtet man dieses schwierige Problem im Lichte der Descendenz Theorie, so ergiebt sich als das Wahrscheinlichste, dass die Zellen der Darnfaserplatte oder des Darmmuskelblattes sich in ähnlicher Weise aus den Zellen des Gastralblattes oder des vegetativen Blattes entwickelı, wie die Zellen Rer Hantfaserplatte oder des Hantmuskelblattes sich ursprïnglich aus den Zellen des Dermalblattes oder des animalen Blattes hervorbilden. Für letzteren Yorgang ist die wichtige Entdeckumg von Kuennenberg höchst bedeutsam, wonach die Muskelfasern der Hydra (die erste Anlage des Mesoderms) noch nicht einmal selbstständige Zellen. sondern bloss faserförnige Fortsätze der nervösen Zellen des äusseren Keimblattes, der "N euro-Muskel-Zellen" sind.

Damit ist nun keineswegs gesagt, dass überall das Mesoderm aus diesen beiden Blättern ursprünglich zusammengesetzt wird. Di beide Muskelblätter hiernach unabhängig von einander entstanden wären. das dermale - der Hautmuskelschlauch - als Bewegungs-Organ für die $\mathrm{H}$ a ut. das gastrale - der Darmmuskelschlauch -.. als Bewegungs-Organ fïr den Darm, so ist auch phylogenetisch der Fall denkbar. dass nur eines von Beiden zur Entwickelung gelangt. Dieser Fall liegt in der That bei einigen Bydroiden und wahrscheinlich bei der Mehrzahl der Acalephen vor; das Darmmuskel-Blatt fehlt hier und das ganze Mesoderm 
ist Product des Exoderms, entspricht also mit allen seinen Theilen nur clem Hautmuskel-Blatt.

Dass bei den Wirbelthieren die beiden Muskelblätter im Axentheile des Körpers anfünglich zusammenhängen und erst später sich scheiden, Jässt sich aus einem sehr alten Verwachsungsprocess der vier ursprünglich getrennten secundären Keimblätter erklären der in der Axe des Körpers bei den ältesten Acranien stattfand und mit der Entstehung eines inneren, centralen Axen-Skelets (der Chorda) in ursächlichem Zusammenhange stand. Dass gerade hier in dem .Axenstrang" die Keimblätter sich schon frühzeitig inniger verbanden und dadurch vieffach eine ontogenetische Trïbung und Abkürzung der ursprünglichen phylogenetischen Vorgänge erfolgte, darauf deutet auch die sehr frühzeitige Differenzirung der Chorda und viele andere eigenthümliche Vorgänge hin. welche in diesem axialen Körpertheile frühzeitig stattfinden. Hingegen lassen sich durch die Annahme. dass dieser centrale „Axenstrang" ein secundäres Verwachsungs-Product ist, und dass demnach beide primäre Keimblätter (bei den fünf höheren Thierstämmen!) an der Zusammensetzung des Mesoderms Theil nehmen. nicht allein viele von jenen eigenthümlichen Vorgängen. sondern auch die Widerspriiche der meisten Autoren befricdigend aufklären.

Bei dieser Auffassung lässt sich anch die Entstehung der L eibeshöhle sehr einfach physiologisch erklären. Man kann sich dieselbe ganz mechanisch vorstellen. sobald man sich die so eben entwickelten beiden Muskelblätter in gleichzeitiger und von einander unabhängiger Action denkt. Es wird dann zwischen Beiden sich nothwendig eine Spaltung herstellen und in der so entstandenen Höhle Flïssigkeit ansammeln. Diese durch die Darnwand in die primitive Leibeshölle transsudirte Flüssigkeit ist das erste Blut, und einzelne während der Transsudation abgelöste Zellen des Darmfaser-Blattes, welche in dieser primitiven BlutHiissigkeit bleiben und sich vermehren, sind die ersten Blutzellen. Dje wahre Leibeshöhle der 'Thiere, das Coeloma (oder' die sogenannte ,Pleuroperitoneallö̈hle: ${ }^{6}$ ) ist demnach phylo-

1) Die technische Be'zeichunng Coeloma, welche ich in der Biologie der Kalkschwärnme für die wahre Leibeshöhle der Thiere vorgeschlagen habe (s. 468) verdient vol (lem hisher üblichen Ausdrucke Pleuroperitoneulhöhle nicht allein wegen der grösseren hürze und Bequemlichkeit den Vorzug; sondern vor allem desshalb. weil die letztere Bezeichnung auf die Wirbellosen im eigentlichen Sinne gar nicht anwendbal ist und eigentlich sich aut den jüngsten und 
genetisch ebenso durch Auseinanderweichen der beiden Muskelblätter oder mittleren Keimblätter entstanden, wie das ontogenetisch aus der Embryologie der Wirbelthiere seit Rемак sicher bekannt ist. Da wo die beiden Blätter in Zusammenhang bleiben und den Darm an der Leibeswand festgeheftet erhalten, bildet sich das Mesenterium. Ich habe meine morphologische Auffassung der Leibeshöhle bereits in der Biologie der Kalkschwämme (S. 467) auseinandergesetzt und begnüge mich daher hier damit, nochmals ausdrücklich hervorzuheben. dass nach meiner Auffassung das Coelom durch den angegebenen Vorgang (Auseinanderweichen (ler beiden Muskelblätter) zuerst bei den Würmern entstanden ist und sich von diesen auf die vier höheren Thierstänme vererbt hat. Das Coelom oder die wahre Leibeshöhle fehlt hingegen noch sämmtlichen Zoophyten (Spongien und Acalephen), sowie den niedersten Würmern, den Plath elminthen (Turbellarien, Trematoden, Cestoden). Mit dem Coeloma fehlt diesen Thieren zugleich das Blut und das Gefäss-System überhaupt. Denn diese Theile sind untrennbar verbunden. Wo sich die erste Spur von wahrer Leibeshöhle zeigt, da ist auch schon das erste Blut vorhanden, nämlich der Saft, der letztere erfüllt, die primitive .Haemolymphe" oder ,.Haemochylıs".

Bei dieser Auffassung des Coeloma befinde ich mich in fundar.entalem Gegensatze zu der von den meisten Zoologen getheilten Ansicht von Leuckakт. der den Zoophyten (seinen Coelenteraten, ein echtes Coelom zuschreibt und (noch 1869) den Satz vertheidigte: „Die Leibeshöhle der Coelentraten liegt nicht zwischen Exoderm und Entoderm, sondern wird von lezterem umschlossen" "?. Eben so wenig kann ich die Auffassung von Kowalevskx theilen.

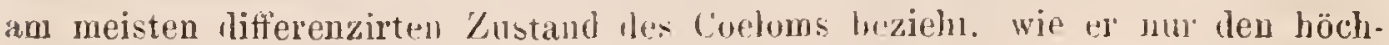
sten Wirbelthicren zukummt.

1) Leuchart sagt (im Arch. für Naturg. 1870. 11, S. 270): ,Die Ammahme. lass der imere Höhlenapparat der Coelenteraten nach semer morphologischen Bedentung der Leibeshöhle ies ibrigen libiese entspueche. has ziemlich allgemein Eingang in unsere Wissenschaft gefunden - eme Auffas. sung. welche die anatonischen Verhältnisse nicht bloss rechtfertigen, sondem dem Beobachter geradezn aufhängen u. s. w." Hiergegen ist $z n$ hemerken. lass schon $V_{A N}$ der Howres 20 . Jahre fiöher in semer Naturgeschichte (zu der Levckart "Berichtigungen" liefurte) (lie Acalephen ganz richtig mit folgenden Worten charditerisinte. .Ventriculus parenchynate corporis sine vavitate abdominali inclusns; canales e ventricnlo ortum ducentes." Später haben in demselben simne Gegenbauk (1861), Xoschis (1865). Semper (1867) und KowALEVSKy (1868) das coelentericche Höhlen-System der Zooplyten richtig als Darmhöhle aufgefasst. 
welcher die Furchungshöhle oder Segmentationshöhle für die erste Anlage der Leibeshöhle erklïrt. Ich kann in diesem Hohlraum. der sich während der Furchnng zwischen den Furchungszellen bildet und später die Höhlnng der Keimblase (Vesicula blastodermica) bildet, nur eine vorïbergehende Höhlung ohne jede bleibende morphologische Bedeutung erblicken. In der That verschwindet dieselbe anch immer wieder im Lanfe ter Ontogenese und geht niemals direct in das wahre Coelom iiber. Dieses letztere erscheint erst viel später, als eine wahre Neubildung. eine Spalte zwischen den beiden Muskelblättern. Nach Kowalersky's Ansicht wïrde das Coelom phylogenetisch viel älter als die Darmhöhle sein, während in der That das Umgekehrte der Fall ist. Der Darm hat als Primitiv-Organ bei den Zoophyten und Acoelomen sicher sehr lange existirt, bevor sich (bei den Coelomaten) zwischen Darmwand mol Jeibeswand die wahre Leibeshöhle entwickelte.

j. His systematische Beflentuig Her tiastrapa-Theorie.

Für das natürliche System des Thierreichs, oder was dasselbe ist, für seinen Stammbaum, ergeben sich aus den bisherigen Erörterungen folgende Schlüsse, welche ich zum Theil bereits in ler Biologie der Kalkschwämme, zum Theil in der vierten Auflage der .,Natïrlichen Schöpfungsgeschichte" (im 18. Vortrage) angedeutet habe. Zunächst zerfällt das ganze Thierreich in zwei grosse Hauptgruppen, deren scheidende Grenzmarke die Gastrula bildet: einerseits die Stammgruppe der Urthiere (Protozoa) anderseits die sechs höheren Thierstämme. dic wir jenen als Keimblatthiere (Metazoa oder Blastozoa) gegenüber stellen. Bei den Urthieren (Protozoa) besteht der ganze Körper entwerder 1) aus einer einfachen Cytode (Moneren, Monothalamien) oder 2) aus einem Aggregate von Cytoden (Polythalamien) oder 3) aus einer einfachen Zelle (Amoeben, einzellige Gregarinen, Infusorien) oder 4) aus einem Aggregate von einfachen, gleichartigen Zellen (vielzellige Gregarinen, Synamoeben), oder endlich 5) es sind zwar die Zellen des Körper's in geringem Grade differenzirt, aber sie bilden noch keine Keimblätter, und umschliessen noch keine wahre Darmhöhle: Die Individualität der Urthiere bleibt stets auf sehr niedriger Stufe stehen. Sie bilden nämlich entweder ein Morphon erster Ordnung, eine einfache Plastide (eine Cytode oder eine Zelle); oder sie bilden höchstens ein Mor- 
phon zweiter Ordnung, ein "Organ" in rein morphologischem Sinne, ein I do rgan (Vergl. die Individualitätslehre in der Biologie der Kalkschwämme, S. 103 u. s. w.). Niemals aber erheben sich die Protozoen zu dem Formwerthe eines Morphon dritter oder vierter Ordnung, einer Person oder eines Stockes (in dem an letzterem Orte festgestellten Begriffe). Ebenso wie den Protozoen ein wirklicher D a r'm fehlt (das erste und älteste Organ der Keimblatt-Thiere), ebenso fehlen ihnen alle differenzirten Organ-Systeme, welche sich bei den letzteren finden. Es fehlen ihnen NervenSystem, Muskel-System, Gefäss - System, Dermal - System u. s. w. Ebenso fehlen ihmen die differenzirten Gewebe.

Aus den tiefliegenden Gründen, welche ich im zweiten Buche der generellen Morphologie und in meiner Monographie der Moneren ausführlich entwickelt habe, erscheint es für das Verständniss der generellen Biologie von wesentlichem Vortheil, mindestens einen grossen Theil der sogenannten Protozoen aus dem Thierreich überhaupt auszuscheiden und als Angehörige des neutralen, zwischen Thierreich und Pflanzenreich mitten inne stehenden ProtistenReiches zu betrachten. Dahin gehört ein Theil der Moneren, der Amoeboiden und der Flagellaten, fermer die Catallacten, die Labyrinthuleen, die Myxomyceten und die ganze formenreiche Classe der Rhizopoden mit allen ihren verschiedenen Abtheilungen: Acyttarien Radiolarien u. s. w.). Alle diese Protisten sind als selbstständige organische Stämme oder Phylen zu betrachten, welche mit dem Thierreich in keinerlei genealogischem Zusammenhange stehen und mithin auch nicht in sein natürliches System gehören. Hingegen sind diejenigen einfachsten Organismen, welche zu den wirklichen Stammformen des 'Thierreichs gehören und die wahre Wurzel des thierischen Stamıbaumes begründen, oder welche selbstständige Wurzelausläufer jener Wurzel repräsentiren, sowie endlich auch jene einfachsten Organismen, welche unzweifelhaft thierischen Charakter zeigen (wie die Infusorien), als wirkliche Urthiere oder Protozoen von jenen neutralen Urwesen oder Protisten zu trennell. Als solche echte Urthiere wären diejenigen Moneren und Amoeben anzusehen, welche wirklich die ältesten Stammformen des Thierreichs repräsentiren, und die ich in der vierten Auflage der Schöpfungsgeschichte als Eithiere (Ovularia) zusammengefasst habe, weil sie den Formwerth der einfachen (kernhaltigen) Eizelle oder der (kernlosen) Eicytode besitzen. Ferner wären dahin die der Planula entsprechenden Thierformen (Planäaden), endlich die Gre- 
garinen, die Acmeten und die rchten bewimperten Infusorien (Ciliata) zu rechnen.

Die zweite Hauptabtheilung des Thierreichs bilden die sechs höheren Thierstämme, welche sämmitlich von der gemeinsamen Stammform der Gastraea abzuleiten sind. Wir fassen sie als Keimblatthiere (Metazoa oder Blastozoa) oder Darmthiere (Gastrozoa) zusanmen. Bei allen diesen Thieren, von den Spongien bis zu den Vertebraten hinauf, entwickelt sich der Leib ursprünglich stets aus zwei primären Keimblättern, dem animalen Exoderm und dem vegetativen Entoderm. Das letatere umschliesst stets eine wahre Darmhöhle mit Mundöffnung '). Demnach hat der Körper den Formwerth eimes Morphon dritter Ordnung, einer wahren Person, oder ist aus mehreren Personen zusanmengesetzt, also ein Form-Individuum vierter Ordnung, ein Stock (Biologie der Kalkschwänme, S. 103 u. s. w.). Zum Mindesten besitzen alle diese Keimblatt-Thiere zwei differen-

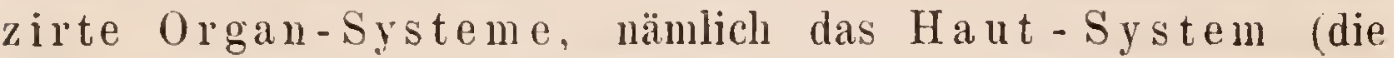
Decke des äusseren Keimblattes mit ihren Derivaten) und das Darmsystem (die Darmauskleidung des inneren Keimblattes mit ihren Derivaten).

Für die weitere Classification der Metazoen könnte man in erster Linie vorzüglich drei verschiedene Eintheilungs-Principien verwerthen: 1) Den Mangel oder Besitz (les Coeloms;2) die verschiedene Zahl der secundären Keimblätter; 3) die radiale oder bilaterale Grundform.

Wenn man das Hauptgewicht auf das Coelon und das damit zusammenhängende Gefäss-System oder Blutsystem legen will, so zerfällt die Hauptabtheilung der Metazoen zunächst in zwei verschiedene Gruppen: einerseits die niederen líeimblattthiere, ohne Coelom und ohne Haemolymphe: Zoophyten und Acoelomen (Plathelminthen); anderseits die höheren Metazoen, mit Coelom und mit Haemolymphe: die Co elom at en und die aus ihnen hervorgegangenen vier höchsten Thierstämme: Echinodermen, Arthropoden, Nollusken und Vertebraten (Vergl. die Biologie der Kalkschwämme, S. 465, 468). Für diese beiden Gruppen könnte man im strengsten

1) Die wenigen darmlosen Thiere unter den Blastozoen, die Cestoden und Acanthocephalen, düren hier nicht als Einwurf geltelı, da sie offenbar den Darm durch Parasitisnus verloren haben und nrsprünglich von darmführenden Würmerı abstammen. Dies geht aus ilı'er vergleichenden Anatomie und Ontogenie unzweifelhaft hervor (Vergl. Generelle Morphologie Bd. II, S. LXXX). 
Sinne des Wortes (aber allerdings nicht in der entsprechenden Begrenzung ihres Autors) dié uralten Bezeichnungen des Anistotrales: Anaema und Enaema anwenden. A n a ema oder wahre ;blutlose“ Metazoen sind die Zoophyten und Plathelminthen (Acoelomen) : Enaema oder wahre,.Blutthiere" sind hingegen die Coelomaten (Würmer mit Blut und Coelom) und die daraus entsprungenen vier höchsten Thiel-Phylen. Erstere könnten als Anaemaria, letztere als $\mathrm{H}$ a emataria bezeichnet werden.

Der Versuch, die Zahl und Differenzirung der constituirenden Keimblätter als fundamentales Eintheilungs - Prinzip für die Hauptgruppen des Thierreichs zu verwerthen, ist in neuester Zeit zweimal in verschiedener Weise ausgeführt worden, von Gustav J Aeger und von E. Ray-Lankestel. Der erstere liefert in seinem gedankenreichen Lehrbuche der allgemeinen Zoologie (1871) ein besonderes Kapitel iiber die "Lehre von den Schichten und den Schichtengruppen: Stratogl aphie des Thierkörpers". JAEGER unterscheidet hier: 1) Zweischichtige Thiere (,Die niedrigsten mehrzelligen Thiere"); 2) Dreischichtige Thiere (Coelenteraten); 3) fünfschichtige Thiere (Enteraten oder Darmthiere: unsere Bilaterien. die fünf höheren Thierstämme). So anerkennenswerth der Versuch ist, in dieser Weise die ,Stratographie" für die animale Morphologie zu verwerthen, so müssen wir ihn doch im Einzelnen füı misslungen erklären. Es ergiebt sich dies sofort durch Vergleichung voln JAEGER's Darstellung (besonders $\$ 55,67$ ) mit unserer Darstellung in rorliegenden Aufsatze, der die Gastraea-Theorie zur Basis hat. Ebenso kann ich auch dem Versuche ron RaYLankester (a. a. O. S. 325) nicht in Einzelneu beistimmen. Er unterscheidet 1) Homoblastica: ohne differenzirte Keimblätter (Protozoa), 2) Diploblastica: mit zwei Keimblättern (Coelenterata), 3) Triploblastica: nnit drei Keimblättem (die fünf höheren Stämme, unsere Bilaterien).

Nach unserer eigenen Ansicht wiirde man vielmehr, wenn man in dieser Weise die Hamptgruppen des Thierreichs durch die Zahl der Keimblätter charakterisiren wollte, folgende 4 oder 5 Abtheilungen zu unterscheiden haben: 1) Ablasteria: Thiere ohne Keimblätter (Protozoa); 2) Diblasteria: Thiere mit zwei permanenten Keimblättern (Gastraeaden und Spongien, niederste Acalephen); 3) Triblasteria; Thiere mit drei Keimblättern (die Mehrzahl der Acalephen: Hydromedusen, Ctenophoren, Corallen) 4) Tetrablasteria: Thiere mit vier Keimblättern (Hautsinnesblatt, Hautmuskelblatt, Darmmuskelblatt, Darmdrïsenblatt): Die 
Bilaterien oder die vereinigten fünf höheren Thierstämme. Unter diesen letzteren würden die A c o elom en (die Würmer ohne Leibeshöhle und ohne Blut, die Plathelminthen) den niederen Entwickelungszustand darstellen, aus welchem sich erst secundär durch Auseimanderweichen der beiden Muskelblätter die Coelomaten (die Wiirmer mit Leibeshöhle und mit Blut) entwickelt haben. Divergirende Descendenten von vier verschiedenen Coelomaten-Formen sind die vier höchsten Thierstämme: Echirodermen, Arthropoden, Mollusken, und Vertebraten. Die Ableitung dieser vier typischen Phylen aus der geneinsanen Stammgruppe der Würmer ist nicht schwer. Noch jetzt zeigt uns die vergleichende Anatomie und Ontogenie, dass dieselben nahe Verwandte unter den Coelomaten haben. Die Anneliden führen $\mathrm{zu}$ den Arthropoden und Echinodermen, die Bryozoen (?) zu den Mollusken, die Tunicaten (Ascidien) zu den Vertebraten hinüber (Vergl. den XVIII. Vortrag der Natürlichen Schöpfungsgeschichte). Wenn man im Simne JAEGer's das (durch Spaltung des animalen und vegetativen Muskelblattes entstandene) Coelom und die dazu gehörigen Zellen (Coelom-Epithelien, Lymphzellen, Blutzellen) als Repräsentanten einer besonderen fü $\mathrm{ften}$ Schicht, eines intermediären fünften Keimblattes ansehen wollte, so würde man als Tetrablasterien nur die Acoelomen (Plathelminthen) und vielleicht einen Theil der Acalephen auffassen haben. Hingegen würden alle mit Coelom versehenen Thiere (die Coelomaten und die vier höchsten Thierstämme) eine besondere fünfte Hauptgruppe bilden; Pentablasteria (mit fünf Keinblättern oder principalen Gewebsschichten: 1. Hautsinnesblatt, 2. Hautmuskelblatt, 3. Coelomblatt oder Lymphblatt, Gefässblatt in modificirtem Sinne, 4. Darmfaserblatt, 5. Darmdrïsenblatt).

Eine Zusammenstellung dieser fünf Hauptgruppen des Thierreichs mit den bekannten gewöhnlich angenommenen "Typen" würde folgende Resultate ergeben:
1. Ablasteria
1. Protozoa
Protozoa
Protozoa
2. Diblasteria
2. $\left\{\begin{array}{l}\text { Gastraeda } \\ \text { Spongiae }\end{array}\right.$
3. Triblasteria
3. Acalephae
4. Tetrablasteria
4. Acoelomi
כ. Pentablasteria

5. $\left\{\begin{array}{l}\text { Coelomati } \\ \text { Nollusca } \\ \text { Echinorlerma } \\ \text { Arthropoda } \\ \text { Vertebrata }\end{array}\right.$
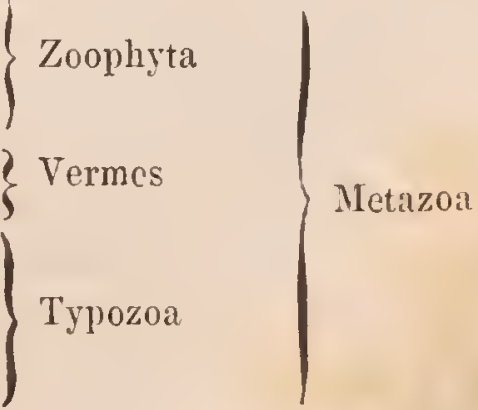
So verlockend es nun auch von phylogenetischem Gesichtspunkte aus erscheinen könnte, in dieser Weise die Zahl und Differenzirung der Keimblätter als Basis für die Classification des Thierreichs zu verwerthen, so ergeben sich doch bei näherer Betrachtung bedenkliche Hindernisse, welche die strenge Durchführung diese Eintheilungs-Princips nicht, gestatten. Abgesehen davon, dass wir iiberhanpt die Ontogenese vieler Thiere (besonders aus den niederen Stämmen) noch gar nicht genügend kennen, finden sich vermittelnde Uebergangs-Formen zwischen den fünf angeführten Gruppen, welche keine scharfe Trennung zulassen, und ausserdem kommen in den niederen Phylen der Metazoen Fälle vor, in denen nahe verwandte Formen eines Stammes zu verschiedenen Gruppen der Blasterien gestellt werden müssen. Obwohl die meisten Acalephen (Hydromedusen, Ctenophoren, Corallen) wahrscheinlich Triblasterien sind, kommen doch unter ihren niederen Formen (Hydra) Diblasterien und unter ihren höheren Formen wahrscheinlich viele Tetrablasterien vor. Unter den Acoelomen (Plathelminthen) finden sich wahrscheinlich neben den vorwiegenden Tetrablasterien viele Triblasterien oder selbst Diblasterien u. s. w.

Aus diesen und anderen Gründen erscheint es vielmelı' geboten, für die weitere Eintheilung der Metazoen als maassgebendes Princip lediglich die Grundzüge ihrer Phylogenie zu verwerthen, wie sie sich aus der vergleichenden Anatomie und Ontogenie der Metazoen ergeben, und wobei die stereometrische (radiale oder bilaterale) Grundform der Körperanlage eine entscheidende Rolle spielt. Die weitere Entwickelung der Gastrula erscheint hier zunächst bestimmend. Dieser folgend bin ich bereits in der Biologie der Kalkschwämme zu der Annahme gelangt, dass die Descendenten der Gastraea, als der gemeinsamen Stammform aller Netazoen, sich zunächst in zwei Linien spalteten : den Protascus, welcher als die Stammform aller Zoophyten, und die Prothelmis, welche als die gemeinsanie Stammform aller fünf höheren Thierstämme anzusehen ist. Die Spaltung dieser beiden Hauptlinien ist ganz mechanisch durch die zweifach verschiedene Lebensweise bedingt, der sich die Descendenten der monaxonien (weder "radiären", nach ,bilateralen") Gastraea zunächst anpassten. Die eine Gruppe gab die frei bewegliche Lebensweise der schwimmenden Gastraea auf, setzte sich mit dem aboralen Pole ihrer Körperaxe fest und entwickelte sich damn eo ipso weiterhin zum sogenannten "radialen Typus" (Zoophyten). Die andere Gruppe der Gastraea-Descendenten be- 
hielt die freie Ortsbewegnng bei, ging aus der schwimmenden Bewegungsform in die kriechende auf den Meeresborlen iiber, und entwickelte sich eo ipso zum sogenannten, hilateralen Typus" (die fünf höheren Thierstämme, Würmer und 'Typozoen). Ich betrachte demmach lediglich einerseits die festsitzende Lebensweise bei der Stammform der Zo ophyten (Protascus), als die mechanische ,wirkende Ursache“ ihres radialen Typus oder genaner ausgedrückt ihrer a ctin oten (regulär-pyramidalen) Grundform; anderseits die kriechiende Lebensweise bei der Stammform der Wirmer (1'rothelmis) als die mechanische causa efficiens ihres bilateralen 'Typus oder genaner ausgedrückt ihrer dipleuren (amphithect-pyramidalen) Grundform. Diese hat sich von den Würmern auf die vier höchsten Thierstämme vererbt.

Auf Grund dieser phylogenetischen Betrachtung können wir die sämmtlichen, urspriinglich bilateralen Descendenten der Gastraea (die Abkömmlinge der Prothelmis) in eine natürliche Hauptabtheilung zusammenfassen, welche wir kurz Bilateria oder Sphenota („Keilthiere“, wegen der keilartigen Grundform im Sinne Bross's) nennen wollen. Diese Gruppe umfasst sämmtliche Würmer und die davon abzuleitenden vier höchsten Thierstämme: Mollusken, Echinodermen, Arthropoden, Vertebraten').

\section{Die Bedeutung der Gastraea-Theorie für die Homologie der Typen.}

Durch die Vergleichung der Keimblätter bei den verschiedenen Thierstämmen werden wir zu der wichtigen Frage geführt, wie weit überhaupt die Organe und Organsysteme bei den sieben Phylen des Thierreichs einer morphologischen Vergleichung zugänglich sind, wie weit zwischen denselben eine wirkliche $\mathrm{Homologie}$ im strengsten Simne (also Ho mophylie) durchzufülıren ist. Diejenigen, welche an der BaEk-Cuviek'schen Typen-Lehre in ihrer ursprünglichen starren Fassung festhalten und alle Typen des

1) Bei den sämmtlichen Wirbelthieren, Gliederthicren und Weichthieren ist die dipleure oder bilatcrale Grundfor'm ebenso unbestritten, wie bej den Würmerm. Aber auch die Stammform der Echinodermen besitzi dieselbe Grundform. Als solche betrachten wir nach nnserer Echinodiermen-Theorie die gegliederte Wurm-Person, welche im Asteriden-, , Arm" noch am meisten ihre Selbstständigkeit bewalnt hat. Die radiale Form der entwiclielten Echinodermen-Stöcke (sternförmige Cormen ans 5 oder mehr Personen) bildet daher ebenso wenig einen Einwurf dagegen, als die radiale Form der Synascidien-Stöcke (Botryllus). 
Thierreichs als völlig gesonderte morphologische Einheiten betrachten, müssen natürlich jene Frage überhaupt verneinen. Diejenigen hingegen, welche die Typen-Theorie im Lichte der Descendenz-Theorie betrachten und die von uns hier versuchte Modification derselben durch die Gastraea-Theorie, sowie die damit zusammenhängende Generalisation der Keimblätter-Theorie gelten lassen, müssen bis zı einem gewissen Grade eine solche morphologische Vergleichung gestatten. In der That hat sich auch GegenbaUr neuerdings in diesem Sinne ausgesprochen '), und ebenso Kowalevsky in seiner neuesten Arbeit ${ }^{2}$ ).

So ausserordentlich wichtig und interessant diese Frage nach den Homologien der Thierstämme für die vergleichende Anatomie und Phylogenie ist, so schwierig und verwickelt erscheint bei dem gegenwärtigen unvollkommenen Zustande der Morphologie ihre sichere Beantwortung. Ich lege daher den nachfolgenden Erörterungen nur den Werth eines provisorischen Versuches bei. Das Phylum der Protozoen bleibt natiurlich von dieser Betrachtung ganz ausgeschlossen, da nach unserer vorher dargelegten Ansicht kein Thier dieser Wurzelgruppe sich bis zur Bildung von Keimblättern erhebt, und demmach auch die aus letzteren entwickelten Organe den Protozoen völlig abgehen. Mithin lalten wir z. B. jede morphologische Vergleichung irgend eines Theiles des Infusorien-Körpers mit einem scheinbar entsprechenden (und physiologisch vielleicht gleichwerthigen, also analogen) Theile eines Keimblatt-Thieres für ganz unzulässig. Wie ich bereits in dem Aufsatze „Zur Morphologie der Infusorien“ (a.a. O.) gezeigt habe, kann z. B. der Darm der Ciliaten physiologisch als solcher aufgefasst und mit dem Darm der Metazoen verglichen werden. In morphologischer Beziehung können diese Theile aber überhaupt nicht verglichen werden. Der Ciliaten-Darm ist Bestandtheil einer einzigen hoch differenzirten Zelle; der Metazoen-Darm ist ein Hohlraum, der von dem vielzelligen inneren Keimblatte umschlossen ist. Nur zwischen den sechs Stämmen der Metazoen, die alle von der Gastraea abzıleiten sind, können Homologien existiren.

Als die sicherstc und allgemeinste Homologie, welche durch die ganze Reihe der Metazoen (von den Spongien bis zu den Vertebraten) durchführbar ist, ergiebt sich die Vergleichung der-

1) Gegenbaur, Grundzïge der vergl. Anatomie II. Aufl. S. 82.

2) Kowalevskx, Embryologische Studien an Würmem und Arthropoden 1871, Schluss. 
jenigen Organe, welche bei den einfachsten Mctazoen, den Gastraeaden und den niedersten Spongien) bereits differenzirt sind, und bei diesen zeitlebens in ihrer cinfachsten Anlage verharren. Das ist erstens der primitive Darmeanal mit seinem Lipithelium (dem Darmdrüsenblatt, Entoderm der Gastrula); und zweitens die oberflächlichste Körperbedeckung, das Hantsinnesblatt oder die Epidermis, Exoderm der Gastrula). Bezüglich dieser letzteren ist ausdrücklich hervorzuheben, dass zwar dic ursprüngliche complete Homologie der Epidermis bei den scchs MetazoenPhylen durch frühzeitig cintretende Häutungs-Processe vielfach gestört und incomplet werden kann, indem die ursprïnglich oberste Epidermis-Schicht in eine vergängliche embryonale Huille verwandelt oder abgestreift wird (Z. B. Hydra, Kleinenberg); dass aber nichtsdestoweniger mindestens e in e Zellenschicht der Epidermis sich constant erhält und als Ausgangslager für die iibrigen dient, mithin die Fpidermis als Ganzes, und als Derivat des einfachen Exoderms der Gastrula, bei allen sechs Metazoen-Stämmen homolog ist ').

Sehr schwierig ist dic Frage nach der Homologic des Centra l-Nerven-Systems. Unzweifelhaft ist dasselbe bei allen sechs Stämmen der Metazoen aus dem Exoderm hervorgegangen; abcr das Centrahnerven-System der Zoophyten ist sicher unabhängig von demjenigen der Würmer entstanden und diesem in

1) Die Bildung vieler embryonaler Hüllen, welche ontogcnetisch aus dem ohersten Keimblatt (dem Hornblatt) entstehen, ist wohl phylogenetisch durch H ä u tungen (oder ,Mauserungen“) zu erklären, welche die Torfahren des hetreffenden Organisnus in früheren Perioden der Erdgeschichte erlitten haben. so ist namentlich die Larvenhaut vieler höheren Crustaceen, die innerhalb der Eischale entsteht mi selbst melufach gewechselt wird, auf wiederholte Häutungen der Crustaceen-Stanmform, des Nauplins, und anderer aus diesem entstandenenen alten Stammformen zu deuten (Vergl. die bezüglichen Angaben und Deutungen in den betreffencien Schriften von Fritz Müller, Edodard van BenEDFe, A. DoHra u. s. w.). Ebenso ist vielleicht auch das sogenamute Amnion bei manchen Thieren zu denten. Das Amnion der Wirbelthiere ist dagegen sicher anderen Ursprungs. Was die specielle Homolugie dieses Amnion bei Vertebraten und. Arthroporlen betrifft, wie. sie von Kowar.svskr und Anderen behauptet wird, so wird dieselbe, abgesehen von anderen Grimden, schon dadurch widerlegt, dass das Amnion nu den drei höheren Wirbeltherklassen (Amnioten) zukommt. Offenbar hat sich dasselbe hier also erst während der Entstehung der Amnioten-Stammformen aus den Amphibicn entwickelt, und ist gänzlich unabuängig von dem Amnion der Arthropoden. Letzteres ist dem letzteren nur analog (und homomorph) aber nicht wirklich homolog (homophyl). 
keiner Weise zll vergleichen. Hingegen ist die einfachste Form des Centralnerven-Systems, welche sich bei den Würmern findet, nämlich das ïber dem Schluude gelegene einfache NervenknotenPaar, das sogenannte obere Schlundknoten-Paar oder Ur. hirn erstens in allen Classen des Würmerstammes als homolog zu betrachten, und zweitens auch dem gleichnamigen Theile der Mollusken und Arthropoden, sowie der ursprünglichen Medullarrohr-Anlage der Wirbelthiere zu vergleichen (von der das Gehirn der letzteren nur der vorderste differenzirte Abschnitt ist '). Bei den Echinodermen ist dieses ursprüngliche Central-Organ verloren gegangen; ihr Schlundring ist nur eine secundäre Commissur zwischen den fünf radialen Nervensträngen, welche bei den Asteriden in der ursprünglichsten Form auftreten. Jeder dieser fünf Radial-Nerven der Echinodermen ist homolog dem gegliederten Bauchmark der Anneliden und Arthropoden. Vorbedingung für die Annahme dieser scheinbar paradoxen Vergleichung ist die Richtigkeit meiner Theorie voun Ursprung der Echinodermen, wonach als die Stammform dieses Phylum die Asteriden-Form zu betrachten ist, ein Stock von fünf sternförmig verbundenen, gegliederten Würmern. Diese Theorie ist zwar von Claus, Leuckant Semper und Anderen verworfen worden, ohne dass sie jedoch irgend eine andere naturliche Theorie an deren Stelle gesetzt und den Versuch zur Erklärung der Echinodermen-Entstehung gemacht hätten. Auf der anderen Seite hat meine Theorie, welche diese Entstelnung vollständig crklärt, die vollkommene Zustimnung von zwei Zoologen ersten Ranges erhalten, auf deren morphologisches Urtheil ich das grösste Gewicht lege, Gegennaur und M. Sars (senior), letzterer bekanntlich einer der genauesten Kenner der Rchinodermen ${ }^{2}$ ).

1) Nicht homolog ist selbstrerständlich nach dieser Auffassung das Rïckenmark der Wirbelthiere und has Banchmark der Gliederthiero; diese konnen ehenso wenig verghichen werden, als der sympathische Grenzstrang der ersteren und las Bauchmark del letzteren.

2) llie Entstehung des Centrahnerven-Systems aus der urspringlichen Uberlaut les Thierkörpers, dem Hornblatte, ist eines der schlagendsten Buispiele fïr den Wrertl der phylogenetischen Auffassung und ihre Bedeutung für das Verstandniss der ontogenetischen Processe. Bisher bat man fast allgemein jent: Entstehung des, ,inne en" Vervenstystems aus dem äusseren Keinblatte wunderbar und paradox gefunden. Solvald man sich aber die Frage stellt: "Wic kam ülorhaupt las Nervensystem \%uerst (phyletisch) entstanden sein", so wirl man nach reiffichem Nachdenken dariber nur die eine Ant-

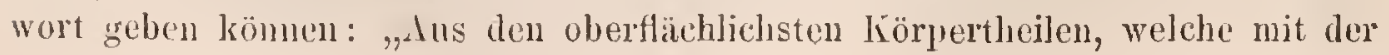


Die Sinnesorgane der verschiedenen Thierstämme sind zum grössten Theile (mit Ausnahme der Haut als T'ast-Organ, vielleicht sämmtlich!) nicht homolog; ist hier doch sogar innerhalb eines jeden Stammes die Homologie oft nicht nachzuweisen oder selbst immerhalb einer Klasse bestimmt ausgeschlossen, wie z. B. bei dem Gehörorgane der verschiedenen Insecten! Alles deutet darauf hin, dass dieselben polyphyletischen Ursplungs, aus verschiedenen Stïcken des oberen Keimblatts zu verschiedenen Zeiten entstanden sind. Dieser vielfach verschiedene und selbstständige Ursprung der Simnes-Organe ist auch phylogenetisch ganz gut begreiflich.

Wahrscheinlich haben aus dem oberen Keimblatte auch die Primordial-Nieren ihren Ursprung genommen und wahrscheinlich sind diese Organe bei allen Bilaterien (bei sämmtlichen Mitgliedern der fünf höheren Thierstämme) homolog. Die einfachste Form würden die sogenannten „Excretions-Organe oder Wasserge-

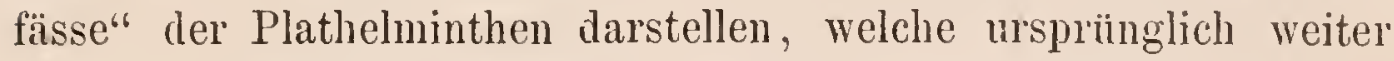
nichts als mächtig entwickelte schlauchförnige Hautdriisen (gleich (len Schweissdrüsen) sind. Die vergleichende Anatomie wird später wohl in Stande sein, nachzuweisen, dass diese Urnieren der ungegliederten Plathelminthen, welche sich in jedem Metamere der gegliederten Würmer als sogenannte Schleifencanïle oder Segmental-Organe wiederholen, sowohl den Nieren der Mollusken als den Urnieren der Wirbelthiere ihren Ursprung gegeben haben '). Unter' den Arthropoden hat bereits Geginbaun die Homologie der "Scha-

Aussenwelt bestänlig in Berührung waren". Nur ans dieser beständigen Berührung komnte sich die erste „Empfindung" entwickeln. Secundär, lat sich dam das Nerven-System in das gesehütztere Invere des hörpers zurückgezogen, „vom Hornblatt abgeschnürt". Die Amahme eines besonderen "Nervenblattes", welches manche Embryologen vom Hautsinmesblatt trennen, halte ich nicht für gerechtfertigt.

1) Bei Amphioxus ist vielleicht als Homologon oder als ludinentärer Rest der ursprünglichen Uriere der von Rathke entluckte und ron J. Müluen genauer beschriebene weite Canal zu denten, welcher jederseits in der Hantfalte des Bauches (unmittelbar an der Aussenflache der Scxual-Drüsen) verläuft und sich hinten zu beiden Suiten des Porus ahdominalis nach aussul affnet. (Eine zweite, vordere Oeffnung in die Mundhöhle ist problenatisch.) Wem die Vergleichung dieses Irautcanales von Amphioxus (Fig. 40 auf J. MülıEn's Taf. I) mit der Urniere der Wirbęthiere und dem ähnlichen Excretions-Organe der Würmer richtig wäre, so würde damit eine sehr interessante Verbindung zwischen den beiden letzteren Organen hergestellt mi zugleich die Entstehung des Unieren-Ganges der Vertebraten aus dem äusseren Kieimblatt erklär't sein. 
lendrüse" der niederen Crustaceen (und der ,grünen Drüse“ der Decapoden) mit den Urnieren der Würmer nachgewiesen. Die Tracheaten haben dieses Excretions-Organ ganz verloren und an seine Stelle sind die Malpighischen Röhren des Darmcanales getreten. Wenn man die Urniere in dieser Weise ursprünglich (phylogenetisch) als eine ausscheidende Hautdrüse auffasst, so erklärt sich auch ihre ursprïngliche oberfächliche Lage beim Tertebraten-Embryo. Sie wird hier jedenfalls vom oberen Keimblatt abzulciten sein, entweder direct vom Hornblatt, oder indirect, durch Zellen des „Axenstranges", welche vom Hornblatt in das Hautfaserblatt eingewandert sind.

Das Hautmuskelblatt oder das Hautfaserblatt (die „Fleischschicht" von BaER, die Hautplatten und Urwirbelplatten von REMaK) ist als Ganzes in seiner ursprünglichen einfachen Anlage wahrscheinlich bei allen sechs Metazoen-Stämmen, oder doch wenigstens bei den fünf Phylen der Bilaterien, homoloy. Vermuthlich ist dasselbe bei den Würmern ebenso wie bei den Zoophyten (Hydra u. s. w.) aus dem oberen Keimblatte entstanden und hat sich von den Würmern auf die vier höheren Thierstämme vererbt. Als die beiden primitivsten Spaltungsprodukte desselben sind das Corium und der Hantmuskelschlauch zu betrachten, die beide wohl imnerhalb der fünf höheren Phylen (der Bilaterien) desselben Ursprungs, also homolog sind. Auch die Rumpfmuskeln der Wirbelthiere gehen aus diesem Blatte hervor.

Nicht homolog sind dagegen die Skelet-Systeme in den verschiedenen Thierstämmen. Sowohl die inneren Skeletbildungen der Zoophyten, als diejenigen der Echinodermen und der Wirbelthiere, obwohl alle drei aus dem Hantfaserblatt zu entstehen scheinen, sind völlig verschiedene Bildungen, für jedes Phylum eigenthïmlich. Das Haut-Skelet der Würmer und Arthropoden, welches bloss eine chitinisirte Ausscheidung der Epidernis (der sogenannten Hypodermis oder Chitinogen-Membran) ist, sowie die Kalkschalen der Mollusken (ebenfalls Exsudate der Epidermis) kommen hierbei gar nicht in Betracht.

Das Coelom oder die Leibeshöhle, die ursprüngliche „Plenroperitoneal-Höllle", welche den Protozoen, Zoophyten und den Acoelomen (Plathelminthen) gänzlich fehlt, ist sicher bei den Coelomaten und den vier höheren Thierstämmen homolog. Ueberall entsteht sie als Spalt zwischen den beiden Muskelblätter'n und hat sich offenbar von den Coelomaten, den blutführenden Würmern, auf dic vier höheren Thierstänme vererbt. Hiergegen ist 
diese Homologie nicht durch die Vergleichung mit der Segmentations-Höhle zu begründen, aus der Kowalevsky das Coelom hervorgehen lässt (vergl. oben S. 27). Ursprünglich ist das Coelom mit einer Fliissigkeit gefüllt, welche ihres indifferenten Characters halber als $\mathrm{Haemolymphe}$ oder Haemochylus bezeichnet werden kann. Aber schon bei den höheren Würmern differenzirt sich diese Ernährungstliissigkeit in zwei versehiedene Bestandtheile, in den farblosen Chylus oder die Lymphe, welche die Leibeshöhle erfïllt, und in das gefärbte Blut, welches in dem geschlossenen Gefässsystem circulirt. Dieselbe Differenzirung kehrt auch bei den Wirbelthieren wieder.

Das Darmmuskelblatt oder das Darmfaserblatt (die „Gefässschicht" von Bakn, die Darmfaserplatten und Mittelplatten voll Reмaк) scheint in dem Stamme der Zoophyten theils (bei den Spongien und niedersten Acalephen) ganz zu fehlen, theils (bei den höheren Acalephen) in eigenthümlicher Form sich zu entwickeln. Bei den Acoelonen beginnt sich dasselbe bereits als "Darmmuskelschlauch" auszubilden und hat sich von diesen auf die höheren Würmer (die Coelomaten), von letzteren auf die vier höchsten Thierstämme vererbt. Es steht Nichts im Wege, eine allgemeine Homologie desselben innerhalb dieser fünf Thierstämme (der Bilaterien) anzunehmen.

Dars Blutgefäss-System als Ganzes, welches sich im Zusammenhang mit dem Coelom entwickelt hat, ist demnach ebenfalls innerhalb der fünf höheren Thierstämme zu vergleichen. Dic Frage jedoch, in wie weit die einzehnen Theile desselben und namentlich das Herz homolog sind, ist sehr schwierig zu entscheiden. Nach der scharfsimnigen Vergleichung von Gegenbaur ist das Her'z der Artluropoden und Nollusken einem Abschnitte des dorsalen, hingegen das Herz der Ascidien und Vertebraten einem Abschnitte des ventral en Hauptgefässstammes der Würmer ursprünglich homolog.

Das Darmdrisenblatt, welches als epitheliale Auskleidhung des Darmcanals und seiner drüsigen Anhänge in dem ganzen Thierreiche (nur die Protozoen ausgenommen) von den Spongien bis zu den Vertebraten sich constant erhält, ist sicher iiberall homolog; überall direct aus dem Entoderm der Gastrula abzuleiten. Allerdings ist Kowalevsky neuerdings zu der Annahme gelangt, dass das Darmdrüsenblatt der Insecten hiervon eine Ausnahme bilde und vielmehr als eine eigenthümliche Neubildung sui generis zu betrachten sei (Embryologische Studien an Würmern u. s. w., 
1871, S. 58). Diese Ansicht erscheint mir nicht stichhaltig. Wenn irgend ein Organ bei ailen sechs Metazoen - Phylen homolog sein kann, so ist es sicher der Darmcanal mit seinem auskleidenden Epithelium, dem Dar'mdrüsen-Blatt. Hingegen ist die Frage von der Homologie der Darmmiindungen, Mund und After, zur Zeit noch ganz dunkel, und nur so viel sicher, dass die Mundöffnung nicht überall dieselbe ist. Die ursprüngliche Mundöffnung der Gastrula, der Urmund oder das Prostoma scheint sich nur auf die Zoophyten und vielleicht auf einen Theil der Würmer vererbt zu haben. Sie scheint sich noch in dem Rusconischen After der Vertebraten zu wiederholen. Hingegen sind die Mundöffnungen der Vertebraten, der Arthropoden, der Echinodermen, eigenthimliche Neubildungen, und sicher nicht dem Urmund homolog:

7. Die phylogenefiscie Bedeutung del ontogenptischen Succession der virgan-iysteme.

Die gesetzmässige Reihenfolge, in welcher bei den verschiedenen Thierstämmen die Organ-Systeme während der Ontogenese nach einander auftreten, gestattet uns nach dem biogenetischen Grundgesetze einen sicheren Schluss auf die historische Reihenfolge, in welcher sich die thierischen Organ-Systeme während des langen und langsamen Laufes der organischen Erdgeschichte nach einander und aus einander entwickelt haben. Diese paläontologische Altersfolge der Organ-Systeme, wie sie sich a posteriori ans den Thatsachen der Ontogenese empirisch ergiebt, entspricht im Grossen und Ganzen vollständig den Vorstellungen, welche man sich darïber a priori durch physiologische Reflexion und durch philosophische Erwägung der Causal-Nomente bilden könnte.

Zunächst ergiebt sich aus der Vergleichnng der Gastrula, und des, ihr entsprechenden zweiblättrigen Keimzustandes bei den verschiedensten Thierstämmeu, dass bei den àltesten Metazoen, den Gastraeaden, sich in erster Reihe zwci primäre OrganSysteme gleichzeitig differenzirten: das innere Darm-System und das äussere Decken-System. Die ursprüngliche, ganz einfache Magenhöhle oder der Urdarn der Gastrae ist in der That das älteste Organ des Metazoen-Körpers; gleichzeitig aber mit seiner Entstehung ist die Sonderung der beiden Zellenschichten seiner Wand vor sich gegangen; des inneren ernährenden Epitheliums (des Gastral-Blattes oder Entoderms) und des äusseren deckenden Epitheliums (des Dermal-Blattes oder Exoderms). 
In zweiter Reihe bildeten sich (bei der Mehrzahl der Metazoen?) Elemente des Skelet-Systems ans, und zwar in Exo. derm, wie uns die Spongien lehren. Obgleich bei den Schwämmen die beiden primordialen Keimblätter (allgemein?) in ihrer ursprïnglichen Einfachlheit erhalten bleiben und kein drittes Keimblatt sich aus ihnen entwickelt, finden wir dennoch bei Vielen derselben in dem verdickten Exoderm ein sehr entwickeltes und mannichfach differenzirtes Skelet-System vor. Ja sehon die Protozoen bilden sehr allgenein schïtzende und stützende Skelettheile. Es braucht nicht hinzugefügt zu werden, dass im Uebrigen das Skelet-System bei den verschiedenen Thierstämmen verschiedenen Alters und polyphyletischen Ursprungs ist.

In dritter Reihe bildeten sich gleichzeitig Nervensystem un « Muskelsystem aus. Die sehönen Untersuchungen KLEInenbergs über die Ontogenese der Hydra haben uns über die gleichzeitige Entstehung dieser beiden Organ-Systeme belehrt, die in der innigsten Wechselwirkung sieh befinden. Das höchst interessante Neuromuskel-System der Hydla führt sie uns unmittelbar in statu nascenti vor Augen. Die aus dem Exoderm der Hydra entwichelte Neuromuskelzelle zeigt uns die Functionen beider noch in einem einzigen Individum erster Ordnung vereinigt. Erst mit deren Trennung, mit der Arbeitstheilung derselben in Nervenzeilen und Muskelzellen treten die beiden Organsysteme sich selbständig gegenüber. Wirkliche Muskeln im strengsten Sime des Begriffes giebt es daher elst bei denjenigen Thieren, wo es auch wirkliehe Nerven giebt, und umgekehrt. Wie die Acalephen uns zeigen, ist zunächst nur das dermale oder parietale Neuromuskel-System aus dem äusseren Keimblatte entstanden. Wahrseheinlich unabhängig davon ist erst später in ganz analoger Weise das gastrale oder viseerale Neurom uskel-System (Darmmuskeln und Darmnerven) aus dem Darmdrïsemblatte entstanden. Es spricht Nichts bis jetzt gegen die Annahme, dass das viscerale Nerven-System unabhängig von dem parietalen entstanden ist; das erstere ebenso im Zusammenhang mit dem Darmmuskelblatt, wie das letztere mit dem Hautmuskelblatt.

In vierter Reihe hat sich das Nieren-System oder das Excretions-System entwickelt, dessen physiologisehe Bedeutung für den Thier-Organismus in Allgemeinen grösser ist, als diejenige des jüngeren Blutgefäss-Systems und des damit verbundenen Coeloms. Diese Auffassung wird gerechtfertigt durch die Plathel- 
minthen, welche noch kein Coelom und Blutsystem, wohl aber Urnieren (Excretions-Canäle) besitzen; ferner durch die allgemeine Verbreitung derselben durch die ganze Thierreihe, und endlich besonders durch das frühzeitige Auftreten der ,Urnieren“ im Embryo. Aus Allem ergiebt sich, dass wir es hier mit einer sehr alten und wichtigen Organisations-Eimrichtung zn thm haben, die schon bei den Acoelomen vor der Entstehung des Blutsystems und des Coeloms existirte, und sich von da aus auf die höheren Thierstämme vererbt hat.

In fünfter Reihe erst hat sich nach dem Nieren-System das Blutgefäss-System mit den Coelom entwickelt. Wir haben bereits gezeigt, dass diese beiden Theile in untrembarem Zusammenhange stehen, und dass die wahre Leibeshöhle oder das Coelom geradezu als der erste Anfang des Gefäss-Systems zu betrachten ist. Erst nach eingetretener Entwickelung des Darmfaserblattes bildete sich mit seiner Ablösung von den anliaftenden Hautfaserblatte zwischen diesen beiden Muskelblättern eine Höhle, welche sich mit dem durch die Darmwand transsudirenden Clyylus fiillte. Das war das Coelom in seiner einfachsten Gestalt und erst später hat sich dieses Haemochylus- System oder primordiale Urblut-System in zwei verschiedene Saftsysteme differenzirt, in das Lymphsystem und das eigentliche Blutsystem ${ }^{1}$ ).

In sechster Reihe erst hat sich morphologisch als selbständiges Organ-System (!) das Genital-System entwickelt. Allerdings ist dasselbe physiologisch schon längst vorhanden, ehe alle andern Organ - Systeme sich differenzirten. Treffen wir doch schon bei den Spongien im Entoderm des Darmrohres zerstreut einzelne Zellen, welche sich zu Eiern und andere, welche sich zu Spermazellen ausbilden; und wahrscheinlich ist dasselbe schon bei den Gastraeaden der Fall gewesen. Allein bei allen Zoophyten bleibt die Bildung der beiderlei Sexualzellen auf das Epithelium einzelner Theile des Gastrocanal-Systems beschränkt; und selbst

1) Eine sehr abweichende Auflassung des Coeloms und des Blutsystems, sowie des Nieren-systems bat RaY-Lankester in dem mehrfach citirten Anfsutz entwickelt (Annals and Mag. of nat. hist, Mai 1873). Derselle hält diese beiden Organ-Systeme für jlentisch mud meint, dass die "Excretions-Organe oder Wassergefässe" der Acoelomen den ersten Anfang einer Leibeshöhle bilIlen und dass demuach dicses Coelon von Anfang an nach aussen geöfuet ist. Nach mcinel Ansicht hingegen ist das Coelom primär geschlossen, erst später und mablängige von dem älteren Unueren-system entstanden. Die Verbindung Beider wäre demnach secundär. Die Ontogenese der Bilaterien scheint mir Lax-LankEster's Auflitssung zu widerlegen. 
noch bei vielen Würmern sind keine selbständigen persistenten Sexual-Organe in morphologischem Sinne vorlanden. Bei vielen Würmern (Bryozoen, Anneliden u. s. w.) entwickeln sich periodisch einzelne Coelom-ZKellen, zerstreute Zelien des "Pleuroperitoneal-Epithels," zu Sexualzellen. Eine selbständige Differenzirung besonderer Gesehlechts-Organe scheint demnach erst später eingetreten zu sein, vielleicht in den verschiedenen Thierstämmen zu verschiedenen Zeiten. Die Entscheidung dieser sehr schwierigen Frage hängt mit der Frage nach der Homologie der Sexual-Organe ïberhaupt und nach dem primären phyletischen Ursprung der Sexual-Zellen zusammen, einem der schwierigsten Probleme der Ontogenie und der Phylogenie. Den Bemerkungen, die ich ïber diesen Gegenstand in der Biologie der Kalkschwämme )S. 469 , 471) gemacht habe, möchte ich hier noch die Eventualität hinzufügen, dass möglicherweise beide primäre Keimblätter sich an der Bildung von Sexual-Zellen betheiligen. Denn obgleich in den meisten Fällen der Ursprung der Sexual-Zellen aus Zelleu des Darmfaserblattes oder selbst des primären Gastralblattes nachzuweisen ist, so scheinen dieselben doch in anderen Fällen ihren Ursprung eben so sicher aus dem Hautfaserblatt oder selbst aus dem primären Dermalblatte zu nehmen (Hydra).

Bei de: Bestimmtheit, mit welcher die entgegengesetzten Angaben über den Ursprung der Sexual-Zellen selbst imnerhalb der Zoophyten-Gruppe sich gegeniuber stehen, dürfte endlich auch noch zu erwägen sein, ob nicht eine Dislocation derselben so frühzeitig (schon während der laurentischen Periode) stattgefunden hat, dass ihre scheinbare Ursprungsstätte in der That erst ihre zweite Heimath ist. Bei den Kalkschwänmen habe ich nachgewiesen, dass die im Entoderm ursprünglich entstandenen Eizellen vermittelst ihrer amöboiden Bewegungen oft schon frühzeitig in das Exoderm hinüber wandern und dort weiter wachsen. Bei vielen Calcispongien sind die Eizellen viel leichter im Exoderm (ihrer secundären Lagerungsstätte) als in Entoderm (ihrer primären Ursprungsstätte) aufzufinden, so dass ich sogar frïher selbst ihre ursprüngliche Entstehung im ersteren annahm. Nun dürftman wohl annehmen, dass diese frühzeitige D is location der Zellen aus einem primären Keimblatt in das andere durch fortwährende ,abgekürzte oder zusammengezogene Vererbung، im Laufe der Generationen immer weiter in der Ontogenese zuriick verlegt wird, bis sie schliesslich schon während der Differenzirung der gleichartigen Furchungszellen in die beiderlei Zellenformen 
der beiden primären Keimblätter stattfindet. Dann würden Zellen die ursprünglich (plyylogenetisch) dem inneren Keimblatte angehörten, doch (ontogenetisch) scheinbar zuerst im äusseren Keimblatte auftreten und ungekehrt. Ich vermuthe, dass dies bei den Sexnalzellen oft wirklich der Fall ist und dass überhaupt eine solche frühzeitige Dislocation der Zellen, eine durch Vererbung constant gewordene Lagenveränderung und Versetzung aus einem Keimblatt in das andere, eine bedeutende Rolle spielt. Auch fïr unsere oben dargelegte Ansicht von der ursprünglichen Verschiedenheit der beiden Muskelblätter besitzt dieselbe grosse Bedeutung und diurfte z. B. bei der frühzeitigen axialen Concrescenz, bei der Verschmelzung der Keimblätter im Axenstrange der Vertebraten, wie bei ihrer späteren Divergenz, Vieles erklären.

\section{Die Bedeutung der Gastraea-Theorie fül die Typen-Theorie.}

Wenn man die vorstehend gegebene Begründung der Gastraea-Theorie für genügend hält und die daraus gezogenen Folgeschlüsse im Ganzen als richtig anerkennt, so wird man damit. zugleich die Ueberzengung gewonnen haben, dass durch dieselbe die sogenannte Typen-Theorie, welche noch heute allgemein als die tiefste Basis des zoologischen Systems gilt, in ihrer bisherigen Bedeutung aufgehoben ist, und einer wesentlich verschiedenen Classification des Thierreichs Platz machen muss. Bekanntlich gipfelt diese hochberühmte und hochverdiente TypenTheorie, zu welcher im zweiten Decennium unseres Jahrhunderts zwei der bedeutendsten Zoologen gleichzeitig auf verschiedenen Wegen gelangten, in der Vorstellung, dass im Thierreiche mehrere grundverschiedene Hauptgruppen zu unterscheiden seien, von denen jede ihren eigenthümlichen "Typus", d. h. einen ganz charakteristischen immanenten und persistenten "Bauplan" besizt; dieser „Bauplan" wird bestimmt durch die eigenthümliche Lagerung und Verbindung der constituirenden Organe, und ist völlig unabhängig von dem Grade der Vollkommenheit und Ausbildung, den die verschiedenen Thierklassen jedes Typus innerhalb desselben durchlaufen. Sowohl George Cuvier, welcher auf dem Wege der vergleichenden Anatomie, als $\mathrm{C}_{\text {ARL }}$ Ennst $\mathrm{B}_{\mathrm{AER}}$, welcher selbstständig und unabhängig von ersterem auf dem Wege der vergleichenden Ontogenie zu dieser Vorstellung gelangte, unterschieden im ganzen Thierreich nur vier solcher Typen, welche $B_{A E R}$ nach dem verschiedenen Modus der Ontogenese folgender'maassen charak- 
terisirte: 1) Ra di a ta: mit strahlenförmiger Entwickelung (covlutio radiatn); 2) Molluscal: mit gewundener Entwickelung (evolutio conforta); 3) A rticulata: mit symmetrischer Entwickelung (evolutio gemina): 4) Vertebrata: mit doppelt symuretrischer Entwickelung (erolutio bigemina). Sowohl Cuvrer als Bafr hielten jeden Typus für etwas durchans constantes und trotz aller Modificationen im tiefsten Grunde unveründerliches; sie liessen daher auch durchaus keinen Zusammenhang und keinen Uebergang zwischen den vier verschiedenen 'Typen zu. BAER hob insbesondere noch hervor, dass der Typus bei den niedersten Formen jeder der vier Hauptgruppen schon eben so bestimmt ausgesprochen sei, wie bei den höchsten, und dass mithin der Typus der Entwickelung völlig unabhängig von dem Grade der Ausbildung sei.

Gegenüber der früher herrschenden irrthümlichen Vorstellung, dass das ganze Thierreich eine einzige ununterbrochene Stufenleiter von Formen darstelle, und dass eine einzige continuirliche Entwickelungsreihe von dem niedersten Infusorium durch die verschiedenen Classen hindurch bis zum Menschen hinauf gehe, war die Typen-Theorie von $\mathrm{B}_{\mathrm{Aer}}$ und Cuvier ein gewaltiger Fortschritt. Das helle Licht, welches sie auf die verschiedensten Theile der Zoologie, namentlich aber auf die vergleichende Anatomie und Entwickelungsgeschichte warf, verschaffte ihr schnellen Eingang auch in das zoologische System, und bald waren die vier Typen ziemlich allgemein als die Basis jedes strengeren wissenschaftlichen Systems der Thiere anerkannt. Allerdings wurde man bald durch rie Fortschritte in der Kenntniss der niederen Thiere genöthigt, den ganz unnatürliclien Typus der Radiata aufzulösen: Siebold trennte 1845 davon zuerst die Protozoen ab und schied zugleich die Articulaten in Arthropoden und Würmer; LevcкarT unterschied 1848 zuerst als zwei besondere Typen die Coelenteraten und Echinorlermen; so wurden aus den ursprünglichen vier Typen die sieben verschiedenen Hauptgruppen, welche auch heute noch in den allermeisten Systemen als die obersten und allgemeinsten Hauptabtheilungen des Thierreichs gelten. Allein das eigentliche Wesen und die ursprüngliche Bedeutung der TypenTheorie wurde durch diese Vermehrung der Typen-Zahl nicht berührt. Vielmehr bemïhten sich die neveren Zoologen, den selbstständigen und ganz eigenthümlichen Charakter der vier neueren Typen (Protozoen, Coelenteraten, Echinodermen, Würmer) in demselben Sinne zu präcisiren und jeden derselben als isolirte FormenEinheit mit besonderem "Bauplan" festzustellen, in welchem die 
drei beibehaitenen älteren Typen (Arthropoden, Mollusken, Vertebraten) von $B_{A E R}$ und Cuvien aufgefasst worden waren. Die seitdem immer mehr befestigte Vorstellung vour dem völlig selbstständigen Charakter und dem immanenten „Bauplan" dieser sieben Thier-Typen ist auch lseutzutage noch die allgemein herrschende, so dass z. B. Cuaus noch in der neuesten Auflage seiner Zoologie (1872, S. 41) die Typen-Theorie als ,den bedentendsten Fortschritt der Wissenschaft seit Aristoteles und als Grundlage des natiurlichen Systems" bezeichnet. Ja Hopкins nennt die Typen sogar die "Keppler'schen Gesetze in rler Thierkunde" nnd erblickt in ihnen mit Kefersteis und Anderen ,die schlagendste Widerlegung von Darwin's Irrlehre" und den stärksten Beweis gegen die Wahrheit der Descendenz-Theorie.

Mit dieser letzeren Wendung haben unsere Gegner selbst, ohne es zu ahnen, die Achilles-Ferse der Typen-Theorie bezeichnet. Denn es ist ganz richtig, dlass die Typen-Theorie in dem urspriinglichen Sinne ihrer Urheber allerdings mit der Descendenz-Theorie in einem fundamentalen Widerspruche steht. Dieser Widerspruch liegt nicht sowohl darin, dass die Typen als völlig unabhängige und getrennte Hauptgruppen des Thierreichs betrachtet werden, als vielmehr in dem teleologischen Grundprincip ihrer. Auffassung. Die Vorstellung, dass die Typen völlig unabhängige Formengruppen bilden, ist allerdings unvereinbar mit jeder monophyletis chen Auffassung des Thierreichs, welche alle Thiere als Nachkommen einer einzigen gencinsamen Stammform betrachtet; sie liesse sich aber dadurch mit der Descendenz-Theorie in Einklang bringen, dass man für jeden Typus eine selbstständige Stammform, mithin für das ganze Thierreich eine polyphyletische Descendenz statuirt; soviel Typen, soviel Phylen. Völlig unvereinbar mit der Descendenz-Theorie ist hingegen die Vorstellung von dem immanenten ursprünglichen „Bauplan der Typen", welche das eigentliche teleologische Grundprincip der TypenTheorie bildet.

Sobald daher die durch $\mathrm{D}_{\text {Anwin }}$ refomirte Descendenz-Theorie an die - Cuvier'sche Typen-Theorie herantrat und die letztere nöthigte, sich mit ihr auscinander zu setzen, musste erstens dieses teleologische Grundprincip anfgeben und zweitens zugleich das Verhältniss der Typen zu einander völlig umgestaltet werden. Den ersten Versuch hierzu habe ich 1866 in meiner allgemeinen Entwickelungsgeschichte gemacht (im zweiten Bande der generelien Morphologie, im 16., 19., 24., und 25. Capitel). Erstens habe 
ich dort bereits nachgewiesen, dass „BaEk's Typus der Entwickelung weiter Nichts ist als die Folge der Vererbung, und BaEk's Grad der Ausbildung weiter Nichts als die Folge der Anpassung (a. a. O. S. 11); damit ist einerseits der dualistische Begriff des Typus oder des teleologischen „Bauplans" auf das mechanische Princip der Vererbung (mithin auf die physiologische Function der Fortpflanzung) zurückgeführt (a. a. O. S. 171); anderseits wird dadurch der dualistische Begriff der Vervollkommnung oder des teleologischen Fortbildungszieles auf das mechanische Princip der Anpassung, mithin auf die physiologische Function der Ernährung reducirt (a. a. O. S. 193). Zweitens habe ich damals bereits gezeigt, dass die verschiedenen höheren Typen des Thierreichs nur in genealogischem Sinne als Stämme oder Phylen aufgefasst werden können, dass aber die höheren Phylen des Thierreichs (Vertebraten, Mollusken, Arthropoden, Echinodermen) als divergirende Descendenten des niederen Würmerstammes zu betrachten sind, die aus verschiedenen Zweigen dieser viclgestaltigen niederen Thiergruppe ihren Ursprung genommen haben; und dass endlich die Würmer und die Coelenteraten aus der niedersten Organismen-Gruppe der Protozoen oder Protisten abgeleitet werden müssen (a. a. O. S. 413, 414). Bestimmter habe ich diese Ansicht dann in der ersten Auflage der „Natürlichen Schöpfungsgeschichte" (1868) ausgesprochen und in den folgenden Auflagen derselben zu verbessern gesucht. Es fehlte mir aber, um zur vollen Klarheit zu gelangen, damals die Gastraea-Theorie, auf welche ich erst durch die Monographie der Kalkschwämme geführt worden bin. Erst durch die Gastraea-Theorie und ihre Consequenzen wird das phylogenetische Verhältniss der Thier-Typen zu einander vollständig aufgehellt.

Man könnte behaupten, dass die Gastraea-Theorie nur eine Reform oder eine Modification der Typen-Theorie sei, weil drei von den ursprünglichen vier Typen (Vertebraten, Mollusken, Arthropoden) nahezu in dem ursprünglichen Umfange ihres Begriffes beibehalten worden sind; allein der Inhalt dieses Begriffes ist ein völlig verschiedener geworden. Ausserdem besteht aber zwischen den beiden Theorien der höchst wesentliche Unterschied, dass in der Typen-Theorie die Typen als coordinirte selbstständige Formengruppen von gleichem morphologischen Werthe neben einander und unabhängig von einander erscheinen, während in der Gastraea-Theorie die Phylen als theilweise coor- 
dinirte, theilweise subordinirte Gruppen von völlig verschiedenem morphologischen Werthe theils neben, theils iiber cinander, alle aber in gemeinsamem $\mathrm{Zusammenhange} \mathrm{er-}$ scheinen.

In der vortrefflichen Auseinandersetzung, welche Gegenbaur in der zweiten Auflage seiner Grundzüge der vergleichenden Anatomie $(1872$, S. 72) ,von den thierischen Typen" gegeben hat, sind diese verschiedenartigen Beziehungen der ungleichwerthigen Typen zu einander klar erörtert und weiterhin durch die scharfsinnigsten Ausführungen im Einzelnen auf dem sicheren Fundamente der vergleichenden Anatomie fest begründet. Gegenbaur zeigt; dass die sieben Typen oder Phylen theils ziemlich scharf, theils gar nicht von einander abgegrenzt sind; dass man niedere und höhere Typen unterscheiden nuss, und dass die verschiedenen höheren Typen oder Phylen in den nicderen ihren gemeinsamen Ausgangspunkt erkennen lassen. Durch diesen nachweisbaren Znsammenhang der Phylen wird ,für das gesammte Thierreich eine Verbindung hergestellt, wodurch einer monophyletischen Umfassung der Boden bereitet erscheint. Durch diese erkennbaren Verknüpfungen muss die starle Auffassung der Stämme, wie sie von der ersten Typenlehre her entstand, bedeutend nachgiebiger werden; indem wir die Bcziehungen der Typen zu einander in keiner anderen Weise treffen, als die Abtheilungen innerhalb der Typen: in genealogischer Gliederung" (a. a. O. S. 77).

Mit dieser Auffassung ist thatsächlich die Typen-Theorie von BaEr und Cuvier aufgehoben; sowohl dem Umfang, wie dem Inhalt des Typus-Begriffes nach. Der "Typus" hat danach seine frühere Bedeutung vollständig verloren und besitzt als Kategorie des Systems keine andere philosophische Bedeutung, als die niederen Kategorien der Klasse, Ordnung, Genus, Species u. s. w.; er ist nur relativ (durch seine Höhe), nicht absolut von letzteren verschieden. Thatsächlich ist also auch Gegensaur auf dem Wege der vergleichenden Anatomie zu derselben Stellung gegenüber der Typen-Theorie gelangt, zu welcher uns der Weg der vergleichenden Ontogenie geführt hat. Die Typen-Theorie hat ihr ausserordentliches Verdienst um die Zoologie gehabt und als oberstes Classifications - Princip des Thierreichs nach allen Seiten hin ungemein fruchtbar und anregend gewirkt. . Ihre Wirksamkeit ist aber jetzt als beendet anzusehen. Der consequenten Anwendung und Durchführung der Descendenz-Theorie gegenüber ist sie nicht 
mehr genïgend und an ihre Stelle wird zunächst diejenige phylogenetischo Classification des Thierreichs treten müssen, deren wesentliche Basis unsere Gastraea-Theorie bildet.

\section{Anhang. \\ Synoptisehe phylogenetische Tahellen.}

Zur anschaulichen Uebersicht der allgemeinen Resultate, welche wir vorstehend ans der Gastraea-Theorie entwickelt haben, sollen die nachstehend folgenden vier phylogenetischen Tabellen dienen. Gegenüber den vielfachen Missdentungen, welche die ähnlichen Tabellen und Stammbäume in meiner' „Generellen Morphologie" und „Natürlichen Schöpfungsgeschichte", sowie in der „Monographie der Kalkschwämme" gefunden haben, will ich ausdrücklich hervorheben, dass dieselben durchans keine dogmatische Geltung beanspruchen, vielmehr lediglich Versuche sind, mit Hülfe der Gastraea-Theorie $\mathrm{zu}$ einer klaren Einsicht in die wichtigsten Verhältnisse der ontogenetischen und der phylogenetischen Entwickelung des Thierkörpers und seiner fundamentalen Organ-Systeme zu gelangen. Wer diesen Versuchen nicht beistimmen kann, mag etwas besseres Positives an ihre Stelle setzen, sich aber nicht mit der negativen Verwerfung derselben begnügen, wic es gewöhnlich geschieht. Jedenfalls schliesst sich das hier vorgeschlagene System des Thierreichs enger an die wichtigsten Thatsachen der Entwickelungsgeschichte an, als alle anderen bisher unternommenen Classifications-Versuche. 


\section{I.}

Tabelle über die phylogenetische Entwickelung der Organ-Systeme der Wirbelthiere, gegründet anf die Gastraea-Theorie und die ontogenetische Vergleichung der Wirbelthiere mit den Wirbellosen.

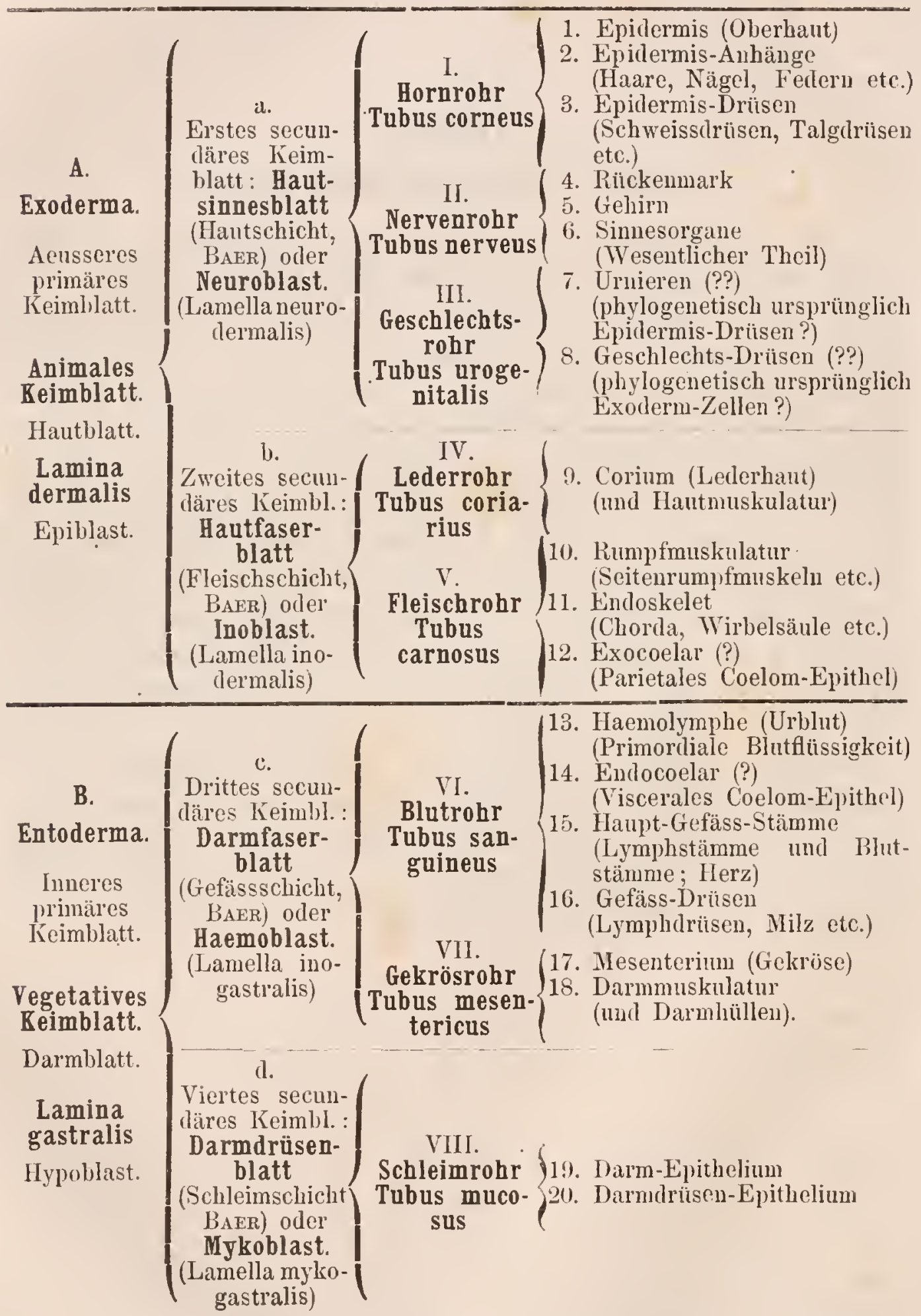


II.

Synoptische Tabelle über diejenigen Urorgane, welche mit Wahrscheinlichkeit bei den Würmern, Gliederthieren, Weichthicren und Wirbelthieren als homolog zu betrachten sind.

\begin{tabular}{|c|c|c|c|}
\hline Vermes & Arthropoda & Mollusca & Vertebrata \\
\hline \multicolumn{4}{|c|}{ I. Differenzirungs-Producte des Hautsinnesblattes. } \\
\hline Epidermis & $\begin{array}{c}\text { Hypodermis } \\
\text { (Chitinogen -Mem- } \\
\text { bran) }\end{array}$ & Epidermis & Epidermis \\
\hline $\begin{array}{l}\text { Urhirn } \\
\text { (Oberer Sichlund- } \\
\text { knoten) }\end{array}$ & $\begin{array}{l}\text { Gehirn } \\
\text { (Oberer Schlund- } \\
\text { knoten) }\end{array}$ & $\begin{array}{l}\text { Gehirn } \\
\text { (Oberer Schlund- } \\
\text { knoten) }\end{array}$ & $\begin{array}{l}\text { Markrohr oder } \\
\text { Medullarrohr } \\
\text { (Vorderster Theil!) }\end{array}$ \\
\hline $\begin{array}{l}\text { Excretionsorgane } \\
\text { („,Wassergefässe, } \\
\text { Segmental-Organe“) }\end{array}$ & $\begin{array}{l}\text { Schalendrüse der } \\
\text { Crustaceen }\end{array}$ & Nieren & Urnierengảuge \\
\hline
\end{tabular}

II. Differenzirungs-Productedes Hautfaserblattes.

\begin{tabular}{c|c|c|c}
$\begin{array}{c}\text { Corium } \\
\text { (und Kingmuskel- } \\
\text { schlauch?) }\end{array}$ & Corium (Rudiment) & $\begin{array}{c}\text { Corium und Haut- } \\
\text { muskulatur } \\
\text { (Erste Anlage!) }\end{array}$ & $\begin{array}{c}\text { Corium und Hant- } \\
\text { inuskulatur } \\
\text { (Erste Anlage!) }\end{array}$ \\
$\begin{array}{c}\text { Lüngsmuskel- } \\
\text { Schlanch }\end{array}$ & $\begin{array}{c}\text { Rumpfmuskeln } \\
\text { (Longitudinal) }\end{array}$ & $\begin{array}{c}\text { Innere Rumpf- } \\
\text { Muskulatur }\end{array}$ & $\begin{array}{c}\text { Seitemrumpfmus- } \\
\text { keln }\end{array}$ \\
\hline
\end{tabular}

III. Differenzirungs-Productedes Darmfaserblattes.

\begin{tabular}{c|c|c|c|} 
Coelom & Leibeshöhle & Leibeshöhle & $\begin{array}{c}\text { Pleuro-Peritoneal- } \\
\text { Höhle }\end{array}$ \\
$\begin{array}{c}\text { Dorsales } \\
\text { Hauptgefäss }\end{array}$ & Herz & Herz-Kammer & $\begin{array}{c}\text { Aorta } \\
\text { (primordialis) }\end{array}$ \\
$\begin{array}{c}\text { Ventrales } \\
\text { Hauptgefäss }\end{array}$ & & & $\begin{array}{c}\text { Herz } \\
\text { (nebs Arterien- } \\
\text { Bulbus) }\end{array}$ \\
$\begin{array}{c}\text { Darmwand } \\
\text { (exclus. Epithel) }\end{array}$ & $\begin{array}{c}\text { Darmwand } \\
\text { (exclus. Epithel) }\end{array}$ & $\begin{array}{c}\text { Darmwand } \\
\text { (exclus. Epithel) }\end{array}$ & $\begin{array}{c}\text { Darmfaserlant } \\
\text { und Mesenterium }\end{array}$ \\
\hline
\end{tabular}

IV. Differenzirungs-Productedes Darmdriusenblattes.

$\begin{array}{ccc}\text { Darm-Epitheliun } & \begin{array}{c}\text { Darm-Hypodermis } \\ \text { (zum grössten Theil) (zum grössten Theil) }\end{array} & \begin{array}{c}\text { Darm-Ëpithelium } \\ \text { (ausgenommen }\end{array} \\ & \begin{array}{c}\text { Mundlıöble und } \\ \text { Afterhöhle). }\end{array}\end{array}$


III.

Entwurf einer phylogenetischen Classification des Thierreichs, gegründet auf die Gastraea-Theorie und die Homologie der Keimblätter, des Urdarms und des Coeloms.

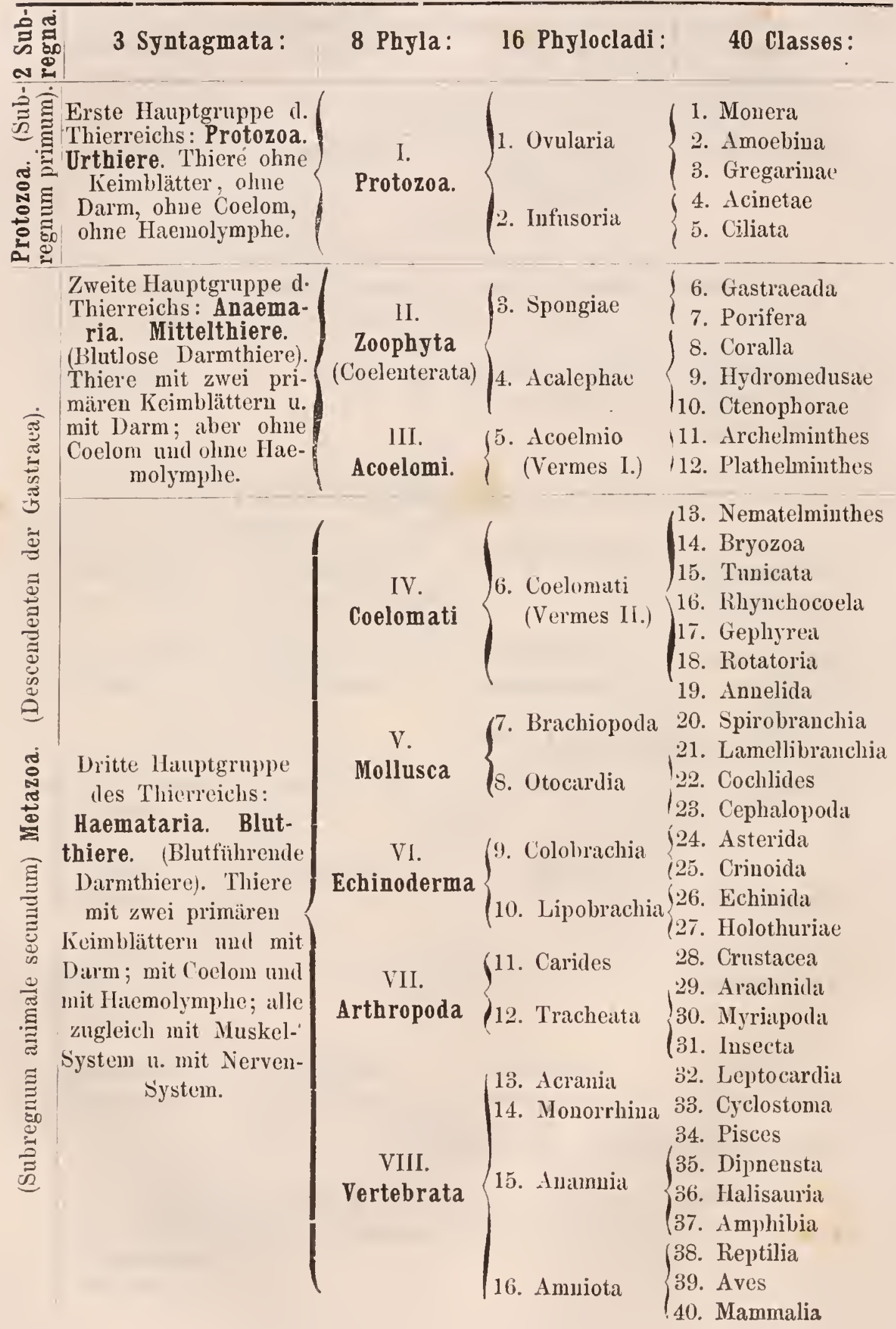


IV.

Monophyletischer Stammbaum des Thierreichs, gegründet auf die Gastraea-Theoric und die Homologie der Keimblätter.

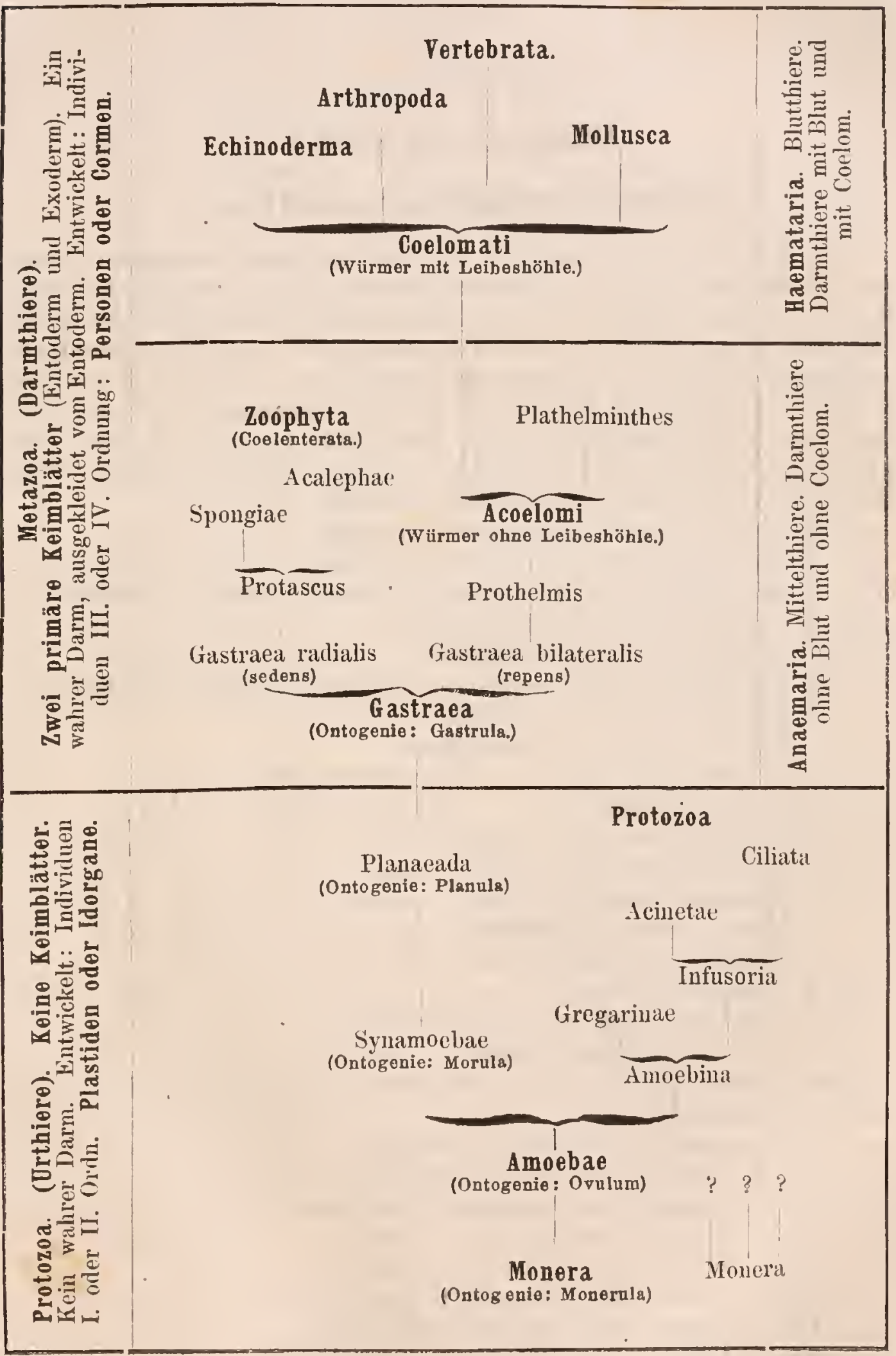




\section{Erklärung der 'Tafel I.}

\section{Schematische Illustration der Gastraea-Theorie.}

Die Tafel I enthält schematische Durchsehnitte durch die Jugend-Zustände von Repräsentanten aller versehiedenen Metazoen-Phylen, und soll die Homologie der beiden primären Keimblätter bei denselben, sowie den Ursprung der vier secundären Keimblätter veranschaulichen. Fig. 1-8 sind schematische Längsschnitte, Fig. 9-16 schematische Querschnitte. In allen Figureu ist das primäre innere Keimblatt (Gastralblatt, Entoderm, vegetatives Keimblatt) nebst den davon abgeleiteten Theilen durch rothe Farbe bezeichnet; hingegen das primäre äussere Keimblatt (Dermalblatt, Exoderm, animales Keimblatt) dureh blaue Farbe. Die Buchstaben bedeuten überall dasselbe:

a) Urdarm (Progaster); primitives Darmrohr

o) Urmund (Prostoma); primitive Mundöffinung

i) Gastralblatt (Entoderma); inneres primäres Keimblatt; Hautblatt

d) Varmdriisenblatt (Mykogastralblatt)

f) Darmfaserblatt (Inogastralblatt)

e) Dermalblatt (Exoderm); äusseres primäres Keimblatt; Darmblatt

m) Haitfiaserblatt (Inodermalblatt)

1) Hautsinnesblatt (Neurodermalblatt)

c) Coelom (Leibeshöhle oder Pleuroperitoneal-Höhle)

n) Urhirn (Medullarrohr)

x) Axenstab oder Chorda dor'salis

t) Dorsales Darmgefäss (Aorta)

z) Ventrales Darmgefäss (Herz)

r) Dorsale Seiteurumpf-Muskehı

b) Ventrale Seitenrumpf-Muskeln

l) Lederhant (Coriumı)

k) Keimdrüsen (Anlagen der Sexual-Irüsen)

ii) Uruieren (Excretions-Canäle).

Fig. 1-8 stellen schematische Längsschnitte der Gast rula von acht verschiedenen 'Thierformen dar.

Fig. 1. Gastrula einer' Spongie (Olynthus).

Fig. 2. Gastrula einer Coralle (Aetinia).

Fig. 3. Gastrula eines Acoelomen (Turbellaria).

Fig. 4. Gastrula eines 'Tunicaten (Ascidia).

Fig. 5. Gastrula eines Mollusken (Limnaeus).

Fig. 6. Gastrula eines Asteriden (Craster).

Fig. 7. Gastrula eines Crustaceen (Nauplius).

Fig. 8. Gastrula eines Vertebraten (Amphioxus). 
Fig. 9-16 stellen schematische Querschnitte durch Repräsentanten von aclit verschiedenen Typen dar.

Fig. 9. Querschnitt durch eine einfachste Spongie (Olynthus) oder eine einfachste Hydromeduse (Hydra). 1)ie Wand des Urdarms besteht (wie bei der Gastrula) zeitlebens nur aus den beiden primären Keimblättern.

Fig. 10. Querschnitt durch cine einfache Acalephen-Form (Hydroid). Zwischen dem Gastrablatt (i) und dem Hautsinnesblatt (h) ist das Hautfaserblatt (m) angelegt.

Fig. 11. Querschnitt durch einen Acoelomen-Embryo (einer Turbellarie). Der Schnitt gcht mitten durch das Urhirn oder den-oberen Schlundknoten (n). Zwischen dem IIautsinnesblatte (h) und dcm Darmdrïsenblatte (d) sind ausserdem nur die beiden Faserblätter sichtbar, welche dicht an einauder liegen: das äusscre Hautfaserblatt $(\mathrm{m})$ und das innere Darmfaserblatt (f).

Fig. 12. Querschnitt durch eine Ascidien-Larve, vor der Basis des Schwanzes, wo sich das vorderste Ende der Chorda (x) zwischen das Medullarlohr (n) und das Darmrohr (d) einschiebt. Zwischen Hautfaserblatt (m) und Darmfaserblatt (f) ist das Coelom sichtbar.

Fig. 13. Querschnitt durch eine Amphioxus-Larve (Vergl. Kowalevsky, Entwickelungsgeschichte des Amphioxus Taf. II, Fig. 20). Das Darmtaserblatt (f) ist noch gänzlich von dem Hautfaserblatt $(\mathrm{m})$ getrenut. Der ganze Körper besteht bloss aus den vier secundären Keimblättern.

Fig. 14. Querschnitt durch eine etwas ältere Amphioxus-Larve. Das Medullarrohr (n) hat sich vom Hornblatt (h) vollständig abgeschnürt. Das Hautfaserblatt $(\mathrm{m})$ ist mit dem Darmfaserblatt (f) in der dorsalen Mittellinie (Mesenterial-Linie) verwachsen und in Lederbaut (l) und Rumpfmuskeln (r) differenzirt. Zwischen dem Darmrohr und dem abgeschnürten Medullarrohr (II) hat sich die Anlage der Chorda (x) gebildet.

Fig. 15. Querschnitt durch einen Wurm-Embryo (Kopf-Segment eines Anneliden). Zwischen dorsalen (r) und ventralen (b) Längsmuskeln treten die Urnieren (Scgmental-Orgaue, u) von der Hautoberfläche hindurch in die Leibeshöhle (c). Oberhalb des Urdarms (a) ist das dorsale Längsgefäss ( $t$ ), unterhalb desselben das ventrale Längsgefäss ( $z$ ) sichtbar, beide eingeschlossen in das Darmfaserblatt (f).

Fig. 16. Querschnitt durch einen Wirbelthier-Embryo (Körpermitte eines Fisches). Zwischen dorsalen (r) und ventralen (b) Seitenrumpf-Muskeln tritt die Urnieren-Anlage (u) von der Haut hindurch zur Leibeshöhle (c). Oberhalb des Urdarms (a) ist die primordiale Aorta (t), unterhalb desselben die Anlage des Herzens (oder des Arterienbulbus, z) sichtbar, beide eingeschlossen in das Darmfaserblatt (f). Der einzige wesentliche Unterschied zwischen dem typischen Querschnitt des Vertebraten-Körpers und des Wurmkopfes (Fig. 15) besteht darin, dass sich bei ersterem zwischen Medullarrohr (n) und Urdarm (a) die Chorda eutwickelt (x).

J ena, am 29. September 1873. 

II.

\title{
Die Gastrula und die Vifurchumg der Thiere.
}

\author{
(Hierzu Tafel II---VIII.)
}

In hal t: 9. Die Bedeutung der Palingenie und der Cenogenie. 10. Die vier Hauptformen der Eifurchung und Gastrulabildung. 11. Die Eifurchung und Gastrulalildung in den Hanptgruppen des Thierreichs. 12. Die phylogenetische Bedeutung der fünf ersten ontogenetisehen Entwickelungsstufen. 



\section{Die Bedentung der Palingenie und der Cenogenie.}

Die Gastraea-Theorie lat sich in den drei Jahren, welche seit Publication ihrer Grundzïge in meiner Monographie der Kalkschwämme (1872) verflossen sind, als ein leitendes Princip bewährt, welches nach vielen Richtungen hin geeignet ist, Ordnung in das bunte Chaos der massenhaft angehäuften zoogenetischen Beobachtungen zu bringen und die causale Erkenntniss der wichtigsten Vorgänge in der Entwickelungsgeschichte der Thiere wesentlich zu fördern. Zu diesem Schlusse bin ich bereehtigt einerseits dureh die vielfache fruehtbare Verwendung, welche die Folgerungen der Gastraea-Theorie inzwischen bei zahlreichen Anhängern der monistischen Entwickelungslehre gefunden haben; anderseits durch die nicht minder zahlreichen und lebhaften Angriffe, welche dieselbe durch die dualistischen Gegner der letzteren erfahren hat. Wie Jene bestrebt gewesen sind, mittelst der Gastraea-Theorie und der daran geknüpften Consequenzen den einheitlichen Zusammenhang der Entwickelungs-Vorgänge im ganzen Thierreiche zu erkennen, so haben sich Diese umgekehrt bemüht, durch Widerlegung unserer Theorie darzuthun, dass ein solcher einheitlicher Zusammenhang nicht existirt, und dass die verschiedenen Entwickelungserscheinungen im Thierreiche ein zusammenhangloses Aggregat unverständlicher und wunderbarer Thatsachen bilden.

Inzwischen bin ich ununterbrochen bestrebt gewesen, die mannichfaltigen Folgerungen der Gastraea-Theorie weiter zu entwickeln und ihre Anwendung auf die phylogenetische Classification des Thierreichs, auf die Feststellung der Homologien in den verschiedenen Thierstämmen u. s. w. durchzuführen. Wie fruchtbar dieselbe sich für die zusammenhängende Erkenntniss der Keimesund Stammesgeschichte sowohl im Ganzen als im Einzelnen erweist, 
habe ich an dem Beispiele des menschlichen Organismus in meiner, im vorigen Jahre veröffentlichten Anthropogenie darzuthun versucht. Doch blieben trotz dieser unausgesetzten Bemühungen zur Befestigung der Gastraea-Theorie immer noch manche dunkle Stellen und schwache Seiten übrig, welche den Gegnern Gelegenheit zu mannichfachen Angriffen darboten. In der Absicht, diese Dunkelheiten und Schwächen möglichst $\mathrm{zu}$ beseitigen, habe ich eine neue Reihe von vergleichenden Beobachtungen über die ersten EntwickelungsVorgänge in den verschiedenen Hauptgruppen des Thierreichs angestellt. Um dieselben, vorzüglich durch Untersuchung niederer Seethiere, zu einem vorläufigen Abschlusse zu bringen, unternahm ich im Frühling dieses Jahres eine Reise nach Corsica, wo ich in Gesellschaft meiner beiden Schüler und Freunde, der Doctoren OsCar und Richard Hertwig, während der Monate März und April verweilte. Der felsenreiche Strand von Ajaccio, der Hauptstadt der Insel, bot uns für unsere Zwecke eine reiche Fülle von niederen Seethieren aus allen Hauptgruppen, und auch die pelagische Fischerei mit dem Mö́lLER'schen Netze an der Oberfläche des weiten Golfes von Ajaccio lieferte uns manches werthvolle Material, unter diesem namentlich pelagische Eier von Knochenfischen, welche für mehrere streitige Fragen in der Ontogenie dieser Thiere von entscheidender Bedeutung sind. Auf den ausgedehnten Strandfelsen, welche bei niederem Wasserstande weit entblösst werden, wuchert eine reiche Algen-Flora, und mit dieser gemischt eine nicht minder üppige Vegetation von Spongien, Hydroiden, Alcyonarien und anderen Zoophyten. Auch an Würmern, Mollusken, Echinodermen und Crustaceen war kein Mangel und ich konnte die Entwickelung der Eier wenigstens von einzelnen Repräsentanten dieser Gruppen in den ersten, mir vorzugsweise wichtigen Stadien vergleichend verfolgen. Zugleich gelang es mir, eine Reihe von früheren ontogenetischen Beobachtungen zu ergänzen, welche ich 1865 auf Helgoland, 1867 auf der canarischen Insel Lanzerote, 1869 an der Küste von Norwegen, 1871 auf der dalmatischen Insel Lesina und 1873 im Hafen von Smyrna angestellt hatte. Indem ich über verschiedene Resultate dieser und früherer Untersuchungen mir spätere Berichterstattung vorbehalte, beschränke ich mich zunächst für diesmal auf die Mittheilung der abgerundeten Ergebnisse, welche ich über die Eifurchung und die Gastrulabildung in den verschiedenen Hauptgruppen der Metazoen erhaiten habe. 
Unstreitig sind es vor allen die mannichfaltigen Verhältnisse der thierischen Eifurchung, welche die ursprïngliche Einheit der Gastrulabildung in den verschiedenen Thierklassen verdecken und demzufolge von den Gegnern rer Gastraea-Theorie ganz naturgemäss als Haupt-Argumente gegen dieselbe benutzt worden sind. Diese vielfachen und auffallenden Verschiedenheiten in der Eifurchung, welche anscheinend gänzlich verschiedene Keimformen zu Folge haben, lassen sich aber nur dann richtig beurtheilen und auf den ursprünglichen Entwickelungsgang der reinen Gastrulabildung zurückführen, wenn man die höchst wichtige, bisher nicht entfernt gewürdigte Unterscheidung zwischen Palingenie und Cenogenie, zwischen primären und secundären KeimungsVorgängen möglichst scharf verfolgt und durchführt. Unter den secundären cenogenetischen Erscheinungen aber, welche den primären palingenetischen Entwickelungsgang der Keimformen verdecken und fälschen, sind wiedler vor Allen wichtig die einflussreichen Verhältnisse des Nahrungsdotters in Gegensatz zum Bildungsdotter, sowie die mannichfaltigen ontogenetischen Heterochronien und Heterotopien. Ausserdem sind auch einige andere Vorgänge, die auf gefälschte und abgekürzte Vererbung sich zuriickführen lassen, von bedeutendem Einflusse.

Durch gehörige Verwerthung dieser Erscheinungen, durch jahrelanges Nachdenken ïber das Verhältniss der Palingenie zur Cenogenie, und durch die neuen Beobachtungsreihen, die ich von diesem Gesichtspunkte aus angestellt habe, ist es mir, wie ich hoffe, gelungen, alle die auffallenden Verschiedenheiten in der Eifurchung und friihesten Keimbildung der Thiere auf vier verschiedene Hauptformen zurückzuführen und von diesen letzteren wieder eine einzige als die ursprüngliche Grundform nachzuweisen, aus der sich die drei anderen Hauptformen phylogenetisch hervorgebildet haben. Diese eine Grundform ist die primordiale Eifurchung, und ihr Product die reine einfache Gastrula (,Archigastrula'), wie sie z. B. beim Amphioxus und bei der Ascidie sich noch heute findet (Vergl. Taf. VIII und die V. Tabelle S. 65). Ferner ist es durch diese Reduction möglich geworden, bei sämmtlichen Thieren (- natürlich stets mit Ausnahme der Protozoen, die überhaupt keine Keimblätter bilden -) übereinstimmend jene fünf primitiven Entwickelungsstufen nachzuweisen, welche ich bereits in der Monographie der Kalkschwämme (Bd. I, S. 465) als gemeinsame ontogenetische Urformen sämmtlicher Metazoen hingestellt und nach dem biogenetischen Grundgesetze phylogene- 
tisch gedeutet hatte (Vergl. die VI. synoptische Tabelle S. 66). Jeder, der unter den verschiedenen, gegenwärtig möglichen, phylogenetischen Hypothesen über den Ursprung des Thierreichs die e in f a chs te vorzieht, und demgemäss eine monophyletische Descendenz sämmtlicher Metazoen von der Gastraea annimmt, der kann jetzt auch noch weiter gehen, und fussend auf dem gemeinsamen, nunmehr nachgewiesenen Entstehungsmodus der Gastrula (durch Einstülpung der Blastula a. s. w.) auch jene fünf Urstufen der thierischen Formbildung bei allen Metazoen für homolog halten; oder - mit.anderen Worten - den ersten gemeinsamen Ursprung aller Thiere bis zum denkbar einfachsten Organismus, bis zum Moner hinab verfolgen. Denn bei gehöriger Berücksichtigung der verschiedenen cenogenetischen Veränderungen, welche der Nahrungsdotter in dem palingenetischen Processe der primordialen Eifurchung hervorgebracht hat, ist es in der That möglich, nicht nur die Gastrula, sondern auch die vorhergehenden vier Bildungsstufen dieser wichtigsten Keimform, auf das gemeinsame Urbild der primordialen Eifurchung bei allen Metazoen zu reduciren (Vergl. die VII. synoptische Tabelle S. 67).

Was die vier Hauptformen der Furchung betrifft (die primordiale, inaequale, discoidale und superficiale) so sind es dieselben, welche ich bereits in der Anthropogenie (S. 166) unterschieden habe. Ich hatte dort ausserdem noch zwei andere Hauptformen als pseudototale und seriale Furchung aufgeführt. Indessen lassen sich diese beiden Formen unter die inaequale Furchung subsumiren. Das Verhältniss dieser vier wichtigsten Furchungsformen zu den beiden, bisher allein unterschiedenen Hauptformen der totalen und partiellen Furchung gestaltet sich so, dass die primordiale und inaequale Furchung (rein äusserlich betrachtet) unter den Begriff der totalen, hingegen die discoidale und superficiale unter den Begriff der partiellen Furchung fallen (Tabelle V). Jedoch sind scharfe und abschliessende Grenzen ebenso wenig zwischen unseren vier Hauptformen, als zwischen der totalen und partiellen Furchung zu ziehen. Vielmehr sind alle durch Uebergänge verbunden, und alle lassen sich auf die ursprüngliche Form der primordialen Eifurchung phylogenetisch zurückführen. 
V.

Synoptische Tabelle über dic wichtigsten Verschiedenheiten in der Eifurchung' und Gastrulation der 'Thiere.

(Die sechs Stämme der Metazoen sind durch die Buchstaben $a-f$ bezeichnet: a Zoophyten (Coclenteraten), b Würmer, $c$ Mollusken, d Echinodermen, $e$ Arthropoden, $f$ Vertcibraten.)

\begin{tabular}{|c|c|c|}
\hline $\begin{array}{c}\text { I. } \\
\text { Totale } \\
\text { Furchung. } \\
\text { (Ovila holo- } \\
\text { blasta). }\end{array}$ & $\begin{array}{l}\text { 1. Primordiale Fur } \\
\text { (1)vila archiblas }\end{array}$ & $\begin{array}{l}\text { a. Vie meisten P'flanzenthiere } \\
\text { (Niedere Schwämme, Hyıloi- } \\
\text { den, Medusen, ('orallen). } \\
\text { b. Viele niedere Würmer } \\
\text { (Sagitta, Phoronis, Ascidien, } \\
\text { viele Nenatoden u. s. w.). } \\
\text { c. Einige niedere Mollusken } \\
\text { (Spirobranchien u. s. w.). } \\
\text { d. Die meisten Echinodermen. } \\
\text { e. Einige niedere Gliederthiere } \\
\text { (Einige Brancliopoden, Pte- } \\
\text { romalinen?). } \\
\text { f. Die Acranier (Amphioxus). }\end{array}$ \\
\hline $\begin{array}{c}\text { Primäre } \\
\text { Gastrula. } \\
\text { (Hologasırula). }\end{array}$ & $\begin{array}{c}\text { Ampligastrula. } \\
\text { 'Taf. VII. }\end{array}$ & $\begin{array}{l}\text { a. Viele Pflanzenthiere } \\
\text { (Manche Spongien, Medusen } \\
\text { undCoralleı; Siphonophoren, } \\
\text { Ctenophoren). } \\
\text { b. Die meisten Würmer (Acoe= } \\
\text { lomier, Anneliden u. s. w.). } \\
\text { c. Die meisten Mollusken. } \\
\text { d. Einzelne Echinodermen. } \\
\text { e. Niedere Arthropoden (sowolı } \\
\text { Crustaceen, als Tracheaten). } \\
\text { f. Cyclostomen, Ganoiden, Am- } \\
\text { phibien, Placentalien (?). }\end{array}$ \\
\hline $\begin{array}{l}\text { II. } \\
\text { Partielle } \\
\text { Furchung. } \\
\text { (Ovula mero-1 } \\
\text { blasta). }\end{array}$ & $\begin{array}{l}\text { 3. Discoidale Furchung. } \\
\text { (Ovula discoblasta). }\end{array}$ & $\begin{array}{l}\text { c. Die meisten Cephalopoden. } \\
\text { e. Manche Arthropoden. } \\
\text { (Sowohl Clustacecn, als Tra- } \\
\text { cheaten). } \\
\text { f. Sclachier, Teleostier, Repti- } \\
\text { lien, Vögel, Monotremen u. } \\
\text { Didelphien (?). }\end{array}$ \\
\hline $\begin{array}{l}\text { Secundäre } \\
\text { Gastrula. } \\
\text { (Merogastrula). }\end{array}$ & $\begin{array}{l}\text { 4. Superficiale Furchung. } \\
\text { (Ovula periblasta). } \\
\text { Perigastrula. } \\
\text { Taf. VI. }\end{array}$ & $\begin{array}{l}\text { b. Einige höhere Würmer (?). } \\
\text { e. Die meisten Arthropoden, } \\
\text { sowohl Crustaceen als Tra- } \\
\text { cheaten. }\end{array}$ \\
\hline
\end{tabular}


VI.

Synoptische Tabelle über die fünf ersten Keimungsstufen der Metazoen, verglichen mit ihren fünf ältesten Ahnenstufen.

Formwerth

der fünf ersten Entwicke- Die fünf ersten Stufen lungsstufen der Metazoen. der Keimes-Entwickelung.
Phylogenesis:

Die fünf ersten Stufen der Stammes-Entwickelung.
I.

Erste Formstufe:

Cytoda.

Eine einfachste Cytode

(kernlose Plastide).

II.

Zweite Formstufe :

\section{Cellula.}

Eine einfachste, inclifferente, amoeboide Zelle (kernhaltige Plastide).

III.

Dritte Formstufe : Polycytium.

Ein einfachstes Aggregat von einfachen, gleichartigen, indifferenten Zellen.

IV.

Vierte Formstufe:

Blastosphaera.

Eine einfache, mit Flüssigkeit gefülltc Hohlkugel, deren Wand aus einer cinzigen Schicht gleichartiger Zellen besteht.

$$
\mathrm{V} \text {. }
$$

Fünfte Formstufe:

\section{Metazoarchus.}

Ein einfacher, einaxiger Hohlkörper mit,einer Oeffnung, dessen Wand aus zwei verschiedenen Zellenschichten besteht.
I.

Erste Keimungsstufe: Monernla.

Das befruchtete Ei nach Verlust des Keimbläschens.

II.

Zweite Reimungsstufe: Cytula.

„Die erste Furchungskugel" (das befruchtete Ei mit neugebildetem Zellenkern).

III.

Dritte Keimungsstufe: Morula.

"Maulbeerdotter", kugeliger Haufen von einfachen gleichartigen Furchungskugeln.

\section{IV.}

Vierte Keimungsstufe: Blastula. "Keimhantblase" oder „Keimblase!" (Vesicula blastodermica oder Blastosphaera) oft auch "Planula" genaunt.

$$
\text { V. }
$$

F'ünfte Keimungsstufe: Gastrula.

Einfacher einaxiger Darmschlauch (Urdarm) mit Urmund; Wand aus den beiden primären Keimblättern gebildet.
I. Erste Ahnenstufe:

\section{Moneres.}

A elteste, durch Urzeugung entstandene Stammform der Metazoen.

II.

Zweite Ahnenstufe:

Amoeba.

Einfachste, älteste, inclifferente Stammzelle.

III.

Dritte Ahnenstufe:

\section{Synamoebium.}

Einfachste älteste Gemeinde von gleichartigen indifferenten Zellen.

\section{IV.}

Vierte Ahnenstufe:

\section{Planaea.}

Hohlkugel, deren Wand aus ciner Schicht von Flimmerzellen besteht? (ähnlich der heutigen

Magosphaera). $\mathrm{V}$.

Fïnfte Ahnenstufe: Gastraea. Gemeinsame Stammform aller Nctazoen, gleich der Archigastrula des Amphioxus, der Ascidic u. S. W. 
VII.

Synoptische Tabelle über die fïnf ersten Keimungsstufen der Metazoen, mit Rücksicht auf die vier verschiedenen Hauptformen der Eifurchung:

\begin{tabular}{c}
$\begin{array}{c}\text { A. Totale Furchung. } \\
\text { (Ovula holoblasta) }\end{array}$ \\
$\begin{array}{c}\text { b. Inaequale } \\
\text { Furchung. } \\
\text { Frimordiale }\end{array}$ \\
$\begin{array}{c}\text { Forchung. } \\
\text { archiblasta). }\end{array} \quad(0$. amphiblasta). \\
\hline
\end{tabular}

I. Archimonerula. I. Amphimonerula.

Das befruchtete Ei ist Eine Cytode, die am eine Cytode, in der animalen Pole BilBildungsdotter und dungsdotter, am veNahrungsdotter nicht getativen Pole Nahzu unterscheiden rungsdotter besitzt, sind.

\section{Archicytula.}

Eine Zelle, ans der Archimonerula durch Amphimonerula durch Neubildung eines K'ernes entstanden.

\section{Archimorula.}

Eine solide (meist kugelige) Masse, aus lauter gleichartigen Zellen gebildet.

\section{Archiblastula. IV Amphiblastula.} Eine (meist kugelige) Eine rundliche Blase, hohle Blase, deren deren Wand am aniWand aus einer ein-malen Pole aus kleizigen Schicht gleich-nen Exoderm-Zellen, artiger Zellen besteht. am vegetativen Pole aus grossen Entodermzellen besteht.

\section{Archigastrula.}

Die ursprüngliche

\section{Amphigastrula.}

Glockenförmige Gareine Gastrula-Form strula, deren Urdarm mit leerem Urdarm, zum Theil von geohne Nahrungsdotter; furchtem Nahrungsprimäre Keimblätter dotter erfüllt ist. einschichtig.

\begin{tabular}{|c|c|}
\hline $\begin{array}{c}\text { B. Partielle Furchung. } \\
\text { (Ovata meroblasta). }\end{array}$ \\
$\begin{array}{c}\text { c. Discoidale } \\
\text { Furchung. } \\
(0 . \text { discoblasta }) .\end{array}$ & $\begin{array}{c}\text { d. Superficiale } \\
\text { Furchung. } \\
\text { (O. periblasta }) .\end{array}$ \\
\hline
\end{tabular}

I. Discomonerula.

I. Perimonerula.

Eine Cytode, die am Das befruchtete Ei animalen Pole Bil- ist eine Cytode, die dungsdotter, am ve- an der Peripherie getativen Pole Nah- Bildungsdotter, im rungsdotter besitzt, Centrum Nahrungsdotter enthält. ander getrennt.

\section{Discocytula.}

Eine Zelle, aus der Discomonerula durch Neubildung eines Kernes entstanden.

\section{Discomorula.}

Eine flache Scheibe, Eine geschlosseue aus gleichartigen Zel-Blase, aus einer Zellen zusammengesetzt, lenschicht bestehend, dem animalen Pole die den ganzen Nahdes Nahrungsdotters aufliegend.

\section{Discoblastula.}

Eine rundliche Blase der'en kleinere Hemisphäre aus den Furchungszellen besteht; grössere. Hemisphäre aus dem ungefurchten Nahrungsdotter.

\section{Discogastrula.}

Scheibenförmige aus- Blasenförmige Gastrugebreitete Gastrula, la, deren Urdarm deren Urdarm ganz klein, deren grosse von ungefurchtem Turchungshöhle von Nahrungsilotter er-' N'ahrungsdottcr erfüllt ist. rungsdotter umschliesst.

\section{Periblastula.}

Eine geschlossene Blase, aus einer Zellenschicht bestehend, die den ganzen Nahrungsdotter umschliesst (= Perimorula).

\section{Perigastrula.}

füllt ist. 
I. Das phylogenetisçhe Verhältniss der Palingenie zur Cenogenie.

Die Unterscheidung zwischen Palingenie und Cenogenie, die Erkenntniss der ganz verschiedenen Bedeutung dieser beiden ontogenetischen Erscheinungs-Gruppen und insbesondere die Feststellung des phylogenetischen Verhältnisses derselben zu einander scheint mir von ganz fundamentaler Wichtigkeit für das Verständniss der Gastraea-Theorie, wie für die causale Beurtheilung und mechanische Begründung der Keimesgeschichte iiberhaupt zu sein. Denn diejenigen ontogenetischen Processe, welche unmittelbar nach dem biogenetischen Grundgesetze auf eine frühere, vollkommen entwickelte, selbständige Stammform zu beziehen und von dieser durch Vererbung übertragen sind, besitzen offenbar eine primäre Bedeutung für die Erkenntniss der causalen phylogenetischen Verhältnisse; dagegen können diejenigen keimesgeschichtlichen Vorgänge, welche erst später durch Anpassung an die Bedingungen des Embryolebens oder des Larvenlebens entstanden und demgemäss nicht als Wiederholung einer früheren selbstständigen Stammform gelten dürfen, offenbar für die Erkenntniss der Stammesgeschichte nur eine ganz untergeordnete, s e cun däre Bedeutung beanspruchen. Die ersteren habe ich als palingenetische, die letzteren als cenogenetische bezeichnet. Von diesem kritischen Gesichtspunkte aus betrachtet wird die gesammte Ontogenie in zwei verschiedene Hauptheile zerfallen: erstens $\mathrm{Pa}$ lingenie oder "Auszugsgeschichte“, und zweitens Cenogenie oder "Fälschungsgeschichte". Die erstere ist der wahre ontogenetische Auszug oder die kurze Recapitulation der alten Stammesgeschichte; die letztere ist gerade umgekehrt eine neuere, fremde Zuthat, eine Fälschung oder Verdeckung jenes Auszuges der Phylogenie.

Um sofort an einem Beispiele klar zu machen, was ich durch diese Unterscheidung zu erreichen wïnsche, brauchen wir bloss einen Blick auf die Ontogenie des Menschen oder irgend eines anderen Amnioten zu werfen. Als palingenetisclie Processe, welche unmittelbar auf eine frühere selbständige Stammform zu beziehen, und offenbar getreu durch Vererbung übertragen sind, müssen wir bei allen Amnioten unter Anderen folgende betrachten: die Sonderung der beiden prinıären Keimblätter, das Auftreten einer einfachen Chorda zwischen Markrohr und Darmrohr, die Erscheinung des einfachen knorpeligen Urschädels, der Kiemen- 
bogen und ihrer Gefässe, der Urnieren, die einfache Anlage der fünf Hirnblasen, die einkammerige Urform des Herzens, das Auftreten der primitiven Aorten und der Cardinal-Venen, die hermaphroditische Anlage der inneren und äusseren Geschlechts-Organe u. s. w. Hingegen werden wir als cenogenetische Processe, welche keineswegs auf eine frühere selbständige und völlig entwickclte Stammform zu beziehen, vielnehr durch Anpassung an die Bedingungen des Eilebens oder Embryolebens entstanden sind, zu betrachten haben: die Bildung des Nahrungsdotters und der Eihüllen, des Amnion, der Allantois, die Verhältnisse des embryonalen Dotter-Kreislaufs und Allantois-Kreislaufs, die vorübergehende embryonale Trennung von Urwirbelplatten und Seitenplatten, den secundären Verschluss der Bauchwand und Darmwand, die Nabelbildung, dle zusammengekrümmte Keimform u. s. w.

Oder um ein Beispiel aus der Entwickelungsgeschichte der Crustaceen anzufïhren, für die uns Fritz MüLler-Desterro durch seine bahnbrechende Schrift „Für Darwin“ (1864) ein so bedeutungsvolles und alle Theile der Biogenie erhellendes Licht angeziindet hat, so werden wir für die Palingenie dieser Thierklasse vor Allen zu verwerthen haben: die wesentlich übereinstimmende Bildung und Zusammensetzung der Nauplius-Larven in den verschiedenen Ordnungen der Crustaceen, die ursprüngliche, einfache Bildung ihres Darmcanals, ihres unpaaren Stirnauges, ihrer drei Paar Schwimmfüsse u. s. w. Ebenso stellt für die höheren Crustaceen, insbesondere die Malacostraca, die charakteristische "Zoëa" mit ihrer typischen Gliederung und Gliedmaassenbildung eine palingenetische Keimform dar. Hingegen wird durch die Cenogenie der Crustaceen zu erklären sein: die partielle Eifurchung und die Bildung des Nahrungsdotters bei der Mehrzahl der Cruster, die Umwachsung desselben durch das Blastoderm, der secundäre Verschluss der Rückenwand, die Krümmung des Embryo innerhalb der Eischale, sowie die Bildung jener mannichfaltigen, sonderbaren Embryonalformen und Larvengestalten, die nicht von den Stanmformen ererbt, sondern vielmehr ,in dem Kampfe um's Dasein erworben sind, welchen die frei lebenden Larven zu bestehen haben." (Fritz Müller l. c. p. 77.)

Offenbar ist die Unterscheidung jener primären palingenetischen und dieser secundären cenogenetischen Processe für das phylogenetische Verständniss und somit für dic mechanische Erklärung der ontogenetischen Thatsachen von der grössten Bedeutung; und zwar um so mehr, je mehr der primäre ursprüngliche 
Entwickelungsgang des Embryo durch die secundäre Ausbildung von Eihüllen, von Nahrungsdotter u. s. w. gefälscht, und je mehr durch andere Ursachen die getreue Wiederholung der langen Stammesentwickelung durch die kurze Keimesentwickelung abgekürzt oder verdeckt ist. Wenn man diese höchst wichtigen, aber bisher fast ganz vernachlässigten Verhältnisse nicht gehörig in's Auge fasst, so wird man weder das wahre Causal-Verhältniss zwischen jenen beiden Entwickelungs-Reihen verstehen, noch überhaupt die Bedeutung des biogenetischen Grundgesetzes begreifen können. Schon in der "Generellen Morphologie" (1866), und eingehender später in der Anthropogenie (1874) habe ich darauf hingewiesen, ,wie wichtig es für die richtige und kritische Anwendung des biogenetischen Grundgesetzes ist, stets beide Seiten desselben im Auge zu behalten. Die erste Hälfte dieses fundamentalen Entwickelungsgesetzes öffnet uns die Bahn der Phylogenie, indem sie uns lehrt, aus dem Gange der Keimesgeschichte denjenigen der Stammesgeschichte annährend zu erkennen: Dic Keimform wiederholt durch Vererbung dic entsprechende Stammforn (Palingenesis). Die andere Hälfte desselben schränkt aber diesen leitenden Grundsatz ein, und macht uns auf die Vorsicht aufmerksam, mit welcher wir denselben anwenden müssen; sie zeigt uns, dass die ursprüngliche Wiederholung der Phylogenese durch die Ontogenese im Laufe vieler Millionen Jahre vielfach abgeändert, gefälscht und abgekürzt worden ist: D i e Keimform hat sich durch Anpassung vou der entsprechenden Stammform entfernt" (Cenoyenesis). Anthropogenie S. 626.

Fuir dic Palingenesis oder die „Auszugs-Entwickelung" sind demnach von hervorragender Bedeutung die Gesetzc der ununterbrochenen (continuirlichen), der befestigten (constituirten), der gleichörtlichen (homotopen) und den gleichzeitlichen (homocluronen) Vererbung (Generelle Morphologic, Vol. II, p. 180-190). Diese höchst wichtigcn, Vererbungs-Gesetze gestatten uns noch heute, aus den vorliegenden Thatsachen der Keimesgeschichte ganz positive Schlüsse auf den ursprïnglichen Gang der Stammesgeschichte zu thun. Hingegen sind für die Cenogenes is oder die „Fälschungs-Entwickelung" ganz besonders wichtig die Gesetze der abgeküurten (abbreviirten) und der gefälschten (modificirten), ganz besonder's aber der ungleichörtlichen (heterotopen) und der ungleichzeitlichen (heterochronen) Vererbung. Diese Vererbungsgesetze haben für die Phylogenie nur einen negativen Werth. Für die gesammte Morphologie, und speciell für die Phylogenie, 
ist selbstverständlich die Palingenesis von ganz anderer Bedeutung, als die Cenogenesis. Die Morphologie, welche ihre Aufgabe richtig begriffen hat, wirl den versteckten Pfad der Phylogenie in dem schwierigen Gebiete der Ontogenie nur dann finden; wenn sie die palingenetischen Processe möglichst hervorsucht, die cenogenetischen möglichst eliminirt. Die Physiologie wird umgelrehrt an der näher liegenden Cenogenie in vielen Fällen ein weit höheres Interesse haben, als an der. Palingenic.

\section{Ontogenetische Heterochronien und Heterotopien.}

Unter den mannichfaltigen secundären Erscheinungen, welche uns die Cenogenesis darbietet und welche in mehr oder minder ausgeprägtem Gegensatze zu den primären Phänomenen der Palin. genesis stehen, sind von besonderer Wichtigkeit vor Allen die Ausbildung des Nahrungsdotters und was damit zusammenhängt; demnächst aber diejenigen Entwickelungs-Vorgänge, welche ich in der Anthropogenie als ,ontogenetische Heterochronien und Heterotopien" bezeichnet habe. Gerade diese Processe der Keimesentwickelung, welche $z u$ den entsprechenden Vorgängen der Stammesentwickelung in einem diametralen Gegensatze zu stehen, die Palingenesis $\mathrm{z}$ negiren und das ganze biogenetische Grundgesetz zu erschüttern scheinen, lassen sich durch die Cenogenesis befriedigend erklären. Wie ich in der Anthropogenie bemerkte, ,sind die ontogenetischen Heterochronien, welche durch Verschiebung der phylogenetischen Succession entstehen, nicht minder bedeutungsvoll als die ontogenetischen $\mathrm{Heterotopien,} \mathrm{die} \mathrm{durch}$ frühzeitige phylogenetische Wanderung der Zellen aus einem secundären Keimblatt in das andere bewirkt werden; dort wird die Zeitfolge, hier die Raumfolge gefälscht". Als wichtigste Leuchte zur Erkenntniss dieser cenogenetischen Processe dient uns die vergleichende Anatomie, ohne deren Hülfe wir überhaupt die Räthsel der Cenogenesis nicht lösen und den ursprünglichen Pfad der Palingenesis nicht erkennen würden.

Einleuchtende Beispiele solcher Processe liefert uns die Keimesgeschichte der verschiedensten Metazoen in Menge. Was zunächst die Heterochronie betrifft, die ontogenetische Zeitverschiebung, oder die cenogenetische Abänderung der palingenetischen Zeitfolge, so können wir im Allgemeinen Fälle von verfrühtem und von verspätetem Auftreten der Organe unterscheiden. Fälle von ontogenetischer Acceleration oder Verfrühung 
(wo in der Keimesgeschichte das Organ viel früher erscheint, als es in Verhältniss zu den übrigen Organen ursprünglich in der Stammesgeschichte der Fall war) bietet z. B. bei den Wirbelthieren: das frühzeitige Auftreten der Chorda, die auffallend frühe Entstehung des Gehirns und der Augen (besonders bei den Knochenfischen), der Kiemenspalten, des Herzens (vor den Gefässen) u. s. w. Die Gliederthiere zeigen solche ontogenetische Acceleration besonders in der frühzeitigen Ausbildung gegliederter Extremitäten und der Metamerenkette (des „Primitivstreifs"); die Traclieaten in dem frühen Auftreten der Tracheen, die Crustaceen in der vorzeitigen Ausbildung einer mächtigen Leber. Unter den Mollusken erscheinen in Folge beträchtlicher cenogenetischer Verfrühung auffallend bald die Kalkschalen und die Gehörbläschen; bei den Muscheln die Byssus-Drüse, bei den Schnecken die Radula. Bei den Echinodermen bilden sich oft unverhältnissmässig früh in der Ontogenese die Kalktheile des Skelets aus, die in der Phylogenese sicherlich späteren Ursprungs sind.

Umgekehrt erkennen wir eine ontogenetische Retaldation oder Verspätung (wo in der Ontogenie das Organ verhältnissmässig später auftritt, als es ursprünglich in der entsprechenden Phylogenie der Fall gewesen sein muss) z. B. in folgenden Vorgängen: das späte Auftreten der Sexualdrüsen bei den meisten Metazoen, die sehr verspätete Ausbildung des Darmcanals und des Coeloms bei Vielen derselben. Ein sehr auffallendes Beispiel liefert die späte Bildung der Vorkammer-Scheidewand (Septum atriorum) im embryonalen Herzen der höheren Wirbelthiere, welche der Entstehung der Kammerscheidewand (Septunı ventriculorum) nachfolgt. In der Phylogenie der Wirbelthiere ist umgekehrt die crstere der letzteren vorausgegangen, wie die Dipneusten, Amphibien und Reptilien beweisen.

Eine nicht minder wichtige Rolle spielen in der Keimesgeschichte der Wirbelthiere die ontogenetischen Ortsverschiebungen oder Heterotopien, die cenogenetischen Abänderungen der palingenetischen Raumfolge. Vor Allen kommen hierbei dic Zellenwanderungen und Zellenverschiebungen innerhalb der primären und secundären Keimblätter in Betracht, sowie die secundären Ortsveränderungen der alus den Keimblättern entstehenden Organe. Eine grosse Rolle spielen die ersteren z. B. bei der Entstehung des ,mittleren Keimblattes“, des Mesoderms. Als das urspriingliche palingenetische Verhältuiss der Mesodermbildung habe ich in der Anthropogenie die Bildung der 
vier secundären Keimblätter hingestellt, indem ich das Hautfaserblatt vom Exoderm, das Darmfaserblatt vom Entoderm ableitete. Beide Faserblätter zusammen, obwohl verschiedenen Ursprungs, verbinden sich secundär zum scheinbar einheitlichen Mesoderm. Die bekannte Spaltung des letzteren in Hautfaserblatt und Darmfaserblatt ist demnach ein tertiärer, kein primärer Vorgang. Wenn also jetzt (wie die meisten Ontogenisten annehmen) das Mesoderm als Ganzes aus einem der beiden primären Keimblätter allein entsteht und wenn das andere daran keinen Antheil nimmt, so ist das meiner Ansicht nach durch Heterotopie zu erklären, und zwar durch sehr trühzeitige (vielleicht schon wälrend der Furchung eintretende) Zellenwanderung aus einem primären Keimblatt in das andere. Ebenso muss ich anch die (von den Meisten angenommene) ontogenetische Entstehnng der Sexualdrüsen im Mesoderm als einen cenogenetischen Vorgang deuten, weil diese ursprünglich auf eines der beiden primären Keimblätter zurückzuführen und palingenetisch aus diesen entstanden sind. Auch die voriibergehende Trennung der Urwirbelplatten von den Seitenplatten, sowie viele auffallende Unterschiede in der Bildung der ersten Organ-Anlagen, welche wir bei ontogenetischer Vergleichung der verschiedenen Wirbelthier-Klassen wahrnehmen, dürften durch solche Heterotopien zu erklären sein.

Fuir Jeden, der das biogenetische Grundgesetz anerkennt und einen tiefen immeren Causalnexus zwischen Ontogenie und Phylogenie annimmt, bedarf es wohl kaum noch eines besonderen Hinweises daranf, welche ansserordentliche Bedeutung diesen bisher noch gar nicht gewürdigten Heterochronien und Heterotopien in der Ontogenie zukommt. Erst wenn man über diese merkwürdigen, bisher unbeachtet bei Seite gelassenen Thatsachen reiflich nachdenkt und den cenogenetischen Charakter derselben anerkennt, wird man das scheinbare Paradoxon verstehen, dass oft bei nahe verwandten Thieren die Ontogenie so beträchtliche Differenzen zeigt, und der Verlauf derselben so bedeutend von dem entsprechenden Verlauf der Phylogenie sich entfernt. Das letztere muss um so mehr der Fall sein und die ursprüngliche Palingenesis muss um so mehr in den Hintergrund treten, je zahlreicher und bedeutender sich jene cenogenetischen Zeitverschiebungen und Ortsverschiebungen im Laufe der Jahrtausende allmählig ausgebildet und zu complexen Phänomenen zusammengeballt haben. Ein solches complexes Phänomen ist z. B. die Bildung eines sogenannten „Primitivstreif $s^{66} d$. h. das frühzeitige und imponirende 
Auftreten einer Summe von axialen Körpertheilen, welche an der Oberfläche des Keimes in der Hauptaxe derjenigen dipleuren (oder "bilateral-symmetrischen") Metazoen erscheinen, deren Körper den Formwerth einer Metamerenkette oder einer "gegliederten Person" besitzt ${ }^{1}$ ). Als solche höchst complexe Gesammt-Resultate, die sich aus zahlreichen und mannichfaltigen cenogenetischen Heterochronien und Heterotopien zusammensetzen, sind ferner offenbar viele Fälle von sogenannter "Zusammenziehung und Vereinfachung" der Ontogenesis zu deuten, wie sie z. B. Gegenbaur in der Bildung des Schädels und Gehirns bei den Wirbelthieren, Fritz Müller in der Gliederung und Differenzirung des Crustaceen-Körpers so einleuchtend nachgewiesen haben. Auch die scheinbar ,directe Entwickelung“, ist so zu erklären, welche die Cephalopoden (das Veliger-Stadium der Schnecken überspringend) uns darbieten; und ebenso diejenigen Echinodermen, welche den ursprünglichen Generationswechsel (oder die sogenannte „Metamorphose") der Mehrzahl dieses Stammes gegenwärtig nicht mehr besitzen.

Von besonderer Bedentung dürfte für die richtige Würdigung der cenogenetischen Heterochronien und Heterotopien der Umstand sein, dass durch sie im Laufe der Zeit immer auffallender diejenigen Organe in den Vordergrund der Ontogenie gedrängt werden, welche fïr die betreffenden Hauptgruppen (Stamm, Classe, Ordnung) vorzugsweise charakteristisch und wichtig sind. So treten bei den Wirbelthieren unverhältnissmässig früh und mächtig die Chorda dorsalis und die Kiemenbogen auf; bei den Gliederthieren der sogenannte „Primitivstreif", die Metamerengrenzen und die Anlagen der gegliederten Extremitäten; bei den odontophoren Mollusken die Radula; bei vielen Echinodermen die Kalktheile des Skelets und die Anlagen des Ambulacral - Systems. Umgekehrt werden im Laufe der Jahrtausende immer mehr diejenigen Organe in den Hintergrund der Ontogenie gedrängt, welche die allgemeinste Bedeutung für sämmtliche Metazoen be-

1) Der sogenaunte "Primitivstreif" hat demnach in den verschiedenen Thierstämmen eine ganz verschiellene Bedeutung, so namentlich bei den Anneliden und Arthropoden einerseits, bei den Vertebraten anderseits. Immer aber ist der Terminus "Prinitivstreif" ein sehr unklarer Auscluck für eine complexe Summe von Phänomenen, die theils palingenctischen, theils cenogenetischen Ursprungs sind. Die Unterscheidung von "Entwickelung mit oler ohne Primitivstreif", wie sie $z$. B. Leuckart, Claus und viele Andere fiur seh" wichtig balten, ist im Grunde ganz unwichtig und werthlós. 
sitzen, vor Allem also Urdarm und Urmund in ihrer ursprünglichen Gestalt. Desshalb ist auch die reine, primordiale Gastrula (Archigastrula), welche durch Invagination einer einfachsten Blastula (Archiblastula) entsteht, vorzugsweise bei den niedersten, indifferentesten und ältesten Formen der verschiedenen Gruppen bis heute an getreuesten conservirt werden (Gastrophysema, Monoxenia, Sagitta, Phoronis, Argiope, Terebratula, Uraster, Toxopneustes, Ascidia, Amphioxus).

III. Palingenetischer Bildungsdotter und cenogenetischer Nahrungsdotter.

Die auffallendste und für die frühesten Keimungs-Processe der Metazoen weitaus wichtigste von allen cenogenetischen Erscheinungen ist die Ausbildung eines sogenannten ,Nahrungsdotters", im Gegensatze zu dem „Bildungsdotter“. Bei sehr vielen Thieren der verschiedensten Gruppen, namentlich aber bei den niederen und unvollkommneren (also phylogenetisch älteren) Formen fehlt ein separater Nahrungsdotter ganz und der Embryo entsteht einzig und allein aus dem "Protoplasma" der Eizelle, dem Bildungsdotter (Morphoblastus oder Protolecithus, Vitellus formativus). Zn diesem primären Bildungsdotter tritt nun aber bei vielen anderen Thieren, namentlich höheren und vollkommneren (also phylogenetisch jüngeren) Formen in sehr verschiedenen Klassen die besondere, zur Ernährung des Embryo dienende Vorrathsmasse, welche als „Deutoplasma" (van Beneden) sich zum Protoplasma der Eizelle hinzugesellt, der Nahrungsdotter (Trophoblastus oder Metalecithus, Vitellus mutritivus).

Diese Sonderung von Bildungsdotter und Nahrungsdotter bedingt voll Anfang der Keimesentwickelung an höchst auffallende Unterschiede bei den verschiedenen, oft nahe verwandten Thierklassen (ja selbst oft bei nahe verwandten Thieren einer Klasse); Unterschiede, welche ihre Wirkung bald auf kürzere, bald auf längere Zeit des Embryolebens erstrecken, die palingenetische Identität der Keimesentwickelung bei nahe verwandten Thieren oft ganz verdecken und überhaupt eine Masse von Täuschungen hervorrufen. Wenn man das Chaos von widersprechenden Beobachtungen, unvereinbaren Ansichten und entgegengesetzten. Meinungen überblickt, welches gegenwärtig die Keimesgeschichte der Thiere darbietet, besonders in Betreff der frühesten und wichtigsten Stadien der Entwickelung, - so wird man wohl nicht irre gehen, wenn man in 
der grossen Mehrzahl der Fälle die eigentliche Urquelle dieser Verwirrung in dem Auftreten des Nahrungsdotters und den davon abhängigen cenogenetischen Veränderungen sucht.

Je auffallender nun diese Unterschiede in den ersten Stadien der Keimesentwickelung sich darstellen, je mehr die Anwesenheit oder Abwesenheit eines Nahrungsdotters selbst nahe verwandte Thiere zu trennen scheint, desto wichtiger ist es, den cenogenetischen Charakter aller dieser secundären Veränderungen im Auge $\mathrm{zu}$ behalten und sich das ursprüngliche Bild der dadurch verdeckten palingenetischen Processe nicht trüben zu lassen. Denn in allen Fällen ist der Nahrungsdotter ein secundäres cenogenetisches Product, welches den primären palingenetischen Entwickelungsgang des Keimes zwar vielfach abändern und verdecken, aber dessen morphologische Bedeutung nicht im Mindesten abschwächen kann. Während viele Ontogenisten, geblendet durch die Grösse und die oft sehr complicirte Zusammensetzung des Nahrungsdotters, einen höchst wichtigen und selbst die Formbildung des werdenden Thieres unmittelbar beeinflussenden Kölper in demselben erblicken, werden wir umgekehrt denselben stets nur als einen ganz untergeordneten Factor der Keimesgeschichte ansehen, der zwar für die Physiologie des Embryo höchst bedeutungsvoll sein kann, für die Morphologie hingegen werthlos ist.

Um das Verhältniss des Nabrungsdotters zur Eifurchung richtig $\mathrm{zu}$ beurtheilen, müssen wir uns stets an drei wichtige Grundsätze erinnern, erstens, dass das Ei ursprünglich stets eine einfache Zelle ist, zweitens, dass die Eifurchung nichts anderes als eine einfache oft wiederholte Zellentheilung ist, und drittens, dass der Nahrungsdotter zur primären Eizelle stets als ein secundäres Product hinzutritt, welches an den activen Veränderungen der ersteren nur einen mehr oder minder ausgedehnten passiven Antheil nimmt'). Als actives Element der Eifurchung können wir überall nur das Protoplasma und den

1) Die gegenwärtig zur Geltung gelangte Vorstellung, dass das Thier-Ei eine einfache lebendige Zelle und die Eifurchung eine wiederholte Zellentheilung ist, steht mit der Zellentheorie wie mit der Phylogenie in bestem Einklang. Die ganz entgegensetzten, wunderlichen, allgemeinen Ansichten, welche GoETTE kürzlich in seiner Keimungsgeschichte der Unke publicirt hat, werden jene fundamentale Ueberzengung nicht erschüttern. Obwohl es kaum nöthig ist, meinen principiellen Gegensatz zu den meisten allgemeinen Anschaumgeu Goetre's hier zu constatiren, thue ich es doch, weil seine speciellen Anschaumgen irber Gastrulabildung (und besourlers ïber die Invagination der Gastrula) wesentlich mit den meinigen übereinstinmen. 
Nucleus der Furchungszellen betrachten. Der Nahrungsdotter hingegen ist nur ein passiver Bestandtheil des Eies, eine Vorrathskammer oder ein Proviant-Magazin, aus dem der entstehende Embryo den Nahrungsstoff entnimmt. Allerdings kann bisweilen der Nahrungsdotter noch längere Zeit nach der erfolgten primären Furchung des Bildungsdotters einer secundären Zerklüftung unterliegen. Aber auch die so entstehenden wirklichen „Dotterzellen" spielen nur eine untergeordnete und passive Rolle gegenüber den formbildenden activen „Bildungszellen" der Keimblätter. Je nach dem verschiedenen Massen-Verhältniss, in welchem das „Deutoplasma“" des Nahrungsdotters zu dem ursprünglichen „Protoplasma“ der Eizelle hinzukommt, und je nach der verschiedenen Vertheilung: des ersteren im letzteren wird derselbe an der Furchung einen sehr verschiedenen passiven Antheil nehmen.

Die Verhältnisse des Nahrungsdotters zur Eizelle und zur Eifurchung sind in den beiden Preisschriften von Edouard van BENEDEN ${ }^{1}$ ) und von Hubert Ludwig ${ }^{2}$ ) so ausführlich erörtert worden, dass wir hier nicht weiter darauf einzugehen brauchen, sondern einfach auf letztere verweisen können. Wenngleich unsere Auffassung in einigen Finzelheiten abweicht, stimnt sie doch in allem Wesentlichen mit derjenigen von van Beneden und Ludwig überein. Die zahlreichen neuen Beobachtungen über die verschiedenen Arten der Eifurchung, welche in jüngster Zeit angestellt worden sind, scheinen übrigens geeignet, die von van Beneden unterschiedenen Kategorien der Eifurchung, welche auf der (l. c. p. 260) von ihm gegebene Tabelle übersichtlich zusammengestellt sind, wesentlich zu vereinfachen. Wenn man die Gastrula als das gemeinsame Endresultat der Furchung bei sämmtlichen Metazoen im Auge behält, so dürfte die Unterscheidung derjenigen vier Hauptformen der Eifurchung und Gastrulabildung vorläufig genügen, welche ich in den beiden synoptischen Tabellen V und VI (S. 65 und 66) zusammengestellt habe. Nur bei der "primordialen Eifurchung" bildet der active Bildungsdlotter für sich allein, als primärer palingenetischer Organismus, das ganze $\mathrm{Ei}$ und den daraus hervorgehenden Keim. Bei den drei übrigen Furchungsformen hingegen, bei der inaequalen, discoidalen und superficialen Eifurchung tritt der passive Nahrungsdotter, als secundäres cenogenetisches Pro-

1) Edodard van Beneden, Recherches sur la Composition et la Signification de l'oeuf. Bruxelles 1870.

2) Hobert Lodwig, Ueber die Eibildung in Thierrciche. Würzburg 1874. 
duct, $\mathrm{zu}$ ersterem hinzu, bald nur theilweise und nicht scharf geschieden (inaequale Furchung), bald vollständig und scharf getrennt discoidale und superficiale Furchung).

\section{Die vier Hauptformen der Eifurchung und Gastrula- bildung.}

I. Die primordiale Furchung und die Archigastrula (Taf. VIII).

Bei Beurtheilung der zahlreichen verschiedenen Formen, unter welchen die Eifurchung und die erste Anlage des embryonalen Körpers bei den verschiedenen Thieren auftritt, wird zuerst die Frage $\mathrm{zu}$ stellen und $\mathrm{zu}$ beantworten sein, ob wir eine einzige Form derselben als die ursprünglichste und als gemeinsamen Ausgangspunkt für die übrigen Formen betrachten dürfen. Wie die vergleichende Anatomie als Phylogenie der Organe die Aufgabe hat, alle stammverwandten entwickelten Formen einer natürlichen Hauptabtheilung, z. B. alle Wirbelthiere, auf eine gemeinsame ursprüngliche Stammform zurückzuführen, so stellt sich die vergleichende Ontogenie die entsprechende Aufgabe, auch die verschiedenen Formen der Eifurchung und Keimbildung bei allen Gliedern einer solchen Hauptabtheilung aus einer gemeinsamen ursprünglichen Grundform abzuleiten. Wer aber die monophyletische Descendenz nicht nur für alle Glieder eines Stammes fordert, sondern auch, unserer Hypothese folgend, die gemeinsame Abstammung aller Metazoen-Stämme von einer einzigen Stammform, der Gastrae a annimmt, der muss auch dem entsprechend alle verschiedenen Keimformen sämmtlicher Metazoen auf eine ursprüngliche gemeinsame Gastrula zurückzuführen suchen.

Die Entstehung dieser einfachen, ursprünglichen und unverfälschten Gastrula liegt noch heute in der Keimesgeschichte zahlreicher niederer Thiere klar vor Augen und beweist sowohl durch die auf einander folgenden, überall wesentlich gleichen Stufen ihrer Bildung, wie durch ihre Verbreitung bei den niedersten, indifferentesten und ältesten Thierformen der verschiedenen Stämme, dass sie als der Ausgangspunkt für das Verständniss an die Spitze gestellt werden muss. Ich bezeichne daher diese älteste und wichtigste Form der Eifurchung als die primordiale, und die daraus hervorgegangene ursprüngliche Gastrula-Form als die Archigastrula (Taf. VIII). 
Wir finden diese primordialc Form der Furchung und der reincn Gastrulabildung noch heute in vollständiger Uebereinstimmung wohl erhalten bei den niedersten Repräsentanten sämmitlicher Thierstämme: a) unter den Zoophyten (Coclenteraten) bei den Gastraeaden (Gastroplysema, Taf. VIII), bei verschiedenen Spongien, Hydroiden, Medusen und Corallen; b) unter den Wü rmern bei vielen niederen Wurmformen verschicdener Classen, z. B. Sagitta, Phoronis, Ascidia; c) unter den Mollusken bei den meisten (?) Spirobranchien, sowie vielleicht bei einigen Muscheln und Schnecken; d) unter den Echinodermen bei der grossen Mehrzahl dieses Stammes, suweit man nach den jetzt vorliegenden Untersuchungen schliessen darf; e) unter den Arthropoden bei einigen niederen Formen, sowohl Crustaceen (einige Branchiopoden) als Tracheaten (Pteromalinen?); f) unter den Wirbelthieren einzig und allcin bei den Acraniern (Amphioxus). Um den Nachweis der weiten Verbreitung dieser primordialen Furchungsform und der daraus entstehenden Archigastrula hat sich vor Allen A. Kowalevsky verdient gemacht, der sie u. A. zuerst beobachtet hat bei Amphioxus, Phallusia, Asteracanthion, Ophiura, Echinus, Argiope, Phoronis, Sagitta, Actinia, Cereanthus, Pelagia, Cassiopeja, Rhizostoma u. S. w.

Wir dürfen es als eine ontogenetische Thatsache von höchstem morphologischen Interesse und von grösster phylogenetischer Bedeutung hervorheben, dass bei allen diesen Thieren, also bei Angehörigen sämmtlicher Metazoen-Stämme, ganz dieselbe Form der primordialen Furchung sich ebenmässig wiederholt und auf ganz gleiche Weise zur Entstehung einer und derselben Archigastrula-Form führt (Fig. 119, 120). In allen Fällen führt uns hier der palingenetische Process fünf auf einander folgende Hauptstadien der Keimbildung vor Augen, welche beim Mangel jeglicher cenogenetischen Störung unmittelbar auf die ältesten phylogenetischen Entwickelungsstufen sämmtlicher Metazoen bezogen werden können. Ich habe diese fünf ontogenetischen Stadien bereits früher, in der Natürlichen Schöpfungsgeschichte (S. 444) und in der Anthropogenie (S. 396) mit den fünf ersten Stufen der systematischen Entwickelung in Parallele gesetzt und demgemäss phylogenetisch gedeutet (Vergl. die VI. Tabelle). Es scheint mir jetzt, mit Rücksicht auf das phylogenetische Verhältniss der primordialen Furchung zu den drei anderen Furchungs-Formen, zweckmässig, die besonderen Eigenthümlichkeiten jener fünf ältesten Formstufen bei den archiblastischen Eiern auch in deren Benennung 
zum Ausdruck zu bringen und durch ein vorgesetztes "Archi" zu bezeichnen. Ich nenne demnach jene fünf palingenetischen Keimstufen der archiblastischen Eier, aus denen die entsprechenden cenogenetischen Keimformen der amphiblastischen, discoblastischen und periblastischen Eier erst secundär entstanden sind: 1. Archimonerula, 2. Archicytula, 3. Archimorula, 4. Archiblastula und 5. Archigastrula (Vergl. die VII. Tabelle, S. 67).

Die Archimonerula (Taf. VIII, Fig. 111), das erste Stadium der primordialen Furchung, zeigt uns das befruchtete Ei, nach Verlust des Keimbläschens und nach Verschmelzung der Spermazellen mit der Dottermasse, in jenem denkbar einfachsten Formzustande, welcher der phylogenetischen Stammform des Moneres vollkommen entspricht. Ich habe schon früher wiederholt darauf hingewiesen, welche hohe Bedeutung in dieser Beziehung die Monerula besitzt und komme später nochmals darauf zurück. Hier sei nur noch besonders hervorgehoben, dass unter den vier Hauptformen der Monerula die Archimonerula allein das primordiale Formverhältniss vollkommen rein wiederholt. Da ein vom Bildungsdotter gesonderter Nahrungsdotter nicht nachzuweisen ist, müssen wir die Archimonerula als eine Cyto de von denkbar einfachster morphologischer Beschaffenheit betrachten.

Ebenso stellt sich uns die A rchicytula (Fig. 112), die zweite Keimungsstufe der archiblastischen Eier, als eine ganz einfache, indifferente Zelle dar; aus der Archimonerula durch Neubildung eines Nucleus entstanden. Diese Zelle, die sogenannte „erste Furchungszelle" zeigt in ihrem Protoplasma ebenfalls keinerlei Differenz von Morpholecithus und Tropholecithus. Bei der weitern Entwickelung unterliegt diese Zelle einer vielfach wiederholten, vollkommen regelmässigen Zellentheilung, so dass zuerst 2, dann 4, darauf 8, 16, 32, 64, 128 Zellen u.s. w. entstehen. Diese Furchungszellen bleiben bis zur Beendigung des FurchungsProcesses völlig gleich und lassen keinerlei Unterschiede erkennen (Fig. 113, 114).

Die Archimorula, das dritte Stadium des primordialen Furchungs-Processes (Fig. 115), zeigt uns demzufolge eine ,maulbeerförmige oder brombeerförmige" solide Kugel, welche aus lauter gleichen indifferenten Zellen zusammengesetzt is t. Irgend welche Differenzen zwischen plastischen und trophischen Furchungskugeln, zwischen "Bildungszellen" und „Nahrungszellen", sind auch nach vollständig beendigter Furchung an diesem kugeligen Zellenhaufen durchaus nicht wahrzunehmen. 
Dasselbe gilt auch noch von den sämmtlichen Zellen, welche den Keim der vierten Stufe, die Archiblastula zusammensetzen (Taf. VIII, Fig. 116; 'Taf. II, Fig. 20, 29; Taf. III, Fig. 41).

Die gleichartigen Zellen welche bisher dicht zusanmengedrïngt die solide Morula bildeten, sind jetzt durch Ansammlung von Flüssigkeit oder Gallert im Inneren der Maulbeerkugel aus einander getreten und haben sich sämmtlich an die Peripherie derselben begeben. Der Keim stellt demnach jetzt eine mit Flüssigkeit gefüllte Hohlkugel dar, deren Wand aus einer einzigen Schicht von gleichartigen Zellen besteht. Die davon umschlossene Höhle ist die F u r chung ghöhle oder Baer'sche Höhle; Blastocoeloma, Cavum segmentationis). Die einfache, gleichartige, epithelförmige Zellenschicht ist dic Keimhaut oder das Blastoderma. Irgend welche formbestimmende Axen und überhaupt irgend welche Differenzen verschiedener Körpertheile sind an dieser Keimform noch nicht vorhanden. Zwar dürfen wir auf Grund der nachfolgenden Invagination annehmen, dass physiologische (resp. physikalisehe und chemische) Differenzen zwischen animalen und vegetativen Zellen an den beiden Hälften der Hohlkngel bereits bestehen. Aber morphologiseh sind diese virtuellen Verschiedenheiten noch nicht ausgeprägt und treten erst bei der nun folgenden Bildung der Archigastrula actuell in die Erscheinung.

Die Archigastrula bildet die fünfte Stufe der primordialen Furchung (Taf. II, Fig. 17, 21, 22, 23, 25, 31, 33; Taf. III, Fig. 43, 44; Taf. VIII, Fig. 119, 120). Der einaxige blasenförmigc Keim unschliesst eine einfache einaxige Höhle, den Urdarm (Progaster oder Protogaster, a). Dieser ist an dem einen (animalen) Pole der Axe geschlossen; an dem anderen (vegetativen) Pole dersclben mündet er durch eine einfache Oeffnung nach aussen: $\mathrm{Ur}$ m und (Prostoma oder Protostoma, o). Die Wand der Urdarmhöhle (dic Darmwand und Leibeswand zugleich ist), besteht aus zwei verschiedenen, eng an einander liegenden Zellenschichten, den beiden primären Keimblättern: aussen Hautblatt oder Exoderma (auf Taf. II und III blau gezeichnet); innen D a rmb latt oder Entoderma (auf beiden Tafeln roth gezeichnet). Die Zellen des Hautblattes oder die ,animalen Keimzellen" sind gewöhnlich zahlreicher, kleiner, heller und weniger reich an Körnchen, als die Zellen des Darmblattes oder die ,vegetativen Keimzellen".

Die Entstehung der Archigastrula aus der Arehiblastula erfolgt ursprünglich stets durch Einstülpung oder Invagina- 
tion (Gastrula invaginata, RAY-LANkEster). Diese bedeutungsvolle Einstiilpung hat zuerst Kowalevsky bei den angeführten Repräsentanten aller Typen beobachtet. Ausserdem ist sie aber auch von vielen anderen Beobachtern bei den verschiedensten Metazoen nachgewiesen worden. Ich selbst habe diesen Process in ganz übereinstimmender Form bei Gastroplysema (Fig. 118), bei mehreren Corallen (Actinia, Monoxenia), bei Echinus und bei Phallusia beobachtet, und mich von der Richtigkeit der ïbereinstimmenden Beobachtungen von $\mathrm{C}_{\mathrm{ARL}} \mathrm{R}_{\mathrm{ABL}}$ bei Limnaeus überzeugt (Fig. 29-31). Die Invagination beginnt stets damit, dass an einer bestimmten (physiologisch determinirten, aber morphologisch noch nicht differenzirten) Stelle der Oberfläche sich im Blastoderm eine kleine kreisrunde Grube bildet. Diese vertieft sich durch fortschreitende Einstülpung zu einer Höhle, die sich auf Kosten der dadurch verdrängten Furchungshöhle vergrössert. Letztere schwindet zuletzt ganz und nunmehr ist der Urdarm der einzige Hohlraum des Gastrula-Körpers. Jedloch bleibt bei mancher Archigastrula (z. B. von vielen Echinodermen, Fig. 33) die Einstïlpung unvollständig und bleibt auch noch ein Rest der Furchungshöhle $(s)$ neben der Urdarmhöhle $(a)$ bestehen.

Mit der Einstiilpung der Blastula tritt die erste Axenbildung im Keim auf, der Gegensatz zwischen oralem und aboralem Körperende. Da der Urmund der Gastrula bei allen Metazoen an dem späteren aboralen Ende der Längsaxe zu liegen scheint, so muss anch dieser vegetative Pol eigentlich als aboraler bezeichnet werden: Indem durch die fortschreitende, voin Protostom-Pol gegen den Oral-Pol gerichtete Einstiilpung der Blastula die Furchungshöhle Schritt für Schritt sich verengt und schliesslich verschwindet, legt sich zugleich das eingestülpte, innere, vegetative Blatt (Entoderma) unmittelbar an das nicht eingestülpte, äussere, animale Blatt (Exoderma) an. Der höchst bedeutungsvolle fundamentale Gegensatz zwischen den beiden primären Keimblättern, der in den beiden Hemisphären der Archiblastula physiologisch jedenfalls schon vorhanden war, also potentiell existirte, tritt durch die Invagination der Archigastrula zuerst actuell in die Erscheinung und wird morphologisch offenbar.

Von ganz besonderer Bedeutung für die Organogenie und Histogenie der Metazoen ist der Mundrand der Ar'chigastrula, oder genauer gesagt der Urmundrand (Properistoma). So nenne ich den kreisförmigen Ring, in welchem das Entoderm in das Exoderm 
unmittelbar iibergeht. Fr ist identisch mit dem viel besprochenen und höchst wichtigen, „R and w I I t oder K eimw ulst" der discoblastischen Metazoen und verdient als erster Ausgangspunkt für die : iltesten Anlagen der wichtigsten M esoderm-Producte ganz besondere Beriicksichtigung. Innerhalb dieses Urmundrandes, in dem ringförmigen Falze zwischen Entoderm und Exoderm, sondern sich von den primären Keimblättern zuerst einige grosse Zellen ab, welche die früheste Grundlage des Mesorlerm bilden.

\section{Die inaequale Furchung und die Amphigastrula} ('Taf. VII).

An die primordiale Segmentation schliesst sich zunächst diejenige Form an, die ich in der Anthropogenie als inaequale Furchung bezeichnet habe, und deren Product die Ampligastrula ist. Bisher hat man diese wichtige Form der Eifurchung mit der primordialen unter dem Gesammtbegriff der ,totalen Furchung“ vereinigt, obleich sie sehr wesentlich von der letzteren verschieden ist. Allerdings sind beide Furchungsformen durch eine continuirliche Reihe voll vermittelnden Zwischenformen mit einander verbunden; wie auch zweifellos die inaequale aus der primordialen phylogenetisch entstanden ist. Allein nicht nur das Endproduct ist sehr verschieden, sondern auch der Furchungs-Process selbst schlägt entweder von Anfang an oder doch während seines Verlaufes eine wesentlich verschiedene Richtung ein.

Am längsten bekannt und am genauesten untersucht ist die inaequale Furchung bei den Fröschen und anderen Amphibien; in ganz gleicher Form ist sie später bei Petromyzon und bei Accipenser wiedergefunden worden. Wahrscheinlich dürfte sie auch bei den Dipneusten sich finden. Auch die Furchung der meisten Säugethiere (wahrscheinlich aller Placentalthiere) ist in diese Gruppe zu rechnen. Somit besitzt die inaequale Furchung unter den Wirbelthieren eine ausgedehnte Verbreitung. Unter den Wirbellosen finden wir ganz dieselbe ungleiche Segmentation zunächst bei der grossen Mehrzahl der Mollusken wieder; bei den meisten Schnecken und Muscheln, wahrscheinlich auch bei einigen Cephalopoden und vielen Brachiopoden. Unter den A rthropoden ist dieselbe, wie es scheint, bei den niederen Crustaceen und Tracheaten ziemlich verbreitet, jedoch in den meisten Fällen nicht hinreichend genau untersucht. Im Stamme der Echinodermen scheinen nur wenige Formen (z. B. einzelne Asteriden und Holo- 
thurien mit abgekiirzter, sogenannter "directer" Entwickelung) dịeselbe zu besitzen. Dagegen ist sie unter den Wiormern sehr verbreitet und wahrscheinlich der grossen Melrrzahl derselben eigen (Anneliclen, Gephyreen, Rotatorien, Nematoden, Acoelomen u.s. w.). Wie weit die inaequale Furchung unter den Pflanzenthieren verbreitet ist, lässt sich zur Zeit noch nicht übersehen; die Ctenophoren und Siphonophoren liefern ausgezeichnete Beispiele; doch scheint sie auch bei anderen Hydromedusen, bei Corallen und Spongien häufig vorzukommen.

Meine eigenen Untersuchungen über inaequale Furchung und Amphigastrula-Bildung betreffen vorzugsweise einige Siphonophoren, Anneliclen, Crustaceen, Gasteropoden und Amphibien. Als vorzugsweise geeignete Paradigmata stiitze ich mich in der folgenden Darstellung hauptsächlich auf einen röhrenbewohnenden Borstenwurm (Fabricia, aus der Familie der Sabelliden; Taf. VII, Fig. 91102), und auf eine gasteropode Schnecke (wahrscheinlich Trochus oder ein verwandtes Genus, Taf. VII, Fig. 103-110. Der Laich beider 'Thiere war auf den Strandfelsen von Ajaccio nicht selten und eignete sich bei der geringen Grösse der Eier und der mässigen Undurchsichtigkeit der Nahrungszellen besonders zur Verfolgung der Gastrulabildung. Insbesondere gewälirten Präparate, welche init Carmin und Hämatoxylin gefärbt waren und dann länger' Zeit in Glycerin gelegen hatten, sehr befriedigende Ansichten.

Obgleich die inaequale Furchung sich einerseits an die primordiale eng anschliesst und durch zahlreiche vermittelnde Zwischenstufen unmittelbar mit ihr verbunden isf, so erscheint sie doch anderseits frïher oder später wesentlich verschieden und bietet eben so allmähliche Uebergangs-Formen zur discoidalen Furchung. Ihre wesentliche Eigenthïmlichkeit besteht darin, dass sich früher oder später, entweder schon im Beginn oder im weiteren Verlaufe des Furchungsprocesses, jedenfalls vor Ablauf desselben, ein Gegensatz zwischen der animalen und der vegetativen Hälfte des Eies offenbart und somit auch eine durch diesen Gegensatz beider Pole charakterisirte Axe entsteht. Bei der primordiaIen Furchung tritt dieser Gegensatz und die Bildung der ersten Axe erst viel später auf, nämlich nachdem die Blastula ausgebildet ist und sich einzustïlpen beginnt. Bei sehr vielen amphiblastischen Eiern ist der Gegensatz zwischen animaler und vegetativer Hemisphäre sogar schon vor Beginn der Furchung erkennbar, indem diejenige (meist untere, weil schwerere) Hälfte der Eizelle, aus der später die Entodermzellen hervorgehen, sich durch besondere Fär- 
bung (Anhäufung von Pigmentliörncrn) oder durch Ansammlung einer grösseren Menge von Fettkörnern oder von eigenthümlichen Formelementen dles Dotters auszeichnet; hingegen vermisst man diese in der entgegengesetzten (meist oberen und helleren) Hälfte der Eizelle, welche den Kern umschliesst, und welche später das Material für die Exodermzellen liefert. Stets offenbart sich bei den amphiblastischen Eiern der Antagonisums zwischen jenen vegetativen und diesen animalen Zellen früher oder später dadurch, dass die ersteren sich langsam, die letzteren rascher vermehren. Immer aber ist trotzdem die Furchung vollständig, und es bleibt kein Rest von ungefurchtem Nahrungsdotter zurück, wie bei den discoblastischen und cryptoblastischen Eiern.

In jenen Fällen, wo das Deutoplasma der vegetativen Eihälfte sich durch Pigmentirung oder Reichthum an rlunkeln Fettkörnern u. dergl. auffallend von dem hellen Protoplasma der animalen Eihälfte unterscheidet, wie bei unserer Fabricia, ist auch schon der Cytoden-Zustand der befruchteten Eizelle als Amphimonerula deutlich charakterisirt (Taf. VII, Fig. 91). Vom Amphibien-Ei hat Goєтte dieselbe Amphimonerula abgebildet (Ontogenie der Unke, Atlas Taf. I, Fig. 13).

Die Amphicytula (Fig. 92), die „erste Furchungskugel" des amphiblastischen Eies, ist in diesen Fällen natiirlich gleicherweise schon an der Differenz der animalen und vegetativen Henisphäre erkennbar. In der ersteren liegt der neugebildete Kern. Gewöhnlich spricht sich dann die Differenz beider Hemisphären anch schon beim Beginne der Furchung darin ans, dass die erste Theilungs-Ebene die Amphicytula in zwei ungleiche Hälften theilt, eine kleinere animale Zelle (die Mutterzelle des Exoderm) und eine grössere vegetative Zelle (die Mutterzelle des Entoderm). Das ist bei vielen Anneliden der Fall (Fabricia, Fig. 93), und ebenso bei Rotatorien und Gephyreen. Gewöhnlich theilt sich dann zunächst bloss die kleinere animale Zelle weiter (in 2, 4, 8 u. s. w.), während die grössere vegetative Zclle erst später nachfolgt (Fig. 94, 95, 96). Bei vielen anderen amphiblastischen Eiern (besonder's von Mollusken) sind die ersten vier oder acht Furchungskugeln von gleicher Grösse und erst bei der weiteren Theilung der Furchungskugeln treten allmählich die Unterschiede zwischen den animalen und vegetativen Zellen hervor. Sehr häufig sind hier namentlich die vier ersten Furchungszellen, welche durch zwei auf einander senkrechte Meridianfurchen getrennt werden, gleich gross (Fig. 103). Damn aber entsteht eine Ringfurche nicht im Aequator 
des Eies, sondern diesem parallel, näher den animalen Pol, so dass jede dieser vier Furchungskugeln (eigentlich Kugel-Quadranten) in zwei verschiedene Hälften zerfällt, eine obere (animale) kleinere, und eine untere (vegetative) grössere Hälfte (Fig. 104, 105). Die vier kleineren Zellen bilden die erste Grundlage des Exoderms, die vier grösseren diejenige des Entoderms (Fig. 34). Im weiteren Verlaufe theilen sich die ersteren stets rascher als die letzteren, so dass am animalen Pole der Eiaxe eine grössere Anzahl von kleineren Zellen, am vegetativen eine kleinere Anzahl von grösseren Zellen zu finden ist. So folgt z. B. bei unserem Trochus-Ei (wie bei sehr vielen anderen Schnecken-Eiern) auf das achtzellige Stadium (Fig. 104, 105) ein Stadium, in welchem acht animale auf vier vegetativen Zellen liegen (Fig. 106, 107); später ein Stadium mit sechzehn animalen und acht vegetativen Zellen (Fig. 108). Wenn die Theilungsfähigkeit der vegetativen Zellen schon frühzeitig erlahmt, während diejenige der animalen Zellen fortlauert, so geht die inaequale Furchung allmählich in die discoidale über. In Uebrigen bietet dieselbe eine grosse Anzahl specieller Verschiedenheiten dar, auf welche einzugehen nicht im Bereiche unseres Zieles hier liegt. Die bekannten zahlreichen Arbeiten über die Eifurchung der Amphibien, der Schnecken, Anneliden, Rotatorien u. s. w. schilder'n eine Fülle von mehr oder minder auffallenden, meist aber unwichtigen Modificationen.

Die Amphimorula, welche aus dieser inaequalen Furchung des amphiblastischen Eies hervorgeht, erscheint stets bereits als ein einaxiger (monaxonier) Körper, dessen beide Pole meist schon äusserlich, immer aber auf einem durch die Axe gehenden Meridian-Schnitt eine wesentlich verschiedene Zusammensetzung zeigen (Fig. 97 und 108). Die animale Hemisphäre zeigt sich aus einer bedeutenden Anzall kleiner (meist helleren) Zellen („Bildungszellen“), die vegetative Hemisphäre lingegen aus einer geringen Anzahl grosser (meist dunkleren) Zellen zusammengesetzt („Nahrungszellen“). Erstere repräsentiren den animalen „Bildungskeim", die Exoderm-Anlage, letztere den vegetativen „Nahrungskeim", die Entoderm-Anlage. In vielen Fällen dei amphiblastischen Furchung tritt schon frühzeitig im Imneren der Zellenmasse die „Furchungshöhle $(s)$ auf, so dass die Amphimorula unmerklich in die Amphiblastula übergeht; so z. B. bei den Amphibien (Fig. 51) und Cyclostomen (Fig. 45, 46).

Die Amphiblastula, das vierte Stadium der inaequalen Furchung, ist von der Amphimorula wesentlich nur durch die voll- 
ständige Ausbildung jener excentrischen, mit Flüssigkeit gefüllten „Furchungshöhle" verschieden. Während diese ,Segmentationshöhle oder BaEr'sche Höhle" häufig, wie bemerkt, schon frühzeitig oder selbst im Begimne des Furchungsactes zwischen den aus einander weichenden Furchungskugeln erscheint, so gelangt sie dagegen in vielen anderen Fällen erst nach beendigter Furchung zur selbstständigen Abrundung und Abgrenzung (Fig. 26, 27, 98, 109). Es treten dann die Furchungszellen an die Peripherie der in Inneren sich ausdehnenden Höhle, deren Wand sie bald in einschichtiger, bald in mehrschichtiger Lage zusammensetzen. Einschichtig ist z. B. die Wand der Amphiblastula bei Unio (Fig. 26,27), wo eine einzige colossale, erst später sich theilende Entodermzelle den Schlussstein eines Gewölbes von zahlreichen kleinen Exodermzellen bildet. Mehrschichtig ist dagegen die Wand der Amphiblastula bei den Amphibien und Cyclostomen, wo der animale Eipol nach oben, der vegetative nach unten gerichtet ist, und wo die Furchungshöhle (s) eine fast halbkugelige Form hat (Fig. 45, 46, 47 von Petromyzon, Fig. 51, 52 von Bombinator). Hier wird die halbkugelig gewölbte „Decke der Furchungshöhle" von den kleineren Exodermzellen, der ebene "Boden" derselben von den grösseren Entodermzellen in mehrfacher, oft vielfacher Schicht gebildet. Je nachdem eine grössere oder geringere Menge von. Flüssigkeit sich im Inneren ansammelt, wird die Furchungshöhle grösser oder kleiner. In vielen Fällen ist sie von so geringer Ausdehnung, dass sie bisher übersehen worden ist, und nicht selten kommt sie gar nicht zur Erscheinung, indem die Furchungszellen bis nach beendigter Segmentation überhaupt nicht aus einander weichen. Solche Fälle sind durch abgeküurte Vererbung zu erklären. Die Amphimorula geht dann direct in die Amphigastrula ïber.

Die Ampligastrula, das fünfte Stadium der inaequalen Furchung, ist ebenso wie die Amphiblastula und die Amphinorula bei den verschiedenen amphiblastischen Eier'n von sehr mannichfaltiger Beschaffenheit (Fig. 18, 19, 24, 28, 32, 47, 48, 53, 100, 101, 110). Diese inaequale oder amphiblastische Gastrula ist bald kugelig, bald ellipsoid; bald einaxig, bald kreuzaxig (und zwar dipleurisch); 'sie umschliesst einen primitiven Urdarm (Protogaster), welcher bald leer, bald theilweise oder selbst ganz mit Entodermzellen erfültt ist. Am vegetativen Pole der primären Axe öffnet sich der Urdarm meistens durch eine Mündung nach aussen. Jedoch kann dieser Ulmund (Protostoma) auch fehlen, wenn er durch einen "Dotterpfropf" von Entoderm-Zellen verstopft 
ist (Fig. 53). Die Furchungshöhle kann eine Zeitlang noch neben der Urdarmhöhle, mit der sie nicht communicirt, fortbestehen. In diesem Falle wird fortlauernd ein Theil ihrer Wand (die „Decke") von Exoderm-Zellen, der andere Theil (der „Boden“) von EntodermZellen gebildet (Fig. 47, 53).

Die Amphigastrula entsteht aus der Amphiblastula entweder durch Einstïlpung (Embole, richtiger Eutobole) oder durch Umwachsung (Epibole). Durch Einstülpung (Entobolie oder Invagination) bildet sich die Amphigastrula bei der inaequalen Furchung ganz ebenso, wie die Archigastrula bei der primordialen Furchung. Der Unterschied ist nur der, dass schon bei der Amphiblastula der Einstülpungspunkt an vegetiven Pole der Eiaxe durch die grösseren Zellen ausgesprochen ist, während dies bei der Archiblastula noch nicht der Fall ist. Die erstere steht der letzteren um so näher, je geringer die Grössen-Differenzen zwischen den beiderlei Furchungszellen sind. Werden diese Differenzen sehr bedeutend, und überwiegt das Volum der grossen vegetativen „Nahrungszellen" ganz unverhältnissmässig das Volum der kleinen animalen „Bildungszellen", so scheint bei der Gastrula-Bildung das peripherisch sich ausdehnende Exoderm die voluminöse Masse der" "Dotterzellen" zu umwachsen und der ganze Vorgang imponirt äusserlich als Unwachsung (Epibolie oder Circumcrescenz). In Wahrheit ist aber dieser Process nicht wesentlich von der „Einstülpung" zu unterscheiden, vielmehr lässt er sich stets auf letztere zurückführen. Die Amphigastrula circumcreta der Amphibien und Cyclostomen, sowie mancher Schneckon, welche mittelst "Unwachsung der Dotterzellen durch die Keimzellen" entsteht, und die Amphigastrula invaginata vieler Schnecken, Wiirmer und Zoophyten, welche durch „Einstülpung der Dotterzellenmasse in die Keimhölle" entsteht, sind wesentlich nicht verschieden. Ueberall ist der Process ursprünglich and wesentlich eine ,Einstülpung" oder Invagination; nur durch die unverhältnissmässigc Grösse der Nahrungszellen wird diese Entobolie oft verdeckt und imponirt dann, äusserlich betrachtet, als ,äussere Umwachsung" oder Epibolie.

Am längsten bekannt und am genauesten untersucht ist die A inphigastrula der Amphibien, über welche schon vor 20 Jahren REмак in seinen classischen, "Untersuchungen iiber die Entwickelung der Wirbelthiere" höchst wichtige A ufschlïsse und nenerdings Goetre in der Ontogenie der Cnke die genauesten Darstellungen gegeben hat (Fig. 52, 53). Die, ,sichelförmige oder elliptische 
Ruscovi'sche Höhle" der Amphibien-Eier ist der Urdarm (a) und deren Oeffinung, , der Ruscon'sche After"(o), ist der Urmund der Gastrula der Amphibien. Dieser Urmund ist verstopft durch den "Dotterpfropf". Wie REмaK (l. c. j. 141) erzählt, kam er schon 1850 , zul der Ansicht, welche nummehr ausser Zweifel gesetzt ist, dass Ruscon's elliptische Höhle die Nahrungshöhle sei, sich auf Kosten der BaEr'schen Höhle (oder „Furchungshöhle") vergrössert und durch eine Einstïlpung von unten her sich bildet". Aus verschiedenen anderen Aeusserungen Remak's (z. B. p. 143, 183 u. s. w. l. c.) geht hervor, dass dieser geniale Forscher mit prophetischem Blicke schon damals , die Entstehung der Nahrungshöhle durch eine blindsackige, von aussen nach iunen vordringende Einstïlpung" für höchst wichtig und weit verbreitet hielt, und der Gastrula-Erkenntniss sehr nahe war.

Bei den Amphibien und Cyclostomen, wie bei vielen Mollusken und Würmern, bleibt die "BaER'sche Furchungshöhle" (Fig. $28,47,53$ s) neben (ler ,primitiven Nahrunǵshöhle" (Fig. 28, 47, 53 a) noch lange bestehen, bis sie durch die letztere ganz verdrängt wird. Eigentlich ist mit dieser Verdrängung erst die reine Gastrula-Bildung vollendet (Fig. 48). Allein in Folge sehr verbreiteter cenogenetischer Processe, namentlich beträchtlicher Heterochronien, tritt häufig schon eine weitere Differenzirung in dem rascheren Exoderm ein, bevor die Furchungshöhle durch das trägere Entoderm ausgefüllt wird.

Wichtiger als dieses Verhältniss ist der cenogenetische Umstand, dass der Urdarm hier bei den Amphibien und Cyclostomen sogleich excentrisch (nämlich concav gegen die Eiaxe gekrimmt) angelegt wird, und somit schon eine Differenziung der beiden secundären Richtaxen (Sagittal-Axe und Dorsoventral-Axe) gegeben ist, welche der Gastrula von vornherein den dipleuren (oder bilateral-symmetrischen) Typus aufdrückt. Hingegen bleibt bei vielen Mollusken und Würmern insofern das palingenetische Verhältniss erhalten, als der gerade Urdarm central eingestiilpt wird, seine Axe mit dler Eiaxe zusammenfällt, und somit die Amphigastrula (gleich ler Archigastrula) anfangs einaxig ist und erst durch spätere Differenzirung dipleurisch wird.

Ein anderer wichtiger Unterschied betrifit das Verhalten der Entodermzellen zm Darmbildung. Es wird nämlich bei einer Abtheilung der anphiblastischen Eier das gesammte Entoderm zur Bildung der Darmwand selbst verwendet, während bei 
einer anderen (wohl viel grösseren) Abtheilung derselben mur ein Theil des Entoderms zur Bildung der Darmwand („Darmdrüsenzellen") direct verwendet wird, ein anderer Theil nur indirect benutzt, nämlich von den ersteren aufgezehrt und als "Dotterzellen" verbraucht wird. Hierin verhalten sich aber wiederum die amphiblastischen Eier zweifach verschieden, indem die "Proviantzellen" bald nach innen, bald nach aussen von den Darmdrüsenzellen liegen, welche in der Bildung der Darmwand aufgehen.

Im ersteren Falle liegen die Proviantzellen in der Ur darmhöhle, welche sie oft ganz ausfüllen, und werden von den ringsum die Darmwand bildenden äusseren Entodermzellen aufgezehrt (z. B. Euaxes, Purpura). Im letzteren Falle hingegen liegen die Proviantzellen in der Furchungshöhle, welche sie bald theilweise, bald ganz ausfüllen, und werden durch die äussere Fläche der innen anliegenden Darmdrïsenzellen resorbirt (so bei vielen Würmern, Mollusken und bei den meisten (?) ampliblastischen Arthropoden).

Sehr verschieden ist ferner das Verhältniss der Zellenschichtung in den beiden primären Keimblättern der Amphigastrula. Bei den älteren und ursprïnglicheren Formen derselben, welche sich am nächsten an die Archigastrula anschliessen, besteht sowohl Exoderm als Entoderm (gleichwie bei der letzteren) nur aus einer einzigen Zellenschicht (z. B. Unio Fig. 28, Fabricia Fig. 100). Häufiger besteht schon von Anfang der Gastrulabildung an jedes der beiden primären Keimblätter (oder auch nur eins von beiden) aus zwei, drei oder mehreren Zellenschichten (z. B. Petromyzon Fig. 47, Bombinator Fig. 53, Troclus Fig. 110).

Wie weit alle diese verschiedenen Modificationen der Amphigastrula bei den verschiedenen Metazoen-Gruppen verbreitet sind, lässt sich heute noch nicht ermessen, da die beziiglichen Beobachtungen (hauptsächlich wegen der Undurchsichtigkeit der grossen dunkeln Proviantzellen) schwierig und in den meisten Arbeiten nicht hinreichend klar dargestellt sind. Dasselbe gilt anch von der seln' wichtigen Frage, wie sich hier der primäre Urdarm (Protogaster) zum secundären Nachdarm (Metagaster), sowic die Oeffnung des ersteren (der Rusconi'sche After) zum bleibenden After verbält. Wir kommen später hierauf zurück.

Als besondere Modification der inaequalen Furchung dürfte wohl diejenige der Sängethiere und mancher Würmer zu betrachten sein. Auf die eigenthümliche Segmentation der Sängethiere, welche ich in der Anthropogenic (S. 166) als pseudototale unterschieden habe, werde ich nachher (bei specieller Besprechung 
der Gastrula der Wirbelthiere) näher eingehen. Diejenige Form, die ich ebendaselbst als seriale Furchung bezeichnet habe, und die sich im Beginne durch die Vermehrung der Furchungszellen in ar ithmetischer Progression auszeichnet (so z. B. bei vielen Räderthieren und anderen Würmern) ist durch unmittelbare Zwischenformen mit der gewöhnlichen (in geometrischer Progression begiunenden) inaequalen Furchung verknüpft. Ausdriicklich muss endlich nochmals hervorgehoben werden, dass die inaequale Furchung mit allen drei übrigen Hauptformen der Eifurchung durch vermittelnde Zwischenformen verbunden ist; so zwar, dass sie gegenüber der primordialen als spätere, gegenüber der discoidalen und. superficialen Segmentation als frühere Furchungsform erscheint. Die Amplnigastrula ist daher einerseits mit der Archigastrula, andererseits mit der Discogastrula und Perigastrula durch eine Reihe von Uebergangsformen eng verkniipft.

III. Die discoidale Furchung und die Discogastrula (Taf. IV, V).

Wie man die beiden vorstehend untersuchten Formen der Eifurchung, die primordiale und inaequale, trotz ihrer bedeutenden Verschiedenheit bisher allgemein als totale Segnentation zusammenfasste, so hat man auch die nummehr folgenden beiden Formen der discoidalen und superficialen Furchung stets unter dem Begriffe der partiellen Furchung vereinigt. Die letzteren beiden sind aber nicht weniger von einander verschieden, als die ersteren beiden. Gemeinsame Eigenthümlichkeit der discoidalen und superficialen Furchung ist die Ausbildung eines selbständigen grossen "Nabrungsdotters", der mehr oder minder scharf gesondert von dem „eigentlichen Keime“ oder Bildungsdotter sich absetzt. Bei der primordialen und inaequalen Furehung soll nach der herrschenden Ansicht dieser Gegensatz noch fehlen. Indessen gilt das eigentlich nur für die primordiale Furchung. Bei der inaequalen Furchung ist, wie wir gesehen haben, derselbe viehmehr ebenfalls vorhanden; nur ist die Sonderung des Bildungs- und Nahrungs-Dotters nicht so vollständig. Bei vielen amphiblastischen Eiern, sondern sich bereits von den Darmdrüsenzellen der Darmwand andere Fntodermzellen $a b$, welche die beginnende Bildung eines selbstständigen Nahrungsdotters einleiten. Auch sind zwischen jenen Formen der Amphigastrula, welche cine sehr ansehnliche Masse von Proviantzellen besitzen und jenen For'men der Discogastrula, 
bei denen der Nahrungsilotter noch relativ klein ist, so zahlreiche Zwischenstufen zu finden, dass eine scharfe Grenze gar nicht zu ziehen ist.

Die discoidale Furchung spielt die grösste Rolle im Stamme der Wirbelthiere, wo sie sich bei den meisten echten Fischen, insbesondere allen (?) Selachieren und Teleostiern findet, ferner bei säınmtlichen Reptilien und Vögeln, und wahrscheinlich auch bei den niederen Säugethiern, den Monotremen und Didelphien (?). Ausserdem finden wir sie im Stamme ller Mollusken bei den Cephalopoden; auch die eigenthümliche Furchung "einer Anzahl von höheren Arthropoden, welche nicht die vorherrschende superficiale Furchung dieser Gruppe theilen, ist als discoidale aufzufassen (z. B. unter den Crustaceen bei vielen Copepoden und Isopoden, unter den Tracheaten beim Scorpion, einigen Spinnen und einer Anzahl von Insecten).

Bei allen Eiern, welche der discoidalen Furchung unterliegen und demgemäss eine Discogastrula ausbilden, sehen wir den Gegensatz zwischen "Bildungsdotter" und „Nahrungsdotter" schon sehr frühzeitig während der Ausbildung des Eies im Eierstock sich entwickeln. Das reife unbefruchtete Ei zeigt uns stets eine voluminöse Masse von Nahrungsdotter (Deutoplasma) und auf dieser aufliegend eine verhältnissmässig geringe Menge von Bildungsdotter, das eigentliche Protoplasma der Eizelle, welches deren Kern, das Keimbläschen, umschliesst. Die genauere Untersuchung lehrt jedoch, dass ursprünglich stets eine dünne Schicht des Protoplasma die gesammte Masse des voluminösen Deutoplasma überzieht, so dass das Ei trotz seiner ausserordentlichen Grösse doch den morphologischen Werth einer einzigen Zelle behält. Mag der Nahrungsdotter der discoblastischen Eier noch so mächtig sein und mag derselbe noch so viele verschierlene Formbestandtheile (Dotterplättchen, Fettkugeln u. s. w.) einschliessen, so wird dadurch die einzellige Natur der ganzen grossen Zelle doch nicht aufgehoben, so wenig als der einzellige Charakter der Infusorien dadurch vernichtet wird, dass sie andere einzellige Organismen oder Bestandtheile von solchen gefressen haben. An demjenigen discoblastischen Objecte, welches am läufigsten und genauesten untersucht wurde und trotzdem die meisten Irrthümer und Missverständnisse hervorgerufen hat, am Vogel-Ei hat schon Gegenraur')

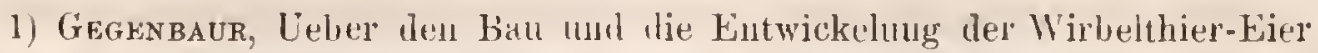
mit partieller Dotterfurchung (Archiv für Allat. Phys. 1861, S. 491). I)je Au- 
(1861) die Einzelligkeit klar dargethan; Edouard van Beneden und H. Ludwa (in den citirten Preis-Arbeiten) haben dieselbe noch ausführlicher begründet.

Die noch gegenwärtig herrschende irrthümliche Auffassung der discoblastischen Eier und ihrer discoidalen Furchung beruht offenbar wesentlich darauf, dass der gewaltige Nahrungsdotter theils wegen seiner unverhältnissmässigen Grösse, theils wegen seiner eigenthümlichen Zusammensetzung den meisten Beobachtern nicht als das erschien, was er wirklich ist: nämlich ein untergeordneter secundärer Bestandtheil der Eizelle; - sondern vielmehr als ein dem „Bildungsdotter oder Keime“ coordinirter oder gar superordinirter Körper; ja viele ältere Beobachter, stets von der grossen gelben Dotterkugel des Hühner-Eies mit ihren verschiedenartigen Folm-Bestandtheilen ausgehend, hielten denselben für das Wichtigste am ganzen Ei. In der That aber ist der ganze grosse Nahrungsdotter mit allen seinen Einschlïssen doch nur ein InhaltsBestandtheil (ein passives, inneres Protoplasma-Product") der Eizelle, und bei der Furchung, wie bei der Gastrulabildung spielt er zwar eine wichtige physiologische, aber nur eine ganz untergeordnete morphologische Rolle. Wenn man die zahlreichen Modificationen der amphiblastischen Eier vergleichend betrachtet, welche sich einerseits an die archiblastischen, anderseits an die discoblastischen Eier unmittelbar anschliessen, so erhält man eine ununterbrochene Stufenleiter von zusammenhängenden Formen und wird dann kein Bedenken mehr tragen, auch die grössten discoblastischen Eier mit ihrem ,colossalen Nahrungsdotter" als einfache Zellen, homolog der ursprünglichsten und einfachsten Formen der Eizellen, aufzufassen.

Wie wir diese einheitliche Auffassung durch das vergleichende Studium des unbefruchteten discoblastischen Eies gewinnen, so werden wir sie selbstverständlich auch auf das befruchtete Ei uibertragen müssen. Wie bei den archiblastischen und amphiblastischen, so scheint auch bei den discoblastischen Eiern (nach den übereinstimmenden Angaben der meisten Beobachter) zunächst nach erfolgter Befruchtung das Keimbläschen $\mathrm{zu}$ verschwinden und demnach das Ei auf das kernlose Cytoden-Stadium zurückzuschlagen, welches als Recapitulation des phylogenetischen Moneren-Stadiums

griffe von KLEBs und Anderen, welche GEGEnBaur's naturgemässe Auffassung zu widcrlegen suchten, haben dieselbe nicht im Mindesten zu erschüttern vermocht. 
zn deuten ist. Wir würden dem entsprechend diese Ausgangsform der discoblastischen Keimung, mit welcher der neuerzengte Organismus seine individuelle Existenz beginnt, als Discomonerula $\mathrm{zu}$ bezeichnen haben. Diese specielle Cytoden-Form unterscheidet sich von den Monerula-Formen der übrigen Eier dadurch, dass am einen (animalen) Pole der einaxigen Cytode eine relativ geringe Menge von Bildungsdotter auf dem unverhältnissmässig grossen Nahrungsdotter aufliegt; beide mehr oder minder scharf gesondert.

Auch die Discocytula, die ,erste Furchungszelle“ der discoblastischen Eier ist durch diese monaxonie Grundform und durch die einseitige Anhäufung des „Bildungsdotters" am animalen Pole der Eiaxe ausgezeichnet. Die Discocytula unterscheidet sich von der Discomonerula wesentlich nur durch den neugebildeten Kern, welcher ihr wieder den Zellencharakter verleiht. Dieser Kern ist der Stammvater sämmtlicher Kerne der „Furchungskugeln“ und somit auch der aus ihnen hervorgehenden Kerne der Keimblätterzellen.

Ueber den discoidalen Furchungsprocess dieser Discocytula, sowie über die daraus hervorgehende Discogastrula lauten die zahlreichen Angaben der verschiedenen Beobachter nur in den ersten Stadien übereinstimmend, in den späteren Stadien dagegen sehr abweichend. Meine eigene Auffassung desselben stimmt im Wesentlichen mit derjenigen überein, welche in neuester Zeit Goztre und Rauber über die discoidale Furchung und Gastrulation des Hülınchens gegeben haben (S. unten). Ich stütze mich dabei vor allen auf meine eigenen Beobachtungen über discoblastische FischEier, welche ich kürzlich auf Corsica angestellt habe. Unter den verschiedenen Teleostier-Eiern, welche wir während unseres Aufenthaltes in Ajaccio erhielten, waren von besonderem Interesse einige vollkommen durchsichtige pelagische Laich-Arten, welche wir mit dem feinen MülLer'schen Netze von der Oberfläche des Meeres fischten. Jedoch war nur eine von diesen Laich-Arten so häufig, dass ich sie genauer untersuchen konnte. Dieser Laich bildet kleine weiche Gallertklumpen, in welche zahlreiche, kleine, vollkommen dnrchsichtige Eier eingebettet sind. Leider gelang es nicht, die daraus hervorgehenden, ganz durchsichtigen Fischchen so lange zu züchten, dass sich mit Sicherheit Genus und Species, oder auch nur die Familie hätte bestimmen lassen. Ich vermuthe jedoch, dass dieselben entweder Lota oder einem Lota verwandten Gadoiden (Motella?) angehören, angesichts der auf unsere Eier passenden Schilderung, welche Retzıus von den ähnlichen Eiern 
des Gadus lota gegeben hat '). Ich werde daher dieselben in Folgendem kurz als Gadoiden-Eier bezeichnen, jedoch mit dem ausdrücktichen Vorbehalt, dass diese Vermuthung nicht vollständig begründet ist. Uebrigens tinden sich diesc und ähnliche pclagische Teleostier-Eier, deren Entwickelung meines Wissens bisher noch nicht untersucht ist, und welche ein ganz vorzügliches Object für viele wichtige Fragen in der Ontogenie der discoblastischen Eier bilden, anch an anderen Orten des Mittelmeeres nicht selten vor. Ich kemne dieselben seit dem Jahre 1856, wo ich sie zuerst in Nizza beobachtete und habe sie seitdem gelegentlich meiner Untersuchungen ïber Radiolarien und andere pelagische Thiere auch in Messina und in Gibraltar wiederholt gesehen, ohne sie jedloch näher zu untersuchen.

Die fraglichen, vorläufig als Gadoiden-Eier zu bezeichnenden, pelagischen Teleostier-Eier sind vollkommen farblose und durchsichtige Kugeln von 0,64-0,66 Mm. Durchmesser (auf Taf. IV sind sie 60 Mal vergrössert). Das jüngste von wir gesehene Stadium zeigt die befiruchtete Eizelle bereits in $4 \mathrm{Furchungszellen}$ zerfallen (Fig. 55, 56). Die äussere Eihaut ist vollkommen homogen und structurlos, sehr dünn, aber fest und elastisch. Den grössten Theil des Innenraums erfüllt der Nahrungsdotter, welcher aus zwei völlig getrennten Theilen besteht, einer grossen wasserhellen Eiweisskugel und einer kleinen glänzenden Fettkugel. Da die Fettkugel der specifisch-leichteste Theil des Eies ist, so ist sie an dem schwimmenden Ei stets nach oben gekehrt, während der kleine, an entgegengesetzten Pole der Eiaxe befindliche "Bildungsdotter" nach unten gekehrt ist. In den Abbildungen auf Taf. IV und $\mathrm{V}$ habe ich das Ei jedoch umgekehrt dargestellt (den Bildungsdotter nach oben, die Oelkugel nach unten gerichtet), um die Homologie mit den übrigen, auf Taf. VI und VII dargestellten Eiern nicht zu stören. Die Eiweisskugel des Nahrungsdotters, welcher mit gelber Farbe gedruckt ist, besitzt an beiden Polen der Eiaxe eine kleine, grubenförmige Vertiefung. In der seichteren Grube am animalen Pole (welcher in den Figuren 55-76 aufwärts, in natürlicher Lage abwärts gekehrt ist), liegt der Bildungsdotter; hingegen ist die tiefere, fast kugelige Grube der Eiweisskugel am entgegengesetzten vegetativen Pole der Eiaxe, von der stark lichtbrechenden Oelkugel ausgefüllt. Die Oelkugel ist nicht vollständig

1) Retzius, Ueber den grossen Fettropfen in den Eiern der Fische. MülleR's Archiv f. Anat. Phys. 1855, S. 34. 
von der Eiweisskugel eingeschlossen, sondern berührt mit dem obersten Drittel ihrer Peripherie die äussere Eihaut. Beide Bestandtheile des Nahrungsdotters, sowohl die Eiweisskugel, als die Fettkugel, sind völlig homogen, durchsichtig und structurlos. Von dieser wichtigen Thatsache, dass der gesammte Nahrungsdotter durchaus keine geformten Bestandtheile einschliesst, auch keinerlei Unterschied von ,centraler Dottermasse und Rindensubstanz" zeigt, davon kann man sich sowohl an den frischen Eiern als auch durch Behandlung der conservirten Eier mit den verschiedendsten Reagentien bestimmt überzeugen. Am frischen Ei erscheint der ganze Nahrungsdotter so klar und homogen wie ein Wassertropfen oder wie eine Glasperle. Sticht man das Ei an oder zerdrückt dasselbe, so tritt der kugelige Eiweisstropfen als zähflïssige homogene Masse heraus und trennt sich von der Oelkugel. Gegen Reagentien verhält sich diese ganze homogene Eiweisskugel wie gewöhnliches Eiweiss aus dem Vogel-Ei, und gerinnt namentlich auf Einwirkung aller Substanzen, welche letzteres zur Gerinnung bringen. Die geronnene Masse erscheint bei starker Vergrösserung fein granulirt, von äusserst feinen und kleinen dunkeln Pünktchen durchsetzt. Von „Dotterplättchen, Dotterkugeln, Dotterzellen, Dotterkernen" und wie sonst die geformten Inhaltsbestandtheile bei anderen Fisch-Eiern genannt werden, ist, - ich wiederhole es ausdrücklich - keine Spur zu finden. Ebenso vollkommen homogen und structurlos ist auch die am vegetativen Pole befindliche Oelkugel, ein Fetttropfen von 0,16-0,17 Mm. Durchmesser (also ungefähr $1 / 4$ des Dotter-Durchmessers). Dass auch diese Oelkugel keinerlei geformte Einschlüsse besitzt, lässt sich ebenso leicht und sicher feststellen. Während also bei den meisten übrigen Fischen, wie bei Vögeln und Reptilien, die beiderlei wichtigsten Bestandtheile des Nahrungs-Dotters, Eiweisskörper und Fettkörper, in Form einer gröberen oder feineren Emulsion mit einander gemengt sind, sehen wir sie hier völlig getrennt neben einander liegen. Im weiteren Verlaufe der Keimung wird die Eiweisskugel allmählig aufgezehrt, während die Fettkugel lange Zeit unverändert bleibt und erst spät verschwindet.

Die falsche Parablasten-Theorie von His und alle ähnlichen Theorien, wonach bei den discoblastischen Wirbelthier-Eiern aus dem separaten Nahrungsdotter gewebebildende Embryonalzellen unabhängig von den beiden primären Keimblättern und in morphologischem Gegensatze zu diesen entstehen sollen, werden demnach durch unsere Teleostier-Eier bündig widerlegt. Denn da 
sich hier innerhalb der äusseren Eihülle neben ein wenig klarer Fliissigkeit nu die beiden structurlosen Bestandtheile des Nahrungsdotters finclen, dic grosse Eiweisskugel und dic klcine Fettlugel, ganz getrennt von den Furchungszellen des Bildungsdotters, so kömnen nur die Furchungszellen einzig und allein die Grundlage des entstehcnden Fischkörpers bilden. Die Eiweisskugel ebensowohl wie die Fettkugel erzeugen durchaus keinerlei cmbryonale Zellen, sondern werden einfach als Nahrungsmaterial von dem Embryo verbraucht und von dem sich bildenden Darme umwachsen, in welchem wir später ihre letzten Reste finden (Fig. 80).

Auf das jüngste, von nir gesehene Stadium (welches vier glciche Furchungskugeln zeigt) folgt ein Stadium mit 8, dann eins mit 16 Zellen (Fig. 57, 58) mit 32, 64 Zellen u. s. w. Die zuerst auftretenden Furchungsebenen sind Meridian-Ebenen und anfangs liegen daher alle Furchungszellen in einer einzigen Schicht. Aber schon in dem Furchungsstadium mit 16 Zellen (Fig. 57, 58) tritt eine horizontale Furchungsebene auf, welche die Zellen in zwei Schichten ordnet, und dann folgen, wechselnd mit neuen Meridianfurchen, noch mehrere Furchungsebenen parallel dem Aequator (und also senkrecht auf jenen Meridian-Ebenen) und nunmehr liegen die Furchungszellen in mehreren Schichten über einander. Nach vollendeter Furchung stellt unser Fisch-Keim eine kreisrunde linsenförmige Scheibe dar, die Keimscheibe (Discus blastodermicus oder kurz Blastodiscus; Fig. 59, 60). Diese Scheibe besteht aus lauter gleichartigen Furchungszellen', welche noch durchaus keine morphologischen Unterschiede darbieten und am Rande der Keimscheibe in einfacher, in der Mitte in mehrfacher (drei-bis vierfacher) Schicht ïber einander liegen (Fig. 73, im Meridiandurchschnitt). Alle Zellen zeigen einen hellen kugeligen Kern (ungefähr von ein Drittel des Zellendurchmessers), mit einem dunkeln, sehr kleinen Kernkörperchen; in dem ziemlich klaren Protoplasma sind wenige, sehr kleine Körnchen vertheilt. Die linsenförmige Keimscheibe liegt am animalen Pol oder Bildungspol der Dotterkugel in einer seichten Depression ihrer Oberfläche, ohne rlass zwischen beiden ein Zwischenraum existirte. Dieses Stadium entspricht offenbar der Archimorula der archiblastischen Eier und ist demnach als Discomorula zu bezeichnen.

Nunmehr tritt in der linsenförmigen Keimscheibe eine Verschiebung der constituirenden Zellen (wahrscheinlich mit gleichzeitiger Vermehrung derselben) auf, welche sich (wenigstens äus- 
serlich betrachtet) kurz als centrifugale Wanderung bezcichnen lässt. Im Centrum wird die Scheibe verdünnt, am Rande umgekehrt verdickt. Während die linsenförmige Keimscheibe vorher in der Mitte 2-3 Mal so dick war, als in der Nähe des scharfen Randes, ist dieselbe nunmehr umgekehrt in der Nähe des wulstförmig verdickten Randes 2-3 Mal so dick als im Centrum (Fig. 61, 62). Zugleich hebt sich letzteres von der darunter liegenden Dotterkugel $a b$ und es entsteht nunmehr zwischen beiden eine kleine, mit klarer Flüssigkeit erfüllte Höhle (Fig. 74). Diese Höhle, welche in Meridianschnitt (Fig. 62) halbmondförmig erscheint, ist die "Furchungshöhle oder BaEr'sche Höhle" (= Keimhöhle oder Blastocoeloma). Ihr Hach gewölbter Boden wird vom Nahrungsdotter, ihre stark gewölbte Decke vom Blastoderma gebildet. Der Keim entspricht jetzt dem Stadium der amphiblastischen Eier, das wir Ampliblastula nannten und ist demgemäss als Discoblastula zu bezeichnen.

Jetzt folgt der höchst wichtige und interessante Vorgang, den ich als Eiustülpung der Blastula auffasse und der zur Bildung der Gastrula führt (Fig. 63, 64). Es schlägt sich nämlich der verdickte Saum der Keimscheibe, der "Randwulst" oder das Properistom, nach innen um und eine dïnne Zellenschicht wächst als directe Fortsetzung desselben, wie ein immer enger werdendes Diaphragma, in die Keimhöhle hinein. Diese Zellenschicht ist das entstehende Entoderm (Fig. $64 i, 74 i$ ). Die Zellen, welche dieselbe zusammensetzen und aus dem innern Theile des Randwulstes hervorwachsen, sind viel grösser aber flacher als die Zellen der Keimhöhlendecke und zeigen ein dunkleres grobkörniges Protoplasma. Auf dem Boden der Keimhöhle, d. h. also auf der Eiweisskugel des Nahrungsdotters, liegen sie ummittelbar auf und rïcken hier durch centripetale Wanderung gegen dessen Mitte vor, bis sie dieselbe zuletzt erreichen und nunmehr eine zusammenhängende einschichtige Zellenlage auf dem ganzen Keimhöhlenboden bilden. Diese ist die erste vollständige Anlage des Darmblatts, Entoderms oder „Hypoblasts", und von nun an können wir, im Gegensatz dazu den gesammten übrigen Theil des Blastoderms, nämlich die mehrschichtige Wand der Keimhöhlendecke als Hautblatt, Exoderm oder ,Epiblast" bezeichnen. Der verdickte Randwulst (Fig. $64 w, 74 w$ ), in welchem beide primäre Keimblätter in einander übergehen, besteht in seinem oberen und äusseren Theile aus Exodermzellen, in seinem unteren und inneren Theile aus Entodermzellen. 
In riesem Starlum ontspricht unser Fischkeim einer Amphiblastula, welche mitten in eler Invagination begriffen ist, und bei welcher die entstehentle Urdarmhölle eine grosse Dotterkugel anfgenommen hat. Die Invagination wird nunmehr dadurch vervollständigt und die Gastrulabildung dadurch abgeschlossen, dass die Keimhöhle verschwindet. Das wachsende Entoderm, dem die Dotterkugel innig anhängt, wölbt sich in die letztere hinein und nähert sich so dem Exoderm. Die klare Flüssigkeit, in der Keimhühle wirl resorbirt und schliesslich legt sich die obere convexe Flïche des Entoderms an die untere concave des Exoderms eng an: die Gastrula des discoblastischen Eies oder die "Discogastrula" ist fertig (Fig. 65, 76; Meridiandurchschnitt Fig. 66, 75).

Die Discogastrula unsers Knochenfisches in diesem Stadium der vollen Ausbildung stellt nummehr eine kreisrunde Kappe dar, welche wie ein gefüttertes Mützchen fast die ganze obere Hemisphäre der hyalinen Dotterkugel eng anliegend bedeckt (Fig. 65). Der Ueberzug des Mützchens entspricht dem Exoderm (e) sein Futter dem Entoderm (i). Ersteres besteht aus drei Schichten von kleineren Zellen, letzteres aus einer einzigen Schicht von grösseren Zellen. Die Exodermzellen (Fig. 77) messen 0,006-0,009 Mm., und haben ein klares, sehr feinkörniges Protoplasma. Die Entodermzellen (Fig. 78) messen 0,02-0,03 Mm. und ihr Protoplasma ist mehr grobkörnig und trüber. Letztere bilden auch den grössten Theil des Randwulstes, den wir nummehr als Urinundrand der Gastrula, als "Properistoma" oder auch als „Rusconi'schen After" bezeichnen können. Der letztere umfasst die Dotterkugel, welche die ganze Urdarmhöhle ausfüllt und weit aus der dadurch verstopften Urmund-Oeffnung vorragt.

Es liegt nicht im Bereiche unserer Aufgabe, die Keimentwickelung unsers Knochenfisches hier noch weiter zu verfolgen und ich will nur bei dieser Gelegenheit noch auf ein par Eigenthümlichkeiten aufmerksam machen, durch welche sich derselbe vor den bisher beschriebenen Teleostier-Embryonen auszeichnet (Fig. 6772, Fig. 80). Wie bei den letzteren, erfolgt auch hier die erste Anlage der dorsalen Axentheile, oder die Bildung des sogenannten „Primitivstreifs", durch welche der einaxige Keimkörper kreuzaxig (und zwar dipleurisch oder bilateral-symmetrisch) wird, nicht in der ganzen Länge der Hauptaxe, sondern am einen Pole derselben. Hicr entsteht zuerst die Anlage des Kopfes, dessen beide Seitenhälften (Antimeren) als zwei parallele längliche Wülste auftreten, durch eine dunkle gerade Linie getrennt (Fig. 67). Wäh- 
rend aber bei den bisher beschriebenen Keimen von Knochenfischen die erste Anlage dieser "Axenplatte" entweder schon am Blastodiscus vor der vollen Ausbildung der Discogastrula bemerkbar wird oder doch durch eine bedeutende Verdickung des Keimwulstes an dieser Seite der Keimscheibe sich bemerkbar macht, sehen wir bei unserem Gadoiden-Ei zumächst eine reguläre einaxige Gastrula entstehen (Fig. 65, 76). Erst nachdem diese Discogastrula ausgebildet ist, entsteht an einer Seite ihres Urmundrandes durch lebhafte Zellen-Vermehrung die Verdickung, von welcher die erste Anlage des „Embryonalschildes" oder der „Axemplatte" ausgeht (senkrecht auf der Peripherie des Mundrandes, also in einem Meridian (ler Gastrula) (Fig. 67).

Die Discogastrula umwächst nunmehr die Dotterkugel, welche ihre Urdarmhöhle ausfüllt und aus ihrem Urmund frei vorragt, vollständig (Fig. 67-71). Wenn das Properistom den Aequator erreicht, hat die Urmundöffnumg ihre grösste Weite erlangt und verengt sich wiederum, nachdem der Keimwulst den Aequator ïberschritten hat (Fìg. 69). Immer mehr nähert sich der kreisförmige dicke Rand des Urmundes dem vegetativen Pole der Eiaxe, an welchem die Oelkugel des Nahrungs-Dotters liegt, und wächst schliesslich über letzterem zusammen (Fig. 71). In der Nähe des Punktes, wo der Ver'schluss des Urmundes (oder des „Rusconi'schen Afters") erfolgt, bildet sich später die bleibende After-Oeffnung.

Gleichzeitig mit dieser "Unwachsung“ der Dotterkugel durch die Discogastrula treten in den dorsalen Axentheilen weitere Differenzirungen auf. Das Markrohr erweitert sich vorn zum Gehirn, aus dem frïhzeitig die beiden grossen Augenblasen vorwachsen (Fig. 69, 70). Beiderseits der Chorda differenziren sich die Urwirbel-Stränge (Fig. 71, 72) und zwischen ihnen tritt unterhalb des Rückenmarks die Chorda deutlich hervor. Später erscheinen die ersten Anlagen der Nase (Fig. $80 n$ ) und des Gehörorgans (Fig. $80 \mathrm{~g}$ ). In dem Raume zwischen Gehörorgan, Auge und Nahrungsdotter macht sich die erste Anlage des Herzens bemerkbar (z). Weiter davor bildet sich in der äusseren Haut die Mundgrube, welche später sich vertieft, die Rachenhaut durchbricht, und so mit dem blinden vorderen Ende des (noch vom Reste des Nahrungsdotters erfüllten) Urdarms in offene Verbindung tritt.

Besonders beachtenswerth ist die erste Anlage des Mesoderms, die ich leider nicht genau genug verfolgen, konnte um so mehr aber künftigen Beobachtern empfehlen möchte. Dieselbe scheint nämlich vom Properistom (vom verdickten Rande des 
Rusconi'schen Afters oder des Urmundes der Discogastrula) und zwar unmittelbar von der Kopfanlage aus in einer doppelten Weise. zu erfolgen: crstens durch Abspaltung (Delamination) der bilateralsymmetrisch auftretenden Urwirbelstränge vom Exoderm (Anlage des $\mathrm{H}$ autfaserblattes); und zweitens durch Abspaltung einer tieferen Zellenschicht vom Entoderm (Anlage des Darmfaserblattes). Die letztere besteht aus sehr beweglichen amöbcnartigen Wanderzellen (Fig. 79), welche durch die Lücken zwischen den Zellen des Darmdriisenblattes (Fig. 78) hindurchwandern und sich theils auf der Obertläche des Nahrungsdotters, theils im Embryo-Körper selbst ausbreiten. Diese a möb oiden Wanderzellen des Darmfaserblattes (Fig. 79) verwandeln sich theils in Blutzellen, theils in Bindegewebszellen und Pigmentzellen. Da sie auf der Obertläche des Dotters sich zerstrenen (und bei anderen Fisehen sogar im Innern desselben umherkriechen und Proviant sammeln) sind sie wahrscheimlich in vielen Fällen für freie Producte des Nahrungsdotters selbst gehalten worden. Viele Angaben verschiedener Autoren ïber ,Zellen, welche durch freie Zellbildung im Dotter, unabhängig von den primären Keimblättern, entstanden" sein sollen, dürften sich durch solche wandernde Entoderm-Zellen erklären. Die Gesammtheit dieser amöboiden Wanderzellen und der unmittelbar über dem einschichtigen Darmdriisenblatt liegen bleibenden (ahgespaltenen) Zellenschicht, welche später die Nuskelwand des Darmrohres bildet, fasse ich als Darmfaserblatt auf. Dasselbe scheint in der gesammten Peripherie der Discogastrula gleichzeitig angelegt zul werden, (nicht dipleurisch!), während die erste Anlage des Hautfas erblattes (resp. der Urwirbelplatten) beiderseits der Chorda von Anfang an jene auffallende Dipleurie (oder bilaterale Symmetrie) zeigt, welche zuerst $\mathrm{C}_{\mathrm{ARL}} \mathrm{R}_{\mathrm{ABL}}$ in ihrer hohen Bedeutung für alle Bilaterien erkannt hat ${ }^{1}$ ).

Die discoidale Furchung, wie ich sie hier vom Gadoiden-Ei beschreibe, verläuft am Bildungsdotter ohne jede Bethciligung des Nahrumgsdotters; dieser verhält sich völlig passir und wird lediglich als Nahrungsmaterial von dem sich bildenden Embryo verzehrt. Er wird zusehends kleiner in dem Maasse als der letztere grösser wird. Im Mitteldarme des reiferen Embryo, sowie des jungen, aus dem Ei ausgeschlüpften Fischchens (Fig. 80), finden

1) Carl Rare, Die Untogenie ler Süsswassur-Pulmonaten. Jen. Zeitschr. f. Naturw. 1875. IX. Bd. S. 202, 236. 
wir noch den Rest des Nahrungsdotters, und zwar seine beiden Bestandtheile: die grössere Eiweisskugel (d) und die kleinere Fettkugel $(f)$. Letztere füllt jetzt den hintersten Theil der Darmhöhle aus und liegt nahe dem bleibenden After (Fig. $80 y$ ). Es kann demnach kein Zweifel bestehen, dass in diesem Falle die Discogastrula und der aus den beiden primären Keimblättern derselben hervorgehende ganze Fisch-Körper einzig und allein. a us den Zellen sich aufbauen, welche durch Furchung des Bildungsdotters entstehen.

Ander's scheinen sich viele andere discoblastische Eier zu verhalten, bei denen die Trennung des Bildungsdotters vom Nahrungsdotter nicht so vollständig ist, wie bei unseren Teleostier-Eiern, und welche sich demnach näher an die amphiblastischen Eier anschliessen. Hier nimmt noch ein Theil des Nahrungsdotters, und zwar derjenige, welcher zunächst an Bildungsdotter anliegt, an der Furchung Theil und liefert Zellen, welche theils als "Dotterzellen", (gleich dem ungefurchten Nahrungsiotter) verzehrt werden, theils in Blutzellen und Bindegewebs-Zellen überzugehen scheinen. Da wir vom phylogenetischen Gesichtspunkte aus den gesammten Nahrungsdotter iiberhaupt als Entoderm-Product anffassen, so müssen wir auch jene Dotterzellen als Zellen des Entoderms oder des Darmblattes in weiterem Sime betrachten. Mit Rücksicht auf ihre spätere Verwendung werden sie theils als Darmdrüsen-theils als Dar'mfaser-Zellen zu betrachten sein.

Bei den discoblastischen Vogel-Eiern hat zuerst GoETTE ') nathgewiesen, dass die Furchung sich nicht bloss, wie man bisher anniahm, auf den Bildungsdotter beschränkt, sondern dass anch noch ein kleiner Theil des Nahrungslotters derselben unterliegt und darlurch in „Dotterzellen“ zerlegt wird, welche ,theils zur Bitbildung, theils zur Ernährung des entwickelten Embryo verbrancht werden" (1. c. p. 195). Sodann hat kiirzlich BaLfouk ${ }^{2}$ ) bei Haifischen gezeigt, dass ein grosser Theil des Nahrungsdotter's nach abgelanfener primärer Furchung des Bildungsslotters ebenfalls einer solchen secundären Furchung unterliegt. Endlich hat Ray-LankesTE: $^{3}$ ) bei den discoblastischen Eiern der Cephalopoden in dem

1) A. GoEтte, Beiträge zur Entwickehungsgeschichte der Wirbelthere. Arch. finr mikl. Allat. 1874, Tol. X, 1. 140.

2) Balfour, Development of the Elasmolnanch Fishes. Quatrt. Jouris. Micr. Sc. 1874 . Oct.

3) Fay-Lankester, Develophent of the cephalopoda. Guart. Journ. Micr. c. 1875 . No. LVII. 
secundär zerklïfteten Nahrungsdotter zahlreiche Zellen entstehen sehen, welche er als "Autoklasten“ den aus der primären Furchung des Bildungsdotters entstandenen Furchungskugeln, den ,Klastoplasten" entgegensetzt. Auch hier sind jene "Antoklasten oder Dotter'zellen", welche sich theils in Bindegewebszellen, theils in Blutzellen zu verwandeln scheinen, histogenetisch als EntodermProducte und speciell als Theile des Darmfaserblattes zu betrachten. Ich fasse diese discoblastischen Eier als vermittelnde Zwischenglieder zwischen den amphiblastischen Eiern und jenen rein meroblastischen Eiern anf, bei denen (wie bei unsern TeleostierEiern), der Dotter gar keinen Antheil mehr an der Furchung nimmt.

IV. Die superficiale Furchung und die Perigastrula (Taf. VI).

Nicht geringere Schwierigkeiten und Differenzen der Beurtheilung, als die discoidale Furchung, hat die zweite Hauptform der sogenamiten partiellen Segmentation, die oberflächliche oder superficiale Eifurchung hervorgerufen, deren Endresultat die Bildung der Perigastrula ist (Taf. VI, Fig. 87, 88). Fanden wir schon bei jener die verschiedenen Autoren hinsichtlich der principiellen morphologischen Auffassung weit aus einander gehen und zu sehr entgegengesetzten Ansichten gelangen, so ist das bedieser letzten und abweichendsten Furchungsform fast in noch höherem Maasse der Fall. Bei dem Versuche, dieselbe zu erklären, sind die meisten Beobachter gänzlich fehlgegangen oder sind selbst zu dem Resultate gelangt, dass hier überhaupt keine „eigentliche Eifurchung“ vorliege.

Die superficiale Eifurchmng und die Perigastrula-Bildnng findet sich sehr weit verbreitet, vor Allen im Stamme der Arthropoden, sowohl bei den Crustaceen als bei den Tracheaten. und wir dürfen vermuthen, dass die grosse Mehrzahl aller Gliederthiere aus diesen beiden Hamptgruppen jene specielle Form der Segmentation besitzt. Hingegen ist es sehr zweifelhaft, ob dieselbe Furchungsform noch in anderen Thierstämmen ausserdem vorkommt. Vielleicht findet' sie sich bei einigen höheren Würmern vor.

Bei der grossen Mehrzahl der Arthropoden, namentlich bei allen höher entwickelten Formen, ist ein ansehnlich grosser, fettreicher Nahrungsd otter vorhanden; und dieser zeigt sich nach beendigter Furchung ringsum von einer blasenförmigen Keimhat 
(Blastoderma) umschlossen, welche aus einer einzigen Schicht von gleichartigen Zellen besteht, den Furchungsproducten des Bildungsdotters (Taf. VI, Fig. 85, 86). Das ist der Fall bei sämmtlichen Insecten, mit sehr wenigen Ausnahmen, ferner bei den meisten höheren Arachniden und Myriapoden, und wohl auch bei der Mehrzahl der höheren Crustaceen. Dass demnach bei der ïberwiegenden Mehrzahl aller dieser höheren Arthropoden auf einer frühen Keimungsstufe eine solche blasenförmige, einschichtige, den ganzen Nahrungsdotter umhüllende Keimhaut besteht, dariiber sind fast alle Autoren einig; dagegen stehen sich daruiber, wie diese Keimhaut aus dem Bildungsdotter hervorgeht, die widersprechendsten und sonderbarsten Ansichten gegeniiber. Die meisten Autoren sind der Meinung, dass hier überhaupt die Eifurchung fehle, und statt dessen plötzlich (durch Neubildung zahlreicher Kerne in einem oberflächlichen Keimhautblasten, eine Art ,freier Zellbildung") das Blastoder'm entstehe. Ihren bestimmten Ausdruck findet diese Ansicht u. A. in den Grundzügen der Zoologie von CLaus (III Aufl. 1875, 1. 627) in folgenden Satze: "Anstatt der Dotterfurchung beginnt die Embryonalbildung der Insecten wit der Anlage eines peripherischen Keimhautblastems, welches sich durch Auftreten von Kermen mit später erfolgender zelliger Umgrenzung zu der, wie es scheint, stets aus einer einfachen Lage von Zellen zusammengesetzten Keinhaut gestaltet. Ueber die $\mathrm{Ab}$ stammung dieser Kernbläschen sind die Beobachter verschiedener Ansicht. Während Meтschnikoff dieselbe bei den Aphiden anf Derivate des Keimbläschens zurückfüln't, sollen sie nach WEIsmanN bei den Dipteren, nach Mecnikoff bei Donacia unabhängig von dem längst geschwundenen Keimbläschen selbständig entstehen."

Gegenüber dieser herrschenden Auffassung, welche sich vorzugsweise auf Wismann's Keimesgeschichte der Dipteren und auf Claparède's Beobachtungen über die Ontogenie der Arachniden stützt, zeigten Edouard van Beneden und Emil Bessels in ihlen Untersuchungen iuber die Blastodermbildung der Crustaceen' '), dașs anch hier uiberall eine wahre Eifurchung sich fintet, bei welcher die Theilung der Kerne der Theilung der Protoplasmi-Portionen vorausgeht. Jedoeh wird der centrale Nahrungsdotter, der bei den verschiedenen Arthropoden in sehr verschiedenem Unfange entwiekelt ist, von dieser wiederholten Theilung des obertfächlichen

1) Edouard ran benedex et Gunde liessels, Sur lit Formation du hlastuderme chez les Crustacés. Bulletins et Mémoires de l'A caul. Belge. 1868 et 1869. 
Bildungsdotter's nicht mit betroffen, und die Eitheilung erscheint daher hier in Walnheit als eine oberfläehliche „Furchung" im cigentlichen Sinne.

Bei manchen periblastisehen Eiern ist die scharfe Sonderung des peripherischen Bildungsdotters von den centralen Nahrungsdotter sehon an dem unbefruehteten Ei meln oder weniger deutlich nachweisbar. Gewöhnlich aber ist dieselbe erst an dem befruchteten Ei nach Verlust des Keimbläschens wahrzunehmen und erscheint somit als erstes Resultat des Befruchtungs-Actes und als erstes Zeichen der begimnenden Keimesentwickelung. So sagt z. B. Wersmans: „Die erste Veränderung all befruchteten Ei der Arthropoden scheint ganz allgemein eine Veränderung der peripherischen Schicht des Dotter's zu sein, welche von einer Zusammenziehming del gesammten Dottermasse begleitet ist: es bildet sich ein Keimhautblastem" "). Dieses sogenannte ,Keimhantblastem", eine zähfliissige, klare, körnchenarme Protoplasmaselicht an der gesanmten Oberfläche des Eies, ist in Wahrheit der ,Bildungsdotter" und setzt sich mach inuen mehr oder weniger scharf von den dunkleren, undurehsichtigen, körnerreichen, centralen "Nahrungsilotter" ab. Das Arthropoden-Ei in diesem Stadium, ummittelbar nach erfolgter Befruchtung und nach Verlust des Keimbiischens, stellt die charakteristisehe Keimform der Perimoner'ula dar, eine kernlose Cytode, deren Protoplasma als peripherische Hülle das centrale Deutoplasma allseitig umschliesst.

Die Pericytula, die ,erste Furchungskugel" der periblastischen Eier, entsteht ummittelbar aus jener Perimonerula durch Neubildung eines Zellenkerns. In vielen Fällen (besonders bei viclen Ciustaceen) ist dieser Kern der ersten Furchungszelle dentlich wahrgenommen und als Stammvater der Kerne sämmtlicher Embryonalzellen nachgewiesen worden, so namentlich von vas Benfoen und Bessels (1. c.). In anderen Fällen dagegen (besonders bei vielen Tracheaten) ist derselbe vermisst worden; er hat sich hier wahrscheinlich darlurch dem Blicke entzogen, dass er entweder in der centralen Dottermasse verborgen lag oder dass sein Lichtbrechungs-Vermögen von demjenigen der Rindensehicht in der er eingebettet lag, nieht hinreichend verschieden war. Der wirkliche Nachweis des Kernes der Pericytula in jenen ersteren Fällen berechtigt uns, seinc Existenz auch in diesen letzteren an-

1) Weisman, Die Entwickelung der Dipteren. Leipzig 1564, s. 90. Tat. IV, Fig. 52. 
zunehmen. Die Pericytula ist demnach allgemein als eine echte, kernhaltige Zelle aufufassen, deren peripherisches Protoplasma von dem ansehnlichen centralen Deutoplasma mehr oder minder scharf gesondert ist. Beide verhalten sich zu einander, wie die hyaline Rindenschicht (Exoplasma) und die granulöse Markmin asse (Endoplasma) bei vielen anderen Zellen ').

Die superficiale Furchung der Pericytula ist gewöhnlich wegen des ansehnlichen Unfangs und der Undurchsichtigkeit des centralen Nahrungsdotter's sehr schwierig zu verfolgen. Diejenige Methode der Untersuchung, welche hier, wie bei den meisten ïbrigen Fällen der Eifurchung, die sichersten Aufschlüsse giebt, die Vergleichung zahlreicher, successiver, gefärbter Querschnitte vom Beginne der Eifurchung an, ist bei der superficialen Furchung im Ganzen noch zu wenig angewendet worden. Doch hat u. A. KowALEVSKY $^{2}$ ) wichtige Resultate damit erzielt, vor Allen aber BoBRETZK $^{3}$ ) in seinen volzïglichen Keimesgeschichten verschiedener Crustaceen (Astacus, Palaemon, Oniscus). Mit Recht hebt letzterer hervor, dass die sorgfältige Tinction der Querschnitte von hervorragender Bedeutung sei, um die Kerne von den kernähnlichen Form-Elementen des Dotters zu unterscheiden. Ich selbst habe nach der von ihm angegeben vortrefflichen Methode ${ }^{4}$ ) eine grosse Anzahl von Querschnitten durch die erhärteten Eier eines Peneus (membranaceus?) angefertigt, und bin dabei zu Resultaten gelangt, welche wesentlich nit denjenigen von Вовкетzку iabereinstimmen. Ich gebe hier zunächst meine eigene Beobachtungen wieder und werde dann versuchen, das Verhältniss derselben zu den iibrigen, meist sehr abweichenden Angaben über superficiale Furchung zu erläutern.

Die frühesten Stadien der superficialen Furchung; welche mir von Peneus zu Gesicht gekommen sind, betreffen Eier mit vicr Furchungszellen (Taf. VI, Fig. 81, 82), Das ellipsoide Ei, welches von cinem dünnen, homogenen und ganz durchsichtigen, aber

1) Uebre die wichtige Differenzirung des Zellen-Protoplasma in eine äussere klare himdensubstanz (Exoplasma) und cine iuncre kö̀nige Marksubstanz (Emloplasma) vergl. meine Monographie del Kalksc]wämme, 1872, lỉ. I, S. 138.

2) Kowalevsky, Embryologische studien an Whümexn und Arthropoden. Nem. de l'Alcad. Petersb. 1871.

3) Borrktzky, Russische Abhandlung übel die hémesgeschjehte von Astacus mul Palaemon. Kiew 1873.

4) Bubretzky, Zur Jimlnyologie des Uniscas mulacius. Zeilschr. f. Wiss. Zool. 1874, Bd. XXIV, s. 180. 
festen Chorion umschlossen ist, zeigt zwei auf einander senkrechte Ringfurchen, eine aequatoriale (dem längsten Durchmesser des Enlipsoids entsprechend) mud eine meridianale (dem kürzesten Durchmesser correspondirend). Eine ganz undurchsichtige Markmasse (mehr als die imnere Hälfte des Radius einnehmend), geht nach aussen, ziemlich scharf abgesetzt, in eine hellere Rindensehicht über, und in dieser liegen sehr oberflächlich, deutlich durchschimmernd, die kugeligen Kerne der vier Zellen; jeder Kern ungefähr in der Mitte der Oberfläche seines Quadranten (Fig. 81). Auf Querschnitten (Fig. 82) zeigt sich dentlich, dass die TrennungsEbenen der vier Zellen (die „Furchen" der Oberfläche) nicht durch die ganze Eimasse hindurchgehen, sondern bloss die helle, äussere, feinkörnige Rindensehicht, den ,Bildungsdotter" in vier Portionen theilen, während die centrale Markmasse, der dunkle, grobkörnige, an kleinen Fettkugeln reiche, undurchsichtige „Nahrungsdotter", eine völlig ungetheilte ellipsoide Centralmasse darstellt.

Ganz dasselbe Verhältniss der oberfächlichen „Furehungszellen" zu dem centralen ungetheilten Nahrungsdotter bemerken wir an len folgenden Furchungsstadien, mit acht, sechzehn, zweiunddreissig Zellen u. s. w. Das letztgenannte Stadium zeigt Fig. 83 ron der Oberfläche, Fig. 84 in Meridianschnitt. Das Ei wird von acht Meridianfurchen und drei darauf senkrechten Parallelkireisen geschnitten. Die Furchen gehen auch hier nur durch die Rindenschicht des Bildungsdotters hindurch, und lassen die centrale Iarkmasse des Nahrungstotters unberïhrt. Der Bildung der Furchen geht immer die Theilung der Kerne vorher, welche aus einander rücken, aber ihre oberfläehliche Lage beibehalten. Auch alle folgenden Furchungen durehschneiden bloss die Rindenschicht, und so erhalten wir nach vollendeter Furchung die Perimorula, welche in Fig. 85 von der Oberfläche, in Fig. 86 im Meridianschnitt dargestellt ist. Die gesammte Masse der gleichartigen Furchungskugeln, welche nummehr aus der wiederholten Theilung der' Eizelle entstanden sind, bildet eine einzige oberflächliche Zellenlage, welche als geschlossene "hi eimhaut" (Blastoderma) blasenförmig den gesammten ungefurchten Nahrungsdotter umgiebt. Die "Furchen", d. h. die Grenzlinien der einzelnen Blastoderm-Zellen "lie den morphologischen Werth der Morula-Zellen haben, gehen nur durch die helle Rindenschicht hindureh. Eine scharfe Grenze zwischen den hellen, feinkörniggen Zellen der letzteren, und der dunkeln, grobkörnigen Centralmasse des Nahrungsdotter's ist nicht wahn'nehmbar. 
Da der ganze centrale Nahrungsdotter an dem Furchungsprocesse keinen Antheil nimmit, so mïssen nothwendig die Furchungszellen, welche aus der fortgesetzten Theilung des superficialen Bildungsdotters hervorgehen, an der Oberfläche des ersteren sich in eine epithelartige Schicht neben einander stellen, statt sich zu einer wirklichen Morula zusammenzuballen. Eine nothwendige Folge dieses Verhältnisses ist aber, dass bei der superficialen Eifurchung das dritte und vierte Stadium des Furchungs-Processes zusammenfallen, dass also die Perimorula zugleich Periblastula ist. Denı die centrale ungefurchte Hasse des fettreichen Nahrungsdotter's verhält sich nunmehr zu der einschichtigen Zellenhïlle des Blastoderms gerade so, wie die wasserhelle, klare Flüssigkeit oder Gallertmasse der Archiblastnla zu der umschliessenden Zellenschicht der letzteren. Der Raum, in welchem dort der Nahrungsdotter, hier das klare Fluidum sich befindet, ist in beiden Fällen die Furchungshöhle, Keimhöhle oder BaEr'sche Höhle, das, "Blastocoeloma".

Aus dieser Periblastula (Fig. 85, 86) entstelit nun die Gastrula der periblastischen Eier wiederum anf diejenige Weise, welche wir als die ursprüngliche ansehen, nämlich durch eine Einstülpung des Blastoderms, welche mit Bildung einer Grube an dessen Oberfläche beginnt. Diese höchst wichtige und interessante Invagination hat zuerst Bовкетzкy bei Astacus und Palaemon genauer geschildert und ich kann die Richtigkeit seiner Darstellungen im Wesentlichen nur bestätigen. Was ich bei Peneus sah, schliesst sich unmittelbar an des Letzteren Angaben von Palaemon an. An einer bestimmten Stelle der Ei-Oberfläche, und zwar nicht an einem der beiden Pole der Längsaxe, sondern in der Mitte der letzteren bildet sich eine kleine, anfangs sehr seichte, grubenförmige Vertiefung, welche sich rasch ausdehnt und als radial gerichteter Blindsack in den Nahrungsdotter, gegen die Mitte des Eies, hineinwächst (Fig. 87, 88). Dieser cylindrische, am blinden Ende etwas kolbig erweiterte Blindsack ist der Urdarm (a), seine äussere Oeffnung der Urmund (o). Die einfache Zellenschicht, welche denselben auskleidet und deren Zellen sich durch bedentendere Höhe von denen des übrigen Blastoderms auszeichnen, sind die ersten Entoderm-Zellen, denen sich alle anderen nunmehr als Exoderm-Zellen gegeniiberstellen.

Die Perigastrula, welche so entsteht, und welche Fig. 87 von der Obertläche, Fig. 88 in Meridianschnitt zeigt, muterscheidet sich von der Archigastrula eigentlich nur durch die ansehnliche 
Masse des die Furchungshöhle erfüllenden Nahrungsrlotter's, welche zwischen den beiden primären Keimblättern liegen bleibt, und welche die vollständige Annäherung des eingestülpten Entoderms an das nicht eingestülpte Exoderm verhindert. Dieser NahrungsDotter wird von den Entoderm-Zellen des wachsenden Urdarms resorbirt; theilweise scheint derselbe auch noch später einer secundären Zerklüftung zu unterlicgen. Die Exoderm-Zellen (e), welche den Nahrungsdotter von aussen umschliessen, sind kleine, helle Zellen mit centralem Kern, welche anfangs noch cylindrisch sind, später sich abplatten. Die Entoderm-Zellen hingegen (i) sind schlanke Cylinderzellen oder Pyramiden, deren Kern in der nach aussen gerichteten Basis der Pyramiden, ganz nahe an Nahrungsdotter, sich befindet. Durch fortgesetzte Theilung werden die Entoderm-Zellen immer dünmer und schlanker; zugleich werden sie aber auch länger, indem ihre äusseren kernhaltigen Enden (die Basen der schlanken Pyramiden) immer tiefer in den Dotter hineinwachsen.

Das Properistom, der Umschlagsrand des Blastoderms, an welchem das Exoderm (e) in das Entoderm (i) übergeht, und welcher den Mundrand der Perigastrula darstellt, ist auch hier der erste Ausgangspunkt für die Bildung des Mesoderms (Fig. 89 $m$ ). Hier erscheinen schon kurz nach Beginn der Darm-Einstülpung die ersten Spuren eines mittleren Keimblattes in Gestalt von wenigen grossen Zellen, von denen sich namentlich die unmittelbar in dem Falze des Umschlagsrandes gelegenen durch besondere Grösse auszeichnen. Zugleich geht die einaxige Grundform der Perigastrula in die dipleure Grundform über, indem der Urmund seine centrale Lage verlässt und nach demjenigen Pole der Längsaxe hinrïckt, welcher dem späteren Hinterende des Körpers entspricht. Es wird dies durch ïberwiegendes Wachsthum des späteren Vordertheils, resp. durch eine Zellenverschiebung im Exoderm bewirkt, welche mit der Bildung einer vor dem Urmund auftretenden Hautgrube, der ersten Anlage des Vorderdarms (g) im Zusammenhang steht. Vor der letzteren erscheint ein klappenartiger Vorsprung, die Anlage der Oberlippe $(l)$; hinter derselben sprossen drei Paar kleine stumpfe Höcker als Auswüchse des Exoderms hervor, die ersten Anlagen der drei Paar Nauplius-Gliedmaassen (Fig. 89 I, II, III). Wie durch das Auftreten dieser äusseren Theile die dipleure oder bilateral-symmetrische Grundform sich bereits deutlich ausspricht, so geschieht es auch innerlich durch dic weitere Fortbildung des Darmcanales. 
Die Anlage des Vorderdarms ( $g$ ) wächst dem blinden Vorderende des Urdarms entgegen. Der Nahrungsdotter zwischen beiden verschwindet und beide I)armhöhlen sind nur noch durch eine dümue Scheidewand getrennt, welche aus zwei Zellenschichten besteht, dem Exoderm der Schlundwand und dem Entoderm der Urdarmwand. Später wird diese Scheidewand (Rachenhaut) durchbrochen und der Vorderdarm communicirt nunmehr frei mit dem Urdarm. Aus letzterem geht bloss der Mitteldarm hervor, und vielleicht auch der Enddarm, falls sich (was noch unentschieden ist) der Urmund hier in den bleibenden After verwandelt. Der durch secundäre Finstiilpung des Exoderms entstandene Vorderdarm bildet nicht nur die Mundhöhle und den Schlund, sondern auch die ganze Speiseröhre und den Kannagen des Krebses. Beiläufig sei noch bemerkt, dass die Anlage des Postabdomen, welches bei Astacus und Palaemon frühzeitig hinter dem Urmund als Verlängerung des hinteren Körperendes hervrisprosst, bei unserm Peneus erst später aufzutreten scheint. Die in Fig. 89 und 90 dargestellte Keimform (die älteste, welche ich beobachtete) ist ein reiner Nauplius und möglicherweise schliipft bei dieser Peneus-Art, wie bei der von Fritz MülLer beobachteten, das Thier als Nauplius aus dem Ei.

Die superficiale Furchung und die Perigastrula-Bildung, wie ich sie hier nach meinen eigenen Beobachtungen an Peneus geschildert habe, scheint in wesentlich iibereinstimmender Form bei vielen Arthropoden verschiedener Gruppen, sowohl Crustaceen, als Tracheaten, wiederzukehren. Bei vielen anderen Thieren dieses Stammes weicht sie dagegen mehr oder minder von jenem Typus ab und unterliegt vielfachen Modificationen. Schon die wenigen sicheren Angaben, die wir gegenwärtig besitzen, deuten daranf hin, so namentlich diejenigen von Wersmans über die Musciden, von Boвretzky iiber Astacus und Palaemon, von Kowalevsky über Hydrophilus und Apis. Auch die zahlreichen Beobachtungen von Metschnikoff über die Ontogenie verschiedener Arthropoden scheinen diese Annahme zu stützen. Nur sind leider die meisten Angaben dieses fleissigen, aber kritiklosen Beobachters wegen ihrer Oberflächlichkeit und wegen der Unbekanntschaft desselben mit den wichtigsten Grundbegriffen der Morphologie, und besonders der Histologie nicht sicher zu verwerthen.

Als die auffallendste Modification der superficialen Furchung müssen wir wohl Diejenige ansehen, welche zuerst Weismans bei den Dipteren beschrieben hat und als weit verbreitet bei den Arthropoden betrachtet. Es sollen hier in der Rindenschicht der 
Pericytula, iiberall in dem ,peripherischen Keimhautblastem das rings den Nahrungsdotter umschliesst", gleichzeitig und plötzlich zahlreiche Zellkerne neben cinander anftreten und so das einschichtige peripherische Blastoderm erzeugen. Höchst wahrscheinlich haben wir es hier mit einer sehr beschleunigten superficialen Furchung zu thun, bei welcher die Kerntheilung entweder imnerhalb des undurchsichtigen Nahrungsdotters verläuft und sich so dem Blick entzieht, oder aber innerhalb des durchsichtigen Nahrungsdotters (der „Blastemschicht") so rasch vor sich geht, dass die zahlreichen Kerne alle gleichzeitig aufzutreten scheinen; vielleicht ist anch das gleiche Lichtbrechungsvermögen der Kerne und des ungebenden Protoplasma der "Blastemschicht" die Ursache, dass die fortschreitende Theilung der ersteren nicht beobachtet wurde. Jedenfalls ist das Eudresultat der Eifurchung auch hier dieselbe Pcrigastrula, wie bei Peneus.

Die Vermuthung, dass sich jene auffallendste Modification der superficialen Furchung in dieser oder in einer anderen Weise anf die von uns geschilderte Form derselben bei Peneus zurückführen lasse, wird dadurch bekräftigt, dass auch die iibrigen Modificationen, welche theils das Verhalten des Nahrungsdotters, theils dasjenige des Bildungsdotter's bei verschiedenen Crustaceen und Tracheaten darbietet, sich in gleicher Weise durch secundäre cenogenetische Abänderungen erklären lassen. Auch verdient der Umstand noch besonders hervorgehoben zu werden, dass von nahe verwandten Arthropoden einer Familie (oder selbst einer Gattung, 7. B. Gammarus) die einen Arten superficiale, die anderen inaequale oder discoidale Furchung besitzen. Endlich bietet uns die superficiale Eifurchung so viele Uebergänge zur discoiclalen sowohl als zur inaequalen Eifurchung, dass wir sie als ans der letzteren hervorgegangen betrachten und demnach in letzter Instanz. wicderum auf die primordiale Furchung zurückführen dürfen.

\section{Die Fifurchung und Gastrulabildung in den Hauptgrup- pen des Thierreichs.}

I. Gastrula und Eifurchung der Zoophyten.

Der Stamm der Zoophyten (oder der Coelenteraten in weiteren Sinne), der niederste und älteste unter den sechs NetazoenPhylen, besitzt noch heute, wie von vornherein zu erwarten ist, die primordiale Furchung in vielen verschiedenen Gruppen; 
und wir finden daher auch deren Endproduct, die ursprüngliche reine A rchigastrula, bei sehr vielen Pflanzenthieren - wahrscheinlich bei der Mehrzahl derselben - getreu conservirt. Da die Urform der Metazoen, die Gastraea, selbst im zoologischen Systeme $\mathrm{zu}$ den Zoophyten gestellt werden muss, und da sejbst die völlig ausgebildeten Pflanzenthiere der niedersten Stufe (Haliphysema, Olynthus, Hydra) nur sehr wenig von der Gastraea sich entfernt haben, so erscheint die weite Verbreitung der Archigastrula in der Ontogenie dies Stammes sehr natürlich.

Von besonderem Interesse ist es dabei, dass eines der niedersten unter den bekannten Zoophyten, Gastrophysema, uns die ursprüngliche Entstehung der Archigastrula (durch Einstülpung der Archiblastula) noch heute in typischer Form zeigt ('Taf. VIII). Wie bei diesem Gastraeaden, so ist die primordiale Furchung auch bei mehreren Spongien (Calcispongien '), Fig. 17, und Myxospongien) von mir beobachtet worden, ebenso gelegentlich bei Hydroiden und Medusen verschiedener Gattungen. Bei den Myxospongien (Halisarca) hat GIARD die Archigastrula zuerst nachgewiesen ${ }^{2}$ ). Bei verschiedenen Hydroiden ist dieselbe von C. Gegendaur ${ }^{3}$ ), Agassiz $^{4}$ ), Allman ${ }^{5}$ ), Hincks $^{6}$ ), A. Kowalevsky ${ }^{7}$ ) 11. A. beobachtet worden. Der Letztere hat auch die reine primordiale Furchung und die typische Entstehung der Archigastrula durch Einstülpung der Archiblastula bei mehreren höheren Discomedusen genau verfolgt (Cassiopeja, Rhizostoma, Pelagia, 1. c. Tab. I-III). Vergl. Taf. II, Fig. 22. Unter den Corallen hat derselbe sie ebenso bei Actinia (ibid. Taf. IV), Caryophyllia, Gorgonia und Cereanthus gesehen (ibid. Taf. V, VI). Vergl. Taf. II, Fig. 20, 21. Ich selbst habe die typische Form der primordialen Furchung und die Entstehung der echten Archigastrula durch Einstülpung der Archiblastula bei einer Actinia und bei der solitären Octocoralle Monoxenia verfolgt (Vergl. meine "Arabische Korallen“, Berlin 1875).

1) E. HaEckel, Monographie der Kalkschwämme, 1872. Taf. 13, 30, 44.

2) GiaRD, Archives de Zoologie expérimentale. 1873. Vol. II. Pl. XIX, Hig. $15,16$.

3) Gegenbaur, Zur Lehre vom Generationswechsel und der Fortpflanzung der Mednsen und Polypen. Würzburg 1854.

4) Lours AGassiz, Contributions to the nat. hist. etc. Vol. IV. 1863.

5) Allman, Monograph of the tubularian Hydroids. 1871.

6) 'Гhomas Hincks, History of the British Hydroid Zoophytes. London 1868.

7) A. Kowalevsky, Russiscbe Abhandl. üter Ontogenie der Coelenteraten. Moskau 1873. 
Dass demmach bei sehr vielen Zoophyten aus verschiedenen Classen die primordiale Furchung in der typischen ursprünglichen Weise, wie bei Gastrophysena (Taf. VIII) verläuft und die echte Arehigastrula der Pflanzenthiere sehr oft sich durch Einstiilpung oder Invagination der Archiblastula bildet, steht also unzweifelhaft fest. In vielen Fällen soll allerdings statt dieser Gastrula invaginala vielmehr eine Gastrula delaminata entstehen, d. h. es soll sich das einschichtige Blastoderm der Blastula in der Fläche spalten und so zweischichtig werden. Die Mundöffuung soll sich dann erst später bilden, indem die Wand dieser „Planula" durchbrochen wird. So soll durch „Delanination oder" Abspaltung" namentlich die Gastrula mancher Spongien und $\mathrm{Hy}$ (hroid-Polypen, z. B. Cordylophora'), Campanularia ${ }^{2}$ ) entstehen. Gerade dieses Verhältniss haben die Gegner der Gastraea-Theorie mit besonderem Nachdruck als vernichtendes Argument gegen dieselbe geltend gemacht. Allein erstens sind die bezüglichen, Beobachtungen lieineswegs immer vollkommen klar und zweifellos; zweitens lassen dieselben - ihre volle Richtigkeit vorausgesetzt die Dentung zu, dass die Gastrula delaminata eine secundäre Keimform ist, durch cenogenetische Abänderung aus der primären Gastrula imvaginata entstanden; und drittens wird jener scheinbar so wesentliche Unterschied dadurch als völlig bedeutungslos erwiesen, dass von ganz nahe verwandten Thieren einer natiirlichen Familie, oder selbst von nächststehenden Arten einer Gattung (z. B. Actinia) die Gastrula der einen durch primäre "Invagination", die Gastrula der anderen angeblich durch secundäre „Delamination" entsteht. Schon RAY-Lankester ${ }^{3}$ ) hat wiederholt darauf hingewiesen, dass die letztere sich auf die erstere zurückführen lässt; und ebenso hat sich neuerlichst GoEtre ausgesprochen ${ }^{4}$ ). Ich selbst bin gegenwärtig ganz überzeugt, dass auch diejenigen Gastrula-Formen, welche heute wirklich ontogenetisch durch "Delamination" oder Abspaltung sich bilden, ursprünglich (phylogenetisch) durch "Invagination" entstanden sind. Sehr viele Angaben über Delamination sind auch wohl auf Beobachtungsfehler zurickzuführen, die bei den sehr schwierigen und delicaten

1) Franz Eilhard Schulze, Ueber den Bau und die Entwickelung von Cordylophora lacustris. 1871. S. 38. Taf. V.

2) Kowalevsky, Russ. Abhandl. üher Ontogenie der Coelenteraten. 1873. Taf. I.

3) E. Ray-Lankester, Ann. Mag. nat. hist. 1873, Vol. XI, p. 330.

4) Goetre, Keimesgeschichte der Unke. 1875, S. 870. 
Objecten sich leicht einschleichen. Wird doch z. B. bei den Geryonien die Einstülpung der Blastula, aus der die Magenhöhle hervorgeht, von Kowalevsky (1. c.) klar beschrieben, während Fot, und Metschnikoff von einer solchen Nichts wissen. Bis demnach ganz genaue und unzweifelhafte Angaben über die wahre Gastrula delaminata geliefert sind, dürfen wir deren Existenz einstweilen noch bezweifeln; und selbst wenn sie erwiesen sein sollte, würden wir sie auf die ursprüngliche Gastrula invaginata zurückführen und annehmen, dass sie aus dieser durch gefälschte oder abgekürzte Vererbung, oder durch andere cenogenetische Processe secundär entstanden ist.

Auch die Gastrula der Spongien, welche in sehr mannichfaltigen und stark abweichenden Modificationen vorzukommen scheint, dürfte durch Annahme solcher cenogenetischen Veränderungen sich erklären und auf den einheitlichen Gastrula-Typus zurückführen lassen. Diese Annahme ist vorläufig um so mehr gestattet, als bei einzelnen Schwämmen die Archigastrula in reiner Form sicher gestellt zu sein scheint (Fig. 17), während in anderen Fällen sehr abweichende Formen von Amphigastrula sich finden. Die ausführliche Darstellung der Eifurchung und Gastrulabildung der Spongien, welche ich zuerst in meiner Monographie der Kalkschwämme gegeben habe '), ist später von Метschnikoff auf das Heftigste angegriffen worden ${ }^{2}$ ). Auch OsKar Schmid hat in einer kürzlich erschienenen Arbeit sich gegen meine Auffassung, gleichzeitig aber auch gegen diejenige von Метschnikoff ausgesprochen $^{3}$ ).

1) E. HaEckel, Monographie der Kalkschwämme, 1872, Bd. I, 1. 328-346.

2) Euıs Metschnikoff, Zur Entwickelungsgeschichte der Kalkschwämme. Zeitschr. f. wiss. Zool. 1874. Bd. XXIV, p. 1. Taf. I. Die ausserordentliche Geringschätzung und ingrimmige Erbitterung, mit welcher sich Metschnikoff in diesen und den darån angeschlossenen Aufsätzen über meine wissenschaftlichen Arbeiten ausspricht, erklärt sich ganz einfach und befriedigend aus den diametral entgegengesetzten allgemeinen Standpunkten, welche wir Beide in der Zoologie einnehmen. Für Elias Metschnikoff ist die Natur ein grosses Curiositäten-Museum, welches um so ,interessanter und merkwürdiger" ist, je wunderbarer und unerklärlicher die tausendfältigen Formbildungen unverbunden und unvermittelt neben einander stehen. Er sucht daher auch möglichst zahlreiche und grosse Unterschiede zwischen verwandten Formkreisen aufzufinden. Meine eigenen Bestrebungen sind gerade anf das Gegentheil gerichtet, indem ich diese Unterschiede auszugleichen und jene Mamichfaltigkeit bunter Erscheinungen anf eine gemeinsame Einheit zurïckzuführen und so zn erklären suche. Die herzliche Verachtung, welche Metschnikoff diesem Bestreben bezeigt, erwidere ich natürlich mit gleicher Innigkeit.

3) OSKar Schmidt, Zur Orientirung über die Entwickelung der Spongien. Zeitschr. f. wiss. Zool. 1875. Suppl. Bd. XXV, p. 127; Taf. VIII-X. 
Da ausserdem O. Schmm selbst bei nahe verwandten Spongien schr verschiedene Keimungsformen beschrieben lat, bedarf die gesammte Ontogenie der Schwämme, wie er auch selbst hervorhebt, dringend nener ausgedehnter Untersuchungen. Uebrigens scheinen mir sowohl die Beobachtungen von O. Schmot als von Mвтьсникоғғ (ihre Richtiglieit, vorausgesetzt!) einer Deutung fähig, welche ihre Zurückführung anf die inaequale Ampligastrula-Bildung wohl gestattet, demnach auch mit der Gastraea-Theorie sich vercinbaren lässt. Ich werde später darauf zurückkommen und will vorläufig nur hervorheben, dass die beiden genannten Autoren mit keinem Worte des Olynthus gedenken, jener wichtigsten und lehrreichsten Spongien-Form, welche ich als die Urform der Kalkschwämme betrachte und auf welche sich meine ganze Betrachtungsweise vorzüglich stützt. Der Olynthus ist wesentlich nur eine festsitzende Gastrula, welche geschleclitsreif geworden ist, Hautporen und Kalknadeln gebildet hat. Der junge, noch nicht geschlechtsreife Olynthus (ohne Hautporen und Kalknadeln) ist die Ascula (von der Merschnikoff behauptet, dass ich sie nie gesehen habe!). Sowohl der Olynthus als die Ascula sind sehr häufige und äusserst wichtige Schwammformen, die jederzeit leicht zu haben sind. Es kann sich also nur um die Frage handeln, wie diese, der Gastrula ganz nahe stehenden, festsitzenden Formen aus der freischwimmenden Flimmerlarve entstanden sind? Wenn diese letztere eine Invagination erleidet (wie Metschnikof angiebt) und kine Delamination (wie ich annahm) so ist mir das für die Gastraea-Theorie natürlich nur um so lieber!

Die ina equale Furchung, welche zur Bildung der Amphigastrula führt, scheint unter den Zoophyten nicht selten vorzukommen, wenn auch im Ganzen viel weniger verbreitet als die primordiale Furchung und die Archigastrula. Unter den Spongien ist die inaequale Furchung möglicherweise ziemlich verbreitet, namentlich bei den Kieselschwänmen. Schon bei einigen Kalkschwämmen (die meistens archiblastisch $\mathrm{zu}$ sein scheinen), finden wir Uebergänge zur amphiblastischen Form, so z. B. bei Sycyssa Huxleyi (Fig. 18). und Sycandra raphanus (Fig. 19). Unter den Hydromedusen finden wir sie bei vielen Siphonophoren ${ }^{1}$ ); sonst scheint sie in dieser Classe selten zu sein. Häufiger ist sie vielleicht bei den Korallen (Kowalevsky 1. c. Taf. IV, V). In ganz

1) E. HAECKEL, Iintwickelnngsgeschichte der Siphonophoren. Utrecht 1869. 
exquisiter Form aber findet sic sich bei den meisten (oder allen ?) Ctenopholen, wo sie von A. Kowalevsky ${ }^{1}$ ), Hermann Fol ${ }^{2}$ ) und Alexander Agassiz ${ }^{3}$ ) genau beschrieben und durch zahlreiche $A b-$ bildungen erläutert worden ist.

$\mathrm{Ob}$ die discoidale Furchung und die daraus hervorgehende Discogastrula im Zoophyten-Stamme vorkommt, ist heute noch zweifelhaft. Vielleicht findet sie sich bei einigen Siphonophoren und Ctenophoren. Die ansehnliche Grösse, welche die Masse der grossen „Dotterzellen" des Entorlerms bei einigen Siphonophoren erreicht, so dass dem gegenüber der kleine "Blastodiscus" der Exodermzellen nur eine Hache Keimscheibe am animalen Pole der Eiaxe bildet, vermittelt den Uebergang zu' Discogastrula.

Dagegen ist es sehr zweifelhaft, ob die superficiale Furchung und deren Endproduct, die Perigastrula, unter den Zoophyten sich findet. Nach einigen Abbildungen scheint es, als ob sie bei manchen Spongien, bei einigen Siphonophoren und Korallen (Alcyonien) vorkommt.

II. Gastrula und Eifurchung der Würmer.

Im Stamme der Würmel fincien wir die ursprüngliche Form der primordialen Furchung und die daraus hervorgehende Urform der Archigastrula bei niederen Helminthen sehr verschiedener Gruppen noch heute wohl erhalten. Unter den Plathelminthen ist dieselbe wahrscheinlich bei den Turbellarien (deren Keimesgeschichte leider nur sehr wenig untersucht ist) weit verbreitet, ebenso bei einer Anzahl Trematoden und wahrscheinlich auch bei vielen Cestoden ${ }^{\mathbf{q}}$ ). Bei den Nemertinen ist sie von Metschnikoff ${ }^{5}$ ) und Dieck $^{6}$ ) beschrieben worden. Anch bei den Enteropneusten (Balanoglossus) scheint sie in ganz reiner Form erhalten zu sein. Ebenso finden wir sie bei den Chae-

1) Kowalevsky, Entwickelung der Rippenquallen. Mém. de l'Acad. S. Petersb. Tom. X. 1866.

2) Hermann fol, Anatomie und Fintwickelnng einiger Rippenquallen. Berlin 1869.

3) Alex. Agassiz, Embryology of the Ctenophorae. Cambridge 1874.

4) Édodard van Bexeden, Recherches sur la composition et la signification de l'oenf. Bruxelles 1870.

5) Mетschinoff, Ueber die Entwickelung der Echinodermen und Nemertinen. Mém. de l'Acarl. de S. Petersb. Tom. XIV, 1869, No. 8. Taf. IX.

6) Geora Dieck, Beiträge zur Entwickelungsgeschichte der Nemertinen. Jenaische Zeitschr. f. Nat. Bd. VIII, 1874. Taf. XX. 
tognathen ${ }^{1}$ ) (Sagitta) vor (Fig. 23). Ferner scheint dieselbe auch bei den Nematoden verbreitet zu sein; wenigstens geht dies aus einer kürzlich erschienenen Mittheilung von Bürschu hervor, der sie bei Cucullanus genau beschreibt ${ }^{2}$ ). Bei anderen NematodenGruppen dürfte gewöhnlicher die Amphigastrula auftreten. Gleiches gilt wohl auch von der Mehrzahl der Bryozoen. Unter den Tunicaten liennen wir die reine Arehigastrula durch Kowalevskx's ${ }^{3}$ ) und Kupfarr's ${ }^{*}$ ) Untersuchungen über verschiedenen Ascidien; der' erstere hat sie auch bei Phoromis unter den Gephyreen nachgewiesen.

Weit häufiger als die primordiale findet sich im Stamme der Würmer die ina equale Furchung, die zur Bildung der Amphigastrula führt (Fig. 91-102). Soweit es der heutige beschränkte Zustand unserer Kenntnisse zu beurtheilen erlaubt, ist diese Form der Eifurchung unter den Würmern bei weitem am meisten verbreitet und namentlich unter den höheren Helminthen die heirschende Keimungsform. Alle verschiedenen Modificationen derselben finden sich hier vor, bald unten bei den niederen Wïrmern in Anschluss an die primordiale, bald oben bei den höheren Würmern in Anschluss an die discoidale und superficiale Furchung. Dabei ist das Verhältniss der zahlreichen kleinen, hellen Zellen des animalen Bildungskeimes zu den wenigen grossen, dunkeln Zellen des vegetativen Nahrungskeimes äusserst mannichfaltig. Bald erscheint die aus den letzteren gebildete vegetative Hemisphäre in die von den ersteren formirte animale Hemisphäre „eingestülpt" (Entobole, Amphigastrula invaginata); bald scheint vielmehr die letztere die erstere zu „umwachsen“ (Epibole, Ampligastrula circumcreta). Gerade hier lässt sich (wie auch bei den Mollusken) sehr schön zeigen, dass beide Formen der inaequaleı Furchung nur durch die relative Grösse und Masse der „Nahrungszellen" im Verhältniss zu den „Bildungszellen" verschieden und durch unmerkliche Uebergänge verbunden sind. Unter der Plathelminthen ${ }^{5}$ ) scheinen solche Uebergänge sehr verbreitet zu

1) A. Kowalevsky, Embryol. Stud. an Würmerus und Arthropodell. Méd. de l'Acad. de S. Petersb. 1871. Tom. XVI, N. 12. Taf. I.

2) Bütschli, Zur Entwickelungsgeschichte des Cucullanus elegans. Zeitschr. f. wiss. Zool. 1875; Bd. XXVI, S. 103. Taf. V. Fig. 5-7 Archigastrula.

3) A. Kowalevsky, Entwickelungsgeschichte l. einfachen Ascidien. Mém. Acad. Petersb. Tom. X. Nr. 15. 1866. Taf. I.

4) KupHFer, Die Stamnverwandtschaft zwischen Ascidien แnd Wirbelthieren. Alehiv f. mikr. Auat. 1870. Vol. VI, 'iaf. VIII.

5) A. Keferstein, Beiträge zu Anatomie und Entwickelungsgeschichte d. Seeplanarien. 1868. 
sein; wahrscheinlich auch unter den Nematoden und namentlich bei den Anneliden. Unter den letzteren hat sie vorzüglich CLAPARÈDE ') schon 1869 in ausgedehnter Verbreitung nachgewiesen und später Kowalevsky ${ }^{2}$ ) auf Querschnitten gellauer studirt (l. c.). Bei den meisten Chaetopoden verläuft die inaequale Furchung nach demselben Modus, den ich oben nach meinen eigenen Beobachtungen bei Fabricia geschildert habe (Taf. VII, Fig. 91102). In gleicher oder ähnlicher Form entwickelt sich die Amphigastrula aber auch bei vielen anderen Würmern, namentlich den Räderthierchen, wo sie von $\operatorname{Leydig}^{3}$ ), Salensky ${ }^{4}$ ) u. A. beschrieben worden ist. Sie tritt hier meistens, wie bei vielen Anneliden, in derjenigen Modification auf, welche ich in der Anthropogenie (S. 166) als , seriale Furchung" unterschieden habe, ausgezeichnet durch die arithmetische Progression, in der sich dic Furchungszellen anfänglich vermehren. Andere Modificationen der inaequalen Furchung scheinen bei Gephyreen, Tunicaten und andern Würmer'n vorzukommen, müissen jedoch noch genauer untersucht werden. Von Phascolosoma hat kürzlich Selenra eine ausfïhrliche Darstellung gegeben $\left.{ }^{5}\right)$.

Die discoidale Furchung und die daraus entstehende Discogastrula scheint zwar in so reiner Forn, wie bei den Cephalopoden, Scorpionen, Vögeln u. s. w. bei den Würmern nicht vorzukommen. Aber vollständige Uebergänge zu derselben bildet die Amphigastrula der Würmer nicht selten. Einen solchen hat Kowalevsky bei Euaxes sehr genau beschreiben (1. c. Tab. III); und ähnliche werden sich wahrseheinlich anch noch bei manchen anderen Würmern mit sehr voluminösem Nahrungsdotter finden. Offenbar führt hier die starke Massenzunahme des letzteren zu einer Modification der Amphigastrula, welche sich unmittelbar der Discogastrula anschliesst ${ }^{6}$ ). Ob wahre superficiale Furehung

1) Ed. Claparède, Beiträge zul Kenutniss der Entwickeluugsgeschichte der Chactopoden. Zeitschr. für wiss. Zool. BA. XIX. 1869. 'Taf. XII-XVII.

2) Kowalevsky, Embryol. Stud. an Wïnern etc. 'Taf. I11-V Euaxes; 'Taf.' VI, VII Lumbricus.

3) LEYDIG, Ueber den Ban mu die systenatische Stellung der Räderthieres. Zeitschr. f. wiss. Zool. Bı. VI, 1854.

4) Salensky, Entwickelung des Brachionus. Zejtschr. f. wiss. Zool. 1872. Bd. XXII, 'Tat. XXXVIII.

5) Selenks, Eifurchung und Larvenlildung von Pliascolosoma. Zeitschr. f. wiss. Zool. 1875, Iid. XXV, 'Taf'. XXIX.

6) A. Kowalevsky, Eubryol. situdien an Würmern ets. (1. c. Tab. HI, 1V). duf den Querschnitten seiner Tatfel IV könnte min Fig. 25 und 26 als Disco. 
und die darans entstehende Perigastrula, wie wir sie bei den meisten Arthropoden finden, auch bereits bei höheren Würmern, namentlich Ammeliden, vorkommt, ist gegenwärtig noch nicht sicher bekamnt, jedoch nicht unwahrscheinlich.

III. Gastrula und Eifurchung der Mollusken.

Der Stamm der Weichthiere schliesst sich bezüglich seiner Eifurchung und Gastrulabildung auf das Engste an die Gruppe der höheren Wü̈mer an, aus der er phylogenetisch hervorgegangen ist. Die primordiale Furchung mit der Archigastrula scheint im Ganzen nur selten rein conservirt zu sein; so namentlich bei den niedersten Mollusken, den Spirobranchien oder Brachiopoden (Fig. 25). Hier hat sie Kowalevsky neuerlich von Argiope, Terebratula u. A. beschrieben ${ }^{1}$ ). Unter den Schnecken hat sie schon 1862 Lereboullet bei Lymnaeus richtig erkannt ${ }^{2}$ ); und kürzlich haben sie bei derselben $R_{A Y}-L_{A N K E S T E R}{ }^{3}$ ) und am sorgfältigsten $\mathrm{C}_{\mathrm{ARL}} \mathrm{R}_{\mathrm{ABL}}{ }^{4}$ ) beschrieben. Das Vorkommen der reinen Archigastrula ist hier un so interessanter, als die primordiale Furchung einen vorübergehenden Anlauf zur inaequalen nimmt. Nachdem nämlich die ersten vier Furchungszellen von gleicher Grösse gebildet sind, werden dieselben durch eine dem Aequator parallele Kreisfurche in vier grössere und vier kleinere Zellen getheilt, wie bei sehr vielen Würmern und Mollusken (Fig. 104). Dann aber ,theilen sich die grossen Furchungskugeln rascher und öfter als die kleinen, so dass schliesslich alle Zellen ungefähr die gleiche Grösse besitzen." (RABL 1. c.).

Viel häufiger als die prinordiale tritt bei den Mollusken die inaequale Furchung mit der Ampligastrula auf, welche in diesem Thierstamme, wie bei den Würmern, die bei weitem häufigste Keimungsform zu sein scheint. Die meisten älteren Be-

morula, Fig. 27 u. 28 als Discoblastula, Fig. 29 u. 30 als Discogastrula denten, mit Rücksicht auf die entsprechenden Fläcbenansichten der Tat. II.

1) Kowalevsky, Russische Abhandl. über Ontogenie der Brachiopoden. Kasall 1873. Taf. I.

2) Lereboullet, Embryologie du Lymuée. Amules d. sciens. 11 at. Vol. XVIII, 1862, Taf. 11. Fig. 25 Archiblastula. Fig. 26 Archiblastula invaginata. Fig. 26 Archigastrula.

3) Ray-Lankestke, Observations on the development of the Pond-Sinail. Quart. Journ. of microsc. Science, Vol. XIV, 1874.

4) Card Rabl, Die Ontogenie der Süsswasser-Pulmonaten. Jen. Zeitschr. f. Naturw. 1875̃. Vol. IX, Taf. VII. 
schreibungen der Keimung von Muscheln und Schnecken sind auf diese Form zu beziehen, obwohl die Mehrzahl derselben nicht hinreichend genau ist. Auch diejenigen Brachiopoden, welche viel Nahrungsdotter in Ei angehäuft haben (z. B. Thecidimm), haben an Stelle der ursprïinglichen primordialen allmählich die inaequale Furchung angenommen. Ueber die Amphigastrula der Muscheh hat die genauesten (noch nicht veröffentlichten) Untersuchungen $\mathrm{C}_{\mathrm{ARL}} \mathrm{R}_{\mathrm{ABL}}$ an Unio angestellt. Ich habe mich von deren Richtigkeit an sehr guten, von $R_{A B L}$ angefertigten Querschnitten mit eigenen Augen ïberzeugt. Seiner freundlichen Mittheilung verdanke ich die in Fig. 26-28 auf Taf. II gegebenen Abbildungen. Das eingestiulpte Entoderm der Amphigastrula zeigt sehr hohe schmale Cylinderzellen im Gegensatze zu den niederen Plattenzellen des Exoderm. An der Amphiblastula von Unio (Fig. 26) ist das ganze Entoderm nur durch eine einzige sehr grosse Zelle repräsentirt, während das Exoderm bereits ein Gewölbe vou vielen kleinen Zellen bildet ${ }^{1}$ ). Vou den Schnecken hat die Amphigastrula besonders genau Selenka bei Purpura beschrieben ${ }^{2}$ ). Der Nahrungsdotter ist hier so gross, dass die primär gefurchte Schicht der kleinen hellen Bildungszellen am animalen Bildungspole des Eies eine fast halbkugelige Kappe bildet. Diese ,umwächst" die grosszellige, erst secundär gefurchte, subsphärische Masse der grossen dunkeln Nahrungszellen: „Epibolie“ (Amphiblastula, l. c. Fig. 3). Hierauf schlägt sich der verdickte Rand der primären hellen Keimschicht ain untern „Nahrungspole" nach innen um und seine cingestülpte Verlängerung wächst als ,,secundäre Keimschicht" (Entoderm) zwischen den grossen Dotterkugeln und der „primären Keimschicht" (Exoder'm) nach dem oberen "Bildungspole“ zuriick (Amphigastrula circumcreta, 1. c. Fig. 4, 5). Vergl. Fig. 32. Wird der Nahrungsdotter noch grösser, wie es bei einigen höheren Cochliden der Fall ist, so breitet sich die primäre Keimschicht noch flacher, scheibenförmig auf dem Nalırungsdotter aus, den sie später umwächst. Die Amphigastrula geht so in die Discogastrula iiber (Fig. 104-110).

Die discoidale Furchug mit der Discogastrula wird

1) Paul Flemmng bemerkt in len kïrzlich erschienenen ,Stulien in ter Entwickrlungsgeschichte der Najalen" (Witul. Acau. Sitzungsher. 1875. Vol. LXX1), dass eine rigentliche Gastrula hier nicht vorkomme. Er hat dieselbe offenbar lesshitb ibersehen, weil er keine Querschnitte durch das GastrulaStadium allgefertigt luat.

2) SElenka, Die Anlage der Kiemblatter hei l'nopura Japillus. Hatulem 1872. Taf. XVII. 
dergestalt schon bei den höheren Schnecken durch die zunehmende Vergrösserung des Nahrmugsdotters allmählig eingeführt. Sie findet sich allgemein bei der höchsten Mollusken-Classe, den Cephalopoden vor, und verläuft hier in einer form, welche im Wesentlichen mit derjenigen der Vögel und Reptilien, wie der meisten Fische, identisch zu scin scheint. Bekanntlich ist diese Bildung einer Keimscheibe (Blastodiscus) bei den Cephalopoden schon 1844 von Kölliker ${ }^{\prime}$ ) entrleckt und neuerdings von E. RAY-Lankester ${ }^{2}$ ) und $\mathrm{Ussow}^{3}$ ) auf Querschnitten studirt worden. Die Abbildung, welche Ray-Lankester (1. c. Taf. IV, Fig. $1 x$ ) von einem Meridianschnitt durch die Keimscheibe cines Loligo-Eies giebt, scheint mir keinen Zweifel zu lassen, dass die Discogastrula sich auch hier bei den Ccphalopoden, ganz ebenso wie bei den discoblastischen Wirbelthicren, durch Invagination bildet. Die linsenförmige Keimscheibe (Discomorula) verdümnt sich in der Mitte, während die Ränder sich verdicken, und hebt sich in der Mitte von dem darunter liegenden Nahrungsdotter ab (Discoblastula). Hierauf schlägt sich der verdickte "Randwulst", das Properistom, nach innen um, wächst als secundäre Keinschicht (begimnendes Entoder'm) zwischen den Nahrungsdotter und die primäre Keimschicht (Exoderm) centripetal hinein und bildet schliesslich mit letzterer zusammen eine Hach kappenförmige zweiblätterige Discogastrula, welche darauf den ganzen Nahrungsdotter umwächst.

Die superficiale Furchung mit der Perigastrula scheint unter den Mollusken nicht vorzukommen.

\section{Gastrula und Eifurchung der Echinodermen.}

Im Stamme der Echinodermen überwiegt ganz vorherrschend, soweit sich nach den bisherigen, immer noch lelativ wenig Zahlreichen Beobachtungen schliessen lässt, die primordiale Furchung und die Archigastrula. Die Keimung derselben, welche ganz dem primitiven, auf unserer Tafel VIII von Gastrophysema abgebildeten Typus entspricht, ist neuerdings bei den Asteriden von Alex. Agassiz ${ }^{*}$ ), bei (len Holothurien von Kowa-

1) KöLliker, Entwickelnngsgeschichte der C'ephalopoden. Zürich 1844.

2) E. Ray-Lankester, Ohserv. On the Development of the Cephalopoda. Quart. Jomm. Nicr. Se. 1875. No. 57. Pl. IV, V.

3) M. Ussow, Zoologisch-embryologische Untersuchungen. Arch. f. Naturg. 1874. Hid. 40, S. 340 .

4) ALEx. Irassiz, Un the Embryology of the Starfish. Contributions etc. Vol. V, 1864. 
LEvSKY ${ }^{1}$ ) genall verfolgt worden. Die Gastrulation eines Echiniden, des Toxopneustes lividus, habe ich selbst kürzlich in Ajaccio, gelegentlich der Untersuchungen, welche mein Reisegefährte, Herr Dr. Oscar Hertwig, über die Eibildung desselben anstellte, verfolgt, und mich dabei überzeugt, dass sie in nichts Wesentlichem von der primordialen Furchung und der Archigastrula-Bildung der Asteriden und Holothurien abweicht. Der Umstand, dass bei vielen Echinodermen die Einstülpung der Archiblastula nicht vollständig wird und zwischen Entoderm und Exoderm der Archigastrula ein ansehnlicher, mit klarer Flüssigkeit oder Gallertmasse (,Gallertkern", Hensen) gefüllter Hohlraum, der Rest des Blastocoeloms, längere Zeit bestehen bleibt, ist natiirlich nicht von Belang (Fig. 33 s). Dass die primordiale Furchung unter Echinodermen aller Gruppen weit verbreitet ist, lässt sich aus der Vergleichung der verschiedenen Larven- oder Ammenformen erschliessen.

Neben der vorherrschendęu primordialen Furchung scheint bei vielen Echinodermen inaequale Furchung und Amphigastrula vorzukommen; insbesondere bei jenen Formen, welche der sogenannten "directen Entwickelung" unterliegen und den ursprünglichen Generationswechsel sehr stark abgekürzt oder ganz verloren haben. Da hier offenbar keine ursprüngliche ,directe Entwickelung" vorliegt, sondern vielmehr eine cenogenetische Abkürzung und Fälschung des ursprïnglichen palingenetischen Entwickelungsganges (- wie unter Anderem der ,provisorische Larvenapparat" der Embryonen bei der lebendig gebärenden Amphiura squamata deutlich beweist -), so ist von vornherein zu elwarten, dass auch die ursprüngliche Form der primordialen Eifurchung secundäre Modificationen erlitten haben wird. Wahrscheinlich wird sich hier bei Vielen im Laufe der Zeit eine mehr oder minder bedeutende Quantität von Nahrungsdotter gebildet haben und die Furchung mehr oder minder inaequal geworden sein. Zwar ist eine deutliche Amphigastrula bisher erst bei wenigen Echinodermen beobachtet worden, allein ihre weitere Verbreitung lässt sich aus den obigen Grïnden vermuthen. Insbesondere dürften die lebendig gebärenden oder sonst in der Keimung vom gewöhnlichen Typus des Generationswechsels abweichenden Artell darauf zu untersuchen sein: unter den Asteriden Uraster Mülleri, Echinaster Sarsii, Pteraster militaris, Amphiura squa-

1) Kowatevsky, Beiträge zur Entwickehnggsgeschichte der Holothurien. Mém. Acad. Petersb. 1867. 
mata und die verwandten viviparen Arten '); unter den Crinoiden wahrscheinlich viele Species; unter den Echiniden der lebendig gebärende Anochanus chinensis und verwandte Arten; unter den Holothurien Thelenota tremula, Phyllophorus urna, Synaptula vivipara und vielleicht noch viele Andere. Die genaueste Darstellung der inaequalen Furchung hat kürzlich Selenka von Cucumaria doliolum gegeben. Bei der Amphiblastula dieser Holothurie ist die Invagination ebenfalls nicht vollständig und zwischen Entoderm und Exoderm der Amphigastrula bleibt ein ,glasheller Gallertkern zurück, welcher die Rolle eines ungeformten Nahrungsdotters spielt. Wahrend hinten die Reste dieses Gallertkerns allmählig eingeengt und endlich durch Resorption ganz zum Verschwinden gebracht werden, bleibt im vorderen Drittel derselbe noch lange bestehen. Es kommt hier zur Bildung eines grossen Oeltropfens, welcher die Larve schwimmend an dem Meeresspiegel hält, den hinteren Pol nach unten gewendet. Erst später tritt ein Schwund dieses Gebildes und damit der Furchungshöhle überhaupt ein" ${ }^{2}$ ).

$\mathrm{Ob}$ bei einigen von denjenigen Echinodermen, bei denen der palingenetische Gang dej Keimung durch cenogenetische Anpassungen abgekiirzt und gefälscht worden ist, die Ansammlung des Nahrungsdotters einen höheren Grad erreicht und somit zur discoidalen Furchung und zur Discogastrula hinüber führt, ist aus den bisherigen, sehr unvollständigen Beobachtungen nicht sicher zu ersehen; indessen keineswegs a priori umwahrscheinlich.

Dagegen ist es nicht wahrscheinlich, dass bei irgend einem Echinodermen die superficiale Furchung und die Perigastrula sich findet.

\section{Gastrula und Eifurchung der Arthropoden.}

Im Stamme der Arthropoden, sowohl bei den Crustaceen, wie bei den Tracheaten, scheint die primordiale Furchung und die Archigastrula nur in sehr wenigen Fällen rein conservirt zu sein. Wahrscheinlich findet sie sich noch heute bei einzelnen Crustaceen aus den Ordnungen der Branchiopoden und Copepoden, bei denen vor der ursprünglichen Nauplius-Form eine rasch vorübergehende zweiblätterige Keimform auftritt, welche als Archi-

1) Sars, liatula littoralis Norvegiae. Vol. I, 1846, Tatf. VI; Vol. II, 1856, Taf. VIII.

2) SELENKa, Embryologie von Cucumaria doliolum. Sitzungsber. der physik. medic. Soc. zu Erlangen. 1875. 
gastrula zu betrachten ist '). Als solche ist wahrscheinlich auch der Keim der Tardigraden oder Arctisken zu deuten, welchen $\mathrm{K}_{\mathrm{AuF}}$ uaNN beschrieben hat ${ }^{2}$ ). Ebenso ist vielleicht auch der einfache, von Nahrungsdotter ganz entblösste Embryo der inerkwürdigen Pteromalinen (Platygaster, Polynema, Ophioneurus, Teleas), welchen wir durch $\mathrm{G}_{\mathrm{ANIN}}{ }^{3}$ ) kennen gelernt haben, als Archigastrula zu deuten und vermuthlich durch Invagination einer primordialen Archiblastula entstanden. Allerdings beschreibt Ganin die „totale Furchung" dieser parasitischen Hymenopteren in abweichender Weise. Indessen dürfte dieser Unterschied entweder durch genauere histologis che Untersuchung des Furchungsprocesses auszugleichen oder auf eine geringfügige cenogenetische Modification zurückzuführen sein. Möglich bleibt es immerhin, dass hier keine ursprüngliche Archigastrula-Bildung vorliegt, sondern eine eigenthümliche Modification der Eifurchung, welche lurch den tertiären cenogenetischen Verlust des secundären, bei den Vorfahren der Pteromalinen noch vorhandenen Nahrungsiotters bedingt ist.

Ziemlich verbreitet unter den niederen Arthropoden, und jedenfalls viel häufiger als die primordiale, ist die inaequale Furch ung und die daraus hervorgehende Amphigastrula. Unter den $\mathrm{Cr}_{1}$ ustaceen scheint dieselbe in den allermeisten Fällen aufzutreten, in denen der echte Nauplius noch heute conservirt ist; jene bedeutungsvolle Keimform, welche zuerst FriTz MüLler in seiner ideenreichen Schrift „Für Darwin" als Wiederholung der gemeinsamen Stammform aller Crustaceen nachgewiesen hat ${ }^{*}$. Die Entstehung des Nauplius und der zweiblätterigen, der Gastrula entsprechenden Keimform scheint in der Mehrzahl der Fälle durch inaequale Furchung zu geschehen. Wird die Nasse des Nahrungsdotters, die den Nauplius-Darm erfüllt, beträchtlich, so kamn die inaequale Furchung bald in die discoidale, bald in die superficiale Furchung übergehen. Die genauesten Untersuchungen, die wir bisher über diesen Vorgany besitzen, namentlich diejenigen von Ed. van Beneden und Emil Besseus ${ }^{3}$ ), lassen vermuthen, dass hier

1) Ed. van beneden et Eyil Bessels (1. c.).

2) Joseph Kaufrans, Ueber die Entwickelung uml system. Stellung des Tardigrarlen. Zeitschr. f. Wissensth. Zool. 1851. Vol. Ill, S. 220, Taf. VI.

3) M. Ganın, Heiträge Zur Erkenntniss der Entwickelungsgeschichte bej den Insecten. Zeitschr. f. wissensch. Zool. 1869. Vol. XIX, 'Taf. 30-33.

4) Fritz Müller, Füu Darwili. Lrijugig 1864.

5) Edouard van beneuen ('t linu. Bessels, Sul la Fornation du Bhastoderme chez les Crustacés. Bulletius et Mémoires de l'Acarl. Belge. 1868, 1869. 
eine ziemlich ausgedehnte Stufenreihe von Uebergangsformen der intequalen Eifurchung bestehen wird, welche sich dinerseits unten an die frïhere primordiale, oben an die spätere discoirlale und superficiale Furchung anschliessen. Dasselbe ist auch von den nierleren 'Tracheat en zu vermuthen, sowohl Insecten, als namentlich Spinnen. Auch hier schemen manche (vorzüglich kleine Arten, deren kleine Eier wenig Nahrungsilotter enthalten) cine inaequale Eifurchung durchzumachen, die sich bald mehr an die primordiale, bald mehr art dic discoidale, bald endlich unmittelbar an die superficiale Furchung anschliesst.

Wie weit die discoidale Furchung und die Discogastrula unter den Arthropoden verbreitet ist, lässt sich heutzutage noch nicht annähernd bestimmen. Nur so viel scheint sicher, dass sie sowohl unter den Crustaceen als unter den Tracheaten ziemlich häufig vorkommt, insbesondere bei grösseren, differenzirteren Formen, die einen ansehnlichen Nahrungsdotter erworben haben. Sie muss hier überall vorkommen, wo sich, an einem Pole des Eies eine Keimscheibe (Blastodiscus) bildet, welche den Nahrungsdotter umwächst, indem sie sich allmählich bis zu dem entgegengesetzten Pole hin ausdehnt". So finden wir sie bei der Nauplius-Bildung von grösseren Crustaceen verschiedener Ordnungen (van Beneden et Bessers 1. c.). Vom Oniscus hat sie Boвretzky ${ }^{1}$ ) sehr genau besclirieben (Fig. 35, 36, 37). Ebenso sehen wir sie bei verschiedenen Tracheaten, insbesondere bei den Scorpionen verlaufen. Die Discogastrula des. Scorpions, welche auf unserer Fig. 40 copirt ist, entspricht derjenigen der Vögel und Reptilien ${ }^{2}$ ).

Die grösste Rolle spielt im Stamme der Gliederthiere, sowohl unter den Crustaceen, als unter den Tracheaten, die superficiale Furchung und die daraus resultirende Perigastrula (Fig. 38). Ja diese eigenthimliche Keimungs-Form ist sogar recht eigentlich für diesen Stamm charakteristisch und wir müssen es noch dahin gestellt sein lassen, ob dieselbe in einem der anderen Stämme (insbesondere bei den Würmern), in derselben ausgeprägten Form sich findet. Bei vielen niederen und bei der grossen Mehrzahl der höheren Crustaceen (namentlich der Malacostraken), bei den Poecilopoden (Limulus), bei der Mehrzahl der Arachniden und Myriapoden und namentlich bei den allermeisten Insecten scheint

1) Boвretzix, Zur Embryologie des Oniscus murarius. Zeitschr. f. wiss. Zool. 1874. Bd. XXIV, S. 178, Taf. XXI.

2) Metschnкоғғ, Embryologie des Scorpions. Zeitschr. f. wissensch. Zool. 1871, Vol. XXI, S. 204. 
sich der Embryo auf diesem eigenthümlichen Wege zu entwickeln. Als die genamesten Beobachtungen, welche wir darüber besitzen, wurden bereits vorher diejenigen von Bobketzky ${ }^{1}$ ), E. van Benteden und Bessels (l. c. l. c.), Weismann ${ }^{2}$ ) und Kowalevskx ${ }^{3}$ ) hervorgehoben. Aber auch die Angaben von Clapakìde ${ }^{*}$ ) Metschnikoff und vielen anderen Beobachtern lassen sich wohl auf jene zurïckführen.

Soweit man nach den zahlreichen, gegenwärtig vorliegenden - allerdings bei dem ungeheuren Umfang des Arthropoden-Stammes immer noch relativ spärlichen - Angaben urtheilen darf, ist die echte superficiale Furchung mit derjenigen Perigastrulabildung, welche ich von Peneus geschildert habe (Taf. VI) unter den höheren Crustaceen und Tracheaten allerdings die vorherrschende Form. Allein es scheinen unter den zahlreichen Modificationen derselben auch viele $Z$ wischenformen vorzukommen, welche als vermittelnde Uebergänge theils zwischen der superficialen und discoidalen, theils zwischen der superficialen und inaequalen, theils zwischen der superficialen und primordialen Furchung zu deuten sind. Selbst bei nahe verwandten Gliederthieren finden sich in dieser Beziehung höchst auffallende Unterschiede vor, wie schon van Beneden und Bessels (l. c.) mit Recht hervorgehoben haben. Sie fanden z. B. bei verschiedenen Species das Genus Gammarus die Furchung und das Verhalten des Nahrungsdotters höchst verschieden.

Aus diesen Gründen dürfen wir schliessen, dass die superficiale Furchung und die Perigastrula-Bildung der Arthropoden bald direct aus der primordialen, bald indirect aus der discoidalen, oder aus der inaequalen Furchung (wie sie bei anderen Thieren dieses Stammes vorkommt) sich phylogenetisch entwickelt hat. Da wir aber sowohl die discoidale als die inaequale Furchung als secundäre Processe nachgewiesen haben (aus der primordialen Furchungsform durch cenogenetische Abänderungen entstanden), so werden wir auch die superficiale Furchung direct oder indirect anf letztere zurückzuführen haben. Sehr oft wird die superficiale Furcliung

1) BoBREtzKy, Russische Abhandlungen ïber Ontogenie der Arthropoden. Kiew 1873.

2) Weismann, Die Entwickelung der Dipteren. Leipzig 1864.

3) Kowalevsky, Embryol. Studien an Würmern und Arthropoden. Mém. Acad. Petersb. 1871.

4) Ed. Claparìde, Recherches sur l'évolution des Araignèes. Genève 1862. Studien an Acarideu. Zeitschr, f. wissensch. Zool. 1868. Vol. XVIII, S. 488. 
ans der primordialen direct entstanden sein, indem der im Centrum der Eizelle angesammolte Nahrungsdotter sich an der Theilung des peripherischen Bildungsdotters zu betheiligen aufhörte.

\section{Gastrula und Eifurchung der Wirbelthiere.}

Im Stamme der Vertebraten ist die Eifurchung und die daraus resultirende Keimblätterbildung seit mehr als einem halben Jahrhundert von zahlreichen Beobachtern auf das Genaueste untersucht worden, und es sind darüber mehr verschiedene und eingehende Darstellungen veröffentlicht worden, als über die ersten Keimungs-Vorgänge in allen übrigen Thierstämmen zusammengenommen. Ja die betreffenden Verhältnisse der Wirbelthiere bildeten eigentlich noch bis vor wenigen Jahren den Mittelpunkt der gesammten Keimblätter-Theoric; und als man dann anfing, diese auch auf die Wirbellosen auszudehnen, lieferten die Vertebraten das ausgebildete Schema, von welchem ausgehend man die verschiedenen Verhältnisse der Wirbellosen zu beurtheilen versuchte. Bekanntlich haben viele Zóologen noch bis vor zehn Jahren die Bildung und Sonderung der Keimblätter überhaupt als einen den Wirbelthieren eigenthümlichen Differenzirungs-Process aufgefasst. Als man dann aber auch bei den Wirbellosen diesen Vorgang in grosser Ausdehnung nachzuweisen begann, war es ein verhängnissvoller Umstand, dass man die am häufigsten und am genauesten untersuchte Keimung des Hühnchens zum Ausgangspunkt wählte. Die hier auftretende discoidale Furchung und Discogastrula-Bildung, eine sehr stark modificirte secundäre Keimungsform, wurde unglücklicher Weise als Erklärungs-Basis für die viel einfacheren, primären Keimungsformen niederer Thiere hingestellt und das Verhältniss des kleinen Bildungsdotters zum grossen Nahrungsdotter völlig verkehrt aufgefasst. Die wichtigsten Keimungsprocesse, die Bildung der Blastula und die Entstehung der Gastrula durch Invagination der letzteren wurden dabei ganz iubersehen. und erst in neuester Zeit gelang es, diese auch hier nachzuweisen,

Soweit sich gegenwärtig die Keimungsverhältnisse der Vertebraten übersehen lassen, finden wir von den vier Hauptformen der Eifurchung und Gastrulation die superficiale hier gar nicht vor, die primordiale nur beim Amphioxus. Dagegen findet sich die inaequale Furchung bei den Cyclostomen, Amphibien, Ganoiden, Marsupialien (?) und Placentalien (wahrscheinlich auch bei den 
Dipneusten); die discoidale Furchung bei den Selachiern, Telenstiern, Reptilien, Vögeln nnd Monotremen (?).

Die ursprüngliche reine Form der primordialen Furehung und die daraus hervorgehende Arehigastrula hat unter den Wirbelthieren bis auf den heutigen Tag einzig und allein der A mphioxus getreu conservirt (Taf. III, Fig. 41-44). Wie wir durch Kowalevsky's epochemachende Entlleckung 1866 erfahren haben, durchläuft das Ei dieses ältesten Wirbelthieres eine vollkommen reguläre totale Furchung, die sich in keiner Weise von derjenigen anderer archiblastischer Eier unterscheidet '). Aus der Archimorula entsteht eine echte Archiblastula (Fig. 41); diese stülpt sich unipolar ein (Fig. 42); das eingestülpte Entoderm legt sich an das nicht eingestülpte Exoderm an (Fig. 43) und wir erhalten somit eine ellipsoide Archigastrula (Fig. 44). Wie wir den Amphioxus aus vergleichend-anatomischen Gründen als den letzten überlebenden Repräsentanten einer untergegangenen formenreichen Classe von schädellosen Wirbelthieren (Acrania) betrachten müssen, so müssen wir auch aus vergleichend-ontogenetischen Grïnden den Schluss ziehen, dass die von ihm conservirte primordiale Furchung diesen letzteren (wenigstens zum Theil) gemeinsam war.

Aus der primordialen Furchung und der Archigastrula der Acranier, welche unter den Wirbelthieren der Gegenwart nur noch der Amphioxus besitzt, hat sich zunächst die inaequale Furchung und die Amphigastrula entwickelt, welche wir bei vielen niederen Wirbelthieren in bemerkenswerther Uebereinstimmung antreffen: bei den Cyclostomen, den Ganoiden und den Amphibien, höchstwahrscheinlich auch bei den Dipneusten. Die inaequale Furchung der Cyclostomen hat znerst Max Schultze ${ }^{2}$ ) von Petromyzon beschricben (Fig. 45-48); vermuthlich wird sich dieselbe Form auch bei den Myxinoiden finden, deren wichtige Keimesgeschichte leider noch ganz umbekannt ist. Die Amphimorula von Petromyzon (Fig. 46) zeigt eine geräumige Keimhöhle (s), deren gewölbte Decke von der animalen Hemisphäre, deren vertiefter Boden von der vegetativen Hemisphäre der Furchungszellen gebildet wird. Bei der daraus hervorgehenden Amphiblastula (Fig. 47 ) ist die Keimhöhle $(s)$ noch bedeutend erweitert, während schon die Einstülpung des Urdarms beginnt $(a)$. Später verschwindet

1) A. Kowalevsky, Entwickelungsgeschichte des Amphioxus lanceolatus. Mém. Acad. Petersb. 1867. Tom. XI. No. 4.

2) Max Schultze, Die Entwickelungsgeschichte von Petromyzon Planeri. Haarlem 1856. 
mit der fortschreitenden Einstiilpung des Urlarms die Furchungshöhle ganz und die typusche Amphigastrula ist fertig (Fig. 48). ber Urmund der letzteren oder der "Ruscons'sehe After" (o) geht nach $M_{A x}$ Scnutaz; , bestimmt in den definitiven After des Embryo iiber".

Ueber die inaequale Furchung der Ganoiden besitzen wir bis jetzt bloss die vorläufige Mittlıeilung, welche Kowalevskx, OwsuanNikow und Wagner iiber die Keimung der Störe 1869 gegeben haben. Demnach stimmt dieselbe in Wesentlichen mit derjenigen des Petromyzon and der Amphibien ïberein. Auch die Amphigastrula des Accipenser scheint von derjenigen des Petromyzon und der Amphibien nicht wesentlich verschieden zu sein ').

Am längsten bekannt und am genauesten untersucht ist die inaequale Furchung bei den Amphibien, über welche vor allen (lie höchst sorgfältigen Beobachtungen von Rемак ${ }^{2}$ ) und Goette ${ }^{3}$ ) vollständigen Aufschluss gegeben haben (Fig. 51-53). Als Eigenthïmlichkeiten derselben sind besonders hervorzuheben: das lange Bestehen der Furchungshöhle $(s)$ neben der Urdarmhöhle $(a)$, welehe zum grössten Theile mit Dotterzellen ausgefüllt ist, und deren Urmund (o) durch den BaER'schen Dotterpfropf (gewöhnlich mit Un'echt nach Eскек benannt) ausgefüllt wird. Daher ist eine scharfe Grenze weder zwischen der Amphimorula (Fig. 51) und der Amphiblastula (Fig. 52), noch zwischen dieser letzteren und der Amphigastrula (Fig. 53) zu ziehen.

Eine ganz eigenthümliche Modification der inaequalen Furchung und der Amphigastrula-Bildung scheinen die Säugethiere darzubieten. Seit den ersten genauen Beobachtungen, welche uns Bischoff $^{2}$ ) ïber die Eifurchung der Säugethiere gegeben hat, nimmt man allgemein an, dass dieselbe als , reguläre totale Furchung" verläuft, in derselben primordialen Form, welche unter den Wirbelthieren sonst nur beim Amphioxus zu finden ist. Als Endproduct der wiederholten Eitheilung wird eine reguläre Archimorula geschildert, ein solider kugeliger Zellenhaufen, der aus

1) A. Kowalevsky, P. Owsjannikow und N. Wagner, Die Entwickelungsgeschichte der Störe. Bulletin Acad. Petersb. 1870. Tom. XIV, S. 318.

2) Robert Pemak, Untersuchungen über die Entwickelung der Wirhelthiere. 1855. Taf. IX.

3) Arexander Goette, Entwickelungsgeschichte der Unke (Bombinator). 1875. Taf. I, II.

4) Bischоғт, Entwickelmugsgeschichte des Kaninchen-Eies. 1842 . - des Huncle-Eies. 1845. 
lauter gleichartigen Zellen zusammengesetzt ist ${ }^{1}$ ). Aus diesem soll dann eine reguläre "Keimblase oder Vesicula blastodermica", also eine Archiblastula entstehen, indem im Innern desselben sich Flüssigkeit ansammelt und sämmtliche Zellen zur Bildung einer einschichtigen Wand der Hohlkugel zusammentreten ${ }^{2}$ ). Wäre diese „Keimblase“ der Säugethiere wirklich, wie man fast allgemein annimmt, der einfachen Archiblastula des Amphioxus, der Ascidien und anderer archiblastischer Thiere homolog, so müsste der mit klarer Flüssigkeit gefüllte Hohlraum die Furchungshöhle sein. Nun ist derselbe aber vielmehr, wie sich aus der späteren Entwickelung zweifellos ergiebt, die Höhle des mit Fliissigkeit gefüllten Dottersacks, oder - mit anderen Worten - die Urdarmhöhle. Unmöglich aber kam sich die Furchungshöhle, welche zwischen Exoderm und Entoderm liegt, unmittelbar in die ganz davon geschiedene, bloss vom Entoderm umschlossene Urdarmhöhle umwandeln.

In der That liegen aber die Furchungs-Verhältnisse der Säugethiere nicht so einfach, wie man bisher annahm, sondern vielmehr ziemlich complicirt. Das lässt sich schon a priori erwarten aus dem Verwandtschafts-Verhältniss der Säugethiere zu den übrigen Vertebraten. Unmöglich können die Mammalien als höchst entwickelte Classe des Stammes den ursprünglichen einfachsten Process der primordialen Furchung bis heute conservirt haben, den allein der Amphioxus noch besitzt, während alle übrigen Wirbelthiere modificirte Furchungsformen zugleich mit dem Nahrungsdotter erworben haben. Auch ist ja in der That die Archigastrula, die das Resultat der primordialen Furchung sein müsste, nirgends bei den Sängethièren nachzuweisen und ich habe desshalb schon in der Anthropogenie (S. 166) ihre Eifurchung als "pseudototale" bezeichnet. Ausserdem lässt sich aber schon aus den wenigen und lückenhaften Beobachtungen, die überhaupt über die Furchung der Säugethiere vorliegen, mit Sicherheit schliessen, dass hier nirgends primordiale, sondern überall abgeleitete und modificirte FurchungsVerhältnisse sich finden.

Leider sind die höchst wichtigen Vorgänge, welche die Eifurchung der Säugethiere begleiten, bisher noch viel zu wenig erforscht, und neue, umfangreiche und mit Rücksicht anf die leitende

1) Die angebliche Archimorula des Säugethieres ist von Bischoff abgebildet: „Kaninchen-Ei" Taf. IV, Fig. 28, 30; „Hunde-Ei“ Taf. II, Fig. 16, 19.

2) Die angebliche Archiblastula des Säugethieres jst von Bischofr abgebildet: „Kaninchen-Ei", Taf. VI, Fig. 35. 36; Taf. VII, Fig. 37. 
Gastraca-Theoric angestellte Untersuchungen sind das dringendste Bediurfniss. Von den drei Hauptgruppen der Säugethiere sind die beiden niederen, Ionotremen und Didelphien, iiberhaupt noch gar nicht anf die Furchung untersucht, und nur uiber einige wenige l'Jacentalien besitzen wir unvollständige und unzureichende Beobachtungen. Von den grossen Eiern der Monotremen, die einen mächtigen Nahrungsdotter besitzen, lässt sich mit Sicherheit vermuthen, dass sie discoidale Furchung besitzen und eine Discogastrula billen werden wic die Vögel und Reptilien. Dasselbe gilt vielleicht auch von einem Theile der Marsupialien (?), während ein anderer Theil derselben (und wohl die grosse MehrZalhl) sich vermuthlich an die Placentalien anschliessen wird. Die Placentalien der Gegenwart besitzen wahrscheinlich sümmtlich inaequale Furchung und bilden eine eigenthümlich modificirte Ampligastrula. Man kömte versucht sein, diese unmittelbar von derjenigen der Amphibien abzuleiten, da ja die Säugethicre überhaupt - direct oder indirect - jedenfalls als Descendenten der Amphibien aufzufassen sind. Viel wahrscheinlicher ist es aber, dass die Amphigastrula der Placentalien (und Didelphien ?) durch Riickbildung - insbesondere durch Reduction und Verflüssigung des Nahrungsdotters - aus der Discogastrula der Monotremen und somit die inaequale Furchung der ersteren nicht primär, sondern tertiär aus der secundären discoidalen Furchung der letzteren entstanden sein wird.

Dass in der That die Eifurchmng der Placentalien die in aequale und nicht die primordiale ist, lässt sich schon aus den Angaben und Abbildungen von Brschoff über die Keimung des Meerschweinchens und des Rehes entnehmen. Bereits in frïhen Stadien der Furchung treten hier Furchungszellen von sehr ungleicher Grösse und Beschaffenheit neben einander auf ${ }^{1}$ ). Aber anch schon die früheren Beobachtungen desselben Forschers über die Keimung des Kaninchens und des Hundes führen zu demselben Schlısse. Denn jener bekannte hügelförmige oder lialblkugelige „Rest von dumkeln Furchungskugeln an einer Stelle der Innenfläche der hellen Keimblase" beweist allein schon, dass diese "Vesicula blastorlermica" keine wahre primäre Archigastrula, sondern eine modificirte secundäre oder tertiäre Amphiblastula ist, und dass schon während des Furchungsprocesses eine Differenzi-

1) ВıзсноғF, Eutwickelungsgeschichte des Meerschweinchens, 1852 (Taf. I, Fig. 7-12). - des Rehes, 1854 (Taf. I, Fig. 5-10). 
rung zwischen zweierlei Zellen, kleineren, hellen, animalen (Exoderm-) Zellen, und grösseren, dunkeln, vegetativen (Entoderm-) Zellen eingetreten ist. Daraus lässt sich dann auch ferner schliessen, dass die Annahme einer Spaltung oder Delamination des Blastoderms in die beiden primären Keimblätter unbegründet ist.

Meines Wissens hat bis jetzt nur ein einziger Beobachter diese wichtigen Verhältnisse in der inaequalen Furchung des Säugethier-Eies richtig ins Auge gefasst und den Weg angerleutet, auf welchem das schwierige Verständniss der eigenthümlichen SäugerFurchung gesucht werden muss. In der kurzen vorläufigen Mittheilung, welche Alexander Goette „Zur Entwickelungsgeschichte des Kaninchens" 1869 veröffentlichte, sagt rerselbe wörtlich Folgendes: „An Eiern von 2-3 Mm. Durchmesser sah ich an der Innenfläche der hellen Keimblase einen dunkeln Fleck, oder den eigentlichen Zellenhaufen, und in weitem Umfang um denselben einen hellen Hof, welcher von einer dünnen Zellenanhäufung herrührt (vegetatives Blatt der Keimblase der Autoren). Von dem kreisförmigen Rande dieser zarten Schichte wächst alsdann ein Ring gegen das Innere der Keimblase vor und schliesst sich bald zu einer continuirlichen Haut, welche sich an jene Zellenschichte, aus deren Umschlage sie hervorging, anlegt." 1 ) Offenbar ist dies ganz derselbe Vorgang, den ich oben vom discoblastischen Teleostier-Ei (Taf. IV und V) näher geschildert habe. Der Unterschied ist nur der, dass statt des soliden grossen Nahrungsdotters hier die mit Flüssigkeit gefüllte Keimblase der Säugethiere sich findet. Diese sogenannte Keimblase ist aber nicht homolog der wahren primären Archiblastula, sondern vielmehr als eine secundäre Amphiblastula aufzufassen, vielleicht sogar richtiger als eine Discoblastula, bei welcher der hügelförmig innen vorspringende "Rest von dunkeln Furchungskugeln" die Grundlage des Fruchthofs, den wahren Blastodiscus darstellt. Wie Goetre in seiner Keimesgeschichte der Unke wohl richtig bemerkt (S. 144) „muss man sich dazu die Dotterzellenmasse des holoblastischen Eies nachträglich aufgelöst und verflüssigt denken", und man muss ferner annehmen (S. 866 Anm.), „dass die während der Auflösung des Nahrungsdotters secundär entstehende einschichtige Keimblase in keiner unmittelbaren Beziehung zur Gastrula steht, sondern eine von dem eigentlichen Eie sich ảblösende zellige Eihülle darstellt,

1) Alexander Goette, Centralblatt für die medic. Wissensch. Berlin 1869. No. 55 . 
welche auch thatsïchlich in der Bildung des Chorion aufzugehen scheint". Die Abbildung, welche Bischoғf (l. c. Tab. II, Fig. 19-24) von der Blastula und Gastrula des Hunde-Eies giebt, scheint diese Auffassung lediglich zu bestätigen. Offenbar entsteht auch hier die eigenthümliche Amphigastrula durch Invagination ans der Amphiblastula; und lıöchst wahrscheinsch gilt dies für den Menschen ebenso wie für alle übrigen Placentalthiere. Ich fasse demwach die inaequale Eifurchung der Placentalien (die ich in der Anthropogenie als ,pseudototale" bezcichnet habe) als eine besondere Modification auf, welche durch Verflïssigung und Rückbildung des Nahrungsdotters phylogenetisch aus der discoidalen Furchung der Monotremen und überhaupt der älteren Vorfahren der Säugethiere (insbesondere der Protamnien) entstanden ist. Demgemäss ist auch die Amphigastrula der Placentalien aus der Discogastrula der Monotremen (resp. der Promammalien) phylogenetisch hervorgegangen.

Die grösste Rolle spielt im Stamme der Wirbelthiere die discoidale Furchung und die daraus hervorgehende Discogastrula (Taf. IV und V). Die grosse Mehrzahl aller jetzt lebenden Vertebraten scheint diesem Furchungsprocesse unterworfen zu sein, nämlich: alle echten Fische mit Ausnahme der Ganoiden (also sämmtliche Selachier und Teleostier), wahrscheinlich ein 'Theil der Amphibien (Salamandra?), und die umfangreichen Klassen der Reptilien und Vögel, vermuthlich auch die Monotremen und ein Theil der Didelphien (?). Bei weitem an häufigsten und genauesten ist der Furchungs-Process hier beim Hühnchen untersucht worden, und dieser Umstand war insofern sehr verhängnissvoll, als gerade dieses Object zu den schwierigsten gehört. Daher ist die grosse Mehrzahl aller Untersuchungen über die Keimblätter des bebrïteten Hühnchens fehl gegangen. Erst in neuester Zeit ist es den sorgfältigen Untersuchungen von Goeтte') und $R_{\text {AUber }}{ }^{2}$ ) gelungen, auch hier das wahre Sachverhältniss klar zu erkennen und auf die Gastrulabildung durch Einstülpung zurïckzufïlnren; sowie die wesentliche Uebereinstimmung nachzuweisen, die in der Gastrulabildung der Vögel und der Fische besteht. Uebrigens hat schon vor 22 Jahren der Strassburger Embryologe Lere-

1) Almaxder Goette, Die Bilchung der Keimblätter: und tes Blutes im Hiihner-Ei. Arch. für mikr. Anat. 1874. Bd. X, S. 145.

2) A. Rauber, Ueber die embryonale Anlage des IJühnchens. II. Lie Gastrula des Hühnerkeims. Berlin. Nedicin. Centralblatt 1874 No, 50. 1875 \o. $t, 17$. 
воulnet die Gastrulabildung bei den meroblastischen Fisch-Eiern richtig erkannt und hat die Discogastrula der Knochenfische (z. B. vom' Hecht) ganz klar beschrieben und abgebildet (Taf. III, Fig. 50) ${ }^{1}$ ).

Wenn man von diesen, nummehr endgültig gewonnenen festen Boden aus die zahlreichen und sehr divergirenden, oft siclı direct widersprechenden Angaben der Autoren ïber die Eifurchung der discoblastischen Wirbelthiere vergleicht, so gewinnt man die Ueberzeugung, dass auch hier wieder unter der Fülle mannichfaltiger Erscheinungen überall ein und derselbe discoidale Keimungs-Process, die Bildung der Discogastrula, verborgen ist. Theils die Schwierigkeit des Objectes, theils die mangelhaften UntersuchungsMethoden der Beobachter, theils und vor Allem aber der Mangel der leitenden phylogenetischen Gesichtspunkte, welche durch die Gastraea-Theorie gegeben sind, verschulden hier die Masse der Irrthïmer, mit denen die bezügliche umfangreiche Literatur angefüllt ist. Die Schwierigkeiten, alle die verschiedenen Vorgänge, dic hier bei den verschiedenen discoblastischen Wirbelthier-Eier'n vorkommen sollen, auf die fundamentale Entstehung der Discogastrula durch Invagination der Discoblastula (Taf. IV und V) zurïckzuführen, sind vom Standpunkte der Gastraea-Theorie aus nicht grösser, als die leicht lösbaren Schwierigkeiten, welche sich der Zurückführung aller verschiedenen Formen der ampliblastischen Keimung auf die ursprüngliche Urform der archiblastischen Keinung entgegenstellen. Dabei ist noch besonders zu berïcksichtigen, dass die vcrschiedenen Modificationen der Discogastrula-

1) Lerebouldet, Recherehes d'Embryologie comparée sur' le developpement dú Brochet, de la Perche et de l'Eerevisse. Mém. de l'Acad. des se. (siv. étráng.). Paris 1858. Tom. XVII. Brochet, P1. I, Fig. 17-27. Die Entstehung der Discollastula des Hechtes dureh Einstülpung ist hier ganz deutlich mit folgenden Worten beschrieben (p. 488): "Ver's la fin du premier jour le germe embryonnaire a pris la forme d'une vésicule plus on moins aplatie, reposant sur le vitellns (,Discoblastula"!). Pendant la prémiere moitié dn second jour la vesicule blastodermique s'aplatit de plus en plus; ses deux parois opposées se tonchent, et elle se moule comme une séreuse autour de la prortion de l'oeuf, qu'elle recouvre, comme le ferait un verre de montre. Cette nouvelle calotte est d'abord plus epaisse a son centre; mais, quand elle commence à s'étendre, en s'aplatissant de plus cn plus, c'est le contraire qui a lieu: sa partie centrale s'amivcit, tandis que son rebord circulare devient plus épais et forme un véritable bourrelet antour le l'venf. On pent encore, a celte époque, reconnaitre et séparè lés deux feuillets qui composent la calot te blastoder mi que (,Discogaslrulu" !). 
bildung bei den verschiedenen discoblastischen Wirbelthieren cine zusammenhängende Stufenleiter darstellen, welche sich unten unmittelbar an die Amphigastrula der amphiblastischen Vertebraten anschliesst, während sie oben (bei unverhältnissmässig grossem Nahrungsdotter) eine ganz davon verschiedene eigenthümliche Kei. mungsform zu bilden scheint. Während dort noch der Nahrungsdotter am Furchungsprocesse mehr oder minder Antheil nimmt, ist el hier zuletzt ganz davon ausgeschlossen.

Bei den Sclachiern entsteht offenbar die Discogastrula durch Invagination der Discoblastula (Taf. III, Fig. 49); wir können dies aus Balfour's wichtigen Mittheilungen über die Ontogenie der Haifische schliessen, obwohl dieser Autor eine eigentliche „Involution" hier nicht zugiebt'). Ebenso lassen sich die sehr mannichfaltigen und widersprechenden Angaben über die Keimung der Teleostier bei sorgfältiger kritischer Vergleichung sämmtlich auf die discoidale Furchung zurückführen, wie ich sie oben rom Gadoiden-Ei beschrieben habe (Taf. IV und V). Unter allen Autoren hat Goetre hier den Keimungs-Process am richtigsten (vom ForellenEi) beschrieben. „Nach beendigter Furchung bilden die Zellen des Keimes eine linsenförmige Scheibe, welche in einer entsprechenden Vertiefung des Dotters ruht („Discomorula“, vergl. auf Taf. IV meine: Fig. 59, 60, 73). Darauf verdünnt sich die Mitte des Keimes und löst sich vom Dotter, so dass zwischen beiden die Keimhöhle entsteht („Discoblastula“, Fig. 61, 62, 74). Damn schlägt sich der Rand des Keimes auf einer Seite nach unten um und breitet sich an der unteren Fläche des Keimes aus. Dasselbe geschieht später an der übrigen Peripherie. So besteht der Keim aus zwei Schichten, welche im verdickten Rande zusammenhängen („Discogastrula“, Fig. 63-66, 75, 76). Wo jener Umschlag begann, bildet sich die Embryonal-Anlage, indem die tiefere Schicht sich in zwei Blätter sondert, so dass dort im Ganzen drei Blätter über einander liegen"'2). Durch diese vollkommen naturgetreue Darstellung Goetre's, die mit meinen eigenen Beobachtungen uiber verschiedene 'Teleostier-Eier' völlig übereinstimmt, sind alle die übrigen abweichenden Angaben anderer Autoren über die Keimung der Knochenfische erledigt, so insbesondere diejenigen von $\mathrm{C}_{\mathrm{ARL}}$

1) BatFour, Development of the Elasmobrauch Fishes. Quart. Jomrn. of Nikr. Sc. 1874 . No. LVI.

2) Alexander Goette, Jer Keim des Forellen-Eies. Berlin. medicin. Centralbl. 1869, No. 26. Austührliche Darstelluug im Arch. f. mikr. Anat. 1873, Bd. IX, S. 683. Tat. XXVH. 
Vogt' ${ }^{1}$ ), Kupfaer ${ }^{2}$ ), van Bambecke $^{3}$ ), Rieneck ${ }^{4}$ ), Oeltacher ${ }^{5}$ ), StriскеR $^{6}$ ) u. S.w. Unter diesen Mittheilungen sind diejenigen Kupfren's von besonderem Interesse und stimmen auch in vielen Beziehungen mit unseren eigenen Beobachtungen überein; die Discogastrula von Gasterosteus ist daselbst abgebildet auf Taf. XVI, Fig, 1-3; von Gobius auf Taf. XVII, Fig. 16-20. Die discoidale Furchung und die Discogastrula-Bildung der Reptilien ist bisher noch nicht genauer untersucht; indessen kann es a priori nicht zweifellaft sein, dass dieselbe im Wesentlichen völlig mit der Keimung der nahverwandten Vögel übereinstimmen wird. Ueber diese haben uns, wie schon angeführ't, erst die neuesten Untersuchungen von GoztтE $^{7}$ ) 'und $\mathrm{R}_{\mathrm{Auber}}{ }^{8}$ ) (l. c.) einen völlig befriedigenden Aufschluss gegeben, indem sie auch hier, ganz wie bei den Teleostiern, die Entstehung der Discogastrula durch Invagination der. Discoblastula nachgewiesen haben (Fig. 54). Dadurch sind auch hier alle die zahlreichen entgegenstehenden Angaben anclerer Beobachter in einem, der Gastraea-Theorie vollkommen entsprechenden Sinne erledigt, so insbesondere diejenigen von $\operatorname{Remax}^{9}$ ),

1) Charles Vogt, Embryologie des Salmones. Neuclatel 1842.

2) Kupfater, Beobachtungen über die Entwickelung der linochenfische. Arch. f. mikr. Anat. Br. IV, 1868. S. 209, 'Taf. XVI-XVIII.

3) vas Bambecke, Embryogénie des poissons ete. Compt. rend. 'Tom. 74. No. 16.

4) Rieneck, Ueber die Schichtmug des Forellen-Keims. Arch. f. mikr. Auat. 1869. Br. V, S. 356. Taf. XXI.

5) Ofluacher, Beiträge zur Entwickelungsgeschichte der Knochenfische. Zeitschr. f. wiss. Kool. 1873. Bd. XXII, S. 371. Bd. XXIII, S. 1.

6) Salomon Strricker, Handbuch der Gewebelehre. 1872. S. 1211.

7) Goztrte, Die Bildung der Keimblätter in Hühner-Ei. 1874 (1. c. S. 16:2): „Ein Theil der ans der Dotter-Theilung hervorgehenden Zellen sondert sich zu einer primären Kíeimschicht ab (,Discomorula"6), welche bei ihrer Aushreitung sich verdünnt, dabei einen dickeren Rund erhält (,Discoblastulat") und darauf von diesem durch eine Art vou Unischlag uach unten und innen ("Invagination") die secumläre Keimschicht erzengt (,Discogastrula“).

8) Rudber, lie Gastrula des Hühnerkeims (1. c.) hetont zum ersten Male gehörig die Bildung der wahren Tis coblas tula ler Vögel, als ejner wirklicben , Keimblase", deren untere Hälfte der oberen sich nähert und anschmiegt (l. c.). Hus, der anfangs diese richtige Anffassung Tauber's aut das heftigste hekämptite, suchte später, nachdem er sich von ihrer Richtigkrit ubcrzeugt hatte, sie ersteren zn entziehen und als sein Eigenthum auszugeben! Vergl. die heilerseitigen Erklärungen im Berlin. medic. Centralblatt 1875.

9) REmak, Untersuchungen iber die Entwickehmg der Wirbchthiere. 1850 


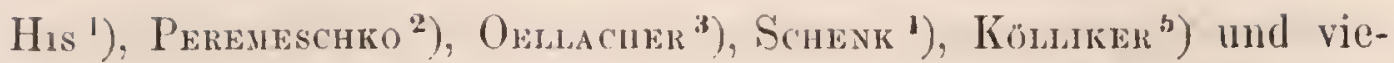
len anderen Autoren. Unter sich in vielfachen und unvereinbarem Widerspruche, koniten diese letzteren auch mit der GastraeaTheorie nicht zusammenstimmen.

Die gleiche discoidale Furchung und Discogastrula-Bildung wie dic Fische, Reptilien und Vögel werden voraussichtlich auch die Monotremen unter den Säugethieren besitzen und vielleicht auch ein Theil der Didelphien. Aus dieser Keimungsform wird diejenige der Placentalien durch Verflüssigung und Rückbildung des Nahrungslotter's hervorgegangen sein. Dass auch die inaequale Furchnn und die Amphigastrula-Bildung der Placentalien (mit Inbegriff des Menschen) remgenäss ursprünglich auf Invagination einer Blastula (orler Blastosphaera) zuriickzuführen ist, wurde bereits vorher (S. 133) gezeigt und soll hier schliesslicl? nochmals ausdriicklich hervorgehoben werden.

Während so bei den Vertebraten die discoidale Furchung und die Discogastrula die grösste Bedeutung besitzt, fehlt die superficiale Furchung und die Perigastrula in diesem Stamme ganz; ein sehr charakteristischer Gegensatz zu den Arthropoden, bei denen umgekehrt diese letzte Form der Eifurchung und Gastrulation die grösste Rolle spielt. In allen Fällen aber lassen sich diese cenogenetischen Formen der Gastrulation direct oder indirect (durch Vermittelung der inaequalen Furchung und Amphigastrula-Bildung) auf die ursprüngliche, palingenetische Form der primordialen Furchung und der Arehigastrula-Bildung zuriickführen.

\section{Die phylogenetische Bedentung der fünf ersten onto- genetischen Entwickelungsstufen.}

I. Das Moner und die Monerula.

Wenn die Descendenz-Theorie wahr ist, wemn die tausendfältigen Formen der Organismen nicht durch iibernatürliche Schöpfung, sondern durch natiurliche Entwickelung aus gemeinsamen

1) His, Lntersuchungen äbu dic erste Anlage des Wirbehthierleilues. 1868.

2) Perenescuko, Ueber die Hildung der Keimbläter in Hühner-Ei. Wien. Akalen. Sitzungsher. 1868.

3) Oeflaciner, Lntersuchungen äber die Furchung und Blätterbildung in Ilihner-Ei. Wien 1870.

4) Sconesk. Vergleichende limbryologie der II inbehtiuno. Wien 1874.

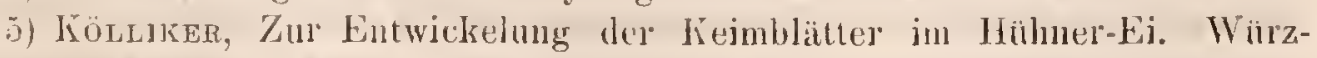
burger Verhandl. 1874. Neue Folge Bd. VIl. 
einfachen Stammformen entstanden sind, so existirt auch jener innige Causal-Nexus zwischen Ontogenie und Phylogenie, welcher in unserem biogenetischen Grundgesetze seinen präcisen Ausdruck findet. Jede Keimform ist dann ursächlich auf eine frühere Stammfor'm zu beziehen; und zwar ist die erstere eine mehr oder minder treue Wiederholung der letzteren, wenn die Keimesgeschichte vorwiegend palingenetisch ist; hingegen wird die Zurückführung der Keimform anf die entsprechende Stamnform mehr oder minder schwierig sein, wemn der ontogenetische Process vorwiegend cenogenetisch verläuft. In allen Fällen aber wird es möglich sein, bei richtiger kritischer Bemrtheilung der palingenetischen und cenogenetischen Verhältnisse, die verschiedenen Keimformen der verwandten Organismen auf ursprïngliche gemeinsame Stammformen zurückzuführen.

Von diesem phylogenetischen Gesichtspunkte aus betrachtet gewinnt die Untersuchung der ontogenetischen Thatsachen, welche uns die Eifurchung und die Gastrulation der Thiere darbietet, ein ausserordentliches Interesse. Denn sie führt uns zur Erkenntniss der ältesten und ursprünglichsten Entwickelungs-Verhältnisse des Thierreichs in jener alter'sgrauen laurentischen Urzeit hinab, über deren primordiale Fama uns keine Versteinerungen Aufschluss geben können. Sie gewährt uns die Möglichkeit, den zusammenliängenden und - ununterbrochenen Entwickelungsgang aller Thierformen bis zum ältesten, durch Urzeugung entstandenen Moner hinab zu verfolgen. Sie eröffnet uns zugleich die Möglichkeit, die Formverwandtschaft der Thiere nicht bloss innerhalb der „Typen“ oder "Phylen" anuähernd festzustellen, sondern auch darïber hinaus den gemeinsamen ursprünglichen Zusammenhang der verschiedenen Typen an ihrer Wurzel zu erkennen und so durch die Gastrula ein natürliches monophyletisches System des Thierreichs vor'zubereiten. Gerade darin liegt ja, wie ich schon früher (im 5 . und 6. Abschnitte) gezeigt habe, die hohe allgemeine Bedeutung der Gastraea-Theorie.

Die Reihe von zusammenhängenden monistischen Vorstellungen, welche hierbei für meine monophyletische Auffassung des Thierreichs maassgebend sind, habe ich bereits in fritheren Schriften so ausführlich erläutert, dass es unnöthig ist, dieselben hier nochmals zu wiederholen. Ich verweise in dieser Beziehung namentlich auf den zweiten Band der "Generellen Morphologie“ (1866) und auf den crsten Band der ,Monographie der Kalkschwämme* (1872). Dagegen scheint es mir angenessen, hier noch eimmal kurz auf 
eine zusammenhängende Uebersicht der fünf ersten ontogenetischen Entwickelungsstufen der Metazoen und auf deren phylogenetische Bedeutung zurückzukommen. Kwal habe ich auch diese bereits im vierten und siebenten Capitel der ,Killkschwämme" (S. 342-347 und S. 464-473) eingehend besprochen. Aber es fehlten mir damals bei Begriudung der Gastraea-'Theorie nach mancherlei wichtige Thatsachen, die erst durch die Forschungen der letzten Jahre an das Licht gefördert worden sind; und es blieben damals verschiedene Lücken und dunkle Stellen übrig, die ich erst jetzt be. friedigend auszufüllen und aufzuhellen im Stande bin. Doch werde ich mich bei dieser Ausführung kurz fassen, um so mehr, als bereits meine 1874 erschienene "Anthropogenie" das Wichtigste enthält (vergl. namentlich den VI. und XVI. Vortrag). Die VI. synoptische Tabelle (S. 66), auf welcher , ,lie fünf ersten Keimungsstufen der Metazoen mit ihren fünf ältesten Ahnenstufen verglichen" sind, ist eine verbesserte Wiederholung der entsprechenden Tabelle, welche ich schon seit Jahren in der "Natürlichen Schöpfungsgeschichte" (S. 444) gegeben habe und welche auch in der" "Anthropogenie" (S. 396) verwerthet worden ist. Um die fünf primordialen Entwickelungsstufen des Thier-Körpers, welche hier in natürlicher Reihe auf cimander folgen, als gemeinsames Erbgut sämmtlicher Metazoen, vou den Spongien und Korallen bis zu den Affen und Menschen hinauf anzuerkennen, ist es nothwendig, zunächst nur die ursprüngliche palingenetische Form derselben in's Auge zu fassen, wie sie uns die archiblastischen Thiere darbieten (Erste Spalte, i, in der VII. Tabelle, S. 67). Das Verständniss der entsprechenden Stufen bei den amphiblastischen, discoblastischen und periblastischen Thieren (zweite, dritte und vierte Spalte in der VII, Tabelle, b, c, d) ergiebt sich erst, wenn man diese sämmtlich als cenogenetische betrachtet und sie als secundäre Modificationen auf die erstere, palingenetische Form zurückführt.

Dic erste Stufe der Metazoen-Keimung, die Monerula, ist vor Allem desshalb von hohem Interesse, weil sie nach dem biogenetischen Grundgesetze als die ontogenetische Wiederholung der primordialen Urform aller Organismen, des Mo neres zu deuten ist (Vergl. Kalkschwämme, Bd. I, S. 330, 342; Anthropogenie. S. 143, 384). Jede natürliche Entwickelungs-Theorie, welche kein Wunder, keinen ïbernatürlichen Eingriff zweckthätiger Schöpferkräfte in den natürlichen und nothwendigen Entwickelungsgang der Körperwelt zulässt, ist gezwungen, die crste Entstehung lebender Organismen auf unserem Erdball durch dic unentbehrliche Hypo- 
these der Urzeugung zu erklären. Vernunftgemäss ist aber nur diejenige specielle For'm dieser Hypothese zulässig, welche ich als "Antogonie der Moneren" im VI. Capitel der "Generellen Morphologie" (S. 167-190) und in den ,Studien über Moneren“" (1870) eingehend erörtert habe. In letzterer Arbeit ist insbesondere der Abschnitt iiber "Bathybius und das freie Protoplasma der Meerestiefen" (S. 86-106), sowie über "Die Moneren und die Urzeugung" (S. 177-182) zu vergleichen.

Wenn nun demgemäss die Moneren, als die denkbar einfachsten unter allen Organismen, diejenigen Urformen des Lebens sind, auf die wir den ältesten Ursprung aller übrigen Organisnıen phylogenetisch zuriickzuführen gezwungen sind, so ist es offenbar eine ontogenetische Thatsache vom allerhöchsten Interesse, dass auch die meisten, wenn nicht alle, höheren Organismen ihre individuelle Existenz in einer Form beginnen, welche denselben morphologischen Werth besitzt, wie das Moner, in der Form der Cytode. Die allermeisten unter den neweren und genaueren Untersuchungen über die Ontogenie der Metazoen stimmen darin überein, dass die thierische Eizelle entweder vor oder nach der Befruchtung ihren Kern (das „Keimbläschen") verliert und somit von der höheren Plastiden-Form der kernhaltigen Zelle auf die niedere PlastidenForm der kernlosen Cytode zurücksinkt. Wemn diese höchst merkwürdige und. bedentungsvolle Thatsache richtig ist, so kann sie nach dem biogenetischen Grundgesetze nur als „Rückschlig der einzelligen Urform in die primordiale Stammform des Moneres" gedentet werden, wie ich bereits bei verschiededenen Gelegenheiten, insbesondere in der Ontogenie der Kalkschwämme (Bd. I, S. 330) hervorgehoben habe.

Allerdings ist ausdrücklich zu bemerken, dass jene merkwuildige Thatsache, auf die wir diesen Schluss griunden, keineswegs unbestritten dasteht. Bekanntlich haben verschiedene Beobachter -- und darunter Zoologen ersten Ranges: Baler, Johannes Mülleki, Gegenbaur, Lexdig - behauptet, dass das Keimbläschen nicht verschwinde, sondern persistire und der directe Stammvater aller „Furchungszellen" sei, die durch wiederholte Theilung ans demselben hervorgehen. Ich selbst labe mich in meiner "Entwickelungsgeschichte der Siphonophoren" (Utrecht, 1869) auf Grumd eigener Beobachtungen dieser Ansicht angeschlossen, ,welche für die theoretisch wichtige Frage von der Continuität der Zellengenerationen von hoher Bedeutnng ist" (1. c. p. 18). Diesen ,positiven" Beobachtungen gegenüber" stellt nun allerdings die grosse 
Mohrzahl der neneren Beobachter dis: "negative" Behauptung auf,

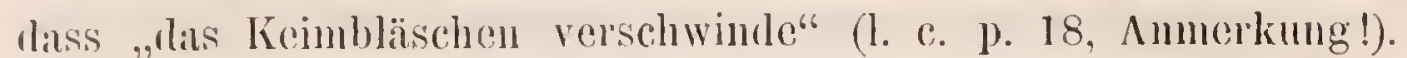
An seine Stelle soll ein nencr Nucleus, der ,Cytula-Kern" oder (ler „Korn der crsten Furchungskugel" treten. Dieser soll aus dem Plasson der Eicytode durch Differenzirung in Protoplasma und Nucleus entstehen und durch fortgesetzte Theilung die Kerne sïmmtlicher „Furchuingszellen" el'zeugen.

Die Bcohachter, die diese Ansicht vertreten, zerfallen aber wieder in zwei verschiedene Gruppen, indem die einen das heimblïschen vor erfolgter Befruchtung der Eizelle, die anderen nach derselben verschwinden lassen - eine Differenz, die principiell von hoher Bedeutung ist. Denu im letzteren Falle wïrde der „Riickschlag der Zcllenform in die primordiale Cytodenform" (oder die „Monerula") als die numittelbare Folge des Befruchtungs-Actes erscheinen und demnach von viel höherer phylogenetischer Bedeutung sein, als im ersteren Falle. Dabei kömmt die schwierigc lirage von der Natur der Befruchtung und der geschlechtlichen Zeugung ïberhaupt in's Spiel. Nach unserer morphologischen Auffassung ist diese wesentlich als "Verwachsung oder Concrescenz zweier verschiedener Zellen zu betrachten, der weiblichen Eizelle und der männlichen Spermazelle" (Anthropogenie, S. 135-138). Dass der letzteren dabei eine ebenso wichtige physiologische Rolle wie der ersteren zukömmt, ergiebt sich einfach aus der Thatsache ller amphigonen Vererbung (Generelle Morphologie, Bd. II, S. 183). Denn diese höchst wichtige, obwohl von den bisherigen Fortpflanzungs-Theorien nicht entfernt gewürdigte Thatsache lehrt uns, dass jeder geschlechtlich erzeugte Organismus eine Summe individueller Eigenschaften von beiden Eltern erbt. Der.Beginn der individuellen Existenz ist daher für jeden durch Amphigonie entstandencn Organismus in den Augenblick der Befruchtung zu setzen, in das Moment, in welchem die Verschmelzung oder Concrescenz der beiderlei Scxualzellen thatsächlich stattfindet.

Ist nun die nächste Folge dieser Concrescenz wirklich das "Ver'schwinden des Keimbläschens", so repräsentirt der Organismus im Beginne seiner individuellen Existenz eine Cytode, welche als das gemeinsame Product der weiblichen Eizelle und der mänmlichen Spermazelle die erblichen Eigenschaften von Beiden in sich vereinigt. Die Zelle aber, welche ans dieser "Monerula" durch Neubildung eines ,ersten Kernes" entsteht, ist natürlich ein ganz anderes Wesen, als die ursprïngliche Eizelle; und der neugebildete 
Kern dieser "Cytula" oder „ersten Furehungskugel" ist etwas ganz Anderes, als das ursprüngliche Keimbläschen.

Bei den zahlreichen und unvereimbaren Widersprïchen, welche angenblicklich in der umfangreichen ontogenetischen Literatur betreffs der wichtigsten Verhältnisse der Befruchtung sich gegenüberstehen, erscheint es unfruchtbar, hier noch weitere Reflexionen über deren Bedeutung anzustellen. Diese grosse offene Frage kann nur durch erneute Anstellung zahlreicher Beobachtungen iiber die Befruchtung verschiedener Organismen aus allen Klassen erledigt werden. Einen neuen Anstoss dazu haben die sehr wichtigen Untersuchungen von Auerbach ${ }^{1}$ ), Bütschli ${ }^{2}$ ), Strasburger ${ }^{3}$ ) und Oscar Hertwig gegeben. Der letztere hat während unseres gemeinsamen Aufenthaltes auf Corsica im Frühling dieses Jahres eine lange Reihe von höchst sorgfältigen Beobachtungen iiber die Befruchtung von Toxopneustes lividus angestellt, welche ein neues Licht auf diese wichtige Frage zu werfen scheinen. Da dieselben aber noch nicht publicirt sind, enthalte ich mir hier jeder weiteren Bemerkung darüber. Wenn ich hier als nächste Folge des Befruchtungs-Actes die Entstehung der „Monerula“ annehme und diese nach dem biogenetischen Grundgesetze als eine, durch Vererbung bedingte palingenetische Wiederholung der gemeinsamen autogonen Stammform des Moneres betrachte, so geschieht dies, weil die grosse Mehrzahl der neveren Beobachter darin übereinstimmt, dass ,das Keimbläschen nach erfolgter Befruchtung der Eizelle verschwindet" und somit die Zelle in die Cytode zurickschlägt. Sollte, was wohl möglich ist, dieser Rückschlag nur bei einem Theile der Thiere vorkommen, bei einem anderen Theile derselben dagegen fehlen, so würde wohl der erstere Fall als palingenetischer, der letztere als cenogenetischer Process zu deuten sein.

\section{Die Amoebe und die Cytula.}

Je zweifelhafter und dunkler augenblicklich die MonerulaFrage steht, desto sicherer können wir für den monophyletischen Stammbaum der Metazoen die Cytula verwerthen, mit welchen

1) Auerbach, Organologische Studiell. I. und II. Heft. Zur Charakteristik und Lebensgeschichte der Zellkerne. Breslau 1874.

2) BütschuI, Vorläufige Mittheilung über das befiuclitete Ei von Nematoden und Schnecken, sowie über die Conjugation der Infusorien und die Zelltheilung. Zeitschr. f. wissensch. Zool. 1875, Vol. XXV, S. 201 u. 426.

3) Strasburger, Ueber Zellbildung und Zelltheilung. Jena 1875. 
Ausdrucke wir cin für alle Mal kurz die sogenannte "erste Furchungskinger" oler lichtiger , die erste Furchungs\%elle" bozeichnen. Jie grosse Mehrzahl aller besseren Beobachter stimmt gegenwärtig in der Annahme iiberein, dass cine solche ,erste Furchungskugel" existirt, gleichviel ob diese Cytula als eine nene, aus der Nonerula durch Nenbildung eines Kernes entstandene Stammzelle, oder als dic modificirte und durch die Befruchtung verïnderte Eizelle mit persistentem Keimbläschen zu betrachten ist. Alle Zellen, welche die Keimblätter und den daraus entstehenden Organismus der Metazoen aufbauen, sind Descendenten jener Stammzelle und durch wiedcrholte Spaltung, entweder Theilung oder Knospung aus der Cytula entstanden. Wenn die Begriffe der "Theilung und Knnospung" so gefasst werden, wie es in der Generellen Morphologie geschehen ist (Bd. II, S. 37-49), so müssen wir die beiden Formen der primordialen und superficialen Furchung als wahre Theilung der Eizelle, hingegen die beiden Formen der inaequalen und discoidalen Furchung als Knospung derselben auffassen (Anthropogenie, S. 153, 166).

Zweifellos durchläuft also jeder viełzellige Organismus im Beginne seiner individuellen Entwickelung eine einzellige Formstufe, und ebenso zweifellos ist die entsprechende phylogenetische Annahme berechtigt, dass auch alle vielzelligen Organismen von einzelligen ursprünglich abstammen müssen. Jede einzellige Keimform ist die palingenetische Wiederholung eincr entsplechenden einzelligen Stammform. Dieser wichtige Satz ist für jeden consequenten Anhänger der Descendenz-Theorie so selbstverständlich klar und nothwendig, dass wir hier wohl auf eine weitere Begrïndung desselben verzichten könnell. Dagegen haben wir kurz die weitere Frage zu erörtern, ob wir aus der Existenz der Cytula bei sämmtlichen Metazoen nach dem biogenetischen Grundgesetze auf eine einzige gemeinsame einzellige Stammform derselben schliessen dürfen und ob wir die Beschaffenheit dieser letzteren annähernd zu bestimmen im Stande sind.

Einen gemeinsamen Ursprung sämmtlicher Metazoen aus einer einzigen einzelligen Stammform sind wir desshalb anzunehmen berechtigt, weil unter allen hier möglichen Hypothesen diese Annahme die einfachste ist. In dem grossen Hypothesen-Gebäude der Phylogenie muss uns ganz ebenso wie in dem ähnlichen Hypothesen-Gebäude der Geologie der Grundsatz leiten, dass die einfachste Hypothese die beste ist. So lange keine bestimmten Thatsachen vorliegen, welche eine ver- 
wickeltere oder zusammengesetztere Hypothese wahrscheinlicher machen, ist die einfachste stets vorzuziehen. Und wie oft schon hat uns die Natur, die stets den einfachsten Gang geht, gelehrt, dass unter vielen aufgestellten Hypothesen die einfachste der Wahrheit am nächsten kam. Ich erinnere nur wiederholt an die allgemein anerkannte Wissenschaft der Geologie, die bei ihrem grossartigen und verwickelten Hypothesenbau ganz ebenso zu Werke geht, ganz nach denselben logischen Methoden der Induction und Deduction verfährt, wie ihre jüngere Schwester, die noch so vielfach verkannte und angefeindete Phylogenie. Es kann nicht genug betont werden, dass diese beiden Schwestern ganz denselben Weg gehen und ganz' denselben philosophischen und naturwissenschaftlichen Werth haben. Nur ist die Aufgabe der jüngeren Phylogenie ungleich schwieriger und verwickelter, als diejenige der älteren Geologie. „Sie ist in demselben Maasse schwieriger und verwickelter, in welchem sich die Organisation des Menschen iiber die Structur der Gebirgsmassen erhebt." (Anthropogenie, S. 297).

Um nun demgemäss die gemeinsame Abstanmung sämmtlicher Metazoen von einer einzigen einzelligen Stammform mit Sicherheit zu behaupten, wäre nur noch nachzuweisen, dass die beträchtliche und mannichfache Verschiedenheit der Cytula bei den verschiedenen Metazoen kein Argument gegen jene monoplyyletische Hypothese bildet. Dieser Nachweis ist aber unseres Erachtens bereits dadurch geliefert, dass wir unter den vier verschiedenen, in der VII. Tabelle (S. 67) aufgeführten Hauptformen der Cytula nur diejenige der archiblastischen Eier, die Archicytula, als die ursprüngliche, palingenetische, einzellige Keimform nachgewiesen haben. Die drei übrigen Cytula-Formen sind aus dieser primordialen Urform erst cenogenetisch entstanden, durch den Erwerb des Nahrungsdotters. Bei der Amphicytula und bei der Discocytula hat sich der Nahrungsdotter an einem Pole (dem vegetativen Pole), bei der Pericytula hingegen im Centrum der Keimzelle angesammelt und von dem Protoplasma derselben gesondert. Diese Sonderung ist bei der Amphicytula noch unvollständig geblieben, hingegen bei der Discocytula und Pericytula vollständig geworden, so dass bei diesen beiden letzteren (meroblastischen) Keimzellen der Nahrungsdotter theilweise oder ganz vom Furchungsprocess ausgeschlossen wird.

Da die cenogenetische Scheidung des Nahrungsdotters vom Bildungsdotter bei den meroblastischen Eiern durch eine immer 
stärker sich geltend machende Heterochronie immer weiter in die friiheste \%eit der Eibildung zurïckverlegt wird, so ist dieselbe gewöhnlich schon innerhalb des Eierstockes an den jungen Eiern desselben frühzeitig wahrzunehmen. Un das richtige Verständniss dieses schwierigen Terhältnisses zu erlangen, (welches den meisten (lanit beschäftigten Autoren wegen des Mangels phylogenetischer (iesichtspunkte ganz abgeht), ist es durehaus erforderlich, das primiire Ur-Ei (Protorum) ron dem secundären Nach-Ei (Metomum) scharf zu unterscheiden (Anthropogenie, S. 152). Nur das amoeboide Ur-Ei, welches noch keinen Nahrungsdotter besitzt, die ganz junge und indifferente Eizelle, erscheint bei sämmtlichen Metazoen im Wesentlichen gleich. Diese Gleichheit wird später durch das ansehnliche Deutoplasma verdeckt, welches zum Protoplasma der Eizelle hinzutritt. Aber auch dann noch ist die Homologie sämmtlicher Nach-Eier festzuhalten, weil sie ursprïnglich überall im Entoderm entstehen, und weil offenbar die amphiblastischen sowohl als die discoblastischen und periblastischen Eier erst secundär aus den archiblastischen Eiern durch den cenogenetischen Erwerb des Nahrungsdotter's entstanden sind. Wollte man gegen diese Homologie der Eier bei sämmtlichen Metazoen geltend machen, dass dieselben nicht ïberall aus demselben Keimblatte ihren ersten Ursprung nehmen, so ist zu erwidern, dass dieser verschiedene Ursprung (- weun überhaupt richtig -) sich durch Heterotopie, durch frühzeitige Wanderung der Eizellen aus einem Keimblatt in das andere erklären lässt, wie ich sie z. B. bei den Kalkschwämmen thatsächlich beobachtet habe (Bd. I, S. 157-160).

Wie die palingenetische Archicytula als die gemeinsame $\mathrm{Ul}^{1-}$ for'm aller einzelligen Keimstufen, so ist auch in gleicher Weise die Archimonerula als die palingenetische Urform aller CytodenKeimstufen zu betrachten, aus welcher sowohl die Amphimonerula als dic Discomonerula und die Perimonerula durch die cenogenetische Bildung des Nahrungsdotter's erst secundär hervorgegangen sind. Durch die Neubildung eines Zellen-Kernes verwandeln sich diese vier Hautformen der Monerula in die entsprechenden vier Hauptformen der Cytula.

Wie wir im Stande sind, demgemäss sämmtliche Cytula-Formen aller Metazoen auf die palingenetische Urform der Archic ytu la zurïckzuführen, so können wir auch durch die einfachste Hypothese die Frage beantworten, von welcher Beschaffenheit die gemeinsame einzellige Stammform der Metazoen gewesen sein mag, welche durch die einzellige Keimform der Archicytula 
noch heute wiederholt wird. Offenbar wird jene einzellige Stammform ursprünglich einen möglichst einfachen und indifferenten Charakter besessen haben, da alle differenzirten Formen von einzelligen Organismen wieder aus einer ganz indifferenten Stammform abgeleitet werden müssen. Nun sind aber unzweifelhaft die einfachsten und indifferentesten unter allen selbständigen einzelligen Organismen, welche wir kennen, die Amoeben. Die nackten „amoeboiden Zellen", welche weder irgend eine Hülle, noch differenzirte "Plasma-Producte" in ihren ganz einfachen Zellenleibe besitzen, sind die indifferentesten und primitivsten von allen Zellen-Arten. Demgemäss dürfen wir denn auch phylogenetisch die A moebe als die gemeinsame, der ontogenetischen Cytula entsprechende, einzellige Stammform sämmtlicher Metazoen betrachten, wie ich bereits in der Anthropogenie ausfïhrlich gezeigt habe (S. $93-114$ ind 383,396 ).

\section{Das Synamoebium und die Morula.}

Die dritte Formstufe in der Keimesgeschichte der Metazoen bildet die Morula oder die Maulbeerform des Keims, das nächste Resultat der Eifurchung. Mit der Ausbildung dieser Keimform beginnt der Metazoen-Organismus sich zu einem Individuum zweiter Ordnung, einem vielzelligen „Idorgan" zu erheben, während die beiden ersten Formstufen, Cytode und Zelle, als isolirte „Individuen erster Ordnung“ unter den Begriff der „Plastide oder des Elementar-Organismus" fielen. Welcher wichtige Fortschritt für die Individualitätslehre, für die tectologische Auffassung des thierischen Organismus damit gegeben ist, habe ich in der Tectologie der Kalkschwämme erläutert (Bd. I, S. 89-124). Zugleich habe ich daselbst die im dritten Buche der Generellen Morphologie (Bd. I, S. 239-374) aufgestellten Kategorien des organischen Individuums einer näheren Bestimmung und einfacheren Begrenzung unterzogen, so dass alle verschiedenen Erscheinungsformen der thierischen Individualität sich folgenden vier Hauptstufen unterordnen lassen: I. Plastide. II. Idorgan. III. Person und IV. Stock.

Die morphologische Bedeutung, welche demnach die Morula, als das nächste Product der Eifurchung, für das Metazoen-Individuum besitzt, muss gleicherweise auch die entsprechende phylogenetische Stammform beanspruchen, die wir als Synamoebium bezeichnet haben. Auch die Annahme dieser Stammform bedarf kaum einer näheren Begründung, da sie bei einigem Nachdenken 
sich als nothwendige Entwickelungsstufe von selbst ergiebt. Denn die ersten vielzelligen Organismen, welche in frïher laurentischer Urzeit auf unserem Erdballe auftraten, werden einfache Colonien von gleichartigen indifferenten Zellen gewesen sein und eine solche einfachste Gemeinde von amoeboiden Zellen ist auch unser hypothetisches Synamoebium. Wenn anfänglich nur autogone Moneren entstanden und später sich aus diesen die ersten Zellen, eimzeln lebende Amoeben entwickelten, wird der nächste weitere Fortschritt des organischen Lebens darin bestanden haben, dass dic Nachkommenschaft dieser Einsiedler-Zellen sich zu kleinen Gemeinden versammelte und die erste "Zellen-Colonie", den ersten vielzelligen Organismus bildete. Anfangs werden alle Mitglieder dieser ältesten Zellengemeinden noch von gleicher Beschaffenheit gewesen sein, wie uns ja anch noch hente die Labyrinthuleen, viele Diatomeen, die socialen Myxodictyen und Microgromien, viele Desmidiaceen u. s. w. gleiche einfache Zellengeschaften vor Augen führen, deren Mitglieder noch keine Differenzen zeigen. Das Synamoebium, als eine ganz indifferente Gemeinde von gesellig lebenden, ganz gleichartigen Amoeben, dürfte demnach in der Stammesgschichte der Metazoen, als die erste Stufe der vielzelligen Ahnenreihe, wohl keinem Bedenken unterworfen sein.

Die getreue ontogenetische Wiederholung dieser dritten phylogenetischen Formstufe führt uns noch heute die Archimorula der archiblastischen Thiere vor Augen: ebenfalls ein einfacher Haufen von ganz gleichartigen und indifferenten Zellen (Fig. 115). Während diese palingenetische Keimform vollständig dem hypothetischen Synamoebium entspricht, weichen dagegen die drei anderen Hauptformen der Morula, die Amphimorula, Discomorula und Perimorula mehr oder minder von jenem palingenetischen Urbilde des „Maulbecrkeimes" ab. Auch diese Abweichung erklärt sich ganz leicht als eine cenogenetische Wirkung des Nahrungsdotters, der von Anfang an einen mehr oder minder modificirenden Einfluss auf den Furchungs-Process ausübt. Die Differenzen, welche hier sclıon bei der inaequalen Furchung sich zwischen kleineren, animalen und grösseren vegetativen Zellen geltend machen, und welche bei der discoidalen und superficialen Furchung in einer sehr abweichenden Morula-Bildung zu Tage treten, sind selbstverständlich nicht als palingenetische Wiederholungen entsprechender selbstständiger Stammformen, sondern als cenogenetische Modificationen der A rchimorula aufzufassen, durch die Ausbildung des Nahrungsdotters bedingt. 
Diese Auffassung ist um so mehr zu betonen, als die mannichfaltigen Morula-Formen der verschiedenen Metazoen allerdings bei blosser ontogenetischer Vergleichung sehr beträchtliche Verschiedenheiten darzubieten scheinen. Diese Differenzen betreffen namentlich die Grundform. Nur die palingenetische Archimorula (Fig. 115) hat die homaxonie Grundform der Kugel meistentheils conservirt, da die Lagerungs-Verhältnisse der völlig gleichen MorulaZellen hier noch ganz gleichartig sind. Auch die Perimorula hat in vielen Fällen die ursprüngliche Kugelgestalt noch beibehalten, während in vielen anderen Fällen bereits eine Axe ausgebildet und demnach die homaxonie Promorphe in die monaxonie (meist ellipsoide) Grundform übergegangen ist (Fig. 83-86). Die Amphimorula ist ganz allgemein deutlich monaxon, weil der polare Gegensatz zwischen Bildungs- und Nahrungsdotter immer schon während des Furchungs-Processes in der Lagerung der beiderlei Zellen an beiden Polen der Urdarm-Axe sich geltend macht (Fig. 93-97; 104-108). Ebenso ist auch die Discomorula in allen Fällen von Anfang an ausgesprochen einaxig (meist linsenförmig), wie das bei der unipolaren Lagerung des Bildungsdotters nicht anders sein kann (Fig. 55-60 und 73).

Alle diese und die sonst noch vorkommenden Differenzen in der Morulabildung sind selbstverständlich cenogenetischer Natur, und offenbar wieder durch den Nahrungsdotter direct oder indirect bewirkt. Dieser allein bedingt auch bei den periblastischen Eiern das eigenthümliche Verhältniss, dass das dritte und vierte Stadium der Keimung, Perimorula und Periblastula, in Eines zusammenfallen; die Furchungshöhle ist hier von Anfang an mit Nahrungsdotter erfüllt (Fig. 81-86). Wenn die Furchungshöhle sich sehr frïhzeitig während der Furchung ausbildet, so ist eine scharfe Grenze zwischen drittem und viertem Stadium überhaupt nicht zu ziehen. So geht namentlich die Discomorula (durch Heterochronie) oft ganz unmerklich in die Discoblastula über (Fig. 45, 46, 51, 52). Alle diese cenogenetischen Modificationen lassen sich auf die palingenetische Archimorula zurückführen und sind durch diese auf das Synamoebium phylogenetisch zu beziehen.

\section{Die Planaea und die Blastula.}

Mehr Angriffen und verschiedenen Ansichten als die vorhergehende dritte und als die nachfolgende fünfte Entwickelungsstufe der Metazoen, dürfte die vierte Keimungsstufe derselben begegnen, 
die Blastosphaera oder Blastula, deren entsprechende Stammform wir Planaea genannt haben. Auch hier wieder kömmt Alles darauf an, sich nicht durch die mannichfach verschiedenen, secundären, cenogenetischen Formen beirren zu lassen, sondern die ursprüngliche, primäre, palingenetische Form aufzusuchen, und die ersteren auf die letztere zurückzuführen.

Als diese palingenetische Urform der Blastula ist ohne Zweifel die Archiblastula der archiblastischen Eier aufzufassen, wie sie uns bei den niedersten und ursprünglichsten Formen der verschiedensten Klassen vorliegt, z. B. bei Gastrophysenı (Fig. 116, 117), Actinia (Fig. 20), Limnaeus (Fig. 29), Amphioxus (Fig. 41). Ueberall, wo die primordiale Eifurchung in ihrer ursprünglichen palingenetischen Form rein abläuft und zur Bildung der Archigastrula führt, da sehen wir auch zunächst aus der Archimorula die Archiblastula hervorgehen, aus der dann weiterhin die Archigastrula durch Invagination entsteht (Fig. 118). Ueberall scheint ursprünglich diese Archiblastula dadurch zu Stande zu kommen, dass die zusammenhängenden, meist dicht an einander liegenden, gleichartigen Zellen der Archimorula Flüssigkeit nach innen ausscheiden, durch welche sic auseinander und an die Peripherie des kugeligen Morula-Körpers gedrängt werden. Hier bilden sie dann schliesslich eine einzige, zusammenhängende, einfache Zellenschicht, die Keimhaut oder das Blastoderma. Der mit Flïssigkeit oder Gallerte gefüllte Hohlraum der so gebildeten Hohlkugel ist ,die Bafr'sche Höhle, Keimhöhle, Furchungshöhle, Segmentationshöhle oder das Blastocoeloma" (s).

Eine störende Ausnahme scheinen hier nur diejenigen archiblastischen Eier zu machen, bei welchen die Archigastrula nicht durch Invagination, sondern durch Delamination entstehen soll; so namentlich die Ejer mancher Zoophyten, sowohl Spongien, als Hydroiden. Hier soll sich theils eine einfache, echte Archiblastula bilden, die nicht durch Einstülpung, sondern durch Flächenspaltung des Blastoderms und secundären Durchbruch der Mundöffnung an einem Pole der "Keimhöhle“ entsteht, so dass letztere unmittelbar zur „Urdarmhöhle" würde. Theils sollen sich die Zellen der Archimorula schon während der Ausbilchng einer centralen Höhle von Anfang an in $z$ wei verschiedene Zellenschichten ordnen, die zu den beiden primären Keimblättern sich gestalten, so dass also jene centrale Höhle von Anfang an nicht das Blastocoelom, sondern die Protogaster ist. In diesem letzteren Falle liegt offenbar eine cenogenetische Abkïrzung der Ontogenie vor; bei 
welcher das Blastula-Stadium einfach übersprungen wird und so die Archimorula direct in die Archigastrula iibergeht. Aber auch in ersteren Falle dürfen wir wohl eine cenogenetische Modification der ursprünglichen palingenetischen Bildung vermuthen - voransgesetzt, dass überhaupt die bezüglichęn, schwierig anzustellenden Beobachtungen richtig sind. Da ich diese Verhältnisse schon früher wiederholt erläutert habe, ist es nicht nöthig, hier von Neuem darauf einzugehen, und soll nur nochmals ausdrücklich hervorgehoben werden, dass bei einer vergleichenden Uebersicht aller archiblastischen Keimungsverhältnisse sich die Archiblastula mit befriedigender Sicherheit als das ursprüngliche palingenetische Mittelglied zwischen der Archimorula und der Archigastrula herausstellt.

Eine andere Schwierigkeit für die Auffassung der Blastula als gemeinsamer ursprïnglicher Entwickelungsform aller Metazoen ergiebt sich aus den sehr abweichenden Formen, welche dieselbe in Folge verschiedener, oft sehr weit gehender, cenogenetischer Abänderungen angenommen hat. Diese Schwierigkeit wird aber durch die vergleichende Zusammenstellung aller der verschiedenen Stıfen cenogenetischer Modification gelöst, weỉche uns in ununterbrochener Kette von der ursprünglichen palingenetischen Archiblastula bis zu den auffallendsten, am weitesten entfernten Modificationen der Blastosphaera-Form hinführen. Da sind wieder besonders instructiv die mannichfaltigen Abstufungen der inaequalen Furchung; welche sich einerseits unten an die primordiale, oben an die discoidale und superficiale Furchung anschliessen. Bei vielen amphiblastischen Eiern ist die Amphiblastula nur dadurch von der palingenetischen Archiblastula verschieden, dass die Zellen des Blastodel'ms nicht alle von ganz gleicher Beschaffenheit sind. Am einen (animalen) Pole der Amphiblastula finden wir kleinere, neist hellere, am anderen (vegetativen) Pole grössere, meist dunklere Zellen. Der Unterschied in der Grösse und molecularen Zusammensetzung der beiderlei Zellen ist in vielen Fällen nu' sehr unbedentend, kaum bemerkbar; in anderen Fällen tritt er schon auffallender hervor; und endlich begegnen wir bei der Mehrzahl der amphiblastischen Eier einer so starken Differenzirung der animalen und vegetativen Zellen, dasis erstere sofort als Bildungszellen, letztere als Nahrungszellen erkenubar sind und sich scharf von einander seheiden (so z. B. bei Unio Fig. 26, 27; bei Petromyzon Fig. 45, 46; bei Bombinator Fig. 51, 52; bei Fabricia Fig. 98; bei Trochus Fig. 109 u. s. w.). Hier ist oft 
schon der Hohlraum des Blastocoeloms sehr reducirt durch die sich hineindrängenden mächtigen „Dotterzellen" des Nahrungsdotter's; und statt des einschichtigen Blastoderms finden wir oft von Anfang an ein mehrschichtiges. Lin Theil der letzteren Formen bildet bereits den unmittelbaren Uebergang zur D iscoblastula der discoblastischen Eier, bei denen meist nur eine enge und kleine Furchungshöhle sich findet. Die gewölbte Decke der letzteren wird von den Zellenschichten des gefurchten „Bildungsdotters", ihr ebener oder vertiefter Boden von dem voluminösen, ganz oder grösstentheils ungefurchten "Nahrungsdotter" gebildet (Fig. 49; 54). Sehr klar liegt dies Verhältniss bei unserem pelagischen GadoidenEi vor (Fig. 61, 62, 74). Dass auch bei dem am stärksten modificirten discoblastischen Vogel-Ei die Furchungshöhle nicht fehle und somit auch der Hühnerkeim vorübergehend eine bedeutungsvolle $B$ lase bilde, hat neuerdings namentlich $R_{\text {AUBEn }}$ hervorgehoben (l. c.). Er bemerkt mit Recht: „damit ist nicht etwa Gleichgültiges behauptet; demn mit dieser Veränderung tritt das Hühnchen in Beziehung zu weit niedriger stehenden Geschöpfen".

Gleicherweise ist nun auch die Periblastula auf die palingenetische Urform der Archiblastula mit Sicherheit zurïckzuführen (Fig. 83-86). Demn diese cenogenetische Blastosphacra der periblastischen Eier ist ja eigentlich nur dadurch von der Archiblastula verschieden, dass der Hohlraum der Keimhantblase, das Blastocoelom, nicht mit klarer Fliissigkeit oder Gallertmasse, sonder'n mit dem massiven Nahrungsdotter erfüllt ist. Da dieser schon vor Beginn der Keimung das Centrum des Eies erfüllt, muss hier nothwendig die Periblastula mit der Perimorula zusammenfallen.

Wenn demnach alle verschiedenen Modificationen der Blastula sich als cenogenetische Abänderungen der ursprünglichen palingenetischen Archiblastula nachweisen lassen, so ist uns auch nach dem biogenetischen Grundgesetze die einfachste Hypothese gestattet, welche diese wichtige ontogenetische Thatsache phylogenetisch dentet und verwerthet. Wir dürfen dam sagen, dass sämmtliche Metazoen von einer gemeinsamen uralten Stammform abstammen, welche im Wesentlichen der Archiblastula gleichgebildet war: diese längst ausgestorbene laurentische Stammform ist dic Planaea.

Selbständige entwickelte Organismen, welche dieser hypothetischen Planaea in Wesentlichen gleich gebildet sind, leben zahlreich anch noch in der Gegenwart. Vor allen dürften hier die coloniebildenden Flagellaten, und namentlich die Volvocinen 
zum Vergleich herbeizuziehen sein: frei schwimmende Gallertkugeln, deren Peripherie durch eine Schicht von gleichartigen Geisselzellen gebildet wird. Auch die von mir an der Norwegischen Küste beobachtete Magosphaera planula, die wahrscheinlich den Volvocinen, z. B. der Synura nahe verwandt ist, tritt hier als eine der ausgestorbenen Planaea sehr ähnliche Protisten-Form in den Vordergrund ${ }^{1}$ ). Gleich diesen Catallacten und Volvocinen werden höchstwahrscheinlich auch die ausgestorbenen Planaeaden, die verschiedenen der Planaea nächststehenden Genera und Species, sich mittelst eines Flimmerkleides schwimmend im laurentischen Urmeere unher bewegt haben.

Wenn ich hiel" die Bezeichnung, "Planaea" für diese vierte Ahnenstufe der Metazoen beibehalte, und sie nicht durch die passendere Benennung ,Blastaea" ersetze, so geschieht es, um nicht noch einen neuen Namen gerade für diese Entwickelungsstufe einzuführen, die ohnehin schon verschiedene andere Bezeichnungen früher erhalten hat. Die Bezeichnung Blastula für die entsprechende Keimungsstufe hat bereits in mehreren andern Aufsätzen Eingang gefunden und ist der Küurze wegen der früher von mir gebrauchten Benennung Blastosphaera volzuziehen; und ebenso der älteren Bezeichnung: Vesica blastodermica. Der an anderen Orten dafür gebrauchte Name Planula wird wohl am besten ganz zu eliminiren sein, da er von vielen verschiedenen Autoren in einem ganz abweichenden Sinne verwendet wird. Dalyell, der 1847 den Ausdruck "Plannla" zuerst eingefüht hat, verstand darunter weiter Nichts, als kleine (meist mikroskopische) flimmernde Larven von Zoophyten anf sehr verschiedenen Entwickelungszuständen. Spätere Autoren laben dam darunter bald frei bewegliche und flimmernde Formen von Morula, bald ebensolche Formen von Blastula, bald echte Gastrula-Formen verstanden. Ausserdem sind auch oft verschiedene, weiter entwickelte Jugendformen niederer Thiere als "Planula" bezeichnet worden, die weiter Nichts mit einander gemein haben, als geringe Grösse, einfache Körperform und eine flimmernde Körperbedeckung. Auch der sogenanute „,infusorienartige Embryo" vieler anderen Autoren gehört in die Kategoric dieser falschen "Planula“. Da demnach augenblicklich gar keine allgemein anerkannte Bestinmung des Planula-Begriffes nach Inhalt und Umfang existirt, und da noch in nenester /eit

1) E. Haecket, Die Catallacten, eine neue Yrotisten-Gruplet. Jen. Zeitschn. f. Naturw. Vol. VI, 1871, S. 1 'Tat. I. 
viele Autoren denselben in ganz verschiedenem Sinne gebrauchen, so ist es wohl am besten, iln ganz fallen zu lassen. Will man ihn trotzdem beibehalten, so kann man ihn vielleicht am zweckmässigsten zur Bezeichnung jener cenogenetischen Keimform verwenden, die ich in der Monographie der Kalkschwämme Plamula genannt habe (Bd. I, S. 332).

Mit dem weitschanenden Blicke des genialen Naturphilosophen hat schon im Jahre 1828 der grosse BAER die hohe allgemeine Bedeutung der Blastula erkannt. Im ersten Bande seiner classischen ,Entwickelungsgeschichte der Thiere" (S. 223; $\$ 4$ des V. Scholions) findet sich folgender Satz: „Je weiter wir in der Entwickelung zurückgehen, um desto mẹr finden wir auch in sehr verschiedenen Thieren eine Uebereinstimmung. Wir werden hierdurch zu der Frage geführt: ob nicht im Beginne der Entwickelung alle Thiere im Wesentlichen sich gleich sind, und ob nicht für alle eine gemeinschaftliche Urform besteht. Da der Kein das unausgebildete Thier selbst ist, so kann man nicht ohne Grund behaupten, dass die einfache Blasenform die gemeinschaftliche Grundform ist, aus der sich alle Thiere nicht nul der Idee nach, sondern historisch entwickeln." Der Abschnitt, in dem dieser merkwürdige Satz enthalten ist, trägt lie Ueberschrift: „Beim ersten Auftreten sind vielleicht alle Thiere gleich und nur hohle Kugeln."

\section{Die Gastraea und die Gastrula.}

Die fünfte ontogenetische Entwickelungsstufe der Metazoen, die Gastrula, ist zugleich die letzte, welche allen diesen Thieren usprünglich gemeinsam zukommt. Denn von hier an scheiden sich die Wege der Keimesentwickelung; sie führen von der monaxonien Gastrula einerseits zu den monaxonien Spongien und den stauraxonien Acalephen, anderseits zu den dipletren oder bilateralen Bilaterien; und zwar zunächst zu den Würmern, alus denen sich die vier typischen Stämme der Mollusken, Echinodermen, Arthropoden und Vertebraten erst später hervorgebildet haben. Da :lber in der Keimesgeschichte aller dieser verschiedenen Thiere die Gastrula entweder als reine palingenetische Archigastrula oder als mehr oder weniger modificirte, auf die letztere aber zuriickführbare, cenogenetische Gastrula nachzuweisen ist, so dürfen wir nach dem biogenetischen Grundgesetze auf eine gemeinsane Ahnenform aller Metazoen schliessen, welche der Archigastrula im Wesentlichen gleich gebildet war; und das ist die Gastraea. 
Da diese phylogenetische Hypothese den Kern unserer ganzen Gastraea-Theorie bildet und da alle die anderen, hier vertretenen allgemeinen Ansicliten über Entwickelung der Thiere jene fundamentale Hypothese stiitzen und durch sie zugleich erklärt werden sollen, so ist es nicht nöthig, an dieser Stelle nochmals die phylogenetische Bedeutung der ontogenetischen Gastrula-Form zu begründen und die Gastraea als wahre Urquelle der Metazoen-Bildung, als wirklichen „Metazoarchus" nachzuweisen. Nur auf einige der wichtigsten Punkte, auf deren richtiges Verständniss es vorzugsweise ankommt, möchte ich hier schliesslich wiederholt hinweisen und damit zugleich die erlieblichsten, gegen die GastraeaTheorie erhobenen Einwendungen widerlegen.

In erster Linie ist es auch hier wieder vor Allem erforderlich, sich nicht durch die mannichfaltigen cenogenetischen Modifieationen der Keimform beirren zu lassen, sondern die ursprüngliche palingenetisehe Keimform scharf und bestimmt in's Auge zu fassen. Diese liegt uns ganz rein und unverfälscht in der einfachen Archigastrula vor, wie sie sich in identischer Form bei den niedersten Angehörigen aller Typen findet: bei Gastrophysema Fig. 119, 120; Olyntlus Fig. 17; Actinia Fig. 21; Pelagia Fig. 22; Sagitta Fig. 23; Argiope Fig. 25; Limmaeus Fig. 31; Uraster Fig. 33; Amphioxus Fig. 43, 44. Wenn wir uns vorstellen, dass wir diesen verschiedenen Gastrula-Formen im Meere begegneten, ohne ihre Herkunft zu kennen, so würden wir sie ganz gewiss als unbedeutende Modificationen einer einzigen Entwickelungsform betrachten; und wenn wir sie geschlechtsreif anträfen und also als selbstständige Thierarten zu beurtheilen hätten, so würden wir sie ganz gewiss nur als leichte Varietäten einer einzigen „bona Species" oder höclistens als nahe verwandte Species eines einzigen Genus betrachten. Jeder Anhänger der Entwickelungstheorie würde kein Bedenken tragen, sie als wenig divergirende Descendenten einer einzigen gemeinsamen Stammform zu betrachten. Und doch liegen uns in diesen verschiedenen, so wenig von einander abweichenden Archigastrula-formen in Wahrheit Repräsentanten sämmtlicher Metazoen-Typen vor: Zoophyten, Würmer, Mollusken, Eehinodermen, Arthropoden und Vertebraten. Das ist eine Thatsache von grösster Bedeutung!

In jedem dieser Thierstämme sind es nur noch einzelne uralte Formen der niederen Klassen, welche die palingenetische Arehjgastrula seit Millionen von Jahren rein bis auf den locutigen Tag bewahrt haben. Bei der grossen Mehrzahl, und namentlich bei 
allen höher entwickelten Metazoen ist an deren Stelle eine modificirte cenogenetische Gastrula-Form getreten. Da finden wir zunächst im engsten Anschluss an die erstere die Amphigastrula, deren Urdarmhöhle bald noch leer, bald schon mit Dotter'zellen erfüllt ist (Fig. 18, 28, 48, こ3 , 100, 110). Die Amphigastrula geht yanz allmälılich, indem der Nahrungsdotter mächtig anwächst und damit die Theilungsfähigkeit der Dottermasse erlahmt, in die Discogastrula über. Obgleich nun diese in ihrer extremen Ausbildung sich zu einer so abweichenden Keimform gestaltet, lässt sie sich dennoch stets durch Termittelung einer Reihe von Zwischenformen auf die Amphigastrula zuriickführen; und selbst in jenen extremen Fällen, wie sie uns die Cephalopoden, Teleostier und Vögel darbieten, ist diese Reduction durch die neuesten Beobachtungen möglich geworden (Fig. 37, 40, 49, 50, 54, 65, 66, 75, 76). Ebenso lässt sich auch auf der anderen Seite die Perigastrula gleichfalls auf die Archigastrula zurückführen, und die Schwierigkeit, welche gerade diese cenogenetische Gastrula-Form vol"zugsweise der Gastraea-Theorie entgegen zu halten schien, existirt gegenwärtig nicht mehr (Vergl. Fig. 87-90).

Demgemäss können wir zunächst eine allgemeine Homologie der Gastrula bei sänmmtlichen Metazoen behaupten, und diese Belatuptung wird begruindet theils durch den gleichen morphologischen Werth, den die beiden primären Keimblätter überall besitzen, theils durch den nummehr gelieferten Nachweis, dass der ursprüungliche Bildungsmodus der Gastrula überall die Einstülpung oder Invagination der Blastula ist.

Wenn es uns num so mit Hülfe der vergleichenden Ontogenie gelungen ist, alle die verschiedenen Gastrula-Modificationen, alle die verschiedenen Formen des ,zweiblätterigen oder zweischichtigen lieimes" auf die eine gemeinsame Urform der Archigastrula zuriickzuführen, so ist uns die einfachste phylogenetische Hypothese gestattet, welche diese bedeutungsvolle ontogenetische Thatsache mechanisch-causal zu deuten vermag. Diese einfachste hier mögJiche Hypothese lässt sich in dem monophyletischen Satze zusammenfinsen: Alle Metazoen stammen von einer einzigen gemeinsamen Stannform ab, welche im Wesentlichen der Archigastrula gleich grebildet war. Diese uralte, längst ausgestorbene Stammform, die schon wïhrend der laurentischen Periode gelebt haben muss und damals wahrscheinlich durch viele verschiedene Genera und Species vertreten wal, ist unsere Gastracil. Die ganze hypothetische Gruppe von ausgestorbenen ältesten Metazoen, welche durch die 
nächsten Descendenten der Gastraea gebildet wurde, habe ich als Gastraead en bezeichnet.

Diese ältesten Gastraeaden werden der heutigen Archigastrula im Wesentlichen ganz gleich gebildet und wahrscheinlich nur darin wesentlich verschieden gewesen sein, dass sie bereits sexuelle Differenzirung besassen. Vermuthlich werden sich bei ihnen einzelne Zellen des Entoderms zu Eizellen, einzelne Zellen des Exoder'ms zu Spermazellen umgebildet haben, wie es auch bei den niedersten Zoophyten (Spongien, Hydroiden) noch heute der Fall ist. Gleich den frei im Meere schwimmenden Formen der Archigastrula werden auch jene Gastraeaden sich mittelst Flimmerhaaren, Geisseln oder Wimpern bewegt haben, welche als Fortsätze der Exodermzellen sich entwickelten.

Ob noch heute echte, frèi schwimmende Gastraeaden existiren, ist nicht bekannt, indessen durchaus nicht unwahrscheinlich. Vielleicht sind manche, als Infusorien beschriebene Thierformen nicht echte, einzellige Infusionsthiere, sondern Gastraeaden. Wohl aber existiren noch heute einige festsitzende, höchst einfache Zoophyten, welche ihrer ganzen Organisation nach als Gastracaden zu beurtheilen sind, die jedoch bisher im System einen ganz anderen Platz besassen. Das eine von diesen noch lebenden Gastraeaden ist das merkwürdige, von Bowerbank beschriebene $\mathrm{Ha}$ liphysema'); eine andere nahe verwandte Form ist die von $\mathrm{C}_{\text {ARTER }}{ }^{2}$ ) unter dem Namen Squamulina scopula zu den Polythalamien (!) gestellte interessante Thierform, die ich Gastrophysema nemne, und deren Ontogenie auf Taf. VIII abgebildet ist. Beide Genera sind gegenwärtig noch durch mehrere Arten vertreten. Ich werde die genaue Beschreibung dieser beiden Gastraeaden der Gegenwart, Halipleysema und Gastropleysema, demnächst folgen lassen.

Wenn die Ar'chigastrula, wie ich für sicher halte, die getreue palingenetioche Wiederholung der Gastraea ist, dann muss auch die letztere ursprünglich eben so aus der Planaea (oder Blastaea) entstanden sein, wie die erstere noch hente aus der Blastula (oder Blastosphaera) entsteht. Die Gastraea muss dam durch Einstülpung (oder Invagination) aus der Planaea hervorgegangen sein. In der That ist auch diese phylogenetische Hypothese eben-

1) Bowerbank, Nonograph of the British Spongiatac, Vol. I, 1. 179; Pl.

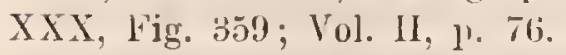

2) Carten, Un two new Species of the Foraminiferous genus Squamulina. Aw. Mag. nat. hist. 1870, Vol. V, p. 309. Pl. IV, Fig. 1 11. 
so rlurch die nachweisbare Invagination der Archiblastula für die morphologische Auffassung sicher zu begrunden, wie sie für die physiologische Betrachtung durch Erwägung der bezüglichen CausalVerhältnisse durchaus wahrscheinlich wird. Denn wem wir uns fragen, welche phylogenetischen Veränderungen die Entstehung der zweiblätterigen Gastraea aus der cinblätterigen Planaea hervorriefen, so ist als die wichtigste causa efficiens derselben unzweifelhaft jene älteste Arbeitstheilung der Zellen hervorzuheben, welche die Differenzirung der beiden primären Keimblätter bewirkte, die A rbeitstheilung der Planaea-Zellen (oder „Blastoderm"-Zellen) in locomotive und nutritive Zellen. Die locomotiven Zellen der Planaeaden, welche vorzugsweise deren schwimmende Ortsbewegung besorgten, bildeten die animale Hemisphaere derselben, die zum Exoderm wurde; die nutritiven Zellen hingegen, welche vorzüglich der Nahrungsaufnahme und Assimilation sich hingaben, bildeten die vegetative Hemisphäre, die sich zum Entoderm gestaltete. Nun war es aber für die letzteren offenbar von grossem Vortheil, wenn sie nicht mehr eine convexe Oberfläche (wie bei der Planaea) zur Nahrungsaufnahme und Assimilation bildeten, sondern an deren Stelle eine concave Vertiefung an der Oberfläche der Flimmerkugel herstellten. Hier konnten Nahrungsmittel längere Zeit verweilen und besser assimilirt werden. Diese concave Vertiefung, welche die Invagination der Planaea einleitete, war der erste Anfang zur Bildung des Urdarms. Die Vervollständigung derselben war die einfache Wirkung der natürlichen Züchtung. Denn je tiefer die Einstülpung und je ausgedehnter damit die nutritive Epithelfläche wurde, desto besser war für die Ernährung der sich bildenden Gastraea gesorgt. Mit der vollständigen Einstülpung verschwand das Blastocoelom der Planaea und an dessen Stelle trat die Protogaster der Gastraea.

Gleiche einfache physiologische Reflexionen geben uns Aufschluss über die Causalverhältnisse der historischen Veränderungen, welche überhaupt die älteste Reihe der Metazoen-Ahnen vom Moner bis zur Gastraea durchlief (Anthropogenie XVI. Vortrag). Diese physiologischen Erwägungen über die Phylogenie der ältesten Functionen erläutern zugleich die mechanische Phylogenie der niedersten Thierformen, welche uns in den fünf ersten Keimungsstufen der Metazoen noch heute als ontogenetische Wiederholung jener fünf ältesten Ahnenstufen entgegen treten. Indem wir hier die ganze Mannichfaltigkeit der cenogenetischen Keimformen auf die ursprüngliche palingenetische Keimform zurïckführen und diese phylogene- 
tisch denten, gelangen wir zu einem wahren Verständniss vom ältesten Entwickelungsgang des Thierreichs, und dies Verständniss gewinnen wir nur durch die Gastraea-Theorie.

Jena, den 18. August 1875.

\section{Nachschrift.}

Ueber die Eifurchung und Gastrulation der Spongien erhalte ich so eben, nachdem vorstehende Arbeit bereits gedruckt ist, eine sehr interessante Mittheilung von Franz Eilhard Schulze, welche in erfreulichster Weise die Uebereinstimmung der Spongien mit den übrigen Metazoen bezüglich der wichtigsten Keimungs-Vorgänge bestätigt'). Obwohl Schulze denselben Kalkschwamm (Sycandra raphanus), wie Oskar Schmidt und MetschniкоFF untersucht hat, ist er doch zu ganz anderen Resultaten gekommen. Nach vollendeter Eifurchung entsteht eine echte Blastula, zusammengesetzt, ,aus 48 Zellen, welche zusammen in einschichtiger Lage einen linsenförmigen Hohlkörper formiren. Bei weiter fortschreitender Zellenvermehrung nimmt der Embryo die Gestalt einer Hohlkugel an. Ferner tritt eine Differenzirung ein zwischen acht keilförmigen, den späteren Entodermzellen, und sämmtlichen unregelmässig polyedrischen, helleren, den Ektoderm-Zellen. An der nun zum Verlassen ihrer Entstehungsstätte befähigten Larve ist die Furchungshöhle stark verkleinert, während die Entodermzellen, stark aufgeblüht und mit groben dunkeln Körnchen erfüllt, sich nach aussen vordrängen und etwa die Hälfte der nun eiförmigen Larve ausmachen. Später tritt dann wieder eine Abflachung des halbkugelig vorspringenden Entoder'mlagers und bald darauf sogar eine Einstiilpung desselben gegen die convexe Ektodermkuppe ein, wobei die Furchungshöhle gänzlich schwindet und sich das Entodermzellenblatt unnittelbar an die Innenfläche des Ektodermes anlegt. Durch Ausweitung der so entstandenen doppelblätterigen hohlen Halbkugel und Umgreifen des Ektodermzellenlager's am Oeffnungsrande entsteht eine sackförmige, zweiblätterige Larve mit äusserer flimmernder und innerer nicht flimmernder Zellenlage: eine Gastrula."

1) Franz Eilhard Schulze, Ueber den Bau und die Entwickelung cines Kalkschwanmes, Sycandra raphanus (Tageblatt der 48. Versammlung deutscher Naturforscher und Aerzte in Graz 1875. S. 101). 
Die Eifurchung und Gastrulation der Sycandra raphanus verläuft nach dieser wichtigen, wörtlich wiedergegebenen Mittheilung also ganz in der typischen Form aller Netazoen, indem zunächst eine echte Blastula und durch deren Einstülpung orler Invagination eine echte Gastrula (und zwar eine Amphigastrula) entsteht. An der Genauigkeit dieser werthvollen und detaillirten Angaben zu zweifeln, liegt bei der bekannten Beobachtungs-Schärfe und histologischen Erfahrung von Franz Eilhard Schulze kein Grund vor. Daraus ergiebt sich aber bezüglich der früheren, damit nicht übereinstimmenden Angaben über die Spongien-Gastrula (welche oben, S. 455, 456 erwähnt wurden) in Kürze Folgendes: 1) Die Angaben von Meтschniкoff sind (gleich so vielen anderen Behauptungen dieses obertfächlichen Beobachters) bezüglich der angeblichen Beobachtungen sowohl als der daraus gezogenen Schlïsse ganz falsch; sogar Exoderm und Entoderm sind darin verwechselt! 2) Die Mittheilungen von Oskar Schmidt sind, was die Beobachtungen betrifft, grösstentheils richtig, aber unvollständig; bezüglich der Deutungen grösstentheils unrichtig. 3) Meine eigenen Angaben iiber die Ontogenie der Kalkschwämme sind insofern unvollständig und unrichtig, als ich die Blastula und deren Invagination nicht erkannt, und statt deren zwischen Morula und Gastrula die Bildung einer Planula und Planogastrula angenommen hatte (Monographie der Kalkschwämme, Band I, S. 333). Dagegen sind sie richtig und werden vollkommen durch F. E. Schulze bestätigt in dem wichtigsten Punkte, darin nämlich, dass auch die Keimung der Schwämme mit der Bildung einer echten Gastrula und der beiden primären Keimblätter verläuft.

Dass diese Gastrula der Spongien durch Invagination einer echten Blastula entsteht, und nicht durch Delamination (wie ich irrig angenommen hatte) ist nir natürlich nur höchst erwiinscht, weil dadurch die wesentliche Uebereinstimmung der Spongien mit den übrigen Metazoen hergestellt wird. Höchst wahrscheinlich wird auch in den wenigen anderen Fällen, in denen die Gastrula durch Blätterspaltung des Blastoderms entstehen sollte, sich schliesslich die Einstülpung der Blastula als ursprünglicher EntstehungsModus herausstellen.

Von welcher hohen principiellen Bedeutung die Beobachtungen von Franz Erlhard Schulze für die ganze Naturgeschichte der Spongien sind, brauche ich schliesslich wohl kaum besonders hervorzuheben. Ich hatte bei Ausarbeitung meiner Monographie der Kalkschwämme in erster Linie mich bestrebt zu zeigen, dass diese 
Thiere, und die Spongien überhaupt, keine Protozoen, sondern Metazoen sind; dass ihre beiden Gewebsschichten den beiden primären Keimblättern der ïbrigen Metazoen homolog sincl. und dass die Spongien durch die Bildung ihres Gastrocanal-Systems sich als echte Z o ophyten (orler Coelenteraten) ausweisen. Osкak Sснмm hatte dagegen in seinem oben citirten Aufsatze: „Zur Orientirung über die Entwickelung der Spongien" sich zu zeigen bemüht, dass jene Auffassung falsch sei und dass somit auch alle die wichtigen, daran geknüpften allgemeinen Schlussfolgerungen hinfällig seien'). Die Mittheilungen von F. E. Schulze bestätigen nicht allein die Richtigkeit meiner Auffassung; sondern sie verstärken sie zugleich bedentend dadurch, dass sie die typische Bildung der Gastrula durch Einstïlpung der Blastula auch bei den niedersten Metazoen nachweisen, bei den Spongien.

Jena, den 4. October 1875.

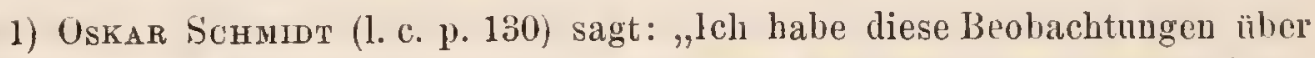
den Bau der Flimmerlarven von Sycandra raphanus und glabra mit peinliclier Sorgfalt wiederholt. Ich kann nur behaupten, dass unsere beiden Arten keine Gastrula bilden, und dass damit leider die vermeintliche durchgreifende Wichtigkeit der Gastrula für die Kalkspongien mit allen den so schönen theoretischen Folgerungen $\mathrm{nicht}$ mehr existirt." Die Figuren 1, 2, 3 mnd 4, 5, 6, welche 0. Sсниidt (1. c.) auf 'Taf. VIII und IX mittheilt, sind wohl als Amphiblastula zu deuten. Die folgende Einstiilpung derselben hat er offenhar nicht beobachtet, und ebenso nicht die daraus hervorgehende $A$ in ${ }^{\text {i h }}$ igastrula. 


\section{Frklairung der Tafeln.}

\section{Taf. II. \\ Eifurchung und Gastrula verschiedener Wirbellosen (Copien).}

[In allen Figuron ist das Entoderm durch rothe, das Exoderm durch blaue Farbe bezeichnct. Der Nahrungsdotter ist meistens roth schraffirt. $s$ Furchungshöhle (Blastocoeloma). a Urdarmhöhle (Protogaster). o Urmund (Protostoma).]

Fig. 17. Archigastrula eines Kalkschwanmes (Asculmis armata). Copie nach HaEckel, Monographie der Kalkschwämme, Taf. 13, Fig. 6.

Fig. 18. Amphigastrula eines Kalkschwammes (Sycyssa Huxleyi). Copie nach HAECKEL, Monographie der Kalkschwämme, Taf. 44, Fig. 15.

Fig. 19. Amphiblastula cines Kalkschwammes (Sycandra raphanus). Copie nach Oskar Schmidt (Zeitschr. tür wissensch. Zool. Vol. XXV, Suppl. Taf. IX, Fig. 5). Die Furchungshöhle ist in dieser Figur fälschlich mit $a$ (statt mit $s$ ) hezeichnet. o muss wegfallen.

Fig. 20. A rchiblastula einer Koralle (Actinia). Copie nach Kowalevsky (Russische Abhandlung über die Ontogenie der Coelentcraten. 1873. Taf. IV, Fig. 1).

Fig. 21. Archigastrula derselben Koralle (Ibid. Taf. IV, Fig. 2).

Fig. 22. Archigastrula ciner Meduse (Pelagia). Copie nach KowalevsKy (Ilbid. 'Taf. III, Fig. 2).

Fig. 23. Arehigastrula eines Wurms (Sagitta). Copie Hach Kowalevsky (Embryologische Studien an Würmern und Arthropoden, Petersburg 1871, Taf. I, Fig. 2).

Fig. 24. Amphiblastula eines Wurms (Euaxes). Copie nach Kowalevshy (Ibid. Taf. IV, Fig. 27).

Fig. 25. Archigastrula eines Brachiopoden (Argiope). Copie nach KoWALEvSKY (Russische Abhandlung über die Ontogenie der Brachiopoden. Moskan 1874. Taf. I, Fig. 3).

Fig. 26. A miphiblastula einer Muschel (Unio). Copie nach einer noch nicht publicirten Abhandlung von CaRL RABL über die Ontogenie der Muscheln.

Fig. 27. Amphiblastula derselben Muschel in einem folgenden Stadium. Copie nach CARL RaBL (Ibid.).

Fig. 28. Amphigastrula derselben Muschel. Copie nach CARL RABL (Ibid.). Links ist eine grosse Mesoderm-Zelle sichtbar.

Fig. 29. Archiblastula einer Schnecke (Limnaens). Copie nach CarL RABL (die Ontogenie der Süsswasser-Pulmonaten. Jenaische Zeitschrift für Naturw. 1875. Vol. IX, Taf. VII, Fig. 9).

Fig. 30. Archiblastula invaginata derselben Schnecke. Copie nach $\mathrm{C}_{\triangle \mathrm{RL}} \mathrm{R}_{\triangle \mathrm{B} L}$ (Ilid. Taf. VH, F'ig. 10. 
Fig. 31. Archigastrula derselben Schnecke. Copie nach CARL RABL (Ibid. Taf. VII, Fig. 11).

Fig. 32. A mphigastrula einer Schnecke (Purpura). Copie pach Selnerka (Keimblätter bei Purpura. Niederl. Arch. f. Zool. 1871. Ileft II, Taf. XVII).

Fig. 33. A rchigastrula eines Seesterns (Asteracanthion). Copie nach AlEx. Ag $\triangle$ SSIz (Embryology of the Starfish. 1864. Taf. I, Fig. 27).

Fig. 34. A mphimorula eines Rhizocephalen (Sacculina). Copie nach ED. van Beneden (Recherches sur l'Embryogenie des Crustacées, 1870. Pl. I, Fig. 21).

Fig. 35. Discomorula einer Assel (Oniscus). Copie nach Bobretzky (Zur Embryologie des Oniscus murarius. Zeitschr. für wissensch. Zool. Vol. XXIV, Taf. XXI, Fig. 3).

Fig. 36. Discoblastula desselben Oniscus. Copie nach Bobretzky (Ibid. Fig. 5).

Fig. 37. Discogastrula desselben Oniscus. Copie nach Bobretzkr (Ibid. Fig. 7).

Fig. 38. Discogastrula eines Wasserkäfers (Hydrophilus). Copie nach Kowalevsky (Embryolog. Studien an Würmern und Arthropoden. Pctersburg 1871, Taf. IX, Fig. 23).

Fig. 39. Archigastrula (?) eines Pteromalinen (Platygaster). Copie nach GaNIX (Entwickel. der Insecten. Zoitschr. f. wiss. Zool. 1869. Bd. XIX, Taf. XXX).

Fig. 40. Discogastrula des Scorpions. Copie nach Metschnikoff.(Embryologie des Scorpions. Zeitschr. f. wiss. Zool. 1871, Taf. XIV, Fig.9).

\section{Taf. III.}

\section{Eifurchung und Gastrula verschiedener Wirbelthlere (Copien).}

[In allen Figuren ist das Entoderm durch rothe, das Exoderm durch blaue Farbe bezeichnet. Der Nahrungsdotter ist meistens roth schraffirt. $s$ Fnrchungsböhle (Blastocoèloma). a Urdarmhöhle (Protogaster). o Urmund (Protostoma).]

Fig. 41. Archiblastula des Amphioxus. Copie nach Kowalevskr (Entwickelungsgeschichte des Amphioxus. Mem. Petersb. Akad. 1867. Vol. XI, Tab. I, Fig. 9).

Fig. 42. Archiblastula invaginata des Amphioxus. Copie nach KoWALEVSKY (Ibid. Fig. 13).

Fig. 43. Archigastrula des Amphioxus im ersten Anfang. Copie nach Kowalevsky (Ibid. Fig. 14).

Fig. 44. A l'chigastrula des Amphioxus, vollständig ausgebildet. Copie nach Kowalevsky (Ibid. Fig. 16).

Fig. 45. A m phim orula des Petromyzon. Copie nach Max Schultze (Entwickelungsgeschichte von Petromyzon. Haarlem 1856. Tab. IV, Fig. 1).

Fig. 46. Amphiblastula des Petromyzon. Copie nach M. Schulqzk (ibid. Taf. IV, Fig. 2).

Fig. 47. A mphigastrula des Petromyzon, in erster Anlage. Copie nach M. Schultze (ibid. Taf. IV, Fig. 5).

Fig. 48. Amphigastrula des Petromyzon, vollständig cntwickelt. Copie nach M. Schultze (ibid. Taf. IV, Fig. 7). 
Fig. 49. Discogastrula eines Ilaifisches (Mustelus). Copie nach BaLFour (Development of the Elasmobranch Fishes. Quarterly Journ. of microsc. Sc. 1874. Vol. XIV, Pl. XIII, Fig. 1).

Fig. 50. Discogastrula eines Kmochenfisches (Esox). Copie nach LerEBoullet (Recherchos d'Embryologie comparée sur le Developpement du Brochet etc. 1853. Pl. I, Fig. 27.

Fig. 51. Amphimorula des Bombinator. Copie nach Goetre (Entwickelungsgeschichte der Unke, 1875. Taf. II, Fig. 27).

Fig. 52. Amphiblastula des Bombinator. Copie nach Goetre (ibid. Taf. II, Fig. 28).

Fig. õ3. Amphigastrula des Bombinator. Copie nach Goetre (ibid. Taf. II, Fig. 33).

Fig. 54. Discogastrula des Hühnchens. Copie nach Goetre (Die Bildung der Keimblätter im Hühnerei. Archiv für mikrosk. Anat. Vol. X, 1874, Taf. X, Fig. 4).

\section{Taf. IV.}

\section{Discoidale Furchung und Discogastrula eines pelagischen Knochenfisches (Gadoiden, Motella ?).}

[Innerhall, der structurlosen Eihülle (c) ist ausser den (am animalen Pol befindlichen) Furchungszellen und dem daraus entstehenden Fischkeime nur der Nahrungsdotter zu sehen, bestehend aus einer wasserhellen structurlosen Eiweisskugel und einer kleineren (am vegetativen Pol befindlichen) stark lichtbrecheuden Oelkngel. Der homogene Nalırungsilotter, der keinerlei gefornte Bestandtheile enthält, ist mit gelber Farbe gedruckt. $e$ Exoderm. $i$ Entoderm. $w$ Keimwulst (Randwulst oder Properistom). $c$ Chorion. $k$ Embryo. $s$ Furchungshöhle. Alle Figuren dieser Tafel sind $60 \mathrm{Mal}$ vergrössert.]

Fig. 55. Zweite Fur chungsstufe: Ei mit vier Furchungszellen.

Fig. 56. Dasselbe Ei (Obere Hälfte) im Meridianschnitt.

Fig. 57. Vierte Furchungsstufe: Ei mit 16 Furchungszellen.

Fig. 58. Nasselbe Ei (Obere Hälfte) im Meridianschnitt.

Fig. 59. Discomorula. Ei nach volleudeter Furchumg. Die gleichartigeu Furchungskugeln bilden cine kreisrunde Keimscheibe (Uiscoblastus), eine bicouvexe Linse, welche in eine kleine Vertiefung am auimalen I'ol des Nahrungsdotters eingesenkt ist.

Fig. 60. Dieselbe Discomorula im Meridianschnitt.

Fig. 61. Jiscoblastula. Die Keimscheibe hat sich peripherisch ausgedehnt, in der Mitte bedeutend verdünnt, an Rande rings umgekehrt verdickt ( $w$ Keimwulst oder Randwulst). Zwischen der abgehobenen Mitte und dem Nahrungsdotter hat sich die Keimhöhle (s) gebildet.

Fig. 62. Dieselbe Dis coblastula im Meridianschnitt.

Fig. 63. Discoblastula invaginata. Uebergang der Discoblastula in die Discogastrula durch Einstiilpung der ersteren. Der untere Theil des verdickten Randwulstes schlägt sich nach innen um und wächst centripetal gegen die Nitte der Keinscheibe in dic Keimhöhle hiucin. Letztere wird enger. 
Fig. 64. Dieselbe Discoblastula invaginata im Meridianschuitt.

Fig. 65. Discogastrula. Die Einstülpung der Jiscoblastula ist vollständig geworden, indem die vom Randwulste in die Keimhöble hereingewachsene Zellenschicht (,secundäre Keimschicht") das Centrum der letzteren erreicht hat und nummehr als zusammenhängendes ,Entoderm“ den Boden der Keimhöhle bedeckt. Letztere verschwindet, indem las Entoderm sich an das Exoderm (die ,primäre Keimschicht", welche die Decke der Furchungshöhle bildet) eng anlegt. Die Kieimscheibe bedeckt als Gastrula wie eine Kappe den animalen Pol des Nahrungsdotters.

Fig. 66. Dieselbe Dis cogastrula im Meridianschnitt.

Fig. 67. Discogastrula mit der ersten Anlage des Axoblast. An einer Seite des verdickten Gastrula-Mundrandes (des „Ploperistoms") erscheint die erste Anlage der Axenplatte und des ,Primitivstreifs" (Ansicht von der Rückenseite. Der optische Meridianschnitt geht durch dic LateralEbene (von rechts nach links).

Fig. 68. Dieselbe Discogastrnla, 1 m 90" gedreht, im optischen Längsschnitt (Meridianschnitt durch die Median-Ebene).

Fig. 69. Fischkeim, weiter entwickelt, mit deutlicher Trennung von Kopf und Rumpf, mol Anlage der Angenblasen. Die Keimscheibe (Discogastrula) lıat bereits ungefähr $3 / \mathbf{3}$ der Peripherie des kugeligen Nahrungsdotters umwachsen, so dass kaum $1 /$ des letzteren am vegetativeu Pole aus dem Gastrula-Munde frei vorragt. Ansicht von der Rückenseite.

Fig. 70. Derselbe Fischkeim, un $90^{\prime \prime}$ gedreht, im Sagitalschnitt, von der linken Seite gesehen.

Fig. 71. Fischkeim, noch weiter entwickelt. Der aborale Körpertheil ist beträchtlich verlängert. Beiderseits der Chorda markiren sich lie Metameren (Urwirhel-Segmente). Die Keimscheibe (Discogastrula) hat den Nahruugsdotter fast ganz umwachsen, so dass nur nocl ein klcines segment des letzteren ann vegetativen Polc frei aus Iem Gastrula-Munde vorragt.

Fig. 72. Derselbc Fischkein, mm 90 "gedreht, in Sigittalschnitt vou der linken Seite geschen.

\section{Taf. V.}

\section{Discogastrula desselben pelagischen Knochenfisches (Gadoiden, Motella ?).}

Fig. 73. Discomorula im Meridianschnitt. Stärkerc Vergrösserung (200) des animalen Segments von Fig. 60.

Fig. 74. Discoblastula im Meridianschnitt. Stärkere Vergrössernng (200) des animalen Segments von Fig. 62 (linke Hälfte) und Fig. 64 (rechte Hälfte). Rechts beginnt die Einstülpung der Blastula, indem die grossen Zellen des Raudwulstes oder Properistoms $(w)$ centripetal gegen die Mitte der Keimhöhle $(s)$ hineinwachsen $(i)$.

Fig. 75. Discogastrula im Meridianschnitt. Stärkerce Vergrösserung des animalen segments vou Fig. 66.

Fig. 76. Discogastrula, vom lebenden Fisch-Ei, nach kurzer Einwirkung einiger Tropfen löchst verdumnter Osmiunsäure. Stärkere Vergrösserung (200) voll Fig. 65. 
Fig. 77. Zehn Exoderm-Zellen derselbon Discogastrula, in Chromsäure. Velgr. 600.

Fig. 78. Acht Entoderm-Zelle u dersclben Discogastrula, in Chromsäure. Vergr. 600.

Fig. 79. Drei Mesolelm-Zellen; amoeboide, mit dunkeln Pigmentkörner'n verschene Wander'zellen des I)armfiserblattes, welche in dem Winkel les Umschlagsrandes zwischen Exodern und Entoderm aus lctzterem cntstehen und nach verschirdenen Orten hinwandern. Vergr. 600.

Fig. 80. Der junge Kn o che $\mathrm{fisch}$ (Gadoide, Motella?), welcher so eben die Eihüllen verlassen hat, vou del linken Seite gesehen. $h$ Hirn. $u$ Auge. $g$ Gehörbläschen. z Herz. a Darm. $d$ Eiweisskugel des Nahrungsdotters. $f$ Fettkugel des Nabrungsdotters. $y$ After. $x$ Chorda. $m$ Seitenrumpfmuskeln.

\section{Taf. VI.}

\section{Superficiale Furchung und Perigastrula eines Grustaceen (Peneus).}

l'ig. 81. Z weite Furchungstufe: Ei mit vier Furchungszellen, von der Oberfläche gesehen. Durch zwei auf eiuander senkrechte Riugfurchen, eine aequatoriale und eine meridiane, werden im peripherischen Theil des Eies vier Zellen geschieden, während der centrale Nahrungsdotter ungetheilt bleibt.

Fig. 82. Dasselbe Ei im Meridiauschnitt.

Fig. 83. Fitufte Fulchungstufe: Ei mit 32 Furchungszellen, von der Ubcrtläche gesehen.

Fig. 84. Dasselbe Ei im Meridiauschnitt.

Fig. 85. Perimorula (und zngleich Periblastula), von der Oberfläche gesehen. Nach vollendeter Furchung bilden die sämıntlichen Furchungszellen an der Oberfläche des Eies eine einzige zusammenhängende Schicht von gleichartigen Zellen (Blastoderma), welche den inneren ungefurchten Nahrungsdotter unschliesst.

Fig. 86. Dieselbe Perimorula im Meridianschnitt.

Fig. 87. Perigastrula, von der Oberfläche gesehen; in der Mitte ist der Urmund (o) sichtbar, welcher in die Einstiilpung des Urdarms fübrt.

Fig. 88. Dieselbe Perigastrula im Medianschnitt. a Urdarm. o Urmund. e Exoderm. $i$ Entoderm. $m$ Mesoderm.

Fig. 89. Nauplius-Stadium, vou der Bauchfläche gesehen. $l$ Uberlippe 1, II, III, die Anlagen der drei Beinpaare.

Fig. 90. Dasselbe $\mathrm{Na} \mathrm{u}$ plius - Stadium, im Sagittalschnitt (von der linken Seite gesehen), a Urdarm. o Urmund $m$ Nesoderm-Zellen. $l$ Oberlippe. p Einstülpung des Schlundes und Kaumagens. e Exoderm. i Entoderm.

\section{Taf. VII.}

\section{Inaequale Furchung und Amphigastrula.}

Fig. 91-102. Inaequale Furchung und Amphigastrula eines chactopoden Anneliden (Fablicia).

Fig. 91. Amphimonerula. Nach der befruchtung ist das Keimbläschen verschwurden und aus der Copulation von spermazelle und Eizelle eine Cytode entstanden. 
Fig. 92. Amphicytula, tie arste Furchungskugel.

Fig. 93. Erste Furchungstufe: Die Amplicytula ist in zwei Zellen getheilt, eine obere, kleinere und hellere animale Zelle (Mutterzelle des Exoderms) und eine untere, grössere und dunklere vegetative Zelle (Mutterzelle des Entoderms).

Fig. 94. Zweite Furchungstufe: Die obere animale Zelle ist in zwei Zellen zerfallen; die untere vegetative Zelle ist ungetheilt.

Fig. 95. Dritte Furchungstufe: Die olere animale Zelle ist durch zwei Meridianfurchen in vier Zellen zerfallen. Die unters vegetative Zelle ist ungetheilt.

Fig. 96. Spätere Furchnngstufe: Die obere animale Zelle ist in zahlreiche kleine lielle Zellen, die untere vegetative Zelle ist in drei grosse dunkle Zellen (eine nutere grössere und zwei obere kleinere) zerfallen.

Fig. 97. A mphimorula. Nach beendigtem inaequalen Furchungsprocesse findet sich oben am animalen Pole eine hemisphärische Masse von zahlreichen kleinen hellen Lellen (Exoderm), unten am vegetativen Pole eine dunkle Masse von wenigen (sechs?) grossen duukeln Zellen (Entoderm).

Fig. 98. Amphiblastula im Meridianschnitt. Im Innern hat sich durch Flüssigkeits-Ansammlung eine Furchungshöhle (s) gebildet; in der oberen (animalen) Hälfte ülorwölbt von ciner hemisphärischen Schicht kleiner heller Exoderm-Zellen, in der unteren (vegetativen) Hälfte geschlosses von wenigen grossen dunkeln Entoderm-Zellen.

Fig. 99. Anphiblastula in Einstülpung, resp. Umwachsung (invinginatacircumcreta). Die grossen duukeln Entoderm-Zelleu werden in die Furchumgshöhle eingestülpt und eo ipso von der äusseren Schicht der kleinen hellen Exoderm-Zellen nmwachsen. Optischer Meridianschuitt.

Fig. 100. A mphigastrula im optischen Meridianschnitt. Die Eiustülpung (Entobole) oder Umwachsung (Epibole) der Amphiblastula ist vollencet, die Furchungshöhle verschwunden und die Urdarmhöhle (a) gebildet. o Urmund.

Fig. 101. Dieselbe A mphigastrula voll der Fläche gesehen.

Fig. 102. Junge Wurmlarve mit einem Wimperleifen.

Fig. 103-110. Inaequale Furchung und Amphigastrula einer Schuecke ('Trochus?).

Fig. 103. Zweite Furchungstufe: Ei mit vier Furchungszellen.

Fig. 104. Dritte Furchung tufe: Ei mit 8 Furchungszellen (4 kleinen hellen animalen und 4 grossen dunklen vegetativen Zellen).

Fig. 105. Dasselbe Ei, im Profil.

Fig. 106. Vierte Furchungs hellen animalen und 4 grossen dunklen vegetativen Zellen).

Fig. 107. Dasselbe Ei, im Profil.

Fig. 108. Amphimorula im Meridianschnitt. Nach beendigter Furchung wird die obere animale Hemisphäre des Eies von 16 kleinen lıellen, die untere vegetative Hemisphäre dagegen von 8 grossen dunkeln Zellen gebildet (4 obere grössere und 4 untere kleinere).

Fig. 109. Ampliblastula, im Meridiauschnitt. Hie Necke der Furchungshöhle wird von 32 kleinen hellen, ilu boden von 8 grossen dunkeln Zelleu gebildet ( 4 obere kleine und 4 untere grössere). 
lig. 110. Ampligastrula, in Meridianschnitt. a Urdarm. o Urmund. Das Exoderm (e) hat das Entoderm (i) völlig unwachsen. Die meisten Zellen des letztem lilden dic Darmwand. Finige grosse Zellen desselhen sind als Nahrumgsiloter ïbrig geblichen $(d)$.

\section{Taf. VIII.}

\section{Primordiale Furchung und Archigastrula von Gastrophysema.}

Yig. 111. Archimonerula. Nach crfolgter Pefruchtung ist das Keimhläschen verschwumden und aus der Copulation ron Eizclle unl Spermazelle eine Cytode entstanden.

Fig. 112. Archicytula. Die erste Furchungszelle.

Fig. 113. Erste Furchungstufe: Die Cytula ist in zwei gleiche Furchungszellen zerfallen.

Fig. 114. Zweite Furchungstufe: Aus der Cytula sind vier Furchungszellen entstanden.

Fig. 115. Archimorula (Maulbeerkeim).

Fig. 116. Archiblastula (die ursprüngliche Form der Blastosphära, Ḱeimhautblase oder "Vesicula blastodermica" ${ }^{6}$ ) von der Fläche geseh'n.

Fig. 117. Dieselbe Archiblastula im optischen Meridianschnitt.

Fig. 118. Archiblastula invaginata. Dieselbe Keimhautblase in der Einstülpung begriffen.

Fig. 119. Archigastrula, von der Fläche gesehen.

Fig. 120. Dieselbe Archigastrula, im optischen Meridianschnitt; dies ist die ursprüngliche, palingenetische Form der Gastrula. 
1
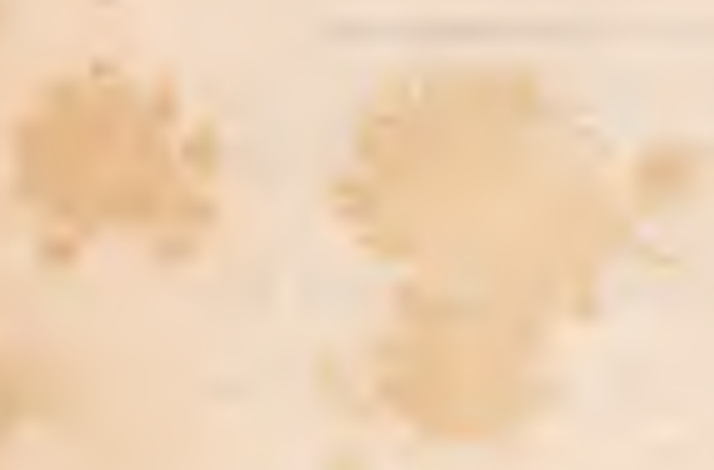

*

$x^{2}$
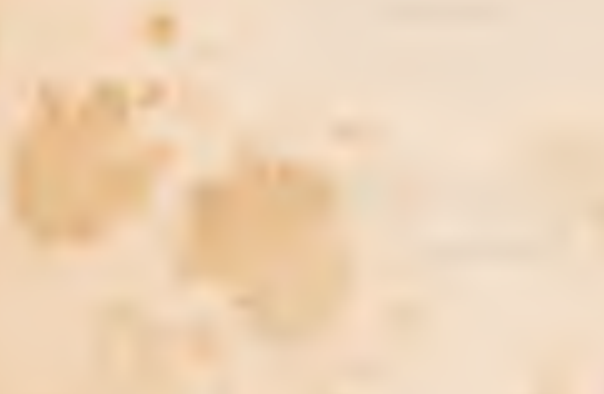
III.

\title{
Die Physemarien \\ (Ilaliphysema und Mastrophysema), Gastracaden der Gegenwart.
}

\author{
Hierzu Tafel IX-XIV.
}

Inhalt: 13. Bisherige Beobachtungen ïber Physemarien. 14. Das Genus Haliphysema. 15. Das Genus Gastrophysema. 16. Organisation und Lebens-Erscheinungen iler Physemarien. 17. Phylogenetische Bedentung der Physemarien. 



\section{Bisherige Beobachtungen iiber Physemarien.}

Wenn wir das natürliche System des Thierreichs im Lichte der Entwicklungs-Theorie betrachten und die morphologischen Verwandtschafts-Beziehungen der versehiedenen Formen phylogenetisch denten, so ergibt sich als eines der interessantesten Resultate die Frscheinung, dass fast alle hervorragenden Entwicklungsformen der Vergangenheit noch in der Gegenwart durch einzelne uralte Ueberbleibsel vertreten sind. Wie uns die vergleichende Culturgeschichte in den verschiedenen Völker-Stämmen noch heute fast alle Entwicklungsstufen der menschlichen Cultur und der staatlichen Organisation vor Augen fuhrt, so zeigt uns auch die vergleichende Zoologie in den verschiedenen Thierclassen noch heute fast alle Entwicklungsstufen des Zelleulebens und der thierischen Organisation neben einander. Die Moneren der Gegenwart berichten uns von den ersten Anfängen des organischen Lebens vor Millionen von Jahren. Die Amoeben von heute geben uns eine klare Vorstellung davon, wie der indifferente einzellige Organismus beschaffen war, der in der "Morgenröthe der Schöpfung“" den Grundstein des Zellenlebens legte. Die niedersten Pflanzenthiere der Gegenwart, Spongien und Hydroiden, erzählen uns von der Grïndung des Metazoen-Reiches. Die Ascidien und Amphioxus berichten uns, wie aus einem Zweige der Wirbellosen der grosse Stamm der Wirbelthiere entstand. Die Cyclostomen geben uns eine Ahnung von der Organisation der ältesten Schädelthiere; die Selachier zeigen uns, wie ungefähr die ältesten Gnathostomen beschaffen waren. Nicht minder berichten uns die heutigen Monotremen von der ältesten Geschichte der Säugethier-Classe und die Anthropoiden von den Anfängen der Anthropogenesis.

So hat jeder grosse Fortsehritt in der Thier-Geschichte seine heute noch sichtbaren Spuren hinterlassen; und von jeder charakteristischen Hauptgruppe des Thierreichs leben noch heute einzelne uralte Epigonen, welche in zäher Vererbung die wich- 
tigsten Eigenthümlichkeiten ihrer längst ansgestorbenen Stammgruppe bis zur Gegenwart getren iibertragen haben. Das hervorragende Interesse, welches sich in dieser Beziehung z. B. an den Amphioxus und die Ascidie, an die Selachier und die Anthropoiden knuipft, ist hentzutage so allgemein anerkannt, dass wir hier Nichts weiter dartiber zu sag'en brauchen. Ein gleiches Interesse aber möchten wir hier fuir einige kleine Thierformen in Anspruch nehmen, welche zwar nicht neu sind, aber bisher wenig bekannt und ganz irrthiimlich gedeutet waren. Das sind die Physemarien, eine kleine Gruppe von niedersten Pflanzenthicren, die der liypothetischen Stammform aller Metazoen, der Gastraea, näher stehen, als alle anderen bis jetzt bekannten Thiere. Bisher durften einerseits die niedersten Spongien, und namentlich der von mir beschriebene Olynthus ${ }^{1}$ ), andererseits die einfachsten Hydroiden, z. B. Hydra, als diejenigen Metazoen gelten, welche sich von der gemeinsamen Wurzel der ganzen Gruppe am wenigsten entfernt hatten. Noch näher aber dieser Wurzel, ja in nächstem, ganz unmittelbarem Zusammenhang mit derselben stehen unsere Physemarien: die Genera Haliplysema und Gastrophysema. Das erstere ist von seinem Entdecker Bowenbank als eine Spongie ${ }^{2}$, das letztere von Carter als eine Foraminifere beschrieben worden. In der That sind beide Genera Gastra ea den, einfache schlauchförmige Thiere, deren Körper zeitlebens nur aus den beiden primären Keimblättern besteht.

Das Genus Haliphysema hat Bowerbank im ersten Bande seiner "Monograph of the British Spongiadae" (1864) mit folgenden Worten charakterisirt: ,Sponge consisting of a hollow basal mass, from which emanates a single cloacal fistula. Skeleton: Spicula of the base disposed irregularly; spicula of the fistula disposed principally in lines parallel to the long axis of the sponge, without fasciculation." Im zweiten Bande derselben Monographie (1866) gibt er die Beschreibung von zwei britischen Arten: 1. Haliphysema Tumanowiczii und 2. H. ramulosa. Eine Abbildung der ersteren findet sich auf Taf XXX des ersten Bandes (Fig. 359); eine Abbildung der letzteren auf Taf. XIII des III. Bandes (1874). Von

1) HAEChel, Monographie der Kalksehwämme, 1872, Bd. I, S. 76: „Die Stammform der Kalkschwämme (Olynthus);"Taf. 1, Fig. 1; Taf. 11, Fig. 6-9; T. af13, Fig. 9.

2) Bowerbayk, Monograph of the British Spongiadae, 1864-18\%4; Bd. I, p. 179; Taf. XXX, Fig. 359 . Bd. II, p. $76-80$; Bd. III, Taf. XIII. 
der ersteren Abbildung (Fig. 359) hat anch Oskar Schmit eine Copie gegeben in seinem „Zweiten Supplement der Spongien des adriatischen Meeres" (1S66, p. 13; Fig. 13).

Haliphysema Tumanowiczii charakterisirt Bowerbank folgendermaassen (Vol. II, p. 76): „Sponge pyriform, pedicelled; base expanded, thick, turgid at the margin; pedicel gradually enlarging upwards, fistular, parietes very thin, surface smooth and even; distal extremity abundantly hispid. Oscula and pores inconspicuous. Dermal membrane thin and translucent. Skeleton membranous, with an incorporation of fragments of spicula of various sizes and forms, and of minute grains of sand." In der ausführlichen Beschreibung, welche Bowerbank dieser Diagnose folgen lässt, bezeichnet er Haliphysema Tumanawiczii als die kleinste britische Spongie. Sie wird kaum eine Linie hoch und sitzt auf den Stämmchen von kleinen Algen und Zoophyten. Die einfache Gestalt des gestielten birnförmigen Schlauchs variirt wenig; nur der Stiel ist bald länger, bald kürzer; bisweilen wird der birnförmige Körper fast kugelig; die planconvexe scheibenförmige Basis des Stiels ist in der Mitte oft nabelförmig eingezogen. Die Höhle der Basis geht dnreh den hohlen röhrenförmigen Stiel unmittelbar in die Körperhöhle iiber. Die Wand des hohlen Schlauchs ist iiberall sehr diinn und ohne Poren; sie besteht aus einer zarten durchsichtigen Membran, mit welcher Sandkörner, Spongien-Nadeln und andere fremde Körper verkittet sind. Merkwürdig ist, dass die Schwamm-Nadeln (wie anch bei den anderen Physemarien) eine regelmässige Lagerung haben. In der scheibenförmigen Basis fiuden sich fast immer nur Bruchstiicke von Nadeln, unregelmässig durch einander gewebt; im cylindrischen Stiel sind die Spicula meistens parallel seiner Längsaxe gelagert; die birnförmige Distalhälfte endlich (,the head of the sponge", wie Bowerbani sagt) ist reichlich mit Nadeln bewaffnet, die nach allen Richtung'en ovalwärts abstehen (aber niemals rïckwärts nach der aboralen Basis gerichtet). Trotz dieser constanten Lagerung der Spongien-Spicula unterliegt es keinem Zweifel, dass dieselben fremde Körper sind und dass Haliphysema selbst keine Spicula bildet; es geht das schon daraus hervor, dass die Nadeln verschiedenen Schwamm-Arten angehören und dass die geknöpften Nadeln mit ihrem stumpfen Ende bald oralwärts, bald aboralwärts vorragen; auch dreistrahlige Nadeln liegen einzeln dazwisehen, ind Sandkörner in wechselnder Menge. Ausdriicklich ist hervorzuheben, dass Bowerbank weder Poren noch 
Oseula an dem vorgeblichen Schwamme entdecken konnte. Er sagt: „I have been unable even with a high microscopieal power, to detect either oscula or pores. Nor have I suceeeded in separating any portion of the dermal membrane from de sponge; but seen in situ it is evidently thin and translucent." (l. e. vol. II, p. 78). Im lebenden Zustande soll der diunwandige Schlaueh durehscheinend und bläulichweiss sein.

Wenig von Haliphysema Tumanowiczï verschieden scheint nach Bowerbank die zweite von ihm beschriebene Art, H. ramulosum, zu sein. (Vergl. mnten Nr. 5.) Anch hier ist der rundliche Körper auf einem hohlen Stiele befestigt, ohne Poren, und in ähnlicher Weise wie dort mit einem Pseudoskelet von Spongien-Nadeln und anderen fremden Körpern ansgestattet. Jedoch ist der Stiel hier verästelt und mehrere Personen sind zu einem Stöekehen vereinigt. Es ist nur ein einziges Exemplar dieser Art bekannt, ein gabelspaltiges Stöekchen von $5 \mathrm{Mm}$. Durchmesser, welehes aus 8 Personen zusammengesetzt ist. Die nähere Beschreibung folgt unten (im 14. Abschnitt).

Während Bowerank die beiden, von ihm zuerst beschriebenen Haliphysema-Arten fuir Spongien hält, ist dagegen ein anderer englischer Spongiolog, H. J. Carter, der Ansicht, dass dieselben Foraminiferen scien (!). Zwar hat Carten jene beiden Arten gar nicht vor Angen gehabt, aber er glaubt einen damit identischen Organismus gefunden und sieh von dessen ForaminifercnNatur ibberzengt zu haben. Nun ist aber dieser, von Carter sehr genau heschriebene und abgebildete Organismus weder eine Foraminifere, noch ist er mit Haliphysema identisch; vielmehr bildet er eine nene, mit letzterem nahe verwandte Gattung, der wir den Namen Gastrophysema beilegen wollen. CarTes kam auf den sonderbaren Gedanken, dass derselbe zu dem Monothalamien-Genus squamulina gehöre, und hat anch unter diesem Namen eine sehr genaue Besehreibung davon gegeben. I) Nun ist aber das Rhizopoden-Gents Squamulina 1854 von Max Schultze in seinem Polythalamien-Werke mit folgender Diagnose aufgestellt worden: „Sehale einer planconvexen, flachen Linse gleichend, mit der planen Seite festgeheftet, kalkig, eine einfache, ungetheilte Höhlung umschliessend; eine grössere Oeffnung auf der eonvexen Seite;

1) Carter (On two new speeies of the foraminiferous Genus Squamulina, and one new species of Difflugia. Ann. and Mag. of nat hist. May 1870, Vol. V, p. 309, Pl. IV, V). 
feine Poren fehlen."1) Hiernach ist Squamulina ein kalkschaliges Monothalamium; hingegen würde der merkwïrdige Organismus, den Carter als Squamulina scopula beschreibt, und den wir Gastrophysema scopula nennen, ein niclit kalkschaliges Polythalamium sein, wenn es iiberhaupt ein Rhizopod wäre; und es bleibt geradezu unbegreiflich, wie CarTer darauf verfiel, gerade die Gattung Squamulina dafür auszusuchen; zumal auch die äussere Gestalt gänzlich verschieden ist. ${ }^{2}$ )

Squamulina scopula (1. c., p. 310; Pl. IV, Fig. 1-11) - unser Gastrophysema scopula - bildet nach der Darstellung von Carten einen kolbenförmigen diunnwandigen Schlauch von einer Linie Länge. Auf einer scheibenförmigen, planconvexen Basis erhebt sich ein schlanker umgekehrt konischer Stiel, der ungefähr die Hälfte der Körperlänge erreicht und durch eine seichte Einschniirung von der anderen birnförmig erweiterten Hälfte geschieden ist. Die letztere zerfällt durch zwei seichte Einschniirungen wieder in drei Abtheilungen, so dass also der ganze Schlauch eigentlich aus fünf hintereinander liegenden und durch engere Thüren verbundenen Kammern besteht. Diese bezeichnet Carten als 1. Fuss." scheibe (pedestal); 2. Säulenstiel (column); 3. Hals (neck); 4. Körper (body) und 5. Kopf (head). Am Ende des letzteren öffnet sich der hohle Schlauch durch eine kleine kreisrunde Mündung. Die Höhlung der Fussscheibe ist unregelmässig in radiale Kammern geschieden, indem mehrere Falten der Wand, gleich unvollständigen radialen Scheidewänden, gegen das Centrum vorspringen.

Die dïnne Wand des schlauchförmigen Körpers soll aus einer chitinartigen Grundsubstanz bestehen, welche mit Sandkörnchen, Schwamm-Nadeln, Anneliden-Borsten und anderen fremden Körperchen verkittet ist. In der grösseren, aboralen Hälfte, in den vier proximalen Abtheilungen, besteht dieses Pseudo-Skelet

1) Max Scaultze, Ueber den Organismus der Polythalamien. Leipzig 1854.

2) Ausser Squamulina scopula beschreibt Carter noch eine zweite angebliche Art derselben Gattung unter dem Namen Squamulina varians (1. c., p. 321, Pl. V, Fig. 1-5). Auch dies ist keine wahre Squamulina, sondern wahrscheinlich eine Diffugia; ibre halbkugelige einkammerige Schale ist aus fremden Körpern gebildet. Hingegen ist wahrscheinlich die angebliche "neue Art von Diffugia", welche CARTER in unmittelbarem Anschluss daran als $D$. bipes beschreibt, keine Diffugia, sondern eine Cyphoderia oder verwandte Gattung! Wie ausserordentlich willkührlich, unlogisch und kritiklos Carter in seinen Arbeiten verfahrt, habe ich schon in meiner Monographie der Kalkschwämme gezeigt (Bd. I, S. 27-31). 
grösstentlıeils aus kleinen farblosen Quarz-Körnchen, gemengt mit kleinen Bruchstuickchen von Spongien-Nadeln. Dagegen ist die fünfte, distale Abtheilung, der "Kopf", mit einem dichten Busehe von längeren Schwammnadeln bewaffnet, welche nach allen Seiten, oralwärts gerichtet, abstehen. Carter vergleicht deshalb die ganze Form mit einem kleinen Besen oder Borstenpinsel („scopula"). Die Spicula riihren von Spongien der verschiedensten Gruppen her, Kalksehwämmen (Sycandra), Kieselschwämmen (Pachymatisma) u. s. w. Die geknöpften Nadeln sind häufig mit dem stumpfen Knopfende auswärts gekehrt.

Durch starken Druck (!) entleerte Carter aus der Mündung des Schlauches eine organische Masse, welche aus „halbdurchsichtiger gelblicher Sarcode" bestehen soll, enthaltend Körnchen, Oelkugeln, Diatomeen, Fucus-Becren und "reproductive cells.“ Letztere sollen besonders in der unteren (proximalen) Hälfte sich finden und werden beschrieben als ,kngelige, durehsichtige, kernhaltige Kapseln, erfüllt mit einer homogenen, schleimigen, eiweiss. artigen Substanz. Als Fundort der "Squamulina scopula" wird angegeben: Beach at Budleigh-Salterton, Devonshire; LaminarienZone; auf Wurzeln von Laminaria, Phyllophora etc.

In der breiten Erörterung, welche $\mathrm{C}_{\mathrm{A} \text { RTER }}$ an diese Besehreibung knüpft, erklärt er seine Squamulina scopula für identisch mit Bowerbank's Haliplysema Tumanowiczii, und macht Letzterem einen herben Vorwurf daraus, dass er diese „Foraminifere" für eine Spongie gehalten habe, ,as mental operations are seldom so correct as visual ones." (!) Wie wenig gerechtfertigt dieser Vorwurf ist, geht daraus hervor, dass erstens beide Organismen offenbar verschiedene Gattungen sind, zweitens weder dieser noch jener eine "Foraminifere“ ist, und drittens beide Gastraeaden viel näher den Spongien als den Foraminiferen stehen. Unbegreiflich ist es dagegen, wie Carter dazu kommen konnte, dieselben kurzweg für eine Squamulina zu erklären; obgleich Max Scudutze dieses Genus ganz klar als eine einkammerige Monothalanie mit compacter. Kalkschale von bestimmter Form bezeichnet.

Noch unbegreiflicher freilich, als diese Vereinigung von Haliphyseina mit Squamu'ina, einer einfachen, kalkschaligen Monothalamie, muss es erscheinen, wenn Canter dieselbe gleichzeitig fiü eine nautiolide Polythalamic erklärt. Man wird vermuthen, dass derselbe dic f'inf' Kammern des Schlauches, welche in ciner Reihe hintercinander liegen, für PolythalamicnKammern hält und demuach die ganze Kammerreihe einer Nodo- 
sarie oder Stichostegie vergleicht. Keineswegs! Vielmehr sollen die unregclmässigen und variablen Ausbuchtungen der engen Höhle in der Basalscheibe (,pedestal"), welche durch rudimentäre Scheidewände unvollstïndig getreunt sind, den Kammern einer nautiloiden Polythalamie entsprechen; die enge Basalhöhle soll die Centrạlkanmer und der ganze gestieltc Schlauch soll nur eine Verlängerung dieser Centralkammer sein. Diese ,comparative morphology" (p. 319) von Carter ist so merkwürdig, dass ich den betreffenden Hauptsatz hier wörtlich wiedergebe: „Now this radiated disk undoubtly has very much the appearence of the radiated septa of an coral polype; but is has a still nearer affinity to the septal divisions of a nautiloid foraminiferous test; and when we compare the whole structure of the pedestal with the latter, we cannot help seeing that the septal divisions are homologous with the septa of a nautiloid foraminiferous test, and that the central area corresponds with the initial or primary cell of a nautiloid individual, which, on being prolonged upwards, in Squamulina scopula, deveiopes a column at the expense of the spire." (!) Eine Kritik dieser "comparative morphology" erscheint iiberfluissig; zumal wenn gleich darauf diese monothalamie Polythalamie (die kein Rhizopode ist!) für nahe verwandt mit den Myxomyceten (Aethalium) erklärt wird (1. c., p. 319); und wenn unmittelbar darnach aus diesen „Homologien" gefolgert wird, dass die Foraminiferen Uebergangsformen $\mathrm{z}$ wischen Spongien und Corallen sind!! (p. 320). ${ }^{1}$ )

Was zunächst die angebliche Rhizopoden-Natur der Squamulina scopula anbetrifft, so ist diese von Carter in keiner Weise näher festgestellt. Denn dass er beim Druck auf die Schläuche gelbliche halbdurchsichtige Sarcode und zahlreiche Reproductions-Zellen entleerte, wird Niemand als Beweis für jene Behauptung gelten lassen; so wenig als den Umstand,

1) Die angeführten Ansichten Carter's iiber "Comparative Morpho$\operatorname{logie}$ " der Thiere erscheinen in noch merkwüdigerem Lichte, wenn wir a. a. O. von ihm erfahren, dass die nächsten Verwandten der Spongien die Tunicaten und zwar die Ascidien sind! On the ultimate structure of marine sponges. Ann. and mag. of nat. hist. 1870, Vol. V1, p. 335. (IVie die Foraminiferen die niedersten Formen der Corallen, so sollen die Spongien die „,initiative forms", der Bryozoen und Tunicaten sein! Anderseits freilich hält Carter die Schwänme wieder für, flagellated infusoria"! (Ibid. 1871, Vol. VIII, p. 1-27). Vergl. meine Monographie der Kalkschwämme, Bd. I, S. 27-31.) 
dass die herausgedriickte Masse unbestimmte Bewegungen zeigte. Die charakteristischen Ps e u d op odien der Rhizopoden und ihre

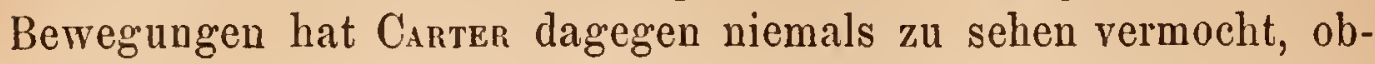
gleich er versichert, an vollkommen lebenden Exemplaren unter den günstigsten Umständen darnach gesucht zu haben. Er sucht das damit zu entschuldigen, dass man die Pseudopodien nur bei starken Vergrösserungen erkennen könne und diese bei dem grossen opaken Objecte nicht anwendbar seien. Das ist aber nicht richtig. Bei Gromien und anderen grossen Rhizopoden lassen sich die umfangreichen Pseudopodien-Netze schon bei schwacher Vergrösserung und häufig sogar mit blossem Auge deutlich erkennen.

Die wahre Natur von Carter's Squamulina scopula wurde mir klar, nachdem ich in Smyrna das nahe verwandte und nur specifisch verschiedene Gastrophysema dithalamium beobachtet hatte. Aus der Anatomie und Ontogenie dieses merkwürdigen Organismus, und aus der Vergleichung desselben mit dem schon friiher von mir in Norwegen beobachteten Haliphysema ergab sich, dass wir es hier mit einer neuen Gruppe von niedersten Pflanzenthieren zu thun haben, die in keine der hente bestehenden Thierclassen ohne Zwang sich einreihen lassen. Die Physemarien, wie wir diese Gruppe nennen wollen, sind weder echte Spongien, noch echte Hydroid-Polypen; noch weniger oder vielmehr gar nicht sind sie mit den Rhizopoden verwandt. Dagegen stehen sie der hypothetischen Gastraea, der zweiblaitterigen Stammform aller Metazoen, näher als alle anderen uns bekannten Thiere, und können daher geradezu als "Gastraeade n der G e genwar" bezeichnet werden. Ich will nun znnächst die genaue Beschreibung der verschiedeneu Arten geben, welche ich von den beiden Gattungen Halipliysema und Gastrophysema beobachtet habe, und daran einige allgemeine Betrachtungen iiber ihre Organisation, ihre VerwandtschaftsBeziehungen und ihre Bedentung fiir das Thier-System ankniipfen.

\section{Das Genus Haliphysema.}

Taf. IX-XI.

Ein Organismus, welcher mit dem Haliphysema Tumanowiczii von Bowerrask sehr nahe verwandt und wahrscheinlich sogar identisch ist, wurde von mir zuerst im Jahre 1869 an der Kiste von Norwegen beobachtet, als ich auf der Insel Gis-Oe unweit Bergen 
nach Kalkschwämmen suchte. Das kleine Wesen interessirte mich sehr wegen der auffallenden Aehnlichkeit, welche es mit der einfachsten Form der Kalkschwämme, mit Olynthus darbot, und ich glaubte zunächst in ihm eine einfachste Form der Sandschwämme oder Psammospongien gefunden zu haben, welche sich zu der gewöhnlichen Form der letzteren, zu Dysidea ebenso verhielte, wie Olynthus zu Dyssycus, wie die Asconen zu den Leuconen. Aber vergeblich suchte ich an dem einfachen schlauchförmigen Körper des vermuthlichen Sandschwammes nach Poren. Erst viel später, als ich in Smyrna mit der Anatomic und Ontogenie des Gastrophysema bekannt wurde, ging mir das Verständniss seiner Organisation auf. Erst dadurch wurde ich in den Stand gesetzt, dasjenige, was ich vier Jahre friiher in Norwegen dariber ermittelt hatte, richtig zu denten und zu Gunsten der GastraeaTheorie zu verwerthen. Ich verschob danals die Mittheilung meiner Beobachtungen, weil ich die Hoffnung hegte, dieselben bei einem wiederholten Aufenthalte an der Meercskiiste und bei genanerer Durclimusterung meiner Sammlung noch vervollständigen zu kömnen. Wenn auch nicht in dem gehofften Maasse, ist das wenigstens theilweise jetzt der Fall gewesen. Als ich im vorigen Jahre Corsica besuchte, gelang es mir, in der Bucht von Ajaccio ein kleines Haliphysema aufzufinden, welches dem $H$. Tumanowiczii der Nordsee sehr nahe steht und welches ich als H. primordiale bezeichnen will (Taf. IX). Ferner fand ich eine andere Art derselben Gattung (H. echinoides) aufsitzend auf dem Eusse einer Tief'see-Spongie aus dem zoologischen Museum in Bergen, welche ich Herrn Dr. Kones verdanke. Diese Art ist wahrscheinlich identisch mit der Wyvillethomsonia Wallichii, welche 1870 E. Perceval-Wrifht beschrieben hat. (Taf. X). Eine dritte, sehr merkwürdige Art ( $H$. globigerina) erhielt ich durch Herrn Ravnopp von den Far-Ö̈r. (Taf. XI). Nimmt man dazu die beiden von Bowerbank beschriebenen Arten, so beläuft sich die Zahl del Species in dieser Gattung bereits auf fiinf. Vier davon kommen auf den nördlichen Theil des atlantischen Oceans, eine auf das Mittelmeer. Ich gebe hier num zunächst die kurze Charakteristik des Genus Haliphysema und seiner fünf Species und schliessen daran die ausführliche Beschreibung der letzteren an.

Charakteristik des Genus Haliphysema: Körper der Person einfach schlauchförmig;, einaxig, ungegliedert; am aboralen Pole der Axe durch einen Stiel am Meeresboden befestigt. Einfache Höhle des Schlauches (Magenhöhle) am oralen 
Pole der Axe durch einen Mund geöffnet. Körperwand aus zwei Schichten gebildet: innere Schicht ein einfaches Geissel-Epithel, in dem einzelne Eizellen zerstrent liegen; äussere Schicht ein kernhaltiges Syncytium, aus verschmolzenen Zellen gebildet, welche eine Masse fremder Körper aufgenommen und so ein festes Psendo-Skelet gebildet haben. (Selten ist der Körper verästelt und bildet kleine Stöckchen).

\section{Uebersicht der Species von Haliphysema.}

\begin{tabular}{|c|c|}
\hline $\begin{array}{l}\text { Stiel des einkan- } \\
\text { merigen Körpers } \\
\text { solid, keine Fort- } \\
\text { setzung der Magen- } \\
\text { höhle enthaltend. }\end{array}$ & $\left\{\begin{array}{l}\text { Stiel einfach, kürzer als del spindel- } \\
\text { formige Körper. Sand-Skelet unten aus } \\
\text { Sandkörnchen, oben aus Schwamm- } \\
\text { nadeln gebildet. } \\
\text { Stiel einfach, 2-3 mal länger als der } \\
\text { kugelige Körper. Sand-Skelet grössten- } \\
\text { theils aus Schwammnadeln und Litha- } \\
\text { sterisken gebildet . . . . . . . . 2: H. echinoides. } \\
\text { Sticl einfach 4-6mal länger als der birn- } \\
\text { förnige Körper. Sand-Skelet grössten- } \\
\text { theils aus Rhizopoden-Schalen, nament- } \\
\text { lich Globigerinen gebildet. . . . . 3. H. globigerina. }\end{array}\right.$ \\
\hline $\begin{array}{l}\text { Stiel des cinkam- } \\
\text { merigen Körpers } \\
\text { hohl, eine Fort- } \\
\text { setzung der Magen- } \\
\text { höhle enthaltend. }\end{array}$ & $\left\{\begin{array}{l}\text { Stiel einfach, ungefäh so lang als der } \\
\text { keulenförmige Körper. Sand-Skelet } \\
\text { unten aus Sandkörnchen, oben aus } \\
\text { Scliwammnadeln gebildet . . . . 4. It. Tumanowiczii. } \\
\text { Stiel veristelt; Aeste 2-4mal länger } \\
\text { als die kugeligen Körper. Sand-Skelet } \\
\text { grösstentheils aus Fragmenten von } \\
\text { Spongien - Nadeln gebildet. (Stock } \\
\text { bildend) . . . . . . . . . . .5. H. ramulosum. }\end{array}\right.$ \\
\hline
\end{tabular}

1. Haliphysema primordiale H.

Taf. IX.

Diagnose: Körper der Person spindelförmig, auf einem kurzen, dicken Stiel befestigt. Stiel solid, cylindrisch, kaum halb so lang als der Körper, Magenhöhle spindelförmig; Mundöffnung einfach. Die fremden Körper, welche das Exoderm incrustiren, bestelien in der unteren (aboralen) Hälfte vorzıssweise aus Sandkörnchen, in der oberen (oralen) Hälfte vorzugsweise aus Nadeln verschicdener Spongien, sowohl Kiesel- als Kalkschwämme; Nadeln oralwäits gerichtet. 
Beschreibung: Haliphysema primordiale stellt in ansgebildetem Zustande einen spindelförmigen Schlauch dar, dessen änssere Gestalt wenig zu variiren scheint (Fig. 121, 122). Die Gesammtlainge beträgt 1,6-1,8, liöchstens $2 \mathrm{Mm}$. Das obere, orale Ende ist fast ellipsoid, 0,5-0,6 Mm. click; das unterc, aborale Ende verdiinnt sich in einen cylindrischen sehr kurzen Stiel von 0,2 Mm. Dicke. Dieser sitzt mit einer schmalen, scheibenförmigen, wenig verbreiterten Basis auf Algen auf, namentlich anf dem Thallus von Zonaria pavonina. Der Durchmesser der Basis beträgt 1/10 - 1/9, höchstens $1 / 8$ der Körperlänge.

Die Aussenfläche des Körper's erschcint bei schwacher Vergrösserung in der aboralen Hälfte glatt, in der oralen Hälfte stachelig. Bei starker Vergrösserung ergibt sich, dass die Incrustation des Exoderms in dem aboralen, cylindrisch-konischen Theile grösstentheils aus Sandkörnchen besteht, lingegen in dem ellipsoiden oralen Theile ans Spongien-Nadeln. Die Sandkörnchen, welche das Skelet des ersteren bilden, erscheinen insofern mit Auswahl zusammengelesen, als sie von ziemlich gleichmässiger Grösse sind; die meisten haben 0,02-0,06 Mm. Dazwischen finden sich viele kleinere, aber nur sehr wenig grössere Steinchen. Mit den Sandkörnchen gemischt, finden sich kleine Fragmente von Spongien-Nadeln und von Echinodermen-Stacheln, hier und da auch Bruchstiickchen von Mollusken-Schalen. In der Mitte des Körpers wird dieses Skelet-Material seltener und an seine Stelle treten die Spicula von Spongien, welche in dem oralen Körperdritttheile fast ansschliesslich die Bewaftnung bilden. Diese Schwammnadeln gehören sehr verschiedenen Gattungen und Arten von Spongien an. Ganz vorherrschend sind die einfachen, an beiden Enden zungespitzten Nadeln von Reniera; dazwischen finden sich aber anch hänfig die stecknadelförmigen, am einen Ende spitzen, am andern Ende mit einem Knopfe versehenen Nadeln von Esperia; und zwar ist hier gewöhnlich das stumpfe oder geknöpfte Ende nach aussen gekehrt, das spitze Ende im Exoderm verborgen; seltener ist das Umgekehrte der Fall. Zwischen den ganzen, wohlerhaltenen Nadeln der Kieselschwämme finden sich verstiimmelte und abgebrochene Nadeln, sowie Fragmente. Auch Spicula von Kalkschwämmen finden sich in geringer und wechselnder Zahl zwischen den Nadeln der Kieselschwämme, insbesondere die characteristischen Dreistrahler von Ascetta blanca und die schlanken, an ihrer lanzenförmigen Spitze leicht kenntlichen Stabnadeln von Ascandra Lieberkiihnii: zwei Asconen die 
in grossel Menge und Formen-Mannigfaltigkeit an der nämlichen Localitiit sich finden. Bei letzterem Kalkschwamme ist stets die einfache Spitze der langen defensiven Stabnadeln im Exoderm verborgen, die Lanzenspitze frei nach aussen gekehrt. Hingegen erscheinen dieselben Nadeln im Körper von Haliphsema primordiale ohne Wahl gelagert, bald die einfache Lanzenspitze aboral im Exoderm versteckt, die Lanzenspitze oralwärts frei vorstehend, bald urngekehrt. Im Uebrigen sind bei $H$. primordiale, ebenso wic bei $H$. Tumanowiczii, die Nadeln sämmtlich mehr oder weniger oralwärts gerichtet, die meisten parallel der Längsaxe des Körpers oder wenig davon abweichend; bald sind sie so dicht gedrängt; dass sie einen pinselartigen Busch oder Besen bilden, bald stehen sie lockerer vertheilt (Fig. 121).

Ein L ïng s s chnitt durch Haliphysema primordiale offenbart sofort die charakteristische Organisation dieses einfachen Gastraeaden (Fig. 122). Der spindelförmige Körper enthält eine geräumige Höhle von gleicher Gestalt, deren dicke Wand aus zwei völlig verschiedenen Schichten besteht. Diese beiden Schichten sind die beiden primären Keimblätter: Exoderm und Entoderm. Nur das Exoderm enthält die fremden Körperchen, welche das stiutzende und schiitzende Skelet der schlauchförmigen Person bilden. Das Entoderm hingegen besteht nur aus einer einzigen Schicht von Geisselzellen, zwischen denen einzelne Eier zerstreut liegen.

Das Exoderma oder Hautblatt, das äussere primaere Keimblatt, zeigt bei genanerer Untersuchung folgende charakteristische Verhältnisse. (Fig. 122e, 123e, 126). Die fremden Körper, welche das Skelet zusammensetzen und welche den grössten Theil der Körperwand einnehmen, sind verkittet durch eine organische Substanz. Diese ist nicht etwa eine structurlose Ausscheidung der inneren Zellenschicht, sondern besteht aus Protoplasma mit eingestreuten Zellenkernen, bildet mithin ein Syncytium in demselben Sinne, in welchem ich dasselbe bei den Kalkschwämmen beschrieben habe (Monogr. Bd. I. S. 160-170). Soweit ich die Beschaffenheit desselben habe ergriunden kïnnen, stimmt es anch in chemischer und physikaliseher Beziehung wesentlich mit letzterem iiberein. Uebrigens ist die Untersuchung. nieht leicht, denu die Sandkörner, die Schwammnadeln und die iibrigen fremden Körper sind meist so dicht mit einander verwebt nud verkittet, dass es nur schwer gelingt, die verbindende Zwischensubstanz, die eigentliche Grundsubstanz des Exoderms, in 
einiger Menge zu isoliren (Fig. 126). Wo dies möglich ist, da zeigt sich dasselbe als eine homogene oder feinkörnige Masse, in welche zahlreiche rundliche Zellenkerne eingestreut sind. Die Nuclei sind meistens länglich-rund, ellipsoid oder eiförmig, bisweilen fast stabförmig gestreckt, von 0,006-0,009 $\mathrm{Mm}$. Durchmesser. Die Substanz der Kerne erscheint ziemlich hell oder feinkörnig. Ein Kernkörperchen ist meist sichtbar. Durch Einwirkung von verdünnter Essigsïure treten sie sehr scharf hervor. Nach längerer Einwirkung von Carmin färben sie sich hellroth, deutlicher als die Grundsubstanz, doch viel schwächer als die Kerne der Entodermzellen. Um jeden Kern herum findet sich ein Hof von sehr kleinen, fettglänzenden, dunkeln Körnchen. Häufig: strahlt dieser Körnchenhof sternförmig aus.

Das Entoderma oder Darmblatt bietet bei H. primordiale folgende Verhältnisse dar (Fig. 122 i, 123 i, 125). Die gesammte Magenhöhle ist von einer einzigen Schicht von flimmernden Zellen ausgekleidet. Dieses Gastral-Epithelium besteht zum grössten Theile aus Geisselzellen (i), zwischen denen im aboralen und mittleren Theile der Darmhöhle amoeboide Eizellen zerstreut sind (0); am oralen Theile findet sich eine Zone von grösseren Geisselzellen, die eine unvollkommene Spirale bildet und als Strudel-Apparat zur Einführung von Wasser und Nahrung fungirt. (Fig. 124).

Die Geisselzellen (Fig. 124), welche den grössten Theil des Gastral-Epitheliums bilden, zeigen in Grösse, Form, Structur und physiologischem Verhalten die grösste Aehnlichkeit mit den Geisselzellen der Kalkschwämme, welche ich in deren Monographie ausfiihrlich beschrieben und durch zahlreiche Abbildungen erläutert habe. (Bd. I, S. 132-144; Bd. III, Taf. 1, Fig. 8; Taf. 25, Fig. 5, 6; Taf. 41, Fig. 7 etc.). Wie bei den Calcispongien, so ist auch bei unseren Gastraeaden das Protoplasma der cylindrischen Geisselzellen deutlich in ein hyalines Exoplasma und ein granuloeses Endoplasma geschieden. Das letztere enthält wechselnde Mengen von feinen fettglänzenden Körnchen und $11 m-$ schliesst den kugeligen Kern (von 0,002-0,004 Mm. Durchmesser). Das hyaline Exoplasma enthält keine Körnchen, und ist von sehr geringer Dicke. Nur an dem freien Theil der Zelle, welcher der Gastralfäche zugekehrt ist, erscheint dasselbe verdickt („Zellhals, Collum") und erhebt sich in Gestalt eines trichterförmigen Ringes („Zellkragen, Collare"). Innerhalb dieses Trichters erhebt sich dic lange und sehr dünne fadenförmige Geissel, deren Basaltheil bis in das körnige Endoplasma hineinragt (Fig. 125). Ihre Schwingungen 
sind ziemlieh lebhaft. Die Länge der Geissel beträgt 0,03-0,04 Mm., Die Länge der Cylinderzellen 0,007-0,01 Mm., ihre Dieke 0,003 Mm. Ihre Form ist wechselnd, eylindrisch-prismatisch oder gegen die Basis konisch verdickt, bisweilen mehr glockenförmig. Wie bei den Spongien, so können auch hier die Geisselzellen ihre Gestalt verändern und isolirt amoeboide Bewegungen ausführen.

Der Strud el-A p p a r at (Fig. 124), welcher die Mundöffnung von Haliphysema primordiale auskleidet, und welcher die beständige Einfuihrung von Wasser und Nahrung vermittelt, ist vielleicht ein eharakteristischer Theil in der Organisation der Physemarien. Er besteht aus einer Spirale von stärkeren Flimmerzellen, die sich sowohl durch ilure Grösse, wie dureh ihre sonstige Beschaffenheit von den iibrigen Geisselzellen des Gastral-Epithels anszeichnen. Die Untersuchung dieses Apparates ist sowohl bei Haliphysena primordiale als bei Gastrophysema dithalamium, bei welchen beiden Arten ich denselben allein deutlich erkannt habe, äusserst schwierig und es werden sich vielleicht bei genauerer Untersuchung an günstigeren Arten noch mancherlei Verhältnisse ermitteln lassen, übel die ich keine befriedigende Klarheit erlangen kounte. An Spiritus-Exemplaren, anch an gut conservirten, lässt sich gerade hierïber sehr wenig ermitteln. Soviel ich bei Haliphysema primordiale, theils an Längschnitten der lebenden Person, theils bei der zufälligen (selten gelingenilen) Einsicht in die Mundöffnung beobachten konnte, stellt der Strudel-Apparat hier eine flache Spirale dar, welche viel Aehnlichkeit mit der adoralen Peristom-Spirale von mancherlei ciliaten Infusorien, namentlich Stentor und Vorticella, besitzt. Die Spirale beginnt an einem Punkte der Mundöffnung und geht in flacher Windung durch die innere Peripherie des kurzen Schlundrohres, wie wir den verengerten Oraltheil der Gastralhöhle bezeichnen können. Sie scheint nur eine vollständige Windung zu beschreiben und verliert sich unten ohne scharfe Grenze zwischen den gewölnnlichen Geissclzellen. Die grösseren Geisselzellen des Peristoms sind 2-3 Mal so dick, anderthalbmal bis doppelt so lang als die gewöhnlichen Geisselzellen und von mehr rundlicher Form. Ihre Länge betrïgt 0,012-0,016 Mm., ihre Dicke 0,005 Mm. Ihr Kern ist ebenso gross oder nur wenig grösser als derjenige der Gastralzellen. Das Endoplasma ist dunklerkörnig und enthält einzelne Oelkiigelchen. Das Exoplasma ist dicker und geht in einen dicken starken Hals iiber, aus dessen Rande sich nur ein niedriger Kragen 
erhebt. In der Axe des trichterförmigen Kragenhohlraums steht cinc schr starke und lange Geissel von 0,01-0,02 Mm. Länge.

Die Eizellen von Haliphysema primordiale gleichen in Bezug auf Grösse, Beschaffenheit und Vertheilung im Gastralraum denjenigen von Olynthus (Monogr. der Kalkschwämme, Taf. 1, Fig. 1 g, $7 \mathrm{~g}, 10-12$; Taf. 11 , Fig. $6 \mathrm{~g}, 7 \mathrm{~g}$ etc.). Die Eier sind nackte, amcoboide Zellen und liegen einzeln zerstreut zwischen den Geisselzellen des Gastral-Epithels. Ihre Grösse beträgt im Durchmesser 0,04-0,06 Mm. Das Protoplasma ist in ein ganz hyalines Exoplasma und ein sehr körnerreiches Endoplasma gesondert. Ersteres schickt stumpfe amoeboide Fortsätze aus, durch deren active Ortsbewegungen die Eizelle im Stande ist, langsam umherzukriechen. In die dickeren Fortsätze tritt auch ein Theil des körnigen Endoplasma ein. Dieses ist sehr truibe, reich an feinen dunkelglänzenden Körnchen und grösseren Oel-Kïgelchen. In der Mitte schimmert ein helles Keimbläschen durch. Wenn man dieses durch Zerdriicken isolirt, erscheint es als ein klares kugeliges Bläschen von 0,02-0,03 Mm. Durchmesser. Dasselbe enthält einen dunkeln, stark lichtbrechenden Keimfleck, in welchem oft ein kleiner Keimpunkt sichtbar ist (Fig. 1220, 1230).

Spermazellen war ich trotz vieler Bemïhungen nicht im Stande nachzuweisen. Wenn sich dieselben im Exoderm entwickeln sollten, so würde der Nachweis sehr schwicrig sein. Vielleicht habe ich aber die Zoospermien iibersehcn oder mit gastralen Geisselzellen verwechselt. Vielleicht ist auch diese Art getrennten Geschlechts. Die Entwicklung der Eier konnte ich nicht beobachten.

Die Lebensersche in ungen, welche ich an dem lebenden Haliphysema primordiale beobachtete, beschränken sich auf die Flimmerbewegungen der Geisselzellen und die amoeboiden Bewegungen der Eizellen. Am Exoderm vermochte ich weder im Ganzen, noch an einzelnen isolirten Stuicken Bewegungen wahrzunehmen, ebenso wenig als an der ganzen Person. Jedoch schien die Mundöffnung zu verschiedenen Zeiten einen verschiedenen Durchmesser zu besitzen.

Die F a rbe ist im Leben bräunlich, getrocknet weisslich.

Fundort: Mittelmeer. Auf Felsen der Bucht von Ajaccio (Corsica), meistens aufsitzend auf dem Thallus von Zonaria pavonia, in Gesellschaft von Ascetta blanca. HaEcikr. 
2. Haliphysema echinoides, H.

Taf. X.

Diagnose: Körper der Person kugelig oder subsphäriseh, auf einem diinnen und langen Stiel befestigt. Stiel eylindrisch, oben konisch verdiekt, solid, 2-3 mal so lang, aber kaum 1/6 so diek als der Durchmesser der Kugel. Magenhöhle rundlich oder subkonisch. Mundöffnung etwas trichterförmig erweitert. Die fremden Körper, welehe das Exoderm inerustiren, bestehen an dem dünnen Sticl aus Sandkörnehen und longitudinal gelagerten Schwamm-Nadeln; an dem kugeligen Körjer aus Nadeln verschiedener Spongien, welche allseitig abstehen, meistens radial in Beziehung auf die Mitte der Kugel.

Specielle Beschreibung: Haliphysema echinoides bildet kleine, kugelige, einem Distelkopf ähnliche Blïschen, die auf einem diinnen und langen soliden Stiele befestigt sind. Ich fand vier Exemplare derselben aufsitzend auf der Basis eines Tiefsecschwanimes (einer stelletta), welcher dem zoologisehen Museum zu Bergen (Norwegen) gehörte und welche mir der Direetor desselben, Herr Dr. Koren, giitigst zur Untersuchung überliess. Das Gläschen, in welchem sich das Präparat vorfand, war ohne nähere Bezeichnung des Fundortes; jedoch rührte sein Inhalt nach Dr. Korex's miindlicher Mittheilung von einer nordatlantischen TiefsceSondirung her. Der Durchnesser des kugeligen Köpfchens beträgt 0,8 Mm., den Stachelpanzer mitgerechnet 1,2-1,5 Mm.; die Länge des Stiels 1--2 Mm., die Dieke desselben 0,1-0,2 Mm.; die konische oder zwiebelförmige Basis, mit welcher der Stiel auf den abgestorbenen Körper des Rindensehwammes befestigt ist, lat $0,6-0,8 \mathrm{Mm}$. Durchmesser.

Der eigentliche sphärische Körper dieses Haliphysema ist so stachelig wic ein Eehinus oder ein Distelköpfehen und starrt von zahlreiehen diinnen und einzelnen dickeren Nadeln, die nach allen Richtungen dicht gedrängt abstehen. (Fig. 127). Die genanere Untersuchung ergibt, dass dieser Stachelpanzer fast aussehliesslich dureh die Spicula verschiedener Spongien gebildet wird, namentlich von Corticaten. Es finden sich darunter zahlreiche stärkere und feinere Ankernadeln, wie sie bei Geodia und Stelletta vorkommen; dazwisehen sehr viele diinne einfache Nadeln. Die vierstrahligen Ankernadeln sind meistens so gelagert, dass der lange Hauptstrahl radial abstht und die drei Ankerzähne 
an seinem freien Ende trïgt, doch kömnen die letzteren auch ungekehrt im Exoderm eingekittet sein. In letzterem finden sich ausserdem noch sehr zahlreiche, kleinere und grössere, sternförmige Spicula von Tethya oder Stelletta und Kieselkugcln ron Geodia oder Caminus. Diese letzteren sind auch in grosser Zahl in den soliden Stiel eingekittet, dessen Oberfläche mit einer Sehicht von einfachen und ankerfömigen Nadeln gepanzert ist. Letztere sind unregelmässig longitudinal neben einander gelagert, die drei gekriummten Ankerzähne bald nach oben, bald nach nuten gerichtet. Unten breitet sich der solide Stiel in eine unregelmässige scheibenförmige Basis aus, welche zum grössten Theile aus dicht verkitteten Kieseltheilen von Corticaten, TethyaSternchen und Geodia-Kiigelchen besteht (Fig. 127).

Ein L ä n g s ch n itt durch den Körper von Haliphysema echinoides (Fig. 12S) zeigt uns eine zicmlich enge, rundliche, fast kegelförmige Darmhöhle, die von einer dicken, zweischichtigen Wand umschlosscn ist. Dic äussere Schicht ist das Exoderm, welches eine sehr feste mörtelartige Masse darstellt. Diese besteht aus einem kernucichen Syneytium, welches mit deu fremden Körperu des Pseudo-Skelets sehr fest verkittet ist; sowohl mit den Basaltheilen der radial abstehenden Spongien-Nadeln, als auch mit schr zahlreichen und dicht gedrängten Fragmenten von SpongienNadeln und Sandkörnchen, hauptsächlich aber Lithasterisken von Tethyen, Stelletten u. s. w. Alle diese Spongien-Skelettheile, zu denen sich auch noch Sandkörnchen, kleine Splitter von zerbrochenen Muschelschalen, Echinodermen-Stacheln n. s. w. gesellen, sind sehr dicht mit einander verkittet durch eine ausnehmend feste und zähe, fast knorpelartige Sarcode-Masse. Zahlreiche, in letatere eingestreute Zellenkerne beweisen, dass wir auch hier wieder ein Syneytium vor uns haben. Die Nuclei sind von unregelmässiger, länglichrunder Gestalt, 0,005-0,007 Mm. gross. Sie sind am zahlreichsten und am leichtesten zu finden an der glatten Innenfläche des Exoderms, während die uuebene, äussere Oberfäche des letzteren fast bloss ron den fremden Körpern eingenommen wird.

Im Grunde der Magenhöhle bildet das Exoderm in deren $\Lambda$ xe einen zapfenartigen konischen Vorsprung (Fig. 128 e). Derselbe wird vou einigen stärkern, als Fortsetzung des Stiels erscheiuenden Spongien-Nadeln gestützt und scheint wesentlich als Träger der gleich zu erwähnenden Eizellen zu dienen. Wir wollen diesen Zapfen als Columella bezeichnen.

Das Entoderm befand sich an den vier, mir zu Gebote 
stehenden Spiritus-Exemplaren in einem so mittelmïssigen Erhaltungszustande, class ich wenig mehr als die Anwesenheit eines einsehichtigen Zellenlagers und im Grunde der Magenhöhle von Eizellen constatiren konnte. Die Epithelzellen der Darmhöhle erschienen rundlich, polyedriseh, von 0,006-0,008 Mm. Durchmesser, mit einem ungefähr halb so grossen Kern. Von dem Hals und Halskragen der Geisselzellen, wie sie H. primordiale zeigte, war nichts zu bemerken, eben so wenig von einer Geissel. Auch die Spur einer adoralen Geisselspirale liess sich nicht auffinden. Dagegen lag im Grunde der Magenhöhle ein unregelmäissiger Haufen von grossen, trïbgranulirten, rundlichen Zellen, die man ihres hellen bläschenförmigen Kernes halber wohl für Eizellen zu halten berechtigt ist (Fig. 128 c, Fig. 131). Dieselben haben 0,08-0,12 Mm. Durehmesser, ihr Keimbläschen 0,02-0,04 Mm. Sie schienen an der Columella des Exoderms anzuhaften.

Haliphysema echinoides besitzt sehr viel Aehnlichkeit mit dem kleinen 'Tiefsee-Bewohner, den E. Perceval-Wright unter dem Namen Wyvillethomsonia Wallichii als eine Zwerg-Spongie beschrieben und abgebildet hat. ${ }^{1}$ ) Der fragliche Organismus wurde von Wallich im October 1860 in einer Tiefe von 1913 Faden (=11,478 Fuss) im atlantischen Ocean zwischen Neufundland und Grönland gefischt $\left(58^{0}, 23^{\prime}\right.$ N. Br.; $48^{05} 0^{\prime}$ W. L.). Der kugelige Körper hat $2 \mathrm{Mm}$. Durchmesser und sitzt auf einem $3 \mathrm{Mm}$. langen Stiele auf; das Skelet besteht ans sehr verschicden geformten Spongien-Nadeln, insbesondere aus dreizähnigen Ankeruadeln, einfachen, an beiden Enden zugespitzten, meist etwas gekriimmten Nadeln, und sehr zahlreichen Kieselsternchen. Die dreizähnigen Anker haben theils drei einfache, theils gabelspaltige Zähne und einen sehr langen, spitzen Stiel. Das sind Elemente, wie sie nur bei den Rindenschwämmen oder Corticaten vorkommen. Allein ihre Lagerung und Anordnung in der kleinen Wyvillethomsonia ist ganz verschieden von derjenigen der Corticaten, wie auch Penceval-Wrignt ganz richtig hervorhebt. Ausserdem fand derselbe bei einem seiner drei Exemplare zwischen jenen Corticaten-Nadeln sechsstrahlige Spieula, wie sie nur die ganz versehiedenen Hexactinellen besitzen. Aus allen diesen Griunden möchte ich glauben, dass Wyvillethomsonia Wallichii keine echte Spongie ist, sondern ein Haliplyysema, welehes sich sein Skelet aus den Spicula

1) E. Perceval Wrigut, On a new genus and species of Sponge from the deep-sea. Quarterly Journ. of micr. sc. 1870; Vol. X, p. 7; Pl. II. 
verschiedener Spongien, vor\%ugweise Corticaten, anfgebaut lat. In der speciellen Zusammensetzung desselben, wie in der gesammten Körperform und Grösse gleicht sie unserem Il. echinoides so sehr, dass mir ihre specifische Identitiit walırscheinlich ist. Eine Abwcichumg wiirde allerdings darin bestehen, dass sich der Stiel bei Wyvillethomsonia durch die Axe der ganzen Magenhöhle fortsetzt, wie cine lange Colnmella. Viclleicht bilden sich hier dic Eier. Eiue kïrzere Colunella besitzt aber auch unser Haliphysema. Von dem Geissel-Epithel des Entoderms sagt Perceval-Wrigut, der nur conservirte Präparate mutersuchen konnte, nichts; ebenso von Poren nichts. Spätere Beobachter derselben Art werden genan darauf zu achten haben.

Fundort: Tiefsee des Nord-Atlantischen Oceans; Wallich, Koren.

3. Haliphysema globigerina, H.

Taf. XI.

Diagnose: Körper der Person birnförmig, auf einem schr dünnen und lang'en Stiel befestigt. Stiel solid, cylindrisch, oben konisch verdickt und 4-6mal so lang, aber kaum 1/10 so dick als der Körper. Magenhöhle birnförmig. Mundöffnung einfach. Dic fremden Körper, welche das Exoderm incrustiren, bestehen aus den Bestandtheilen des Tief'seeschlammes, in der Körperwand zum grössten Theil aus Rhizopoden-Schalen, im Stiele mẹistens aus Coccolithen und Coccosphaeren.

Speciell e Besch re i b u n g: Haliphysema globigerina zeichnet sich vor den iibrigen bis jetzt bekannten Physemarien dadurch aus, dass die Bestandtheile des Skelets zum grössten Theile nicht Schwammnadeln und Saudkörnchen, sondern Rhizopoden-Schalen sind, volzugsweise Globigerinen. Offenbar ist diese eigenthuimliche Panzerbedeckung durch unmittelbare Anpassung an das Banmaterial des Wohnortes, an den Globigerinen-SchIamm gebildet, der die Tiefen des Oceans bedeckt. Ich erhielt diese merkwürdige Physemarie von Herrn Randropp in Thorshavn (Far-Öer). Das mit Weingeist gefüllte Glïschen, in welchem ich dieselben fand, enthiclt ausserdem mehrere Tiefsee-Spongien, aber keine nïhere Bezeichnung iiber Fundort und Tiefe. In derselben Sammlung befanden sich auch die Tiefgrundproben aus dem nordatlantischen Ocean, welche ich meiner Untersuchung vou Bathybius zu 
Grunde gelegt habe. ${ }^{1}$ ) Die Bestandtheile dieses GlobigerinenSeblammes sind ganz dieselben, welche das Pseudo-Skelet unsers Haliphysema zeigt, und daher erscheint die Vermuthung gerechtfertigt, dass das letztere in denselben grossen Tiefen lebte.

Der Körper zeigte bei allen drei mir vorlicgenden Exemplaren ziemlich dieselbe birnförmige Gestalt unıl auch dieselben GrössenVerhältnisse. Die Birnform ist sehr regelmässig. Die Länge beträgt 1-1,3 Mm., die Dieke 0,5-1 Mm. Der sehlanlie, S-förmig gebogene Stiel ist 2-4 Mm. lang, 0,1-0,12 Mm. diek. Unten war der Stiel bei allen drei Exemplaren abgebrochen, so dass er möglicherweise noch eine bedcutendere Länge erreicht. Worauf die Thierchen befestigt waren, liess sich aus diesem Grunde nicht ermitteln.

Das Exoderm besteht aus einer sehr zihen und festen, kernhaltigen Sareode, welehe mit den bekannten Bestandtheilen des Bathybius-Schlammes zu cinem hirten Mörtel verkittet ist. Die Hauptbestand theile sind Rhizopoden-Sehalen und unter diesen vor allen Globigerinen, dickschalige $(K)$ und dünnschalige $(G)$ ungefähr in gleichen Verhältnissen. Dazwisch'n finden sich eimzelne Rotalicn, Polystomellen, Textularien (T) und andere kalkschaligc Polythalamien; ansserdem auch eirzelne Radiolarien: Haliomma (H), Euchitonia (E), 'T'rematodiseus (D) u. s. w. Zwischen den ganzeu Schalen liegen allenthalben Fragmente von zerbrochenen Sebalen, ferner Coecolithen und Coceosphaeren, kleine Sandkörnchen und Fragmente von Spongien-Nadeln, letztere in sehr geringer Quantität. Die flacheren Schalen sind sämmtlich in TangentialEbenen gelagert. In dem verkittenden Sareode-Mörtel zwischen den Schalen sind nur hier und da cinzelne Zcllenkerne wahrzunchmen und diese sind nieht leicht anfzufinden. Dagegen liegt unter dem Pseudoskelet und nicht scharf von ihm zu trennen, eine diinne Sareode-Sehicht, welehe reich an Zellenkeruen ist und nur wenige fremde Körper, meist kleinste Fragmente und Coceolithen enthält. Die innere Oberflache dieses Syncytium, auf welcher das Entoderm auisitzt, ist ganz glatt und unmittelbar unter derselben erscheinen die Nuclei in einer schr regelnässigen

1) HaEcker, Bathybius und das freie Protoplasma der Meerestiefen. Studien über Moneren und andere Protisten, p. 86. Das von H. Randropp exhalteue Gläschen mit Globigerinen-Schlamm trug die Aufschrift: „Dredged of Professor Thomson und Dr. Carpenter with the steamer "Porcupine" on 2435 Fathoms, 22. Juli 1869. Lat. 47038"; Long. 1204". 
Schicht, in gleichen Abständen vertheilt. Die Kerne sind länglich rund, 0,002-0,004 Mm. gross, meistens von cinem kleinen Köruchenlofe umgeben. (Fig. 134.)

Der lange diinne Stiel des Körpers ist sehr fest und zugrleich schl elastisch. Auf einem Querschnitt (Fig. 136) zeigt sich, dass derselbe solid ist und dass seinc centrale Axensubstanz verschieden von der peripherischen Rindensubstanz und zienlich seharf von dieser getrennt ist. Die Axensubstanz besteht fast blos aus Protoplasma, mit selı zahlreichen Kernen, welche in regelmässigen Abstinden und parallel der Längsaxe gelagert sind (Fig. 136n). Die Rindensubstanz hingegen besteht vorzugsweise aus Coccolithen (Discolithen und Cyatholithen). ${ }^{1}$ ) Die Menge des Protoplasma, welches dieselben verbindet, ist sehr gering und cbenso dic Zahl der Kerne, die dazwischen zertreut liegen.

Ein Lä ngs schnitt durch den Körper (Fig. 133) zeigt eine geräumige Magenhöhle von birnförmiger oder fast kugeliger Gestalt und 0,8 Mm. Lurubmesser. Oben offnet sich dicselbe dureh einen kreisrunden Mund von 0,15 Mm. Durehmesser. Diese Mundöfnuug ist nabelförmig eingezogen. Anf einem gut gelungenen Längssclmitt durch die Mitte derselben zeigt sich, dass die Wand der Magenhöhle hier eine förmliche Einstiilpung, eine Art Schlund bildet. Diesem gegeniiber erhebt sich im Grunde der Magenhöhle ein knuzer konischer Zapfen, eine Columella, ähnlich wie bei $H$. echinoides (Fig. 133 e, $135 \mathrm{c}$ ).

Das Verhalten des Entoderms liess sich leider an den wenigen Spiritusexemplaren nicht genau erkenneu. Nur die Anwesenheit eincr einfachen Epithelsehicht liess sich eonstatiren (Fig. 133 i). Dieses Gastral-Epithelium bestand ans einer einzigen Sehicht polyedrischer, kernhaltiger Zellen von 0,004-0,006 Mm. Durchmesser und schicn die ganze Imnenfläche der Magenhöhle gleichmässig zu überziehen (Fig. 134i). An dem kouischen Zapfen im Gruude der Magenhöhle waren diese Zellen etwas grösser, vielleieht Mutterzellen von Eiern? (Fig. 1350). Ob sich das EntodermEpithel auch noch auf die schlundartige Einstiulpung fortsetzte, liess sich nicht entscheiden.

Fund ort: Tiefsee des Nord-Atlantischen Occans. Randropp.

1) Ueber Coccolithen (Discolithen und Cyatholithen) und Coccosphaeren, vergl. den citirten Aufsatz über Bathybius (S. 190 Anmerkung). 
3. Haliphysema Tumanow i czi i, Bowenbank. (Bowerbank, Monograph of the British Spongiade Vol. J, p. 179, Taf. XXX, Fig. 359; Vol. II, p. "76).

Di ag nos e: Körper der Person keulenförmig oder eiförmig, anf einem kurzen, dicken Stiel befestigt. Stiel hohl, cylindrisch, ungefähr so lang als der Körper und halb so dick, unten mit scheibenförmig verbreiterter hohler Basis aufsitzend. Magenhöhle keulenförmig, unten bis in die Basis fortgesetzt. Mundöffnung cinfach. Die fremden Körper, welche das Exoderm incrustiren, bestehen zum grössten Theile ans Spongien-Nadeln und deren Fragmenten; dazwischen finden sich, namentlich im Stiel, zahlreiclıe Sandkörnchen.

Specielle Beschleibung: Haliphysema Tumanowiczii ist das erste Physemarium, von dem eine Beschreibung und Abbildung gegeben wurde. Es geschah dies vor zwölf Jahren (1564) durch Bowerbank (l. c.). Abgesehen davon, dass derselbe das Entoderm nicht erwähnt, welches die Innenfläche der Magenhöhle auskleidet, ist seine Beschreibung sehr genau; auch die Abbildung, von der Oskar Schnidt im zweiten Supplemente zu seinen adriatischen Spongien (Fig. 13) eine Copie gegeben hat, ist recht naturgetren (Vergl. oben S. 173).

Bowerbank erhielt das Haliphysema Tumanowiczii, das er zu Ehren seines Entdeckers benannte, zuerst durch diesen vom DiamantGrund bei Hastings, später auch noch von mehreren anderen Stellen der britischen Kuiste. Ich selbst beobachtete diese Art während meines Aufenthaltes an der norwegischen Küste (1S69), auf der Insel Gis-Oe, in der Nähe von Bergen. Das kleine Physemarium sass daselbst in einzelnen Exemplaren auf den Wurzeln von Laminarien, die ich mit dem Schleppnetz aus einer Tiefe von ungefähr 60-80 Fuss heraufgeholt hatte. In Grösse, Form und Skeletbildung stimmten diese norwegischen Exemplare so sehr mit den von Bowerbani beschriebenen britischen iiberein, dass ich dẹr genauen Darstellung des letzteren hier nur Wenig hinzuzufiigen habe.

Der eigentliche Körper ist oval oder birnförmig, 1-1,2 Mm. lang und halb so dick. Ebenso lang, aber nur ein Viertel so dick ist der hohlc eylindrische Stiel, der sich unten in eine scheibenförmige convexe Basis ausbreitet. Letztere ist an den norwegischen Exemplaren kleiner als an den britischen. Durchschnitte dureh den kleinen 
Schlanch zeigen eine gerïumige Höhle, die sich oben durch eine kreisrunde einfache Miindung öffnet, und deren diume Wand dentlich ans zwei versehiedenen Schichten besteht. Die innere Schicht, das Entoderm, ist ein einfaches Geissel-Epithel; die Geisselzellen desselben schienen mir damals sehr ähnlich denjenigen der Kalkschwiimme zu sein; eine genanere Untersuchung derselben habe ich nicht angestellt. Die ïnssere Sehicht, das Exoderm, ist ein keruhaltiges Syncytiun, gebildet aus verschmolzenen Zellen, welche eine Masse fremder Körper aufgenommen und zu einem Pseudo-Skelet verkittet laben. Die meisten dieser fremden Köruer sind in der unteren Körperhälfte Sandkörnehen und Fragmente von Schwammnadeln; in der oberen Hälfte längere Spongien-Spicula (theils einfache spitzige, theils geknöpfte), welche oralwairts gerichtet abstehen. Hierin stimmten die norwegisehen Exemplare ganz mit Bowerbank's Darstellung iiberein. Eine genauere Untersuchung unterliess ich damals, weil ich eine kleine Psammopongie mit zufällig geschlossenen Poren vor mir zu haben glanbte.

Fundort: Nord-Atlantischer Ocean: Britische Kiisten: „Diamonde ground of Hastings, Tumanowicz; Berwick Bay, Bonnston; Callercoats (?) Alder." Norwegische Kiiste: Gis-Oe bei Bergen, HAECKEL.

5. Ha liphysema ram $\mathrm{m}$ los $\mathrm{s} \mathrm{m}$, Bowehbank.

(Bumeribank, Monograph of the British Spongiadale, Vol. II, p. 79; Vol. III, PI. XIII, Fig. 1.).

Diagnose: Stockbildend. Stöckehen gabelspaltig verzweigt. Gabelïste (oder Personen des Stockes) cylindrisch, am Ende kolbenförmig oder fast kugelig angeschwollen. Die diinne Körperwand umschliesst eine geränmige Darmhöhle; diese öffnet sich am Ende jedes Astes durch einen Mund. Die fremden Körper, welche das Exoderm incrustiren, bestehen zum grössten Theile ans Fragmenten von Spongien-Nadeln, welche parallel der Längsaxe der Aeste gelagert sind. Von den angeschwollenen Enden stehen lïngere Spongien-Nadeln divergirend ab.

Specielle Beschleibung: Haliphysema ramulosum, die zweite von BowenbıNк beschriebene Art, wird von ihm mit folgender Diagnose bezeichnet: „Sponge pedicelled, ramose; branching dichotomonsly; branches cylindrical, smootlı and even; distal termination subglobose, hispid; Oscula and pores inconspicous. Dermal membrane thin and translncent. Skeleton mem- 
branous, with an incorporation of spicula of various sizes and shapes, and of minute grains of sand." Von dieser Art ist uur ein Exemplar bekannt, welches Nonms bei Guerusey auf einem Skeletbruehstück von Gorgonia anfsitzend fand. Dasselbe ist zwei Linien hoch und ebenso breit und zeigt acht cylindrische Gabclisste, die am Ende kolbig, fast kugelig angeschwollen sind. Die Röhren-Wainde sind sehr diinn und bestehen aus organischer Substanz, welche mit feinen Santkörnchen, Bruchstücken von kleinen Schwamm-Nadeln und anderen fremden Körpern verkittet ist. In der Auswahl und Eiuverleibung des fremden SkeletMaterials zeigt sich eine sehr benerkenswerthe Methode. Die Sandkörnchen sind alle innerhalb einer gewissen Grössen-Stufe ansgesucht und alle grösseren sind verschmäht. Ebenso sind anch die Spieulafragmente alle so kurz gewählt, dass sie sich leicht neben einander symmetrisch ordneten, in einer Ebone und parallel der Längsaxe. Nur fiur die Bewaffunng des Endliolbens sind grössere und besser erhaltene Spicula verwendet. Auch hier, wie bei $H$. Tumanowiczii, gehören die Spicula versehiedenen Spongien-Arten an, und anch hier sind die allseitig abstehenden geknöpften Spicula hald mit dem stumpfen Knopf naeh dem aboralen (proximalen), bald wach dem oralen (distalen) Ende gekehrt. Daraus allein schou geht dentlich hervor, dass auch hier die sämmtliehen Skelettheile fremde Körper und keine Producte des angebliehen Sehwammes sind. Powe? Bank wirft daher schliesslich die Frage anf, ob nicht Heliphysema richtiger zu den Sandschwämmen oder Psammospongien (Hornschwäimmen mit SandSkelet, Dysidea etc.), als zu den eigentlichen Kieselschwämnen zu stellen sei, eine Frage, welche (die Spongien-Natur dieses Organismus angenommen) bejaht werden muisste. Aber auch bei H. ramulosum, wie bei $H$. Tumanowizii, fand der englische Beobachter weder Oscula noch Poren, und doch ist der Besitz von Poren für den Begriff der "Porifera" unerlässlich.

Fundort: Britische Küste: Guernsey, Noman.

\section{Das Genus Gastrophysema.}

Taf. XII-XIV.

Die nene Gattung Gastrophysema griinde ich fiir solche Physemarien, deren schlanchförmiger Körper nicht einfach und einkammerig, wie bei Haliphysema, soudern durch eine oder mehrere, 
ringfömige Eiuschniirungen in zwei oder mehrere hinter einander gelegene Kammern abgetheilt ist. Bis jetzt erscheint dieses Genus nur dureh \%wei Species vertreten. Die eine Art (G. dithalamium) ist zweikammerig und lebt im Mittelneer. Bau und Entwickelung derselben bis zur Gastrula-Bildung konnte ich in Snyrna eingehend untersuchen. Die andere Art (G. scopula) ist fuinfkammerig und lebt an den britischen Kiisten. Das ist derselbe Organismus, welchen Carten unter dem Namen Squamulina scopula beschrieben und zu den Foraminiferen gestellt hat. Carten's

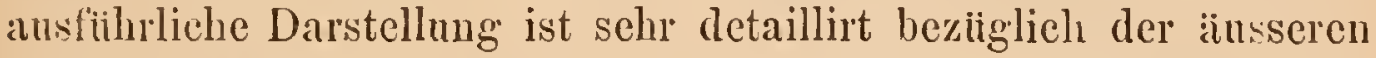
Form-Verhäiltnisse. Dagegen sagt er nichts von dem zweischichtigen lian des schlanchförmigen Körper's und von dem charakteristischen Geissel-Epithel der Magenhöhle. Es bleibt also immerlin möglich, dass der von ihm beobachtete Organismus in eine andere Thicrgruppe gehört. Aber die anffallende Achnlichlicit mit unserem G. dithalamium in der gesammten Gestalt und Grösse, der Kammerbildnng und Skeletbildung lisst es wohl gerechtfertigt erschcinen, wenn ich auch $G$. scopula einstweilen in dieser Gattung anfführe.

Charakteristik des Genus Gastroplysema: Körper der Person einfach schlauchtörmig, einaxig, gegliedert, an aboralen Pole der Axe durch einen Stiel am Meeresboden befestigt. Mehrere $(2-5)$ Glieder von verschiedener Grösse und Form liegen hintereinander, dureh quere Einschniirungen unvollstäudig getrennt. Höhle des Schlanches (Magenhöhle) dem entsprechend in mehrere (2-5) communicirende Kammern getleilt; dic letzte Kammer am oralen Pole der Axe durch einen Mund geöffnet. Körperwand ans zwei Schichten gebildet: innere Schicht ein einfaches Geissel-Epithel, in aboralen Theile Eizellen bildend; äussere Schicht ein kernhaltiges Syncytim, aus verschnolzenen Zellen gebildet, welche eine Masse fremder Körper aufgenommen und so ein festes Psendo-Skelet grebildet haben.

\section{Uebersicht der Species vou Gastrophysema.}

Körper der Person keulenförmig, zweikammerig; die aborale Kammer kugelig, auf einem kurzen Stiel befestigt; die orale Kammer eiförmig, um ein Drittel grösser, mit einer trichterförmigen Mundöffinung.

1. (r. dithalaninum.

Körper der Person keulenförmig, fünfkammerig; die unterste Kammer eine convexe Fussscheibe; die folgenden von der zweiten bis vierten an Grösse zuuehmend; die fünfte viel grösser als die vorlıergehenden, mit einer einfachen IIuudöffinung

2. G. scopula. 


\section{Gastrophysema dithalamium H.}

Taf. XII-XIV.

Diağnose: Körper der Person im Ganzen lïnglich keulenförmig, durch eine mittlere Einschniirung in zwei iiber einander liegende Kammern eingetheilt, auf einem kurzen eylindrischen Stiel befestigt, der mit scheibenartig verbreiterter Basis anfsitzt. Am entgegengesetzten (oberen) Ende eine einfache kreisrunde Mundöfnung. Die obere (distale oder orale) Kammer ellipsoid oder eiförmig, $11 \mathrm{~m}$ ein Drittel in jeder Dimension grösser als die untere (proximale oder aborale) kugelige Kammer. Stiel und Fussscheibe solid. Die Höhlen beider Kammern längen durch einen engen Hals (Sipho) zusammen. In der aboralen Kammer entwickeln sich die Eier (Bruthöhle). In der oralen Kanmer (Magenhöhle) findet sieh nahe der Mundöffnung eine GeisselSpirale. Die fremden Körper, welehe das Exoderm incrustiren, bestehen in der unteren Hälfte zum grössten Theile aus Sandkörnchen und Bruchstücken von Schwammnadeln, in der oberen Hälfte (in der Wand der zweiten, grösseren Kammer) aus längeren Spicula von verschiedenen Spongien-Arten. Diese sind allseitig abstehend, mit den Spitzen oralwärts gerichtet.

Specielle Beschreibung: Gastrophysema dithalamium stellt in ausgebildetem Zustande einen länglichen kolbenförmigen Schlauch von bräunlichgrauer Farbe und von 2-3 Mm. Lainge dar, welcher durch eine mittlere Einschnürung in zwei Hälften von nahezu gleicher Länge getheilt ist. (Fig. 137). Die obere Hälfte besteht aus einem eiförmigen oder ellipsoiden, stacheligen Schlanche, der dicht mit abstehenden Schwammnadeln bewaffnet ist. Dic untere Hälfte besteht ans einem kleineren kngeligen Bläschen, das dureh einen kurzen konischen Stiel anf einer scheibenförmig verbreiterten Fussscheibe aufsitzt. Mittelst der letzteren ist der schlanchförmige Körper anf versehiedenen Gegenständen des Meeresbodens befestigt, namentlich auf alten abgrestorbenen Stöcken von Cladocora caespitosa, welche in grosser Nenge den Boden des Hafens von Smyrna bedecken ${ }^{1}$ ).

1) Ich erhielt dieselben beim Dredgen in dem mittleren Theile des Hafenbeckens von Smyrna, wobei ich mich der Damptbarkasse der k. k. österreichischen Corvette "Zryni" mit grossem Vortheile bedienen konnte. Ich benutze diese Gelegenheit, um dem Commandanten der letzteren, Herrn Cor- 
Vielleieht ist unser Gastrophysema an diesem Orte nicht selten. 'Trotzdem gelingt es mu' sehwer dasselbe zu entdecken, da eine Masse von Spongien, Hydroiden, Bryozoen 11. s. w., gemengt mit Algen, in buntestem Gewirr den schlammigen Boden iiberwuehern. Nur dureh einen glicklichen Zufall wurde ich auf eine kleine Gruppe von drei Gastrophysemen aufmerksam, welehe zwischen den basalen Aesten eines alten abgestorbenen CladocoraStockes versteckt sassen, der mit Bryozoen und Spongien bedeckt war. Bei anhaltendem Snchen fand ich noch einige andere Exemplare theils anf Cladocora-Resten, theils anf Muschel-Fragmenten und Steinen, die mit Phallusia mammillata besetzt waren. Gliicklicherweise waren die meisten Exemplare geschlechtsreif und enthielten Eicr auf versehiedenen Stufen der Entwickelung, bis z.ur Gastrulabildung.

Die Lïnge des vollkommen entwickelten Gastrophysema dithalamium beträg't 2-2, 5, höchstens gegen $3 \mathrm{Mm}$. (Fig. 137, 140). Davon kommt ungefähr die Hïlfte auf die obere (orale) eiförmige Kammer, deren grösste Dicke $0,7 \mathrm{Mm}$. erreicht. Die mntere (aborale) kugelige Kammer hat nur $0,5-0,6 \mathrm{Mm}$, die ringförmige Einschnürung zwischen beiden 0,3 Mm. Durchmesser. Die Dicke des Stiels beträgt in der Mitte seiner Länge (wo er gewöhnlich am diunnsten ist) 0,1 Mm. Der Durchmesser der flach kegelförmigen, massiven Fussscheibe kommt ungefähr demjenigen der unteren Kammer gleich.

Die Gestalt seheint bei Gastrophysema dithalamium ebenso wie bei G. scopula wenig zn vaiiren. Wie Canter bei letzerem constant fünf hinter einander liegende Kammern beobachtete und wie diese immer nahezı diesclben Form- und Grössen-Verhältnisse

vetten-Capitain $\mathrm{L}_{\mathrm{ANG}}$, meinen aufrichtigen Dank für die Liberalität auszusprechen, init welcher derselbe mir den Gebrauch der Dampfbarkasse behufs der Schleppnetzfischerei in der Bai von Smyrna gestattete. Nicht minder bin ich meinem hoch verehrten Freunde, Hern Ritter Dr. Carl vox Scherzer, dem verdienstvollen wissenschaftlichen Leiter der Novara-Expedition (damals k. k. Oesterr. General-Consul in Smyrna, jetzt in London) zum herzlichsten Danke für die zuvorkommende und mir höchst werthvolle Unterstiitzung verpflichtet, durch welche er meine zoologischen Untersuchungen während meines Aufenthalts in Smyrna förderte. Nur seiner lebendigen Theilnahme an denselben, seiner liebenswürdigen Gastfreundsehaft und seiner Bekanntsehaft mit den dortigen Verhältnissen verdanke ich es, dass es mir möglich war, eine Uebersicht der dortigen Verhältnisse zu gewinnen, die Fauna des Hafens kennen zu lernen und die vorliegenden Beobachtungen iber Bau und Entwicklung von Gastrophysema anzustellen. 
darboten, so zeigten anch alle Personen unseres $G$. dithalamium, die ich in Smyrna beobachtete, nur geringe Abweichungen in der Grösse und Form ihres zweikammerigen Körpers.

Die A ussenflä che des Körpers ist allenthalben mit fremden Körpcrn bedeckt, die jedoch nicht etwa, gleich Sabella-Röhren, durch einen ausgesehiedenen und erhärteten Schleim verkittet, sondern wirklich in das Syncytium des Exoderms aufgenommen sind (wie bei den Sandschwämmen oder Psammospongien). Bei schwacher Vergrösserung erscheint die untere (aborale) Hälfte von aussen ziemlich glatt, dagegen die obere (orale) Hälfte stachelig, wie ein Distelköpfchen. Bei starker Ver̈grösserung zeigt sich, dlass das Psendo-Skelet des Exoderms im ersteren Theile gröstentheils aus Sandkörnchen und Fragmenten versehiedener Spongien-Nadeln zusammengesetzt ist, die regellos mit einander gemengt und verkittet sind. Dagegen besteht das Skelet der oralen Körpcrhälfte zum grössten Theile aus längeren Spicula verschiedener SpongienArten. Dieselben stehen allseitig ab und divergiren oralwairts gerichtet. Die Spienla sind theils vollständig, theils zerbrochen. Neben ganz einfachen, nmspitzigen Nadeln finden sich zahlreiche geknöpfte Spicula und eine geringere Zahl von dreizïhnigen Ankernadeln. Die letzteren sind meist so gelagert, das die drei Ankerzïhne answärts gerichtet sind, die Spitze des Hanptstrahls im Exoderm befestigt (Fig. 137). Auch bei den geknöpften Nadeln ist wenigstens das stumpfe Eude answärts, das spitze einwärts gekehrt. Dazwischen finden sich aber auch einzelne Spicula in umgekehrter Lagerung, ferner Fragmente von ander's geformten Nadeln, welche ganz verschiedenen Arten angehören, und endlich feinste Saudkörnchen. Hicraus ergibt sieh mit Sicherheit, dass die Spicula keine Producte des Organismus selbst, sondern fremde Körper sind, welche derselbe aus seiner näichsten Umgebung, aus dem Schlamme des Meeresbodens aufgenommen hat. In der That zeigten die Schlamm-Reste, welche in den Ritzen und Löchern der alten Cladocora-Stöcke sich fanden, die gleiche Zusammensetzung, wie das Skelet der Gastrophysemen, die auf ihnen befestigt waren.

Ein Längs sehnitt durch Gastrophysema dithalamium öffnet uns einen befriedigenden Einblick in die interessante Organisation dieses merkwiirdigen Gastracaden (Fig. 140, 141). Wir sehen, dass beide Kammern eine geräunige Höhle enthalten und durch eine enge Thüre, einen "Sipho", mit einander communiciren (y). Die Höhle der aboralen Kammer (h) ist blind geschlossen. Ilic 
Höhle der oralen Kammer (v) öfinet sich oben durch eine Mündung (m). Die Dicke der Wand ist in der vorderen und hinteren Kammer fast gleieh, 0,0S-0,1 Mm. Nur in der Umgebung der Mundöffnung ist die Wand verdiinnt. Ueberall besteht dic Wand der Höhle deutlich aus zwei scharf getrennten Schichten: den beiden primären Keimblättern. Das Entoderm bildet ein einfaches Geissel-Epithel und entwickelt zugleich in der aboralen Kammer die Eier. Das Exoderm besteht aus einem Syneytium von verschmolzenen Zellen, welehe die fremden Körper anfgenommen baben. Der solide Sticl und die Fussscheibe, die keine Fortsetzung der gastralen Höhlung euthalten, sind blos vom Exoderm und von fremden Skelettheilen gebildet.

Das' Exoderma oder Hantblatt (c) lässt bei genanerer Untersuchung ganz ähnliche Verhältnisse erkennen, wie wir sie bei Haliphysema primordiale geschildert haben. Auch hier iiberzeugt man sich bald bei passender Behandlung, dass dic ganze Dermalschicht der Körperwand von einem wahren Syneytinm gebiluet wird, welehes aus völlig versehmolzenen Zellen zusammengesetzt ist, und in welches die fremden Körper eingebettet sind. Das beweisen deutlich die überall zerstreuten Zellkerne, welche nach Firbung mit Carmin, besonders wenn vorher verdiunte Osmiumsäure kurze Zeit eingewirkt hatte, sehr deutlich hervortreten (Fig. 138n, 139n, 14.1n, 148n). Die Kerne sind theils kugelig, theils länglich rund, ellipsoid oder eifürmign, von 0,004-0,007 Mm. Durchmesser. Auch hier ist häufig jeder Kern von einem rundlichen oder sternfömig aisstrahlenden Körnchenhofe umgeben (Fig. 148n). Doch ist dieser Hof niemals scharf gegen das internucleare Gewebe abgegrenzt und daher seheint es nicht gestattet, den ersteren als eigentlichen Zellenleib, das letztere als Intercellular-Substanz aufzufassen.

Die Grundsubstanz des Syneytium erscheint hyalin oder feinliörnig, hier und da schwach faserig differenzirt. Sehr bemerkenswerth ist, dass diese fibrilläre Differenzirung an zwei Stellen zu cinem wirklichen Zerfall derselben in parallele Fibrillen zu fiihren scheint, dic wahrscheinlich nach Art ron Muskelfibrillen wirksam sind. Es zeigt sich näulich erstens an der Pforte zwischen beiden Kammeru (Fig. 140y, 141g) und zweitens an dem Rande der Mundöff̈nung $(\mathrm{m})$ eine sehwache ringförmige Verdickung des Exoderm-Syncytiums; und wenn es gelingt, sich diese von der inneren Flïche der Gastralhöhle her zur Anschauung zu bringen, so benert.t nan leci stanker Vergröscerung eine Anzahl von sehr 
feinen parallelen Ringstreifen, denen die gestreckten Kerne parallel gelagert sind (Fig. 14S). Wahrscheinlich dienen dieselben zur Verengerung und vielleicht selbst zum zeitweiligen Verschluss der Oeffnungen, welche sie umgeben. Wäre diese Vermuthung richtig, so wiirde Gastrophyscma sein Osculum in ähnlicher Weise dureh eine Mundhant (oder Oscular-Membran) verschliessen könuen, wie ich dies von den Kalkschwämmen beschrieben habe (Monogr. Bd. I, S. 266). In ähnlicher Weise wird vielleicht anch der Hohlraun der oberen Kammer (der eigentlichen Magenhöhle, v) von demjenigen der unteren Kammer (der Bruthöhle, b) durch eine Sphincter-ähnliche Ringmembran zeitweilig ganz oder theilweise abgesehlossen werden können.

Das Entoderma oder Darmblatt bietet bei Gastrophysema ähnliche, jedoch verwickeltere Verbältnisse dar, als wir bei Haliphysema gefunden haben. Allerdings ist auch dort wie hier die ganze gastrale Höhlung des Schlauches von einem zusammenhäingenden einschichtigen Geissel-Epithel ansgekleidet. Während aber dieses Epithelium bei Haliphysema in der ganzen Magenhöhle ein einfaches Lager von gleichartigen Geisselzellen bildet, nur durch die eingestrenten Eizellen unterbrochen und oben an der Mundöffnnng durch die adorale Wimperspirale begrenzt, zeigt das einschichtige Gastral-Epithelium von Gastrophysema dithalamium in beiden Abtheilungen des Körpers eine verschiedene Beseliaffenheit. In der grösseren oralen Kammer liegen zwischen den Geisselzellen einzelne Drüsenzellen (d) zerstreut und eine sehr entwickelte Geisselspirale von mehreren Windungen (a) tritt stark hervor. In der kleineren aboralen Kammer hingegen bilden sich ausschliesslich die Eier und entwickeln sich die befruchteten Eier zu GastrulaEmbryonen. Sie kann daher als Geschlechtskammer, Bruthöhle oder Uterus, bezeichnet werden (b). Die orale Kammer allein scheint hier als ernährende Darmhöhle zu fungiren und kann demnach anch in engerem Sinne als Magenhöhle unterschieden werden (v).

Wir treffen also, wenn wir die einfacheren Verhältnisse von Haliphysema vergleichen, einen interessanten Fortschritt in der Gastraeaden-Organisation. Bei Haliphysema ist die einfache Urdarmhöhle gleichzeitig ernährende Magenhöhle und eierbildende Geschlechtshöhle, wie bei den einfachsten Spongien. Bei unserem zweikammerigen Gastropliysema hingegen sind die beiden fundamentalen Functionen des vegetativen Lebens, Ernährung und Fortpflanzung, bereits gesondert; die erstere ist auf die orale, 
die letrtere auf die aborale Kammer beschräult. Ausserdem aber finden wir auch noch weitere Differenzirungen im Epithelinm, indem in der Magenhöhle zwischen den flimmernden Geisselzellen einzelne nicht flimmerude Driisenzellen zerstrent sind und auch dic adorale Geisselspirale eigenthimlich entwickelt ist. Das genanere Verhalten dieser verschiedenen Entoderm-Formationen ist folgendes:

Das Geissel-Epitlelium der Magenhöhle (Fig. $138 \mathrm{f}$, Fig. $145 \mathrm{f}, 147 \mathrm{f}$ ) bildet ein einschichtiges Lager von cylindrischkonischen Geisselzellen, welche nicht wesentlich von denjenigen des Haliphysema primordiale verschieden sind. Nur erscheint der Leib der Geisselzellen selbst etwas kleiner, hingegen der Hals und Kragen derselben etwas grösser und die Geissel lïnger als bei Maliphysema. Der Kern der Geisselzellen ist von derselben Grösse und Form. Hals und Kragen zeigen je nach den Contractions-Zuständen sehr verschiedene Formen (Fig. 138).

Regelmässig zerstreut zwischen den Geisselzellen finden sich im grössten Theile der Magenhöhle einzelne grössere, nicht flimmernde Zellen, welche wahrscheinlich als einzellige Drüsen zul betrachten sind (Fig. 138 d, 140 d, 145 d, 147 d). Es sind das birnförmige oder flaschenförmige Zellen, welche ungefähr doppelt so gross als die Geisselzellen und dureh ein dunkel pigmentirtes Protoplasma ansgezeiehnet sind. Sie fallen daher schon bei schwacher Vergrösserung als dunkle Punkte auf der helleren Gastralfläche in die Augen (Fig. 140 d). Auf Querschnitten durch die Magenwand (Fig. 145d) zeigt sieh, dass diese birnfömigen Zellen nicht flach auf der Innenseite des Exoderm aufsitzen, wie die benachbarten Geisselzellen, sondern tiefer als diese, ein wenig in das stitzende Gewebe des Exoderm eingesenkt, so dass etwa zwei Drittel ihres Körpers vom Syncytium umschlossen sind (Fig. 138 d, 139 d). Der verdiunnte flaschenförmige Hals der Zellen dagegen liegt zwischen den Geisselzellen und ragt bisweilen etwas iiber deren Epithelfläche vor. Das Protoplasma dieser flimmerlosen Zellen ist sehr triibe und enthält eine Menge dunkler, brauner oder schwärzlicher, rundlieher Pigmentkörner und ausserdem stark lichtbrechende Fettkiigelchen. Bisweilen scheint das Protoplasma etwas aus dem Flasclienhals vorzutreten. Das hyaline Exoplasma erscheint als eine besondere Hautschicht der Zelle differenzirt oder bildet vielleicht wirklich eine Zellenmembran. Der Kern ist gewöhnlich nicht sichtbar, ganz durch die dunkle Umhïillung der Fettkörnchen und Pigmentköruchen verdeckt. Wenn es aber bei starkem Drueke anf die 
isolirten Zellen gelingt sie zu zerdriicken, so tritt der Nucleus deutlich vor, als ein helles Kiigelchen von 0,005 Mm. Durchmesser, mit einem dunklen Nucleolus (Fig. 147). Ich glaube demnach nicht irre zu gehen, wenu ieh diesen pigmentirten birnförmigen Zellen eine secretorische Function zuschreibe und sie als einzellige D r i s e n auffasse.

Der adorale Strudel-A p parat ron Gastrophysema ist viel stärker als derjenige von Haliphysema entwickelt. Während bei letzterem die stärkeren Geisselzellen, die denselben zusammensetzen, nur eine fast ringförmige Spirale bilden, finden wir bei letzterem ein förmliches Schrauben-Gewinde, welches zwei bis drei, vielleicht vier und mehr Windungen innerhalb der Schlundhöhle beschreibt (Fig. 144). Als Schlundhöhle köunen wir den engeren, trichterförmigen Eingangstheil der Magenhöhle, unmittelbar unter der Mundöffnung bezeichnen. Die letztere ist ein kreisrundes Loch von 0,12-0,3 Mm. Durchmesser. Der oberste Theil der Körperwand, welcher den Rand der Mundhöhle bildet, ist stark verdiunnt, der Rand selbst zugeschärft nud zugleich etwas nach aussen gekehrt und ausgeschweift, ähnlich dem Rande einer Urne oder Vase (Fig. $141 \mathrm{~m}$ ). Die Schwammuadeln, welehe denselben numittelbar umgeben, sind derartig divergirend gestellt, dass sie zusammen einen trichterförmigen oder konisehen Kranz bilden, in dessen Tiefe (im Halse des Trichters) die Mundöffuung liegt (Fig. $140 \mathrm{~m}$ ). An einer Stelle ist der Rand der letzteren etwas erhöht und hier beginnt die rechts gervundene Geisselspirale, welche in der Schlundhöhle 3-4 Windungen macht. Dieselbe besteht aus einer einfachen Reilhe von colossalen Geisselzellen, deren Körper 2-3 mal so gross als derjenige der gastralen Geisselzellen ist, nämlich 0,02-0,03 Mm. lang und bis $0,01 \mathrm{Mm}$. dick. Das Protoplasma enthält dunkle, sehr feiue Pigmentkörner, wodurch der Gang der Spirale sehr deutlich hervortritt. Auch die Form dieser Geisselzellen ist sehr eigenthiimlich (Fig. 139f). Auf dem eigentlichen glackenförmigen Zellenleibe erhebt sich ein 3-4mal so langer, schlanker Hals von cylindriseher Form, blos aus hyalinem Exoplasma gebildet. Anf dem freien Ende des biegsamen Halses sitzt ein glockenförmiger Kragen, ein tieferer oder Hacherer Trichter, aus dessen Grunde sich die sehr lange und starke Geissel erhebt. Dureh die Schwingungen dieser mächtigen Geisseln wird ein kräftiger Strudel im Wasser erzengt, der Nahrung in die Hagenhöhle cinfihlrt. Wenn man. fein zerriebenes Carmin oder Indigo dem Wasser zusctzt, iiber- 
zeugt man sich, mit welcher Gewalt der spirale Strudel durch die Mundöffuung eindringt.

Die gastralen Geisselzellen, welche unmittelbar mnter der adoralen Flimmerspirale sitzen, sind ebenfalls pigmentirt, wodurch der Gang der Spicula sehr auffällig vortritt. Die muteren Zellen der letzteren (in der dritten oder vierten Windung) werden allmählich kleiner und gehen ohne scharfe Grenze in die gewöhnlichen Geisselzellen iiber.

Das Epithelium der Bruthöhle oder der aboralen Scxual-Kammer (b) ist von demjenigen der Magenhöhle nicht wesentlich verschieden (Fig. 146). Jedoch fehlen die grossen, nicht flimmernden Drüsenzellen, und zwischen den Geisselzellen liegen überall Eizellen auf verschiedenen Stufen der Ausbildung zerstreut. Die re if en E i zell en (Fig. 1460) sind nackte, kugelige oder sphäroidale Zellen von 0,04-0,05 Mm. Durchmesser. Dieselben gleichen vollkommen den amoeboiden Eizellen des Maliphysema und der Kalkschwämme und sind gleich den letzteren im Stande, amoebenartige Bewegungen auszuführen. Das Protoplasma besteht aus einer dicken hyalinen Rindenschicht (Exoplasma) und einer trübkörnigen Dottermasse oder Marksubstanz (Endoplasma). Das Exoplasma junger Eizellen streckt langsam sich bewegende fingerförmige Fortsätze von veränderlicher Gestalt und Grösse aus (Fig. 143). Der Kern der reifen Eizelle ist ein helles kugeliges Keimbläschen von 0,015-0,02 Mm. Durchmesser (Fig. 143). In demselben tritt der grosse Nucleolus als ein dunkler, stark glänzender Keimfleck von 0,001 Mm. deutlich hervor, nud in diesem ist ein feiner Keimpunkt sichtbar.

Spermazellen habe ich nur an einem einzigen Exemplar von Gastroplysema dithalamium beobachtet, und zwar an einer Person, welche gleichzeitig reife Eier besass. Als ich dasselbe zerzupfte, zeigten sich zwischen den Eiern einzelne Haufen von feineu, lebhaft beweglichen Samenfäden (Fig. 142). Dieselben besassen einen äusserst feinen Geisselfaden (,Schwanz") ron 0,04 $\mathrm{Mm}$. Länge, der erst bei sehr starker Vergrösserung (iiber 800) sichtbar wurde. Der Kopf dieser feinen Geisselzellen war spindelförmig, 0,0012 Mm. lang. Ob diese Zoospermien in die betreffende weibliche Person eingedrungen waren und von einer anderen Person herrührten, oder ob sie im Körper der ersteren selbst gebildet waren, vermochte ich nicht zu ermitteln. Alle Versuche, juingere Entwicklungszustände derselben aufzufinden, oder ihren Ursprung in cinem der beiden Kícimblätter nachzll- 
weisen, waren vergeblich. Möglicherweise entstehen die Zoospermien im Exoderm. Die Eizellen sind offenbar umgewandelte Epithelzellen des Entoderms.

Die meisten Personen von Gastrophysema dithalamium, welche ich in Smyrna zu beobachten Gelegenheit hatte, enthielten reife oder befruchtete Eier auf verschiedenen Stufen der Entwicklung, bis zur vollständigen Ausbildung der Gastrula (Fig. 111-120). Die aborale Kammer war in einigen von diesen trächtigen Personen dicht angefüllt mit gefurchten Eiern und Blastula-Keimen, während andere nur einzelne Gastrulae enthielten (Fig. 140, 141). Es gelang mir, eine vollstïndige Reihe der Keimformen herzustellen, von dem befruchteten Ei bis zur Gastrula. Das Ei enthält keinen Nahrungsdotter und die Form der Eifurchung ist die primordiale. Ich habe dieselbe in dem Absclnitt, welcher ,die vier Hauptformen der Eifurchung und Gastrulabildung" behandelt, bereits ausfïhrlich beschrieben. (Vergl, oben S. 79-83.)

Das befruchtete Ei (Fig. 111) erschien als eine homogene, triibe Protoplasma-Kugel von 0,05 $\mathrm{Mm}$. Durchmesser, in welcher zahlreiche sehr feine Fettkörnchen gleichmässig vertheilt waren. In dieser Archimonerula war weder von einem Kern, noch von den eingedrungenen Zoospermien irgend eine Spur mehr zu erkennen. Das „Keimbläschen" schien völlig verschwunden zu sein. Immerhin ist es möglich, dass ich einen noch vorhandenen Rest desselben, vielleicht den Keimfleck, iibersehen habe, zumal ich meine Aufmerksamkeit damals nicht speciell auf diesen Punkt richtete.

Im nächstfolgenden Stadium zeigt sich in der Dotterkugel wieder ein neu gebildeter Kern (Fig, 112). Derselbe ist kugelig; ziemlich hell, hat $0,016 \mathrm{Mm}$. Durchmesser und schliesst ein grosses Kernkörperchen von 0,003 Mm. ein. An dieser Archicyhula liess sich deutlich eine feine radiäre Streifung wahrnehmen, indem die dunkleren Körnchen strahlig gegen den im Mittelpunkt der Zelle geleg'enen Kern gerichtet waren.

Die Eifurchung selbst verläuft durchaus regelmässig, nach dem Typus der urspriinglichen oder primordialen Theilung. Durch fortgesetzten regelmässigen Zerfall jeder Furchungszelle in zwei Hälften entstehen zuerst zwei, darauf 4, 8, 16, 32, 64 Furchungszellen (Fig. 113-115). Ich habe die Einzelheiten des Furchungsprocesses und namentlich das Verhalten der Kerne nicht näher untersucht. Das Resultat desselben ist die Bildung eines regu- 
lïren Maulbeerkeims, einen soliden kugeligen A rehimorula, die ans 64 Zellen besteht (Fig. 115).

Indem sich im Innern der Archimorula Fliissigikeit ansammelt und sämmtliche Zellen an dic Peripherie treten, entstelıt eine Hohlkngel vou 0,08 Mm. Durchmesser, deren Wand aus ciner einzigen Schicht von gleichartigen Zellen besteht, die Archiblastula (Fig: 116, 11i). Die „Blastoderm-Zellen“ welche diese zusammensetzen, erscheinen durch g'egenseitigen Druck regelmässig abgeplattet, meist sechsseitig-prismatisch (Fig. 116). Jede dieser Zellen streckt einen geisselförmigen schwingenden Fortsatz aus (Fig. 117). Das Blastoderm gestaltet sich so zu einem GeisselEpithel, und durch die Vibrationen desselben bewegt sich die Blastula langsam rotirend in der Gastralhöhle nmher.

Nun erfolgt die typische Einstülpung oder Invagination der Blastula, durch welche sich letztere zur Gastrula, und zwar zur Archigastrula gestaltet. Indem an einer Stelle das Blastoderm grubenförmig eingestiilpt wird (Fig. 118) und indem der innerc eingestülpte Theil desselben sich dem äusseren nicht eingestiilpten Theil bis zur Beriihrung nähert, verschwindet die Furchungshöhle (Blastocoeloma, Fig. 11\%). An ihre Stelle tritt die fertige Urdarmböhle (Fig. 120). Die Einstiilpungsöffnung wird zum Urmund. Die Gastrula von Gastrophysema ist eiförmig, 0,08-0,1 Mm. lang, 0,06-0,07 Mm. dick. Die Exoderm-Zellen der Gastrula sind cylindrische Geisselzellen von 0,018 Mm. Länge und 0,006 Mm. Dicke, mit ovalem Kern und einem dicken hyalinen Saum, durch dessen Mitte die Geissel durchtritt (Fig. 150e) Die Entoderm-Zellen der Gastrula sind rundliche polyedrisehe ocler fast kugelige Zellen von 0,01 Mm. Durchmesser, mit einem kugeligen Ker'n von 0,003 Mm. Ihr Protoplasma ist viel dunkler nud grobkörniger als dasjenige der Exoderm-Zellen und enthält zahlreiche fettglänzende Körner (Fig. 150i).

Die weitere Entwicklung von Gastrophysema dithalamizm konnte ich leider nicht verfolgen. Wahrscheinlich wird dieselbe folgenden Gang einschlagen: die Gastrula verlässt die Mag'enhöhle der Mutter durch die Mundöffnung, schwärmt eine Zeitlang im Meere umher und setzt sich dann mit dem aboralen Pole fest. Die Exoderm-Zellen verlieren ihre Geisseln, verschmelzen mit einander zum Syncytium und nehmen aus dem benachbarten Meeresschlamm die fremden Körper auf, aus denen sie das Skelet zusammensetzen. Die rundlichen Entoderm-Zellen verwandeln sieh in eylindrische Geisselzellen. Das jugendliche Gastrophysema wird 
in diesem Stadium einem Haliphysema gleichen. Später erst wird sich die mittlere Einschnirung bilden, durch welehe die Urdarmhöhle in zwei versehiedene Kammern zerfällt. In der oralen Magenkammer wird sich die starke Geisselspirale ausbilden, sowie die einzelligen Driisen. In der aboralen Brutkammer werden sich einzelne Zellen zu Eizellen, andere zu Spermazellen umbilden.

Ueber die Lebenserscheinungen von Gastrophysema dithalamium wird weiter unten (im folgenden Abschnitt) berichtet werden.

F un d o r t: Mittelmeer, Smyrna. Haeckel.

2. Gastrophysema seopula, H.

(Squamulina scopula, Carrer; Aunals and Mag. of nat. hist. 18\%0, Vol. V, p. 309, PI. IV.)

Diagnose: Körper der Person im Ganzen länglich kenlenförmig, durch vier quere Einschniurungen in fïnf verschiedene Kammern getheilt. Die erste Kammer eine planeonvexe Fussscheibe ("pedestal"), die zweite Kammer eine schlanke cylindrische oder umgekelurt kouisehe Säule („column“), die dritte Kammer fast kugelig, eng (,body"), die vierte Kammer erweitert, fast cylindrisch (,neck"), die fünfte Kammer 2-3 mal so gross als die vorhergehenden, eiförmig oder länglichrund („head"). Am oberen Ende der fünften Kammer eine einfache kreisrunde Mundöffnung. Alle fiinf Kammern sind hohl, mit cinander communicirend. Die Höhle der ersten Kammer (der Fusscheibe) durch mehrere unvollständige Scheidewände mehrfach ausgebuchtet. Die fremden Körper, welche das Exoderm incrustiren, bestehen zum grössten Theile aus Sandkörnehen und kleinen Fragmenten von Sehwammnadeln; in der fünften, letzten und grössten Kammer dagegen aus längeren Spicula von verschiedenen SpongienArten. Diese sind allseitig abstehend, mit den Spitzen oralwärts gerichtet.

Specielle Beschreibung: Vergl. Carter, l. c., p. 309 bis 320 ; sowie oben, p. 176-178.

Fundort:" Britische Kuiste: Beach at Budleigh-Salterton, Devonshire; Laminarien-Zone. Canter. 


\section{Organisation und Lebenserscheinumgen der} Physemarien.

Aus der vorstehenden Beschreibung der beiden Genera Haliphysema und Gastrophysema, und namentlich der beiden von nir lebend beofucheten Arten, ergibt sich mit voller Klarheit, dass wir es hier mit Angehörigen einer eigenthümlichen Thiergruppe zu thun haben, die weder zu den echten Spongien gerechnet werden kann, wie Bowerbank will, noch zu den Rhizopoden, wie Carter behauptet. Immerhin stehen sie den ersteren weit näher als den letzteren, zu denen sie gar keine directen Beziehungen besitzen.

Die allgemeine Charakteristik der PhysemarienGruppe, anf die vorstehenden Beobachtungen gestïtzt, wïrde folgendermassen lauten:

Der Körper des entwickelten Thieres bildet eine einfache schlauchförmige Person, deren eines (aborales) Ende am Meeresboden auf verschiedenen Gegenständen festgewachsen ist, wïhrend am anderen Ende sich die Mundöffnung befindet. Die Grundform der Person ist einaxig. Bisweilen treibt sie durch laterale Knospung Sprossen und bildet so kleine Stöckchen. Die innere Darmhöhle ist entweder einfach (Kaliphysema) oder durch quere ringförmige Einschnür'ungen in zwei oder mehrere zusammenhängende Kammern getheilt (Gastrophysema). Die Wand des schlanchförmigen Körper's, die gleichzeitig Leibeswand und Darmwand ist, besteht blos ans zwei verschiedenen Schichten. Die innere Schicht, das Darmblatt oder Entoderma, bildet ein einfaches Geissel-Epithel, das nach dem Munde hin in ein Geissel-Peristom, eine Spirale von stärkeren Geisselzellen übergeht. Die ïnssere Sehicht, das Darimblatt oder Exoderma, besteht ans verschmolzenen Zellen, welche ein Syncytium zusammensetzen; durch Aufualime fremder Körper, insbesondere Sandkörnchen und Schwammnadeln, gestaltet sich dasselbe zu einem festen Hautskelet. Die Fortpflanzung geschieht durch befruchtete Eier. Die amoeboiden nackten Eizellen (und die stecknadelförmigen Spermazellen?) entwickeln sich ans einzelnen Geisselzellen des Entoderms. Wenn der Schlanch durch Eiuschnürungen in Kammern getheilt ist (Gastrophysema), tritt Arbeitstheilung derselben ein, indem die einen die Ernährung; die andern die Fortpflanzung vermitteln. 
Wenn wir die wiehtigsten Eig'enschaften der Organisation, in welchen alle bisher beobachteten Physemarien iibereinstimmen, ihrer morphologisehen Bedentung entsprechend wiirdigen wollen, so wiirden folgende Punkte besonders hervorzuheben sein. Die Individualität der Physemarien ist die einfache, einaxige oder monaxonie Person, ohne Antimeren, wie ich sie in der Monographie der Kalkschwämme detinirt habe (Bd. I, S. 101). Im engeren Sinne ist diese Person ungegliedert, ohne Metameren. Im weiteren Sinne könnte man die Kammerbildung von Gastrophysema als Metamerenbildung betrachten; dadureh unterscheidet sich dieses gegliederte Genus wesentlich von dem ganz einfachen und ungegliederten Haliphysema. Doeh hat die Metamerenbildung bei ersterem eine andere Bedeutung; als bei anderen gegliederten Thieren. Die Grundform der Person ist die ungl le i h p o lige Ei naxige (Monaxonia diplopola), dieselbe, welche anch bei den meisten Personen der Spongien sich findet. (Monog'r. der Kalkschwïmme, Bd. I, S. 129). Stockbild $\mathrm{ng}^{*}$ ist bisher nur bei einer nicht näher untersuchten Art beobachtet, bei Haliphysema ramulosum, dessen Physemariennatur noch zweifelhaft ist.

Die Organologie von Haliphysema ist vor Allem interessant, weil hier der ganze Thierkörper in vollkommen entwiekeltem Zustande eigentlich nur ein einziges $0 \mathrm{rg}$ an bildet, einen Urdarm mit Urmund; bei Gastrophysema hingegen sind bereits zwei verschiedene Organe differenzirt, indem die orale Kammer des Urdarms nur als digestive Magenhöhle, die aborale Kammer nur als sexuelle Bruthöhle fungirt. Die Darmwand aber, die zugleich Leibeswand ist, besteht in beiden Gattungen einzig and allein ans den beiden primären Keimblättern: Exoderma und Entoderma. In Betreff des letzteren kann gar kein Zweifel entstehen, da bei allen hier beschriebenen Arten (welche ich selbst untersuchen kounte) ein einfaches einschiehtiges Epithelium die gesammte Gastralfläche auskleidet. Dagegen könnte in Betreff des skeletbildenden Exoderms ein Zweifel auftauchen, ob dasselbe nicht eigentlich als Mesoderm zu betrachten und vielleicht auf der äusseren Oberfläche mit einem einfachen Epithelium, einem Exoderm im engeren Sinne, bedeckt sei. Die genaueste Untersuchung der beiden Physemarien, welehe ich lebend beobachtete, ergab aber in dieser Bezichung durchaus negative Resultate. Weder bei Haliphysema primordiale, noch bei Gastrophysema dithalamium war ich im Stande eine Spur eines äusseren Epitheliums nachzuweisen. Sowohl auf' Schnitten durch den lebenden Organis- 
mus, als auf Schnitten durch erhärtete Alkohol-Präparate, welche mit verdiunnter Osmium-Sïure und Carmin behandelt waren, zcigte das Exoderm in seiner ganzen Dicke wesentlich dieselbe Beschaffenheit, ein Syncytium mit eingestrenten Zellenkernen, zwischen welche ïberall die fremden Körper des Pseudo-Skelets eingekittet waren. An der inneren, dem Entoderm zugekehrten Fläche lagen die Kerne des Syncytiums ziemlich regelmässig geordnet, während dieselben nach der äusseren Fläche hin mehr ungeordnet und zerstrent zwischen den dichtgedrängten Skelet-Theilen erschienen. Dasselbe Resultat ergab die Untersuchung der Spiritus-Exemplare von Haliphysema echinoides und H. globigerina, so dass ich alle diese Physemarien fiir echte $\mathrm{z} w \mathrm{iblät}$ erige Thiere halten muss, fuir Zoophyten, deren Körper zeitlebens blos aus Darmblatt und Hautblatt besteht.

Eine organologische Vergleichung der beiden Genera Halipleysema und Gastrophysema lässt das erstere in jeder Beziehung als das primitivere, ältere und niedere erscheinen, aus welchem das letztere durch Arbeitstheilung der Organe und Gewebe hervorgegangen ist. Während bei ersterem die Eizellen regellos und vereinzelt zwischen den Geisselzellen des Entoderms zerstreut liegen, finden wir sie bei letzterem auf die aborale Bruthöhle beschränkt; die orale Magenhöhle ist hier durch die eigenthïmlichen einzelligen Driisen ansgezeichnet. Die Sonderung der verdanenden Magenhöhle und der eierbildenden Bruthöhle muss als eine erste Arbeitstheilung des Urdarms aufgefasst werden. Diese wird schon eingeleitet durch die Beschränkung der eibildenden Zellen auf die Columella im Grunde der Magenhöhle, welche wir bei $H$. echinoides und wahrscheinlich auch bei $H$. globigerina finden. Ferner zeigt sich die adorale Geisselspirale, welche bei Haliphysema primordiale kaum angedentet ist, bei Gastrophysema dithalarnium zu einem mächtig'en, sehr eigenthïmlichen Strudel-Apparat entwickelt. Da ich bei den Spiritus-Exemplaren der iibrigen Arten, die ich untersuchte, nichts davon auffinden konnte, bleibt noch weiterhin zu ermitteln, wie weit diese adorale GeisselSpirale überhaupt in der Physemarien-Gruppe verbreitet und ob sie als allgemeiner Charakter derselben zu betrachten ist.

Die Histologie der Physemarien, soweit ich dieselbe an Haliphysema primordiale und an Gastrophysema dithalamium genater verfolgen konnte, ergibt eine auffallende Uebereinstimmung mit den Spongien. Insbesondere ist der charakteristische Bau der Geisselzellen des Entoderms mit ihrem langen Halse und ihrem 
trichterförmigen Geisselkragen ganz derselbe, wie ich ihn bei den Kalkschwämmen eingehend beschrieben habe (Monographie, Bd. I, S. 132-144). Ganz ebenso wie hier verhalten sich auch dort die nackten amoeboiden Eizellen. Auch das Exoderm der Physemarien scheint mil mit demjenigen der Psammospongien (Dysidea) wesentlich ïbereinzustimmen. Diejenigen Histologen, welche das Exoderm der letzteren als eine Bindegewebs-Formation auffassen, werden auch bei ersteren dazu berechtigt sein. Allein ich bekeune, dass ich mich auch jetzt noch zu dieser Auffassung nicht entschliessen kann. So wenig bei den Psammospongien, wie bei den Physemarien, war ich im Stande, trotz besonders genauen Suchens, eine Spur von einer oberflächlichen Epithelial-Bedeckung aufzufinden. Uebrigens erscheint ja auch der Tunicaten-Mantel als eine Gewebsformation, welche histographisch als Bindegewebe imponirt und doch nicht genetisch als Mesoderm aufzufassen ist.

Die Lebenserscheinungen der Physemarien erfordern noch eine viel genauere Untersuchung. Die wenigen und unvollkommenen Beobachtungen, welche ich dariiber anstellen konnte, denten darauf hin, dass ihre Physiologie im Grossen und Ganzen dcuselben Charakter trägt, wie diejenige der Spongien. Wie bei den letztereu, so ist auch bei den Physemarien die wichtigste physiologische Erscheinung die Wasserströmung, welche durch die Geisselzellen des Entoderms hervorgerufen wird. Auf dicsem Wasserstrome, der ebenso wohl frisches, sanerstoffhaltiges Wasser, wie die in demselben enthaltenen Nahrungsbestandtheile dem Körper zuführt, beruht die Ernährung und der Stoffwechsel dieser kleinen Organismen. Während aber bei den porösen Spongien das Wasser allenthalben durch die Poren der äusseren Hautfläche in die inneren Höhlungen aufgenommen wird und durch das Osculum wieder austritt, dient bei den Physemarien, gleich wie bei den Hydroiden, die Mundöffunng ebenso wohl zur Aufnahme, wie zur Abgabe des Wasserstroms, und die adorale Geissel-Spirale erscheint in dieser Bezichung als eine sehr wichtige und charakteristische Einrichtung. Die physiologische Bedeutung derselben ist ganz gleich derjenigen, welche die bekannten Peristom-Spiralen der ciliaten Infusorien, Stentor, Vorticella u. s. w. besitzen. Thre morphologische Bedentung aber ist uatiirlich ganz verschieden. Denn die Wimperspirale der letzteren ist ein Theil eines einzelligen Organismus. Hingegen die Geissel-Spirale der Physemarien besteht aus einer Reihe von grossen und ausnehmend starken Geisselzellen. Mit welcher Kraft 
dieselben einen trichterförmigen Wasserstrudel crzeugen, davon iiberzengt man sich bei Gastrophysema leicht durch den Zusatz voll fein pulverisirten Farbstoffen. Diese stiirzen mit grosser Geschwindigkeit in die Mundöffnung auf einer Scite hinein, wähhrend gleichzeitig anf der anderen Seite derselben das Wasser mit gleieher Kraft wieder entfernt wird. Bei der Undurehsichtigkeit des Körpers war es mir nicht möglich, die Verhältnisse der Wasserströmung im Innern der Magenhöhle näher zu verfolgen; doch ist es sehr wahrscheinlich, dass ähnlich wie bei dem spiraligen Doppelstrudel einer Stromschnelle, eine absteigende und eine aufsteigende Spiralströmung numittelbar neben einander in den peripherischen Theilen der Magenhöhle existiren, während in der Axe derselben verhältnissmässige Ruhe oder vielmehr eine axiale Rotation herrscht. Eine so mäehtige und ausgezeichnete Geissel-Spirale von mehreren Windungen, wie bei Gastrophysema dithalamizm, habe ich bei den übrigen Physemarien nicht gefunden und es ist möglich, dass hier die Anordnung der Geisselbewegung am Peristom genügt, um den ernährenden Wasserstrudel einzıfithren. Bei Haliphysema primordiale scheint der letztere theils durch die bedentendere Grösse und Stärke der adoralen Geisselzellen, theils durch ihre Anordnung in einer unvollkommenen flachen Spiralwindung bewirkt zu werden.

Einen ähnlichen spiralen Wasscrstrudel, wie er dureh die Geisselspirale in die Mundöffnnng eingefithrt wird, erzcugt im Kleinen jede einzelne Geisselzelle innerhalb des trichterförmigen Kragens, der sich vom Halse der Geisselzclle erhebt. Auch hierin gleichen die Physemarien ganz den Kalkschwämmen, und die merkwiirdigen Bewegnngs-Erscheinungen der Geisselzellen, die ich ron den letzteren beschrieben habe (I. c., Bd. I, S. 373), finden sich ganz ebenso anch bei den ersteren wieder. Hier wic dort dringen feinste Körnchen von Carmin und Indigo, die dem Wasserstrom beigemengt sind, in kiirzester Zeit in den Leib der Geisselzellen ein und sammeln sich rings um deren Kern an.

In der Magenhöhle der meisten von mir untersuchten Physemarien fanden sich Diatomeen, Polythalamien und verschiedene fremde Körper, welche als Bestandtheile des benachbarten Seegrund-Schlammes zu betrachten sind. In wie weit dieselben zur Ernährung dienten oder zufällig - vielleicht erst theilweise post mortem - in die Magenhöble gelangt waren, liess sich nicht ermitteln.

Ebenso liess sich nichts über die Bedeutung des Secretes 
ermitteln, welches die einzelligen Driisen in der Magenhöhle von Gastrophysema dithalamium liefern. Wahrscheinlich wird dasselbe die Ernährung in irgend einer Weise unterstiitzen, vielleicht ähnlich dem Seerete del Nesselzellen tödtlich auf die kleinen Organismen wirken, welche durch den Wasserstrudel in die Magenhöhle eingefiilirt sind.

Die Fortpflanzung der Physemarien scheint in der Regel die geschlechtliehe zu sein und dureh nackte Eizellen zu g'eschehen, welche vermuthlich immer schon in der Magenhöhle selbst befruchtet werden. Doeh habe ich, wie oben bemerkt, nur ein einziges Mal Spermazellen angetroffen, und zwar beim Zergliedern einer Person von Gastrophysema dithalamium, welche gleichzeitig reife Eier in der Bruthöhle enthielt.

Bewegungs - Ersehein ungen des ganzen Körpers habe ich nur bei Gastroplyysema dithalamium beobachtet, und zwar erstens eine abwechselnde Verengertung und Erweiterung der Mundöffuung, und zweitens eine Zusammenzichung und Verkiürzung des ganzen schlauchförmigen Körpcrs. Beide Bewegungen geschahen sehr langsam und waren nicht direct, sondern nur an den veränderten Dimensionen der betreffenden Körpertheile zu verschiedenen Zeiten wahrzunehmen. Der Durchmesser der Mundöflnung variirte bei einer und derselben Person zu versehiedenen Zeiten um das Doppelte. Im erweiterten Zustande erschien der verdiinnte Rand der trichterförmigen Mundöffnung mehr flach ausgebreitet (Fig. 141). Die Contraction des ganzen Körpers der Person bewirkte eine Verkiirzung desselben um ungefähr $1 / 6$ oder $1 / 5$, höchstens $1 / 4$ der Längsaxe. Ausserdem schien es mir, dass aneh die abstehenden Spongien-Nadeln des Skelets an einer und derselben Person bald mehr allseitig abstanden, bald mehr oralwälts gerichtet waren. Alle diese Bewegungen, die noch genauer zul untersuchen sind, werden jedenfalls durch Contractionen des Exoderms bewirkt. Vielleicht kann dadurch aneh ein zeitweiliger Verschluss der Mundöffunng, sowie ein Abschlıss der beiden Kammern von Gastrophysema dithalamium herbeig'eführt werden.

Ob Empfindungen die Personen der Physemarien in höherem Maasse beseelen, als dies bei den nächstverwandten Spongien dèr Fall ist, erscheint sehr zweifelhaft. Hiel wie dort scheint das Empfindungs-Vermögen auf einer sehr niederen Stufe stehen zu bleiben. Nechanische und chemisehe Reizung der lebenden Personen vermochte nicht unmittelbar Bewegungen derselben hervorzurufeu; vielmehr crschienen sie so unempfindlich, wie die 
meisten Schwïmme. Dagegen ist eine psyehisehe Thätigkeit anderer Art in ren Physemarien offenbar sehr ausgebildet. Diesc aitussert sich in der sorgfältigen A us w a h l der Skeletbestandtheile. In ähnlicher Weise, wie die versehiedenen Species der PhryganidenLarven und Röhrenwiirmer ihre schitzenden Röhren aus ganz verschiedenen zusammengelesenen Körpern aufbanen, einige aus Sandkörnchen, andere aus Diatomeen-Schalen, noch andere aus kleinen Mollusken-Schalen, oder aus Pflanzen-Theilen u. s. w. - in ähnlicher Weise sehen wir auch die verschiedenen Arten unserer Physemarien ihr Psendo-Skelet ans ganz verschiedenen fremden Körpern zusammenlesen. Ja sogar die verschiedenen Theile der Per'son, aboraler und oraler Körpertheil, werden mit verschiedenem Ban-Naterial ansgestattet. Bei Haliphysema primordiale, II. Tumanowiczii, Gastrophysema dithalamium und $G$. scopula wird die aborale Hälfte des Körpers zum grössten Theile mit kleinen Sandkörnchen und Spicula-Fragmenten g'epanzert, hingegen die orale Hälfte mit langen Spongien-Nadeln, die als defensive Waffeu oralwärts geriehtet abstehen. Bei Haliphysema echinoides und $H$. rimulosum sind es fast ausschliesslich die Spicnla und Lithasterisken verschiedenen Spongien, sowie die Fragmente solcher Spicula, die das ganze Skelet zusammensetzen. Bei Haliphysemci globigerina endlich sind es nur gewisse Bestandtheile des Tiefseeschlammes, aus denen der ganze Panzer zusammengeklebt wird. Der Stiel dieser Art besteht grösstentheils aus einem dichten Mörtel - von Coccolithen; die Wand der Magenhöhle lingegen fast ausschliesslich aus kalkigen und kieseligen Rhizopoden-Schalen, Polythalamien und Radiolarien, ganz vorwiegend Globigerinen.

Schon Bowerpank, der uns vor 12 Jahren die ersten Beobachtungen iiber Physemarien gab, maehte mit Recht darauf aufmerksam, mit welcher Sorgfalt die Skelettheile ausgelesen und angeordnet sind, so dass er dieselben geradezu für Producte des Thieres selbst hielt. Später hob Carten richtig hervor, dass nicht allein die Auswahl der Skelettheile hinsichtlich ihrer physikalischen Beschaffenheit und Form, sondern auch hinsichtlich ihrer Grösse eine höchst sorgfältige sei. Ich kann die Angaben der beiden britischen Beobachter in dieser Bezichung nur bestätigen. Obwohl natiirlich die Anpassung an die Bedingungen des Wolnortes zunächst die Wahl des Skelet-Materials bedingt, so erfolgt doch die Zusammensetzung des letzteren offenbar mit einer sorgfältigen Auswahl unter den vorhandenen Bestandtheilen. 


\section{1\%. Phylogenetisehe Bedentung der Physemarien.}

Der morphologische Charakter und die damit verkniipfte phylogenetische Bedeutung der Physemarien liegt offenbar vorzugsweise darin, dass diese kleinen Thierchen in vollkommen entwickeltem und geschlechtsreifem Zustande sich weniger von der Gastrula, der gemeinsamen Keimform aller Metazoen, entfernen, als es bei allen anderen bisher bekannten Thieren der Fall ist. Nach dem biogenetischen Grundgesetze ergibt sich darans unmittelbar der Schluss, dass sie anch der gemeinsamen Stammform aller Metazoen, der hypothetischen Gastra e a, näher stehen, als alle anderen bekannten Metazoen. Diese Beziehung halte ich fuir so innig, dass ich nicht anstehe, die Physemarien geradezu mit der hypothetischen Gastrae a in einer Klasse zu vereinigen und als lebende, wenig veränderte Epigonen jener längst ausgestorbenen uralten Stammform zu erklären, als „Gastraeaden der. Gegenwart".

Die hypothetische Klasse der Gastrae ad en hatte ich friiher (1872) fuir das Genus Gastraea selbst und für diejenigen ältesten und einfachsten Metazoen-Formen gegründet, welche als nächstverwandte und wenig veränderte Descendenten jener Gastraea zu betrachten seien. Unsere Physemarien entsprechen diesem Begriffe vollständig. Denn auch bei den Physemarien, wie bei der hypothetischen Gastraea selbst, besteht der Körper zeitlebens einzig und allein aus den beiden primaeren Keimblättern, welche sich noch nicht in secundäre Keimblätter gespalten haben.

Die wesentlichsten Unterschiede, welche unsere Physemarien gegentiber der Gastraea darbieten, bestehen erstens darin, dass die ersteren festsitzend sind, während die letzteren freischwimmend gedacht werden müssen; und zweitens darin, dass die urspriingliche Gastraea sicher nicht das eigenthiimliche Skelet von fremden Körpern besass, welches die Physemarien auszeichnet. Letztere werden daher im System der Gastraeaden-Klasse eine besondere Familie oder Ordnung zu bilden haben, welche der Familie oder Ordnung der ur'sprünglichen, frei schwimmenden (theils skeletlosen, theils schalenbildenden) Gastraeaden gegeniiber steht. Diese lctzteren wollen wir im Folgenden kurz als Gastremarieu bezcichnen (Gastraea ganz nackt, Gastrema mit Schale). 
Schon frïher, als ich ,die phylogenetische Bedeutung der tünf ersten ontogenetischen Entwickelmngsstufen" des Thierkörpers erörterte (im 12. Abschuitt), habe ich zu zeigen gesucht, dass wir aus der bedentungsvollen urspriunglichen Keimform der Archigastrula nach dem biogenetischen Grundgesetze unmittclbar auf die einstmalige Beschaflenheit der unbekannten ausgestorbenen Gastraca-Stammform schliessen können. „Diese ältesten Gastraeaden werden der heutigen Arehigastrula im Wesentlichen ganz gleich gebildet und wahrscheinlich nur darin wesentlich verschieden gewesen sein, dass sie bereits sexmelle Differenzirung besassen. Vermuthlich werden sich bei ihwen einzelne Zellen des Entoderns zu Eizellen, einzelne Zellen des Exoderms zu Spermazellen umgebildet haben, wie es auch bei den niedersten Zoophyten (Spongien, Hydroiden) noch hente der Fall ist. Gleich den frei im Meere schwimmenden Formen der Archigastrula werden anch jene Gastraeaden sich mittelst Flimmerhaaren, Geisseln oder Wimpern bewegt haben, welche als Fortsätze der Exoderm-Zellen sich entwickelten." Die Berechtigung dieser phylogenetischen Hypothese liegt fuir Jeden, der das biogenetische Grundgesetz iiberhaupt anerkennt, wohl klar vol Augen. Denn wenn irgend eine Thatsache in der vergleichenden Ontogenie der Metazoen eine weitreichende phylogenetische Bedeutung besitzt, so ist es sicher die feststehende Thatsache, dass bei Thieren der verschiedensten Stämme und Ǩlassen (und zwar gerade bei den niedersten und ältesten Formen!) der Körper der Person sich aus derselben einfachen Keimform der Archigastrula entwickelt. Alle die mannigfaltigen Keimformen, die in den verschiedenen Thierklassen als Modificationen der Amphigastrula, Discogastrula und Perigastrula auftreten, konnten wir als secundaere, cenogenetische Keimformen erklären, welche durch verschiedene embryonale Anpassungen aus jener primaeren, palingenetischen Keimform der Archigastrula im Laufe der Zeit entstanden waren. Diese primordiale Archigastrula aber zeigte uns iiberall denselben einfachen Bau: Ein einaxiger Schlanch, dessen Höhle („Urdarmhöhle“) sich an einem Ende der Axe durch eine Mündung öffnet („Urmund"), und dessen Wand einzig und allein aus den beiden primaeren Keimblättern besteht: Hautblatt und Darmblatt. Dieselbe Organisation wiirden auch die Gastremarien besessen haben, die Gastraea und ihre nächsten Descendenten. Nur darin werden dieselben höchst wahrscheinlich von der heutigen Keimform der Archigastrula verschieden gewesen sein, dass sie geschlechtsreif wurden. 
Einzelne Zellen ihrer primaeren Keimblätter werden sich zu Eizellen, andere zu Spermazellen entwickelt haben; und aus den befruchteten Eiern wird durch primordiale Eifurchung eine Archiblastula, ans dieser durch Invagination eine Archigastrula entstanden sein. Durch Bildung von Geschlechts-Zellen wurde diese wieder zur Gastraea.

Wenn somit die freischwimmenden Gastremarien in dieser Form die directe $\mathrm{Ha}$ a ptinie an der Wurzel des MetazoenStammbaums bilden, so diirfen wir die $\mathrm{Physemarien}$ als eine untergeordnete Nebenlinie betrachten, welche ans der ersteren durch Anpassung an festsitzende Lebensweise hervorgegangen ist. Die Archigastrula gibt die freischwimmende urspriingliche Lebensweise auf und setzt sich mit dem aboralen Körperpole fest. Um der festsitzenden schlanchförmigen Person reichlichere Nahrung zuzufiuhren, entwickeln sich die Geisselzellen des Entoderms in der Umgebung der Mundöffnung zu stärkeren, kräftigeren Strudel-Organen und bilden so die eigenthiimliche adorale Geisselspirale. Hingegen geeben die Geisselzellen des Exoderms ihre locomotorische, nunmehr iberfluissig gewordene Geisselbewegung auf und verschmelzen miteinander zur Bildung eines Syncytiums, welches durch Aufnahme fremder Körper sich zu einem stiitzenden und schiitzenden Hantskelet entwickelt.

Die hohe phylogenetische Bedentung, welche demgemåss unsere Physemarien als die nächsten Verwandten der Gastraea besitzen, wird anch einen entsprechenden Ausdruck durch ihre Stellung im "Natiirlichen System" des Thierreichs finden müssen. Unzweifelhaft finden sie ihren natïlichen Platz nur im Stamme der Pflanzenthiere oder Zoophyten; und innerhalb dieses Stammes repriisentiren sie die tiefste und älteste Bildungsstufe. Dadurch treten sie aber in die engste Beriihrung und in die näichsten Verwandtschaftsbeziehungen zu denjenigen Zoophyten oder Coelenteraten, welche wir bisher als die einfachsten und niedersten Formen dieses Stammes zu betrachten gewohnt waren. Einerseits treten uns da die einfachsten Spongien, anderseits die niedersten Hydroiden entgegen.

Unter den Spougien miissen wir vor allen anderen die A seonen in Betracht ziehen, jene einfachsten Formen der Calcispongien, die bisher iiberhaupt den primitivsten Typus der SpongienKlasse darstellen. Unter den Asconen aber muss wieder der ganz 
einfache Olynthus als der wahre Prototypus gelten, wie ieh in meiner Mouographie der Kalkschwïmme hinreichend dargethan zu haben glaube. ${ }^{1}$ ) In der That ist eine eehte Spongie von einfacherer Organisation als der Olynthus nicht denkbar, - abgesehen von dem unwesentlichen Umstand, dass derselbe in seinem Exoderm ein Skelet von Kalknadeln bildet, wïhrend die lypothetische Stammform der Schwämme - mnsere A rehis poug i a ${ }^{2}$ als skeletlos anzunehmen ist. Letztere wiirde sich zu den skeletlosen Sehleimsehwämmen oder Myxospongien (Halisarca) ganz ebenso verhalten, wie Olynthus zu den Lenconen. Wenn wir durch Behandlung mit Siiuren die Kalknadeln des Olynthus auflösen, so bleibt die hypothetische Arehispongia iibrig: ein einfacher, schlanchförmiger, einaxiger Körper, der am aboralen Pole der Axe festgewachsen ist, und dessen einfache Darmhöhle sich am entgegengesetzten oralen Pole durch eine einfache Miindung. öfnet; die Wand des Schlauches besteht aus den beiden primären Keimblïttern: einem flimmernden Entoderm und einem flimmerlosen Exoderm; iiberall ist die Wand von vergänglichen Porencanälen durchbrochen, dureh welche ernährende Wasserströme in die Darmhöhle eintreten, um dann durch die Mundöffnung auszutreten.

Vergleichen wir mit dieser einfachsten Spongienform unser Haliphysema, so bleibt nur ein einziger wesentlicher Unterschied zwischen beiden iibrig: die Anwesenheit der Hautporen bei ersterer, ihre Abwesenheit bei letzterem. Nun sind freilich die Poren des Spongien-Körpers vergängliehe Canäle, und wenn dieselben zeitweise gesehlossen sind, so besteht eigentlich (- vom Skelet abgesehen -) gar keine weitere Differenz in der Organisation von Archispongia (oder Olynthus) und Haliphysema ${ }^{3}$ ). Anderseits aber ist der Besitz der Poren für den Begriff des "Poriferen“Körpers so wesentlich und diese Poreneanäle bilden so sehr gerade den eigenthiimlichsten Charakter der Spongien - besitzen

1) Ueber Olynthus, die „Stammform der Kalkschwämme", vergl. Bd. I, S. 76; Taf. 1, Fig. 1; Taf. 11, Fig. 6-9; Taf. 13, Fig. 1.

2) Ueber Archispongia, die hypothetische Stammform der Spongien, vergl. meine Monogr. der Kalkschwämme, Bd. I, S. 454, 465; 'Taf. 11, Fig. 6-9.

${ }^{3}$ ) Vergl. dic Abbildung, welche ich 1. c., Taf. 11, Fig. 6 von dem entkalkten Olynthus fragilis mit geschlossenen Poren gegeben habe. Dasselbe Bild gibt ein Itutipleysema, aus welchem die fromclen Körper cles Skelets entfernt sind. 
eine so hohe morphologische und physiologische Bedentung fiir deren Organisation, - dass wir logischer Weise die Physemarien nicht in die Klasse der echten Poriferen aufnehmen können.

Allerdings glaubte ich avfänglich lange Zeit, dass Haliphysema nur ein einfacher Sandschwamm, eine Psammospongie mit zufällig geschlossenen Poren sei, und dass sie sich zu der gewöhnlichen Form dieser Gruppe (Dysidea) gerade ebenso verhalte, wie Olynthus zu den Lenconen (Dyssycus), oder Archispongia zu Halisarca. Nachdem ich jedoch später die Peristom-Spirale bei Haliplysema entdeckt hatte und mit der Organistation von Gastrophysema genauer bekannt geworden war, kam ich allmählich zu der Ueberzengung; dass beide Physemarien wegen des absoluten Porenmangels und wegen der eigenthïmlichen Peristom-Spirale von den echten Poriferen ganz zu trennen seien.

Immerhin bleibt die bedentungsvolle Uebereinstimmung merkwiirdig, welche zwischen jenen einfachsten Poriferen und unseren Physemarien nicht allein beziiglich der Gesammtbildung, sondern auch im Detail der Organisation besteht. In beiden Fällen verhalten sich die primaeren Keimblïtter nicht allein in organologischer, sondern auch in histologischer Beziehung höchst ähnlich. In beiden Gruppen bildet das Entoderma ein einfaches Geissel-Epithel, und der charakteristische Bau der Geisselzellen mit ihrem schlanken Hals und ihrem trichterförmigen Kragen ist bei Haliphysema und bei Gastrophysema ganz ebenso, wie ich ihn frither bei den Kalkschwämmen beschrieben habe. Auch sind dort ebenso wie hier sämmtliche Zellen des Exoderms zu einem Syncytium verschmolzen; und wie dieses bei den Calcispongien ein Skelet aus Kalknadeln bildet, so nimmt es bei den Physemarien eine Masse von fremden Körpern auf und verarbeitet diese zu einem Pseudo-Skelet, gleich Dysidea.

Fast ebenso innig und ebenso bedeutungsvoll, als die Verwandtschafts-Beziehungen der Physemarien zu den Poriferen, geestalten sich anderseits diejeuigen zu den Hydroiden. Auch hier sind es die niedersten und einfachsten Vertreter der Hyd̈ro. medusen-Klasse, welche den unmittelbaren Ansehluss vermitteln. Als bekannteste Form tritt uns hier der Prototyp der Klasse, H y dra entgegen, und sodann diejenigen Hydroiden, welche sich von der einfachen, typischen Hydra-Organisation am Wenigsten entfernen. Allerdings wiirde eine noch grössere Aehnlichkeit als die armtragende Hydra, dic armlose Protolydra von GreEF dar- 
bieten. $\left.{ }^{1}\right)$ Allein wil sind genöthigt, diese angebliche „Stammform der Coelenteraten" so lange für eine jugendliche Entwickelungsform, fiur eine Larve oder Amme einer anderen Hydromedusen-Form zn halten, als weder Geschlechts-Organe bei derselben nachgewiesen, noch ihre Entwieklung vollstiindig bekannt ist. Wenn GreerF annimmit, dass die von ihm beobachtete "Quertheilung" seiner Protohydra der einzige Fortpflanzungs-Modus derselben sei, so ist diese Anuahne sicher nicht berechtigt; denn anclı vorausgesetzt die Richtigkeit seiner Beobachtung und seiner Dentung, kennen wil bis jetzt keine einzige Art des Zoophytenoder Coelenteraten-Stammes, die sich a usschliesslich auf ungeschlechtlichem Wege fortpflanzte. ${ }^{2}$ ) Vielmehr ist hier die sexuelle Differenzirung ganz allgemein vorhanden, und wenn wir sehen, dass die niedersten Schwämme und die niedersten Acalephen in derselben einfachsten Form ihre Geschlechtsproducte bilden, wie unsere Plysemarien, so liegt darin gerade ein besonderer Hinweis auf deren Bedeutung. In allen Fällen sind es einzelne Zellen der primaeren Keimblätter, entweder des Entoderms oder des Exoderms, welche sich zu Sexual-Zellen umbilden; und wir halten es sogar fuir wahrseheinlich, dass auch bei unseren Physemarien das Verhailtniss dasselbe ist, welches E. van Beneden und G. v. Косн bei verschiecienen Hydroiden beobachtet haben; dass sich auch hier die männlichen Spermazellen aus dem Exoderm, die weiblichen Eizellen aus dem Entoderm hervorbilden.

Bei der Vergleichung der Physemarien mit Hydra und den einfachsten Hydroidpolypen können wir von den Tentakeln der letzteren zunächst absehen. Denn wenn wir die problematische Protohydra auch ganz aus dem Spiele lassen, so sind doch aus anderen Griinden die physiologiseh so wichtigen Tentakeln der Hydroiden als Organe von untergeordneter morphologiseher Bedeutung anzusehen. Sic fehlen vielen Personen der SiphonophorenStöcke und entwickeln sich bei den jungen Thieren meistens erst, nachidem der wiehtigste Theil des Körpers, der Magenschlanch

1) R. Greeff, Protohyrap Leuchartii, eine marine Stammform der Coelenteraten. Zeitschr. für wissensch. Zool. 1870, Bd. XX, S. 37, Taf. IV, V.

2) Die Gründe, weshalb Proto'yydra vorläufig n icht als „Stammform der Coelenteraten" betrachtet werden kann, habe ich in der Monographie der Kalkschwämme entwickelt (Bd. I, S. 459, Anm.). Wenn bewiesen würde, dass Protohydra in dem von Gresfe beobachteten Zustande geschlechtsreif würde und sich durch Eier fortpflanzte, so wiirde Greww's Annahme gerechtfertigt sein. 
mit Mundöffnung, bereits gebildet ist. Wenn wir also den Besitz der Tentakeln als nicht wesentlich betrachten, so bleibt zwischen den Hydroiden und den Physemarien wiederum nur ein einziger wesentlicher Unterschied iibrig, der Besitz der Nesselkapseln bei den ersteren, ihr Mangel bei den letzteren. Die Nessel-Or ga ne sind es, welche die porenlosen Acalephen vor den porenfiihrenden Schwämmen am meisten anszeichnen. Da alle Zoophyten, die wir in der Hauptklasse der Acalephen zusammenfassen: alle Hydromedusen, Ctenophoren, Korallen constant Nesselzellen besitzen, und da diese ebenso constant allen Spongien fehlen, so haben wir bei der Gegeniiberstellung dieser beiden Hauptgruppen von Zooplyyten darauf das g’rösste Gewicht gelegt. ${ }^{1}$ ) Die Physemarien verhalten sich in dieser Beziehung gleich den Poriferen. Dagegen stimmen sie wiederum in dem Porenmangel mit den Hydroiden iberein. Mit diesen theilen sie auch den Mechanismus der Ernährung und unterscheiden sich dadurch wesentlich von den Poriferen. Der mit Nährstoffen beladene Wasserstrom tritt dureh die Mundöffnung ein, während er bei den Poriferen durch die Hautporen eintritt und der Mund nur als After oder "KloakenOeffnung" fungirt. Das einfache Geissel-Epithel des Entoderms, welches die Physemarien mit den Poriferen theilen, besitzen in ganz ähnlicher Form auch viele Hydroiden. Dagegen sind freilich die Physemarien in Beziehung anf die histologische Differenzirung. des Exoderms sehr versehieden von den Hydroiden und stimmen vielmehr mit den Spongien iiberein.

Aus dieser Vergleichung ergiebt sich, das die Physemarien zwischen den einfachsten Formen der Poriferen einerseits nnd den einfachsten Formen der Hydroiden anderseits in der Mitte stehen und dass sie weder mit jenen noch mit diesen im Systeme vereinigt werden können, ohne die bestehenden festen Grenzen jener beiden Klassen zu durehbrechen. Es bleibt daber Nichts iibrig, als eine besondere Klasse fiil dieselben zu griinden, und diese Klasse kann keine andere sein, als diejenige der Gastraeaden, die wir als eine hypothetische Gruppe auf Grund der Gastraea-Theorie schon seit Jahren angenommen haben. Innerhalb dieser Klasse werden als zwei rerschiedene Ordnungen oder Fanilien zu unterseheiden sein: 1) die freisehwimmenden und vielleicht schon ansgestorbenen Gastremarien (Gastrarc,

1), Die Spongien nnd die Acalephen". Monogr. der Kalkschwimme, Bi. J, S. $458-460$. 
Gastrcma ${ }^{1}$ ) - wesentlich gleich einer geschlechtsreilen Archigastrula - und 2) die f'estsitzenden und skeletbackenden Physemari en (Haliphysema, Gastrophysema).

Wenn man die nessellosen Spongien und die nesselnden Acalephen als zwei Hauptklassen der Pflanzenthiere beibehalten will, so wird nıan die Gastraeaden zn den ersteren stellen miissen; und diese Anordnung wird sich um so mehr empfehlen, als doch die Physemarien im Ganzen näher noch den Spongien als den Hydroiden verwandt erscheinen. Man wird damn aber unter den Spongien zwei verschiedene Klassen unterseheiden miissen: I. Die Gastraeaden, ohne Hautporen (mit adoraler Wimperspirale?); und II. die Poriferen, mit Hautporen (ohne adorale Wimperspirale). Das System der Zoophyten wiirde demnach folgende Form annehmen:

Erste Hauptklasse: Spongiae. Klassen: 1. Gastraeada, 2. Porifera.

Zweite Hauptklasse: A e a le p li a e. Klassen: 1. Hydromedusae, 2. Ctenophora, 3. Calycozoa, 4. Coralla.

Die Klasse der Gastracaden wurrde durch folgende $\mathrm{Cha}$ rakteristik zu bezeichnen sein:

Char akter der Gastra eaden: Einfache, schlauchförmige Thiere ohne Anhäinge, deren diinne Körperwand zeitlebens aus den beiden prinaten Keimblättern besteht, und deren einfache Darmhöhle sich durch einen Urmund öfmet. Fortpflanzung dureh befruchtete Eier.

Erste Ordu ung: Gastremaria. (Hypothetische Stammgruppe der Metozoen). Körper freibeweglieh, umherschwimmend mittelst der Flimmerhaare des Exoderms.

Genera: Gastraea (nackt). Gastreme (beschaalt).

Zweite Ordnung: Physemaria. Körper am aboralen Pole festgewachsen. Exoderm nicht flimmernd, durch Versehmelzung der Zellen ein Syncytium darstellend, welches durch Aufnahme von fremden Körpern ein Sand-Skelet bildet.

Genera: Haliphysence (einkammerig). Gastroplysema (mehrkammerig).

1) Unter Gastraea wollen wir die nackten, vollkommen der Archigastrula gleichen Gastremarien verstehen; unter Gastrema dagegen diejenigen, welche sich eine schützende Hülle oder Schale bildeten, Dass letztere neben ersteren in der laurentischen Periode existirten, ist aus vielen Gründen wahrscheinlich. 


\section{Erklairung der Tafeln.}

Taf. IX.

Haliphysema primordiale.

Fig. 121. Eine entwickelte Person, festsitzend auf einer Laminarien-Wurzel. Aeussere Ansicht. Vergrösserung 80.

Fig. 122. Längsschnitt durch dieselbe Person. Die spindelförmige Magenhöhle (v) öflnet sich oben dureh den Mund $(m)$. $c$ Exoderm $i$ Entoderm. o Eizellen. $s$ Spicula. $l$ Steinchen. Vergr. 80.

Fig. 123. Querschnitt durch die Mitte derselben Person. Buchstaben wie in Fig. 122. Die Eizellen (o) liegen zerstrent zwischen den Geisselzellen des Eutoderms (i). Vergr. 80.

Fig. 124. Die adorale Geisselspirale in der Richtung von der Mundöfinnng ans gesehen. Schematisch. Vergr. 250.

Fig. 125. Ein Stückchen Entoderm, mit fünf Geisselzellen, im Profil. Vergr. 800.

Fig. 126. Ein Stiuckchen Exoderm, von der Fläche gesehen. n Zellenkerne. p) Syncytium. l Kieselsteinchen. s Spieula. Vergr. 800.

\section{Taf. $\mathrm{X}$.}

\section{Haliphysema echinoides.}

Fig. 12\%. Eine entwickelte Person, mit Spicula von Corticaten-Spongien bewallnet; in der kugeligen Magenwand viele dreizähnige Ankernadeh; im Stiel und in der konischen Fussscheibe des Stiels viele Lithasterisken von 'Tetlyyen ete. Vergr. 80.

Fig. 128. Längsschnitt durch den Körper derselben Person. Im Grunde der kugeligen Magenhöhle $(v)$ sitzt ein Zapfen (Columella, $c$ ), der mit einem Haufen von Eizellen $(o)$ bedeckt ist. $m$ Mundöflnung. e Exoderm. $i$ Entoderm. Vergr. 80.

Fig. 129. Ein Stiickchen Exoderm. $n$ Zellenkerne. $p$ Protoplasma des Syncytium. Vergr. 600.

Fig. 130. Ein Stiickehen Entoderm, einfache Epithelschicht, von der Eläche rresehen. Vergr. 600 .

Fig. 131. 'Zwei Eizellen aus dem Grunde der Magenhöhle. Im körnehenreichen Protoplasma cin helles Keimbliischen mit Keimfleck. Vergr. 400. 


\section{Taf. XI.}

\section{Haliphysema globigerina.}

Fig. 132. Eine entwickelte Person, mit birnfömigem Körper und einem sehr langen, runden, in der Figur kurz abgebrochenen Stiele. Das Psendo-Skelet des Exoderms besteht zum grössten Theile aus Rhizoporlen-Schalen, ganz überwiegend Globigerina; eine dünnschaligere Form $(G)$ und eine dickschaligere $(K)$, Orbulina $(O)$, ferner einzelne Rotalien und Textilarien (T); dazwischen auch einzelne Radiolarien: Enchitonia (E), Haliomma (H), Trematodiscus (D) u. s. w. Vergr. 100.

Fig. 133. Längsschnitt durch dieselbe Person. Die birnförmige Magenlöhle (v) öfnet sich oben durch eine nabelfömig eingezogene Mündung $(m)$. c Exoderm. $i$ Entoderm. c Säulchen (columella). o Eizellen. Vergr. 40.

Fig. 134. Ein Stückchen des vorigen Längsschnittes, stärker vergrössert. $i$ Entoderm. $c$ Exoderm. $n$ Kerne desselben. $O$ Eine Orbulina. $I I$, $K$ Globigerinen. Vergr. 600.

Fig. 135. Längsschnitt dureh die Columella (c). Der Entoderm-Ueberzug derselben besteht aus grösseren 'Lellen, wahrscheinlich jungen Fizellen (o). Im Exoderm-Protoplasma viele Kerne (n). Vergr. 400.

Fig. 136. Querschnitt durch den runden Stiel. In der Mitte die aus Protoplasma bestchende Axe des Stiels $(p)$, welche keine fremden Körper, dagegen zahtreiche longitudinal gelagerte Zellenkerne enthält $(n)$; in der Peripheric Cocolithen, Coccosphaeren und andere fremde Körper $(x)$. Vergr. 400.

\section{'Taf. XII.}

\section{Gastrophysema dithalamium.}

Fig. 137. Eine entwickelte Person, anfsitzend auf einem abgestorbenen Stock von Cladocora. Der Körper ist im unteren 'Theile mit Sandkörnchen und Nadelfragmenten, im oberen Theile mit abstehenden Spicula verschiedener Spongien bewaffinet. Vergr. 80.

Fig. 138. Ein Stückchen eines Durchschnittes durch die Wand der Magenhöhle im unteren 'Theile. $f$ Geisselzellen des Darm-Epithels. $d$ Drüsenzelle desselben. $n$ Zellenkerne des Exoderms. p Protoplasma. Die fremden Körper des Pseudo-Skelets sind aus dem Syncytinm entfernt. Vergr. 1500.

Fig. 139. Ein Stiickchen eines Durchschnittes durch die Wand der Magenhöhle im oberen Theile, wo die adorale Geisselspirale liegt. " Geisselzellen der letzteren, mit sehr verlängertem Halse. " $l$ Drisenzelle. $n$ Zellenkerne des Exoderms. p Protoplasma desselben. Vergr. 1500.

\section{Taf. XIII.}

\section{Gastrophysema dithalamium.}

Fig. 140. Eine entwickelte geschlechtsreife Person mit Eiern, mit verengertem Mundtrichter, im Längsschnitt. $i$ Geissel-Epithel (Entoderm). v Magenhöhle. $b$ Bruthöhle. y Enge Einschnürung zwischen beiden. 
¿ Drüsenzellen des Magens. a adorale Geisselspirale. m Mundöflnung• o Eizellen. $c$ Exoderm, mit fremden Körpern $(s)$ beladen (in der untern Hälfte grösstentheils Sandkörnchen, in der oberen Spieula von Spongien). $n$ Kerne des Syneytium. Vergr. 80.

Fig. 141. Eine entwickelte trächtige Person mit erweitertem Mundtrichter, zahlreiche ausgebildete Gastrulae $(g)$ enthaltend; die Geschlechtshöhle (b) ist fast ganz von ihnen erfillt; einzelne sind auch in die Magenhöhle $(v)$ übergetreten. Buchstaben wie in voriger Figur. Vergr. 80.

Fig. 142. Vier Spermazellen, beim Zerzupfen einer eierhaltigen Person in Menge isolirt. Vergr. 1200.

Fig. 143. Eine unreife Eizelle, in drei versehiedenen Zuständen der amoeboiden Bew egung. Vergr. 600.

Taf. XIV.

\section{Gastrophysema dithalamium.}

Fig. 144. Längsschnitt durch die Magenhöhle (v), um die adorale GcisselSpirale zu zeigen $(a)$. Schematisch. a die Spirale. $m$ Mund. $e$ Exoderm. $i$ Entoderm. Vergr. 80.

Fig. 145. Hälfte eines Querschnitts durch den oberen Theil der Magenhöhle $(v)$. $f$ Geisselzellen des Entoderms. d Drüsenzellen. a Colossale Geisselzellen der Spirale. $n$ Zellkerne des Exoderms. $p$ Protoplasma desselben. $s$ fremde Körper. Vergr. 200.

Fig. 146. Hälfte eines Quersehnitts durch die Geschlechtshöhle ( $)$ ). $f$ Geisselzellen des Entoderms. o Eizellen. $n$ Kerne des Exoderms $(c)$. $p$ Protoplasma. $s$ fremde Körper. Vergr, 200.

Fig. 14\%. Ein Stückchen Entoderm aus dem adoralen (oberen) Theile der Magenhöhle. $f$ Geisselzellen. $d$ Drüsenzelle. a drei grosse Geisselzellen der Spirale. Von der Flïche gesehen. Vergr. 1200.

Fig. 148. Ein Stuickchen Exoderm, von der innersten Schicht desselben, an der Einschnürungsstelle zwisehen beiden Kammern. Die Grundsubstanz des Syncytium $(p)$ erscheint faserig diflerenzirt, die Kerne $(n)$ den Fasern parallel gelagert. Vergr. 1200.

Fig. 149. Zwei Blastoderm-Zellen der Blastula (vergl. Fig. 118). Vergr. 1500.

Fig. 150. Durchschnitt durch die Wand der Gastrula. e Vier ExodermZellen. $i$ 'Lwei Entoderm-Zellen der Gastrula (Fig. 119, 120). Vergr. 1500.

Jena, den 18. August 1876. 


\section{IV. \\ Nachträge zur Gastraca-Theorie.}

In halt. 18. Histologische Bedeutung der Gastraca-Theorie. 19. Primäre und sccundäre Keimblitter. Exoderm, Mesoderm und Entoderm. 20. Protozoen und Metazoen. 21. Mesozoen, Gastraeaden, Dicyemiden. 22. Gastrulation der Säugethiere. 23. Urdarm und Urmund. Primitiv-Organe. 24. Heuristische Bedeutung der Gastraen-Theoric. 



\section{Histologisehe Bedentung der Gastraea-Theorie.}

Der erfrenliehe Aufschwung und die waehsende Theilnahme weiter Kreise, welche das Studium der Entwicklungsgeschichte im letzten Decennium gewonnen hat, ist auch unserer GastraeaTheorie unmittelbar zu Gute gekommen. Zahlreiche vortreffliche Arbeiten aus der neuesten Zeit, unter denen ieh hier nur diejenigen von E. Ray-Lankester, F. M. Balfour, Eduard van Benfonen, A. Kowalewsir, A. Rauber und Carl Rare hervorheben will, haben nicht nur unsere Kenntnisse in der Ontogenie der verschiedenen Metazoen ansserordentlich erweitert, sondern anch das causale Verstïndniss von deren phylogenetischer Bedentung mäeltig gefördert. Die meisten und zuverlässigsten von diesen neneren Arbeiten haben die Gastraea-Theorie mit ihren wichtigsten Folgerungen bestätigt und weiter ausgefuihrt. Die empirische Grundlage unserer Theorie ist dadurch viel breiter und fester geworden, als ich vor vier Jahren bei ihrer ersten Publication hoffen konnte, und die wichtigsten Einwiirfe, die damals dagegen erhoben wurden, können jetzt als beseitigt gelten.

Aus diesem Grunde erscheint es anch überfliissig, auf die heftigen Angriffe zu antworten, welehe sofort von Carl Claus, Carl Semper, W. Salenshy, Alexamier Agassiz u. A. gegen die Gastraea-Theorie und ihre Consequenzen gerichtet wurden. Ich hatte anfangs die Absicht, am Schlusse dieser Studien zur GastraeaTheorie wenigstens diejenigen von jenen Einwendungen zu widerlegen, welche am besten thatsäehlich begriindet erschienen. Indessen haben die neneren Fortschritte in der vergleichenden Ontogenie selbst diese Widerlegung thatsächlich übernommen. Auf einige der stärksten Angriffe, namentlich diejenigen von Wituelas His und Alexanden Götte, habe ich in meiner Schrift iiber "Ziele und Wege der heutigen Entwicklungsgeschichte" (1875) geantwortet. Viele Einwendungen gegen die Gastraea-Theorie erinnern lebhaft an die Einwände, welche seiner Zeit gegen die 
Zellen-Theorie erhoben wurden. Als ScuLEuben 1838 die ZellenTheorie für das Pflanzenreich begriindete und Scirwans sie unmittelbar darauf für das Thierreich durchführte, da meinten viele, und unter diesen sehr angesehene Naturforscher, diese Theorie sei weder nen noch wichtig. Denn "Zellen" habe man lïngst gekannt, dass alle Gewebe bloss aus Zellen zusammengesetzt seien, sei nicht bewiesen, ansserdem gebe es anch andere Elementartheile, und der Zellen-Begriff sei nicht anf die Bestandtheile aller Gewebe anwendbar. Geradeso erheben die Gegner der Gastraea-Theorie den Einwurf, die Keimformen vom Bau der Gastrula seien schon vorher bekannt gewesen, dass alle Metazoen sich aus GastrulaKeimen entwickeln, sei nicht bewiesen, ansserdem gebe es auch noch andere Keimformen und der Gastrula-Begriff sei nicht auf die Embryonen aller Metazoen anwendbar. Diese Einwiurfe werden aber das feste Fundament der Gastraea-Theorie so wenig erschiittern, als jene gleichen Angriffe vor 38 Jahren die ZellenTheorie widerlegt haben. Wie wir durch die letztere die eimheitliche Auffassung vom elementaren Bau allel Organismen gewonnen und durch den Zellen-Begriff die Zelle als das "Individunm erster Ordnung" erkannt haben, so gelangen wir durch die erstere zu einer einheitlichen Auffassung rom histologischen und organologischen Bat aller Metazoen und erkennen in der Gastraea das "Individuum dritter Ordnung", die Person; in ihren beiden primären Keimblättern die Individuen zweiter Ordnung, die „Idorgane“, ans denen sich die Organisation sämmtlicher Netazoen entwickelt hat. Die Einfachheit und Einheit der Auffassung, die Feststellung klarer morphologischer Elementar-Begriffe und die damit verkniipfte phylogenetische Erkenntniss verleihen der Gastraea-Theorie ihren Anspruch auf Geltung so lange, bis sie durch eine bessere morphologische Theorie ersetzt sein wird.

Statt also hier auf die vielfachen Angriffe meiner Gegner zu antworten, halte ich es für zweckmässiger, in diesen „Nachträgen zur Gastraea-Theorie" noch einige Folgerungen derselben zu erläntern, die frïher nicht die geliörige Betonung gefunden haben und zugleich mit Hülfe wichtiger Beobachtungen aus nenester Zeit einige friiher offen gebliebene Liicken anszufiillen. Zunächst scheint es da zweckmässig, cinige Bemerkungen ïber die histologische Bedeutung der Gastraea-Theorie vorauszuschicken.

Vor allen dïrfte fiir die generelle Histologic der Grundsatz au betonen sein, dass mit der Gastrulation und der Keimbliitter- 
bildung iiberhaupt erst die Bildung eigentlicher Gewebe im Thicrkörper beginnt. Dalıer besitzen nur die Metazoen wahre Gewebe, nieht die Protozoen. 'Jwar wird auch hente noch vielfach bei den Protozoen von Geweben gesprochen; und den Infusorien werden sogar hölere Gewebs-Differenzirungen zugeschrieben. In Interesse klarer und logischer Ordnung der Begriffe sollte dies aber niemals geschehen. Denn unter Geweben verstehen wir solehe Gruppirungen bestimmter Zellenarten, welche eine bestimmte morphologische und physiologische Bedeutung fuir den vielzelligen Thier-Organismus besitzen. Da nun die grosse Mehrzahl der Protozoen einzellig ist, kann bei ilnen iberhaupt nicht von Gerreben in strengerem Sinne die Rede sein. Aber auch bei den vielzelligen Protozoen treffen wir die constituirenden Zellen niemals in der Weise zu bestimmten morpholugisehen Linheiten verbunden, wie sie die Keimblätter der Metazoen und die darans abgeleiteten Gewebe vorstellen.

Die beiden primären Keimblätter der Gastrula sind also die ersten und ältesten differenten Gewebe des Thierkörpers. Wollte man noch einen Schritt weiter zuriickgehen, so könnte man das Blastoderma, die Keimhant der Blastula, als das alleriilteste Gewebe bezeichnen. In der That kann diese einfache Zellenschicht, welche die Wand einer einfachen Hohlkngel bildet, ebenso g'ut auf den Charakter cines echten, einfachen Gewebes Anspruch machen, wie die beiden primären Keimblätter, welche aus dem Blastoderm durel Invagination der Blastula hervorgehen. Das Entoderma ist ja eigentlich nur der eingestuilpte, und das Lx o d e r m a der nicht eingestiilpte Theil des Blastoderma.

Vergleichen wir nun diese ältesten Gewebs-Formationen des Metazoen-Organismus mit den Geweben des vollkommen entwickelten Thierkörpers, so kann es keinen Augenblick zweifelhaft sein, dass dieselben sowohl in morphologischer als in physiologischer Beziehung den Charakter eines einfachen echten Epitheliums besitzen. Sowohl das urspriingliche, ganz einfache Blastoderma, als die beiden daraus dureh Invagination entstehenden primären Keimblätter, Ex oderma und Entoderma, sind echte Epithelien. Die einfache Zellenschicht des Exoderms ist ein primitives Dermal-Epithelium, eine einfachste "Hautdecke"; die ebenso einfache Zellenschicht des Entoderms ist ein primitives Gastral-Epitlolium, eine einfachste „Darmdecke".

Mit Pezug auf lie Planaea und die Gastraea, jene 
ältesten hypothetischen Stammformen, welche den heutigen Keimformen der A rehiblastula und Archigastrula wesentlich gleich gevesen sein miissen, diirfen wir fermerhin die Vermuthung aufstellen, dass jene alleriiltesten, zuerst entstandenen Epithelien - sowohl das Blastoderma, als das Exoderma nnd Entoderma Flimmer-Epithelien waren; und wemn wir den wichtigen Zeuguissen trauen dürfen, welche uns die histologische Beschaffenheit des Entoderms bei den heute noch lebenden Gastraeaden, Spongien und Hydroiden liefert, so waren jene ersten FlimmerEpithelien einsehichtige Geissel-Epithelien, gebildet aus einer einfachen Lage von gleichartigen Geisselzellen, deren jede mit einem einzigen langen, schwingenden Geisselfaden ausgeriistet war (Fig. 117, 118, 120).

Wenn wir zunächst bloss die Arehiblastula (Fig. 20, 29, 116, 117) nnd die Arehigastrula (Fig. 23, 31, 44, 120) beriicksichtigen, welche bei Thieren der verschiedensten Gruppen uiberall dieselbe einfache Beschaffenheit darbieten, so bediirfen die obigen Sätze keines weiteren Beweises. Denn bei allen palingenetischen Thieren, bei allen Thieren, welehe noch heute primordiale Eifurchung besitzen - von Gastrophysema und Olynthus bis zur Ascidie und zum Amphioxus hinauf - sind ja iiberall sowohl das Blastoderma der Blastula, als das Exoderma und Entoderma der Gastrula, ganz einfache, einschichtige Epithelien.

Hingegen erscheint jene Auffassung nicht gerechtfertigt bei den meisten eenogenetischen Thieren, welche nicht die primordiale Eifurchung besitzen, sondern eire der drei anderen Furchungsformen (inacquale, discoidale oder superficiale). Hier tritt erstens der Epithel-Charakter der beiden primären Keimblïtter oft nicht so klar und unzweidentig hervor, als bei jenen archiblastischen 'Thieren; und zweitens erscheinen schon die ersten Anlagen derselben oft nicht einschichtig, sondern mehrschichtig. Zwar wird sich der Epithel-Charakter des Exoderms in keinem Falle verlengnen lassen. Aber das Entoderm wird sehr oft diasen Charakter auf den ersten Blick vermissen lassen, insbesondere dann, wenn ein mäehtiger Nahrungsdotter entwickelt und die Undarmhöllle damit ansgefiillt ist. Hier muissen wir dann stets die secu uläre Natur dieser cenog enetischen Bildung im Ange behalten und uns erimnern, dass wir im Stande waren, sie auf jene primären palingenetischen Verhältnisse zurickznfiihren. In allen Fällen sind die ersteren aus den letzteren erst 
spïter, in Folge embryonaler Anpassungen, hervorgegangen. So siud die mannichfach verschiedenen, oft mehrsehichtigen und nicht flimmernden Keimblätter der Fische, Amphibien und Amnioten alle urspriinglich aus den einschichtigen Flimmer-Epithelien entstanden, welche die beiden primären Keimblätter der Acranier bilden (Amphioxus). Wir sind daher in allen Fïllen zu der Annalıme berechtigt, dass die mehrschichtigen Keimblïtter erst secundiir ans einschichtigen entstanden sind, dass die nicht flimmernden Keimbliatter urspriinglich ans einem Flimmer-Epithel hervorgegangen sind, und dass das Entoderm stets eben so gut ein echtes Epithelium ist, wie das Exoderm. Unser Magen-Epithel bleibt ein echtes Epithel, gleichviel ob unsere Magenhölıle mit Speise erfüllt ist oder nicht; und ebenso bleibt das Entoderm der Gastrula überall ein Epithel, gleichviel ob ihre Urdarmhöhle von einem Nahrungsdotter ausgefiillt ist oder nicht.

Der listologische Nachweis, dass die beiden primären Keimblätter iiberall echte Epithelien sind, gestattet uns nun unmittelbar folgenden bedentungsvollen Schluss: Das Epithelium allein ist das primaic Gewebe, ist das urspriingliche und älteste Gewebe des Thierkörper's und bildete anfänglich den MetazoenOrganismus für sich allein. Alle anderen $\mathrm{Gewebe}$ sind sec undäre Gewebe, sind erst nachträglich aus jenem ersteren hervorgegangen, sind Descendenten des Epithelium. Wie wiehtig und folgenreich dieser Schluss ist, leuchtet ein, sobald wir an die langwierigen und noch hente nicht beendigten Streitigkeiten iuber die Beziehnng'en der Epithelien zu anderen Geweben denken. Wie viele Seiten der histologischen Literatur sind mit den lebhaftesten Streitigkeiten dariiber angefiullt, ob Nerven, Muskeln, Bindegewebe, Blut u. s. w. mit echten Epithelien in Continuität stehen können oder nicht! Und wie leer, wie miissig erscheinen alle diese endlosen Controversen angesichts der einfachen Thatsache, dass alle diese Gewebe ursprünglich ans Epithelien hervorgegangen sind. Blut- und Binde-Gewebe ebensowohl als Nerven- und Muskel-Gewebe sind ursprünglich stets aus Epithelial-Gewebe entstanden.

Durch diese einfache histogenetische Reflexion, durch die Erwägung, dass die beiden primären Keimblätter echte Epithelien sind, und dass alle Gewebe des Metazoen-Körpers einzig und allein aus diesen entstanden sind, werden eine Menge von histologischen Controversen gegenstandslos, mit denen eine Masse von Papier und Zeit nutzlos vergendet worden ist. Vor allen gilt das 
von der vielbesprochenen Parablasten-Theorie von His, welche trotz ihrer Absurdität auch heute noch zahlreiche Anhänger besitzt. Der Kern dieser Theorie gipfelt bekanntlich in dem Satze, dass der Thierkeim aus zwei gänzlich verschiedenen Bestandtheilen zusammengesetzt sei, aus dem Hauptkeim und Nebenkeim. Der Hauptkeim oder Archiblast allein soll von den beiden primären Keimblättern abstammen und NervenGewebe, Muskel-Gewebe, Epithelial- und Drüsen-Gewebe liefern. Hingegen sollen das Binde-Gewebe (nebst Knorpel- und KnochenGewebe), die Blutzellen und die sogenannten Endothelien ${ }^{1}$ ) (die Gefäss-Epithelien) abstammen von dem Nebenkeim oder Parablast, d. h. von Bindegewebszellen des miitterlichen Körpers, welche in den „weissen Dotter" des Eies eingewandert sind, und welche also gar nichts mit den primären Keimblättern zu thun haben. Die Aufstellung dieser ganz verkchrten, aber vielbewunderten Parablasten-Th eorie ${ }^{2}$, die den einfachsten physiologischen und morphologischen Principien Hohn spricht, liisst sich nur durch die ticfe Unkenntniss der vergleichenden Anatomic und Ontogenie entschuldigen, durch welche His sich auszeichnet. Denu alle palingenetischen Thiere besitzen gar keinen Nahrungsdotter, keine Spur von ,w weissem Dotter"; ihr Keim besteht einzig und allein aus den primären Keimblättern, also ans zwei einfachen Epithelial-Schichten; - und doch bilden diese Thiere ebenso gut BindeGewebe, Blut und „Endothclien“, als die cenogenetischen Thicre, bei denen letztere ,ganz anderen Ursprungs" sein sollen. Durch diese unleugbare Thatsache allein schon wird die gauze ParablastenTheorie widerlegt. Blut, Endothelien und Binde-Gewebe entwickeln sich ursprünglich ebenso aus Epithelien, wie Nerven-, Muskelund Driisen-Gewebe. Alle Zellen der verschiedensten Gewebe sind direct oder indirect Abkömmlinge von Epithelial-Zellen. ${ }^{3}$ )

1) Der von $\mathrm{H}_{1}$ eingeführte und jetzt vielfach gebrauchte Ausdruck Endothelium bedeutet wörtlich : „Innerhalb der Brustwarze".

2) KöLliker (Entwicklungsgeschichte, 1I. Aufl. 1876, p. 26) meint, dass "die von His in geistreicher Weise ausfuhrlich beleuchtete ParablastenTheorie viel Bestechendes hat," und "bedaucrt, dieselbe nicht unterstiitzen zn können."

3) 'Trotzdem Hrs gegenwärtig mit rer Archigastrula des Amphioxus bekannt ist, welche fur sich allein schon die ganze Parablasten-Theorie widerlegt, hiilt er doch unbeirrt an letzterer fest. Vergl. meine Anthropogenie (III. Anfl., S. 65\%) und "Ziele und Wege der hentigen Fintwicklungsgeschichte" (1875, S. 32;: 


\section{Primbïre und secundïre fíeimb] itter.}

\section{Exoderm, Mesoderm und Entoderm.}

Die Unterscheidung der primären und secundïren Keimbliitter, anf welche ich bereits in der Monographie der Kalkschwämme (1872) das grösste Gewicht gelegt. habe, scheint mir nicht allein für das Verständniss der Gastraea-Theorie, sondern anch fuir die richtige Auffassung der wichtigsten Keimungs-Vorgänge iiberhanpt von solcher Bedleutung zu sein, dass ich nicht umhin kann, hier nochmals daranf zuriickzukommen. Besondere Veranlassung dazu bieten die vielfachen Streitigkeiten iiber Ursprung und Bedeutung des Mittelblattes oder Mesoderma, welche bis in die neneste Zeit mit zunehmender Verwirrung der Begriffe und Steigerung der Widerspriiche fortgedanert haben. In der That itberzengt uns cin Blick auf die umfangreiche embryologische Literatur der letzten Jahre, dass das M e sode rm-Problem ebenso zu den dunkelsten und schwierigsten, wie anderseits zu den wichtigsten und einflussreichsten Fragen der Keimblätter-Theorie gehört.

Die Mehrzahl der heutigen Embryologen begniigt sich in dieser Beziehung gegenwärtig mit folgender Auffassung: Nachdem Exoderm und Entoderm ansgebildet sind, entsteht zwischen diesen beiden Keimblättern ein drittes, das Mesoderm, und nunmehr besteht der Keim aus drei iibereinander liegenden Blättern: Exoderm, Mesoderm und Entoderm (oder: Epiblast, Mesoblast und Hypoblast). Schon dieser Satz, welcher fast iiberall ohne Bedenken wiederholt wird, enthält einen logischen Fehler, der sich zu einer Quelle verhängnissvoller Irrthümer gestaltet. Er verstösst nämlich gegen die wichtige Thatsache, dass das Mesoderm in allen Fällen ein secundäres Product der primären $\mathrm{Keimblätter}$ ist, entweder beider, oder eines von beiden. Wenn das aber wirklich der Fall ist - und die vergleichende Ontogenie hat jetzt diese fundamentale Thatsache unumstösslich festgestellt! - dann ist das Mittelblatt ein Theil von einem der beiden primären Keimblätter oder von beiden. Da nun der Theil nie gleich dem Ganzen sein kann, so hört mit der Bildung des Mesoderms wenigstens eines der beiden primären Keimblättcr oder beide zugleich - auf, als solche zu existiren; eines oder beide sind dadurch in melnere secundäre Keimblätter zerfallen orler gespalten. 
Der Einfachlheit halber wollen wir die primären und secundären Keimbliitter mit folgenden Buchstaben bezeichnen: $\mathrm{E}=$ Exoderma (äusseres primäres Blatt); $J=$ Entoderma (inneres primäres Blatt); $\mathrm{s}=$ Hautsinnesblatt (Sinnesblatt); $\mathrm{f}=$ Hautfaserblatt (Fleisehblatt); $\mathrm{g}=$ Darmfaserblatt (Gefässblatt); $\mathrm{d}=$ Darmdrüsenblatt (Driisenblatt); $\mathrm{m}=$ Mesoderma (Mittelblatt oder Faserblatt). Das Mesoderm wird allgemein als die Summe von Hautfaserbiatt und Darmfaserblatt aufgefasst, gleichviel auf welche Weise diese aus den primären Keimblättern entstanden sind; also $m=f+g$. Demuach gelten allgemein folgende Gleichungen:

$$
\begin{aligned}
& \text { 1) } \mathrm{E}+\mathrm{J}=\mathrm{s}+\mathrm{f}+\mathrm{g}+\mathrm{d} \\
& \text { oder } \mathrm{E}+\mathrm{J}=\mathrm{s}+\mathrm{m}+\mathrm{d} \\
& \text { 2) } \mathrm{E}=\mathrm{s}+\mathrm{m}+\mathrm{d}-\mathrm{J} \\
& \text { oder } \mathrm{J}=\mathrm{s}+\mathrm{m}+\mathrm{d}-\mathrm{E} \\
& \text { 3) } \mathrm{m}=\mathrm{E}+\mathrm{J}-(\mathrm{s}+\mathrm{d}) \\
& \text { oder } \mathrm{m}=(\mathrm{E}-\mathrm{s})+(\mathrm{J}-\mathrm{d})
\end{aligned}
$$

Alle verschiedenen Ansichten, welche iiber die Bedeutung und Entstehung des Mesoderms und iiberhaupt der seeundären Keimblätter geltend gemacht werden könnten, lassen sich demnach auf folgende drei Möglichkeiten reduciren :

1) $J=m+d$, dann ist $E=s$;

2) $\mathrm{E}=\mathrm{m}+\mathrm{s}$, dann ist $\mathrm{J}=\mathrm{d}$;

3) $\mathrm{E}=\mathrm{s}+\mathrm{f}$ (oder $=\mathrm{s}+\mathrm{m}-\mathrm{g}$ ) und entsprechend $J=g+d($ ode $r=m-f+d)$; dann ist $m=J-d+E-s$. Fassen wir mun diese drei möglichen Fälle noch etwas näher in's Auge, ganz abgesehen davon, dass der letzte derjenige ist, der in organologischer Hinsicht der verstaindlichste und daher in phylogenetiseher Beziehung der wahrscheiulichste ist.

1. Das ganze Mesoderm entsteht a us dem Entoderm nnd spaltet sich elst später in Darmfaserblatt und Hautfaserblatt. Dann ist $J=m+d$ und folgeriehtig $E=s$. Das Exoderm liefert bloss das Hautsinnesblatt, das Entoderm alle iibrigen drei secundären Blätter. Diese Ansicht wird angenblicklich von der grossen Mehrzahl der Embryologen für die riehtige gehalten. liємак hat dieselbe zuerst für die Wirbelthiere aufgestellt, und die meisten neueren Beobachter glauben dasselbe Verhältniss bei den verschiedensten Wirbellosen gefunden zu haben. Wenn dieses Verhältuiss stattfinclet, so hört mit der Bildung des Mcsoderm die Existenz des Entoderms auf; denn J wäre dann $=\mathrm{m}+\mathrm{d}$ und folglich $\mathrm{m}=\mathrm{J}-\mathrm{d}$. $\mathrm{Dcr}$ dreiblätterige Kcim 
besteht demuach ans folgenden Theilen: 1. Exodern (= Hautsinnesblatt); 2. Mesoderm oder Faserblatt (= Hautfaserblatt und Darmfaserblatt); 3. Darmdriisenblatt.

2. Das ganze Mesodermentsteht ans dem Exoderm und spaltet sich erst später in Hantfaserblatt und Darmfaserblatt. Daun ist $\mathrm{E}=\mathrm{s}+\mathrm{m}$ und folgerichtig $\mathrm{J}=\mathrm{d}$. Das Entoderm liefert blos das Darmdrisenblatt, das Exoderm alle ibrigen drei secundären Blätter. Diese Ansicht wird fiil eine Anzahl vou sehr verschiedenen Wirbellosen auch noch in neuester Zeit von namhaften Beobachtern vertreten und kürrlich hat sie KöLLiKER auch für die Wirbelthiere mit aller Bestimmtheit geltend gemacht. ${ }^{1}$ ) Wenu dieses Verhältniss stattfindet, so hört mit der Bildung des Mesoderms die Existenz des Exoderms auf; denn $\mathrm{E}$ ist dann $=\mathrm{s}+\mathrm{m}$, und folglich $\mathrm{m}=\mathrm{E}-\mathrm{s}$. Der dreiblätterig'e Keim besteht demnach aus folgenden Schichten : 1. Hautsinnesblatt; 2. Mesoderm oder Faserblatt (= Hautfaserblatt und Darmfaserblatt); 3. Lntoderm (= Darmdriisenblatt).

3. Das Mesodermentstehttheils a us dem Exoderm, theils ans dem Entoderm; das Hautfaserblatt stammt rom ausseren, das Darmfaserblatt hingegen vom inneren primären Keimblatte. Dann ist $\mathrm{E}=\mathrm{s}+\mathrm{f}$ und $\mathrm{J}=\mathrm{g}+\mathrm{d}$ oder, $\mathrm{da} \mathrm{m}=\mathrm{f}+\mathrm{g}$ ist, so ist auch $\mathrm{E}=\mathrm{s}+\mathrm{m}-\mathrm{g}$ und $\mathrm{J}=\mathrm{d}+\mathrm{m}-\mathrm{f}$. Das Exoderm zerfällt in Hautsinuesblatt und Hautfaserblatt; ebenso spaltet sich das Entoderm in Darmfaserblatt und Darmdriisenblatt. Diese Ansicht ist bekanntlich zuerst von BAkn aufgesellt und mit dem grössten Erfolge für die Erklärung der Organogenese durcligetiihrt worden. Viele ausgezeichnete Beobachter haben dieselben Verhältnisse sowohl bei Wirbelthieren als bei Wirbellosen wiedergefunden. Nach meiner eigenen Anschaung ist diese Auffassung unter allen drei möglichen Fällen diejenige, welche die Entstehung und weitere Verwerthung der secundären Keimblätter phylogenctisch am einfachsten erklärt, und ich habe sie daher in der Anthropogenie zur Grundlage der ganzen Darstellung gewïhlt. ${ }^{2}$ ) Nach dieser Auffassung ist das Mesoderm keine ursprïnglich einheitliche Keimschicht, sondern eine secundäre Ver-

1) Kölliker, Entwickelungsgeschichte des Menschen und der böheren Thiere, II. Aufl. 1876, p. 96. „Das ganze Mesoderma stammt vom Exoderm. Das mittlere Keimblatt ist ganz und gar ein Èrzeugniss des iusseren líeinblattes."

2) Vergl. Anthropogenie, Grundziige der mensehlichen Kieimes- und Stammes-Geschichte. III. Anf. 1877, S. 189, 236. 
bindung von zwei urspriinglich getrennten Schichten: $\mathrm{m}=\mathrm{f}+\mathrm{g}$; und da $\mathrm{f}=\mathrm{E}-\mathrm{s}$, und ebenso $\mathrm{g}=\mathrm{J}-\mathrm{d}$ ist, so können wir anch sagen: $\mathrm{m}=\mathrm{E}-\mathrm{s}+\mathrm{J}-\mathrm{d}$ oder $\mathrm{m}=\mathrm{E}+\mathrm{J}$ $(s+d)$. Mit der Bildung des Mesoderm (durch secundäre Verbindung von Hautfaserblatt und Darmfaserblatt) hört hier dic Existenz beider primären Keimblätter anf; und der dreibliitterige Keim besteht demnach aus folgenden Schichten: 1. Hautsinnesblatt; 2. Mesoderm (= Hautfaserblatt und Darmfaserblatt); 今. Darmdrüseublatt.

Aus diesen einfachen Erwägnngen ergibt sich klar, dass in allen drei möglichen Fällen wenigstens eins der beiden primäiren Keimblätter ( - im dritten Fall beide! -) mit der Ansbildung des Mesoderms als geschlossene morphologische Einheit zu existiren aufhört. Es ist daher vollkommen unlogisch und kann nur Verwirrung stiften, weun man noch immer den dreiblätterigen Keim beschreibt als bestehend aus: Exoderm, Mesoderm, Entoderm. Freilich ist diese allgemein beliebte Metlode der Darstellung dic bequ emste. Denn sie lässt die schwierige Frage vom Ursprung des Mesoderm im Dunkeln und verschweigt damit die unvereinbaren Widerspriiche, welche in dieser Beziehnng zwischen den angesehensten Beobachtern existiren. Damit wird aber der Weg' zur weiteren Aufklärung dieser ebenso wichtigen als dunkelu Frage nicht geebnet, sonderu abgeschnitten.

Die vorstehenden Erwägungen sind rein logischer Natur und sollen nur die Ueberzeugung verbreiten, wie unlogisch fast allgemein in einem der wichtigsten Punkte der Keimblätter-Leln'e verfahren wird. Man darf hier nicht etwa entgegnen, das sei gleichgültig, weil das Mesoderm bei verschiedenen Thieren einen ganz verschiedenen Ursprung and demmach keine bestimmte morphologische Bedeutung habe. Iclı kann daranf erwideru, dass die angefiilurten Unklarheiten und Widersprỉche noch hente bei einem und demselben Objecte bestehen, und zwar bei demjenigen, welches am längsten und meisten untersucht ist. Unzweifelhaft ist das $\mathrm{H}$ ii hnel-Ei dasjenige Object, welches von jeher weit mehr Zeit und Niihe, Arbeitskraft und Papier absorbirt hat, als alle anderen Thier-Eier. Am Hühner-Ei stellte Aristoteles die ältesten embryologischen Untersuchungen an; vom bebriiteten Hiihnchen gab Farricius al Aquapendente 1600 die ersten embryologischen Beschreibungen und Abbildungen; auf die Untersuchung des Hühner-Eies gründete Caspar Friedrici Wolfr 1759 die grundlegende Theurie der Epigenesis; am Hiilnner-Li entdeckte 
Pander zuerst 1817 die beiden mimäiren Keimblitter, und an derselben Keimscheibe des Hiihnchens untersehicd BaEr zuerst 1828 die vier secundïren Keimblïtter; am Hiihmer-Ei stellte Renak 1852 die histogenetische Bedeutung der Keimbliatter fest am Hïhner-Ei entwickelte Hís 1868 seine monströsen „mechanischen" Keimungs-Theorien (die Briefconvert-Theorie, die Gummischlauch-Theorie, die Höllenlappen-Theorie u. s. w.); vom Hiihner-Ei endlich sind in neuester Zeit die glïnzenden ,SchnittSerien" angefertigt worden, welche als "Thatsachen sprechen" sollen, und welche von den meisten Embryologen. deshalb so hochgeschätrt sind, weil sie glauben, dass alles vergleichende Nachdenken und Urtheilen durch diese „exacten Präparate“ überfliissig wird.

Und was sagen uns denn nun alle diese zahllosen Beobachtungen und Untersuchungen des Hiihner-Eies, alle diese Schnitt-Serien und Tinctions-Präparate, was sagen uns alle diese ,sprechenden Thatsachen" iiber jene wichtigsten Grundfragen der Keimblätter-Lehre? Nicht allein iiber die dunkle Entstehung des Mesoderms und der secundären Keimblätter, sondern sogar iiber die einfache und klare Entstehumg der beiden primären Keimbliitter - also über dic ersten Grundfragen - gehen die Ansichten der verschiedenen Beobachter noch heute so weit auseinander als möglich; ja, neben den aufgefiihrten möglichen Ansichten sind auch noch eine Anzahl un möglicher Hypothesen von His und Anderen aufgestellt worden. ${ }^{1}$ ) Wenn wir von den beiden primären Keimblättern hier ganz absehen, deren Entstehung durch Invagination des Blastoderms anch beim Hiihnchen (durch Rauber und GötTE) jetzt sicher nachgewiesen ist, so treffen wir beziiglich der M e s odermBildung des Hiihnehens folgende vier Hauptgruppen von Ansichten: 1. Das Exoderm spaltet sich in Hantsinnesblatt und Hantfaserblatt; das Entoderm zerfällt in Darmfaserblatt und Darmdrüsenblatt (BaEr, 1528); demnach entsteht das Mesoderm secundär durch (axiale) Verwachsung der beiden Faserblätter; 2. Das ganze Mesoderm stammt vom Entoderm (RenaK); 3. Das ganze Mesoderm stammt vom Exoderm (KüLliier); 4. Ein Theil des Mesoderms stammt von den primären Keimblättern (Archiblast: Nerven- und

1) Viele Hühner-Embryologen lassen bekanntlich die Zellen, welche das Mesolerm bilden, ,v o n a us en ${ }^{6}$ zwischen die beiden primären Keimblätter e inw andern. TV oh er diese heimatblosen Auswanderer kommen, wird aber leider meistens nicht gesagt. 
Muskelgewebe); ein auderer Theil desselben stammt direct von fremden Zellev, die „von aussen" (aus dem mütterlichen Körper) eingewandert sind (Parablast: Blut, Endothel, Bindegewebe; His). Von dieser vierten Ansicht, der Parablasten-Theorie von His, die wir nur ihrer Curiosität halber aufführen, könmen wir hier ganz absehen, denn sie wird durch die Thatsachen der vergleichenden Ontogenie auf das bestimmteste widerlegt. (S. oben, p. 332). Dagegen bleibt immer noch die Frage offen, welche von den drei übrigen Ansichten wirklich wahr ist. Eine von allen dreicn kann beim Hïhner-Ei nur wahr sein ${ }^{1}$, und jede der drei Hypothesen wird noch heute durch eine Anzahl hervorragender Beobachter vertreten, die, gestiitzt anf ihre ,exacten" Untersuchungen, mit grösster Bestimmtheit behaupten, das ihre Auffassung die richtige, alle ibrigen aber falsch seien!

Soviel geht denn doch wohl aus dieser komischen Sachlage mit voller Klarheit hervor, dass 1. alle jene, spreehenden Thatsachen" "2) keine objectiven Thatsachen, sondern subjective, einseitige Urtheile iiber unvollkommene (und nichts weniger als exacte) Beobachtungen sind; und 2. dass solche und ähnliche schwierige Probleme niemals auf dem Wege der genauesten Untersuchung eines einzigen Organismus, sondern stets nur durch velgleichende Ontogenie gelöst werden können. Und diese vergleichende Ontogenie, zu welcher nusere Gastraea-Theorie den

1) Meтесnлiкоrғ und ähnliche Embryologen werden bei dieser Sachlage zwar der Ansicht sein, dass das Mesoderm bei einigen Hühnern aus dem Exoderm, bei anderen nus dem Entoderm, und bisweilen auch ans beiden zugleich hervorgehe. Indessen erscheint mir diese Ansieht, für welche МетзсилікоғF's embryologisehe Ansichten viele Parallelen bieten, keiner Erörterung bedïrftig.

2) KöLLIKER sagt in der kürzlich erschienenen II. Aufl. seiner Eutwicklungsgeschichte (p. 382): .,HAEClEL ist der Ansicht, dass für diese Geschöpfe (die Vigel) durch Göttr und Ravber als Embryonalform eine Discogastrula, entstanden durch Invagination einer Discollastula, erwiesen sei, und dass durch die Untersuchungen dieser beiden Forscher alle entgegenstehenden Angaben anderer Beobachter im Sime der Gastraea-Theorie erledigt seien! Wic man aus Früherem weiss, bin ich durch meine Untersuchungen zu ganz anderen Ergebnissen gekommen als Göttr und Rauber, und wird es daher wohl für einmal das Zweckmässigste sein, nur die Thatsachen sprechen und die Gastraea-Theorieganzansser dem Spiele zu lassen." Darf nicht dasselbe jeder andere „exacte" Beobachter (z. B. Göttz oder Raurer) mit gleichem Rechte von KöLLlKkR's subjectiven Ansichten sagen, welche dieser für ,sprechende Thatsachen" hält? 
Weg ebuen soll, lehrt uns zunächst wenigsten die Fragen richtig stellen, wenn auch deren Lösmug noch in weiter Ferne liegt.

Fiir die richtige Stellung und Beantwortung dieser Fragen liefert uns dic Gastraea-Theorie zunächst folgende wichtige Voraussetzungen als feste Grundlagen: 1) der Körper der Metazoen entwickelt sich iiberall urspriinglich aus zwei primären Keimblättern; 2) Das Mesoderm entsteht immer erst secundïr, entweder aus einem jener beiden primären Keimblätter oder aus beiden zngleich. Die Fragen, welche die Beobachter demnächst also zu beantworten haben, sind folgende: 1) Aus welchem der beiden primären Keimblätter entsteht das Mesoderm, und wie verhalten sich die ersteren iiberhanpt bei der Bildung der secundären Keimblätter? 2) Ist das Mesoderm stets aus Hantfaserblatt und Darmfaserblatt zusammengesetzt? 3) Welche Uebereinstimmung oder Verschiedenheit bieten in dieser Beziehung dic verschiedenen Thierklassen? 4) Sind demnach auch die vier secundïren Keimblïtter der verschiedenen Thierstiimme homolog, und wie weit geht diese allgemeine Homologie? (Vergl. die provisorische Tabelle II, S. 53). Einige wichtige, diese Frage betreffenden Momente sind in nenester Zeit von Caru Rabr in seinen ansgezeichneten Untersuchungen über die Ontogenie der Mollusken ${ }^{1}$ ) insbesondere iiber Unio ${ }^{2}$ ) klar hervorgehoben worden. RarL macht namentlich auf zwei sehr wichtige Eischeinungen bei der ersten Entstehung des Mesoderms aufmerksam, welche sämmtlichen Bilaterien - allen Metazoen mit Ausschluss der Zoophyten - gemeinsam zu sein scheinen: 1) Das erste Auftreten der ersten Mesoderm-Zellen in der Umgebung des Properistoms, und 2) die diplenre oder bilateral-symmetrische erste Anlage des Mesoderms. Bei allen Bilaterien erscheinen die ersten selbständigen Mesoderm-Zellen zwischen den beiden primären Keimblättern in der nnmittelbaren Umgebung des Properistoms oder Urmundrandes, also in der Peripherie des Rusconi'schen Afters oder des Gastrula-Mundes, an der kritischen Stelle, wo das Exoderm in das Entoderm nnmittelbar iibergeht. Gerade deshalb lïsst sich anch so schwer entscheiden, ob sie von ersterem oder von letzterem oder von beiden zugleich abstammen. Ferner tritt bei

1) CAIL RABL, Die Ontogenie der Süsswasser-Pulmonaten. Jenaische Zeitschr. 1875. Bd. IX, S. 202, 236, Taf. VIII, Fig. 12, $13 \mathrm{~m}$.

2) C CARL RABL, Entwickelungsgeschichte der Malermuschel. Eine Auwendung der Keimblätter-Theorie auf die Lamellibranchiaten. Jeuaische Zeitschr. 1876, Bd. X, S. 350-360, Taf. Xl, Fig. 24-32. 
allen Bilaterien die erste Anlage des Mesoderms nicht als vollständig zusammenhäingende Schicht, sondern diplenrisch auf, in zwei getrenuten seitlichen Parthien, welche die erste Andentung von der bilateralen Symmetrie des Bilaterien-Körpers geben. Bei Unio besitzen sehon die beiden ersten Mesoderm-Zellen diese charakteristische seitlich-symmetrische Lage in Bezug auf die Körper-Axen des Embryo (Rabl, 1. c. p. 350). Durch zahlreiche nnabhängige Beobachtungen aus nenester Zeit tiber die erste Mesoderm-Anlage sehr versehiedener Bilaterien wird dieses wichtige Verhältniss bestätigt.

Durch rliese, von RabL zusanımengestellten Thatsachen der vergleichenden Ontogenie wird es sehr wahrseheinlich, dass das Mesoderm bei sämmtlichen Bilaterien (-- Wiirmer, Echinodermen, Mollusken, Arthropoden, Vertebraten -) homolog ist (wirklich homophyletiseh); dagegen nicht homolog (- odel vielmehr homomorph --) bei den Bilaterien und den Zoophyten (oder Coelenteraten). Ueberhaupt ist noeh sehr fraglieh, ob das Mesoderm der letzteren nieht bloss Hautfaserblatt ist, und ein eigentliches Darmfaserblatt ganz fehlt (oder umgekehrt?). Bei vielen Bilaterien seheint das Darmfaserblatt sich erst viel später aus dem Entodern zu entwickeln, nachdem das Hantfaserblatt längst (aus dem Exoder'm) gebildet ist. Diese und andere Fragen iiber das Mesoderm lassen sich nur dann richtig beantworten, wenn man vor Allem scin Verhältniss zu den beiden primäien Keimblättern klar gestellt hat.

\section{Protozoen und Metazoen.}

Unter den verschiedenen Folgerungen, welche sich aus der Gastraca-Theorie für die systematische Zoologie erg'eben, hat sich wenigstens eine rasch Bahn gebrochen. Das ist die scharfe Scheidung des ganzen Thierreichs in zwei grosse Hauptgruppen: Protozoen und Metazoen. Gegenbauer, Huxley, Ray-Laniester, Ed. van Benenen, F. E. Schulze und andere namhafte Forseher haben. diese fundamentale Scheidung gebilligt und sic in versehiedener Weise verwerthet. Die Vortheile, welehe dieselbe für die naturgemässe Auffassung der thierischen VerwandtsehaftsVerhäiluisse gewährt, sind theils positiver, theils negativer Natur.

In letzterer Beziehming diirfte es nicht gering anzuschlagen sein, dass damit endlich allen den verfehlten Versuchen ein Ende gemacht 
wird, Homologien zwischen den einzelnen Theilen des Metazoenund des Protozoen-Organisnus aufizustellen, und Organe der ersteren aus Körpertheilen der letzteren abzuleiten. Bekanntlich sind derartige Versuehe bei weitem am liaufigsten und eingehendsten in der Klasse der Infusorien, und ganz besonders bei den Ciliaten unternommen worden. Indem man im einzelligen Ciliaten-Organismus einen Darmeanal mit Mund und After, eine wimpernde Epidermis und cinen darunter gelegenen Hautmustselschlauch zu finden glaubte, inclen man ihre contractile Blase mit dem Herzen, ihren Nucleus mit der Zwitterdriise von Wiirmern verglich, suchte man irrthiimlich nach Homologicu, die gar nicht vorhanden sind. Denn die einzellige Natur des Ciliaten-Organismus ist in nenester Zeit wohl allgemein anerkannt. Nimmermehr aber können einzelne Theile (oder pliysiologische "Organe") e iner einzigen Zelle in morphologisehe Vergleichung gestellt werden mit den morphologischen Organen eines vielzelligen Metazoen-Organismus, welche sich uiberall aus vielzelligen Keimblättern entwickelt haben. Alle solche Vergleichungen können nur Analogicn, niemals wahre $\mathrm{Homologien}$ sein. Iclı will dies hier ausdriicklich nochmals hervorheben, weil jene vergeblichen Versuche, die nur Verwirrung, niemals Aufklärung bringen könuen, sclbst jetzt noch immer fortgesetzt werden. So hat noch H. Inering in seiner so eben erschienenen grosseu „Phylogenic der Mollusken“ den künstlichen Versuch gemacht, die wichtigsten Organe der Metazoen direct aus den angeblich homologen Organen der Protozoen abzuleiten. $\left.{ }^{1}\right)$ Die contractile Blase der Infusorien soll dem Wasser-

1) H. Inering, Vergleichende Anatomie des Nervensystems und Phylogenie der Mollusken. Leipzig 187\%, p. 21: „So zeigt sich, dass die Parallelisirung der Ontogenie mit der Phylogenie vielfach zu irrigen Vorstellnngen fuilırt. Wahrseheinlich wird dies anch fuir die bedentung Geltung haben, welehe HaEcker dem Furchungs-Processe beimisst. Nach Haeckel's Darstellung wären die ersten Metazoen Colonien von einzelligen Protozoen gewesen. Die vergleichende Anatomie drïngt dagegen, wie mil scheint, zu einem ganz anderen Ergebnisse. Danach würden nämlich die niedersten Metazoen vielkernige Protozoen gewesen scin, in denen es erst später zur Differenzirung von Zellen um die einzelnen Kerne gekommen. Vergleichend anatomisch wäre damit die Möglichkeit gegeben, einige Organe der Metazoen und speciell der tiefststehenden Würmer in ihren Anfängen bis zu den Protozoen, namentlich den Infusorien, zu verfolgen, so namentlich den Mund und das Wassergefiassystem, welches letztere also zurückzuführen wäre anf die contractile Vacuole, die bekanntlich bei zahlreichen Infusorien sich in verzweigte Gefassstämme fortsetzt. Sollte diese Vermuthung zutreflen, so ergïbe sich für die 
gefïss-System der Turbellarien und cler Niere der Schnecken homolog sein, ebenso der Mund der Infusorien und Wiirmer u. s. w. Dem ganzen Furchung-Process und der Bildung der Gastrula spricht Inering demgemäss jede phylogenetische Bedentung ab. Damit wird aber natîrlich die ganze Gastraea-Theorie mit allen ihren Folgermingen einfach negirt, und es klingt sonderbar, wenn dieselbe an andern Stellen desselben Werkes Anerkenung findet. ${ }^{\text {) }}$ Wenn wirklich die Eifurehung und die Gastrulabildung irgend eine phylogenetische Bedeutung haben und nicht von Anfang bis zu Ende bloss cenogenetiseher Natur sind, danu ist auch jede morphologisehe Vergleichung, jede Homologie zwisehen Organen der Protozoen und Metazoen völlig ausgeschlossen.

Ebenso falseh wie die Vergleichung der $\mathrm{Org}$ ane ist diejenige der Gewebe zwischen Protozoen und Metazoen. Noch immer spricht man bei clen Infusorien ron „Muskeln“, nennt den contractilen Myophan-Strang im Stiele der Vorticellen einen "Muskel", ihre wimpernde Corticalsehicht (das Exoplasma) ein „Flimmer-Epithel" u. s. w. Auch diese histologischen Vergleiche können nur physiologische, keine morphologisehe Geltung beanspruchen. Denn die waliren Gewebe der Metazoen (Bindegewebe, Muskelgewebe, Nervengewebe), welche sämmtlieh von dem primären Epithelialgewebe der Keimblätter abstammen (vergl. S. 231), sie sind sämmtlich Zell e n-A g g l e gate und kömuen also nimmermehr mit Theilen von einzelligen Organismen in morplologische Vergleichung gestellt werden.

Auf der anderen Seite gewïlnt uns die Scheidung der Protozoen und Metazoen den positiven Vortheil, jede dieser beiden

vergleiehende Anatomie die Mögliehkeit, ein und dasselbe Organ-System dureh eine Reihe von Typen zu verfolgen, da das Wassergefisssystem der Turbellarien der Niere der Platyeochliden homolog ist."

1) Der Hauptfehler Inemic's liegt meines Frachtens darin, dass derselbe in einseitigster Weise die Bedeutung der vergleichenden Anatomie uberschätzt und ihr gegenüber der Ontogenie alle Bedeutung abspricht. Er bildet genıu das extreme Gegenstück zu Görre, der in semem grosseı UnkenBuche die ganze Morphologie allein dureh die Ontogenie erklären will und die vergleichende Anatomie für völlig werthlos erklärt (Vergl. meine „Ziele und Wege der hentigen Entwicklungsgeschichte", 1875, S. 52 I.). Beide Standpunkte sind gleich einseitig. Nur durch gleichmässige kritisel e Beriicksichtigung der vergleichenden Anatomie und Ontogenie, welche sich gegenseitig ergänzen, werden wir in den Stand gesetzt, die Thatsachen der Morphologie richtig zu erkliiren und phylogenetisch zu deuten. 
Ha uptgruppen des Thierreiehs einheitlich charakterisiren und seharf von einander tremnen zu können. Die Metazoen allcin besitzen einen wahren Darm und Mund; sie allein besitzen zwei primäre Keimbliatter, ein Exoderm und Entoderm; sie allein entwiekelı aus diesen beiden einfachen epithelialen Zellenschichten wahre Gewebe, und bauen aus diesen Geweben wahre Thier-Organe in molphologisehem Sinne auf. Die Metazoen erheben sieh somit, und zwar schon in ihrer Ansgangsform - ontogenetisch Gastruli, phylogenetisch Gastraea - anf die Individualitäts-Stufe der P e r s o n, welche den Protozoen ebenso allgemein fehlt. $\left.{ }^{1}\right)$ Man könnte daher anch die Metazoen allein als echte Thiere bezeichnen, wïhrend die Protozoen sämmtlich den indifferenten und neutralen Prot is te n-Charakter beibehalten.

Im Grunde ist die prineipielle Scheidung von Protozoen und Metazoen ganz dieselbe, wie die Gegeniiberstellung des P r o t i s te nreiehs und des Thierreichs, welehe ieh vor zehn Jahrer in der generellen Morphologie vorgeschlagen habe. Nur war ich damals nicht im Stande, diese fundamentale Scheidung so fest zu begriiuden, wie das heute möglieh und fast allgemein anerkannt ist. Demn damals fehlte die Grundlage der Gastraea-Theorie, die Homologie der beiden primären Keimblätter und der Nachweis, class diese letzteren bei allen Metazoen urspringlich vorhanden sind, dass sie bei den versehiedensten Metazoen-Stämmen urspriiuglich eime und dieselbe primordiale Keimform, die Archigastrula bilden. Dieser Nachweis ist inzwischen geliefert und damit eine einheitliche morphologische Auffassung des Thierreichs angebahnt.

Natiirlich ist es eine Frage von untergeordneter Bedentung und nir persönlich sehr gleichgiiltig, ob man die beiden Hanptabtheilungen des Thierreichs als Protozon und Metazoa gegeniiberstellt, wie ich in der Gastraea-Theorie gethan habe, oder als Protista und Animalic, wie ich vor zehn Jahren in der generellen Morphologie vorschlug. Wie tiefe Kluft, welche beide Hauptgruppen trennt und welche durch die mehrfach hervorgehobenen wiehtigsten Organisations-Unterschiede klar bestimmt wirl, bleibt in beiden Fällen dieselbe. Allerdings babe ich inzwischen (in mehreren

1) Ueber den Begriff der Person, wie ich ihn gegenwärtig für das sogenannte „eigentliche Thier-Individu un" mit Hülfe der GastraeaTheorie festgestellt habe, vergl. meine Monographie der Kalkschwämme, Bd. I, S. 113. 
Auflagen der „Natiirlichen Schöpfungrsgeschichte“ und der Anthropogenie) den Versuch gemacht, Protisten und Protozoen zu tremen, und neben dem ganz indifferenten und neutralen Protisteureiche (Rhizopoden, Myxomyceten, Flagellaten u. s. w.) anch noch eine Abtheilung von Protozoen aufrecht zu erhalten, welche die ältesten phylogenetischen Entwicklungsstufen des Thierreichs, vom Monel bis zur Gastraea, enthielt. Allein ich bekemne jetzt, dass ich diesen Versuch für verfehlt und für praktisch nicht durchführbar halte. Freilich wird man in der Theorie Protisten und Protozoen phylogenetisch scharf auseinander halten können; auf der einen Seite wird man als echte Protisten (oder "Urorganismen“) diejenigen indifferenten und völlig neutralen Organismen niederster Stufe betrachten können, welche weder mit echten Thieren (Metazoen), noch mit echten Pflanzen in verwandtschaftlichem Zusammenhange stehen, und welche höchstwahrscheinlich p ol y j hy let is ch en, ganz mubhängigen Ursprungs sind (vor allen die formenreiche Gruppe der Rhizopoden, Acyttarien, Radiolarien u. s. w.); auf der anderen Seite wird man als Protozoen (oder echte "Urthiere") diejenigen cinfachsten Organismen betrachten können, welche die Wurzel des Metazoen-Stammbaums (- „vom Noner bis zur Gastraea" -) bilden (Moneren, Amoeben, Synamocbien, Planaeaden). Aber so berechtigt diese phylogenetische Trennung von Protozoen und Protisten in der Theorie, so werthlos erscheint sie in der Praxis. Demn es fehlen uns - und werden uns wahrscheinlich immer fehlen - alle Anhaltspunkte, um mit Sicherheit eine scharfe Grenzlinie zwischen jenen beiden Gruppen festzustellen, obwohl wahrscheinlich beide einen verschiedenen polyphyletischen Ursprung besitzen und von verschiedenen, autogon entstandenen Moneren urspriinglich abstammen. Der indifferente und neutrale Charakter jener niedersten Lebensformen, die meistens einzellig sind, lässt keine Hoffumg aufkunmen, jemals jene wichtige Ursprungs-Verschiedenheit aufzudecken. Solche ganz indifferente einzellige Organismen, wie die Amoeben und Euglenen, und solche charakterlose Zellen-Aggregate, wie dic Catallacten und Volvocinen, könuen ebenso wohl Protozoen als neutrale Protisten, als endlich auch Protophyten sein. Aus diesen Griinden wird es das 'Zweckmässigste sein - vorläufig wenigstens - die Grenze zwischen Protozoen und Protisten fallen zu lassen, und die beiden Hauptgruppen des Thierreichs entweder als Protiste und Animulia, oder als P'rotozoa und Metazou gegeniiber zu stellen. 


\section{Mesozoen. Gastraeaden. Dicyeniden.}

Unsere ,hypothetische“ Gastraceaden-K lasse hat Gliiek. Kaum lat diese niederste Metazoen-Klasse, deren einstmalige Existenz ich rein theoretiseh auf Grund der Gastrula-Beobachtungen mit Hiilfe des biogenetischen Grundgesetzes behauptet hatte, einen realen Inhalt dureh die P h y s e m a r i e n, diese wahren „Gastraeaden der Gegenwart', erhalten, so wird schon von anderer Seite eine neue interessante Gruppe von lebenden Gastraeaden hinzugefügt. Das sind die merkwiirdigen Dieyemiden, iiber deren wahre Natur soeben Enouard vas Beneden eine höchst interessante Abhandlung veröffentlielit hat. ${ }^{1}$ )

Dieser verdienstrolle Zoologe liefert den Nachweis, dass die Dicyemiden echte Gastraeaden im Sinne nnserer hypothetischen Begriffs-Bestimmung sind. Bekanntlich wurden diese merkwiirdigen kleinen Organismen, welche als Parasiten an den spongiösen Venen-Auhaingen der Cephalopoden leben, und welche KronN 1830 entảeckte, zuerst von KöLLIKER unter dem Namen Dicyema paradoxum genau besehrieben und für Wurmlarven erklärt. Ebenso hielten sie Gumo Wagexer und nenerdings RayLANKESTER für Entwicklungsformen von Wiirmern. Hingegen erklärte sie Chapanème für bewimperte Infusorien, den Opalinen nächstverwandt.

Nach der trefflichen und sehr genauen Darstellung von Enouard vas Benedex miissen wir die Dicyemiden für echte Gastraeaden halten, welche durch Anpassung an parasitische Lebensweise ihren Urdarm und Urmund verloren haben. Der einfache, langgestreckte, cylindrische oder spindelförmige Körper des vollstiindig entwickelten Dicyema besteht aus einer einzigen, colossalen, centralen Ent oderm-Zelle und ans einer einfachen Schicht von platten flimmernden Exoderm-Zellen, welche gleich einem Pflaster-Epithelinm die erstere allseitig umschliesst. Am einen Ende des langgestreckten Körpers sind die letzteren von eigenthiimlicher Form and Besehaffenheit und lassen so die Un-

1) Evovard van Benedin, Recherches sur les Dicyemides, survivants actuels d'un embranchement des II esozoaires. (Extrait des Bulletins de l'Académie royale de Belgique, II. Ser., Tom. XLI No. 6, Tom. XI.II, Nr. 7. Bruxelles 1876.) 
gleichheit der beiden Pole des einaxigen Körpers dentlich hervortreten. In der centralen Entoderm-Zelle bilden sich endogen zweierlei verschiedene Embryonen: Nematogene und Rhombogene. Jeder nematogene Keim besteht aus einer endogenen Zelle, welehe eine inaequale Furehung erleidet und ans welcher sich (durch „Epibolie“ der Segmentellen) eine A mphigastrula entwickelt. Diese letztere besteht ans einer grossen Entoderm-Zelle, welehe haubenförmig von einer einfachen Exodermzellen-Schicht umwachsen wird. Am oralen Pole der Axe ist anfangs eine Ur. mund-Oeffnung, an welcher die Entoderm-Zeile frei zu Tage liegt. Dieser Urmund wäehst aber zu, indem die Exoderm-Zellen sich vermehren. Die Zahl der constituirenden Zellen beträgrt bei der fertigen Gastrula von Dicyema typus und D. Koellikeriana 26. Diese Zahl wird nicht vermehrt; die Zellen nehmen während der weiteren Entwicklung bloss an Volumen zt. Endlich entstehen in der colossal vergrösserten Entoderm-Zelle wieder Embryonen. „Un Dicyemide est une Gastrula permanente dont l'entoderme est constitué par une seule cellule." 1 )

Offenbar ist Dicyema nichts Anderes, als eine uralte GastraeadenForm, welche durch Anpassung an parasitische Lebensweise eigenthümlich rïckgebildet ist. Urdarm und Urmund sind verloren gegangen; bloss die beiden primären Keimblätter sind geblieben und diese bilden für sich allein den ganzen Körper: eine einzige colossale Entoderm-Zelle und eine einfache, diese rings tumbiillende Schicht von wimpernden Exoderm-Zellen. Vas Beneuen beurtheilt auch demgemäss ihre Bedeutung ganz richtig und betrachtet sie als wahre "Gastraeaden".

Während ich diese Auffassung van Benrdes's fiil vollkommen naturgemäss halte, kann ich mich dagegen nieht den weitergehenden Vorschlägen anschliessen, welche derselbe in Bezug auf die Classification des Thierreichs daran kniipft. Er will nämlich das letztere in drei grosse, coordinirte Hauptabtheilungen oder "Unterreiche“ zerlegen und zwischen Protozoen und Metazoen die dritte, in der Mitte stehende Abtheilung der Mesozoen einschalten; letztere soll aus den beiden Klassen der Gastraeaden

1) Die Amphigasivula von Dicyem a erinnert sehr an gewisse Amphigastrula-Formen hoherer Metazoev, oder an jüngere, diesen vorausgehende Blastula-Zustände. Verg]. die schöne und vollkommen naturgetreue ( - nicht, wie Einige meinen, schematische -) Darstellung der Amphiblastula von Unio in der ausgezeichneten „Entwicklungsgeschichte der Malermuschel" von Cant Rab1. Jenaische Zeitschr. 1870, Bd. X, S. 382, Taf. X, Fig. 16). 
und Planuladen ${ }^{1}$ ) bestehen und dadurch charakterisirt sein, dass der Körper zeitlebens nur aus den beiden primären Keimblättern, Entoderm und Exoderm besteht, wïhrend bei allen Metazoen sich zwischen beiden noch ein drittes Kcimblatt, das Mesoderm, entwickelt.

Diesem Vorschlag kann ich aus mehreren Grïden nicht boitreten. Erstens kann ich den Mesoderm nicht die hohe Bedeutung beilegen, welche die meisten neueren Embryologen ihm zuschreiben. Ich halte vielmehr, wie oben (S. 233) erörtert, das Mesoderm stets für ein secundäres Product, welches an morphologischem und phylogenetischem, also auch systematischem Werthe weit hinter den beiden primären Keimblättern zurücksteht. Zweitens aber halte ich es nicht fuir möglich, die Ausbildung eines selbständigen Mesoderms in der vorgeschlagenen Weise als oberstes Classificatious-Princip zu verwerthen. Denn innerhalb der Zoophyten-Gruppe, ja sogar innerhalb der einen Hydromedusen-Klasse finden wir nebencinander nächstverwandte Organismen, von denen die einen ein vollkommen selbständiges Mesoderm besitzen, die anderen nicht.

Vor allen sind hier die Hydroid-Polypen zu nennen, welche grösstentheils (- wenn nicht sämmtlich -) z w e i bläi t tri g sind und kein wahres Mesoderm besitzen. Ich erinnere zunaichst an $\mathrm{Hy} d \mathrm{ra}$, welche uns durch KLeinenberG's ausgezeichnete Monographie (187\%) so genau bekannt geworden ist. Wenn man hier von einem Mesoderm zwischem dem Entoderm und Exoderm sprechen wollte, so könnte man darunter nur die diinne Lage der Muskelfäden verstehen, welche zwischen beiden sich ausbreitet. Diese Muskelfäden sind aber nur innere Fortsätze der äusserlich im Exoderm gelegenon Neuromuskel-Zellen, also unzweifelhaft nur Theile von Zellen und noch dazu kernlose Fortsäitze der kermhaltigen Exoderm-Zellen. Nimmermehr aber kann ich da ein Mesoderm, d. h. ein secundäres Keimblatt anerkennen, wo dasselbe nicht einmal durch eine einzige selbständige Zellenschicht repräsentirt wird, sondern bloss durch kernlose Fortsätze von

1) Planuladen nennt van Beneden eine hypothetische Mesozoen-Gruppe, von der er annimmt, dass die beiden (persistirenden) primären Keimblätter nicht durch Invagination, sondern durch Delamination entstanden sind (wie bei der Gastrula von Geryonia nach FoL). Ich kann letzteren Unterschied nicht als wesentlich anerkennen, sondern nehme an, dass die Gastrula delaminatu secundär (durch cenogenetische Veränderungen) aus der Gastiula invaginata eutstanden ist. Vergl. den letzten Abschnitt (24). 
kernhaltigen Zellen einer anderen Sehieht. Ich halte daher Hydra noch hente für zweiblätterig und wiirde sie daher nach Van Beneden zu den Mesozoa stellen müssen; und dasselbe gilt wahrscheinlich auch von den meisten anderen Hydroid-Polypen. Die genamen Untersuchungen von Franz Euraro Schulze iiber verschiedene Hydroid-Polypen, ebenso die neucste sorgfältige Darstellung des Baues von Podocoryne durch C. Grobren ${ }^{1}$ ) lassen keinen Zweifel, dass die meisten Hydroiden sich der Hydra im Wesentlichen gleich verhalten und kein Mesoderm besitzen. Ueberall erscheinen die Muskelfasern als kernlose fadenförmige Fortsäitze der Neuromuskelzellen des Exoderms. Die von ihnen gebildete Schicht kamn daher ebenso wenig als ein besonderes Keimblatt gelten, wie die innen daran liegende hyaline und structurlose Stützlamelle. Das Mindeste, was ich fiur den Begriff eines Keimblattes verlange, ist eine selbständige Zellenschicht, welche sich von den anliegenden anderen Zellenschichten dentlich absetzt und cine morphologische Einheit bildet. Ebenso zweiblätterig, wie die Hydroid-Polypen, sind wahrscheinlich viele niedere Medusen, bei denen die structurlose Gallertscheibe keine Zellen enthält und anch nichts weiter ist, als eine sehr verdickte hyaline ,Stützlamelle“. Bei den höheren-Medusen hingegen, wo Zellen in die letztere cintreten und das „Gallertgewebe" des Medusen-Schirms, also cine selbständige BindegewebsFormation bilden, da wird unzweifelhaft diese letztere den Werth eines besonderen Keimblattes, eines wahren Mesoderms beanspruchen können.

Es handelt sich bei dieser Auffassung $11 \mathrm{~m}$ eine histologische Principien-Frage, die keineswegs gleichgiiltig ist. Viele Histologen beschreiben Membranen, welche bloss structurlose Ausscheidungen von Zellen sind, als selbständige Gewebe und nehmen daher keinen Austand, auch der strueturlosen, zwischen Entorlerm und Exoderm gelegenen "Stiitzlamelle" der Acalephen den Werth einer besondern Gewebsschicht, ja sogar eines Keimblattes zuzusprechen. ${ }^{2}$ ) Dieser Auffassung kann ich eben so wenig bei-

1) C. Grombran, Ueber Podocoryne carnea, Sitzungsber. der Wiener Ak, 18\%. Nov.

9) KöLLIKER vergleicht in seinen Icones histologicae (II. Abth., I. Heft, 1865, p. 89) die structurlose Gallertscheibe der nielleren Medusen ganz richtig mit einer "colossalen Basement Substance". Gleich darauf aber fasst or sie doch wieder als ein besonderes Gewebe, und zwar als eine „eigenthümliche Bindesubstinz" auf, hanptsiichlich deshalb, weil sie oft ,in Massenhaftigkeit" 
pflichton, als ich etwa die Chitin-Skelete der Givederiniere (o h n e die sie errengende Schicht ron Chitinogen-Zellen) als ein bosonderes „Gewcbe" anerlicnnen kanu. Der" Begriff des Gewebes bezeichnet stets ein einheitliches Aggregat von Zellen von bestimmter morphologischer (und meist auch physiologischer) Bcschafienheit. Desshalb muss ich die Hydroiden und die niederen Medusen fuir zweibliitterig halten (olne Nesoderm), hingegen die Corallen und die höheren Medusen fiur dreibliatterigg (mit Mesodernu).

Ganz ähnlich verhailt es sich mit den Spongien. In meiner Monographie der Kalkschwämme latte ich den Bau dieser Thierklasse - in Uebereinstimmung nit der ailteren Auffassung von Lieneruenx und OsкaR Schint - als zweiblïfterig besclurieben. Bei den einfachsten Kalkschwämnen, den Asconen, ist das Entoderm ein einfaches Geissel-Epithel, das Exoderm eine dünne Schicht ron verschmolzenen Zellen, welche Kalknadeln ausscheiden (Syncytiumu). Diese Auffassung belzämpfte später Franz Eimann Scnulzr, gestuitzt auf seine sehr sorgfältigen Untersuchungen eines Sycon. ${ }^{1}$ ) Er wies nach, dass ich bei den Syconen eine sehr diinne Schieht von Platten-Epithel iibersehen hatte, welche die inssere Oberfläche des Syneytium iiberkleidet. Dieses Epithel dentet er als Exoderm, das Syncytium als Mesoderm, und das Geissel-Epithel als Eutoderm. Von der Existenz jenes äusseren Platten-Epithels bei den Syconen habe ich mich an Schuzz's eigenen, guitigst zur Ansicht iibersandten Präparaten iiberzengt. Dagegen ist es mir nicht möglich gewesen, dasselbe bei den niederen Kalksclıwämmen, den A s conen, wiederzufinden, trotzdem ich mir alle Mühe gegeben habe, mit Hülfe der ron Schulz: angegebenen Methoden es wahrzumehmen. Auch der neueste Untersucher der Kalkschwämme, Kellen ${ }^{2}$ ) (der meine Angaben in allen wesentlichen Punkten bestätigt) hat dasselbe nicht wiederfinden können und hält die Körperwand fuir zweiblätterig. Scuuzze's Deutung kann ich namentlich deshalb nicht theilen, weil jenes Platten-

auftritt, und „eine besondere Function als Stützsubstanz" versieht. Aber weder diese physiologis che Bedeutung noch jene Massenhaftigkeit können nach meiner Ansicht einer solchen structurlosen Ausscheidung den mor phologischen Werth eines besonderen Gewebes verleiben.

1) Fraxz Eumard Sciluze, Ueber den Bau und die Entwicklung von Sycandra raphanus. Zeitschr. für wiss. Zool., XXV. Bd. Supplem., p. $24 \%$.

2) C. Keller, Untersuchungen über die Anatomie und Entwicklungsgeschichte einiger Spongien des Mittelmceres. Ein Beitrag zur Lösung der spongienfrage. Basel 1876. 
Epithel gerade da am deutlichsten ist, wo man es am wenigsten erwarten diirfte, an der inneren Gastralfläclie del Syconen. Diese ist bei dem jungen Sycon (im Olynthus-Stadium) mit dem GeisselEpithel des Entoderms bedeckt. Erst später, wenn die Radial. Tuben durch strobiloide Knospung entstanden sind, verschwindet das Geissel-Epithel an der Gastralfläche und zieht sich in die Hohlräume der Radial-Tuben zuriick. Man kann daher das später an der Gastralfläche $z$ findende Platten-Epithel entweder fiil das umgewandelte Entoderm oder für eine OberfächenDifferenzirung des entblössten Exoderms halten. Jedenfalls würde Schulze's Dentung nur dann vollständig gesicheit sein, wenn durch die Ontogenie gezeigt würde, dass jenes Platten-Epithel urspriinglich zuerst aus dem Exoderm der Gastrula entsteht und dass erst später zwischen ihm und dem Geissel-Epithel des Entoderms sich das Syncytium bildet. Dieser Beweis ist aber noch nicht gefiihrt. So sicher jetzt durch die meisten neueren Beobachter die Existenz der Gastrula bei den Kalkschwämmen festgestellt ist, so selur widersprechen sich ihre Aunahmen dariiber, wie dieselbe sich in den jungen Schwamm verwandelt. Hier fehlen sichere Beobachtungen.

Vergleiche ich Alles, was die neueren Beobachtungen über Ban und Entwickelung der Spongien zu Tage gefördert haben, so komme ich zu der Vermuthung, dass dieselben sich ähnlich wie die Acalephen verhalten. Hier wie dort bestehen die niedern Formen in entwickeltem Zustande bloss aus Entoderm und Exoderm, während bei den höheren Formen zwischen beiden sich ein „Mesoderm" ansbildet. Jedenfalls steht aber so viel schon jetzt fest, dass der Vorschlag van Beneden's, die zweiblätterigen Gastraeaden (und Planuladen?) als Mesozoa den dreiblätterigen Metazoa gegenïber zu stellen, nicht naturgemäss ist. Man wiirde dann die niederen Hydromedusen - ohne Mesoderm - zn den Mesozoa, die höheren Hydromedusen - mit Mesoderm - zu den Metazoa stellen miissen. Daher kann ich das Unterreich der Mesozoen iiberhaupt nicht anerkennen und muss bei meiner früheren Eintheilung des Thicrreichs in Protozoen und Metazoen verharren.

\section{Gastrulation der Säugethiere.}

Zn den wichtigsten und interessantesten Ergebnissen, welche die ontogenetischen Untersuchungen des letzten Jahres herbeigefiihrt 
haben, gehört jedenfalls die Entteckung der wahreu Gastrula

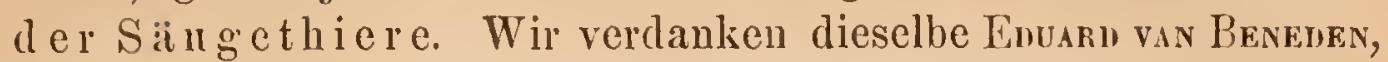
der sich schon so vicle und grosse Verdienste um die Förderung der Entwickelungslehre und um Aufhellung ilırer dunkelsten Punkte erworben hat. Zwar ist die ansfiilnliche Abhandlung noch nicht ersehienen, in weleher dicser ansgezeiehnete Forscher seine Entdeckung eingehend beschreiben und durch Abbildungen erläutern wird, sondern bloss eine vorlïnfige Mittheilung der wichtigsten Resultate. ${ }^{1}$ ) Aber diese "Communication préliminaire" ist so vortrefflich geschricben und zengt von so sorgfiltigen und griindlichen Untersuchungen, dass man sich daraus ein vollkommen klares Bild von der Eifurehung und Gastrulabildung der Sängethiere entwerfen kann. Dieses Bild entspricht vollständig den Voraussetzungen der Gastraea-Theorie und fiillt die grosse, hier bisher bestandene Liicke in derjenigen Weise ans, welche man vom Staudpunkte der vergleichenden Ontogenie und bei der selbstverstaindlichen Annalıme eines monophyletisclien Stammbaums der Wirbelthiere a priori erwarten musste. Ich habe daher auch kein Bedenken getragen, in der kürzlich erschienenen III. Auflage meiner Anthropogenie die Darstellnng van Beneden's vollstïndig zn adoptiren und durch schematisehe, nach seiner Beschreibung entworfene Abbildungen zu erläntern ${ }^{2}$ ).

Bekanntlich sind die ersten Vorgänge bei der Keimung der Säugethiere bisher nur wenig Gegenstand ontogenetischer Untersuchungen gewesen. Die sorgfültigen und für ihre Zeit ausgezeichneten Beobachtungen, welche W. Bischofr iiber die Ontogenie des Kaninchens (1840), des Hundes (1842), des Meerschweinchens (1852) und des Rehes (1854) veröffentliehte, bildeten eigentlich bis hente die einzig'e zusammenhängende Grundlage unserer Kenntnisse von der Keimesgeseliehte derjenigen Thierklasse, der wir selbst angehören. Zwar haben später Remak, Reichert, und Coste, und in nevester Zeit Kölliker, Hensen, Rauber, Lieberkuehn und einige andere Beobachter einzelne, und zum Theil werthvolle Beiträge zu diesem wichtigsten Theile der Naturgeschichte der

1) Edouard vax Bexedex, La maturation de l'oeuf, la fécondation et les premières phases du développement embryonnaire des Mammifères, d'après des recherclses faites chez le lapin. Communication próliminaire. Extrait des Bulletins de l'Acad. royale Belgique, II. Ser., Tom, XL, No. 12. Bruxelles 1875 .

2) Anthropogenie, III. Aufl. 187\%. Fig. 36-41, S. 170-174; ferner 'Taf. II, Figg. 12-17, s. 193. 
Säugethiere geliefert; aber gerade die frïhesten und wichtigsten Vorgänge des Keimungs-Processes sind dabei theils gar nicht beriicksichtigt, theils falsch gedeutet worden. EDUand van Benenen ist bis jetzt der einzige Beobachter, der uns eine griindliche und vollstïndige Untersuchungsreihe iiber die ersten Vorgäng e der Sängethier-Keimung bis zur Bildung der Gastrula und der Gastrocystis gegeben hat; und die von ihn entdeckten Thatsachen harmoniren so schön mit der Gastraea-Theorie, dass ich nicht umhin kann, sie in ihrer Bedeutung für letztere hier kurz zu beleuchten.

Als die wichtigste und interessanteste Thatsache, welche van Benenen's Untersuchungen iibel die Keimung des Kaninchens zu Tage gefördert haben, erscheint uns folgende: Die Eifurchung der Säugethiere ist eine inaequale, und ihr Product eine Amphigastrula. Bisher hatte man irrthiimlich angenommen, dass die Furchung des Säugethier-Eies eine "regelmässige totale“. $d$. h. eine primordiale sei, und dass ihre Morula aus lanter gleichartigen Zellen von gleicher Grösse und Beschaffenheit zusammengesetzt sei. Diese Annahme war aber grundfalsch. Schon mehrere Figuren auf Bischorf's Tafeln (z. B. Fig. 7, Tafel I rom Meerschweinchen) zeigen eine ungleiche Grösse der Furchungszellen, und da seine Figuren im Ganzen sehr genal gezeichnet und naturgetreu sind, so hätte man schon daraus schliessen können, dass die Eifurchung der Säugethiere keine echte primordiale, sondern eine inaequale sei. Ich hatte daher dieselbe anch schon friiher als "psendototale" bezeichnet und der "echten totalen" oder primordialen Furchung des Amphioxus und vieler Wirbellosen gegenüber gestellt. Abgesehen von der verschiedenen Grösse der Furchungszellen berechtigte dazu auch das gänzlich verschiedene Verhalten der aus der Morula hervorgehenden „Keimblase".

Nach vas Benenes verhalten sich die Furchungszellen oder Segmentellen bei der Keimung des Kaninchens folgendermassen. Nachdem aus dem befruchteten kernlosen Ei (Monerula) sich die kernhaltige Stammzelle (Cytula) gebildet hat, zerfillt diese in die beiden ersten Furchungszellen. S chon di es e beiden ers t en Segmentellen haben verschiedene Beschaffenheit und Bedeutung. Die eine ist etwas grösser, heller und fester als die andere. Diese letztere aber, die kleinere, dunklere und weichere, wird durch Carmin, Osmiumsaeure u. s. w. viel intensiver geíarbt als die erstere. Es zeigen also schon die beiden 
ersten Furchungazellen des Säugethieres jene charakteristische Differenz, welche wir allgemein zwisehen den animalen und vegetativen Zellen der amphiblastischen Thiere antreffen. Das Protoplasma der animalen Exoderm-Zelle ist fester, klarer, durehsichtiger als das Protoplasma der vegetativen Entoderm-Zelle, welehes reicher an Körnchen, triiber, weicher, undurehsichtigcr ist und viel mehr Neigung zur Aufnahme von Farbstoffen besitzt. Wie sich aus der weiteren Entwickelung ergicbt, ist die hellere, grössere und festere von den beiden ersten Furchung'szellen des Säugethieres die Mutterzclle des Exoderms oder des animalen Keimblattes; die tribere, kleinere und weichere hingegen ist die Mutter"zelle des Lntoderms oder des vegetativen Keimblattes. Wir können daher schon jetzt die erstere als a nimale, die letztere als vegetative Zelle bezeichnen. Die Säugethiere bieten also ganz dasselbe Verhältniss dar, welches ich friiher bei Fabricia beschrieben habe (Fig. 93) und welehes auch viele andere amphiblastische Eier zeigen.

Die beiden ersten Segmentellen des Säugethieres, welche dergestalt die Mutterzellen der beiden primären Keim. blätter sind, zcrfallen nunmehr dureh gleichzeitige Theilung in je zwei Tochterzellen. Diese vier Furchungszellen liegen gewöhnlich in zwei verschiedenen, auf einander senkrechten Ebenen (seltener in einer Ebene). Die zwei grösseren und helleren Zellen, die 'Tochterzellen rler Exoderm-Mutterzelle, färben sich in Carmin viel weniger intensiv, als die beiden kleineren und dunkleren Zellen, die Töchter der Entoderm-Mutterzelle. Die Linie, welche die Mittelpunkte der beiden letzteren Furehungskugeln verbindet, stelit gewöhnlich senkrecht auf der Linie, welche die beiden ersteren verbindet. Nunmelı zerfällt jede von diesen vier Zellen durch Theilung abermals in zwei gleiche Tochterzellen; wir bekommen acht Furchungszellen, die Urenkelinnen der Stammzelle. Vier grössere, festere und hellere Zellen liegen in einer Ebene: die Enkelinnen der Exoderm-Mutterzelle. Vier kleinere, weichere und dunklere Zellen liegen in einer zweiten, jener parallelen Ebene: die Enkelinnen der Entoderm-Mutterzelle. Wenn wir die Mittelpunkte von je zwei entgegengesetzten Furchungszellen einer Ebene dureh gerade Linien verbinden, so schneiden sich diese letzteren unter rechten Winkeln. Aber die vier Verbindungslinien beider parallelen Ebenen rusammen schneiden sich unter Winkeln von 45 Grad.

Jetzt aber verïndern dic acht Furchungrszellen ihre urspriing- 
liche Lage und ihre kugelige Gestalt. Eine von den vier Entoderm-Zellen tritt in die Mitte des Zellenhaufens und bildet zusammen mit den drei anderen eine Pyramide (oder ein Tetraeder). Die vier Exoderm-Zellen legen sich iiber die Spitze dieser Pyramide haubenförmig heriiber. Das ist der Anfang eines Keimungsprocesses, den wir als abgekiirzte und gefülschte Wiederholung der Einstulpung der Keimhautblase auffassen müssen und der zur Gastrula-Bildung führt. Von jetzt an folgt die weitere Furchung des Säugethier-Eies einem Rhythmus, der demjenigen des Frosch-Eies im Wesentlichen gleich ist. Während bei der ursprünglichen (oder primordialen) Eifurchung der Rhythmus in regelmässiger geometrischer Progression fortschreitet $(2,4,8,16$, 32, 64, 128 u. s. w.), so ist die Zahlenfolge der abgeänderten Progression beim Säugethier-Ei dieselbe wie beim Anphibien-Ei : $2,4,8,12,16,24,32,48,64,96,160 \mathrm{n}$. s. w. Das riihrt davon her, dass von jetzt an die lebhafteren Exoderm-Zellen sich rascher vermehren als die trägeren Entoderm-Zellen. Die letzteren bleiben immer etwas hinter den ersteren zuriick nnd werden von ihnen umwachsen. Diese U m w a c hs un g der inneren Darmblatt-Zelleu ist aber im Grunde nichts Anderes, als die Einstuilpung der vegetativen Halbkugel in dic animale Hemisphäre der Keimhautblase; d. h. die Bildung einer Gastrula.

Zuuächst folgt also jetzt cin Stadium, in wclchem der Säugethier-Keim aus zwölf Furchungs-Zellen besteht. Vier dunklere Entoderm-Zellen bilden eine dreiseitige Pyramide, die von einer Haube von zwölf helleren Exoderm-Zellen bedeckt ist. Das nächste Stadium, mit sechzehn Furchung:'Zellen, zeigt uns vier EntodermZellen im Inneren, vier andere aussen und unten; während die acht Exoderm-Zellen in Gestalt einer halbkugeligen Hanbe die obere Hälfte des Keimes bedecken. Die letztere unwächst die innere Zellenmasse noch mehr, indem nun aus den acht Exoderm-Zellen sechzehn werden; von den acht Entodern-Zellen liegen drei, vier oder fünf im Innern, füinf oder entsprechend vier oder drei an der Basis des kugeligen Keims. Auf dieses Stadium von vierundzwanzig Zellen folgt eins mit zweiunddreissig, indem auch die acht Entoderm-Zellen sich verdoppeln. Weiterhin folgen nun Keimformen mit aehtundvierzig Furchungs-Zellen (zwciund(Hreissig Lxoderm, seehzehn Entoderm); vierundseehzig FurchungsZellen (zwciunddreissig Hautblatt, zweiunddreissig Darmblatt); sechsundnenuzig Furchungs-Zellen (vierundsechzig Exoderm, zweiunddreissig" Lntoderm) u. s. w. Wenn die Zahl der Furchungs- 
Zellen beim Säugethier-Keim auf sechsundneunzig grestiegen ist (- beim Kaninchen ungeführ sicbzig Stunden nach der Befruchtung -) tritt die charakteristische Form der H a u b e n - G a s t r u la (Amphigastrula) dentlich hervor. Der kugelige Keim besteht aus einer centralen Masse von zweiunddreissig weichen, rundlichen, dunkelkörnigen Entoderm-Zellen, welche durch genscitigen Druck vieleckig abgeplattet sind und sich mit Osmium-Siiure dunkelbraun fuirben. Diese centrale dunkle Zellenmasse ist umgeben vou einer helleren kugeligen Hülle, gebildet aus vierundsechzig wiirfelförmigen, kleineren und feinkörnigen Exoderm-Zellen, die in einer einzigen Sehicht nebeneíuander liegen und sich dureh Osmiumsäure. nur sehr schwach färben. Nur an einer einzigen Stelle ist diese Exoderm-Hiille unterbrochen, indem ein, zwei oder drei EntodermZellen hier frei zu Tage treten. Diese letzteren bilden den Dotterfropf und fïllen den Urmund der Gastrula ans. Die centrale Urdarmhöhle ist von Entoderm-Zellen erfiillt. Die einaxige oder monaxonie Grundform der Säugethier-Gastrula ist dadurch deutlich ausgesprochen. (Vergl. die Figuren 36-41 in meiner Authropogenie, III. Autl., S. 170-174; sowie S. 113, Taf. II, Fig. 12-17.)

Erst nachdem diese Ampligastrula der Sängethiere ausgebildet ist, entstelit jene charakteristische und vielbesprochene „K eimblase" der Säugethiele, welche zuerst Regner de Graal, spïiter BaEr beobachtet und welche Bischofr mit dem Namen Vesicula blastodermica belegt hat. Bekanntlich hielt man bis jetrt allgemein diese mit Flüssigkeit erfüllte Hohlkugel für gleichbedeutend mit der Blastula (oder Blastosphuera) des Amphioxus und vieler Wirbellosen, jener einfachen, mit Fliissigkeit erfiillten Hohlkugel, deren Wand eine einzige Zellenselicht bildet, die K cimli a ut (Blastoderina). Aber schon der Umstand, dass sich diese Hohlkngel bei der weiteren Entwicklung hier ganz anders verhält, als dort, musste gewichtige Bedenken erregen, und noch mehr jener vielgedeutete, biconvexe, linseuförmige „Haufen von dunkleren Furchungszellen", welcher an einer Stelle der Innenwand der Siiugethier-Keimblase anliegt. Van Beneuen's Entdeckungen haben auch in diese dunkle Frage volles Licht gebracht und zur Evidenz bewiesen, dass die sogenannte Keimblase der Säugethiere (Vesicula blastodermica) und die wahre Keimblase des Amphioxus und vieler Wirbellosen (Blastula oder Blastosphaera) gänzlich vers chiedene 
Bildungen sind. Letetere geht der Gastrula-Bildung voraus; erstere folgt ihr nach. Letztere verwandelt sich in den ganzen Keim; erstere bildet nur zum kleineren Theil den eigentlichen Keim, zum grösseren Theil die „Nabelblase“ oder den riickgebildeten Dottersack des Süugethieres. Es ist daher durchaus nothwendig; jene beiden, bisher irrthümlich zusammengeworfenen Bildungen gänzlich zil trennen und mit verschiedenen Namen zu belegen. Ich habe in der Anthropogenie (III. Aufl., S. 235) die "Vesicula blastoctermica" der Sängethiere als Ke imdarmblas e (Gastrocystis), hingegen dic echte Keimblase des Amphioxus und der Wirbellosen als Ke im ha th a s e (Blastula) bezeichnet. Die Wand der letzteren bildet die Keimha ut (Blastoderma), welche noch nicht invaginirt und noch nicht in die beiden primären Keimbliitter gesondert ist. Die Wand der ersteren hingegen bildet nicht das Blastoderma, sondern das Entoderma und der ,linsenförmige Haufen von Furchungskugeln", welcher an einer bestimmten Stelle der Innenwand des letzteren anliegt, ist das Entoderma. Die iibliche, von Brschorr eingefuihrte Bezeichnung Vesicula blastodermica ist daher gr un $\mathrm{d}$ fal $\mathrm{s} \mathrm{ch}$.

Die Gastrocystis oder die Keimdarmblase ist mithin ein ganz eigenthiimlicher Keimzustand, welcher bloss bei den Sï ug cthieren (vielleicht sogar bloss bei den Placentalien) vorkonimt und allen anderen Thieren fehlt. Die Entstehung dieser Keimdarmblase aus der vorhergehenden Ampligastrula der Säugethiere ist nach van Beneden folgende: Der Urmund der Amphigastrula verschwindet, indem die Entodermzelle, welche den Dotterpfropf bildete, in das Innere des kugeligen Keims, zu den anderen Zellen des Darmblattes tritt. Der Säugethier-Keim bildet jetzt eine solide Kugel, bestehend aus einem centralen Haufen dunkler polyedrischer, grösserer Entoderm-Zellen, und einer peripherischen Hiille, welehe aus einer einzigen Schicht von helleren, rundlichen kleineren Entoderm-Zellen zusamnengesetzt ist. Nun sammelt sich an einer Stelle zwisehen beiden Keimbliattern klare helle Fliissigkeit an; und diese wächst bald so bedeutend, dass sich die Lxoderm-Hïlle zu einer grossen kugeligen Blase ausdehnt. Die Masse der dunkleren Eutoderm-Zellen, welche eine Kugel von viel kleinerem Durchmesser bildete, bleibt an einer Stelle (nach vis Beneden an der Stelle des Dotterpfropfes) mit dem Exoderm im Zusammenhange. Sie Hacht sich hier erst halbkugelig, darauf linsenförmig, endlich scheibenförmig ab, indem sich die Entodermzellen versehieben und in Gestalt einer kreisrunden Scheibe in 
einer Schickt ausbreiten. So entsteht an einer Stelle der Keimdarmblasen-Wand die bekannte kreisrunde, ,Keimseheibe der Sä ugeth i ere", welche man mit var Benenen als $\mathrm{K}$ eimdalmscheibe (Gastrodiscus) bezeichnen kann. Diese allein besteht aus den beiden primären Keimblättern - einer äusseren Schicht heller Exoderm-Zellen, civer inneren Sclicht triber EntodermZellen, - wïhrend die ganze iibrige Wand der Keimdarmblase bloss aus einer Schicht Exoderm-Zellen besteht. Erst spïter wäichst an deren Innenwand anch das Entoderm vollständig herum und num besteht die Wand der Gastrocyste aus den beiden primären Keimblättern, während im Bezirke des Gastrodiscus oder des "Fruchthofes" sich zwischen beiden bereits das Mesoderm gebildet liat.

Bekanntlich bildet nun später der Gastrodisens allein den Leib des Säugethier-Embryo, wiihrend der übrige Theil der Gastrocysten-Wand den vergänglichen Dottersack oder die Nabelblase darstellt. Letztere verhält sich homolog dem Dottersack der Vögel und Reptilien, und daraus geht klar hervor, was anch aus anderen Griinden der vergleichenden Ontogenic schon längst wahrscheinlich war, dass der kleine und unbedeutende Dottersack der Säugethiere stark rii ckgebildet ist, das Rudiment oder schwache Ueberbleibsel von einem viel grösseren und bedeutenderen Dottersack, welchein die Vorfahren del Säugethiere besassen. Vielleicht ist dieser letztere bei den Monotremen noch hente vorhanden, vielleieht noch bei einem Theile del Marsupialien. Jedenfalls steht zu erwarten, dass die wichtige, leider fast noch ganz unbekannte Keimesgeschichte dieser beiden niederen SäugethierSubclassen uns noch vicle wichtige Aufschliisse iiber die Ontogenie der Placentalien und ihre cenogenetische Entstehung aus älteren Keimungsformen geben wird.

Das cenogenetische Anpassungs-Verhältniss, welches die Riickbildung des rudimentären Dottersacks der Säugethiere veranlasst hat, liegt klar auf der Hand. Es ist die Aupassung an den lange dauernden A funthalt im Uterus der lebendig' gebärenden Säugethiere, deren Vorfahren sicher eierlegend waren. Indem der Proviant-Vorrath des mächtigen Nahrungsdotter's, welchen die oviparen Vorfahren dem gelegten Ei mit auf den Weg. gaben, durch die Anpassung an den längeren Aufenthalt im Fruchtbehäilter bei ihren viviparen Epigonen iiberflissig wurde, und indem hier das miutterliche Blut in der Uterus-Wand sich zur wichtigsten Nahrungsquelle gestaltete, musste natiirlich der 
überflüssig gewordene Dottersack durch „embryonale Anpassung“ riickgebildet werden.

Es ist also klar, dass die ersten Keimungs-Processe der Säugethicre - und vor allen ihre Eifurehung und Gastrulation keineswegs, wie man bisher irrthiimlich glaubte, in einer sehr einfachen und urspriinglichen Form verlaufen, sondern im Gegentheil in einer sehr stark modificirten, zusammengezogenen und abgekürten Form, wie das nach der Gastraea-Theorie von vornherein zu erwarten war. Die Keimung der Säugethiere ist sehr stark cenogenetisch ver ändert, stärker als bei allen anderen Wirbelthieren. Ihre amphiblastische Keimungsform ist wahrscheinlich dureh Riiekbildung des Nahrungsclotters aus der discoblastischen Keimungsform ihrer Vorfahren entstanden. Diese letztere aber muss wieder von der amphiblastischen Keimungsform älterer Ahnen (Amphibien), wie diese letztere von der noch viel älteren archiblastischen Keimungsform der AcranierAhnen (Amilhioxus) abgeleitet werden. Die Ampligastrula der Sängethiere (und des Menschen) hat demnach folgende VorfahrenKette: Amphigastrula, Discogastrula, Amphigastrula, Archigastrula.

\section{Uridarm nnd Urmund. Primitiv-0rgane.}

Die Lehre von den „Primitiv-Organen“ des Thierkörpers gehört zu den widerspruchreichsten Kapiteln der Ontogenie. Die meisten Autoren betrachten unbedenklich dasjenige Organ des Embryo als „Primitiv-Organ", das ihnen zuerst im Laufe der Keimesgeschichte als dentlich erkeunbares und selbständiges Organ entgegentritt. An die erste Vorbedingung der richtigen Erkenntniss, an die scharfe Unterseheidung der pal ing e n e t is c h en und cen ogenetischen Verhältnisse, wird dabei meistens gar nicht gedacht. Daher werden die verschiedensten Organe, Nervensystem, Sinnesorgane, Driisen u. s. w., als Primitiv-Organe aufgefasst, obwohl sie diese Bezeichnung durehaus nicht verdienen. Im Gegensatz hierzu erkennt dic Gastraea-Theorie ïberall nur zwei wahre Primitiv-Organe des Metazoen-Organismus an: das $\mathrm{Hautblatt}$ (Exoderma) und das Darmblatt (Entoderma), welches letztere die Urdarmhöhle nit der Urmundöffnung umschliesst.

Urdarm (Progaster oder Protogaster) hatte ich 1872 in der Monographie der Kalkschwämme (Bd. I, S. 468) die urspriingliche 
Darmliohle der Gastrula genannt, und deren einfache Mundöffunng: U l'm u n d (Prostoma oder Protostoma). E. RAY-Lankester, welcher sich grosse Verdienste um die Förderung der GastraeaTheorie erworben hat, und welcher unabhingig von mir, von anderen Beobachtung'en ansgehend, zu ganz ïhnlichen Folgerungen gekommen war, hat drei Jahre später (1875) den Urdarm der Gastrula als Archenteron und deren Urmund als Blastoporus bezeichnet. ${ }^{1}$ ) Die letztere Bezeichnung, welche von mehreren Autoren angenommen worden ist, hat vor der meinigen den Vorzug der Nentralitiit; sie präjudieirt Nichts iber die urspriingliche Bedentling der Oeffnung, durch welche sich die Urdarmhöhle nach aussen öffnet. Meine Bezeichung hingegen schliesst die Vorstellung ein, dass jene Oeffnung urspringlich und zuerst wirklich als M undöf fn ung der Gastraea und der nächstverwandten ältesten Metazoen fungirt habe; in derselben morphologischen Bedentung des Begriffes, in welcher wir die einfache Darmöffnung der Hydroiden als ihren M und bezeichnen, obwohl dieselbe cine doppelte physiologisehe Function als Mund und After ausiibt. Aber gerade aus diesem Grunde gebe ich auch heute noch meiner Bezeichnung den Vorzug vor der nentralen von Ray-Lankester. Denn ich bin anch hente noch der Ansicht, dass der Urdarm mit seinem Urmund wirklich das älteste Primitiv-O r'ga n der ersten Metazocn darstellte, und dass die einfache, am Oralpole nach aussen mündende Höhle der heutigen Archigastrula mit jener hypothetischen Urdarmhöhle identiseh ist und von der ältesten Gastraea dureh zithe Vererbung Jahrtausende hindurch unveräindert iibertragen wurde. Der Urdarm (Protogaster) und der Urmund (Protostoma) der he $1 \mathrm{tigen}$ Archigastrula sind die paling ene tis che Wiederholung derselben Primitiv-Organe von der Stammform der Metazoen (Gastraea). Dabei kommit gar nicht in Betracht, welche verschiedene Bedeutung etwa diese Primitiv-Organe bei der weiteren Entwicklung der hentigen Metazoen erhalten. ${ }^{2}$ )

1) E. Ray-Lankester, On the invaginate Planula or diploblastic phase of Paludina vivapara. Quarterly Journ. of microsc. science 1875, Vol. XT, p. 163.

2) Aus dem gleichen Grunde nennen wir auch noch hente die embryonalen Schlundspalten und Schlundbogen der höheren Wirbelthiere K i em en bogen und Ki iemenspalten, obgleich sie ihre ursprügliche physiologische Bedeutung, die sie bei den kiemenathmenden Vorfahren der ersteren besassen, längst verloren haben. 
Zunächst wird dieser Satz nur bei denjenigen Keimformen der Metazoen unmittelbar' einlenchten, bei welchen der Urdarm des Keimes wirklich von Anfang an eine einfache, leere Höhle und durch einen Urmund nach aussen geöffnet ist; also bei allen Modificationen der palingenet is chen Archigastrula, und zweitens bei jenen Formen der cenogenetischen Amphigastrula und Perigastrula, welche in dieser Bezichung der Archigastrula gleicheu. Wenn wir aber bei dieser die Gastrulahöhle wirklich als "Urdarmhöhle" und ihre Oeffunng als "Urmundöffnung" mit Sicherheit deuten können, so diirfen wir nach dem entsprechenden Primitiv-Organ auch bei allen anderen Gastrula-Formen suchen, wo dasselbe zn fehlen scheint. Hier ist es gewöhnlich der Nalıungs dotter, welcher die Urdarmhöhle ganz erfiillt, die Urmundhöhle verstopft und so deren Existenz verdeckt. Es ist aber nach meiner Ansicht für die morphologische Bedentung dieser Primitiv-Organe ganz gleichgiiltig, ob dieselben mit Nahrungsdotter erfiillt oder leer sind, gerade so wie Magen und Mund des entwickelten Thieres ihre morphologische Bedentung behalten wenn sie leer oder wenn sie mit Speise gefiullt sind. Ganz besonders lehrreich sind in dieser Beziehung die amphiblastischen Eier; denn sie bilden eine lange Reihe von verschiedenen GastrulaFormen mit theils leerem, theils dottererfuilltem Darm. Am einen Ende dieser Reihe treffen wir Amphigastrula-Formen mit leerem Urdarm und offenem Urmund, welche sich nnmittelbar an die palingenetische Archigastrula anschliessen; am anderen Ende sehen wir Amphigastrula-Formen, deren Urdarm nind Urmund grösstentheils oder gaanz mit Dotterzellen erfiillt sind und die sich unmittelbar an die cenogenetische Discogastrula anschliessen. Zwischen jenen und diesen aber finden sich alle möglichen Uebergäinge vor.

Natiirlich ist es nach unserer Auffassung anch ganz gleichgiiltig, ob die Dottermasse, welche Urdarm und Urmund vieler cenogenetischen Gastrula-Keime erfitllt, ans wirklichen Dotterzelle n besteht, d. h. aus axialen Entodermzellen, welche nicht zur Bildung des bleibenden Entoderms verwendet werden (wie z. B. bei Cyclostomen und Amphibien, Fig. 53) oder ans einer struciurlosen oder nicht zellig organisirten Masse von N a h r u g g sdotter (wie bei vielen Knochenfischen, Fig. 55-75, Reptilien, Vögeln u. s. w.). Anch zwischen diesen beiden Fällen erkennen wir keinen scharfen Unterschied an und sind der Ansicht, dass die letzteren ans ersteren phylogenetisch erst später entstanden 
sind. Da ich in den Untersuchungen iiber "die Gastrula und dic Eifurchung der Thiere" hinreichend dargethan zu haben glaube, dass wir alle verschiedenen Formen der Segmentation und Gastrulation ursprünglich von der primordialen Eifurchung und Archigastrula-Bildung ableiten können, vermag ich in jenen vielbesprochenen Differenzen wirklich keine Schwierigkeit zu crblicken und halte demnach anch heute noch an dem 1872 von mir aufgestellten Satze fest: Urdarm und Urmund sind bei sämmtlichen Metazoen lomologe Primitiv-Organe. Dasselbe gilt natürlich auch von den beiden primäiren Kcimblättern, welche dic Wand des Urdarms bilden. Ganz ohne Einftuss auf diesen Satz sind, wie gesagt, die späteren Schicksale dieser Primitiv-Organe, welche sich bei den verschiedenen Metazoen sehr verschieden gestalten können.

Ueber diese späteren Schicksale des Urdarms und Urmundes bei den verschiedenen Metazoen gehen bekanntlich die Ansichten der verschiedenen Ontogenisten hentzutage noch so weit auseinander, dass es nutzlos sein wiirde, dieselben hier sämmtlich anfunfihren und zn discutiren. Offenbar bedarf es hier noch viel ausgedehnterer, vor Allem aber viel genauerer und mit mehr kritischem Urtheil angestellter Beobachtungen. Denn nicht allein bei verschiedenen (oft bei nahe verwandten) Thieren, sondern sogar bei einem und demselben Thiere lauten die Angaben der verschiedenen „exacten" Beobachter völlig entgegengesetzt. Wir beschränken uns daher auf folgende kurze Bemerkungen.

Der U r'm un d (Protostoma, Blastoporus, R u s con i'scher' A fter, Invaginations-Oeffnung der Gastrula) scheint zu persistiren und sich in den bleibenden Mund zu verwandeln bei den meisten (nicht bei allen!) Zoophyten (Gastraeaden, Spongien, Hydromedusen). Dagegen scheint er frihzeitig im Laufe der Entwicklung zu verschwinden bei den meisten (vielleicht allen?) Bilaterien, d. h. bei den Würmern und den vier höheren typischen Thierstämmen (Mollusken, Echinodermen, Arthropoden, Vertebraten). Sicher scheint es zu sein, dass der Urmund hier nirgends zum bleibenden secundären Munde, zum Nachmunde (Metastoma) sich gestaltet; dieser scheint stets durch Neubildung vom Exoderm aus zu entstehen. Dagegen ist es möglich, dass der Urmund der Bilaterien sich bisweilen zum bleibenden After gestaltet. ${ }^{1}$ )

1) Die Verwandlung des Urmundes in den bleibenden After wird z. B. in neuester Zeit mit grosser Bestimmtheit von Ray-Lankester bei Paludina behauptet. Quart. Journ. of microsc. Sc. 18i6, Vol. XVI, p. $3 \% \%$ 
Jedenfallis entsteht der letztere selı oft an einer Stelle, welche der friiheren Stelle des zugewachsenen Urmundes entsprieht oder ihr wenigstens sehr nahe liegt. Für ganz unmöglich halte ich, was gegenwärtig viele Ontogenisten für wahrscheinlich und einige fiir sicher halten, dass bei verschiedenen Thieren einel n a tï l l i chee K lasse der Urmund bald zum bleibenden Munde, bald zum bleibenden After wird, bald verschwindet. So behauptet z. B. Meтschnikorf, dass der Urmund bei einigen Seesternen zum bleibenden Munde, bei anderen zum After werde. Damit hören alle Homologien zwischen zwei nïchst verwandten Thieren auf.

Der Uldalm (Protogaster, Archenteron, Ruseoui'sche Nahrungshöhle) scheint nur bei sehr wenigen Metazoen sich in den ganzen bleibenden Darmcanal, den Nachdarm (Metagaster) zul verwandeln. Das ist der Fall bei den Gastraeaden, Spongien, Hydromedusen, vielleicht anch bei den niedersten Wiirmern. Bei sämmtlichen iibrigen Bilaterien (sowie bei den Korallen, Ctenophoren ${ }^{1}$ ) und vielleicht auch noch bei anderen Zon. phyten) bildet der Urdarm nur einen Theil, und zwar meistens den mittleren Theil des Nachdarms. Hingegen entsteht der vordere Theil (Schlunddarm) hier wohl immer durch Einstiilpung von aussen, aus dem Exoderm, und ebenso entsteht wohl bei den meisten (oder allen?) mit After versehenen der After. Wie weit aber diese beiden s e cu nd ïr en Einstïlpungen gehen (- die natürlich gar nichts mit der Blastula-Einstiilpung zu thun haben ${ }^{2}$ ) -) ist bei den meisten Metazoen noch ganz umbekannt. Bei vielen diirften sie viel beträchtlicher sein, als man bisher annahm. Bei den Wirbelthieren ${ }^{3}$ ) diurfte nieht allein die Schlundhöhle, sondern auch

1) Bei den Korallen und Ctenophoren ist der sogenannte "Magen" Schlund (vom Exoderm ansgekleidet). Der wahre M a gen (Urdarm) ist bei den Korallen die sogenannte "Leibeshöhle", bei den Ctenophoren der ,Trichter".

2) KöLlıEr (Entwicklungsgesehichte, II. Aufl. 1876, p. 383) sagt: ,Will man die Kieimblase (der Säugethiere) mit den HAEckes'schen Typen vergleichen, so kann man sie nur eine Blastula nennen; dagegen fehlt hier ebenso wie beim Hühnchen, eine invaginirte Blastula oder eine Gastrula ganz; und köunte man bei beiden Wirbelthierformen erst viel später in der Finstuilpung, die bei der Mundbilduag statt hat, vielleicht eine schwache Andentung der Gastrula finden." Die Antwort auf diese Auffassung enthält der vorige Abscbnitt (S. 252-258).

3) Bei den Wirbelthieren nimmt man gewöhnlich (seit Rewak) an, dass die secundäre Einstülpung des Munddarms nur bis zum Gaumenthor reicht und dass Schlund und Speiseröhre schon zum Urdarm gehören. Indessen sprechen viele neuere Beobachtungen dagegen. 
noch die Speiseröhre (- bei den Wiederkïuern vielleicht sogar die drei ersten Magen-Abtheilungen -) zur Exoderm-Einstiulpung gehören. Bei den Gliederthieren hat kiirzlich Paur. Mayer gezeigt, dass wahrscheinlich meistens nur ein sehr kleiner Theil des Mitteldarms, nämlich der nicht von Chitin-C'nticnla bedeckte "Chylus-Magen" oder der "eigentliche Magen" dem Urdarm entspricht. ${ }^{1}$ ) Alles Andere ist secundiire Einstiilpung des Exoderms.

Jedenfalls duirfte es kïnftighin für die klare morphologische Unterscheidung dieser genetisch so verschiedenen Darm-Abtheilungen von Vortheil sein, dieselben durch bestimmtere Bezeichnungen zu markiren, als die bisher iblichen und in sehr verschiedenem Sinne gebranchten Ausdriucke: Vorderdarm, Mitteldarm und Hinterdarm (oder Munddarm, Magendarm und Afterdarm). Wir acceptiren dafür die von Ray-Lankester vorgeschlagenen Ausdriicke: Stomodaeum, Mesodaeum, Proctodaeum. S to m o d a e $11 \mathrm{~m}$ ist der Schlunddarm, vom Exoderm ausgekleidet, Mesod a e u $\mathrm{m}$ der eigentliche M ag endarm oder "Chylusdarm", hervorgegangen aus dem Urdarm, vom Entoderm gebildet; Proctod a eum der Afterdarm, ein Product des Exoderms. ${ }^{2}$ )

Dass die beiden primären Keimblätter, die ursprünglich allein den ältesten Metazoen-Körper bildeten, wilklich PrimitivOrgane sind, wird noch vielfach bestritten. So preist es noch jetzt KöLLIKER ${ }^{3}$ ) als ein Verdienst GötTe's, „Etwas ausgesprochen zu haben, das zwar seit Langem sich vorbereitet, aber doch noch nicht vollkommen zum Durchbruche gekommen war: dass die Keimblätter weder fuir die Organe, noch fuir die Gewebe eine besondere einheitliche Bedeutung haben, mit anderen Worten, dass dieselben weder histologische noch morphologische Primitiv-Organe sind." Dieser Satzlässt sich nur für die höheren Thiere vertheidigen, und anch hier nur in einem gewissen Sinne. Für die niederen Thiere und für die ursprünglichen Bildungs-Verhältnisse des thierischen Organismus ist derselbe entschieden unrichtig. Bei unseren Gastraeaden (bei den Physemarien und Dicyemiden), bei den Iydroiden und Spongien, und in weiterer Fassung überhaupt bei den niederen (wenn nicht bei allen) Pflanzenthieren sind die beiden primären Keimblätter noch hente wahre Primitiv-Organe;

1) Paul Marer, Ueber Ontogenie und Phylogenie der Insecten. Jenaische Zeitschr. für Naturw. 1876, Bd. X, S. 141.

2) RAY-Lankester, An account of Haeckel's recent additions to the Gastraea-Theory. Quarterly Journ. of micr. sc. 1876, Vol. XVI, p. 64.

¿, Külluker, Lntwicklungsgeschichte, II. Aufl. 18\%7, 1) 398. 
und dasselbe gilt von der hypothetischen Gastraea, von welcher wir sïmmtliche Metazoen (monophyletisch oder auch polyplyyletisch) ableiten müssen. Ueberall ist bei diesen niedersten Metazoen das Exoderm, das animale Primitiv-Organ, das Organ der Bewegung and Empfindung, der Deckung und Skeletbildung; cbenso ist hier iiberall das Entoderm (mit der von ihm umschlossenen Urdarmhöhle) das vegetative Primitiv-Organ, das Organ der Nahrungs-Aufnahme, Verdaung, Ausscheidung und wahrscheinlich auch Fortpflanzung. Sowohl jenes animale als dieses vegetative Primitiv-Organ bildet bei allen jenen nierlersten Metazoen eine geschlossene morphologische und physiologische Einheit und ist sowohl organologisch als histologisch scharf charakterisirt.

Anders verhält es sich freilich bei den meisten höheren Thicren, wo im Laufe der historischen Entwicklung von Millionen Jahren die verwickeltsten Beziehungen zwischen den verschiedenen Producten der primären Keimbliitter eingetreten sind. Nicht allein die Arbeitstheilung, sondern auch der Arbeitswechsel hat hier vielfach die Organe und Gewebe auf das Mannichfaltigste modificirt. Namentlich ist aber der Umstand hier von grösster Bedeutung, dass die Keimblätter vielfaclı stellvertretend oder vicariirend sich ersetzt und ihre Functionen sich wechselseitig iibertragen haben. Alle diese rerwickelten Verhältnisse sind aber erst später entstanden, sind secundärer, abgeleiteter Natur. In den primären, ursprïglichen Verhältnissen, wie sic uns die Gastraeaden und Hydroiden bis auf den heutigen Tag bewahrt haben, sind sowohl in physiologischer als in morphologischer Beziehung, sowohl in organologischer als histologischer Bedeutung die beiden primären Keimblätter die wahren Primitiv-Organedes Metazoen-Organismus.

\section{Heuristische Bedentung (ler Gastraea-Theorie.}

Angesichts der verschiedenartigen Beurtheilung, welche die Gastraea-Theorie sowohl bei den Gegnern als bei den Auhängern der Fntwicklungslehre gefunden hat, ist es mir hier am Schlusse dieser Studien wohl gestattet, noch einige Worte iber die heuristische Bedeutung derselben hinzuzufitgen. Unsere Theorie ist mehrfach als ein Complex von Theorien und Hypothesen beurtheilt werden, die sehr verschiedenen Werth und sehr unglcichen Anspruch auf 
Geltung haben. Ich lasse mir diesen Ausspruch gern gefallen, zumal ich wohl einsehe, dass ich im Eifer fuir die Begriindung einer monistischen Entwicklungslehre und in dem Bestreben, derselben durch die Gastraea-Theorie ein sicheres einheitliches Fundament zu geben, bisweilen zu weit gegangen bin. Ich lege selbst den mannichfaltigen Folgerungen, welche ich daraus für verschiedene Gebiete der thierischen Morphologie gezogen habe, einen sehr verschiedenen Werth bei, obgleich ich in der generellen Homologie der Gastrula und ihrer beiden primären Keimblätter bei sämmtlichen Metazoen einen festen Kern der Theorie erblicke, der die meisten daraus entwickelten Folgerungen wohl zu verkniupfen und einheitlich zusammen zu halten im Stande ist.

Die wichtigste Folgerung, welche ich aus jener Homologie der Keimblätter für das natürliche System, oder - was dasselbe ist - fiur die phylogenetische Classification des Thierreichs abgeleitet habe, war die Annahme einer monophyletischen Descendenz aller Metazoen von einer gemeinsamen Stammform, der Gastraea. So wichtig und folgenreich aber auch diese monophyletische Hypothese erscheint, so möchte ich ihr doch zunächst mehr eine heuristische, als eine causale Bedeutung sichern. Denn der Gewinn einer einheitlichen A uffassung der wichtigsten ontogenetischen Processe scheint mir durch die Gastraea-Theorie auf alle Fälle gesichert zn sein, gleichviel ob man daraus die gemeinsame Abstammung sämmtlicher Metazoen von einer einzigen Gastraea folgert oder nicht. Allerdings besteht für diese monophyletische Descendenz-Hypothese jetzt keine theoretische Schwierigkeit mehr. Denn unerschïtterlich fest steht die fundamentale Thatsache, dass sich die niederen Thierformen sämmtlicher Stämme, und Thiere der verschiedensten Classen, aus einer und derselben Keim form, aus der palingenetischen Archigastrula entwickeln -und ebenso fest steht die ebenso wichtige Thatsache, dass sich die cenogenetischen Keimformen aller anderen Thiere, - alle verschiedenen Formen der Amphigastrula, Discogastrula und Perigastrula, - auf jene ursprïngliche Archigastrula direct oder indirect zurückführen lassen. Wenn wir das biogenetische Grundgesetz anerkennen, diirfen wir daraus unmittelbar den Schluss ziehen, dass sämmtliche Metazoen von einer gemeinsamen Stammform, einer der A r c higastrula gleichgebildeten G a stra e a urspriinglich abstammen. Aber auch wenn man jenes Grundgesetz der organischen Entwicklung nicht anerkennt und wenn man dem- 
gemäss diesen monophyletischen Schluss nicht zulässt, auch dann wird man zugeben müssen, dass durch die Zuriickführung aller der mannichfaltigen Keimformen der Metazoen auf die palingenetische Keimform der Archigastrula ein einheitliches „Bild un gsgesetz" für den Metazoen-Keim gefunden sei.

Im letzteren Falle wird man die Homologie aller Gastrula-Formen, und die damit verkniipfte generelle Homologie der beiden primären Keimblätter und des Urdarms, nur als Homomorphie (oder anatomische Homologie) auffassen, im ersteren Falle als $\mathrm{H}$ o mo p h y li e (oder genetische Homologie) ${ }^{1}$ ). Wenn die verschiedenen Gastrula-Formen wirklich nur homomorphe wären, und wenn also die verschiedenen MetazoenGruppen vou vielen ursprünglich verschiedenen und nicht zusammenhängenden Gastraea-Vorfahren abstammten, so wiirde man annehmen müssen, dass die Existenz-Bedingungen der Urzeit so gleichförmig waren, dass sie überall durch gleichartige Anpass ung die werdenden Metazoen-Ahnen in die gleiche BildungsBahn der Gastraea drängten. Wenn man hingegen mit uns annimmt, dass sämmtliche Gastrula-Formen homophylet isch sind, so erklärt sich ihre genetische Homologie (- oder Homophylie -) sehr einfach durch Vererbung von einer gemeinsamen Stammform. Beide Hypothesen lassen sich mit Gründen stiitzen; doch scheint mir die letztere einfacher und natürlicher als die erstere.

Gegen die Homophylie - oder die wahre genetische Homologie - sämmtlicher Gastrula-Formen ist neuerdings wieder mehrfach der Einwurf erhoben worden, dass dieselben auf ganz verschiedene Weise entstünden, bald durch Delamination, bald durch Invagination, und im letzteren Falle bald durch Entobolie, bald durch Epibolie. Dass die letzteren beiden Formen nur verschiedene Modificationen eines und desselben Processes sind, habe

$\left.{ }^{1}\right)$,Homophylie nenne ich die wirklich phylogenetisch begründete Homologie, im Gegensatze zur Hom omorphie, welcher die geneologische Begründung fehlt". Monographie der Kalkschwämme, Bd. I, S. 462. Diese beiden verschiedenen Modi der Homologie, welche ich mit den angeführten Worten 1872 unterschieden habe, fallen nicht zusammeu mit denjenigen Modalitäten der Homologie, welche RAy-Lankester 1870 als Homogenie und Homoplasie, neuerdings aber H. Iherixg als Homogenie und Homoeogenie unterschieden hat. Ich werde darauf bei einer andern Gelegenheit ausführlich zurückkommen. Vergl. Annals and Mag. of nat. hist. 1870, Vol. VI, p. 34, 113, 342; und liering, Phylogenie der Mollusken. $187 \%$. 
ich schon friher gezeigt. Wenn der Nahrungsdotter fehlt oder unbedentend ist, so erscheint die Gastrulabildung in der urspriinglichen Form, als Einstiilpung oder Invag i natiou der B lastula (Entobolie); dieselbe tritt aber unter dem Bilde der "Umwachsung“ (Epibolie oder (ircumerescenz) auf, wenn der Nahrungsdotter sehr gross wird. Was aber ferner die Entstehung der Gastrula durch Delamination oder Abspaltung (Flächenspaltung des Blastoderms in zwei Schichten) betrifft, so hat sich neuerdings immer klarer heransgestellt, dass dieser Vorgang äusserst selten - wenn überhaupt vorhanden ist. ${ }^{1}$ ) Und in diesen sehr wenigen Fällen diirfen wir annehmen, dass ein cenogenetischer Process vorliegt, der erst secundär aus dem palingenetischen Processe der Invagination entstanden ist. Ray-Laniester hat diesen Punkt zu verschiedenen Malen so griindlich und umsichtig erörtert, dass ich hier einfach auf seine ausführliche, mehrfach citirte Darstellung verweisen kann. Ich nehme daher mit Ray-Laskester an, dass die Gastrula ursprünglich iiberall durch Invagination der Blastula entstanden ist, und schliesse nach dem biogenetischen Grundgesetze, dass ebenso ursprünglich die Stammform der Gastraea aus der vorhergehenden Alnen-Stufe der Planaea (oder Blastuea) entstanden ist.

Durch diese Auffassung gewinnt natürlich die monophyletische Gastraea-Hypothese wesentlich an Wahrscheinlichkeit, und wir können eigentlich keinen einzigen Grund mehr gegen die Annahme finden, dass wirklich alle Metazoen ursprünglich von einer Gastraea abstammen. Aber selbst wenn diese monophyletische Hypothese der Wahrheit nicht entspräche, so würde sie zunächst schon bloss als heuristisches Princip von hohem Werthe sein. Ich möchte bei dieser Gelegenheit ausdriicklich hervorheben, welchen unschätzbaren Werth für unsere morphologische Erkenntniss die phylogenetischen Hypothesen (ganz abgesehen von ilurer realen Sicherheit) als heuristische Principien besitzen. Bekanntlich hat man wälırend der ersten Hälfte unseres Jahrhunderts ïberall in der vergleichenden Anatomie und Physiologie mit grösstem Vortheil und Erfolge als heuristisches Princip die Teleologie verwerthet, obwohl dieselbe bloss auf anthro-

1) Augenblicklich liegt eigentlich nur noch ein einziger Fall vor, in dem wirklich die Gastrula durch Delamination, nicht durch Invagination entstehen soll; das ist die Geryonia nach Fol; aber bei derselben Meduse behauptet Kowalevsky, die Invagination gesehen zu haben! 
pomorpher Inagination beruhte und jetzt als wirkliches ErklärungsPrincip allgemein verlassen ist. Um wie viel mehr muss es gestattet sein, sich als heuristischer Principien der phylogenetischen Hypothesen zu bedienen, die in irgend einer Form jedenfalls richtig sind. Zunächst ist hier aber unter den verschiedenen möglichen und gleichberechtigten Hypothesen jedenfalls die einfachste die beste, und schon aus diesem Gruncle ziehe ich die monophyletische Gastraea-Hypothese jeder polyphyletischen Annahme vor.

Welchen ausserordentlichen Werth als heuristisches Princip die monophyletische Descendenz-Hypothese besitzt, zeigt vielleicht kein Thierstamm klarer, als derjenige der Wirbelthiere. Wenn es irgend eine grössere Thiergruppe gibt, deren monophyletische Abstammung wir schon heute mit voller Gewissheit behaupten können, so ist es sicher das Phylum der Vertebraten. Der reiche empirische Urkundenschatz, den uns hier vor allen die greifbaren Thatsachen der Palae ontologie, demnächst die zusammenhängenden Argumente der vergleichenden Anatomie und endlich die nicht minder werthvollen Erscheinungen der vergleichenden Ontogenie zu Gebote stellen, spricht so laut und dentlich, dass wir mit voller Sicherheit die ge meins a me Abstammung aller Wirbelthiere von einer einzigen ge meinsamen Stam $\mathrm{m}$ for $\mathrm{m}$, einem „Urwirbelthier", annehmen diurfen. Wie ich nach meiner subjectiven Auffassung mir diese monophyletische Descendenz der Vertrebraten vorstelle, habe ich in der Anthropogenie (III. umgearbeitete Auflage 1877), gestiitzt vor allen auf Gecienbaur's classische Untersuchungen, ausfiuhrlich dargethan. Mögen nun die dort entwickelten Descendenz-Hypothesen zum grösseren Theil richtig sein oder nicht, so habe ich damit doch jedenfalls auf diesem schwierigen und dunkeln Gebiete einen ersten Versuch gemacht, der als heuristische Hypothese die nachfolgenden besseren Versuche eine Zcit lang leiten wird. Jedenfalls stimmen die competentesten und urtheilsfähigsten Fachgenossen heute darin iiberein, dass die gemeinsame Abstammung aller Wirbelthiere, vom Amphioxus bis zum Menschen hinauf, auf irgend einom Wege gesucht werden muss. ${ }^{1}$ )

${ }^{2}$ ) Die monophyletische Descendenz aller Vertrebraten ist so einleuchtend, dass (meines Wissens) noch kein einziger ernstlicher und nennenswerther Versuch gemacht worden ist, das Phylum der Wirbelthicre in mehrere verschiedene Phylen zu zerlegen und von gänzlich verschiedenen, 
Wenn das nun der Fall ist, so ergiebt sich für die vergleichende Ontogenie der Wirbelthiere sofort die bestimmte Aufgabe, alle verschiedenen Keimungs-Formen derselben auf eine und dieselbe ursprüngliche Keimungs-Form zurïckzufïhren. Nur e in c Keimungsform kann die urspringliche, pal ingenet is che sein; alle anderen muissen abgeleitete, cenogenetische seiu. Und welche unter allen den zahlreichen und so weit divergirenden Keimungs-Formen der Vertebraten jene eine urspriingliche Form ist, das liegt seit zehn Jahren, seit Kowalevsix's epochemachender Entdeckung, klar auf der Hand. Der archiblastische A mplioxus zeigt uns noch heute in der Bildung seiner palingenetischen Archigastrula (entstanden durch Invagination der Archiblastula) die urspriingliche Art und Weise, in der sich die ältesten Wirbelthiere (gleich den niedersten wirbellosen Thieren) aus dem Ei entwickelt haben. Es ist also klar, dass wir alle iibrigen heute existirenden Keimformen der Wirbelthiere in irgend einer Art auf jene Gastrula zuriuckzuffilhren und durch Invagination einer Blastula entstanden denken miissen. Damit ist aber für die vergleichende Keimesgeschichte der Wirbelthiere ein heuristisches Princip von grösster Tragweite gefunden.

Wie viel Miihe und Arbcit, wie viel Streit und Verwirrung wäre der vergleichenden Ontogenie der Vertebraten erspart worden, wenn man jene einfache Reflexion sich angeeignet und auf Grund der Gastraea-Theorie nach einem einheitlichen Zusammenhang der verschiedenen Keimungsformen der Wirbelthiere gesucht hätte. Statt aber diesen Zusammenhang zu suchen, haben sich die meisten Embryologen nur um das eine Wirbelthier bekimmert, dessen Ontogenie sie gerade „exact" untersuchten, und sowohl

wirbellosen Stammformen abzuleiten. Nur CanL Semper blieb es vorbehalten, in neuester Zeit die merkwürdige Entdeckung zu machen, dass das wichtigste (und nächst dem Menschen interessanteste) aller Wirbelthiere, dass der A mphioxuskein Wirbelthier ist, sondern ein Descendent der "Protomollusken", ein nächster Verwandter der Brachiopoden und Bryozoen! (Semper, Die Stammesverwandtschaft der Wirbelthiere und Wirbellosen, 1875, S. 59 ff.) Diese und ähnliche phylogenetische Speculationen von Semper sind so flacher und seichter Natur, dass sic nicht erwähnt zu werden verdienten, wenn sie nicht durch ihr anspruchsvolles und unfehlbares Auftreten eine gewisse Geltung erlangt hätten. Nur durch SEMPer's Mangel an grüdlicher vergleichend-anatomischer Bildung und logischer Schulung lassen sich seine verkehrten Einfalle entschuldigen. 
den Amphioxus, wie die tibligen Vertebraten ganz ausser Acht gelassen. Da ist es denn freilich kein Wunder, wenn nicht nur alle möglichen, sondern auch verschiedene unmögliche Hypothesen als "exacte Beobachtungen" sich geltend machten, und schliesslich zu dem Resultate führten, dass nicht nur die verschiedenen Wirbelthiere, sondern auch verschiedene Exemplare einer und derselben Vertebraten-Species ganz verschiedene Keimungs-Formen besässen!

Dieses eine Beispiel mag geniigen, um die heuristische Bedeutung der Gastraea-Theorie zu erläutern. Weit entfernt, mit derselben nnsere phylogenetischen Forschungen in eine dogmatische Richtung drängen zu wollen, wïnschte ich zunächst nur für den Angriff ihrer höchst schwierigen und verwickelten Aufgaben eine feste einheitliche Basis zu gewinnen. Wie weit es gelingen wird, bei weiterem Ausbau unserer Theorie ihre Folgerungen zu bestätigen und ihren heuristischen Werth in einen causalen zu verwandeln, das lässt sich heute natuirlich weder in günstigem noch in ungiinstigem Sinne vorhersagen. Wenn mir aber meine Gegner vorwerfen, dass die Gastraea-Theorie „zu philosophisch" und „zu wenig empirisch" sei, so darf ich mich gegen diesen Vorwurf wohl mit denselben Worten vertheidigen, mit denen vor 111 Jahren Caspar Friedrich Worff seine grundlegende Theorie der Epigenesis in Schutz nahm: "Wer eine Sache nicht aus der Erfahrung unmittelbar, sondern aus ihren Griinden und Ursachen erkennt, wer also durch diese, nicht durch die Erfahrung, gezwungen wird, zu sagen: "Die Sache muss so und sie kann nicht anders sein, sie muss sich nothwendig so verhalten, sie muss diese Eigenschaften haben, und andere kann sie nicht haben" " - der sieht die Sache nicht nur historisch, sondern wirklich philosophisch ein, und er hat eine philosophische Kenntniss von ihr. Eine solche philo-. sophische Erkenntniss von einem organischen Körper, die von der bloss historischen sehr verschieden ist, wird unsere Theorie der Generation sein!" 


Die Gastraea-Theorie.

Táf I

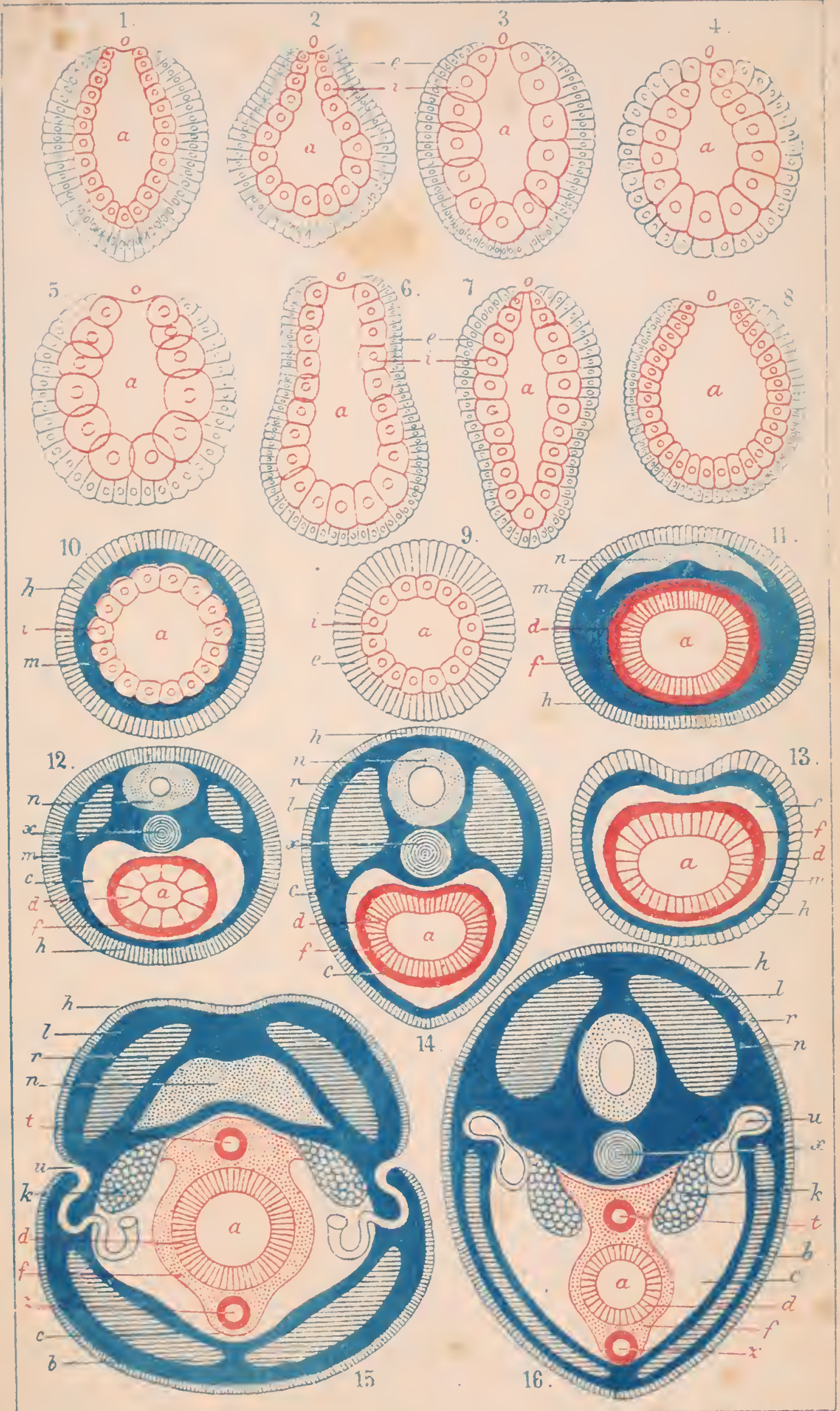

E Hacckel del. 



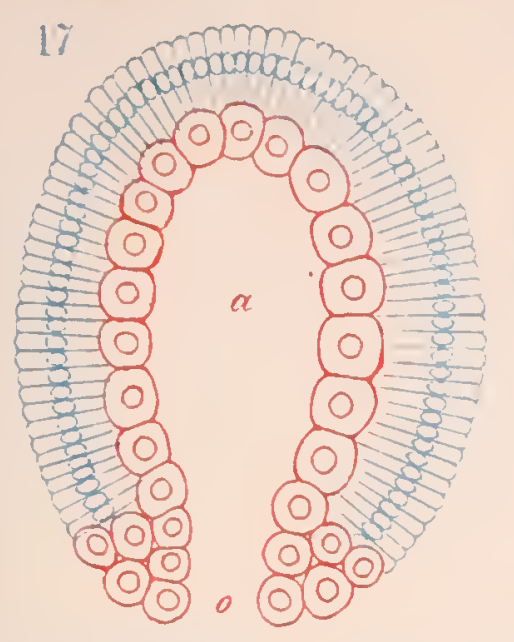

${ }^{23}$

foringo\%

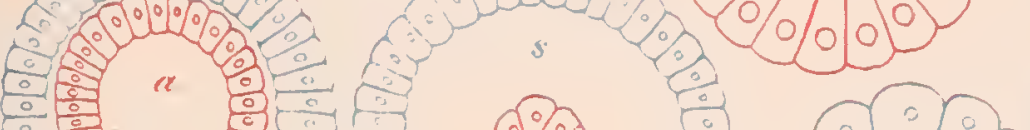

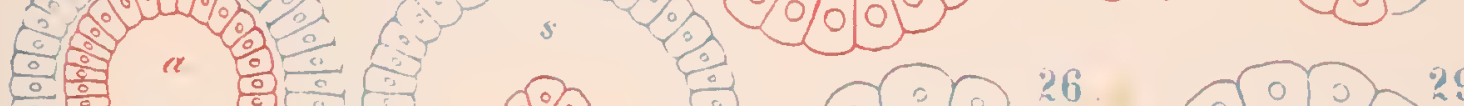

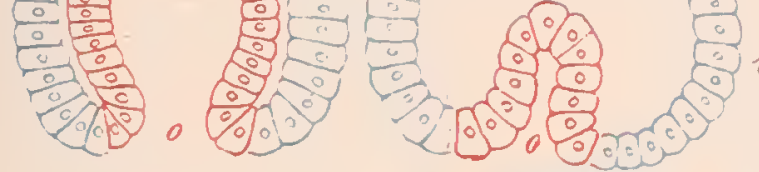
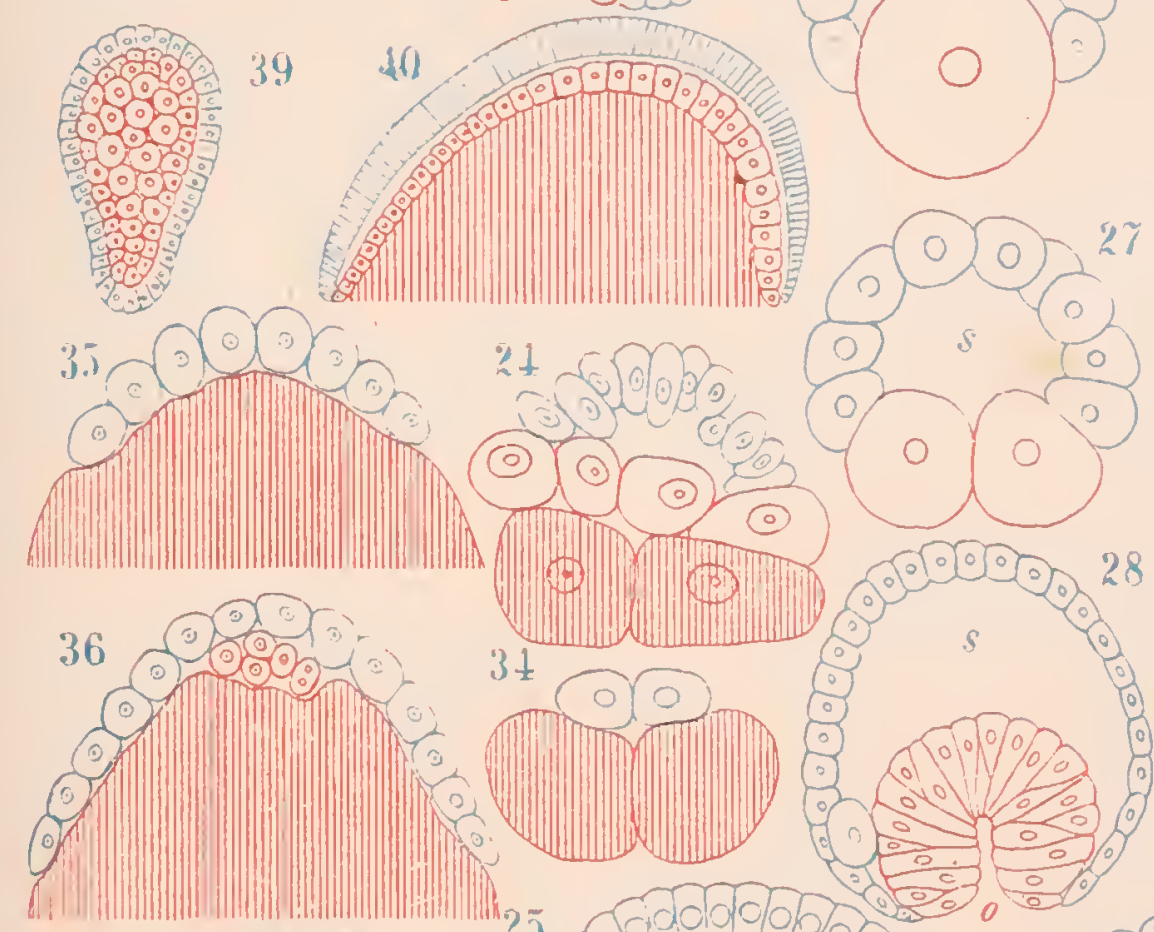

37 तुजणण

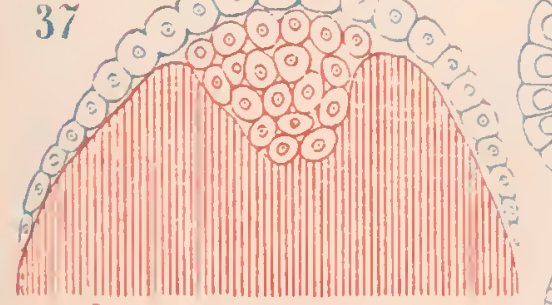

\section{8.}
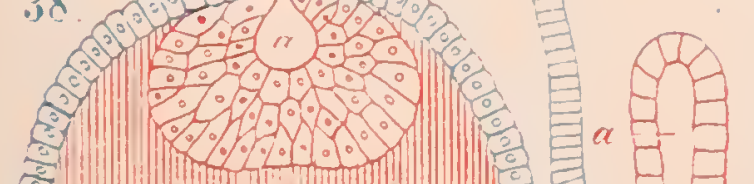
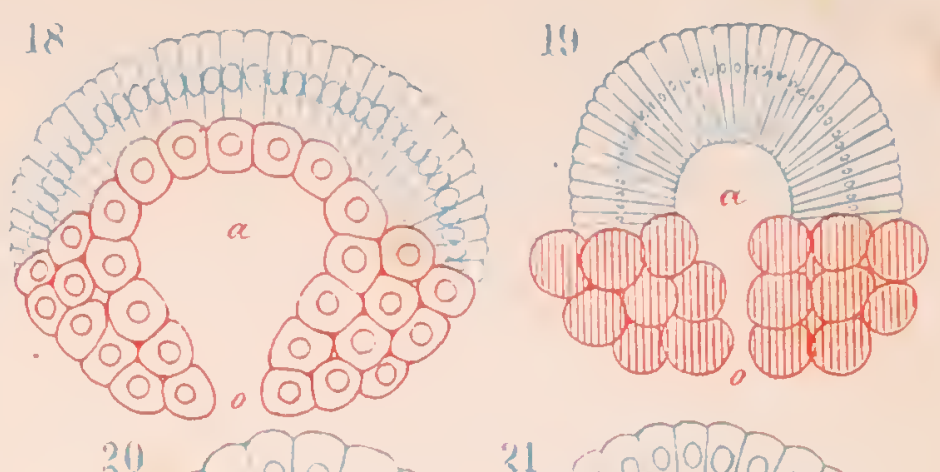

2100000

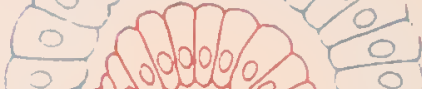

no a है $=0$ (0) 0

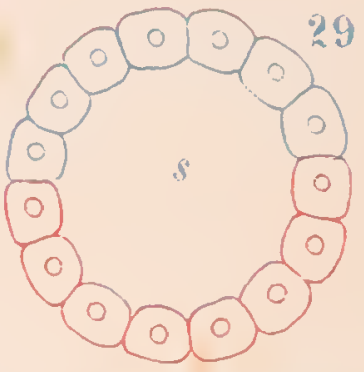

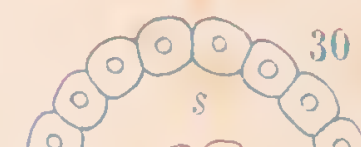

(0)

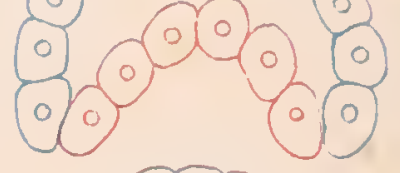

(0) 010031
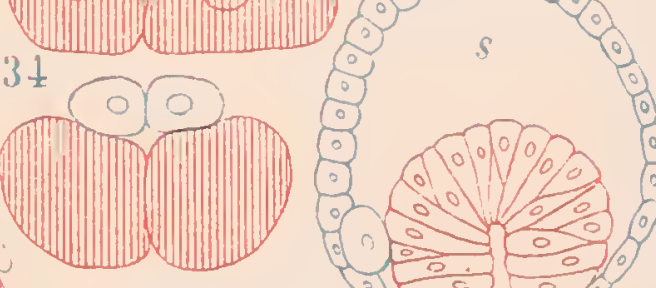

$$
\text { 25. sododolopo }
$$

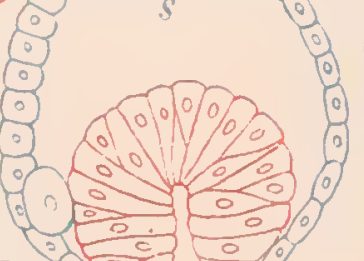

100 a 010

100200

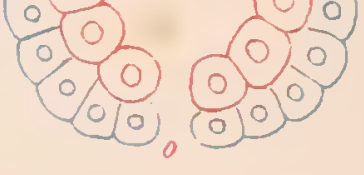

$$
\text { एक: } \frac{0}{0}
$$

olob

$$
\text { o viñ }
$$

s
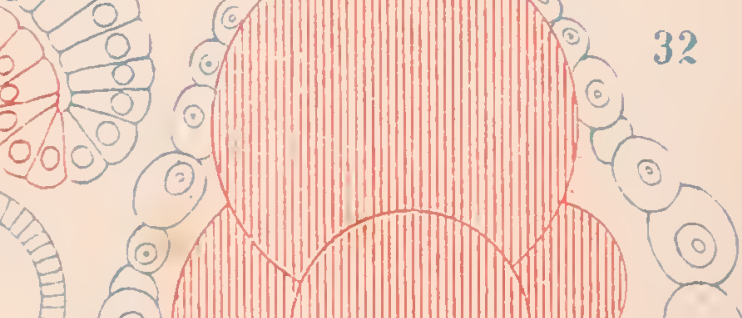

$\left.\frac{2}{9}\right)^{2}$ 

$\pm 1$

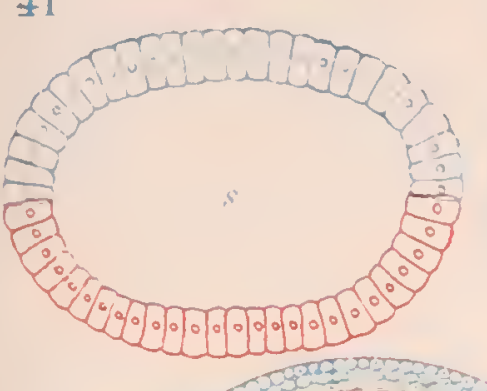

\section{3}

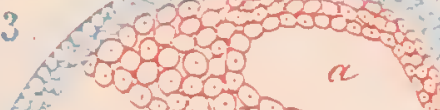

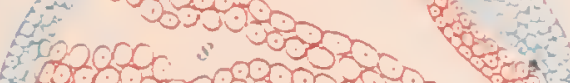

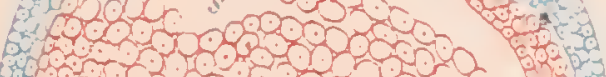

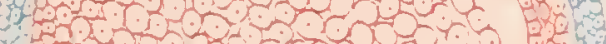

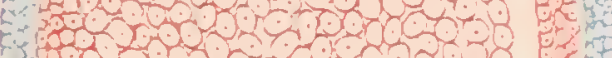
$00-1.000$ $3+20+300$

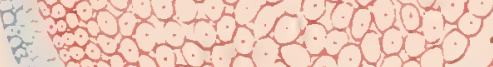
$400-10$ pos

$1 \%$
$5 ?$
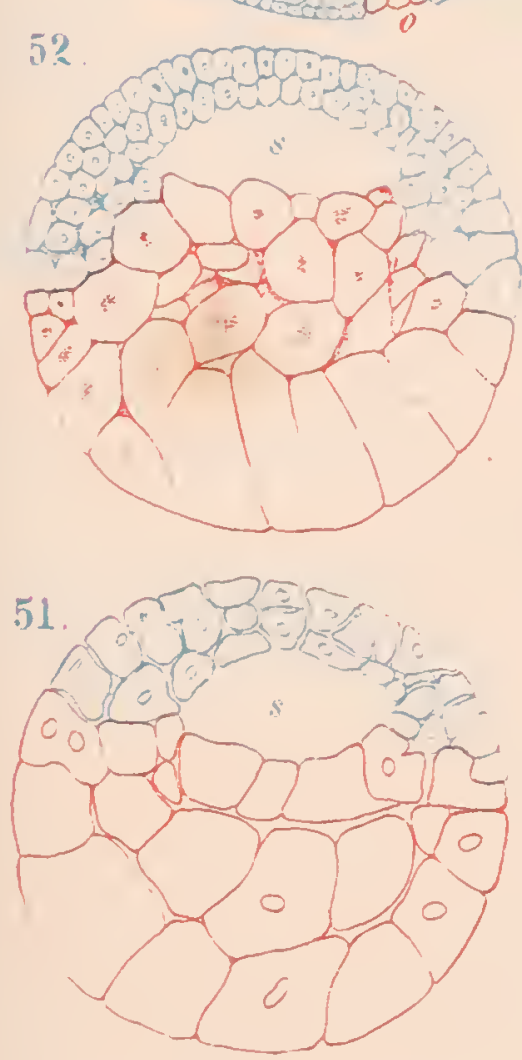

45

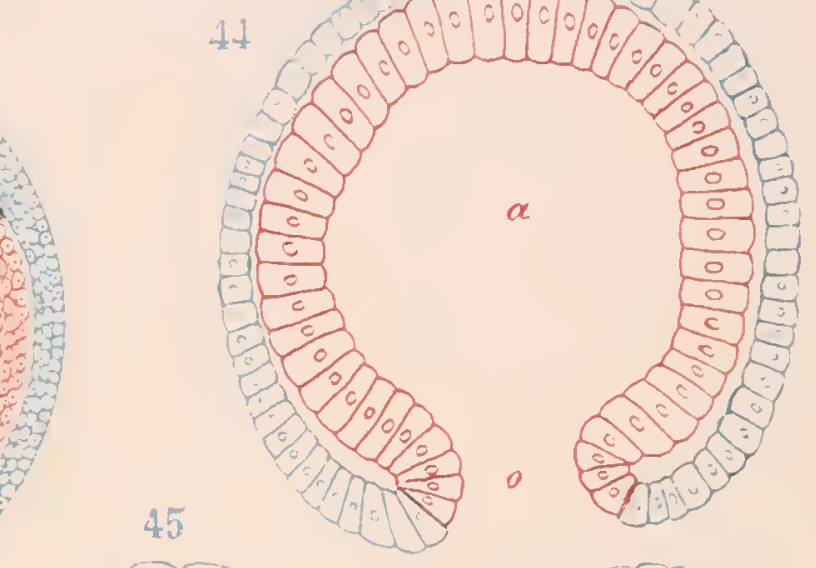

4,3

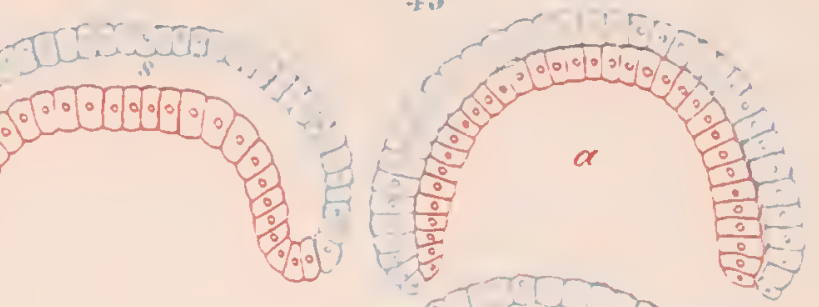

16 करिखरी

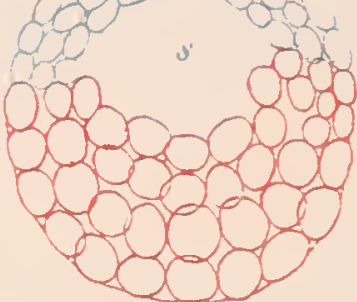

47.

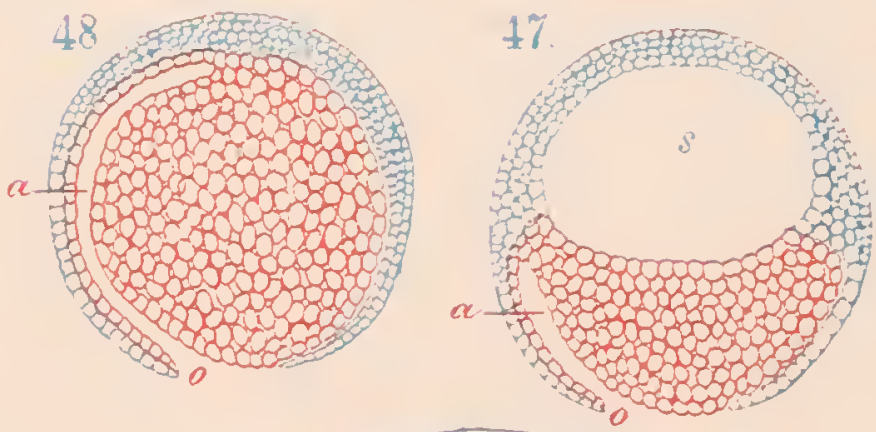

50
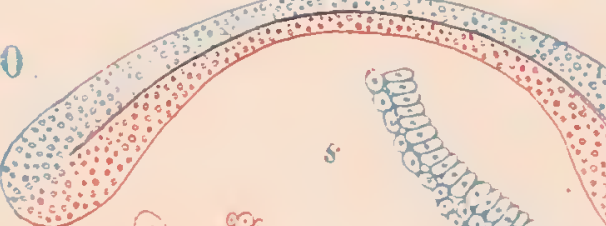

49

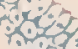

IIIIII) (1)

54 In Tor.t.

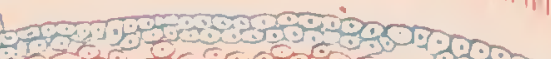



$\therefore 1$

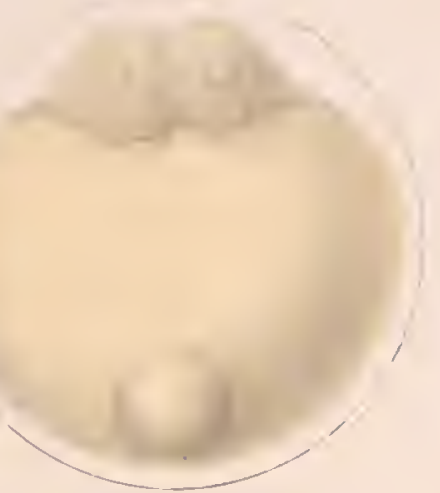

ili

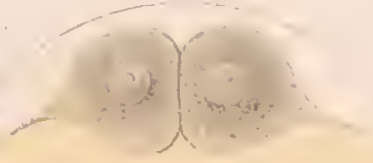

I

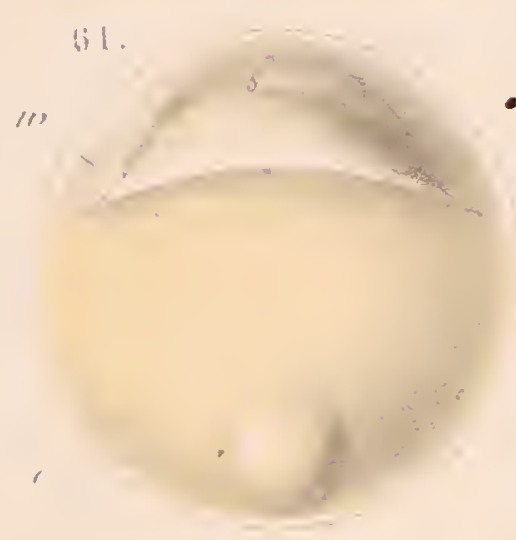

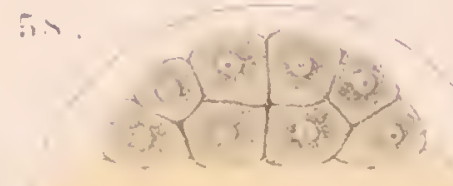

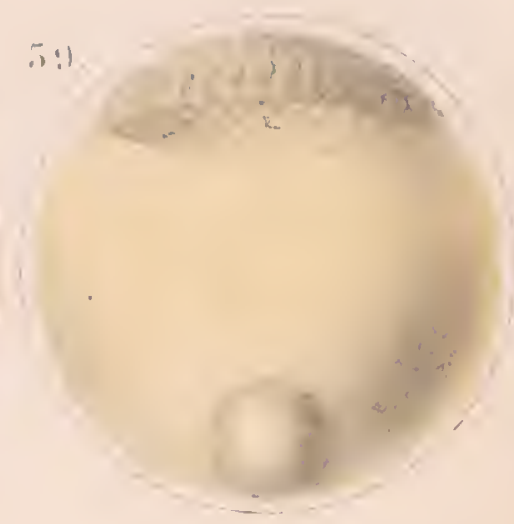

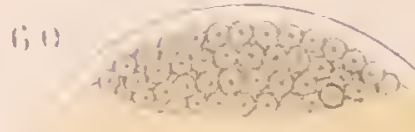
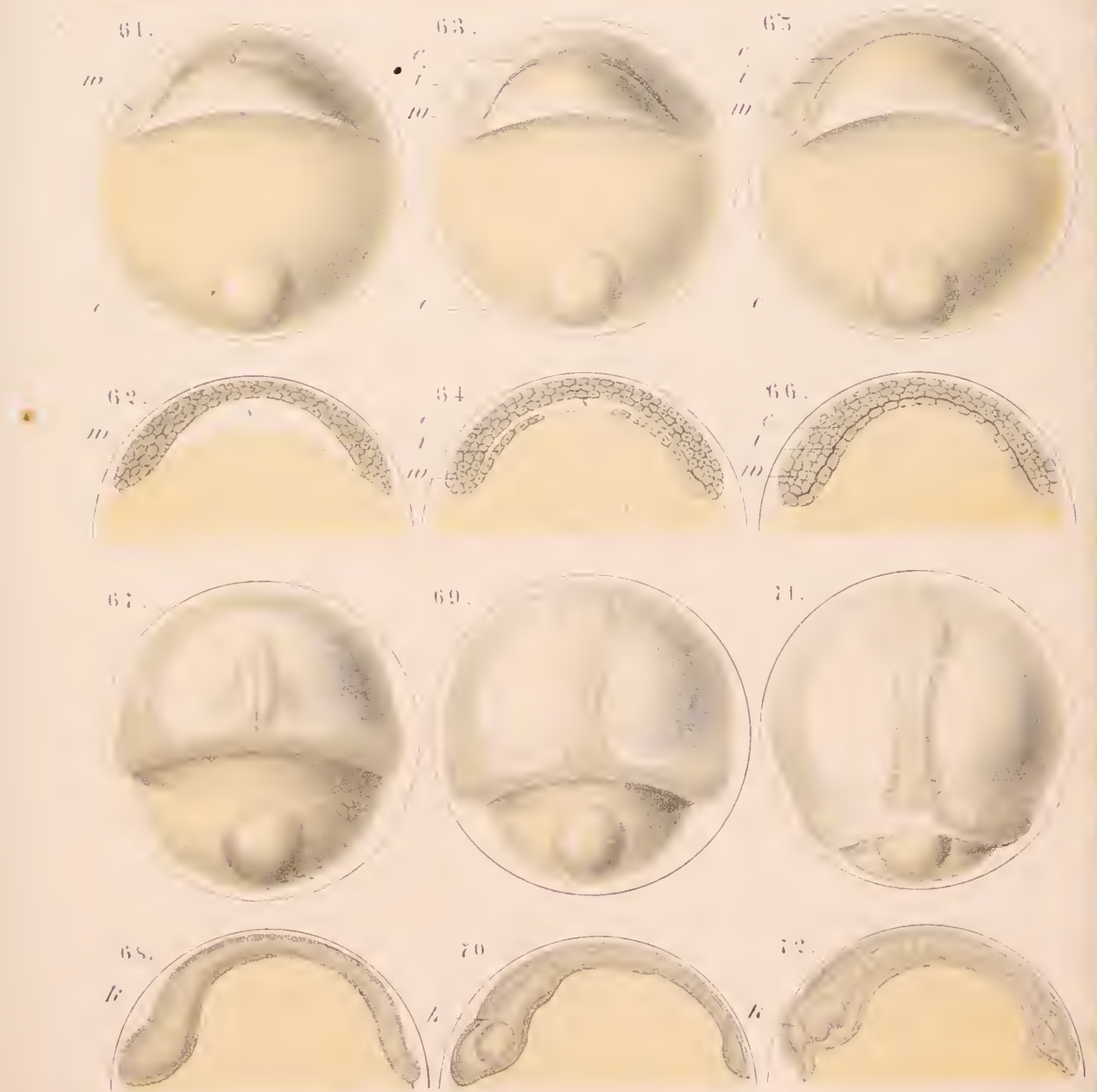



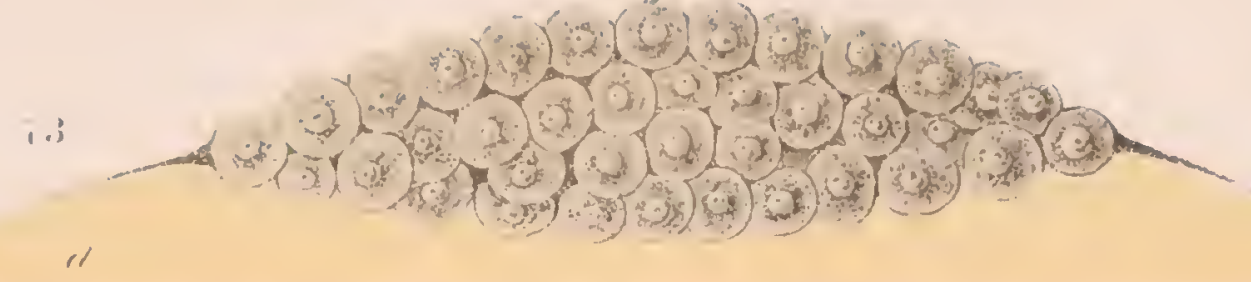
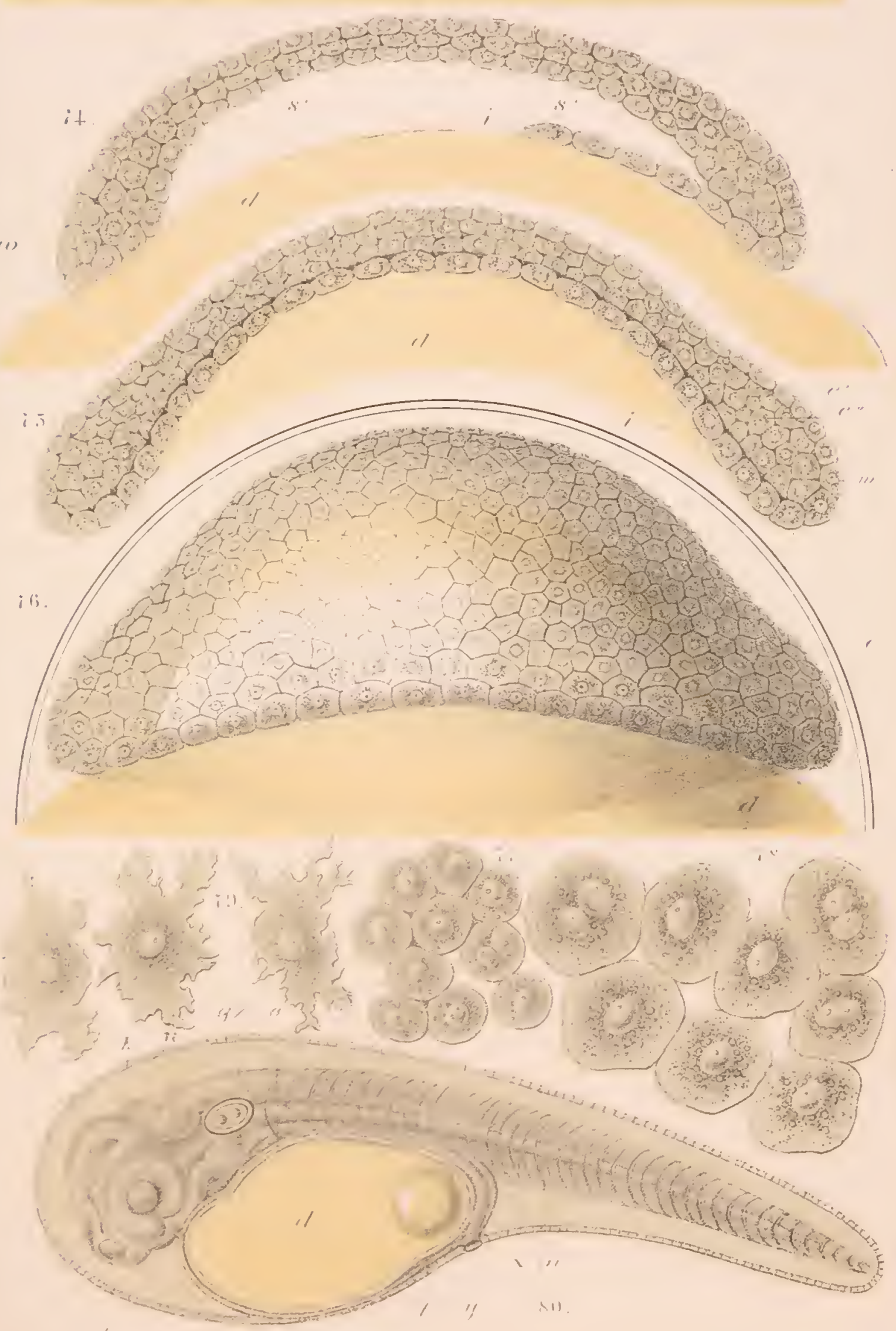


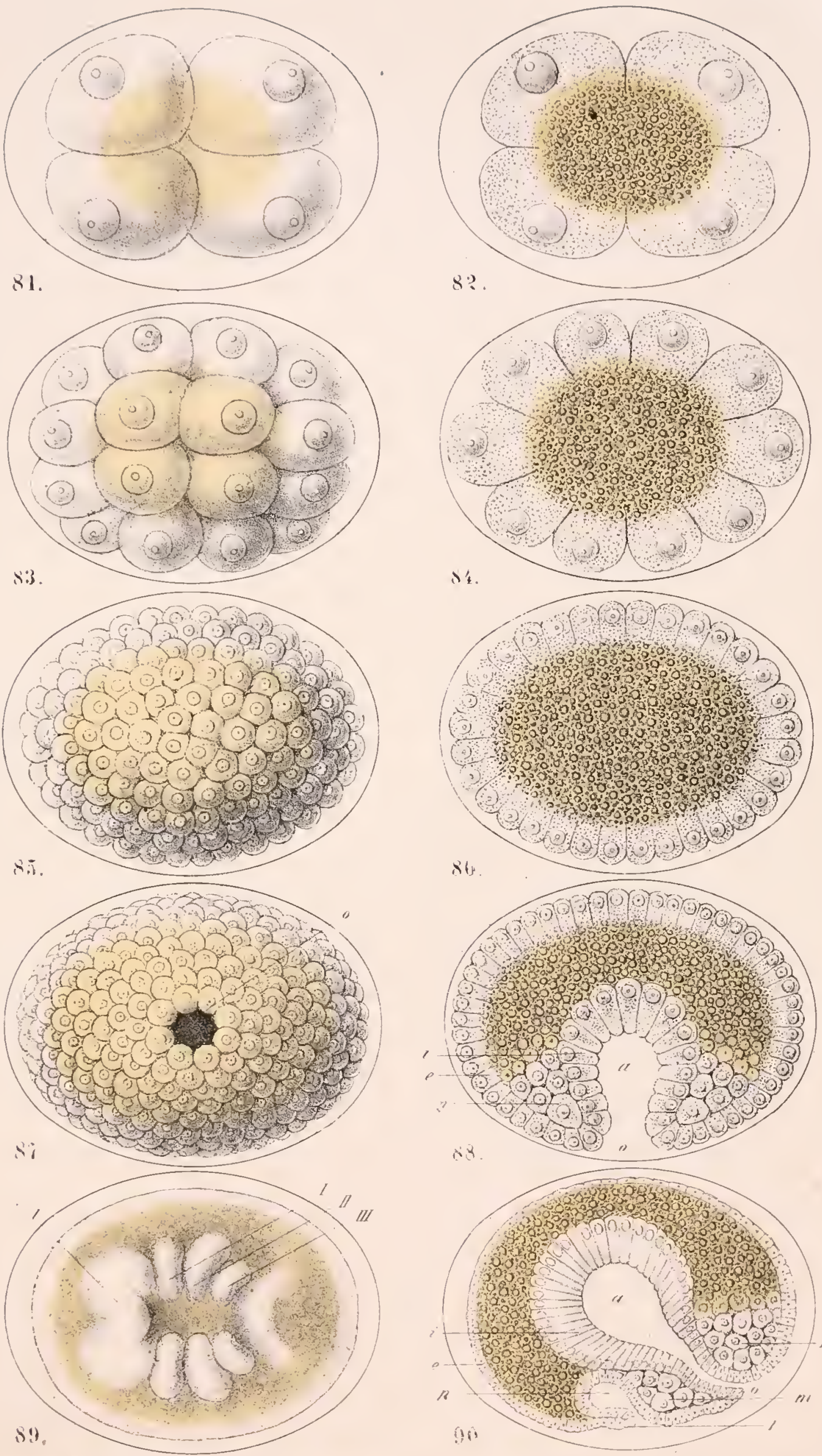


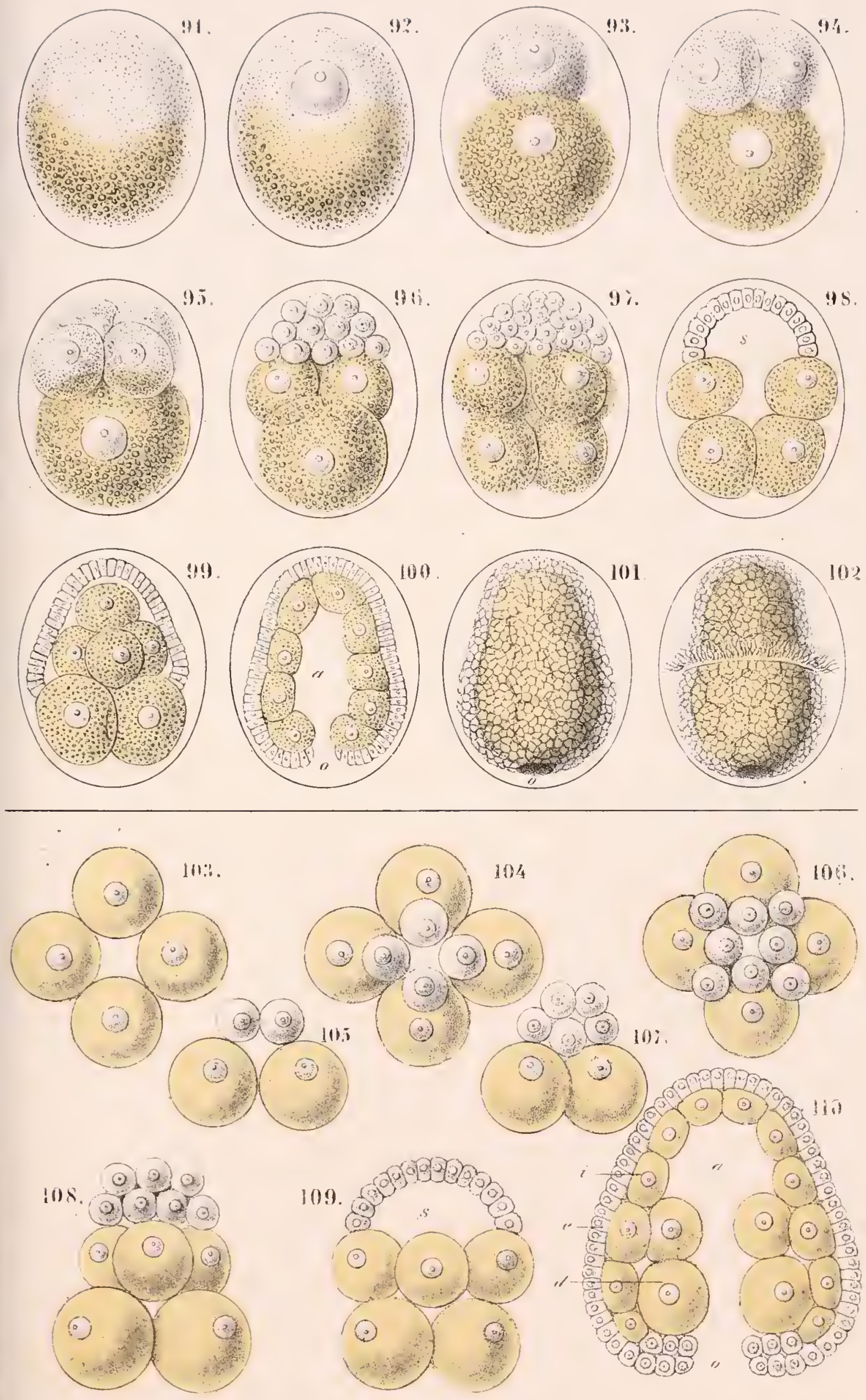

(a)

(a)
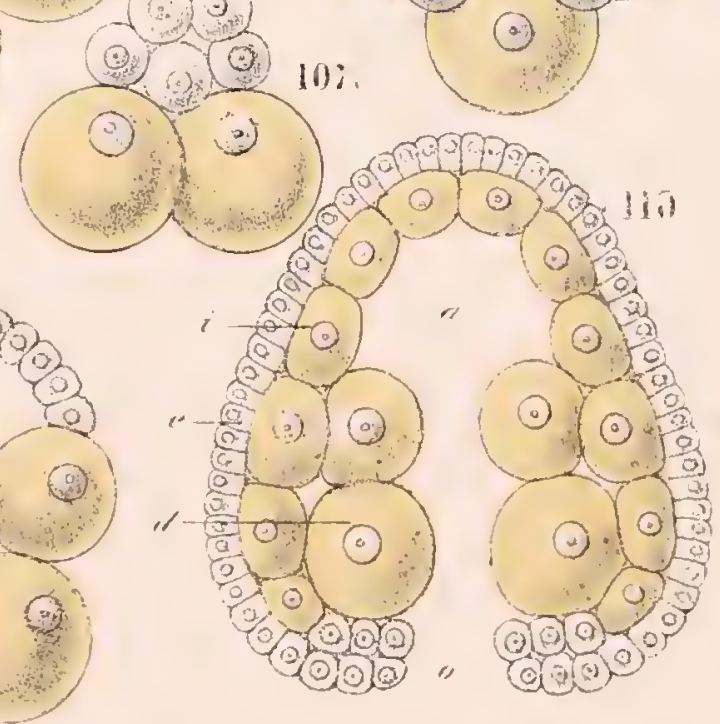


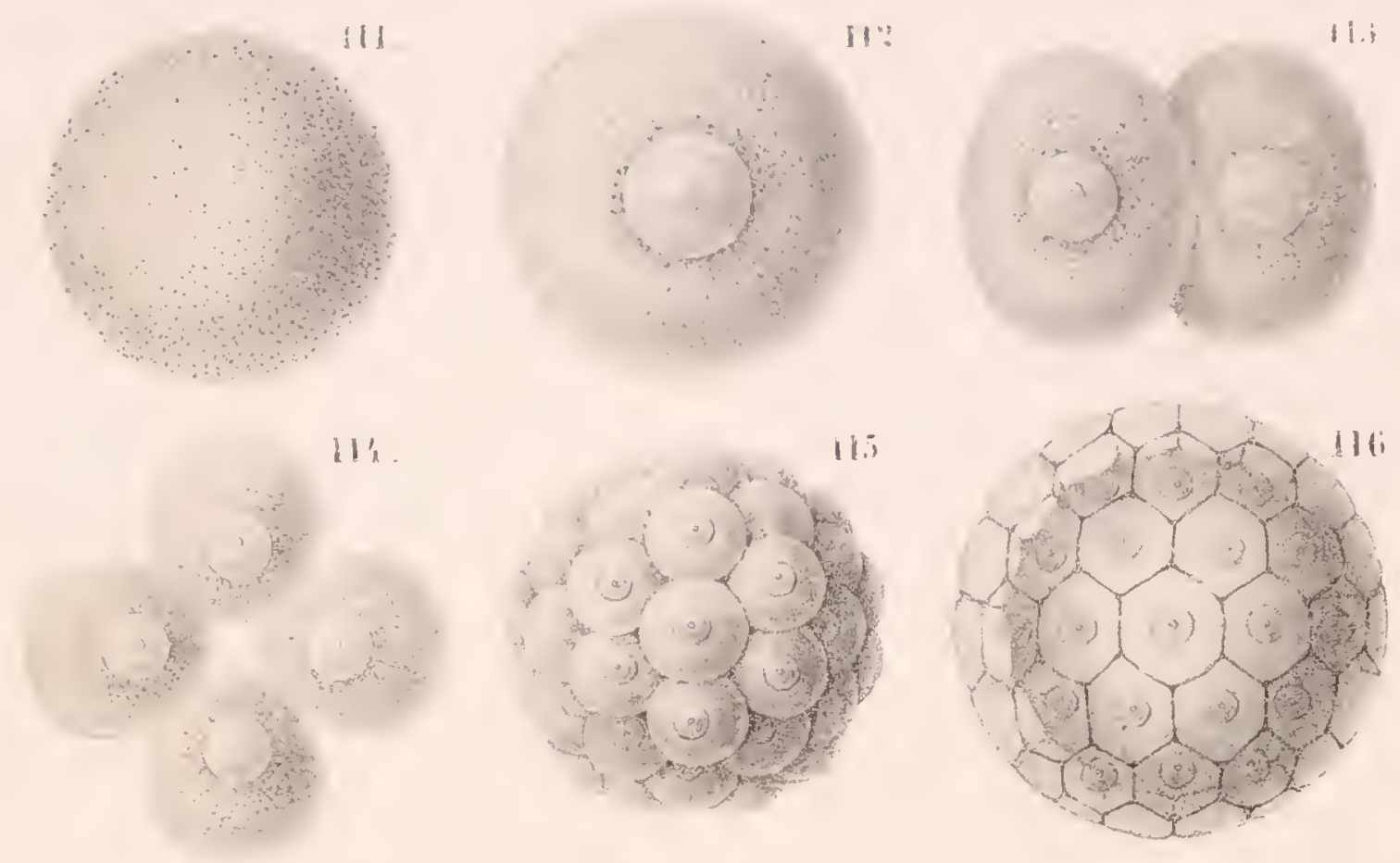

$11 \%$
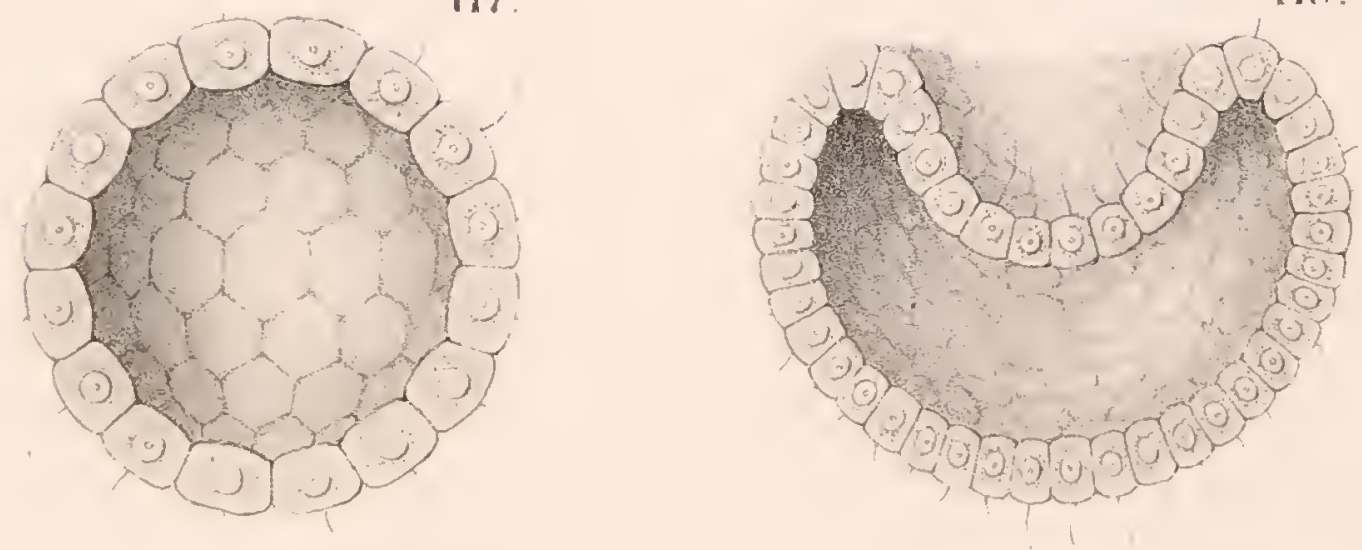

113

$1 ? 11$
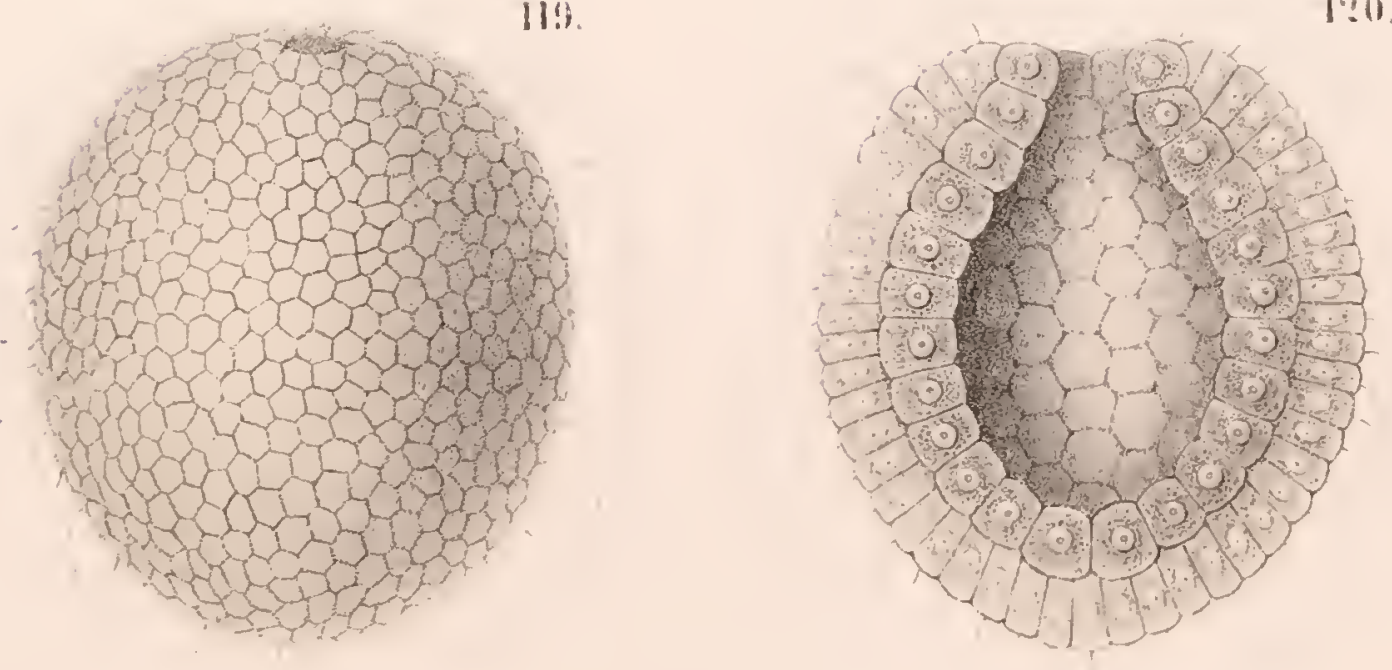


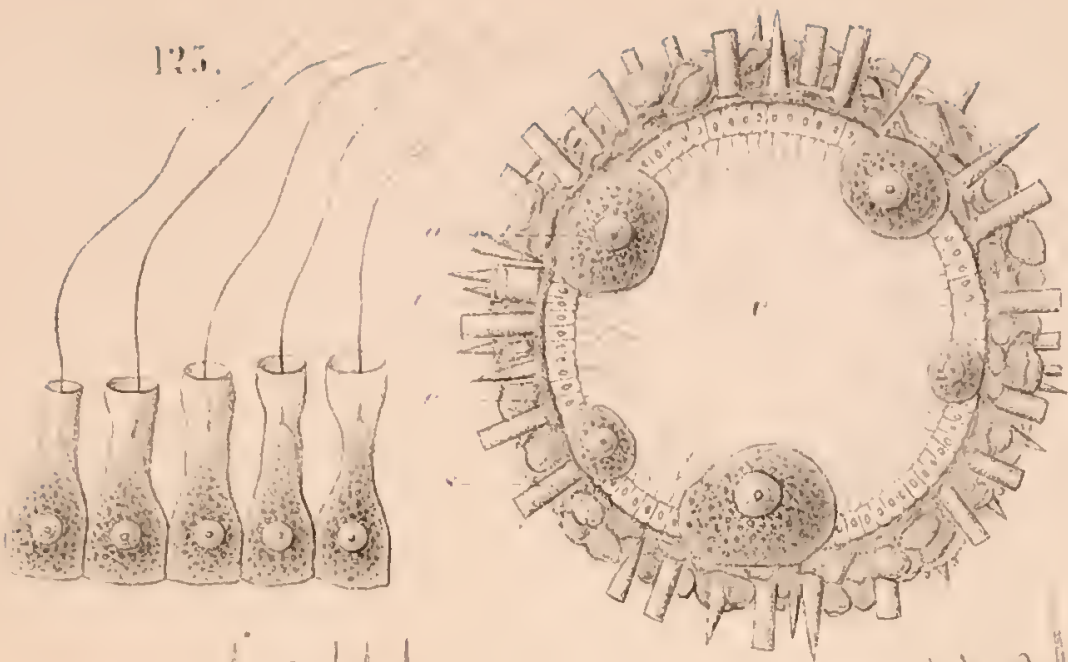

$1: 1$
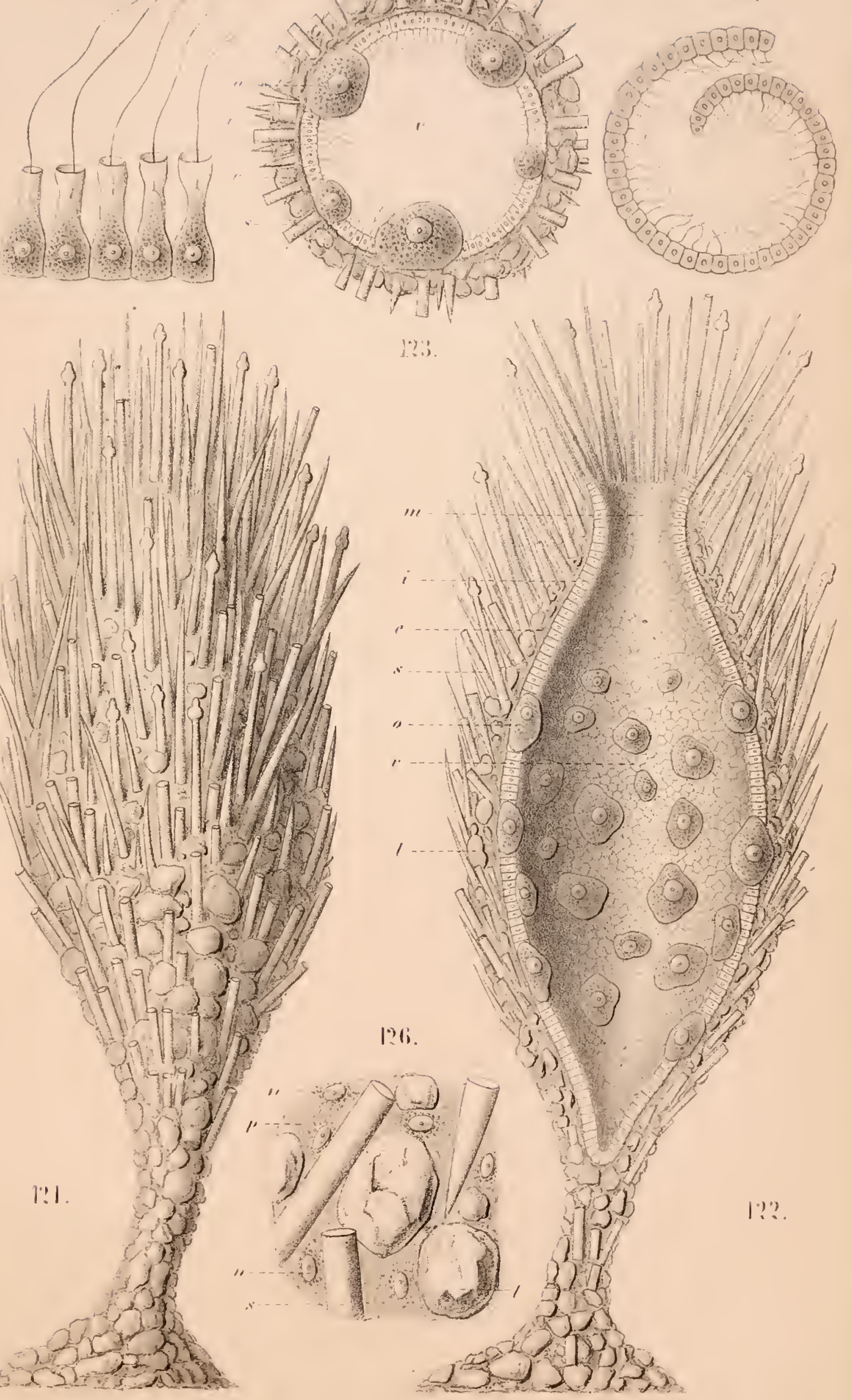



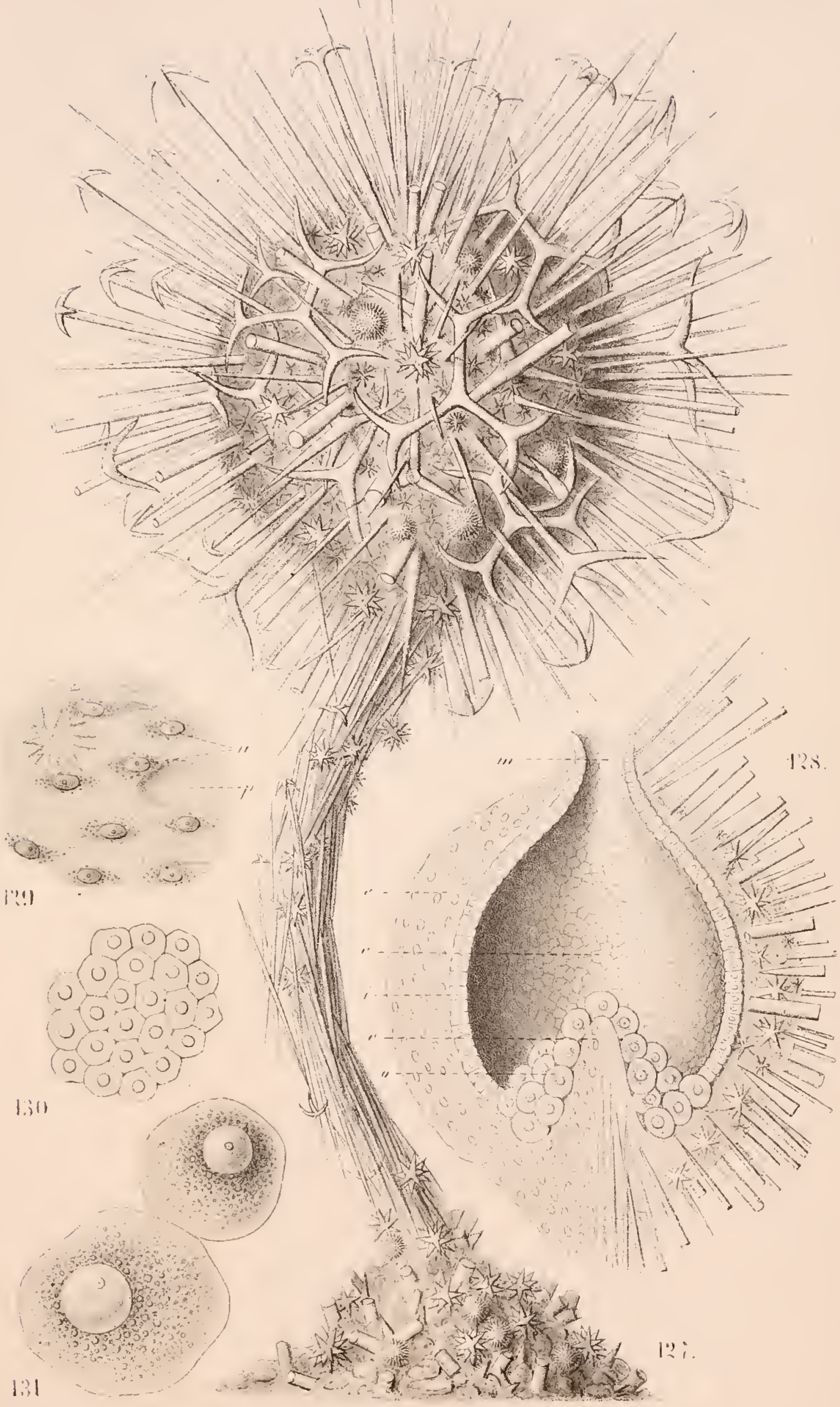



Taf XI.
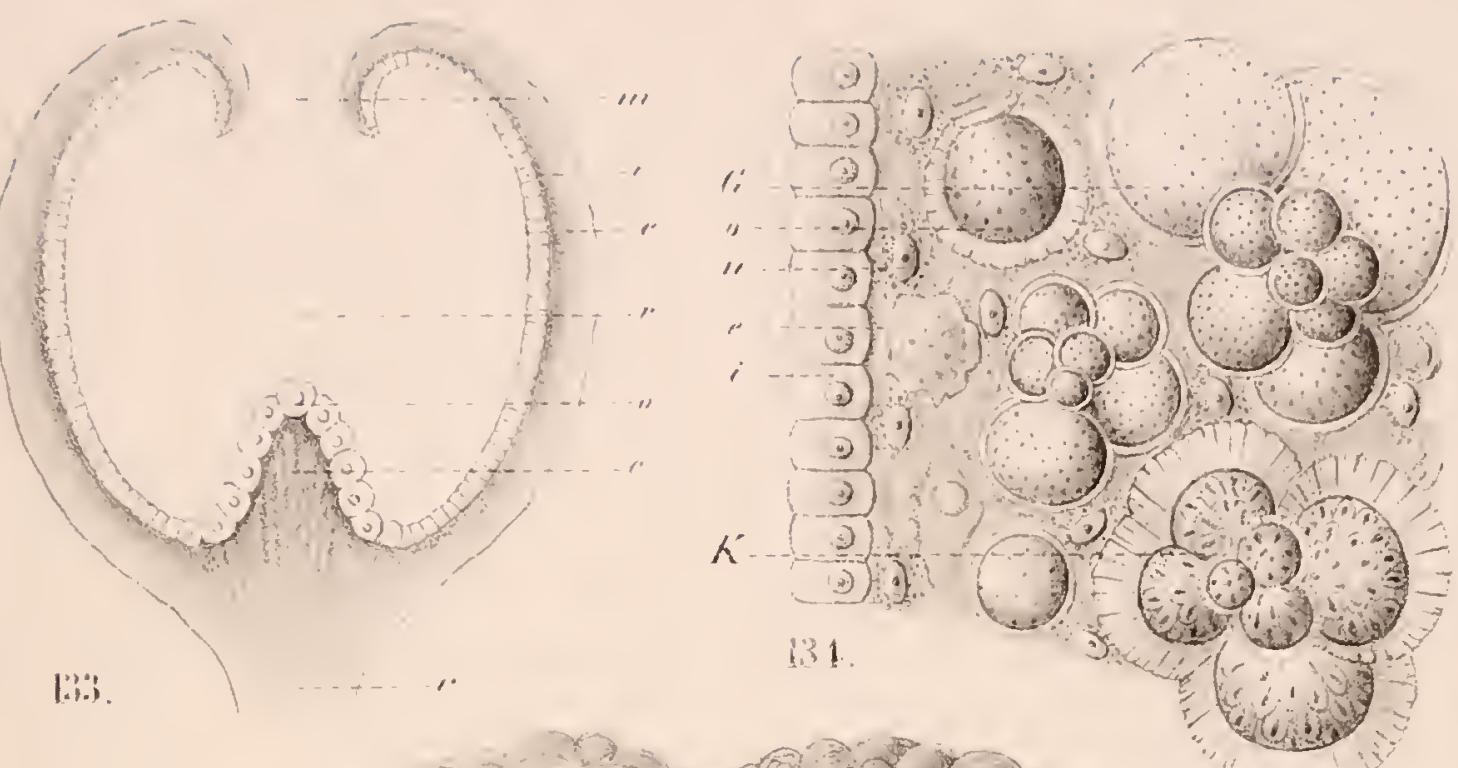

lii:

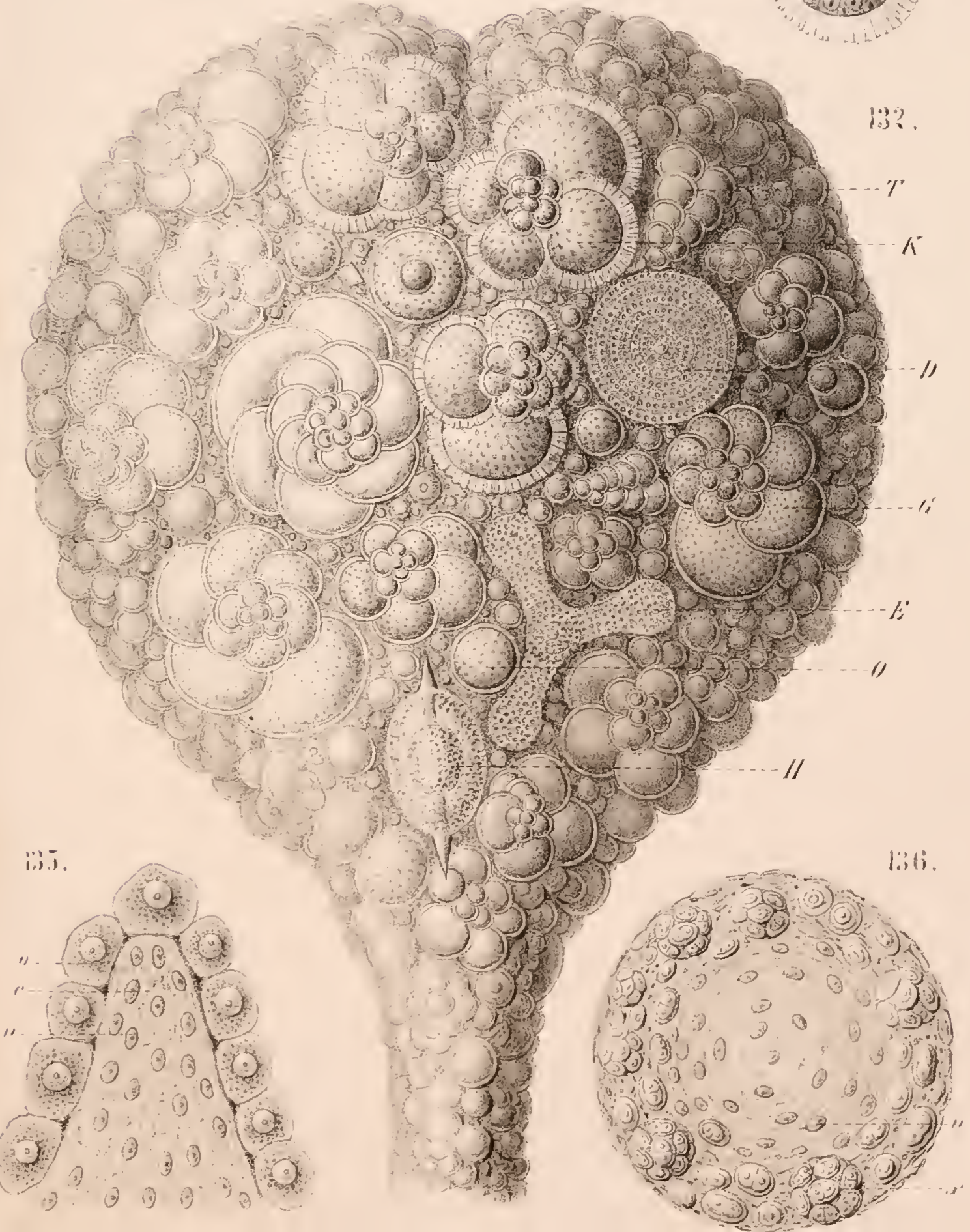





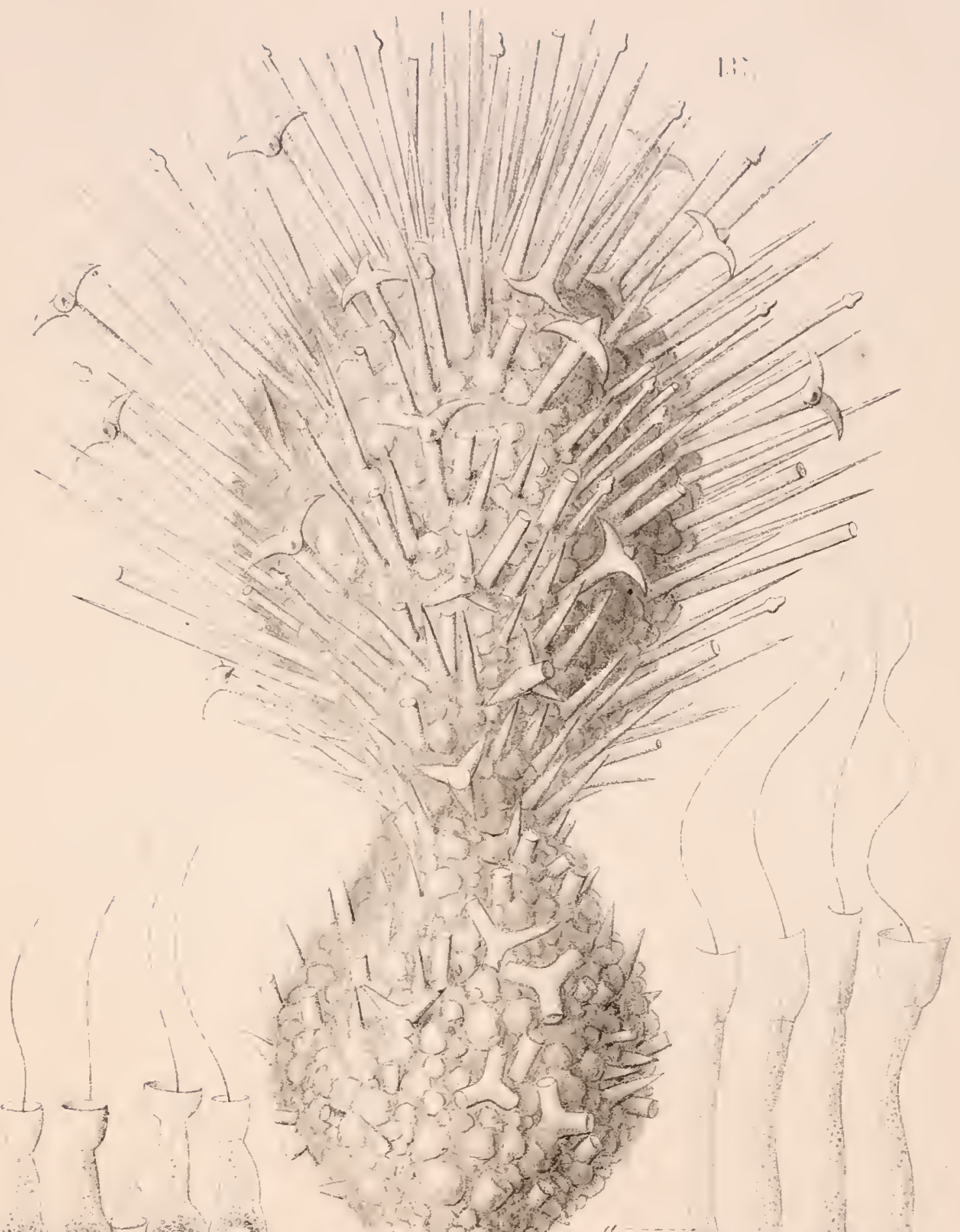

$\rightarrow+y^{2}+y^{2}+2$ 舟 a (3) $\quad 30$, 30 .

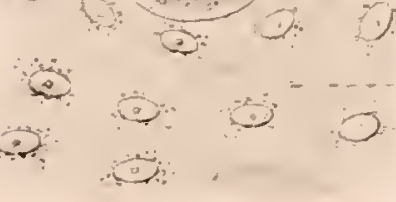

liin. a.

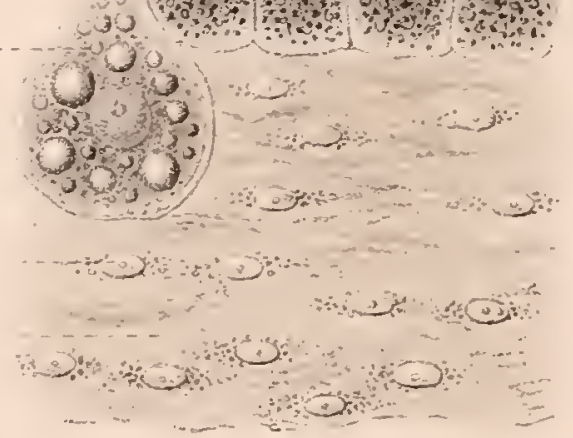
acting 



\section{Wingis}

Ain

will

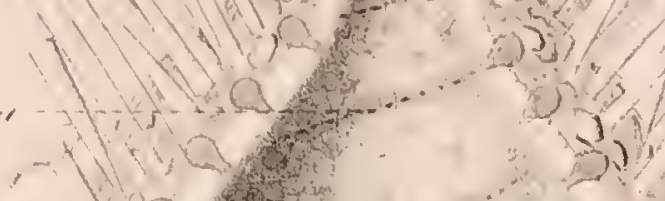

bis

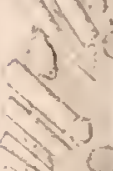

che

$\infty$

set

$=0$

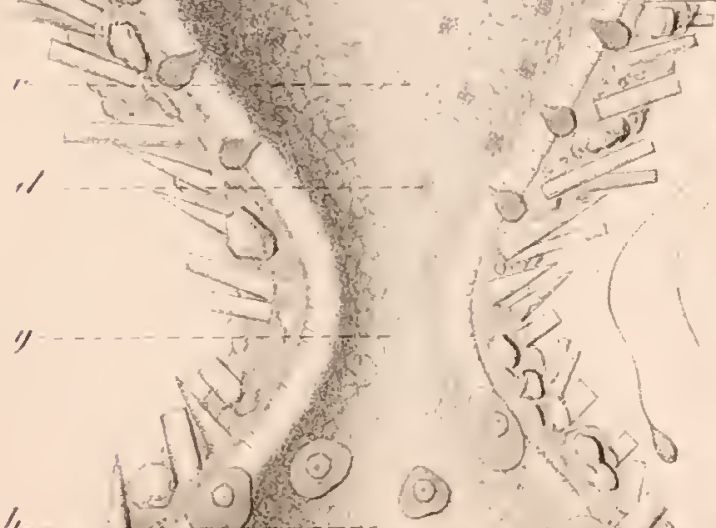

at

,

1,

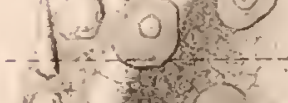

41.0

ill

3) 10,25

I. 1

.

$\frac{1}{3}$

ItI)

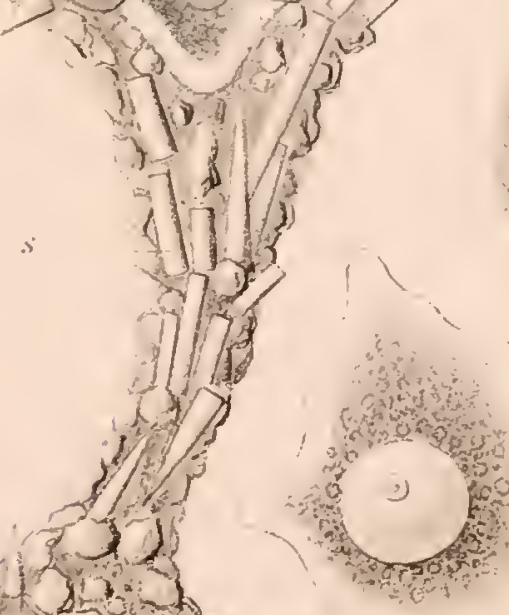

$11 ?$
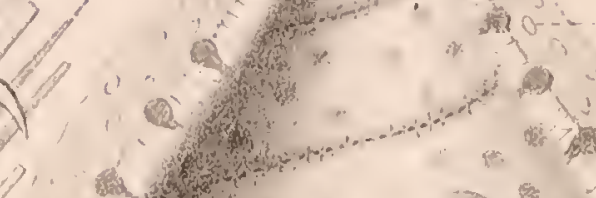

13
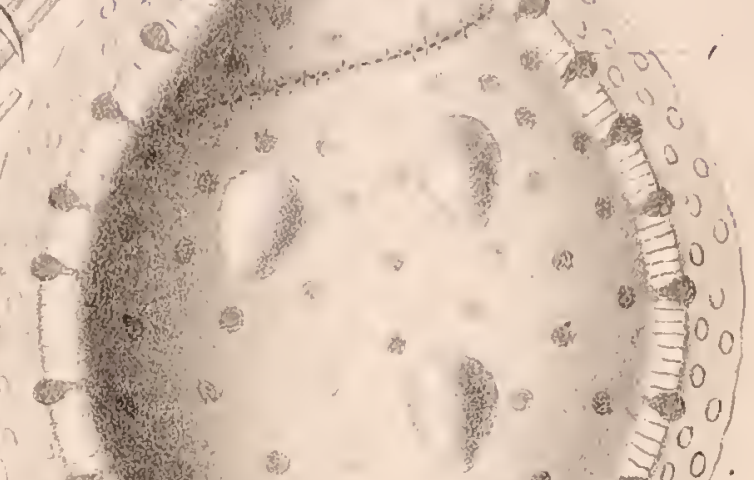

- $20 \%$

(0) 0

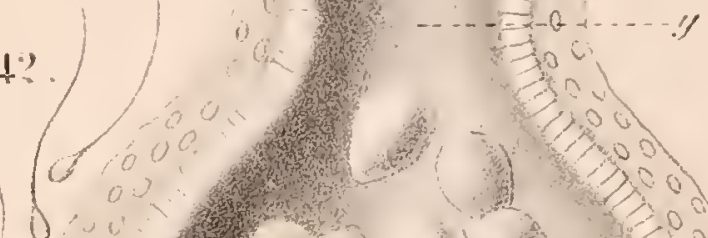

$\begin{array}{lll}3 & 00 \\ 3.5 & 0 \\ 0\end{array}$

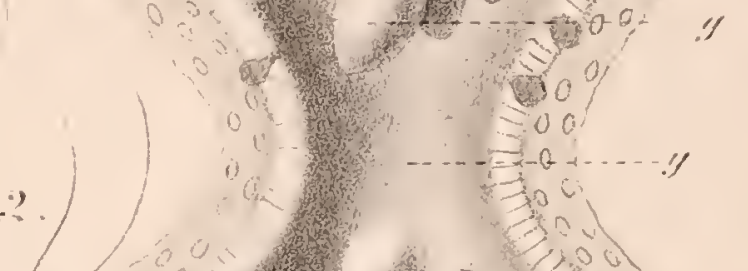





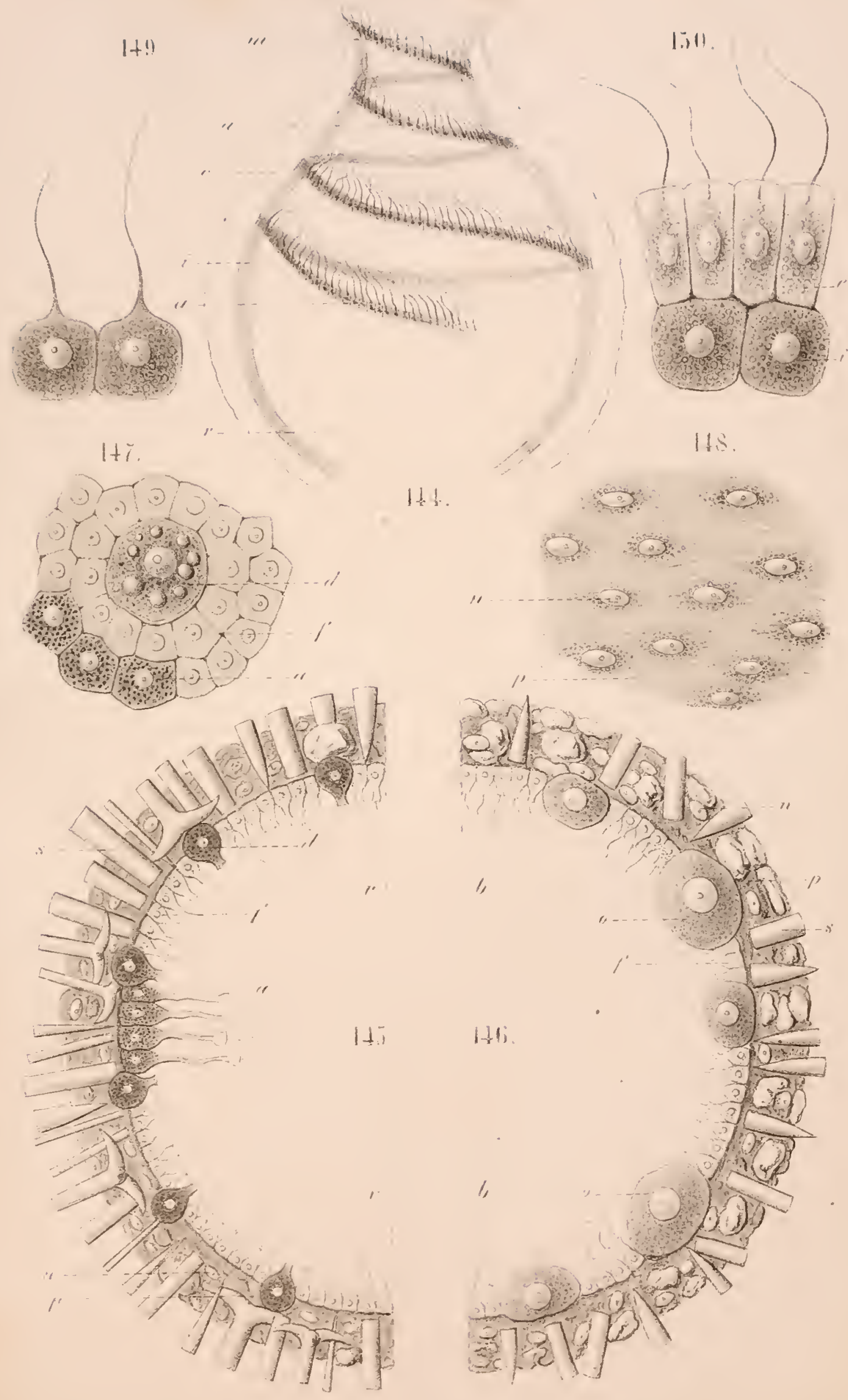










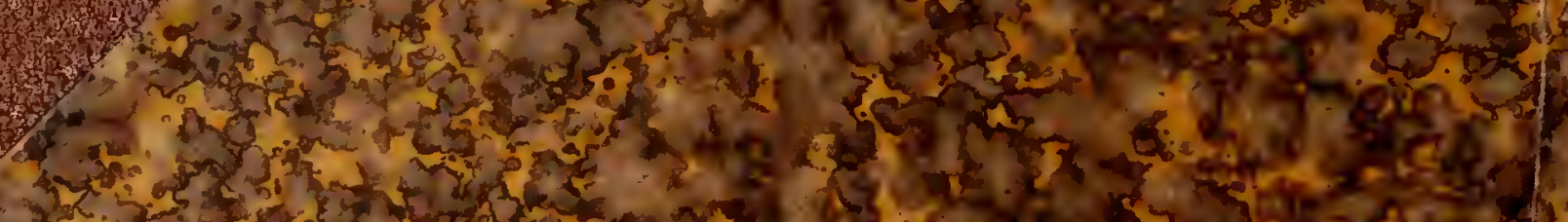

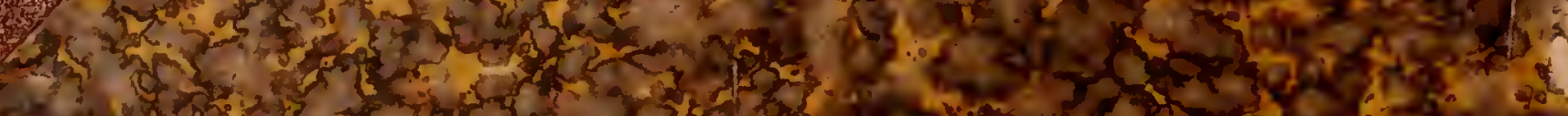

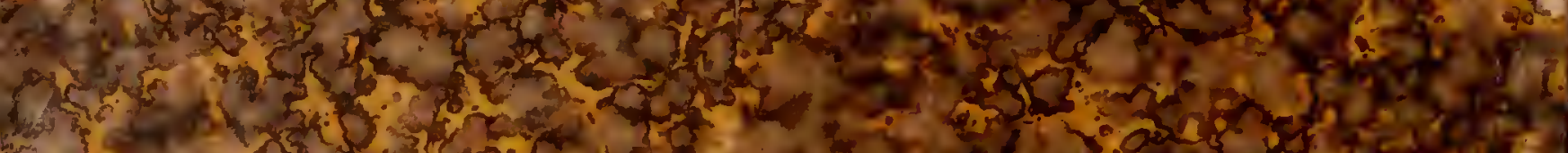

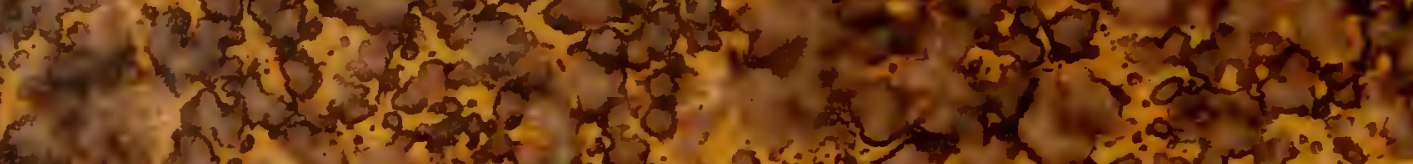

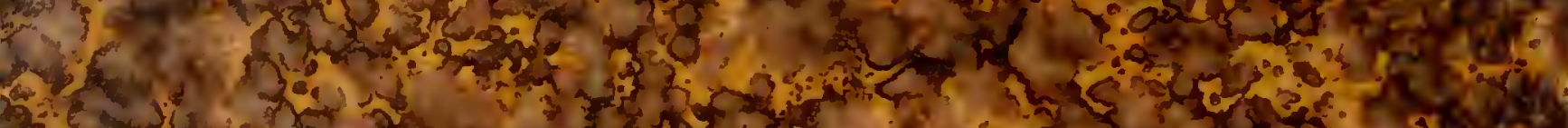

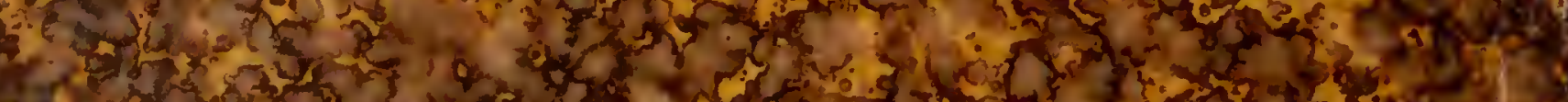

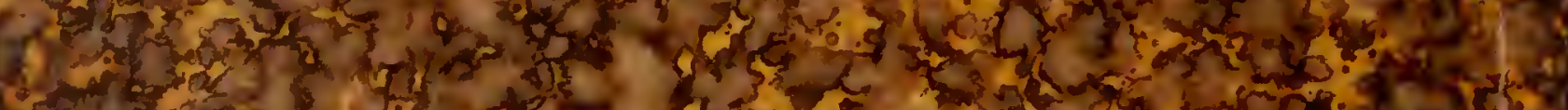

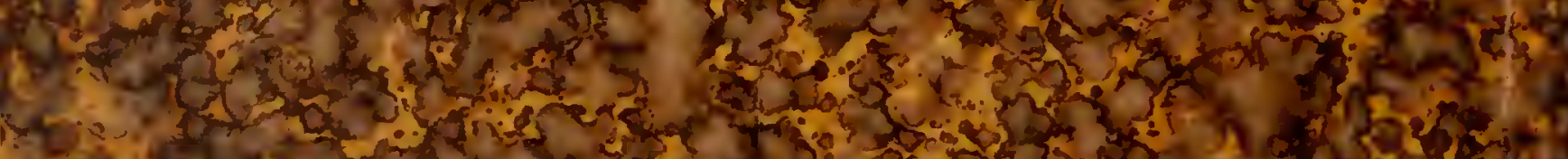

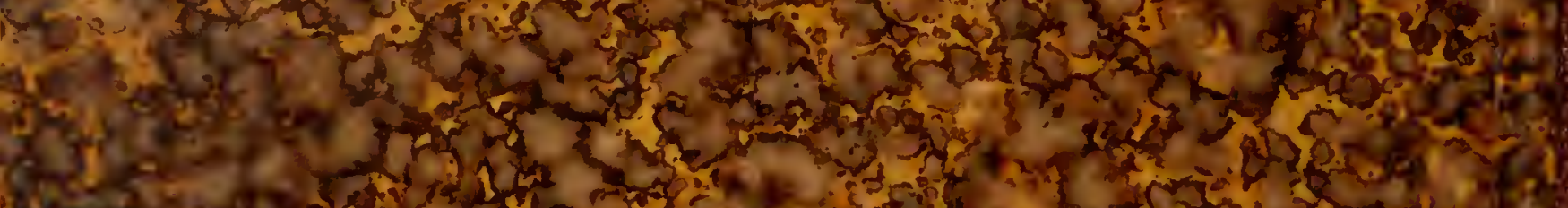

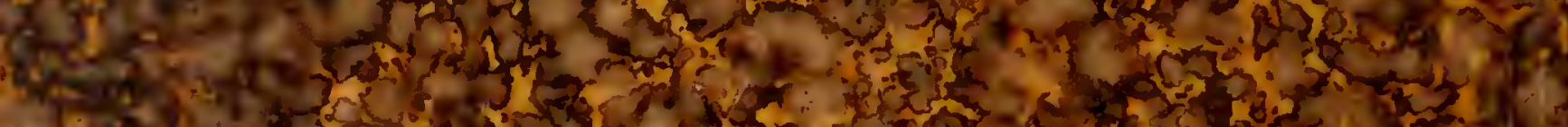

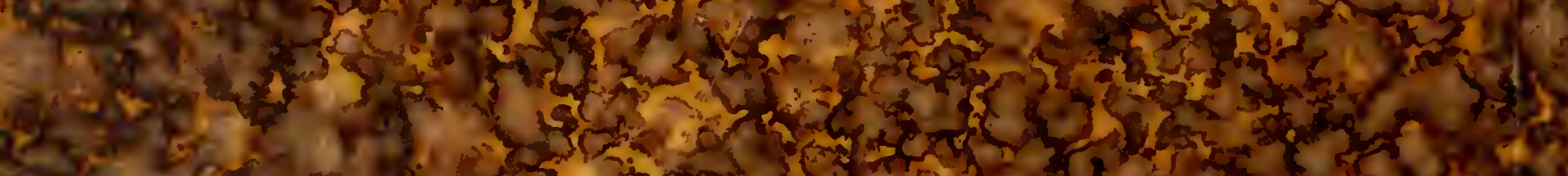

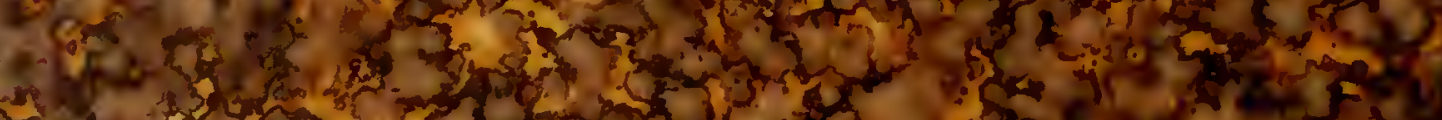

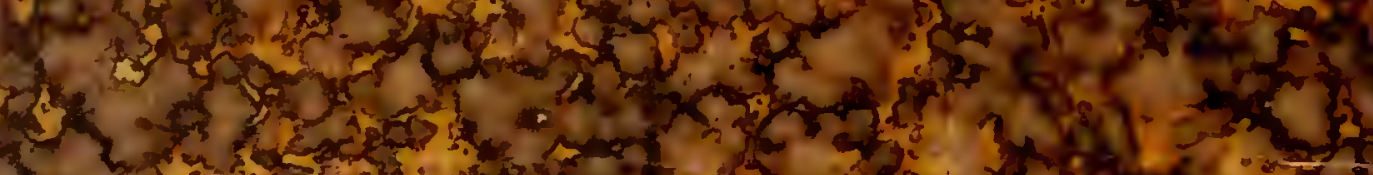

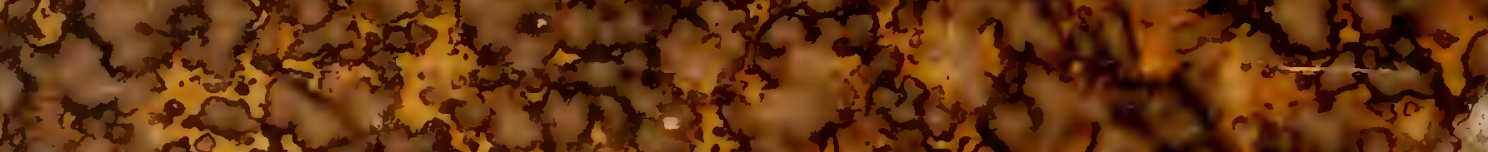

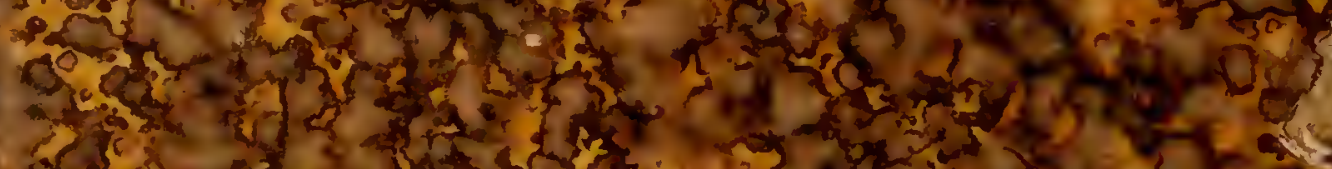

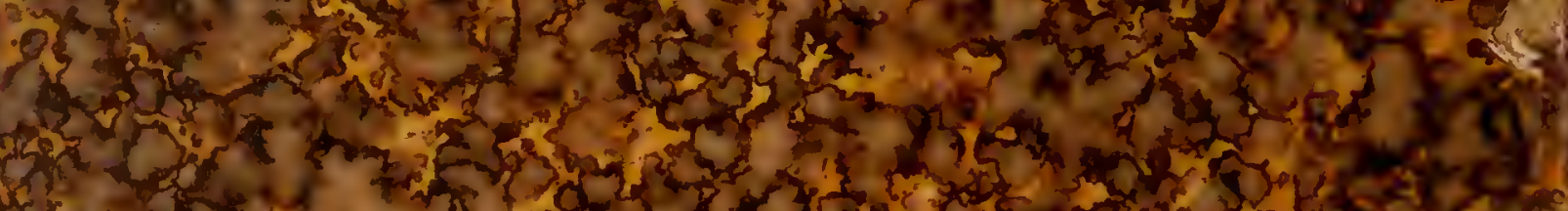

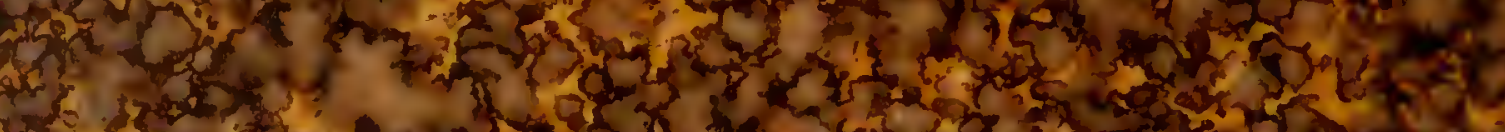
4 -

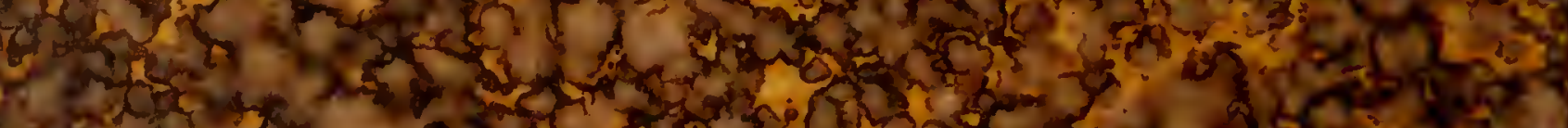
2.

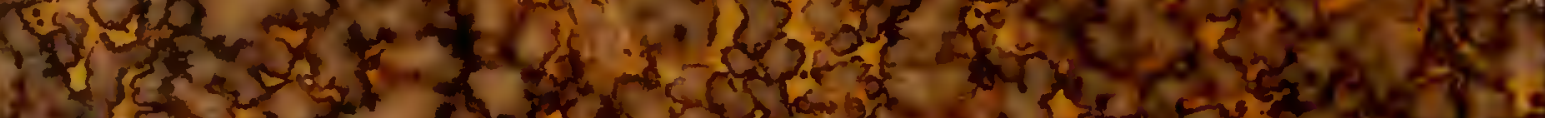

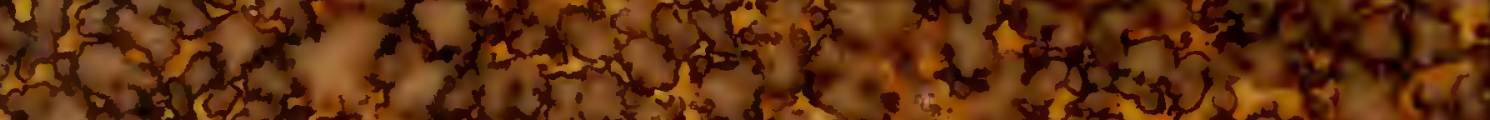

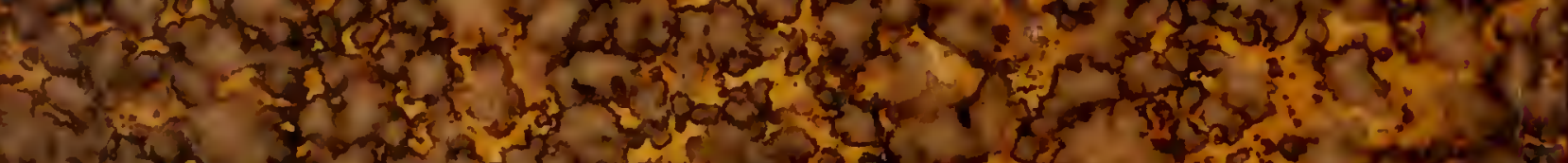

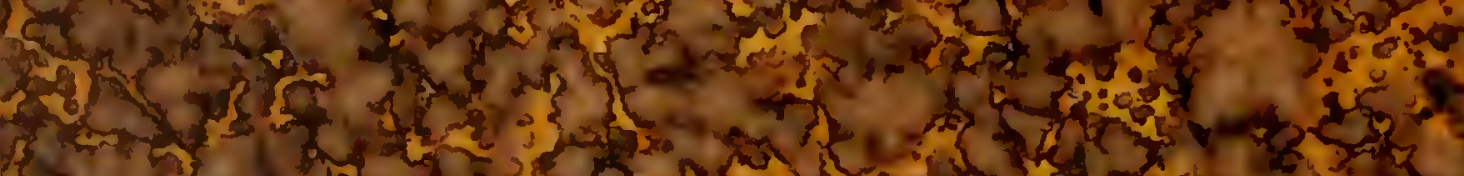

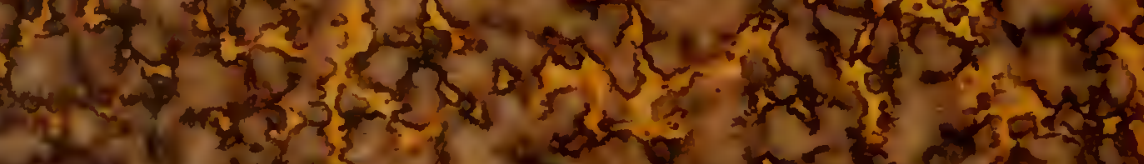

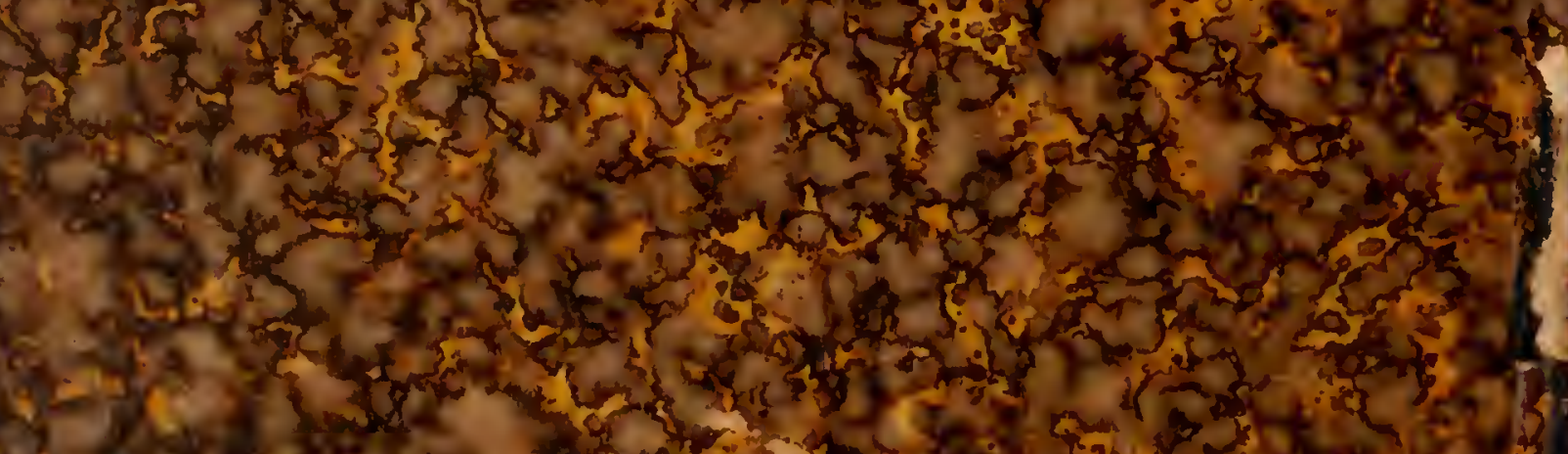

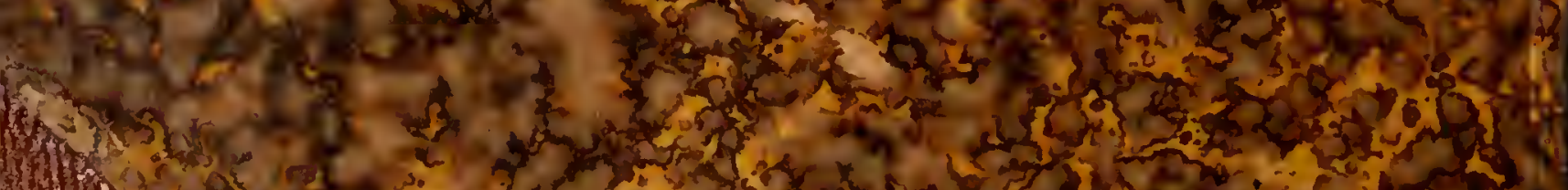

